UCRL-ID-133534

\title{
FY98 Final Report for the Expedited Technology Demonstration Project: Demonstration Test Results for the Integrated MSO Waste Treatment System
}

\author{
Peter C. Hsu \\ Martyn G. Adamson \\ David L. Hipple \\ Robert W. Hopper
}

November 1998

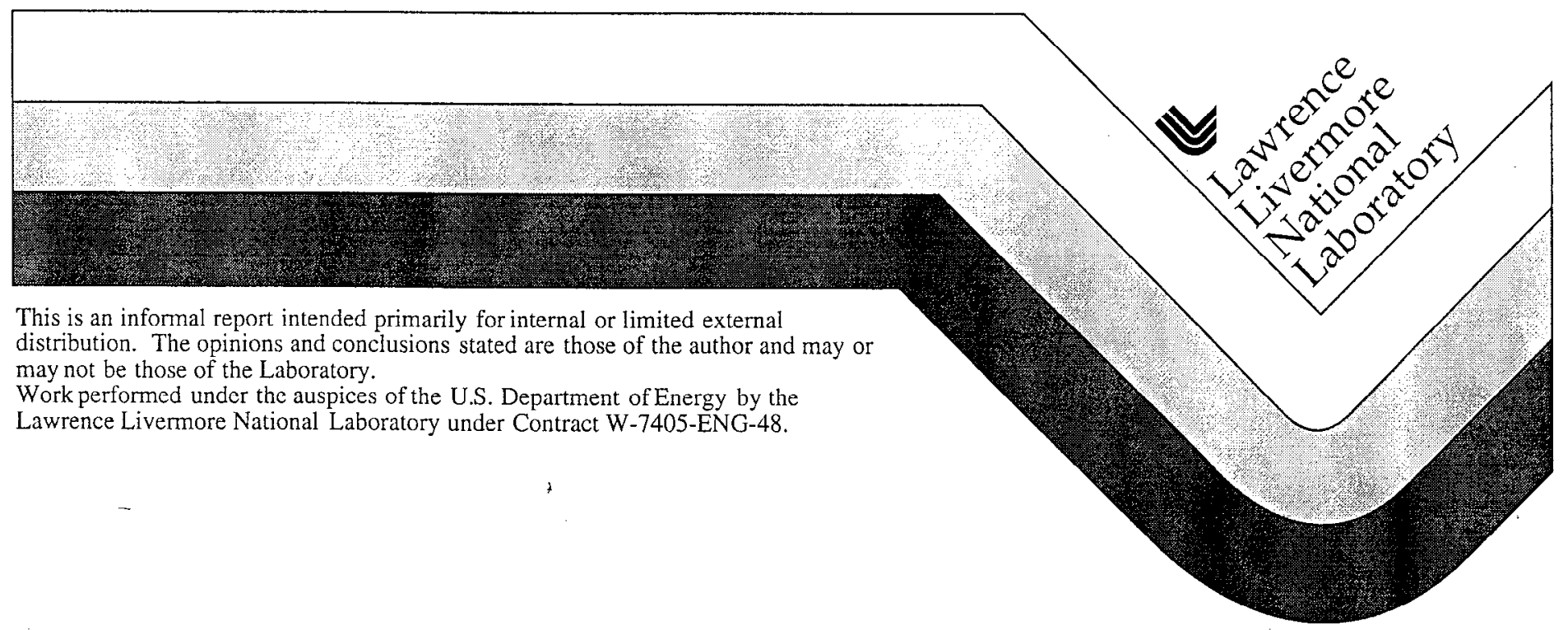




\section{DISCLAIMER}

This document was prepared as an account of work sponsored by an agency of the United States Government. Neither the United States Government nor the University of California nor any of their employees, makes any warranty, express or implied, or assumes any legal liability or responsibility for the accuracy, completeness, or usefulness of any information, apparatus, product, or process disclosed, or represents that its use would not infringe privately owned rights. Reference herein to any specific commercial product, process, or service by trade name, trademark, manufacturer, or otherwise, does not necessarily constitute or imply its endorsement, recommendation, or favoring by the United States Government or the University of California. The views and opinions of authors expressed herein do not necessarily state or reflect those of the United States Government or the University of California, and shall not be used for advertising or product endorsement purposes.

This report has been reproduced directly from the best available copy.

Available to DOE and DOE contractors from the Office of Scientific and Technical Information

P.O. Box 62, Oak Ridge, TN 37831

Prices available from (615) 576-8401, FTS 626-8401

Available to the public from the

National Technical Information Service

U.S. Department of Commerce

5285 Port Royal Rd.,

Springfield, VA 22161 


\section{FY98 Final Report for the Expedited Technology Demonstration Project: Demonstration Test Results for the Integrated MSO Waste Treatment System}

Peter C. Hsu, Martyn G. Adamson, David L. Hipple, and Robert W. Hopper

Lawrence Livermore National Laboratory

Expedited Technology Demonstration Project

Earth \& Environmental Science Directorate

Livermore, CA 94550

Prepared for: U. S. Department of Energy

Oakland Operations Office

Waste Management Division

November 1998 


\section{Contents}

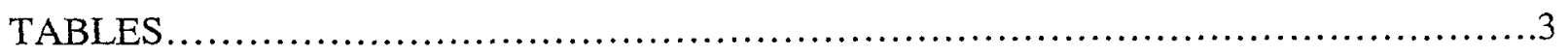

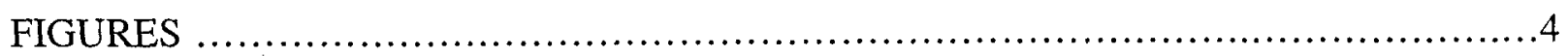

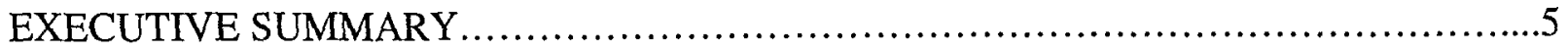

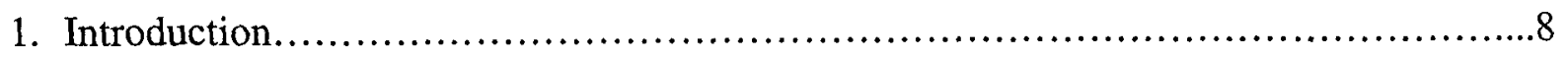

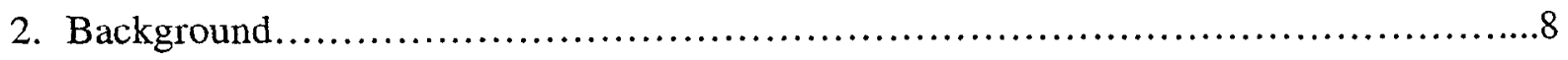

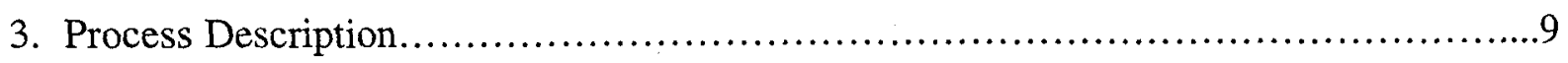

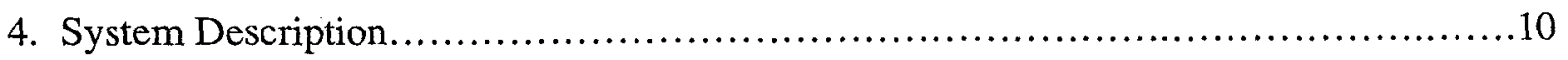

5. Design of Experiments in the MSO/OFF-Gas System................................21

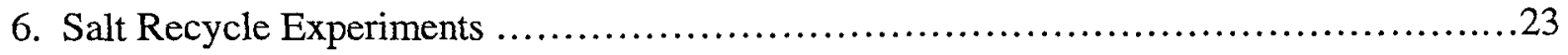

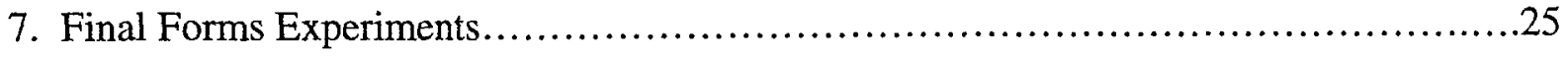

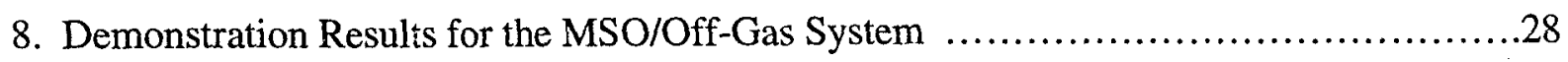

9. Results of the Demonstration of the Salt Recycle System...............................51

10. Results of the Ceramic Final Forms Demonstration......................................55

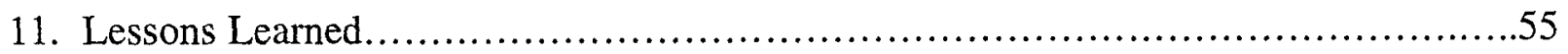

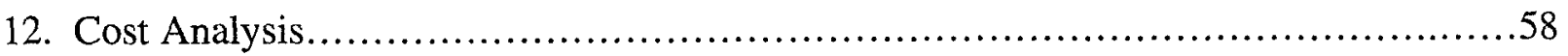

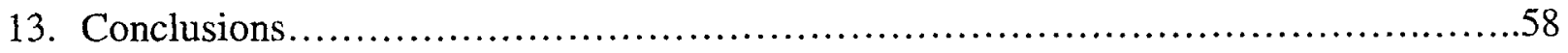

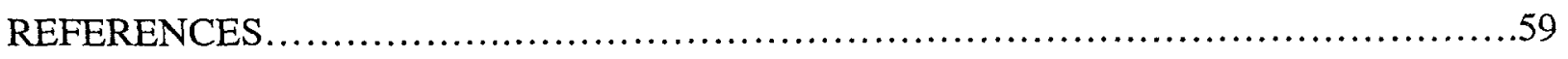

APPENDIX 1 
Tables

Table 1 Run Conditions

Table 2 Effect of Temperature on the Ethylene Glycol Run

Table 3 Effect of \% Excess Air for the Ethylene Glycol Run

Table 4 Effect of \% Excess Air for the Toluene Run

Table 5 MSO Processor Data Sheet for Toluene Run

Table 6 Run Conditions for Heteroatom-containing Organic Liquids

Table 7 Off-gas Composition for Feed of Tolune/Pyridine

Table 8 Conversion of Organic Nitrogen into $\mathrm{NO}_{\mathrm{x}}$ in the Molten Salt

Table 9 Off-gas Composition for the MSO Runs with Halides, Sulfur, and PhosphorousContaining Feeds

Table 10 Run Conditions

Table 11 Off-gas Composition for the Solid Feeds

Table 12 Run Conditions for Test Series IV

Table 13 Off-gas Composition for the Radioactive-spiked Organic Liquids

Table 14 C-14 Level in the C-14 Labeled Toluene Run

Table 15 Off-gas Analyzer Readings

Table 16 Destruction and Removal Efficiency for the MSO Demonstration with Uranium And 2,4-Dichlorophenol-spiked Organics

Table 17 Real Test Specimens for MSO Treatability Study in FY98

Table 18 Test Methods and Locations for the Treatability Study

Table 19 Off-gas Composition for RTS\#1 and RTS\#2

Table 20 Feed Rates, Emission Rates, and DREs for RTS\#1

Table 21 Results for Dioxin and Furan Emissions for RTS\#1

Table 22 Feed Rates, Emission Rates, and DREs for RTS\#2

Table 23 Results for Dioxins and Furan Emissions

Table 24 Cation Compositions of SR1, SR2, SR3 Before and After Salt Recyle

Table 25 Cation Compositions of SR5 and SR6 Before and After Salt Recyle

Table 26 Cation Compositions in SR4 Salt Before and After Salt Recycle

Table 27 Unit Costs for Various Radioactive Feeds Based on 3-Vessel System (in \$/kg) 


\section{Figures}

Fig. 1 Integrated MSO System

Fig. 2 MSO Reaction Vessel

Fig. 3 Off-gas System

Fig. 4 Salt Recycle System Flow Diagram

Fig. 5 Ceramic Waste Form Process Functional Flow Diagram

Fig. 6 Floor Plan (Final Forms)

Fig. 7 Flowsheet for Aqueous Processing of Spent Salt

Fig. 8 Salt Plug in the Drain Pipe

Fig. 9 Toluene Feed at $1.2 \mathrm{~kg} / \mathrm{hr}, 30 \%$ excess air, salt at $950 \mathrm{C} 98 \mathrm{hrs}$ run)

Fig. $103 \mathrm{~kg} / \mathrm{hr}$ Ion Exchange Resin (Amberlite), salt at $950 \mathrm{C}$

Fig. 11 C-14 Activity in Salt \& Off-gas

Fig. 12 MSO Flow Balance for Feed Stream in LLW-008 (Chlorinated Solvents)

Fig. 13 MSO Flow Balance for Feed Stream LLW-009 (PCB Waste Oils) 


\section{EXECUTIVE SUMMARY}

Molten Salt Oxidation (MSO) is a robust thermal treatment process that can be used to oxidatively and efficiently destroy the organic constituents of mixed and hazardous wastes. In the Expedited Technology Demonstration Project, an integrated pilot-scale MSO demonstration facility has been installed and operated at Lawrence Livermore National Laboratory (LLNL). This facility, which has been operational since December 1997, was built to demonstrate the capability of processing organic feed at a commercially useful scale ( 5 to $7 \mathrm{~kg}$ per hour). The integrated MSO treatment train consists of several subsystems: a primary MSO processor (reaction vessel), an off-gas conditioning system, a salt recycle system, and a ceramic final forms immobilization system. The MSO/off-gas system began operations in December 1997, while the salt recycle system and the ceramic final forms immobilization system were activated in May 1998 and September 1998, respectively. During FY98, we have successfully conducted tests in the MSO facility on a variety of liquid and solid organic feeds: chlorinated solvents, tributyl phosphate/kerosene mixtures, PCB-contaminated waste oils and solvents, shredded booties and coveralls, plastic pellets, ionexchange resins, activated carbon, several radioactive-spike organics, and two well-characterized low-level liquid mixed wastes. For the last two feeds, which were samples of real LLNL mixed wastes, the tests were conducted under the California EPA protocol for Treatability Tests.

After initial activation of the MSO/off-gas system (which included demonstration of the effectiveness of the frozen salt plug, and the ability to quickly load and drain salt from the MSO vessel), tests on a variety of simulated and real organic wastes were conducted in five distinct test series (I-V). In Series I, three common organic liquids with a range of viscosities were treated to verify the function of each component in the MSO/off-gas system and to establish/verify the optimum conditions for organic destruction. Toluene, ethylene glycol and oil-toluene mixtures were fed for 1 - to 8 -hr periods at rates of 1.2 to $2.6 \mathrm{~kg} / \mathrm{hr}$ with $10-60 \%$ excess air at process temperatures ranging from 900 to $950^{\circ} \mathrm{C}$. The best DREs (>99.9999\%) and lowest $\mathrm{NO}_{\mathrm{x}}$ levels (8$115 \mathrm{ppm}$ ) were obtained at $925-950^{\circ} \mathrm{C}$ with $30 \%$ excess air; the feed rates and optimal air flow corresponded to superficial velocities of $1 \mathrm{f} / \mathrm{sec}$ through the reactor. Long-term process stability was demonstrated in an 8-hr run with toluene. In Series II, several organic liquid mixtures containing $\mathrm{N}-, \mathrm{P}-, \mathrm{F}-, \mathrm{Cl}-$ or S-containing compounds were processed at $950^{\circ} \mathrm{C}$ with $30 \%$ excess air and feed rates in the range 1.18-2.23 kg/hr. Again, good DREs were obtained (>99.999\%) but, as expected for the $\mathrm{N}$-containing compounds, the $\mathrm{NO}_{x}$ levels immediately after the reactor were high, in some cases exceeding $1000 \mathrm{ppm}$. These high $\mathrm{NO}_{\mathrm{x}}$ levels were reduced by $94 \%$ before off-gas release by use of a catalytic converter. For compounds containing heteroatoms other than $\mathrm{N}$, the heteroatom was retained quantitatively in the carbonate salt bed. In Series III, some surrogate solid waste materials were fed to the MSO reactor using a vibratory feeder and compressed air flowing through an eductor. At a reactor temperature of $950^{\circ} \mathrm{C}$, and with feed rates ranging from 1.45 to $3.0 \mathrm{~kg} / \mathrm{hr}$ using 30 to $65 \%$ excess air, mixed results were obtained, the degree of destruction usually depending on the feed particle dimensions. The best results were obtained with feeds having the smallest particle size, in this case an Amberlite ion-exchange resin. In Series IV, several surrogate organic liquid waste formulations spiked with radionuclides and/or dioxin precursors such as 2,4-dichlorophenol were processed at $900-950^{\circ} \mathrm{C}$ with $30 \%$ excess air and feed rates of 1.2 to $8.2 \mathrm{~kg} / \mathrm{hr}$. Two runs conducted with $\mathrm{C}-14$ labeled toluene as feed showed that the molten carbonate bath acts as an effective sink for $\mathrm{C}-14$ in the feed, and that $\mathrm{CO}_{2}$ in the offgas rapidly equilibrates with carbonate in the salt. Three runs conducted with highly chlorinated feeds helped establish the optimal conditions for treating two real LLNL chlorosolvent waste streams, and also confirmed that, at high chloride loadings in the salt, low total hydrocarbon (THC) levels in the off-gas ( $<1 \mathrm{ppm})$ - which correspond to high DREs - can accompany high CO levels in the post-reactor off-gas. A surrogate waste stream consisting of carbon tetrachloride, 1,1,1-trichloroethane, ethanol, ethylene glycol, 2,4-dichlorophenol and uranyl nitrate (1wt \%), was fed with $30 \%$ excess air to the MSO processor at 2.2 and $3.3 \mathrm{~kg} / \mathrm{hr}$ and superficial velocities of 1 $\mathrm{ft} / \mathrm{s}$ and $1.5 \mathrm{ft} / \mathrm{s}$, respectively, at $950^{\circ} \mathrm{C}$. Using continuous off-gas monitors and separate gas sample analyses, it was shown that the system reached steady-state in 30 minutes and the off-gas 
quality leaving the MSO vessel was very good under both flow conditions ( $<10 \mathrm{ppm} \mathrm{CO}$, $<110$ ppm $\mathrm{NO}_{\mathrm{x}}$ ). DREs of all the principal organic hazardous constituents (POHCs), including 2,4-dichlorophenol, were better than five nines, and dioxins and furans were not detectable.

Series V comprised a treatability study of two real waste specimens from the LLNL mixed waste inventory. The first specimen (LL-W008) was chlorosolvents consisting mainly of 1,1,1trichloroethane with low levels of radionuclides (U, tritium) and trace metals. The second specimen (LL-W009) was hydraulic oil contaminated with PCB (1567 ppm), traces of solvents and metals, and low levels of uranium and tritium. In separate runs using fresh batches of sodium carbonate, five gallons of each waste specimen was processed through the reactor at $950^{\circ} \mathrm{C}$ with $30 \%$ excess air at feed rates of $1.1 \mathrm{~kg} / \mathrm{hr}$ (LL-W009) to $2.3 \mathrm{~kg} / \mathrm{hr}$ (LL-W008). To decrease its viscosity, and hence improve the ease of delivery of LL-W009, toluene was added as a diluent. The off-gas composition was monitored continuously by on-line monitors during the runs, and comprehensive gas sampling was performed by Best Environmental, Inc., using certified EPA methods. Gas sampling was conducted from sampling ports located at the inlet and outlet of the GSS filter and from the vent of the catalytic converter. For LL-W008, the concentrations of CO and THC in the off-gas were $15.6 \mathrm{ppm}$ and $0.2 \mathrm{ppm}$, respectively, considerably lower than the current standards for mixed-waste incinerators. The DREs for the six POHCs were all greater than $99.999 \%$, with the principal constituents, MCM and toluene, exceeding six nines. The particulate

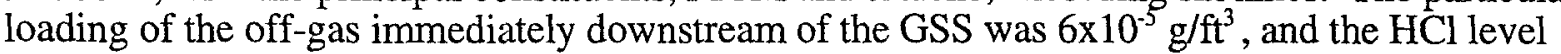
was $<0.0016 \mathrm{~g} / \mathrm{hr}$. Total emission of semi-volatile organics was less than $91.376 \mu \mathrm{g} / \mathrm{min}$ and total emission of volatile organics was less than $31.568 \mu \mathrm{g} / \mathrm{min}$. The total dioxin and furan emissions from the GSS filter inlet and the catalytic converter outlet were $18.534 \mathrm{pg} / \mathrm{m}^{3}$ TEQ and 17.093 $\mathrm{pg} / \mathrm{m}^{3} \mathrm{TEQ}$, respectively. All these values fall within proposed EPA regulatory limits. For the PCB-containing waste specimen LL-W009, the off-gas quality was very good, with $\mathrm{NO}_{\mathrm{x}}<50 \mathrm{ppm}$, $\mathrm{CO}<20 \mathrm{ppm}$, and non-detectable levels of THC. With the marginal exceptions of 1,1dichloroethene and trichlorotrifluoroethane, the DREs for the POHCs all exceeded five nines. The particulate loading of the off-gas was $1.86 \times 10^{-6} \mathrm{~g} / \mathrm{ft}^{3}$, and the $\mathrm{HCl}$ level was $<0.0015 \mathrm{~g} / \mathrm{hr}$. Total emission of semivolatile organics was less than $95.854 \mu \mathrm{g} / \mathrm{min}$ and total emission of volatile organics was less than $17.82 \mu \mathrm{g} / \mathrm{min}$. The total dioxan and furan emissions from the GSS filter inlet and the catalytic converter outlet were $38.743 \mathrm{pg} / \mathrm{m}^{3}$ TEQ and $9.338 \mathrm{pg} / \mathrm{m}^{3} \mathrm{TEQ}$, respectively. These values are again below the EPA regulatory limits.

The salt recycle system was used successfully to treat six batches of spent salt generated from the MSO processor during FY98. For spent salts with high carbonate contents, it removed ash, metals, and radionuclides from the salts to levels of $20 \mathrm{ppm}(\mathrm{Cr})$ to $500 \mathrm{ppm}(\mathrm{U})$ and returned $95 \%$ of the salt for reuse. For spent salts with low carbonate content, salt recycle removed ash, metals, and radionuclides to levels of $0.1 \mathrm{ppm}(\mathrm{U})$ to $1 \mathrm{ppm}(\mathrm{Cr})$ and generated clean sodium chloride brine solutions which are not considered hazardous. For ceramic final forms, FY98 activity was largely devoted to the design and installation of the fabrication facility, and to initial testing of the major equipment items. Although the components of the system were standard commercial equipment, many modifications were needed to ensure safe and efficient operation with toxic and radioactive materials. An OSP was prepared, and initial shake-down operations were carried out. Evolutionary system modifications were in progress at the end of the fiscal year, and two new $R \& D$ issues are being addressed. Integrated operation of the Final Forms system is scheduled to begin in the first quarter of FY99. Mass balances were also calculated for each of the treatability study demonstrations, assuming integrated steady-state operation of the MSO/off-gas system, the salt recycle system, and the ceramic final forms system.

On the basis of the FY98 demonstrations, we have established that MSO is a mature, versatile and effective technology for the treatment of the following classes of organic-based hazardous and mixed wastes: halogenated solvents and refrigerants, PCB-contaminated oils and solvents, solutions of actinide complexants in nonhalogenated solvents, ion-exchange resins, granulated activated carbon, and uranium-contaminated organics. Thus, as a viable alternative to incineration, 
MSO could provide a solution to many vexing waste disposal problems that continue to exist around the DOE complex. This report presents the results from operation of the MSO/off-gas system and the salt recycle system with a variety of simulated and real organic-based mixed wastes, and it also discusses general processing capabilities and our accumulated operational experience with a pilot-scale MSO system. Due to the delay in final commissioning of the ceramic final forms subsystem, evaluation of the ceramic pellets derived from the FY98 tests performed on real wastes and spiked surrogates will be reported in FY99, as will the results from follow-on MSO tests that are being conducted in FY99. 


\section{INTRODUCTION}

MSO is a promising alternative to incineration for the treatment of a variety of organic wastes. Lawrence Livermore National Laboratory (LLNL) has prepared a facility in which an integrated pilot-scale MSO treatment system is being tested and demonstrated. The system consists of a MSO vessel with a dedicated off-gas treatment system, a salt recycle system, feed preparation equipment, and a ceramic final waste forms immobilization system. This integrated system was designed and engineered based on operational experience with an engineering-scale reactor unit and extensive laboratory development on salt recycle and final forms preparation.

The MSO/off-gas system has been operational since December 1997. The salt recycle system and the ceramic final forms immobilization became operational in May and August, 1998, respectively. We have tested the MSO facility with various organic feeds, including chlorinated solvents, tributyl phosphate/kerosene, PCB-contaminated waste oils \& solvents, booties, plastic pellets, ion exchange resins, activated carbon, radioactive-spiked organics, and well-characterized low-level liquid mixed wastes. MSO is shown to be a versatile technology for hazardous waste treatment and may be a solution to many waste disposal problems in DOE sites. This report presents the results obtained from operation of the integrated pilot-scale MSO treatment system through September 1998, and therefore represents a final report for fiscal year 1998 activities.

\section{BACKGROUND}

In response to public concern about the application of incineration as the best demonstrated available technology (BDAT) for the treatment of organic-based mixed wastes, the Mixed Waste Management Facility (MWMF) project was initiated at LLNL in 1992. The focus of this project was to demonstrate integrated, alternative-to-incineration (non-flame) technologies for the treatment of typical low-level mixed wastes (from LLNL's inventory) at the pilot-scale. Selected alternativeto-incineration technologies, including MSO, were to be evaluated against the federal and state treatment standards that identify incineration as BDAT, thus establishing equivalency with the BDAT. The technologies were to be demonstrated in a dedicated facility (test-bed) in integrated treatment trains incorporating state-of-the-art waste characterization and feed preparation technologies, off-gas treatment, waste water treatment, and the preparation of robust ceramic final forms.

In June 1996, written direction was received from DOE-EM to descope the MWMF project and use the remaining uncosted funds to complete a limited demonstration of MSO as an integrated mixedwaste treatment process in Building 292 (B292), an existing building at LLNL. Cost estimates were developed to meet the DOE funding guidance, then incorporated into a new baseline plan titled "Expedited Technology Demonstration Project (ETDP) Baseline Revision 3.0 and FY97 Plan" which was released in October 1996. An updated version of this document was prepared based on the present test plan, and this details the system deployment/demonstration phase of the project in FY98. During FY97 and early FY98, B292 was modified using GPP funds to meet the ETDP requirements. In addition to the MSO primary unit, off-gas, and salt recycle subsystems, which are somewhat smaller than the MWMF reference design, the FY98 demonstrations include the production of ceramic final forms from process mineral residues and a limited capability for feed preparation.

Testing was originally planned to begin in October 1997 with organic compounds of interest, then it would proceed to surrogate feed streams of interest, and finally selected low-level mixed wastes supplied by LLNL's Hazardous Waste Management (HWM). The latter tests will be performed as treatability studies under the purview of California EPA's Department of Toxic Substances Control. In the DOE letter of June 1996, we were also directed to explore the application of MSO to hazardous organic wastes including those generated in weapons dismantlement, and to facilitate the transition of the MSO technology to a commercial entity. Because of a 3-month delay in the 
B292 GPP start date, testing did not actually begin until December 1997. Details of the planned ETD demonstrations for FY98 can be found in Ref. 1.

Waste treatment systems are tested in order to evaluate them relative to the Federal, State and local treatment standards, residual product requirements, and effluent requirements. Ideally, the MSO demonstration waste treatment system under evaluation will be shown to meet all RCRA Land Disposal Restriction (LDR) standards including the Universal Treatment Standards (UTS) for the chosen mixed waste streams. If successful, the treatment evaluation may result in the technology being designated by the EPA as a BDAT (or result in a Determination of Equivalent Treatment to the BDAT) for a specified mixed waste stream. A successful demonstration will result in a clear determination as to whether the MSO treatment process train meets the LDR requirements for the specific waste stream.

\section{PROCESS DESCRIPTION}

MSO is a robust thermal treatment process for destroying organic waste. In this process, organic containing wastes are injected with a stoichiometric excess of oxidant air under a pool of molten carbonate salts at temperatures between $700-950^{\circ} \mathrm{C}$. Flameless oxidation takes place within the salt bath converting the organic components of the waste into $\mathrm{CO}_{2}, \mathrm{~N}_{2}$, and water. The product off-gas leaving the processor is treated to remove any entrained salt particulate and essentially all water vapor before being discharged to the facility off-gas system. Halogens and heteroatoms such as sulfur are converted into acid gases, which are then "scrubbed" and trapped in the salt in forms such as $\mathrm{NaCl}$ and $\mathrm{Na}_{2} \mathrm{SO}_{4}$. Using sodium carbonate in the processor, this process occurs according to the reaction shown in Equations 1,2,3, and 4, where $\mathrm{X}$ represents generic halogens.

$$
2 \mathrm{C}_{\mathrm{a}} \mathrm{H}_{\mathrm{b}}+(2 \mathrm{a}+\mathrm{b} / 2) \mathrm{O}_{2}-\cdots>2 \mathrm{aCO}_{2}+\mathrm{bH}_{2} \mathrm{O}
$$

For nitrogen -bearing organic wastes,

$$
\mathrm{C}_{\mathrm{a}} \mathrm{H}_{\mathrm{b}} \mathrm{N}_{\mathrm{c}}+(\mathrm{a}+\mathrm{b} / 4) \mathrm{O}_{2}--->\mathrm{CO}_{2}+\mathrm{H}_{2} \mathrm{O}+\mathrm{N}_{2}+\mathrm{NO}_{\mathrm{x}}
$$

For halogenated organic wastes,

$$
\mathrm{C}_{\mathrm{a}} \mathrm{H}_{\mathrm{b}} \mathrm{X}_{\mathrm{c}}+\mathrm{c} / 2 \mathrm{Na}_{2} \mathrm{CO}_{3}+(\mathrm{a}+(\mathrm{b}-\mathrm{c}) / 4) \mathrm{O}_{2}--->(\mathrm{a}+\mathrm{c} / 2) \mathrm{CO}_{2}+\mathrm{b} / 2 \mathrm{H}_{2} \mathrm{O}+\mathrm{cNaX}
$$

For sulfur-containing organic wastes,

$$
\mathrm{C}_{\mathrm{a}} \mathrm{H}_{\mathrm{b}} \mathrm{S}_{\mathrm{c}}+\mathrm{cNa} \mathrm{CO}_{3}+(\mathrm{a}+\mathrm{b} / 4+3 \mathrm{c} / 2) \mathrm{O}_{2}--->(\mathrm{a}+\mathrm{c}) \mathrm{CO}_{2}+\mathrm{b} / 2 \mathrm{H}_{2} \mathrm{O}+\mathrm{cNa}_{2} \mathrm{SO}_{4}
$$

Other non-oxidizable inorganic constituents, heavy metals, and radionuclides are held captive in the salt, either as metals or oxides, and are easily separated for disposal.

MSO has several unique characteristics. The large thermal mass of the molten salt provides a stable heat-transfer medium that resists thermal surges and ensures temperature uniformity and is therefore able to tolerate rapid process fluctuations. Flamc-outs are completely avoided, since MSO is a non-flame process that proceeds by catalytic liquid-phase oxidation reactions. Operation of the MSO system is at temperatures hundreds of degrees lower than flame combustion temperatures, which, among other things, minimizes emissions of the radioactive materials from mixed wastes. Acid gases are "scrubbed" by the alkali salts, climinating the need for a wet off-gas scrubbing system. 


\section{SYSTEM DESCRIPTION}

The integrated MSO system, shown in Fig. 1, consists of several subsystems. It includes a reaction vessel, an off-gas treatment system, a salt recycle system, feed preparation equipment, as well as ceramic final waste forms immobilization system. The feed preparation area includes waste receiving drums, centrifuge for solid liquid separation, a shredder for size-reducing solid wastes such gloves, booties etc. The waste is fed to the reaction vessel along with oxidant air using a topfeed injection system designed for solid and liquid waste streams at throughputs up to $7 \mathrm{~kg} / \mathrm{hr}$ for chlorinated solvents. Product off-gas exiting the vessel is then treated in the off-gas system to remove entrained salt particulates, water vapor, and traces of gas species such as $\mathrm{CO}$ and $\mathrm{NO}_{\mathrm{x}}$, As waste is injected into the MSO vessel, residues of inorganic components build up in the salt bed which necessitates periodic removal of salt and replenishment with fresh salt to maintain process efficiency. Because many of the metals and/or radionuclides captured in the salt are hazardous and/or radioactive, without further treatment the removed spent salt would create a large secondary waste stream. A salt recycle system is needed to segregate these materials to minimize the amount of secondary waste, and to reduce the consumption of fresh salt. The segregated inorganic residues are then immobilized as a ceramic final form for disposal. Each subsystem is described below.

\subsection{Reaction Vessel}

The MSO reaction occurs in a 2.74 meter tall processor vessel, shown in Fig 2. The processor is $38.1 \mathrm{~cm}$ inside diameter over the top half and $29.8 \mathrm{~cm}$ inside diameter over the bottom half, with a $30.5 \mathrm{~cm}$ long, tapered transition zone in between. The normal salt load is $160 \mathrm{~kg}$ and fills the vessel to the bottom of the transition zone when quiet. When air and feed injection is occurring, the sait level froths up to the top of the transition zone. The freeboard area of the vessel above the salt level provides a dis-engagement zone for salt spray to separate from the off gas before it exits. There are baffles in this region to assist in separating the salt spray. The air and feed material enter through an injector lance extending through the vessel cover to the bottom of the vessel. The injector is insulated and air cooled to keep the feed temperature low until it leaves the injector and contacts the molten salt.

The vessel is fabricated from $1.27 \mathrm{~cm}$ thick Inconel $600^{\circledR}$ material. Corrosion tests at LLNL have shown an acceptable corrosion rate for Inconel $600^{\circledR}$ in $\mathrm{Na}_{2} \mathrm{CO}_{3}$ and $\mathrm{NaCl}$ salt mixtures at operating temperature (ca. $3 \times 10^{-3}$ ins $/ 100 \mathrm{hrs}$ ). The most severe corrosion attack is due to $\mathrm{NaCl}$, so the life time will be shorter at high $\mathrm{NaCl}$ contents. The vessel is protected against overpressure by placing close limitations on maximum feed rates, by closely monitoring the offgas system to prevent build up of salt deposits that may cause plugging, and by a rupture disk on a dedicated vessel nozzle. The rupture disc is a low pressure disk that discharges into a separate exhaust vent stack.

The vessel will expand about $3.8 \mathrm{~cm}$ over its length when at operating temperature. To permit this, the vessel is held from the top and mounts on a free standing structural support stand. The heaters are radiant electric type and are made up of two major subassemblies: one assembly covering the top half of the vessel and a second subassembly covering the bottom half. The heaters are separately supported from the vessel support stand. The vessel has a salt drain pipe extending from the bottom of the vessel to outside the heated zone. A plug of frozen salt will be established in the salt drain pipe, and when the spent salt is to be removed from the vessel, a separate heater will be turned on to melt the salt in the drain pipe. At that point, the entire salt contents of the vessel will discharge through the salt drain pipe into a collection pan. The collection pan is inside a special canister that contains any salt splashing and misting that may occur. After the salt has cooled, the entire canister with its salt contents is moved to the salt recycle area for extraction of the (now frozen) salt. The vessel temperature is maintained by the control 


\section{Fig. 1 Integrated MSO System}

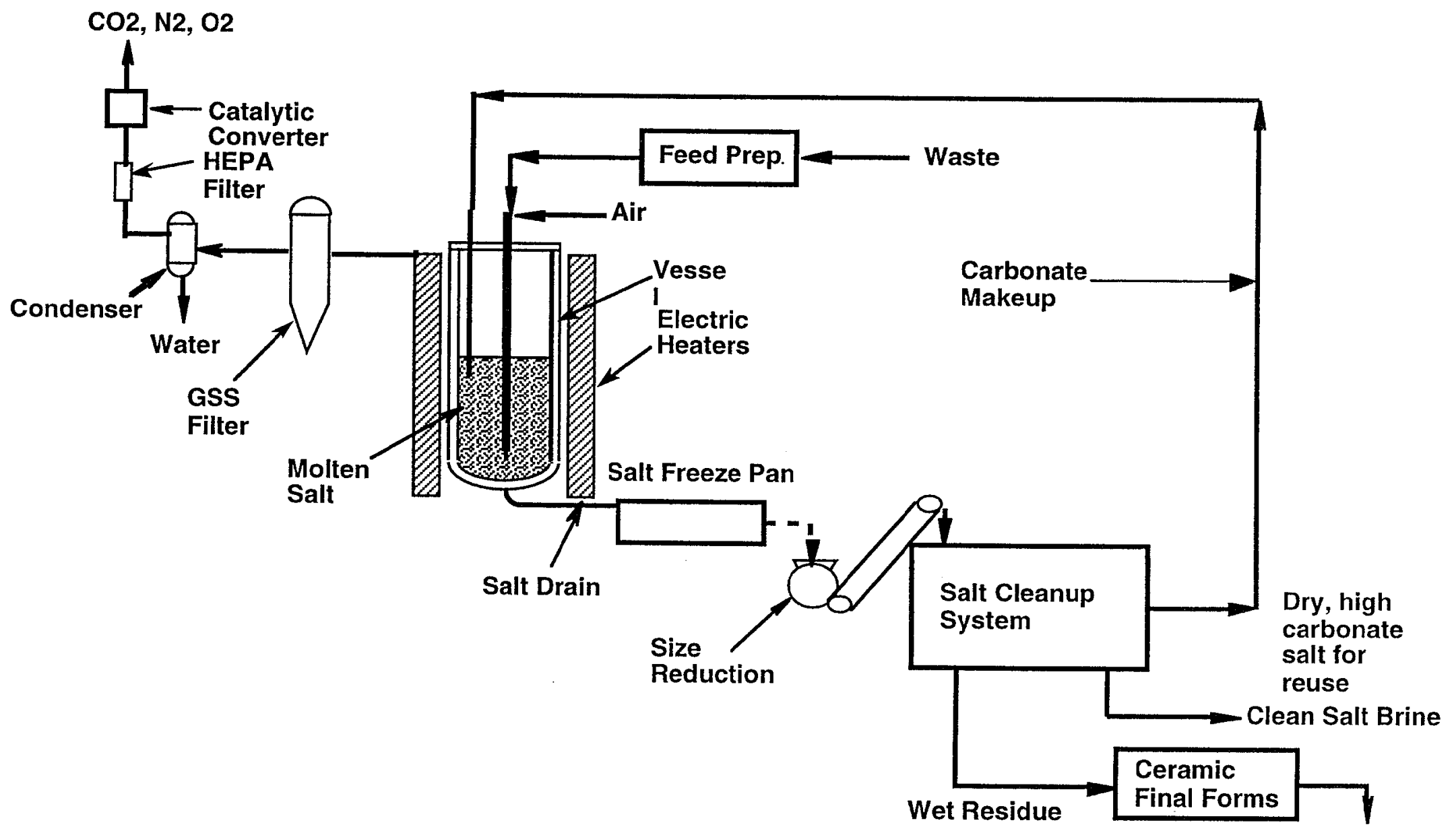




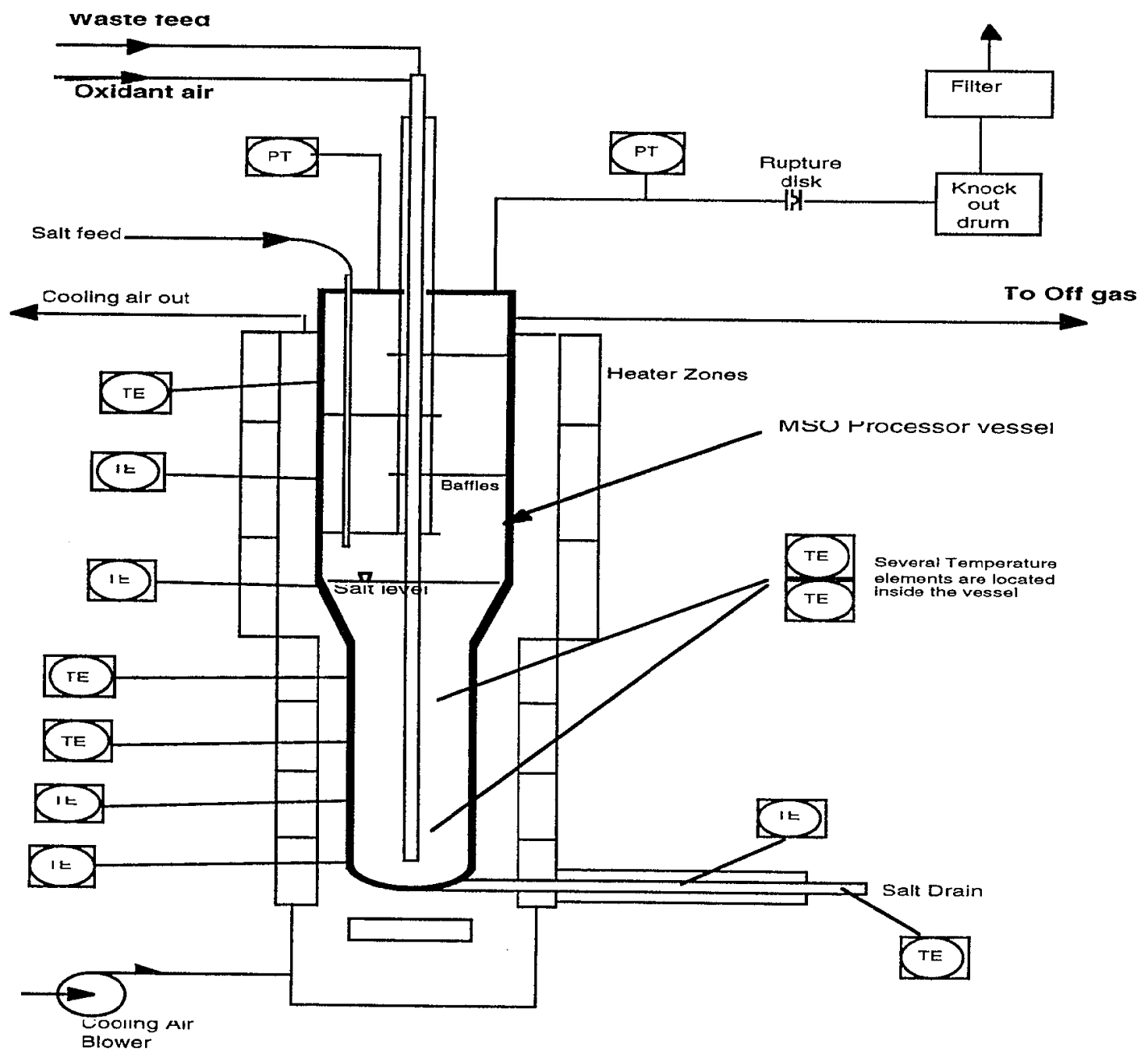

Fig. 2. MSO Reaction Vessel 
system. The heaters are segregated into several zones, each of which is separately controlled to a temperature determined by sensors mounted in blocks on the outside of the vessel. When exothermic materials are being fed, the vessel must be cooled to prevent overheating. A blower is provided for this which blows ambient air though the annular space between the heaters and the vessel wall.

\subsection{Off-gas System}

The purpose of the off-gas system is to remove entrained salt particulates, moisture, and traces of $\mathrm{CO}$ and $\mathrm{NO}_{\mathrm{x}}$ from the off-gas and ensure that clean gas exists the off-gas system. This is accomplished by the following components: a piping section with a gas-to-air cooler, an air cylinder and salt trap, a ceramic filter, a heat exchanger and condenser, an electrical heater, a HEPA filter, and catalytic converter. Figure 3 shows the off-gas system.

The off-gas exiting the reaction vessel is first cooled to $500^{\circ} \mathrm{C}$ by the gas-to-air cooler. The gas-toair cooler consists of two concentric pipes with an annular gap between them. Compressed air flows through the annular gap and cools the gas flowing through the inner pipe. As the gas stream cools, the entrained salt cools and sticks to the inner pipe wall. Salt buildup is removed by a wire brush on the end of a rod that is driven and retracted by the air cylinder. The dislodged salt falls into the vessel on the forward stroke and falls into the salt trap on the reverse stroke. The smaller entrained particles are captured in the pulsating, self-cleaning ceramic filter. The ceramic filter captures particles $\geq 0.5$ micrometers in size and can withstand gas temperatures up to $700^{\circ} \mathrm{C}$. Six, silicon carbide filter elements are pulsed with compressed air to remove caked on salt when the pressure drop across the elements reaches $2.74 \mathrm{kPa}$ (11 inches water). The captured salt in the salt trap and ceramic filter is removed by cycling double dump valves that allow the salt to fall into a drum below them. The double dump valves are used to isolate the negative system pressure from the atmospheric drum pressure. The gas is kept at about $300^{\circ} \mathrm{C}$ to ensure that the gas is well above the dew point $\left(50^{\circ} \mathrm{C}\right)$ to avoid any water condensation and that the salt remains dry.

The filtered off-gas is then cooled to $100^{\circ} \mathrm{C}$ by a shell and tube heat exchanger using LCW. The moisture is removed when the gas is cooled to $2^{\circ} \mathrm{C}$ by the condenser using propylene glycol from a chiller. The gas is then heated to $30^{\circ} \mathrm{C}$ by an electrical heater to ensure dry gas enters the HEPA filter. The HEPA filter serves two purposes. It acts as a pre-filter for the catalytic converter and a barrier for remaining particles in the off-gas. Thus no salt particles escape the process off-gas system. The catalytic converter is designed to abate 50,000 PPM of CO and 30,000 PPM of $\mathrm{NO}_{\mathrm{X}}$. It converts $\mathrm{CO}$ into $\mathrm{CO}_{2}$ in a catalyst bed at elevated temperatures. It also is equipped with an ammonia injection system that converts $\mathrm{NO}_{\mathrm{X}}$ into $\mathrm{N}_{2}$ and $\mathrm{H}_{2} \mathrm{O}$ by selective catalytic reduction. The off-gas leaving the catalytic converter is very clean and is exhausted to a building stack via a ducting system.

\subsection{Salt Recycle System}

The salt recycle system, shown in Fig 4, receives spent salts from MSO processor and off-gas system. The amount of spent salt received is about $160 \mathrm{~kg}$. The size of spent salt is reduced to approximately $6.3 \mathrm{~mm}$ by using hand tools, air-power tools, and a crusher; which are all done inside an enclosure. Small salt particles are then transferred to tank T-101 by a spiral conveyor. Salt samples will be taken during salt crushing for analysis. Salt dissolution is performed in tank T-101 using either deionized or clean recycled water. The salt dissolution step is controlled at $30-40^{\circ} \mathrm{C}$ by an immersion heater and a temperature controller to minimize the amount of water required. Most of mineral residues and ashes precipitates as hydroxides and oxides during the dissolution step. Chemical reagents such as sodium hydroxide, hydrochloric acid, and dithionite is used at various stages of the process to adjust $\mathrm{pH}$ and/or facilitate metals removal. Reagents such as Alum $\left[\mathrm{Al}_{2}\left(\mathrm{SO}_{4}\right)_{3}\right]$ and activated silica is added to facilitate the coagulation \& precipitation 


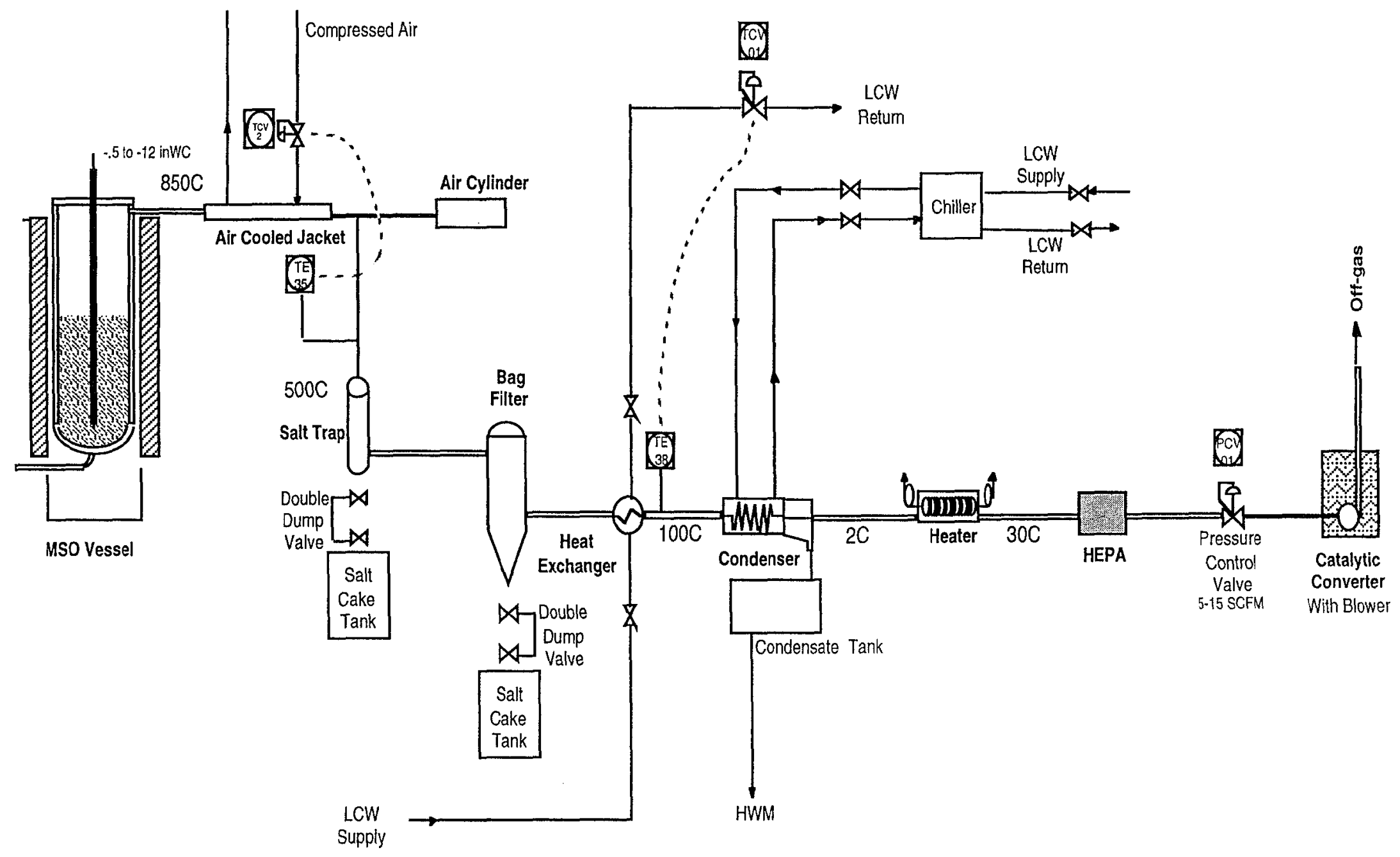

Fig. 3 Off-gas System 


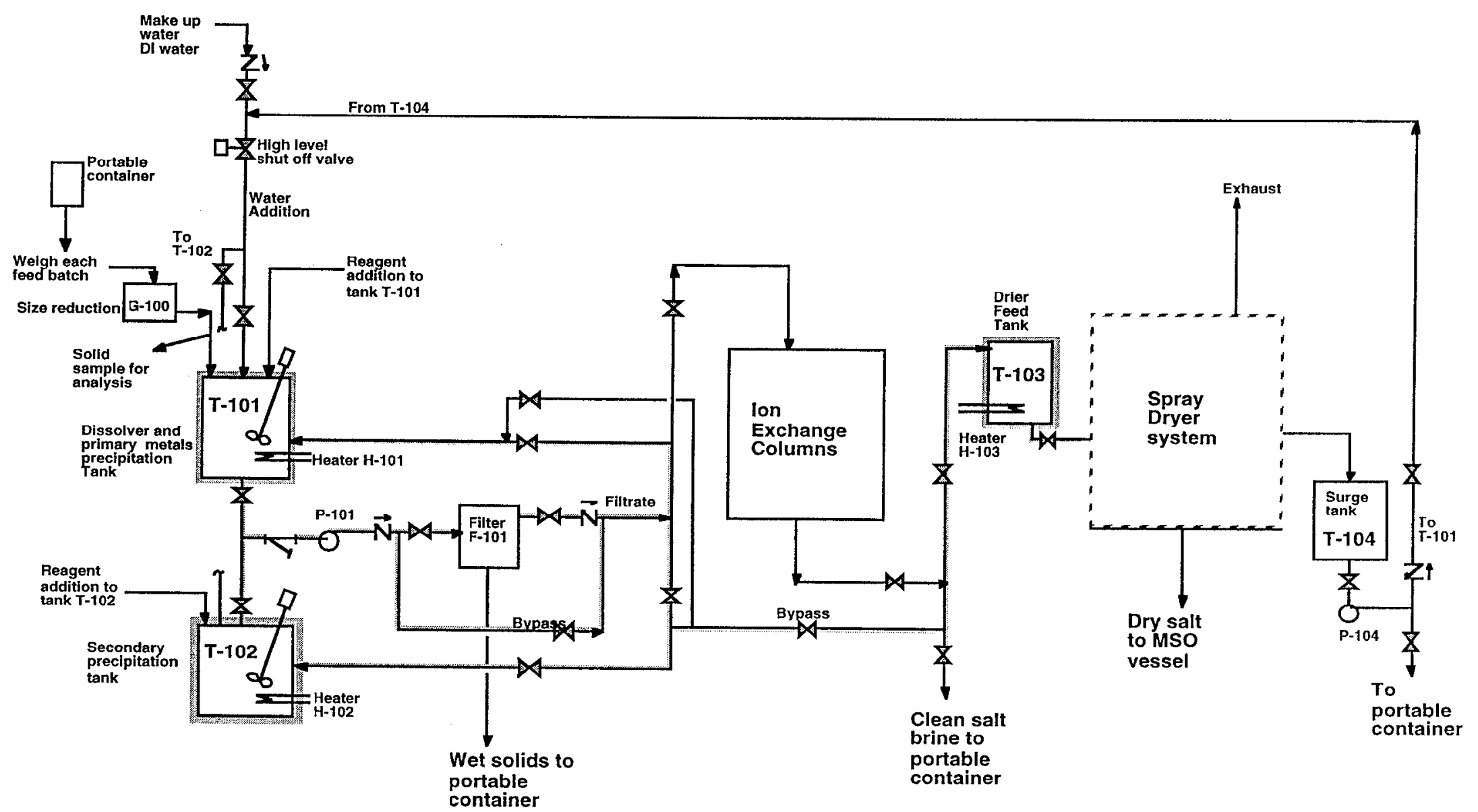

Fig. 4. Salt Recycle System flow diagram 
process to avoid an excessive holding time in the dissolver tank. These reagents can be fed into the $\mathrm{T}-101$ or $\mathrm{T}-102$ by metering pumps or by opening the hatch.

Once precipitated, these solids can then be removed by pumping the solution through F-101. The filter has a filter element of 1 micron and efficiently removes solid particles from the salt solution. The filter element may be pre-coated with a thin layer of diatomaceous earth to facilitate the filtration process. At various stages, the filter cake is removed by opening the filter vessel and relocating the filter cartridge into the wash-off area inside the enclosure. Air and water are used to assist the cake removal. The wet cakes are then sent to the Final Forms for immobilization. The filtration operation is performed inside an enclosure

After metals precipitation, the salt solution goes to a spray dryer, ion exchange columns, and/or portable containers, depending on the concentrations of carbonate and radionuclides. If the spent salt contains high level of carbonate, then the solution is pumped to $\mathrm{T}-103$ for spray drying. If it contains low levels of carbonate and traces of uranium and thorium, then the salt solution is pumped to the ion exchange columns E-101/E-102 for removal of radionuclides. In some instances, the salt solution is pumped to portable containers and shipped to Hazardous Waste Management (HWM) of LLNL.

The spray dryer is part of the salt recycle system. It receives clean salt solution from $\mathrm{T}-103$. The system includes a natural gas-fired air heater, a dryer using hot air as heating medium, a cyclone separator for collecting clean dry salt, and a venturi scrubber as well as an absorber for gas cooling and dust control. The clean dry salt is collected in well-sealed drums for reuse. The air leaving the absorber passes through a HEPA filter and exhausts. The spray dryer is operated at a slight vacuum. Condensate blowdown is pumped to T-104 for reuse or discharge.

\subsection{Ceramic Final Forms}

Final Forms will demonstrate making a ceramic waste form containing and immobilizing the "mineral residues" isolated by the ETDP Salt Recycle system. The demonstration is at the scale of a pilot plant, the basic methods having previously been developed at the benchtop scale [Ref. 12]. Final Forms' operations are largely independent of MSO and Salt Recycle, exceptions being optimizing the filter aid used by Salt Recycle to achieve optimal waste loading of the ceramic, receiving mineral residues from Salt Recycle, and merely sharing a single facility.

The filter cake produced by the salt recycle system will contain residues from the MSO input waste stream(s), and compounds introduced by the MSO process itself and by the salt recycle process. Residues derived from LLNL wastes are expected to be dominated by $\mathrm{Si}, \mathrm{Al}, \mathrm{Mg}, \mathrm{Zn}, \mathrm{Ca}$ and $\mathrm{Fe}$. The filter cake of the present MSO/SR demonstrations, however, will be dominated by the filter aid used in Salt Recycle and by the oxides of $\mathrm{Cr}, \mathrm{Ni}$ and $\mathrm{Fe}$ resulting from corrosion of the MSO reaction vessel. (This is atypical of an extended waste treatment operations; it is a consequence of the small amount of waste treated in each demonstration.) Any of a wide variety of elements may be present in minor or trace amounts. The ceramic final waste form must immobilize the hazardous and radioactive elements present; both the ceramic material and the process to make it must be adaptable to the variable composition of the filter cake; and a high waste loading is desirable. The ceramic is intended to satisfy federal and California leach resistance standards.

The ceramic material is described in Section 7 and in Ref. 12. Briefly, the ceramic comprises four principle crystalline phases chosen because (1) they can be fabricated as a durable ceramic using standard and economical ceramic processing methods; and (2) because they can incorporate, either as major constituents or by ion substitution, all of the dominant elements just mentioned, and most of the hazardous and radioactive elements of concern. In an actual waste processing setting, waste loadings could be optimized by blending residue batches, but this is impractical for ETDP. 
Suitable hazards controls are in place. See Ref. 13. In particular, the powder processing steps are conducted in closed equipment or in fume hoods to avoid dispersion of the powders. The quantities of offgas $\left(\mathrm{H}_{2} \mathrm{O}, \mathrm{HNO}_{3}, \mathrm{CO}_{2}, \mathrm{CO}, \mathrm{NO}_{\mathrm{x}}, \mathrm{SO}_{\mathrm{x}}\right)$ generated by the Final Forms system are far below regulatory limits, but some conditioning is done prior to release. Process control is local to each equipment item; process monitoring is direct to the Final Forms computer. (Automatic data logging was planned but has not yet been implemented.) The system is capable of producing $\sim 2 \mathrm{Kg}$ of ceramic waste form per 8-h working day, in the form of cylindrical pellets approximately $9 \mathrm{~mm}$ dia $\times 6 \mathrm{~mm}$ tall.

The main process steps and equipment items (italics) are as follows:

- Ceramic design and recipe.

- Batching: formulating a batch comprising a mixture of residues, ceramic precursors, and other reagents; done in an ordinary fume hood.

- Wet Milling: mixing and comminuting the batch in an attritor;

- Calcining: drying and calcining it in a rotary calciner;

- Granulation: granulating the resulting powder in a granulator;

- Pellet Pressing: forming pellets by cold-pressing the granulated powder in a pellet press.

- Sintering: sintering the pellets in a large tube furnace.

- Miscellaneous activities: material transfers between the various pieces of equipment, process control tests (including test sintering in a small tube furnace), quality control tests, and equipment maintenance and refurbishment.

These steps and the associated equipment are described below. A process functional flow diagram is given as Fig. 5, and a floor plan showing the layout of Final Forms is given as Fig. 6.

Residue Process Acceptance: Final Forms will receive containers of the mineral residues from Salt Recycle, typically in the form of an aqueous sludge (well-settled, consisting of 3-5 L of "mud" and a similar quantity of a clear supernatant aqueous solution). The residue batch will be accompanied by written documentation of its identity, history, and prior characterization. This information is used to determine the ceramic formulation, and to determine that the residue batch conforms with the OSP and Final Forms' "Process Acceptance Criteria." Receipt of the residue is entered into Final Forms' Tracking Log.

Recipe Design \& Batching: On the basis of the chemical analysis of the mineral residue, a "design" of the ceramic-meaning its phase constitution-will be chosen and a recipe for the starting mixture formulated. The components of the recipe are measured and blended in the "batching" fume hood and transferred via tubes directly to the attritor's grinding tank.

Wet Milling with Attritor: The attritor is a closed machine for wet milling. Its operation mixes the batch and comminutes it. Minor physicochemical changes occur. The slurry is continually recirculated (by a peristaltic pump) through the attritor grinding chamber. Samples are taken for process control measurements (particle size, viscosity, $\mathrm{pH}$ ). Batch properties are adjusted by further additions of reagents. When the slurry is deemed satisfactory, it is diverted from the recirculation line and pumped directly to the calciner inlet. 

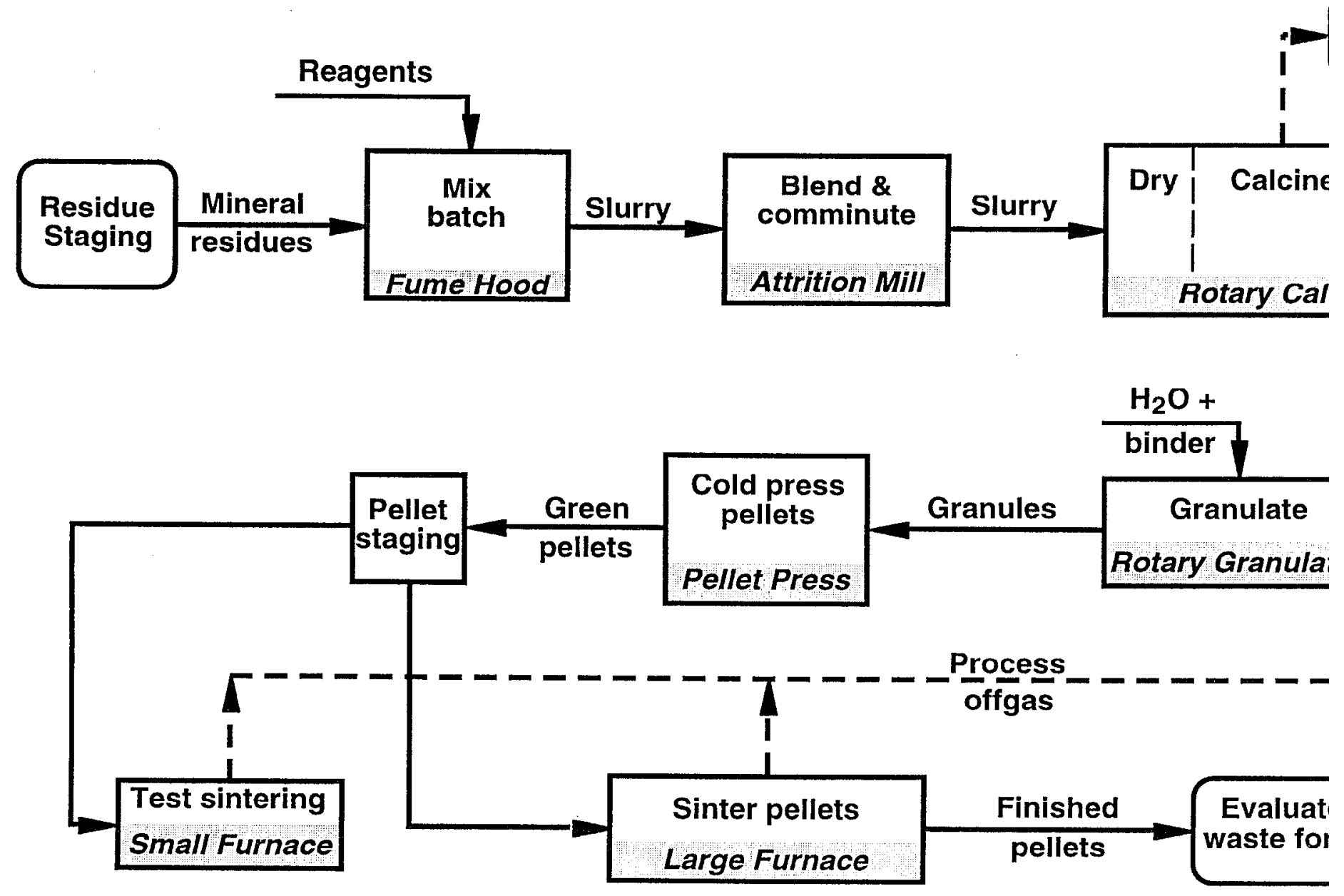

Figure 5. Ceramic waste form process functional flow diagram.

Wastewater streams generated are not shown. 


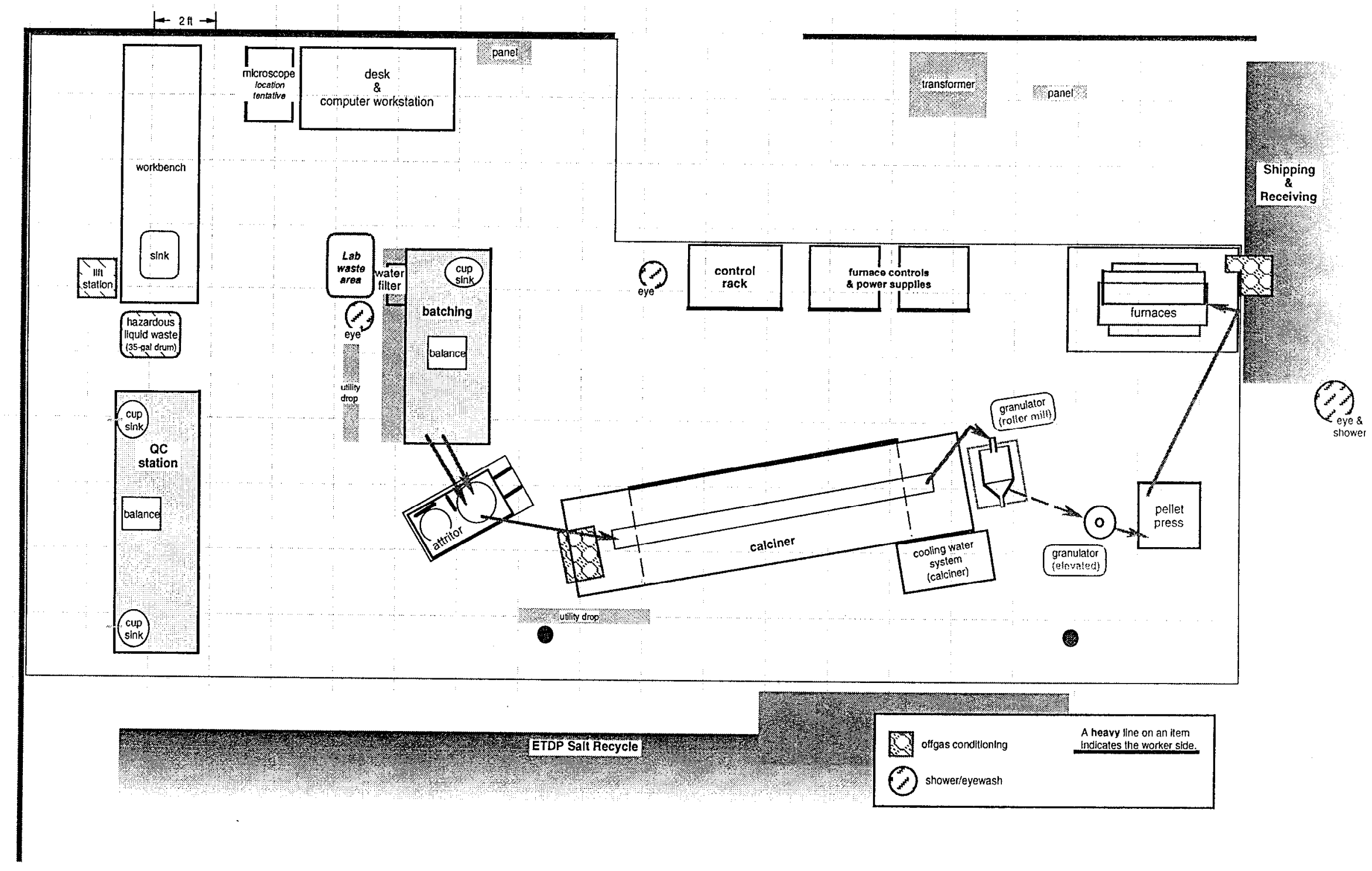

Fig. 6. Floor Plan (Final Forms) 
Calcining: The rotary calciner is an inclined tube furnace with a sealed rotating process tube (tube ID $10 \mathrm{~cm}$, heated length $1.2 \mathrm{~m}, 3$-zone, $900^{\circ} \mathrm{C}$ maximum). It is equipped with an integral cooling section, with a hammer and a scraper (to deal with any caking), feed and discharge systems incorporating air-tight seals, air input and offgas removal systems, and a simple offgas conditioning system. The "charge" (i.e., the batch slurry) enters a cool portion of the process tube and translates downward through it, encountering increasing temperatures that peak at $\sim 650^{\circ} \mathrm{C}$. The batch dries, releasing water and small amounts of $\mathrm{HNO}_{3}$ gas; hydrates, carbonates, nitrates and some sulfates decompose with the release of $\mathrm{H}_{2} \mathrm{O}, \mathrm{CO}_{2}, \mathrm{NO}_{\mathrm{x}}$ and $\mathrm{SO}_{\mathrm{x}}$; and solid-state reactions between batch components occur. Certain inorganic coumpounds (e.g., $\mathrm{Tl}_{2} \mathrm{O}_{3}$ ) will vaporize if present; these are trapped. The charge then passes through a cooling section and into the exil hopper. The "calcine" (i.e., the batch, now a powder) is released though a ball valve into a tube leading to the granulator.

The calciner operates at a slight negative pressure. Offgas is removed from a hot region within the process tube, and passes through a condenser and a local house keeping HEPA filter prior to release to the facility exhaust system. The calciner includes features designed to minimize the likelihood of steam overcoming the negative-pressure operating condition, and to minimize caking of the charge onto the process tube. In the event of a power failure, offgas is removed through a back-up system driven by a blower under emergency power, and the process tube continues to rotate to maintain the translation of the charge along it.

Granulation: Granulation is the conversion of the (potentially) dusty and/or lumpy calcine into small dust-free agglomerates. This is accomplished by tumbling the powder with small amounts of solid organic processing aids (e.g., polyethylene glycol) on a roller mill. The granulator itself is mainly a cylindrical vessel. The calcine passes from the calciner outlet downward through a flexible plastic transfer tube and through the metal inlet tube of granulator. The inlet tube is mounted in a rotary seal, allowing the body of the granulator to rotate on the mill without disconnecting the transfer tube. The outlet end of the granulator is a funncl-shaped hopper. When granulation is complete, the outlet plug is removed and a rubber hose leading to the pellet press is attached. The granulator is then elevated near the pellet press by a manual hoist, and the granulated batch flows to the press.

Pellet Pressing: The batch is cold-pressed in an automatic pellet press of the "sliding anvil" type (maximum force $\sim 36 \mathrm{KN}$, maximum rate 150 strokes $/$ min). Feeding, pressing, and ejection take place internally and automatically. The pressed pellets $(0.45$ in dia $x \sim 0.3$ in high) are removed by a vacuum pickup and dropped though a plastic tube into a container. When operating normally, the pellet press is effectively a closed system. $\Lambda$ malfunction could, however, release loose powder at the sliding anvil mechanism; a small hood covering the top of the press minimizes dispersion. The pressing force is measured intermittently, and sample pellets are removed at intervals for process-control tests. Sintering: Pressed pellets are, held in suitable refractory trays, are manually placed in the retort (a sealed refractory process tube) of one of the two sintering furnaces. The small furnace $\left(1300^{\circ} \mathrm{C}, 5\right.$-zone, $7.6 \mathrm{~cm} \mathrm{ID,}, 91 \mathrm{~cm}$ long) is for process-control test sintering of a few pellets from the batch: each batch is different, and recycling a full batch of improperly sintered pellets would be troublesome. Production sintering is done the large $\left(1300^{\circ} \mathrm{C}, 3-\right.$ zone, $15 \mathrm{~cm} \mathrm{ID,} 91 \mathrm{~cm}$ long). Operation is very similar. The temperature and process air flow is varied under automatic control through the sintering schedule. The organic additives oxidize early in the sequence. Sintering occurs over a period of about an hour at a high temperature, typically in the $1150-1180^{\circ} \mathrm{C}$ range. Process offgas is scrubbed prior to release through HEPA filters. The full sintering cycle from loading to unloading requires less than 24 hours.

Quality Control: The sintered pellets will be evaluated for process development and for waste form performance by Final Forms, other LLNL facilities, and external laboratories. 
These include physical propertics (e.g., density, strength, porosity), phase determination (X-ray diffraction), microsctructure, and leach behavior (Federal TCLP and California WET).

Archiving, Recycling, \& Disposal: When all evaluations of the ceramic waste form pellets are complete, they will either be retained by ETDP as archival specimens, or will be transferred to Hazardous Waste Management for disposal. Some of Final Forms' process "wastes" can be incorporated into a subsequent ceramic batch formulation or an MSO input waste stream. Any wastes not recycled within the ETDP system are disposed of through HWM in the usual manner.

Final Forms' integrated process: The size and nature of Final Forms' equipment dictates the way in which the above steps are integrated into a single process. We refer to the total amount of a Salt Recycle residue to be processed (which may or may not be all of that produced in the Salt Recycle run) as a "batch." Final Forms will process a batch, in a semicontinuous manner, as a series of "sub-batches." The attritor can efficiently mill enough slurry for about two kilograms of waste form at a time. (There are several standard ways whereby this limit could be overcome, but this is beyond the scope of the project.) In contrast, calcining less than enough for about one kilogram at a time is problematical. Accordingly, a residue batch will be mixed (in case settling has led to segregation of the batch components) and divided into sub-batches. Each sub-batch will be mixed and milled with mineralizers and other reagents in the attritor, and the sub-batch pumped into the calciner. As soon as the attritor is free, another sub-batch will be milled. The calciner will be operated continuously. Typically, calcination of a sub-batch will be finished before milling of the next sub-batch is complete. When enough calcine has been collected in the outlet hopper of the calciner, a suitable quantitiy $(\sim 1 \mathrm{Kg})$ will be passed into the granulator and granulated. Meanwhile, additional calcine from subsequent sub-batches will be collecting in the hopper. Thus, the sub-batches become re-combined. When granulation is complete, the contents of the granulator are pressed into pellets; the granulator is charged with more powder; and another granulation step carried out. Granulation is the slowest of these steps, requiring about a day.

\section{DESIGN OF EXPERIMENTS IN THE MSO OFF-GAS SYSTEM}

The experiments performed in the fiscal 1998 were divided into five test series, ranging from functional testing of each hardware component to "treatability test" demonstrations with real waste streams at LLNL. Each test series is described below.

\subsection{Test Series I - Operational check-out and Establish Baseline Operations}

This test series started with startup testing - a "shake down" of the new pilot plant. It included functional verification of all utilities, the control system (including all safety/alarm features), and confirmation that all hardware was operational and fully functional; this included the heater, and off-gas equipment. In this test series, system operational parameters were evaluated and optimized using the liquid injector. Testing included variation of percent excess air, air/feed ratio within injector tubes, amount of cooling air required in injector to maintain injector tip temperature below $200^{\circ} \mathrm{C}$, ability to control temperature within the reactor by varying heater/blower power for both endothermic and exothermic feeds, and determination of heat-up and cool-down profiles for the $160 \mathrm{~kg}$ salt charge (to enable programming of off-shift start-up module within control system). Materials tested were toluene, ethylene, and mineral oil that were previously tested in the Engineering Development Unit (EDU), to facilitate assessment of the effectiveness of scaleup. Testing also included a continuous 8-hour toluene run to test the system long term stability. 
Organic feed rates, oxidant air flow, injector cooling air flow, injector temperature, vessel temperatures and pressure, gas flow, temperatures, and pressures in the off-gas system were closely monitored. Appendix 1 shows all the data recorded for each run (MSO Processor Data Sheet ). Several gas species including carbon dioxide, carbon monoxide, nitrogen oxides, oxygen, sulfur oxides, and total organic carbon were monitored continuously with off-gas analyzers. Nitrogen oxides and carbon monoxide were also monitored downstream of the catalytic converter.

\subsection{Test Series II - Tests with Liquid Organic Surrogates Containing Heteroatoms}

Organic liquids containing heteroatoms were tested in the Test series $I$. These included toluene spiked with organics containing heteroatoms such as chlorine, fluorine, nitrogen, sulfur, and phosphorous. Examples of spikants are pyridine, dimethyl sulfoxide (DMSO), trichloroethylene (TCE), Freon 113, and dimethyl phosphate. Chlorine, fluorine, sulfur, phosphorous in the organics were converted into chloride, fluoride, sulfate, and phosphate, respectively, which stayed in the molten salt. Salt was drained from the vessel, providing surrogate test material to the salt recycle system. This series was followed by two weeks of maintenance including in-situ non-destructive evaluation of reactor corrosion using ultrasonic testing, inspection of rupture disc, GSS filter, and change-over to a solid injector.

For each run in the test series $\Pi$, all the process data including gas species were recorded in the sheet as shown in Appendix 1. Some gas samples were also collected and sent to a laboratory for analysis of POHCs (principal oganic hazardous compounds). This analysis provided information on the DRE of the MSO process for each individual POHC. Spent salt drained out of the reaction vessel was sent to the salt recycle system.

\subsection{Test Series III - Solid Feed Injection}

The objective for Test Series III was to determine essential operational parameters for the solid injector using several prototypical solid feeds. Surrogate materials included ABS plastic pellets, ion exchange resin, shredded booties and gloves, and activated carbon. For each run in the test series $\mathrm{III}$, all the process data including gas species are recorded in the sheet as shown in Appendix 1. Some gas samples were also collected and sent to a laboratory for analysis. Salt containing ash was drained from the MSO vessel and sent to the salt recycle system.

\subsection{Test Series IV - Tests with Radioactive-Spiked Liquids}

Based on the results achieved with materials tested in test series II, surrogate organics were spiked with low-level radioactive materials such as ${ }^{238} \mathrm{U} / \mathrm{D}-38$. The compositions of surrogate materials mimicked the following low-level mixed waste streams at LLNL: LL-W008, LL-W009, LL-W014, and LL-W016. Salt was drained from the reaction vessel and sent to the salt recycle system for processing. A surrogate organic, toluene, was traced with a small quantity of C-14 labeled organics in order to establish accurate mass balances for carbon. Analysis of $\mathrm{C}-14$ was determined using the accelerator mass spectrometry (AMS) technique.

For each run in the test series, all the process data including gas species were recorded in the sheet as shown in Appendix 1. Some gas samples were also collected and sent to a laboratory for analysis. The off-gas leaving the catalytic converter was monitored continuously for radioactivity. For the run traced with C-14, organic feed, off-gas samples, and salt were collected and sent to CAMS (Center for Accelerator Mass Spectrometry) for 
analysis. This analysis determined the carbon exchange and the distribution between organic carbon and carbon in sodium carbonate $\left(\mathrm{Na}_{2} \mathrm{CO}_{3}\right)$ during the oxidative destruction of organics in the reaction vessel.

\subsection{Test Series V - Treatability Studies with Low-level Mixed Waste Specimens}

Two real waste samples were selected from the current LLNL mixed waste inventory, RTS\#1 and RTS\#2. RTS\#1 was chlorinated solvents (LL-W008) and RTS\#2 was a PCB-contaminated waste oil (LL-W009). Both are considered hazardous and difficult to treat or dispose of. Before Series V started, the selected wastes were sampled and sent for a comprehensive analysis. The chlorinated solvent contains mostly methyl chloroform (MCM) with traces of metals and radionuclides such as uranium and tritium. The PCB-contaminated oil contained 1567 ppm PCB.

During the demonstration, toluene was added to the waste specimens for volatility control (chlorinated solvent) and for reducing the viscosity of waste oil (PCB-contaminated oil). All the process data including gas species are recorded in the sheet as shown in Appendix 1. Best Environmental, Inc., a certified off-gas handler, was contracted for the off-gas sample collection and analysis per EPA methods. After each demonstration with the real waste specimen, salt was drained out from the reaction vessel and sent to the salt recycle system for processing.

\section{SALT RECYCLE EXPERIMENTS}

The salt recycle system processes spent salts generated in MSO. If the spent salts contain significant levels of carbonate, the system will spray-dry the resulting clcan salt solution and send the dried salt back to the MSO vessel in order to minimize the generation of sccondary waste as well as to reduce cost. If the spent salts contain very high levels of chloride and are destined for disposal, the SR system can clean up the salts and remove contaminants to a degree which meets the specification acceptable for final disposal. In FY 98, there were six batches of spent salts processed in the salt recycle system, SR1, SR2, SR3, SR4, SR5, and SR6. Processing of each spent salt followed the procedure described in Section 4.3 and Fig. 7. A detailed description of the salt recycle operational procedure can be found in the operational manual [4].

SRI was the spent salt drained from MSO after test series I and II. It was a nonradioactive salt with very low ash content. It also contained some chloride, fluoride, phosphate, and sulfate due to the types of organics fed into the reaction vessel in the test series. Traces metal compounds such as chromium, nickel and iron may exist in the salt. SR2 is the spent salt drained from MSO after test series III. It is a non-radioactive salt with some ash. The ash level in the salt, depending on the types and amounts of solid fed into the reaction vessel, is generally less than $10 \mathrm{wt}$.\% in order to avoid excessive melt viscosity. SR3 was the spent salt drained after the C-14 run and activated carbon run. SR4 was spent salts drained from test series IV and was a high chloride salt. SR5 and SR6 were the salts drained after runs of RTS\#1 and RTS\#2, respectively. They contained lowlevel radionuclides such as uranium along with some chloride and fluoride.

In the salt recycle experiments, the salt solutions and the resulting solid salts were routinely analyzed for a variety of metals using ICP-OES. Additional analyses were occasionally performed for anionic species such as $\mathrm{Cl}^{-}, \mathrm{F}^{-}, \mathrm{NO}_{3}^{-}, \mathrm{SO}_{4}{ }^{2-}, \mathrm{CO}_{3}{ }^{2-}$, and $\mathrm{PO}_{4}{ }^{3-}$ using ion chromatography, and uranium concentrations were determined by using ICP-MS. 


\section{Figure 7 Flowsheet for Aqueous Processing of Spent Salt}

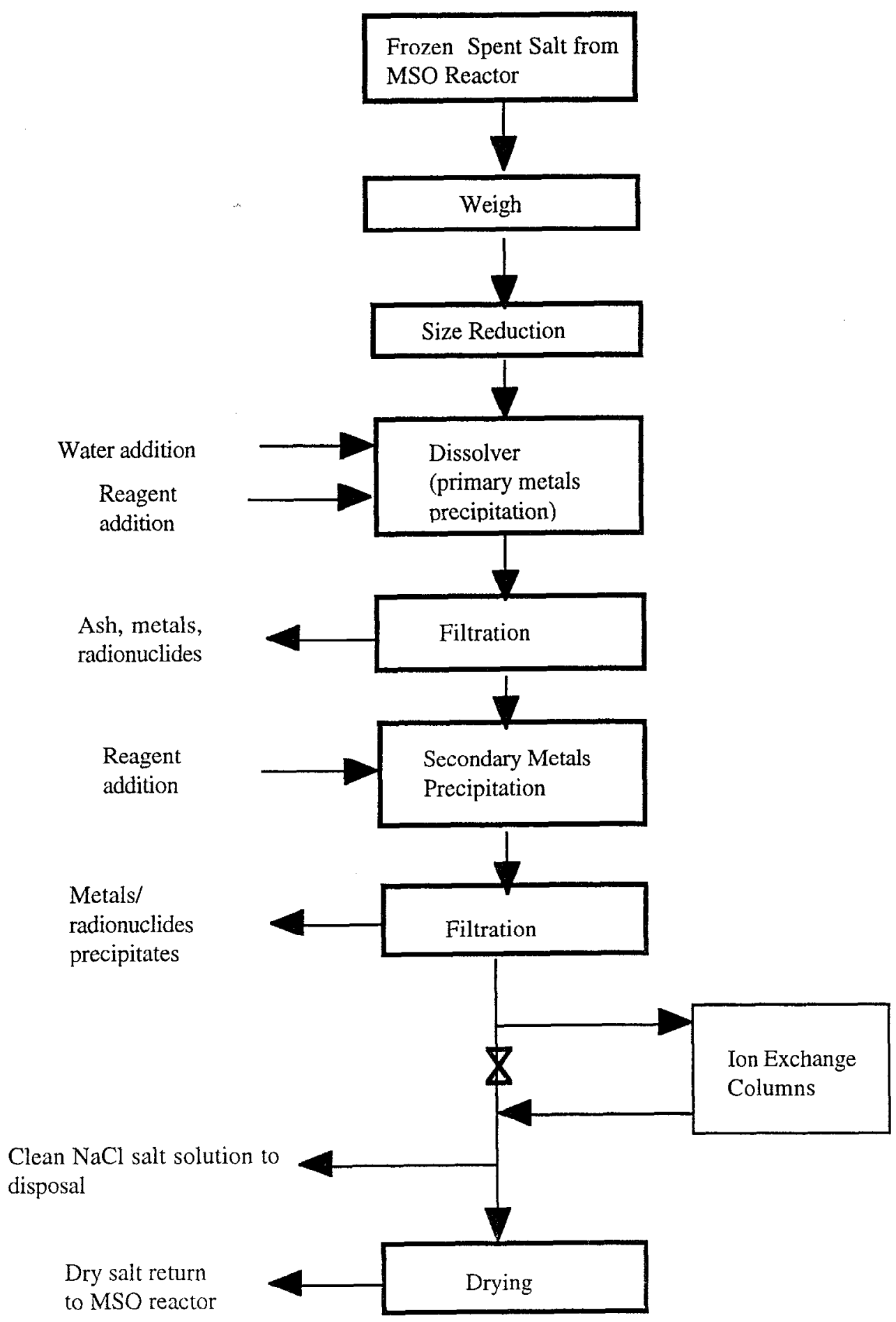




\section{FINAL FORMS EXPERIMENTS}

As described in Section 4.4, Final Forms immobilizes solid inorganic residues of the MSO process. The residues (or surrogate residues) are blended with mineralizers and converted to a ceramic waste form. The goal is to test, demonstrate and evaluate the process and waste form for various MSO-based waste treatment scenarios.

The Final Forms system was installed and tested in FY98, and shake-down operation of individual equipment items began in July 1998 and are continuing into FY99. An OSP, based in part on this experience, was reviewed in September and formally approved in October 1998. Only the minimum I\&C components have been installed.

The Final Forms system-which includes the design of the ceramic material and the process as well as the facility - was designed to demonstrate the process on the scale of a small pilot plant. The design was based on previous bench-scale experience (Ref.12). Each of the process steps described in Section 4.4 had their bench-scale analogue, but the pilotscale processing procedures and equipment are quite different. Adapting the bench-scale process to the pilot scale requires some process development experiments.

In addition, there are significant differences between the residues to be immobilized as part of the ETDP demonstrations and the hypothetical ones on which the bench-scale development was based. Our perception of these differences changed as experience with the MSO and Salt Recycle operations accumulated. Adapting to these changed conditions will be an important part of our FY99 efforts, involving both MSO and Salt Recycle as well as Final Forms. In a broader context of a bona fide waste treatment operation, the significance of these matters depend on the nature of the operation. A brief discussion follows:

\subsection{Residues, ceramic material design, and integrated operations}

The ceramic waste form comprises five principal phases. These, with their base compositions and immobilization rôles are as follows:

$\begin{array}{lll}\text { nepheline } & \mathrm{Na}_{2} \mathrm{O} \cdot \mathrm{Al}_{2} \mathrm{O}_{3} \cdot 2 \mathrm{SiO}_{2} & {[\mathrm{Si}, \mathrm{K}]} \\ \text { spinel } & \mathrm{MgO} \cdot \mathrm{Al}_{2} \mathrm{O}_{3} & {\left[\mathrm{Mg}, \mathrm{V}-\mathrm{Ga} \text { except } \mathrm{Cu}^{1+}\right]} \\ \text { zirconolite } & \mathrm{CaO} \cdot \mathrm{ZrO}_{2} \cdot 2 \mathrm{TiO}_{2} & \begin{array}{l}\text { [Sr, Hf, tetravalent lanthanides and actinides } \\ \left.\text { including } \mathrm{U}^{4+}\right]\end{array} \\ \begin{array}{ll}\text { perovskite } \\ \text { rutile }\end{array} & \mathrm{CaO} \cdot \mathrm{TiO}_{2} & \begin{array}{l}\mathrm{Sr}, \mathrm{Pb} \text {, trivalent lanthanides and actinides] } \\ \text { stabilizes perovskite and zirconolitc }\end{array}\end{array}$

A ceramic waste form "design" is simply the specification of the relative amounts of each phase. This simply a matter of matching the phases to the filter cake composition, subject to the constraints that $\sim 5$ mole \% should be rutile and each of the other four should be $>10$ mole $\%$.

Input waste streams for an integrated MSO-based waste processing facility might include any or all of the following: (1) low-ash, low-halogen; (2) low-ash, high-halogen; and (3) high-ash. All these are found in LLNL's inventory of mixed wastes. To date, only low-ash streams have been treated by ETDP, and these have been in relatively small quantities. For demonstation reasons, the salt has been recycled frequently, so only small amounts inorganic solid residues had accumulated in the salt. Moreover, the "ash" content of the input waste streams was so low that the principal inorganics in the salt have been the products of corrosion of the Inconel $600^{\circledR}$ reaction vessel-oxides of $\mathrm{Cr}, \mathrm{Fe}$ and $\mathrm{Ni}$. $(\mathrm{Cr}$ and Ni are regulated clements.) The amount of "filter aid" used in Salt Recycle's filtration is pretty much a fixed volume, independent of the amount of residue solids to be trapped. Typically, $\sim 2 \mathrm{Kg}$ of diatomaccous carth (amorphous $\mathrm{SiO}_{2}$ ) is uscd. As a consequence of 
all this, the residue batches to be immobilized by Final Forms are dominated by the filter aid and, to a much lesser extent, by the vessel corrosion products.

Now this is not be the natural way to operate a "real" waste processing facility. Instead, the inorganic residues would be allowed to build up in the salt until recycling became necessary either because of the viscosity increase due to the suspended solids, or (when halogenated hydrocarbons are treated) the concentration of $\mathrm{NaCl}$ (or other sodium halide) became high enough to degrade the MSO efficiency. In either case, the filter aid would be used and reused until the amount of residue accumulated interfered with the filtration process (e.g., excessive pressures). In the case of low-ash waste streams, a residue batch would include substantial amounts of filter aid, and of oxides of $\mathrm{Cr}, \mathrm{Fe}$ and $\mathrm{Ni}$; and lesser-but important-quantities of the inorganic contaminants in the input waste, including hazardous and radioactive components. With high-ash waste streams, the "ash" and the filter aid would dominate the filter cake. It was for these scenarios that Final Forms' ceramic material was designed.

It is clear that a convincing demonstration of Final Forms' process must include more than just immobilizing the hazardous and radioactive consistuents in the ETDP demonstraton residues: Final Forms should also immobilize surrogate residues modeled on the normal operation of a real waste precessing facility.

Since silica is the principal component in filter cake from ETDP's demonstrations, the ceramic design requires a high fraction of nepheline. Reasonable levels of spinel and zirconolite are needed to demonstrate the capability to immobilize the corrosion products (intrinsic to the system) and uranium (the main radioisotope of interest). Obviously, a high silica content in the residue implies major additions of other mineralizers (alumina, titania, etc.). This dilutes the other components in the filter cake, thereby perversely lowering the possible loading levels of hazardous and radioactive elements. This can be alleviated by modifying the filter aid. Instead of using only silica, other mineralizers required in the ceramic formulation could be added to the diatomaceous earth to give the standard total volume of filter aid. Filtration efficiency might suffer somewhat (diatomaceous earth is exceptionally effective), but waste form loadings would be higher.

Final Forms' earlier plans were based on the mistaken notion that the filter cakes received from Salt Recycle would be quite small. We therefore planned to immobilize these at the bench scale, and to simulate the pilot-scale immobilization using a carefully matched surrogate. Such coordinated immobilizations (previously termed "Combination Tests") were dropped from the work plan.

The mineral content of residues resulting from processing laboratory trash and certain other solids are affected by their residence in the MSO vessel. Surrogates of such residues prepared by simply blending reagents may not adequately mimic the authentic residues. It is therefore desirable to demonstrate Final Forms' performance with for high-mineral wastes using residues from a special surrogate feed processed through the MSO and SR systems.

The bench-scale development work used calcined kaolin $\left(\mathrm{Al}_{2} \mathrm{O}_{3} \cdot 2 \mathrm{SiO}_{2}\right)$ as the source of $\mathrm{SiO}_{2}$. Though diatomaceous earth provides ample silica needed chemically for the ceramic, the solid- and liquid-state reactions during calcination and sintering will be different. It is not certain that the correct phases will form in the correct amounts. (The ceramic is not a thermodynamically-equilibrated system.) Experimental verification is a top priority for FY99.

As noted above the concentrations of hazardous and radioactive elements in the filter cakes are very small. Final Forms tests will therefore include surrogate formulations to demonstrate process and material performance at high waste loadings. Most of the Salt Recycle filter cakes are large enough that immobilizing half would provide an adequate demonstration. The other half could be augmented with selected hazardous and radioactive 
compounds to test our ability to achieve high waste loadings in a matrix of authentic MSO residues.

\subsection{Startup and Test Schedule}

The schedule of Final Forms activities, actual for FY1998 and planned into FY99, are as follows:

Facility installation (10/97-7/98): The main Final Forms equipment items were installed, mainly by Plant Engineering. Fabrication and installation of the process air/process offgas (PA/POG) system for the tube furnaces will continue into FY1999.

Facility startup (7/98 - 9/98): Testing of individual equipment items, initially with no processing of material. Functional tests of mechanical, thermal and I\&C operation. Tests of containment functions, including fume hoods, waste water collection, and off-gas treatment. Functional tests of individual equipment items, with processing of innocuous material. Determine operational responses of equipment items (for example, the actual time and position temperature profiles of a furnace).

Equipment modifications (8/98 - continuing): As we work with the equipment, various desirable design modifications become apparent. An example is the granulator design, whose operation is proving finicky. Some modifications have been recommended by Hazards Control. The modifications will be scheduled to interfere as little as possible with the processing activities.

Process development I - Individual equipment items (7/98 - 12/99): Fabrication of ceramic waste form from residue surrogates using major equipment items individually. The purpose is to determine the process parameters of the individual process steps, to test all safety and I\&C functions, and to gain experience with a variety of formulations. At first innocuous surrogates will be used, then testing will continue with low-hazard surrogates more typical of the residues expected in practice. Filter aids will be included in varying amounts to determine their influence on the process. No radioactive or particularly hazardous components will be used during this phase. Also included in this phase will be the joint experimental development of filter aids by Salt Recycle and Final Forms. Work in FY98 was mainly with the attritor, the calciner, and the pellet press.

Process development II - system integration (12/98 - 2/99): Process integration of major equipment items, initially pair-wise along with the connections between them. (An example is the attrition mill and rotary calciner along with the slurry pumping system that joins them.) This will be followed by testing and process development of the fully integrated system.

Demonstrations (2/99 -3/99): Demonstration tests of the FFM system will consist of fabricating and evaluating ceramic waste forms. Some tests will use surrogates chosen to mimic residues from waste streams which have not been tested by MSO but which appear sensible. Such waste streams include laboratory trash (paper, protective garments, etc.), machining fluids containing dispersed metals, and contaminated organic liquids. Toxic and low-activity radioisotopes (mainly ${ }^{238} \mathrm{U}$ ) will be included. Immobilization demonstrations using authentic residues from MSO treatment of surrogate wastes will be done. In particular, the residue from the high-mineral waste stream surrogate will be treated/ immobilized. The main demonstrations will be the immobilization of filter cake from MSO/Salt Recycle opcrations. 


\section{DEMONSTRATION RESULTS FOR THE MSO/OFF-GAS SYSTEM}

The pilot-scale MSO/Off-gas system was successfully started up in December 1997. The system had been tested with various liquid feeds including simple organics, organics containing heteroatoms ( $\mathrm{Cl}, \mathrm{F}, \mathrm{N}, \mathrm{O}, \mathrm{P}, \mathrm{S})$, surrogate feeds, and LLNL real wastes. The system was also tested with several solids such as ion exchange resin, plastic, rubber, and activated carbon. The testing was based on the five test series described in Section 5.

\subsection{Results of Test Series I}

\subsubsection{Establishing the Salt Plug}

The MSO vessel has a salt drain pipe extending from the bottom of the vessel to outside the heated zone as described in Section 4.1. A mechanical plug is mounted to the end of the drain pipe. A plug of frozen salt needs to be established in the salt drain pipe before organic is fed into the vessel. The salt is either pure sodium carbonate or a mixture of sodium carbonate and potassium carbonate. The amount of salt used in the MSO vessel is $160 \mathrm{~kg}$, but a lesser amount of salt $(50 \mathrm{~kg})$ can be used for establishing the salt plug. To confirm the existence of the salt plug, the mechanical plug was removed after the salt plug was established. Figure 8 is a picture of a salt plug.

\subsubsection{Results of Testing with Simple Organics}

The function of each component in the MSO/off-gas system was verified with several organic liquids: toluene, mineral oil, and ethylene glycol. Process data were recorded using datasheet as shown in Appendix 1. Toluene and mineral oil were chosen for their range of viscosities. It was expected that viscosities of most of surrogate and real wastes would be in between viscosities of toluene and mineral oil. Table 1 lists the organic liquids and run conditions for the test series.

Table 1: Run Conditions

\begin{tabular}{lll} 
No. & Organic Liquids & Run Conditions * \\
1 & Toluene (50\%), Mineral oil $(50 \%)$ & $950^{\circ} \mathrm{C}, 30 \%$ excess air \\
2 & Ethylene glycol & $30 \%$ excess air, $900 \mathrm{C}, 925^{\circ} \mathrm{C}, 950^{\circ} \mathrm{C}$ \\
3 & Ethylene glycol & $950^{\circ} \mathrm{C}$, varying $\%$ excess air \\
4 & Toluene & $950^{\circ} \mathrm{C}$, varying \% excess air \\
6 & Toluene & $950^{\circ} \mathrm{C}, 30 \%$ excess air, 8-hour run \\
\hline
\end{tabular}

* Note: driver air is the process air fed through the feed tube along with the organic liquid; most of the process air was fed through the oxidant air tube.

Table 2 shows the off-gas compositions from the ethylene glycol run at three salt temperatures, $900^{\circ} \mathrm{C}, 925^{\circ} \mathrm{C}$, and $950^{\circ} \mathrm{C}$. $\mathrm{CO}$ and $\mathrm{NO}_{\mathrm{x}}$ concentrations in the off-gas were very low. It seems that, above $900^{\circ} \mathrm{C}$, the effect of temperature on the off-gas quality was very small. However, it is desirable to maintain the tempcrature of sodium carbonate above 


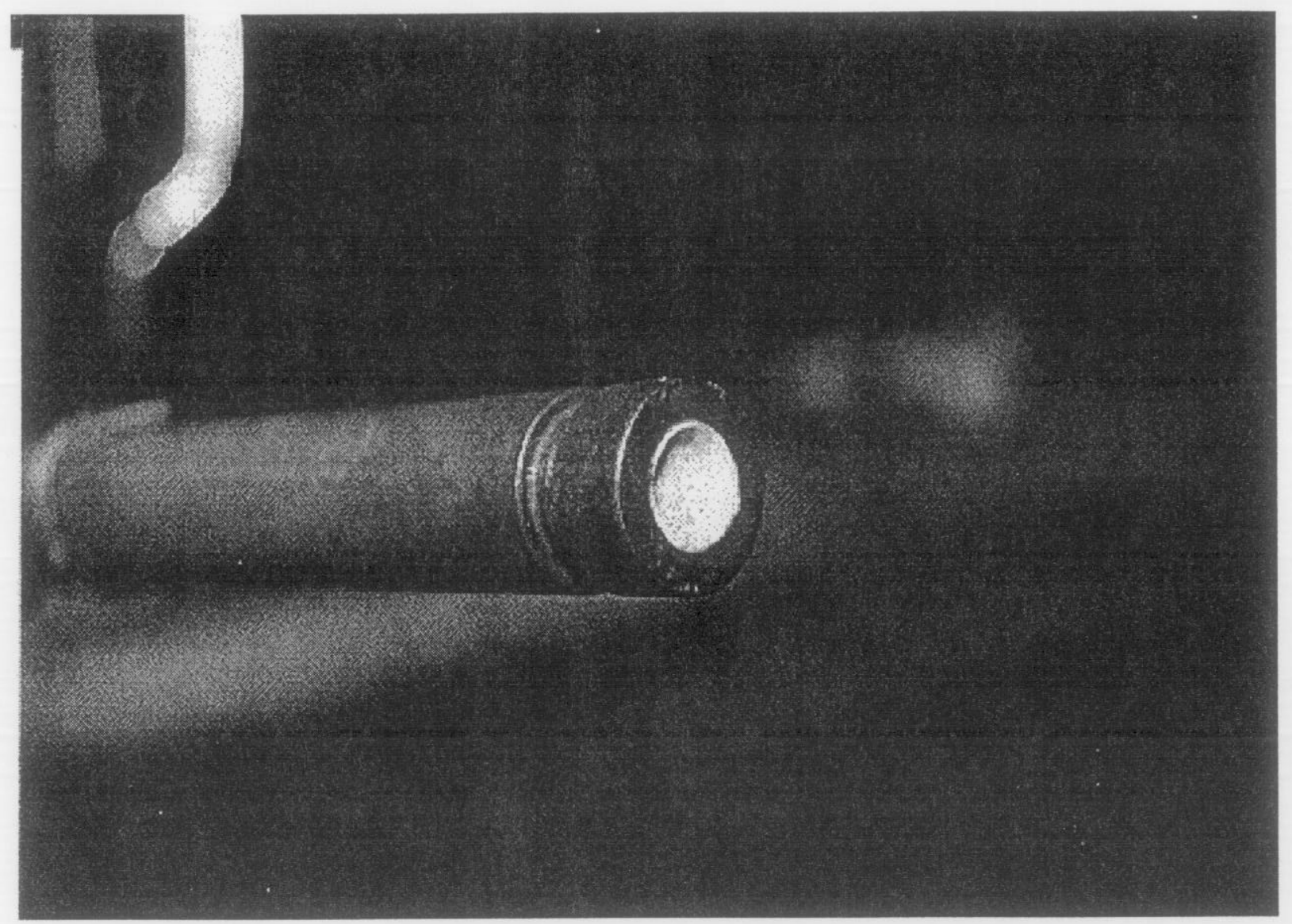

Figure 8. Salt plug in the drain pipe (picture taken on December 4, 1997) 
$900^{\circ} \mathrm{C}\left(50^{\circ} \mathrm{C}\right.$ above its melting point) during the organic feed in order to avoid plugging of the injector tip.

Table 2: Effect of Temperature on the Ethylene Glycol Run

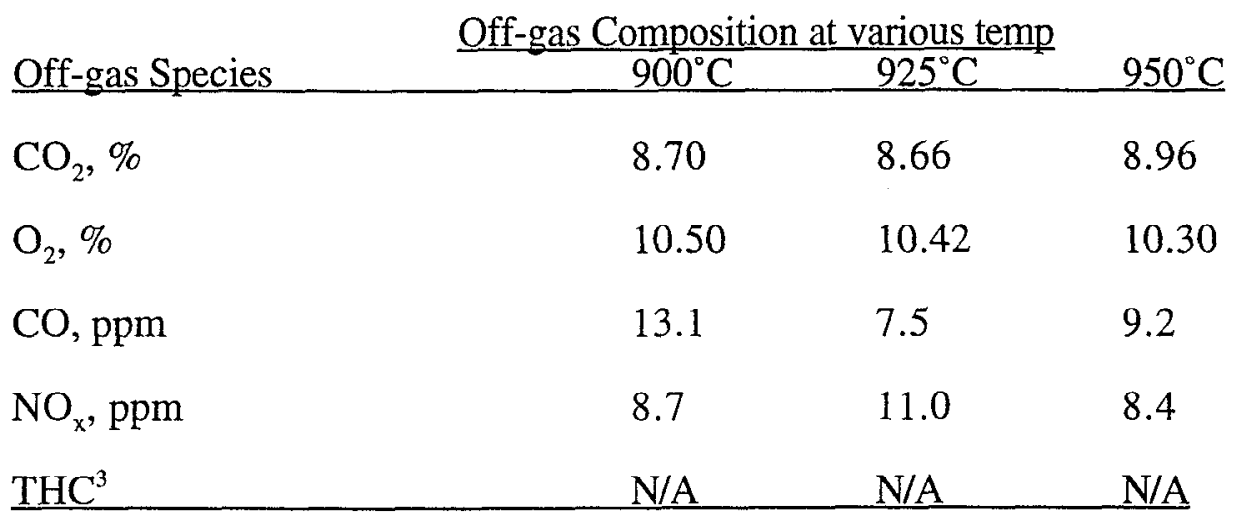

Note: 1 . feed rate of ethylene glycol was $2.6 \mathrm{~kg} / \mathrm{hr}$,

2. $30 \%$ excess air was used.

3. During the time of run, the THC analyzer was being serviced and therefore was not available.

For any oxidation process, excess oxygen/air is needed to maintain a good process efficiency. Higher excess air dilutes $\mathrm{CO}_{2}$ and increases $\mathrm{O}_{2}$ concentration in the off-gas. It also increases off-gas flow. Tables 3 and 4 show the off-gas compositions for the MSO demonstration with ethylene glycol and toluene at various \% excess air, respectively.

They show that the off-gas qualities were not affected by the \% excess air. It is desirable to run the MSO process with at least $10 \%$ excess air or higher to overcome the fluctuation of organic feed rate.

Table 3: Effect of \% Excess Air for the Ethylene Glycol Run

\begin{tabular}{|c|c|c|c|}
\hline Off-gas Species & $\frac{\text { Off-gas Compositi }}{10 \%}$ & ious ex & $60 \%$ \\
\hline $\mathrm{CO}_{2}, \%$ & 10.2 & 8.74 & 7.1 \\
\hline $\mathrm{O}_{2}, \%$ & 8.4 & 10.2 & 12.1 \\
\hline $\mathrm{CO}, \mathrm{ppm}$ & 9.2 & 8.3 & 8.7 \\
\hline $\mathrm{NO}_{x}, \mathrm{ppm}$ & 13.7 & 14.6 & 7.5 \\
\hline $\mathrm{THC}$ & 1.7 & 1.4 & 2.5 \\
\hline
\end{tabular}

Notes: 1. feed rate of ethylene glycol was $2.6 \mathrm{~kg} / \mathrm{hr}$,

2. salt temperature at $950^{\circ} \mathrm{C}$. 
Table 4: Effect of \% Excess Air for the Toluene Run

\section{Off-gas Composition at various excess air}

\begin{tabular}{llll} 
Off-gas Species & $10 \%$ & $30 \%$ & $60 \%$ \\
\cline { 2 - 4 } $\mathrm{CO}_{2}, \%$ & 10.5 & 8.9 & 7.3 \\
$\mathrm{O}_{2}, \%$ & 7.8 & 9.9 & 11.8 \\
$\mathrm{CO}, \mathrm{ppm}$ & 6.2 & 4.5 & 5.0 \\
$\mathrm{NO}_{\mathrm{x}}, \mathrm{ppm}$ & 115 & 97 & 68 \\
$\mathrm{THC}$ & 0.6 & 0.5 & 0.85 \\
\hline
\end{tabular}

Notes: 1 . feed rate of toluene was $1.2 \mathrm{~kg} / \mathrm{hr}$, 2. salt temperature at $950^{\circ} \mathrm{C}$.

For all MSO runs in test series I, run duration was at least one hour or longer in order to reach steady state which typically occurred 30 minutes after feed starts. An 8-hour run with toluene was demonstrated for its long term stability. Figure 9 shows the off-gas composition for the 8-hr toluene run. All the data were recorded in process datasheet as shown in Table 5. Figure 9 and Table 5 demonstrate the stability of the MSO process during the treatment of toluene.

Table 7: Off-gas Composition for Feed of Toluene/Pyridine

\section{Off-gas Species, ppm or \%}

\begin{tabular}{ccccccc} 
Time, hrs & $\mathrm{THC}, \mathrm{ppm}^{*}$ & $\mathrm{NO}_{\mathrm{x}}, \mathrm{ppm}$ & $\mathrm{CO}, \mathrm{ppm}$ & $\mathrm{CO}_{2}, \%$ & $\mathrm{O}_{2}, \%$ & $\mathrm{Vs}, \mathrm{ft} / \mathrm{s}$ \\
\hline 0.3 & 0.61 & $\begin{array}{c}967 \\
(50)\end{array}$ & 10.7 & 9.9 & 11.1 & 1.0 \\
0.8 & 1.1 & $\begin{array}{c}1195 \\
(50)\end{array}$ & 9.7 & 8.8 & 10.8 & 1.0 \\
& & & & & \\
1.3 & 1.2 & $\begin{array}{c}1371 \\
(50)\end{array}$ & 10.0 & 8.6 & 10.5 & 1.0 \\
1.7 & 1.3 & $\begin{array}{c}370 \\
(50)\end{array}$ & 10.3 & 8.4 & 10.6 & 1.0 \\
\hline
\end{tabular}

The conversion of organic nitrogen in the feed to $\mathrm{NO}_{\mathrm{x}}$ depends on the source of organic nitrogen and oxidation temperature. Incineration would generate higher level of $\mathrm{NO}_{x}$ than molten salt oxidation because incinerators operate at scveral hundred degree higher than $950^{\circ} \mathrm{C}$, a typical MSO temperature for waste treatment. Pruneda et.al.[5] reported that less than $1 \%$ of organic nitrogen converted into $\mathrm{NO}_{\mathrm{x}}$ at $750^{\circ} \mathrm{C}$ for the destruction of energetic materials. Table 9 shows the degrees of conversion of pyridine, nitromethane, and urea at $950^{\circ} \mathrm{C}$ along with several explosives at $750^{\circ} \mathrm{C}$. 
Fig. 9. Toluene feed at $1.2 \mathrm{~kg} / \mathrm{hr}, 30 \%$ excess air, salt at $950 \mathrm{C}$ (8 hrs run)

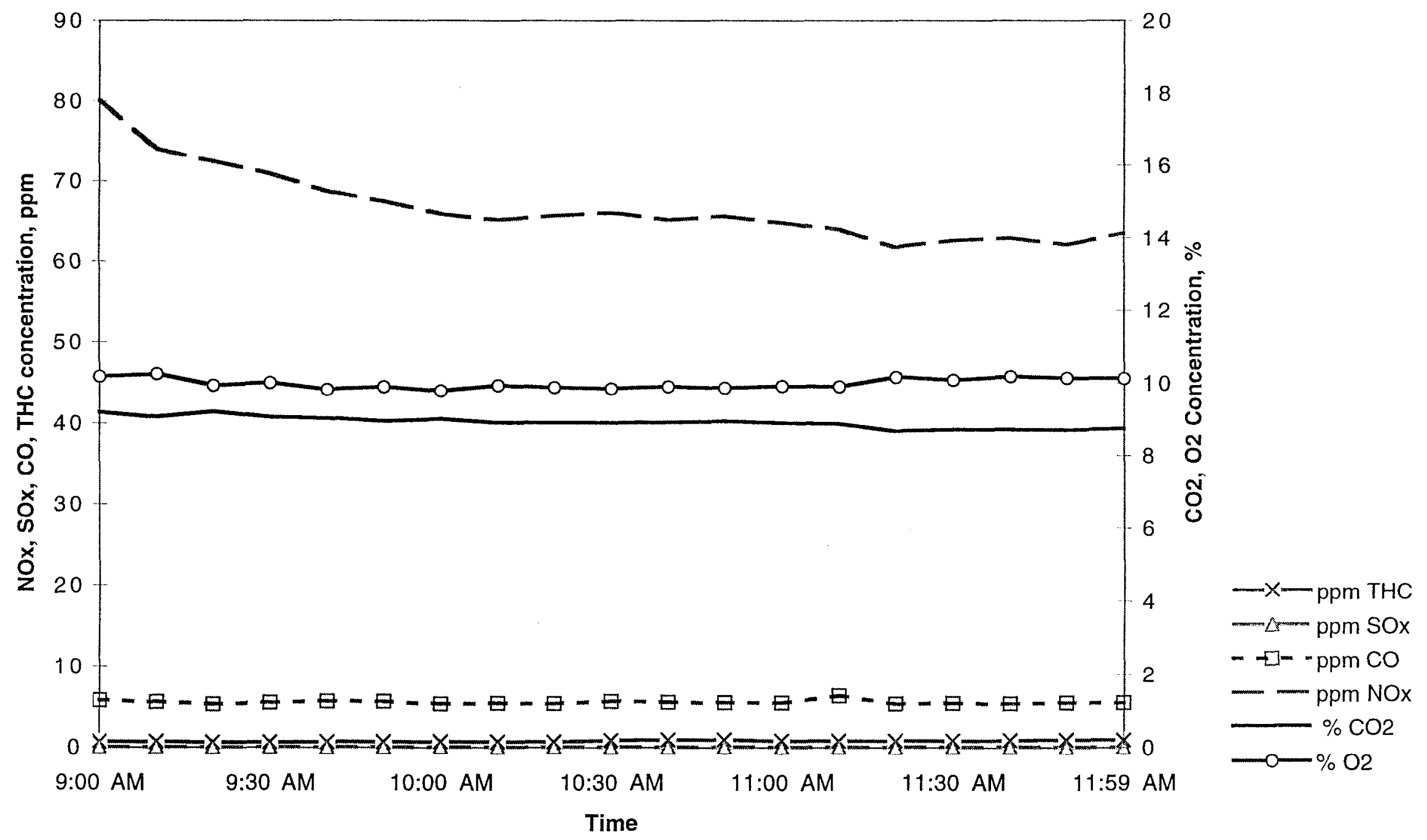


Table 5 MSO Processor Data Sheet fot Toluene Run

Date 1/27/98

Phase No.I

Run No.

Organic: Toluene

Start Time

$7: 50 \mathrm{am}$

Time, min

Elements

\begin{tabular}{|c|c|c|c|c|}
\hline 0 & $3 \mathrm{hr}$ & $4 \mathrm{hr}$ & $6 \mathrm{hr}$ & $8 \mathrm{hr}$ \\
\hline 0 & 20.2 & 20.2 & 20.2 & 20.2 \\
\hline N/A & 19.5 & 19.5 & 19.5 & 19.5 \\
\hline
\end{tabular}

Air Supply Parameters

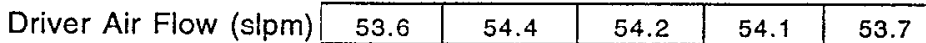

\begin{tabular}{|c|c|c|c|c|c|}
\hline Driver Air Press (psig) & 36.2 & 38.1 & 37.9 & 37.8 & 37.8 \\
\hline
\end{tabular}

\begin{tabular}{|l|l|l|l|l|l|}
\hline Oxidant Air FLow (sipm) & 215.6 & 215.4 & 216 & 215.6 & 215.6 \\
\hline
\end{tabular}

\begin{tabular}{|l|l|l|l|l|l|}
\hline Oxidant air press (psig) & 25.5 & 25.8 & 25.8 & 25.66 & 25.7 \\
\hline
\end{tabular}

\begin{tabular}{|c|c|c|c|c|c|} 
Cooling Air (slpm) & 200 & 200 & 200 & 199 & 200 \\
\hline
\end{tabular}

Purge Air (scfm)

Temperatures $\left(\mathrm{C}^{\circ}\right)$

\begin{tabular}{rr|c|c|c|c|c|} 
Salt & TE17 & 936 & 950 & 950 & 950 & 950 \\
\cline { 3 - 8 } Exit Gas & TE20 & 618 & 662 & 662 & 659 & 658 \\
\cline { 3 - 8 } After Soot Blower & TE35 & 336 & 404 & 403 & 415 & 416 \\
After Salt Trap & TE36 & 172 & 253 & 257 & 270 & 274 \\
After GSS Filter & TE37 & 78 & 125 & 134 & 147.3 & 157 \\
\cline { 3 - 8 } After HTX & TE38 & 36 & 58 & 63 & 69.5 & 58.1 \\
After Condenser & TE40 & 6.8 & 8.2 & 8.6 & 9.3 & 9 \\
\hline After Electric Heater & TE41 & 25.1 & 33.5 & 31 & 42.7 & 33.2 \\
\cline { 3 - 8 } After Cat. converter & TE43 & 22.4 & 25.7 & 270 & 28.3 & 28.9 \\
\hline Injector Tip & TE21 & 876 & 880 & 880 & 880 & 881 \\
\cline { 3 - 8 } & TE25 & 148 & 193 & 195 & 195 & 195 \\
\cline { 3 - 8 } & & & & & \\
\hline
\end{tabular}

Pressures (inches of water)

Vessel PT10/11/12

After Soot Blower PT13

After Salt Trap PT14

After GSS Filter PT15

After HTX PT16

After Condenser PT17

After Electric Heater

After PCV01

After Cat. Converter

\begin{tabular}{l|c|c|c|c|c|}
\cline { 2 - 6 } PT13 & -3 & -2 & -2 & -1 & -5 \\
\cline { 2 - 6 } & -2 & -4 & -4 & -5 & -5 \\
\hline PT14 & -3 & -5 & -5 & -6 & -6 \\
\hline PT15 & -7 & -10.5 & -10.5 & -6 & -11.4 \\
\cline { 2 - 6 } PT16 & -7 & -11 & -11 & -11.6 & -11.9 \\
\hline PT17 & -7 & -11 & -11 & -12 & -12.3 \\
\hline PT18 & -10 & -14 & -14 & -15 & -15.3 \\
\hline PT19 & -11 & -15 & -15 & -17 & -16.6 \\
\hline PT20 & -3 & -3 & -2 & -3 & -2.5 \\
\hline HEPA & 0.17 & 0.17 & 0.16 & 0.17 & 0.17 \\
\hline
\end{tabular}

PT18

PT19

PT20

Delta $P$ of HEPA

Off Gas Analysis

\begin{tabular}{|c|c|c|c|c|c|}
\hline \\
\hline THC (ppm) & 1.7 & 0.79 & 0.9 & 1.3 & 1.6 \\
\hline NOx (ppm) & 27.1 & 62.2 & 63.1 & 59.1 & 58.8 \\
\hline $\mathrm{CO}(\mathrm{ppm})$ & 0.15 & 5.3 & 5.6 & 8.7 & 8.2 \\
\hline \multicolumn{6}{|l|}{$\mathrm{CO}(\mathrm{ppm})$, after the cat. converter } \\
\hline $\mathrm{CO} 2(\%)$ & 0.33 & 8.66 & 8.75 & 8.6 & 8.6 \\
\hline $02(\%)$ & 21.37 & 10.19 & 10.01 & 9.9 & 9.9 \\
\hline $\mathrm{HCl}, \mathrm{ppm}$ & N/A & & & & \\
\hline SOx $(\mathrm{ppm})$ & 2.4 & 0 & 0 & 0 & 0 \\
\hline
\end{tabular}

\section{Other Parameters}

\begin{tabular}{|l|l|l|l|l|l|}
\hline Off-Gas Flow $(\mathrm{scfm})$ & 13.38 & 12.7 & 13.1 & 13.1 & 13.1 \\
\hline
\end{tabular}

Blower Frequency $(\mathrm{hz})$

\begin{tabular}{|c|c|c|c|c|}
\hline 13.38 & 12.7 & 13.1 & 13.1 & 13.1 \\
\hline 30 & 32 & 35 & 37 & 37 \\
\hline
\end{tabular}

Time of activating Soot Blower

Time of GSS blowback

Time of gas sample collection 
Table 8: Conversion of Organic Nitrogen into $\mathrm{NO}_{\mathrm{x}}$ in the Molten Salt

\begin{tabular}{lcc} 
Feed material & Reaction Temperature & $\% \mathrm{~N}$ to NO \\
\hline Pyridine/Toluene & $950^{\circ} \mathrm{C}$ & 44.0 \\
Nitromethane/Ethylene Glycol & $950^{\circ} \mathrm{C}$ & 34.0 \\
Urea/EtOH/Propanol & $950^{\circ} \mathrm{C}$ & 31.0 \\
& & \\
Explosives from ref. 4 & & \\
RDX & $750^{\circ} \mathrm{C}$ & 0.05 \\
HMX & $750^{\circ} \mathrm{C}$ & 0.11 \\
TNT & $750^{\circ} \mathrm{C}$ & 0.45 \\
Comp-B & $750^{\circ} \mathrm{C}$ & 0.09 \\
LX-10 & $750^{\circ} \mathrm{C}$ & 0.019 \\
LX-16 & $750^{\circ} \mathrm{C}$ & 0.14 \\
LX-17 & $750^{\circ} \mathrm{C}$ & 0.20 \\
PBX 9404 & $750^{\circ} \mathrm{C}$ & 0.25 \\
\hline
\end{tabular}

Notes:

RDX- hexahydro-1,3,5-trinitro-1,3,5-triazine; HMX-octahydro-1,3,5,7-tetranitro-1,3,5,7tetrazicine;TNT-2,4,6-trinitrotoluene; Comp-B-(RDX/TNT); LX-10- (HMX/Viton); LX16- PETN/FPC 461); LX-17- (TATB/Kel F); PBX-9404- (HMX/CEF/Nitrocellulose); PETN- 2,2-bisnitoxymethyl-1,3-propanediol dinitrate; TATB- 2,4,6-trinitro-1,3,5benzentriamine.

One of the features of the molten salt process is its ability to retain halides, sulfur, and phosphorous. They stay in the molten sodium carbonate salt bed as sodium halide, sodium sulfate, and sodium phosphate. For the test series II, the following organics containing fluorine, chlorine, sulfur, and phosphorous were tested: Freon 113 (fluorine, chlorine), DMSO (sulfur), TCE (chlorine), TBP (phosphorous). These organics were diluted with toluene and fed into the MSO process vessel at $950^{\circ} \mathrm{C}$ with $30 \%$ excess process air. The off-gas quality from these testing was very good. Table 9 shows the off-gas quality for the testing. The THC levels in the off-gas were very low, an indication of good process efficiency. $\mathrm{SO}_{x}$ in the off-gas was not detectable for each run since all the organic sulfur was converted into sodium sulfate and stayed in the salt bed. Salt samples were later taken for analysis of cations and anions which included fluoride $(\mathrm{F})$, chloride $\left(\mathrm{Cl}^{-}\right)$, sulfate $\left(\mathrm{SO}_{4}{ }^{2-}\right)$, and phosphate $\left(\mathrm{PO}_{4}{ }^{3-}\right)$. The results of salt analysis are reported in Section 9.

Table 9: Off-gas Composition for the MSO Runs with Halides, Sulfur, and Phosphorouscontaining Feeds

\begin{tabular}{llccc} 
Off-gas Species & 4 & \multicolumn{2}{c}{ Off-gas Composition for MSO Runs } \\
\cline { 3 - 5 } $\mathrm{CO}_{2}, \%$ & 8.8 & 9.2 & 13.8 & 7.7 \\
$\mathrm{O}_{2}, \%$ & 10.1 & 9.8 & 8.3 & 10.1 \\
$\mathrm{CO}, \mathrm{ppm}$ & 11.6 & 9.4 & 11.1 & 12.3 \\
$\mathrm{NO}_{x}, \mathrm{ppm}$ & 56.6 & 60.7 & 29.9 & 36.0 \\
$\mathrm{SO}_{x}$ & 0.0 & 0.0 & 0.0 & 0.0 \\
$\mathrm{THC}$ & 0.0 & 0.64 & 0.02 & 0.12 \\
\hline
\end{tabular}


Note: 4-TMP/DMSO/Toluene; 5- Freon 113/DMSO/Toluene; 6-DMSO/TCE/Toluene; 7TBP/Kerosene. * $20 \%$ excess process air was used for run $6,30 \%$ excess process air for runs $4,5,7$.

\subsection{Results of Test Series III -Solids}

Surrogate materials including ABS plastic pellets, shredded booties and gloves, ion exchange resin (Amberlite), and activated carbon were demonstratcd. For each run in the test series III, all the process data including gas species are recorded in the sheet as shown in Appendix 1. Some gas samples were also collected and sent to a laboratory for analysis. Salt containing ash was drained from the MSO vessel and sent to the salt recycle system. Table 10 shows the run conditions for test series III. The solid feeds were fed to the MSO vessel with a vibratory feeder and an eductor and carried into the molten salt bed by the compressed air. A large excess of process air was provided for these runs to overcome the feedrate fluctuation from the vibratory feeder. A larger size of ABS pellet ( 3.0 to $5.5 \mathrm{~mm}$ ) was also tested but the off-gas quality was not good, probably because this increased the residence time of the pellet in the molten salt bed to complete the oxidation process. It was found that solid particles less than $3.0 \mathrm{~mm}$ can be effectively treated by the MSO process if sufficient excess air is provided. The off-gas composition for these runs is shown in Table 11.

Table 10: Run Conditions

No. Feeds Run Conditions

$1 \quad$ ABS pellets $(2.5 \mathrm{~mm})$ $950^{\circ} \mathrm{C}, 1.45 \mathrm{~kg} / \mathrm{hr}, 58 \%$ excess air

2

Shredded booties

$950^{\circ} \mathrm{C}, 1.88 \mathrm{~kg} / \mathrm{hr}, 65 \%$ excess air

3

Ion exchange resin (Amberlite) (0.2 to $1.0 \mathrm{~mm}$ )

$950^{\circ} \mathrm{C}, 3.0 \mathrm{~kg} / \mathrm{hr}, 40 \%$ excess air

4

Activated Carbon

$950^{\circ} \mathrm{C}, 1.45 \mathrm{~kg} / \mathrm{hr}, 30 \%$ excess air

Table 11: Off-gas Composition for the Solid Feeds

\begin{tabular}{|c|c|c|c|c|}
\hline \multirow[b]{2}{*}{ Off-gas Species } & & \multicolumn{3}{|c|}{ Run Numbers } \\
\hline & 1 & & 3 & 4 \\
\hline $\mathrm{CO}_{2}, \%$ & 9.4 & 8.4 & 12.9 & 8.2 \\
\hline $\mathrm{O}_{2}, \%$ & 9.3 & 11.2 & 6.2 & 12.2 \\
\hline $\mathrm{CO}, \mathrm{ppm}$ & 18.6 & 154 & 17 & 326 \\
\hline $\mathrm{NO}_{\mathrm{x}}, \mathrm{ppm}$ & 306 & 6.9 & 150 & 112 \\
\hline $\mathrm{SO}_{\mathrm{x}}$ & 0.0 & 0.0 & 0.0 & 0.0 \\
\hline THC & 2.0 & 1.0 & 0.4 & 1.15 \\
\hline
\end{tabular}

The values in the Table 11 were taken from the off-gas analyzer readings at steady feed rate, they varied when the feed rate fluctuated and may reach as high as $80 \mathrm{ppm}$ for THC, 
and $400 \mathrm{ppm}$ for $\mathrm{NO}_{\mathrm{x}}$ and $\mathrm{CO}$, respectively. Figure 10 shows the off-gas composition for the MSO run with ion exchange resin. The spikes were the result of feed rate variation. Although it is desirable to have a solid feeder which can deliver a constant feed to the MSO vessel, the feed rate variation can be overcome with a large excess of process air. The higher levels of $\mathrm{NO}_{x}, \mathrm{CO}$, and ThC in the off-gas system can be further reduced in the catalytic converter before venting to the facility stack. Effort is underway to find an alternative means to feed organic solids to the MSO vessel, including finding a different type of solid feeder and suspend solid particles in a slurry using water or organic liquid as a carrier. This option will be further studied in FY99.

The MSO demonstration with activated carbon was based on the collaboration between the EM MSO team and the Defense Programs MSO team at LLNL. A granular activated carbon, 8 to 14 mesh size, was used as the surrogate feed. The activated carbon was fed for 4 hours at $1.5 \mathrm{kgs} / \mathrm{hr}$ followed by a 9 hours of air purge. Composition of off-gas was closely monitored with off-gas analyzers. Molten salt samples were taken during the course of demonstration and were sent for carbon analysis. It was found that the instantaneous efficiency of conversion of carbon feed to $\mathrm{CO}_{2}$ slowly increased with time, reaching approximately $80 \%$ after 4 hours. However the overall conversion efficiency of $\mathrm{C}$ to $\mathrm{CO}_{2}$ at this time was considerably lower, and we found the only way to increase it was by stopping the $\mathrm{C}$ feed but continuing to purge air through the reactor. Carbon analyses on salt samples taken after air purging for 2 hours and 9 hours showed that the overall carbon conversion improved to $94 \%$ and almost $100 \%$, respectively. A more detailed description of these experiments can be found elsewhere [6].

\subsection{Results of Test Series IV -Spiked Organic Liquids}

In the test series IV, some surrogate organics were spiked with low-level radioactive materials such as uranium. The compositions of surrogate materials mimicked some of the waste streams at LLNL. A surrogate organic, toluene, was traced with a small quantity of C-14 labelled organics in order to establish accurate mass balances for carbon. Tables 12 and 13 show the run conditions for test series IV and off-gas compositions, respectively.

Table 12: Run Conditions for Test Series IV

No. Feeds Run Conditions

$1 \quad$ C-14 Labeled Toluene

2A, 2B MCM/Toluene

3

4

5
Uranyl Nitrate \&2,4 Dichlorophenol in EtOH/MCM/Toluene/Mineral oil

Perchlor

Uranyl nitrate \& 2,4-Dichlorophenol in $\mathrm{EtOH} / \mathrm{MCM} / \mathrm{CCl} 4 / \mathrm{EG}$ $950^{\circ} \mathrm{C}, 1.3 \mathrm{~kg} / \mathrm{hr}, 30 \%$ excess air

$900^{\circ} \mathrm{C}$ (A) \& $950 \mathrm{C}$ (B), $2.4 \mathrm{~kg} / \mathrm{hr}$, $30 \%$ excess air

$950^{\circ} \mathrm{C}, 1.2 \mathrm{~kg} / \mathrm{hr}, 30 \%$ excess air

$910^{\circ} \mathrm{C}, 8.2 \mathrm{~kg} / \mathrm{hr}, 30 \%$ excess air

$950^{\circ} \mathrm{C}, 2.2 \& 3.3 \mathrm{~kg} / \mathrm{hr}, 30 \%$ excess air 
Fig. $103 \mathrm{~kg} / \mathrm{hr}$ lon Exchange resin (Amberlite), salt at $950 \mathrm{C}$

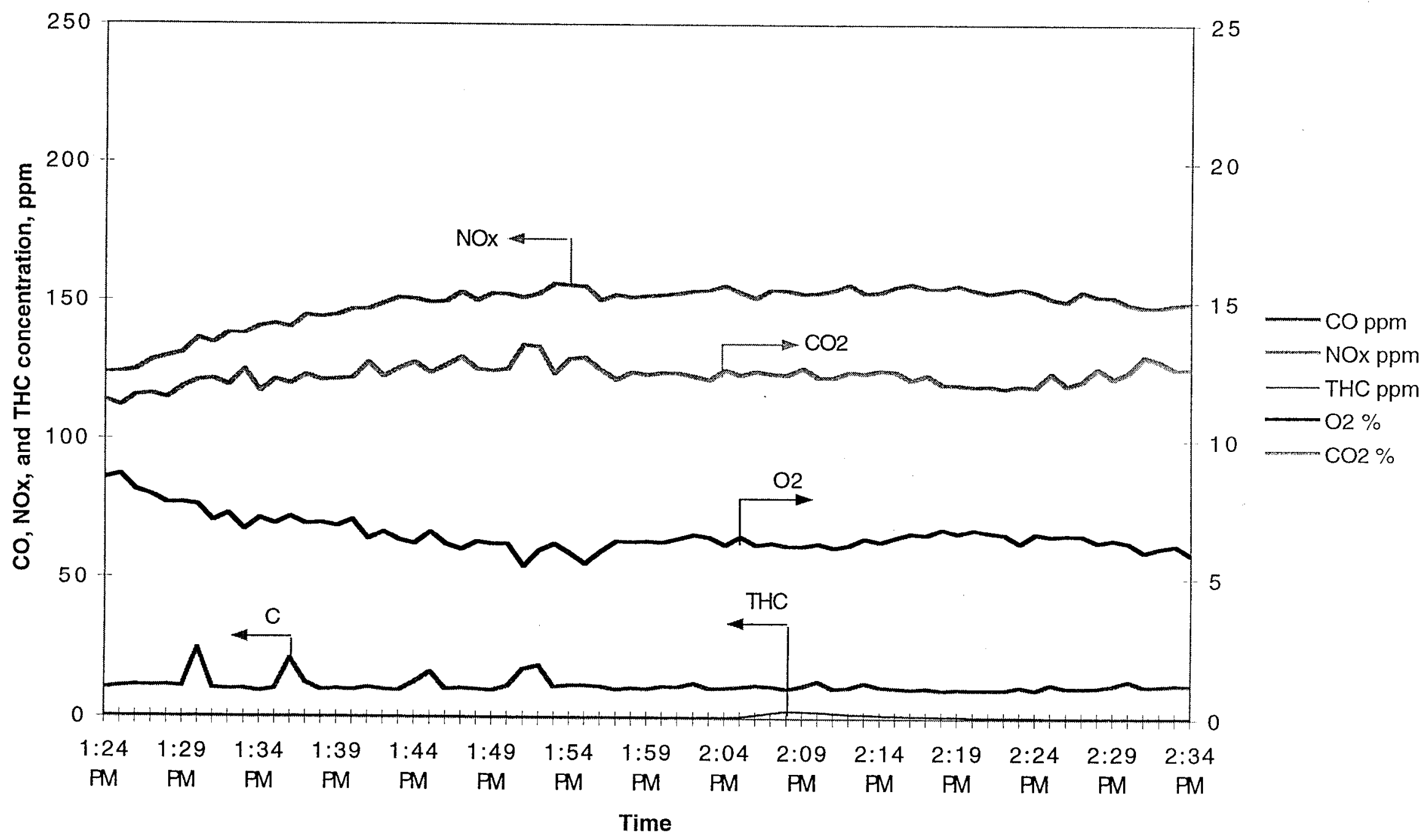


Table 13: Off-gas Composition for the Radioactive-spiked Organic Liquids

\begin{tabular}{|c|c|c|c|c|c|c|}
\hline \multirow[b]{2}{*}{ Off-gas Species } & \multirow[b]{2}{*}{1} & \multirow[b]{2}{*}{$2 \mathrm{~A}$} & \multicolumn{4}{|c|}{ Run Numbers } \\
\hline & & & $\overline{2 B}$ & 3 & $4^{*}$ & 5 \\
\hline $\mathrm{CO}_{2}, \%$ & 10.3 & 11.1 & 11.2 & 7.8 & 16.0 & 8.2 \\
\hline $\mathrm{O}_{2}, \%$ & 7.8 & 10.0 & 9.6 & 10.1 & 14.3 & 10.3 \\
\hline $\mathrm{CO}, \mathrm{ppm}$ & 10.7 & 9.5 & 9.5 & 10.8 & 6200 & 11.3 \\
\hline $\mathrm{NO}_{\mathrm{x}}, \mathrm{ppm}$ & 45 & 131 & 114 & 125 & 19.3 & 50.5 \\
\hline $\mathrm{SO}_{\mathrm{x}}$ & 0.0 & 0.2 & 0.2 & 0.0 & 0.0 & 0.0 \\
\hline $\mathrm{THC}$ & 0.04 & 0.23 & 0.28 & 0.0 & 1.0 & 0.0 \\
\hline
\end{tabular}

*Note: at $8.2 \mathrm{~kg} / \mathrm{hr}$ of Perchlor

\subsubsection{C-14 Labeled Toluene Experiment}

Intuitively, carbon in the feed is expected to exchange with carbon of the carbonate salt during the oxidation process, however no experimental data was available. Therefore, in Run 1 of this test series, toluene was spiked and labeled with C-14 to 9.9 modern (or $9.9 \times 10^{-12}$ fraction C-14 in carbon) and fed into the MSO process vessel in order to determine carbon exchange in the MSO process. C-14 labeled toluene was fed into the molten salt bed at $950^{\circ} \mathrm{C}$ for 2.83 hours followed by a 4 -hr gas purge $\left(9.0 \% \mathrm{CO}_{2}\right.$ in air). Samples including organic feed, off-gas, and salt were taken before the run, during the run, and during the gas purge. These samples were sent to the Center for Accelerator Mass Spectrometry (CAMS) at LLNL for the analysis of C-14. Table 14 and Fig. 11 show the activity of the samples during the run. C-14 labeled toluene was fed into the MSO vessel at $21 \mathrm{~g} / \mathrm{min}$ with $30 \%$ excess process air. The values in the parentheses were the percentages of C-14 fed to the MSO vessel that exchanged with the carbon atom of the carbonate molecule in the molten salt. Table 14 shows that most of C-14 fed into the MSO vessel went through carbon exchange and stayed in the salt. The percentages of the exchange was $75.3 \%, 77.3 \%$, and $73.9 \%$ after $1.0 \mathrm{hr}, 2 \mathrm{hrs}$, and $2.83 \mathrm{hrs}$, respectively. These values are very close and are well within the margin of errors in sampling and analysis. The activity of C-14 in both molten salt samples and off-gas samples increased with time, which indicates that a much longer run time is needed before a true steady state can bc reached.

The feed was stopped after 2.83 hours and then was followed by a gas purge at 215 liters/min for 4 hours. The purge gas consisted of $9.0 \mathrm{~mol} \% \mathrm{CO} 2$ which is a typical $\mathrm{CO} 2$ composition in the off-gas. Gas purging slowly decreased the C-14 activity in the molten salt. Table 14 shows that the $\mathrm{C}-14$ activity decreased from 1.3158 moderns to 1.0883 moderns after 4 hours of gas purge. Based on these results, it would clearly need much longer than 4 hours to completely purge and exchange the $\mathrm{C}-14$ in the molten salt. The $\mathrm{C}$ 14 activity in the off-gas during the feed and the gas purge depends on the C-14 activity in the melt. Table 14 and Fig. 10 also show that the specific activities of $\mathrm{C}-14$ in the salt and in the off-gas are almost equal, indicating that gaseous $\mathrm{CO}_{2}$ and the carbonate salt are in thermodynamic equilibrium.

The C-14 labeled experiment has provided new and valuable technical data for the MSO process. 
Fig. 11. C-14 Activity in Salt \& Off-gas

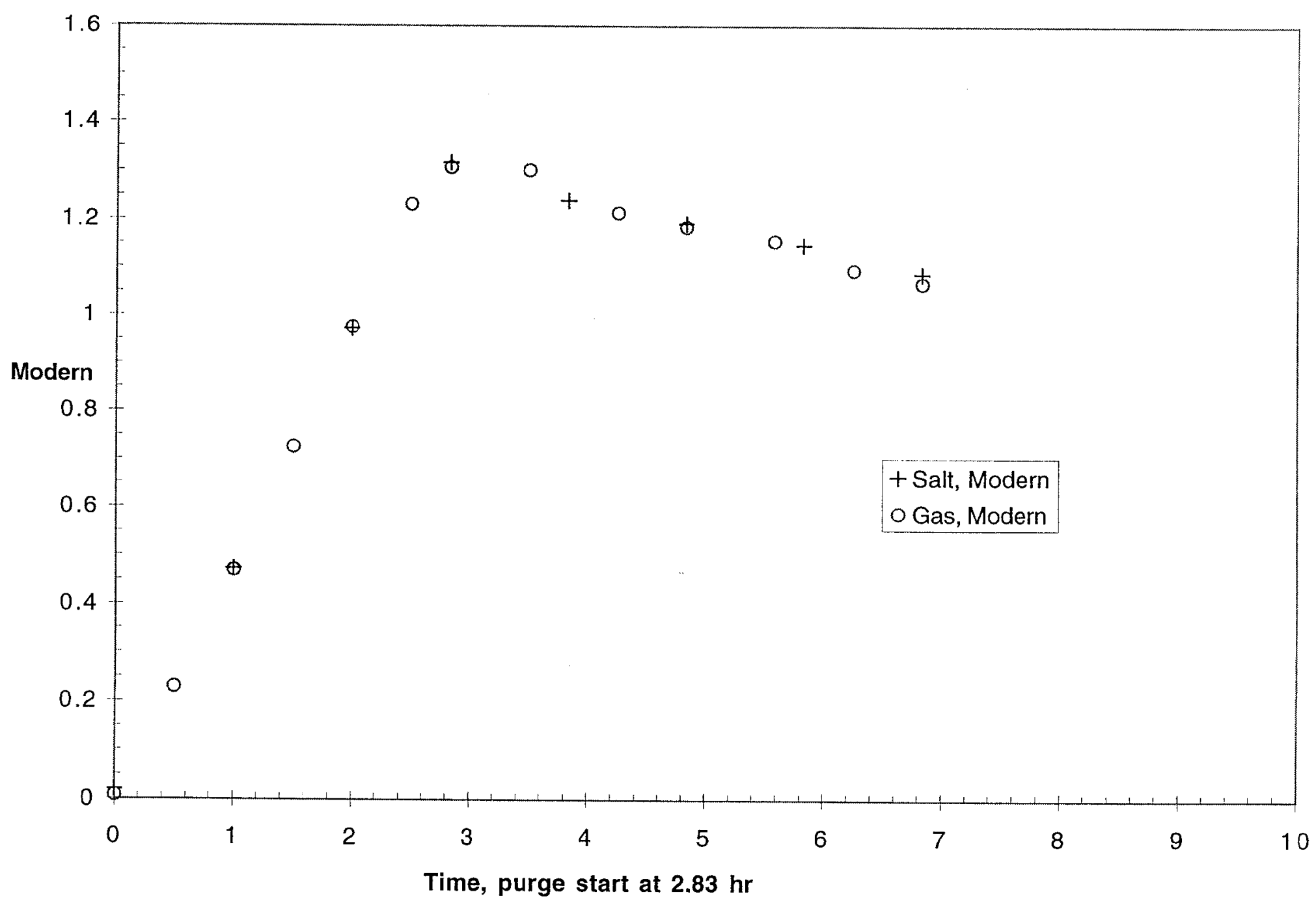


Table 14: C-14 Level in the C-14 Labeled Toluene Run

C-14 in the sampels, modern

\begin{tabular}{lll}
\hline Time, hour & Molten Salt Sample & Off-gas Sample \\
$\begin{array}{l}\text { Organic Feed }(9.9 \text { modern of } \\
\text { C-14 in the feed) }\end{array}$ & & \\
0 (before the feed) & 0.0189 & 0.0075 \\
0.5 & - & 0.2285 \\
1.0 & $0.4712(75.3 \%)$ & 0.4688 \\
1.5 & -- & 0.7256 \\
2.0 & $0.9717(77.3 \%)$ & 0.9748 \\
2.5 & -- & 1.2312 \\
2.83 & $1.3158(73.9 \%)$ & 1.3062 \\
\hline
\end{tabular}

Purge Period (Organic feed terminated)

0 (before the purge) $\quad 1.3158(73.9 \%)$

$0.67 \quad---1.3015$

$1.0 \quad 1.2380(69.5 \%)$

1.42 --- 1.2144

$\begin{array}{lll}2.0 & 1.1920(66.9) & 1.1848\end{array}$

$\begin{array}{lll}2.75 & -- & 1.1564\end{array}$

$3.0 \quad 1.1471(64.4 \%)$

$3.42 \quad 1.0961$

\begin{tabular}{lll}
4.0 & $1.0883(61.1 \%)$ & 1.0684 \\
\hline
\end{tabular}

Note: The salt sample collected in the GSS filter after the run was 0.3542 modern.

\subsubsection{MCM/Toluene and Perchlor Experiments}

There are 4500 gallons of organic liquid wastes in the LLNL waste inventory, and most of them are chlorinated solvents (LLW-008). Over $90 \%$ of the chlorinated waste consists of MCM. One of the runs in the test series was to simulate the composition of LLW-008 waste in order to understand the feed containing mostly MCM. The salt, consisted of sodium carbonate and potassium carbonate, has lower melting point which allowed the MSO vessel to opcrate at lower temperature. The off-gas qualities for the MCM run at both $900^{\circ} \mathrm{C}$ (run $2 \mathrm{~A}$ ) and $950^{\circ} \mathrm{C}$ (run $2 \mathrm{~B}$ ) were very good, as shown in Table 13 . Operating at lower temperature with chlorinated solvents is desirable because as chloride builds up in the 
the melt, the salt becomes more volatile. Operating at lower temperature not only reduces metal corrosion but also depresses sodium chloride volatilization into the off-gas system.

Perchlorethyene, "Perchlor, "consists of $85 \%$ chlorine and was chosen to build up chloride content in the molten salt. Perchlor was fed into the MSO vessel with $30 \%$ excess air at higher feed rates than most organic feeds. The salt temperature was kept at $910^{\circ} \mathrm{C}$ for the run in order to reduce salt volatility. As shown in the Table 13, the THC level in the offgas was only $1 \mathrm{ppm}$, an acceptable value despite the high $\mathrm{CO}$ concentration observed. The high $\mathrm{CO}$ concentration in the off-gas is typical at high chloride loading in the melt. The CO in the off-gas was further treated in the catalytic converter before venting through the facility stack. After the run, the high chloride salt was drained out and sent to the salt recycle system for processing.

\subsubsection{Uranyl Nitrate and 2,4-dichlorophenol spiked organics (runs 3 and 5)}

PCB-contaminated liquid organic waste exists in several DOE sites and presents a difficult problem due to the lack of an efficient treatment technology. Incineration can destroy PCB but it generates toxic off-gas species such dioxins and furans. A PCB-contaminated liquid waste stream, one of the difficult wastes in the LLNL waste inventory, was chosen as one of the treatability study samples. As part of test series IV, a feed containing uranium and 2,4-dichlorophenol (a PCB surrogate as a recognized precursor to the formation of dioxins/furans) was demonstrated in the MSO vessel at $950^{\circ} \mathrm{C}$ before the real PCBcontaminated waste was introduced.

In run 3, uranyl nitrate and 2,4-dichlorophenol were dissolved in ethanol and mixed with MCM, mineral oil and toluene in the feed container. Although it mimicked the composition of PCB-contaminated waste, phase separation occurred due to immiscibility of ethanol and mineral oil. It was fed to the MSO vessel for two hours before the injector experienced minor plugging. Pure ethanol was subsequently introduced to clear up the plugging. The off-gas quality for this run was very good.

In run 5 , the surrogate waste used for the demonstration had the following formulation: Carbon tetrachloride, 4.0 wt.\%; 1,1,1- trichloroethane (MCM), 4.0 wt.\%, 2,4dichlorophenol, 1.0 wt.\%, uranyl nitrate, 0.5 wt. $\%$, ethylene glycol, 46.5 wt. $\%$, ethanol, 45.0 wt.\%. Carbon tetrachloride and 1,1,1- trichloroethane are common RCRA solvents in wastes. Uranyl nitrate and 2,4- dichlorophenol were fed in diluent streams composed primarily of ethylene glycol and ethanol for miscibility. The surrogate feed was delivered to the MSO vessel at $2.2 \mathrm{kgs} / \mathrm{hr}$ and $3.3 \mathrm{kgs} / \mathrm{hr}$ for superficial velocities of $1 \mathrm{ft} / \mathrm{s}$ and 1.5 $\mathrm{ft} / \mathrm{s}$, respectively, with $30 \%$ excess process air. Off-gas quality was monitored by off-gas analyzers during the course of the demonstration. Sample gas was also collected and sent to the Environmental Laboratory in E\&ES for analysis of POHCs (principal organic hazardous compounds), dioxins, furans, and total organics. The surrogate was fed for $3.25 \mathrm{hrs}$. The system reached steady state in 30 minutes. Overall, $8.7 \mathrm{~kg}$ of surrogatc waste was fed into the MSO vessel.

Table 15 shows the off-gas composition during the feed. Table 16 shows the POHCs in the feed and in the off-gas. A blank gas sample was also collected for reference. 
Table 15: Off-gas Analyzer Readings

Off-gas Species, ppm or \%

\begin{tabular}{lcccccc} 
Time, hrs & $\mathrm{THC}, \mathrm{ppm} *$ & $\mathrm{NO}_{2}, \mathrm{ppm}$ & $\mathrm{CO}, \mathrm{ppm}$ & $\mathrm{CO}_{2} \%$ & $\mathrm{O}_{2}, \%$ & $\mathrm{Vs}, \mathrm{ft} / \mathrm{s}$ \\
\hline 0 & 0.0 & 43 & 3.2 & 0.09 & 21.20 & 1.0 \\
0.75 & 0.5 & 103 & 10.8 & 8.13 & 10.4 & 1.0 \\
1.25 & 0.0 & 50.5 & 11.3 & 8.16 & 10.3 & 1.0 \\
1.75 & 0.0 & 40.5 & 11.4 & 8.24 & 10.13 & 1.0 \\
2.75 & 0.0 & 42.8 & 10.8 & 8.47 & 9.89 & 1.5 \\
3.25 & 0.0 & 44.2 & 10.6 & 8.5 & 9.72 & 1.5 \\
\hline
\end{tabular}

* Detection limit of THC analyzer is $0.01 \mathrm{ppm}$. It drifted down to less than $0 \mathrm{ppm}$ during the course of the experiment.

Table 15 shows that off-gas quality was very good with less than $10 \mathrm{ppm}$ of $\mathrm{CO}$ and less than 110 ppm of $\mathrm{NO}_{\mathrm{x}}$ leaving the MSO vessel, respectively. $\mathrm{CO}$ and $\mathrm{NO}_{\mathrm{x}}$ levels in the off-gas were further reduced to undetectable levels in the catalytic converter. Other organic PICs (products of incomplete combustion) in the off-gas were not detectable. It also indicates that operating at the higher flow velocity of $1.5 \mathrm{ft} / \mathrm{s}$ would not adversely affect the off-gas quality.

Table 16 shows that DREs of the MSO process for major organics in the feed were very high, greater than $99.999 \%$. Testing performed with the bench scale MSO unit in 1994 at Oak Ridge National Laboratory yielded similar results [7]. Dioxins and furans in the offgas were not detectable.

\subsection{Results of Test Series V- Treatability Study}

\subsubsection{Description}

Two real waste specimens were chosen for the MSO treatability study in FY98. These specimens were received from the Hazardous Waste Management Division at LLNL (waste stream numbers LL-W008 and LL-W009). The first specimen (RTS \#1) was chlorinated solvent and consisted of mainly 1,1,1-trichloroethane (MCM) with traces of metals and low-level of radionuclides. The second specimen (RTS\#2)was PCB-contaminated waste.

Table 17 shows the composition of these two specimens. Treatment of five gallons of each specimen was successfully demonstrated in the MSO process vessel in August 1998. Off-gas was monitored continuously by off-gas analyzers installed in the off-gas system during the course of the demonstration. In addition to the continuous off-gas monitoring, a comprehensive gas sampling was performed per EPA methods and handled by the Best Environmental, Inc., a certified firm. Gas sampling was conducted from the sampling ports located on the 1.375 " i.d. inlet and outlet of the GSS filter and from the catalytic converter 4" i.d. outlet stack venting emission from the MSO process. The sampling ports were located to meet EPA criteria ( 8 duct diameter downstream and 2 duct diameter upstream from any points of flow disturbance). The source test methods and test locations used for each waste feed are summarized in Table 18. Descriptions of each test method can be found in the report (Appendix 2) submitted by the Best Environmental, Inc. 


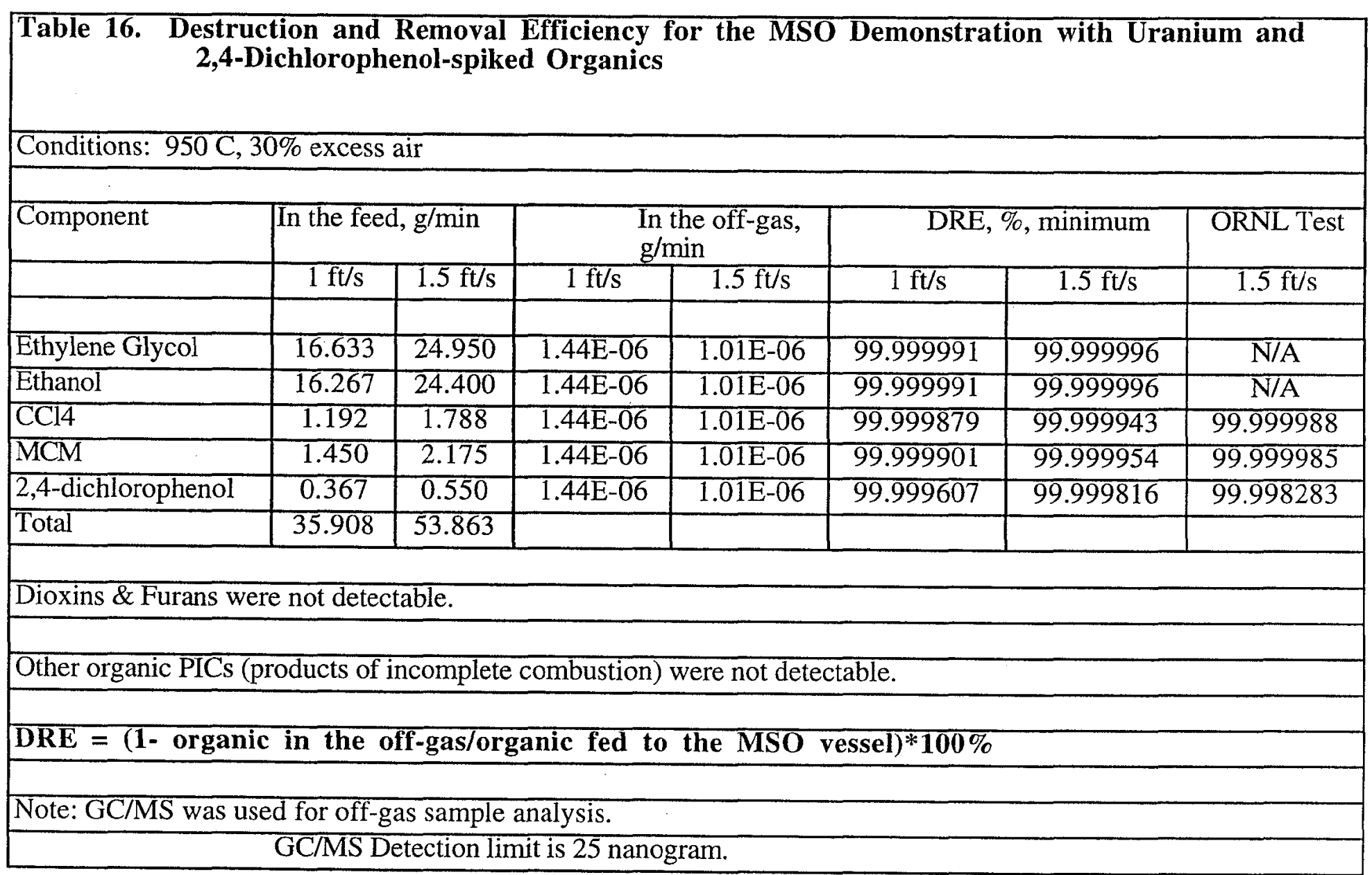


Table 17

Real Test Specimens for MSO Treatability Study in FY 98

\begin{tabular}{|c|c|c|}
\hline & $\begin{array}{l}\text { RTS \#1 } \\
\text { Chlorosolvent } \\
\text { LL-W008 }\end{array}$ & $\begin{array}{l}\text { RTS \#2 } \\
\text { Oill/PCB } \\
\text { LL-W009 }\end{array}$ \\
\hline chloroform $(\mathrm{g} / \mathrm{L})$ & 0.1 & ND \\
\hline 1,1-dichloroethane $(\mathrm{g} / \mathrm{L})$ & 0.5 & ND \\
\hline 1,2-dichloroethane $(\mathrm{g} / \mathrm{L})$ & 0.5 & ND \\
\hline 1,1-dichloroethene $(\mathrm{g} / \mathrm{L})$ & 20 & ND \\
\hline dichloromethane $(g / L)$ & 1.4 & ND \\
\hline tetrachloroethane $(\mathrm{g} / \mathrm{L})$ & 40 & ND \\
\hline toluene $(\mathrm{g} / \mathrm{L})$ & 0.1 & 2.9 \\
\hline dichloroethene & ND & 1.7 \\
\hline trichloroethene $(\mathrm{g} / \mathrm{L})$ & 10 & ND \\
\hline 1,1,2-trichloro, $1,2,2$ trifluoroethane $(\mathrm{g} / \mathrm{l})$ & 28 & 14 \\
\hline methylchloroform $(\mathrm{g} / \mathrm{L})$ & 1226.25 & 11 \\
\hline $\mathrm{Sb}(\mathrm{mg} / \mathrm{L})$ & 0 & ND \\
\hline $\mathrm{Ba}(\mathrm{mg} / \mathrm{L})$ & 1.5 & 2.6 \\
\hline $\mathrm{Be}(\mathrm{mg} / \mathrm{L})$ & 8.2 & ND \\
\hline $\mathrm{Cd}(\mathrm{mg} / \mathrm{L})$ & 0 & ND \\
\hline $\mathrm{Cr}(\mathrm{mg} / \mathrm{L})$ & 1.3 & 0.38 \\
\hline $\mathrm{Co}(\mathrm{mg} / \mathrm{L})$ & 0.2 & ND \\
\hline $\mathrm{Cu}(\mathrm{mg} / \mathrm{L})$ & 11 & 1.7 \\
\hline $\mathrm{Pb}(\mathrm{mg} / \mathrm{L})$ & 11 & 7.4 \\
\hline $\mathrm{Mo}(\mathrm{mg} / \mathrm{L})$ & 2.5 & 0.3 \\
\hline $\mathrm{Ni}(\mathrm{mg} / \mathrm{L})$ & 2 & $\mathrm{ND}$ \\
\hline $\mathrm{K}(\mathrm{mg} / \mathrm{L})$ & 4 & ND \\
\hline $\mathrm{Ag}(\mathrm{mg} / \mathrm{L})$ & 0.3 & 0.07 \\
\hline$U^{\prime}(\mathrm{mg} / \mathrm{L})$ & 20 & 11.5 \\
\hline$V(\mathrm{mg} / \mathrm{L})$ & 3.1 & ND \\
\hline $\mathrm{Zn}(\mathrm{mg} / \mathrm{L})$ & 5.3 & 2.3 \\
\hline $\mathrm{Hg}(\mathrm{mg} / \mathrm{L})$ & 0.04 & 0.35 \\
\hline hydraulic oil, $(\mathrm{g} / \mathrm{L})$ & None & 862.5 \\
\hline $\mathrm{PCB}, \mathrm{mg} / \mathrm{L}$ & None & 1567 \\
\hline Gross Alpha (nCi/L) & 7.26 & 7.8 \\
\hline Gross Beta $(\mathrm{nCi} / \mathrm{L})$ & 11.4 & 0.85 \\
\hline (Tritium $(\mathrm{nCi} / \mathrm{L}))$ & 33.1 & 38 \\
\hline
\end{tabular}


Table 18: Test Methods and Locations for the Treatability Study

$\begin{array}{lllrr}\text { Test Location } & \text { Parameters } & \text { Test Methods } & \text { Runs } & \text { Duration, } \\ & & & \\ \text { GSS Filter Outlet } & \text { Filtable Particulate } & \text { EPA Method 17 } & 3 & 60 \\ & \text { Radionuclides } & \text { EPA Method 114 } & 3 & 60 \\ & \text { Volatiles (VOST) } & \text { EPA Method 30 } & 9 & 20 \\ & \text { HCl } & \text { EPA Method 50 } & 3 & 60 \\ & \text { DSCFM } & \text { EPA Method 1-4 } & 3 & 60 \\ \text { GSS Filter Inlet } & \text { Dioxins/Furan, PCB* } & \text { EPA Method 23 } & 3 & 180 \\ & \text { Semi-Volatiles (MM5) } & \text { EPA Method 10 } & 3 & 180 \\ \text { Catalytic Converter Outlet } & \text { Dioxins/Furan, PCB* } & \text { EPA Method 23 } & 1 & 180 \\ & \text { Semi-Volatiles (MM5) } & \text { EPA Method 10 } & 1 & 180 \\ & \text { Volatiles (VOST) } & \text { EPA Method 30 } & 3 & 20 \\ & \text { Radionuclides } & \text { EPA Method 114 } & 1 & 60\end{array}$

* PCB only for RTS\#2.

\subsubsection{Results of MSO Demonstration with Chlorinated Solvent (LL-W008)}

The specimen was sampled and transferred from the waste container to the feed tank. Toluene was then added to the feed container under mixing to prevent phase separation during the feed to the MSO vessel. The waste liquid was pumped into the MSO vessel at $2.5 \mathrm{~kg} / \mathrm{hr}$ for 14 hours with $30 \%$ excess process air. The longer run was chosen to meet the time requirement for gas sampling. Table 19 shows the off-gas composition at steady state for both RTS\#1 and RTS\#2. Concentrations of CO and THC in the off-gas for RTS\#1 were $15.6 \mathrm{ppm}$ and $0.2 \mathrm{ppm}$, respectively, which were much less than $100 \mathrm{ppm}$ for $\mathrm{CO}$ and $20 \mathrm{ppm}$ for THC, the current standards for mixed waste incinerators [8].

Table 19: Off-gas Composition for RTS\#1 and RTS\#2*

\begin{tabular}{lll} 
Off-gas Species & \multicolumn{2}{c}{ Run Numbers } \\
\cline { 2 - 2 } $\mathrm{CO}_{2}, \%$ & 8.1 & 7.3 \\
$\mathrm{O}_{2}, \%$ & 12.0 & 10.1 \\
$\mathrm{CO}, \mathrm{ppm}$ & 10.2 & 15.6 \\
$\mathrm{NO}_{\mathrm{x}}, \mathrm{ppm}$ & 56.4 & 27.3 \\
$\mathrm{SO}_{\mathrm{x}}$ & 0.0 & 0.0 \\
$\mathrm{THC}$ & 0.2 & 0.0 \\
\hline
\end{tabular}

*The numbers were taken directly from the readings of the off-gas analyzers. 
Table 20 shows feed rates to the MSO vessel and emission rates and DREs for principal organic hazardous contituents (POHCs) along with total dioxin/furan, volatile organics, semi-volatile organic, particulate, gross alpha, gross beta, tritium and $\mathrm{HCl}$ in the off-gas. There were six POHCs in the RTS\#1 feed: MCM, 1,1-dichloroethene, tetrachloroethene, trichloroethene, trichloro-trifluoroethane, and toluene. The DREs for these six POHCs were greater $99.999 \%$, an indication of excellent process efficiency for the demonstration. The particulate emission rate was $0.00011 \mathrm{lbs} / \mathrm{hr}$ at average off-gas flow rate of $13.5 \mathrm{dscfm}$ (dry standard cubic $\mathrm{ft}$ per min) or $0.00006 \mathrm{~g} / \mathrm{ft}^{3}$. This is much less than the particulate loading of $0.08 \mathrm{~g} / \mathrm{ft}^{3}$, the standard for mixed waste incinerators. The low particulate loading in the MSO off-gas system is not surprising because the GSS filter can effectively remove most particles from the gas stream. Table 20 also shows that the molten salt retained and trapped gross alpha and gross beta very well. The percentages of gross alpha and gross beta which was fed into the MSO vessel going into the off-gas were $0.32 \%$ and $0.12 \%$, respectively. $\mathrm{HCl}$ level in the off-gas was less than $0.0016 \mathrm{~g} / \mathrm{hr}$, which indicated that most of the chlorine in the feed (about $50 \mathrm{wt} . \%$ of the liquid feed or $21 \mathrm{~g} / \mathrm{min}$ of chlorine) has been converted into sodium chloride as expected and stayed in the salt bed. Sodium chloride is ten times more volatile than sodium carbonate and its vapor would carry over to the off-gas system. The concentration of sodium chloride vapor at $950^{\circ} \mathrm{C}$ is 0.014 $\mathrm{g} / \mathrm{ft}^{3}[9]$. Most of the sodium chloride vapor condensed in the air-cooled jacket of the offgas system and was pushed back to the MSO vessel by the salt brush. Some of it may end up in the salt trap and GSS filter. After the run, a salt sample was taken from the reactor and analyzed for its chloride content; the sodium chloride composition after feeding chlorinated solvent for 14 hours was found to be $30 \mathrm{wt} . \%$.

In addition to analyzing the off-gas for the feed compounds, EPA method 10 and method were used to determine the emissions of semi-volatile organics (boiling point $>100^{\circ} \mathrm{C}$ ) and volatile organics boiling point $<100^{\circ} \mathrm{C}$ ), respectively. Table 4 and Table 6 in the Appendix 2 show the emissions of each individual semi-volatile organic and volatile organic for RTS\#1. Total emissions of the semi-volatile organics from RTS\#1 was less than 91.376 $\mu \mathrm{g} / \mathrm{min}$ and total emissions of volatile organics was less than $31.568 \mu \mathrm{g} / \mathrm{min}$, respectively.

Dioxins and furans are a group of related compounds which are suspected of having harmful effects in humans. Laboratory tests have shown that $2,3,7,8-\mathrm{TCDD}(2,3,7,8$ tetrachlorodibenzo-para-dioxin), one of most toxic compounds in the group, can cause cancer and toxic effects in laboratory animals. Hence their emissions from a thermal treatment process are subjected to strict regulations. EPA proposed that the regulatory limit for dioxin and furan emissions from hazardous waste treatment systems be $100 \mathrm{pg} / \mathrm{m} 3$ toxic cquivalence quotient (TEQ). The toxic equivalence factor (TEF) of a particular dioxin or furan is defined as the ratio of its toxicity to the toxicity of $2,3,7,8-\mathrm{TCDD}$, which has a TEF of 1 .

Table 21 shows the results of dioxin and furan emissions. Gas samples were taken from the GSS filter inlet and the outlet of the catalytic converter. The table shows the emission rate and concentration of cach individual dioxin and furan and its TEF and TEQ. TEQ is the concentration of each individual dioxin and furan multiplied by its TEF. As shown in the table, the total dioxin and furan cmissions from the GSS filter inlet and the catalytic converter outlet were $18.534 \mathrm{pg} / \mathrm{m}^{3} \mathrm{TEQ}$ and $17.093 \mathrm{pg} / \mathrm{m}^{3} \mathrm{TEQ}$, respectively. These emissions are well below the EPA proposed regulatory limit of $100 \mathrm{pg} / \mathrm{m}^{3}$. 
Table 20: Feed Rates, Emission Rates, and DREs for RTS\#1

$\begin{array}{cccc}\text { Test Parameter } & \text { Feed Rate to the } & \underline{\text { Emission }} & \underline{\text { DRE }} \\ & \underline{\text { MSO Vessel }} & \underline{\text { Rate }} & \underline{\underline{\%}} \\ \text { MCM } & 24.98 \mathrm{~g} / \mathrm{min} & <0.542 \mu \mathrm{g} / \mathrm{min} & >99.999998 \\ \text { 1,1-dichloroethene } & 0.41 \mathrm{~g} / \mathrm{min} & 1.067 \mu \mathrm{g} / \mathrm{min} & 99.99974 \\ \text { Tetrachloroethene } & 0.81 \mathrm{~g} / \mathrm{min} & <0.175 \mu \mathrm{g} / \mathrm{min} & >99.999978 \\ \text { Trichloroethene } & 0.20 \mathrm{~g} / \mathrm{min} & <0.197 \mu \mathrm{g} / \mathrm{min} & >99.99998 \\ \text { Trichloro-trifluoroethane } & 0.57 \mathrm{~g} / \mathrm{min} & <4.372 \mu \mathrm{g} / \mathrm{min} & >99.999233 \\ \text { Toluene } & 14.69 \mathrm{~g} / \mathrm{min} & 3.775 \mu \mathrm{g} / \mathrm{min} & 99.999974 \\ \text { Total PCB } & \text { None } & \text { None } & \text { N.A. } \\ \text { Total Dioxin/Furan } & \text { None } & 56.061 \mathrm{pg} / \mathrm{min} & \text { N.A. } \\ \text { VOST Volatiles } & \text { N.A. } & <31.568 \mu \mathrm{g} / \mathrm{min} & \text { N.A. } \\ \text { Semi-volatiles } & \text { N.A. } & <91.376 \mu \mathrm{g} / \mathrm{min} & \text { N.A. } \\ \text { Particulate } & \text { N.A. } & 0.00011 \mathrm{lbs} / \mathrm{hr} & \text { N.A. } \\ \text { Gross Alpha } & 9,000 \mathrm{pCi} / \mathrm{hr} & 28.55 \mathrm{pCi} / \mathrm{hr} & \text { N.A. } \\ \text { Gross Bcta } & 14,100 \mathrm{pCi} / \mathrm{hr} & 16.73 \mathrm{pCi} / \mathrm{hr} & \text { N.A. } \\ \text { Tritium } & 41,070 \mathrm{pCi} / \mathrm{hr} & 7688 \mathrm{pCi} / \mathrm{hr} & \text { N.A. } \\ \text { HCl } & \text { N.A. } & <0.0016 \mathrm{~g} / \mathrm{hr} & \text { N.A. }\end{array}$

Table 21: Results for Dioxin and Furan Emissions for RTS\#1

\begin{tabular}{|c|c|c|c|c|c|c|c|}
\hline$\underline{\text { Species }}$ & TEF & $\frac{\text { @ GSS Filter }}{\text { Inlet, pg/min }}$ & $\frac{@ \text { GSS Filter }}{\text { Inlet, pg/m3 }}$ & $\frac{\mathrm{TEO}}{\mathrm{pg} / \mathrm{m} 3}$ & $\begin{array}{l}\frac{@ \text { Catalytic }}{\text { Converter }} \\
\frac{\text { Outlet }}{\text { pg/min }}\end{array}$ & $\frac{\frac{\text { @ Catalytic }}{\text { Converter }}}{\frac{\text { Outlet. }}{\mathrm{pg} / \mathrm{m} 3}}$ & $\frac{\mathrm{TEQ}}{\mathrm{pg} / \mathrm{m} 3}$ \\
\hline $\begin{array}{l}2,3,7,8- \\
\text { TCDD }\end{array}$ & 1 & 4.941 & 12.973 & 12.973 & 5.108 & 10.941 & 10.94 \\
\hline TCDF & 0.1 & 4.033 & 10.583 & 1.058 & 5.325 & 11.407 & 1.141 \\
\hline $\mathrm{PeCDF}$ & 0.05 & 7.318 & 19.214 & 0.961 & 10.216 & 21.882 & 1.094 \\
\hline $\mathrm{HxCDF}$ & 0.1 & 2.359 & 6.201 & 0.620 & 2.391 & 5.121 & 0.512 \\
\hline $\mathrm{HpCDF}$ & 0.01 & 0.772 & 2.034 & 0.020 & 1.195 & 2.561 & 0.026 \\
\hline OCDF & 0.001 & 1.536 & 4.047 & 0.004 & 0.967 & 2.072 & 0.002 \\
\hline $\mathrm{PeCDD}$ & 0.5 & 1.921 & 5.048 & 2.524 & 2.934 & 6.285 & 3.143 \\
\hline $\mathrm{HxCDD}$ & 0.1 & 0.892 & 2.351 & 0.235 & 0.880 & 1.886 & 0.189 \\
\hline HpCDD & 0.01 & 2.219 & 5.854 & 0.059 & 1.087 & 2.328 & 0.023 \\
\hline \multirow[t]{2}{*}{ OCDD } & 0.001 & 30.07 & 79.599 & 0.080 & 10.542 & 22.581 & 0.023 \\
\hline & & 56.061 & 147.904 & 18.534 & 40.645 & 87.064 & 7.093 \\
\hline
\end{tabular}

Figure 12 shows the mass balance for the MSO demonstration with the chlorinated solvent waste stream. This assumes an integrated operation of the MSO/off-gas system, the salt recycle system, and the ceramic final forms at steady state. The feed rate of organic liquid is assumed at 2 liters $/ \mathrm{hr}(2.31 \mathrm{~kg} / \mathrm{hr})$ along with traces of metal and radionuclides. The amount of air required for the process including purge air, and oxidant air, is 887 moles/hr 
LLW-008

Chlorinated solvent $2310 \mathrm{~g} / \mathrm{hr}$

C $\quad 84.2$ moles $/ \mathrm{hr}$

(2 liters $/ \mathrm{hr}$ )

$\mathrm{H} \quad 103.5$ moles $/ \mathrm{hr}$

$\mathrm{Cl} \quad 33.4 \mathrm{moles} / \mathrm{hr}$

F $\quad 0.51$ moles $/ \mathrm{hr}$

Off-gas at 650 degree $\mathrm{C}$ $\mathrm{CO} 284.2 \mathrm{moles} / \mathrm{hr}$

$\mathrm{H} 2 \mathrm{O} 51.7$ moles $/ \mathrm{hr}$

O2 76.0 moles $/ \mathrm{hr}$

N2 701 moles $/ \mathrm{hr}$

Metals $0.072 \mathrm{~g} / \mathrm{hr}$

Radionuclides $75.6 \mathrm{nCi} / \mathrm{hr}$
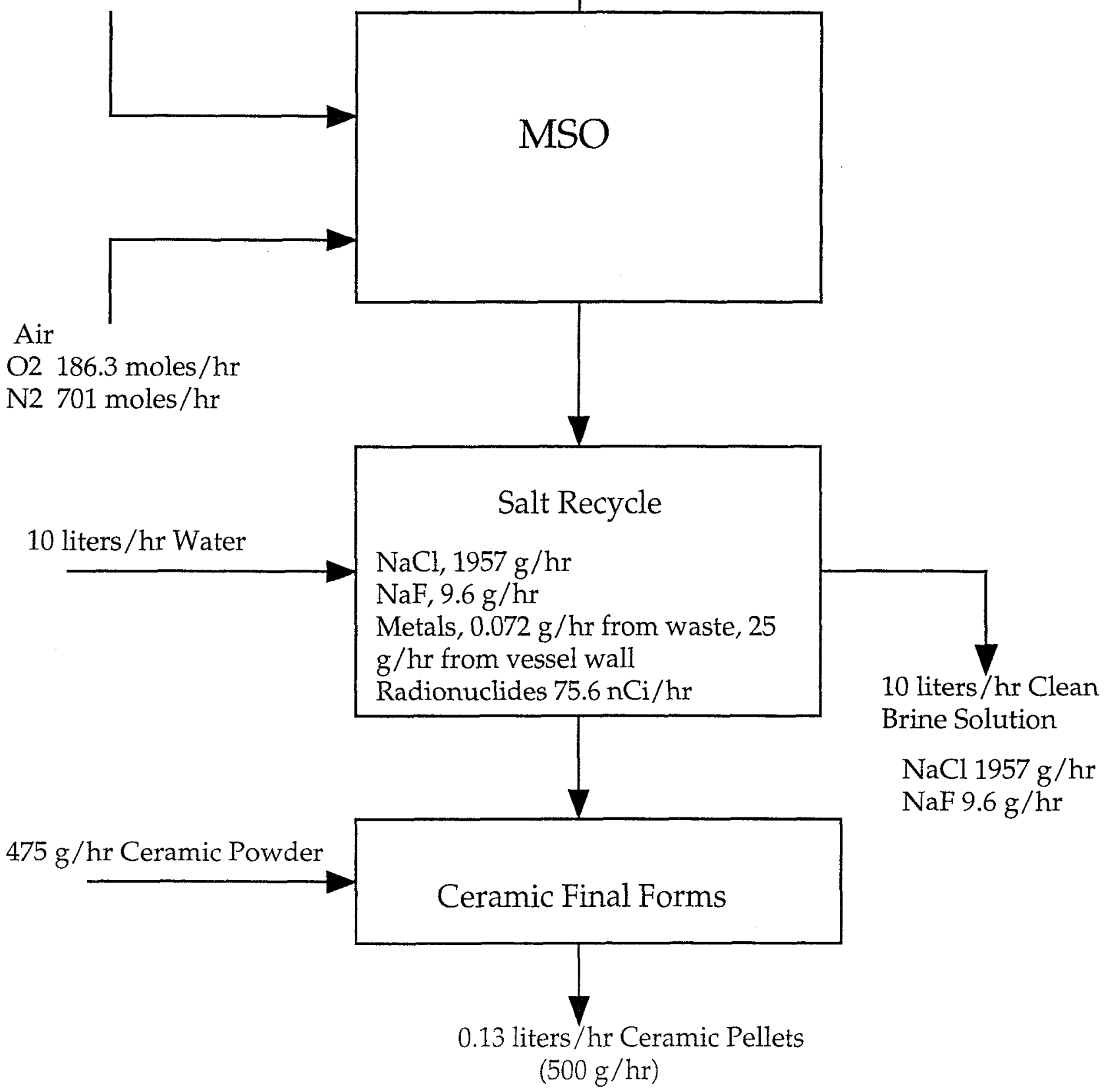

Fig. 12. MSO Flow balance for feed stream LLW-008 (Chlorinated Solvents) 
and the off-gas discharge rate is 913 moles. Assuming continuous salt withdrawal from the MSO system to the salt recycle system, the water required to process the spent salt would be 10 liters/hr. The salt recycle process discharges 10 liter/min clean salt brine solution which consists of sodium chloride and sodium fluoride. Metals, metal oxides, and radionuclides are sent to the ceramic final forms system to generate ceramic pellets. As shown in the diagram, 475 grams of ceramic powder is required to stabilize the waste stream from the salt recycle system. As a result, 0.13 liters/hr of ceramic pellets would be generated.

\subsubsection{Results of MSO Demonstration with PCB-Contaminated Organics (LLW-009)}

PCB-contaminated wastes are difficult to treat by incineration due to the formation of dioxins and furans, cancer-causing agents, at the incineration temperature, which is typically above $1200^{\circ} \mathrm{C}$. To demonstrate that MSO is an efficient alternative to treat these wastes, 5 gallons of a PCB-contaminated waste specimen (RTS\#2) was fed into the process vessel as part of the treatability study. The main objective of the experiments was to show that dioxin and furan emissions from the system were below the proposed regulatory limit of $100 \mathrm{pg} / \mathrm{m}^{3}$ gas as 2,3,7,8-tetrachlorodibenzo-para-dioxin equivalents or toxic equivalence quotient.

The PCB-contaminated waste was delivered to the MSO facility from the Waste Management Division of LLNL in a five-gallon container. The waste was sampled and sent for analysis. Table 17 shows the composition of the waste. Toluene was used as a diluent to reduce the viscosity of the waste for the ease of feed delivery. The waste, containing mostly hydraulic oil with over $1000 \mathrm{ppm}$ PCB and traces of metals and radionuclides was fed into the MSO system at $1.1 \mathrm{~kg} / \mathrm{hr}$ along with $30 \%$ excess air for 13 hours. The molten salt bed, containing $160 \mathrm{~kg}$ sodium carbonate, was controlled at $950^{\circ} \mathrm{C}$ during the course of the demonstration. The GSS (gas/solid separation) filter was backflashed with compressed air periodically to prevent excessive buildup of salt cake in the filter element. $\mathrm{CO}_{2}, \mathrm{O}_{2}, \mathrm{CO}, \mathrm{NO}_{x}, \mathrm{SO}_{\mathrm{x}}$ in the off-gas were continuously monitored with off-gas analyzers. Sampling was conducted from the sampling ports located on the inlet and outlet of the GSS filter and from the catalytic converter outlet. The sampling ports were located to meet the 8 duct diameter downstream and 2 duct diameter upstream from any points of flow disturbance criteria. Best Environmental, Inc. handled the off-gas sampling operation during the demonstration. All the collected samples were sent to EPA-certified laboratories for analysis.

The off-gas quality, as shown in Table 19 was very good with less than 50 ppm $\mathrm{NO}_{x}$, less than $20 \mathrm{ppm} \mathrm{CO}$, and nondetectable THC in the off-gas. Table 22 shows that feed rates and emission rates of POHCs, total dioxins and furans, volatile organics, total semivolatile organics, particulate, gross alpha, gross beta, and $\mathrm{HCl}$. The particulate cmission rate was $0.0000034 \mathrm{lbs} / \mathrm{hr}$ at average off-gas flow rate of $13.8 \mathrm{dscfm}$ or only $0.0000016 \mathrm{~g} / \mathrm{ft}^{3}$. The destruction efficicncics of the POHCs were greater than $99.99 \%$. 
Table 22: Feed Rates, Emission Rates, and DREs for RTS\#2

\begin{tabular}{|c|c|c|c|}
\hline Test Parameter & $\begin{array}{l}\text { Feed Rate to the } \\
\text { MSO Vessel }\end{array}$ & $\frac{\text { Emission }}{\underline{\text { Rate }}}$ & $\frac{\underline{\mathrm{DRE}}}{\underline{\mathscr{\sigma}}}$ \\
\hline $\mathrm{MCM}$ & $0.168 \mathrm{~g} / \mathrm{min}$ & $<0.291 \mu \mathrm{g} / \mathrm{min}$ & $>99.999827$ \\
\hline 1,1-dichloroethene & $0.025 \mathrm{~g} / \mathrm{min}$ & $1.073 \mu \mathrm{g} / \mathrm{min}$ & 99.99571 \\
\hline Tetrachloroethene & N.A. & $<0.166 \mu \mathrm{g} / \mathrm{min}$ & N.A. \\
\hline Trichloroethene & N.A. & $<0.187 \mu \mathrm{g} / \mathrm{min}$ & N.A. \\
\hline Trichloro-trifluoroethane & $0.213 \mathrm{~g} / \mathrm{min}$ & $<4.151 \mu \mathrm{g} / \mathrm{min}$ & $>99.99805$ \\
\hline Toluene & $2.78 \mathrm{~g} / \mathrm{min}$ & $1.069 \mu \mathrm{g} / \mathrm{min}$ & 99.999962 \\
\hline Total PCB & $0.0233 \mathrm{~g} / \mathrm{min}$ & $<0.0414 \mu \mathrm{g} / \mathrm{min}$ & $>99.99982$ \\
\hline Hydraulic oil & $14.98 \mathrm{~g} / \mathrm{min}$ & N.A. & N.A. \\
\hline Total Dioxin/Furan & None & $108.86 \mathrm{pg} / \mathrm{min}$ & N.A. \\
\hline VOST Volatiles & N.A. & $<17.82 \mu \mathrm{g} / \mathrm{min}$ & N.A. \\
\hline Semi-volatiles & N.A. & $<95.854 \mu \mathrm{g} / \mathrm{min}$ & N.A. \\
\hline Particulate & N.A. & $0.000034 \mathrm{lbs} / \mathrm{hr}$ & N.A. \\
\hline Gross Alpha & $8,140 \mathrm{pCi} / \mathrm{hr}$ & $15.53 \mathrm{pCi} / \mathrm{hr}$ & N.A. \\
\hline Gross Beta & $890 \mathrm{pCi} / \mathrm{hr}$ & $0.961 \mathrm{pCi} / \mathrm{hr}$ & N.A. \\
\hline Tritium & $39,700 \mathrm{pCi} / \mathrm{hr}$ & $\begin{array}{c}3,564,582 \\
\mathrm{pCi} / \mathrm{hr}\end{array}$ & N.A. \\
\hline $\mathrm{HCl}$ & N.A. & $<0.0015 \mathrm{~g} / \mathrm{hr}$ & N.A. \\
\hline
\end{tabular}

Table 23 lists the emission rates of each dioxin and furan, the toxicity equivalent factor (TEF), and its toxic equivalence quotient (TEQ). Total TEQs of dioxins and furans in the GSS filter inlet and the catalytic converter outlet were $38.743 \mathrm{pg} / \mathrm{m} 3$ and $9.338 \mathrm{pg} / \mathrm{m} 3$, respectively. These values are again below $100 \mathrm{pg} / \mathrm{m}^{3}$, the EPA proposed regulatory limits.

Table 23: Results for Dioxins and Furan Emissions

$\begin{array}{cccccc}\text { Species } & \text { TEF } & \begin{array}{c}\text { @ GSS Filter } \\ \text { Thlet, } \mathrm{pg} / \mathrm{m} 3\end{array} & \begin{array}{c}\text { TEQ } \\ \mathrm{pg} / \mathrm{m} 3\end{array} & \begin{array}{c}\text { @ Catalytic Converter } \\ \text { Outlet, } \mathrm{pg} / \mathrm{m} 3\end{array} & \begin{array}{c}\text { TEQ } \\ \mathrm{pg} / \mathrm{m} 3\end{array} \\ \begin{array}{c}\text { 2,3,7,8-TCDD } \\ \text { TCDF }\end{array} & 1 & 22.301 & 22.301 & 7.506 & 7.506 \\ \text { PeCDF } & 0.1 & 78.954 & 7.895 & 3.503 & 0.350 \\ \text { HxCDF } & 0.1 & 50.310 & 2.516 & 5.505 & 0.275 \\ \text { HpCDF } & 0.01 & 12.521 & 1.252 & 1.426 & 0.143 \\ \text { OCDF } & 0.001 & 4.204 & 0.042 & 1.051 & 0.011 \\ \text { PeCDD } & 0.5 & 8.542 & 0.003 & 1.776 & 0.002 \\ \text { HxCDD } & 0.1 & 3.593 & 4.264 & 1.877 & 0.939 \\ \text { HpCDD } & 0.01 & 4.684 & 0.359 & 1.001 & 0.100 \\ \text { OCDD } & 0.001 & 64.379 & 0.047 & 1.101 & 0.011 \\ & & \text { Total TEQ } & 0.064 & 2.352 & 0.002 \\ & & & & & 9.338\end{array}$


Note: The oxygen concentration in the off-gas was $10.1 \mathrm{vol} . \%$. Volume of off-gas sample collected was about $4 \mathrm{~m}^{3}$.

Figure 13 shows the mass balance for the MSO demonstration with PCB-contaminated waste oil. This again assumes an integrated operation of the MSO process which includes process vessel, off-gas system, the salt recycle system, and the ceramic final forms at steady state. The feed rate of organic liquid is assumed at 1.2 liters $/ \mathrm{hr}$. The amount of air required for the process including purge air and oxidant air is $861 \mathrm{moles} / \mathrm{hr}$, and the off-gas discharge rate is 904 moles. Assuming continuous salt withdrawal from the MSO system to the salt recycle system, the water required to process the spent salt would be only 0.18 liters $/ \mathrm{hr}$. The salt recycle process discharges $0.18 \mathrm{liter} / \mathrm{min}$ clean salt brine solution which consists of sodium chloride and sodium fluoride. Metals, metal oxides, and radionuclides are sent to the ceramic final forms system to generate ceramic pellets. As shown in the diagram, 475 grams of ceramic powder is required to stabilize the waste stream from the salt recycle system. As a result, 0.13 liters $/ \mathrm{hr}$ of ceramic pellets would be generated. For the PCB-contaminated oil, for every 1.2 liters treated, the MSO process would generate 0.18 liters of clean brine solution and 0.13 liters of stabilized ceramic pellets.

\section{Results of the Demonstration of the Salt Recycle System}

Salt recycle is an important element of the integrated MSO system. It was developed based on extensive small-scale laboratory experiments to prove the concept with subsequent scale-up to the pilot system as part of an integrated MSO facility. The salt recycle process separates metals, mineral residues, and radionuclides from spent salt generated by the MSO process. It includes salt size reduction with a grinder, salt dissolution in water, precipitation, chemical reduction, filtration, $\mathrm{pH}$ adjustments, ion exchange, and drying. Each component in the salt recycle system was shown to work as designed.

The salt recycle system has successfully treated six batches of spent salt generated from the MSO vessel in FY 98. For spent salts with high carbonate contents (SR1, SR2, SR3, SR5, SR6), it removed ash, metals, and radionuclides from the salts and returned $95 \%$ of the salt for reuse. Table 24 shows the concentrations of cations in the spent salt and clean salt for SR1, SR2, and SR3. These salt consisted of mostly sodium carbonate with traces of sodium chloride, sodium floride, sodium phosphate, sodium sulfate along with some metals such as nickel and chromium. The presence of chromium and nickel in the spent salt was expected because the vessel was made of Inconel 600 which contains chromium and nickel as major components. Table 24 shows that almost all the nickel was removed and more than $90 \%$ of chromium in the spent salt was removed in the salt recycle system. It was impossible to remove chromium to less than $20 \mathrm{ppm}$ in the carbonate salt due to the solubility of both $\mathrm{Cr}+3$ and $\mathrm{Cr}+6$ in the salt solution.

SR5 was the spent salt generated from the first treatability specimen (RTS\#1) which consisted mostly of methyl chloroform with traces of metals and uranium. SR6 was the spent salt from the second treatability study specimen (RTS\#2) which was PCBcontaminated hydraulic oil. Table 25 shows the concentrations of cations and radionuclide (uranium) in the starting spent salts and reusable clean salt for SR5 and SR6. It again shows that almost all the nickel was removed and more than $90 \%$ of chromium in the spent salt was removed in the salt recycle system. Uranium concentration in the salt did not change significantly after the salt recycle because uranium forms the tricarbonate uranyl complex ion and stays in the carbonate solution. But if the uranium concentration in the salt solution is significantly higher than $100 \mathrm{ppm}$, it can be reduced by adding caustic alkali to precipitate out uranium as sodium diuranate [10]. 
LLW-009, PCB Waste Oils

$1088 \mathrm{~g} / \mathrm{hr}$ (1.2 liters $/ \mathrm{hr}$ )

Off-gas at 650 degrees $\mathrm{C}$

C $\quad 78.6$ moles $/ \mathrm{hr}$

$\mathrm{H} \quad 157.5$ moles $/ \mathrm{hr}$

$\mathrm{Cl} \quad 0.48$ moles $/ \mathrm{hr}$

F $\quad 0.21$ moles $/ \mathrm{hr}$

$\mathrm{CO} 278.6$ moles $/ \mathrm{hr}$

$\mathrm{H} 2 \mathrm{O} 78.7$ moles/hr

O2 66.2 moles $/ \mathrm{hr}$

N2 680.2 moles $/ \mathrm{hr}$

Metals $0.024 \mathrm{~g} / \mathrm{hr}$

Radionuclides $62.4 \mathrm{nCi} / \mathrm{hr}$

Air

O2 180.8 moles $/ \mathrm{hr}$

N2 680.2 moles/hr

0.18 liters /hr Water
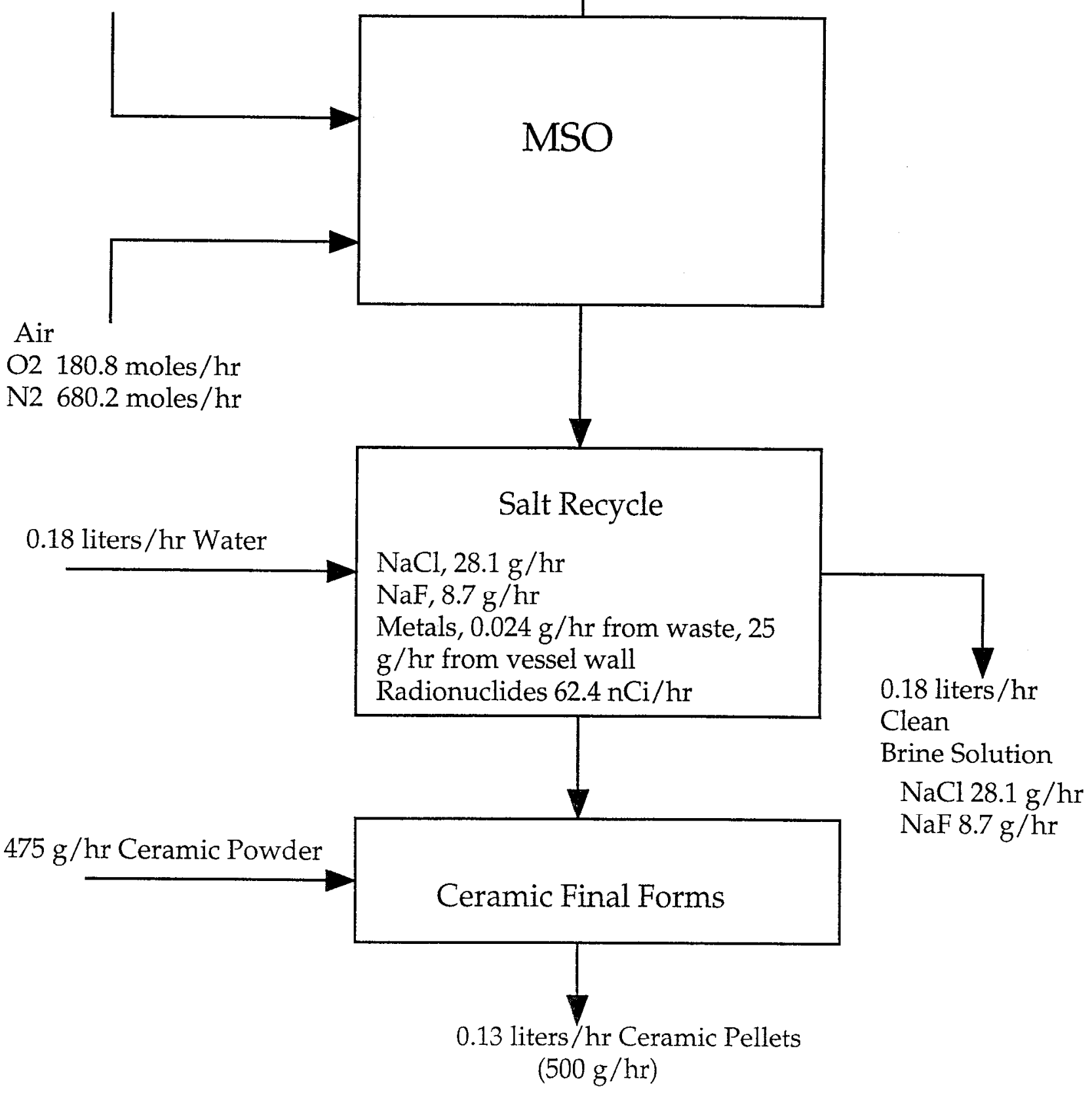

Fig. 13. MSO Flow balance for feed stream LLW-009 (PCB Waste Oils) 


\begin{tabular}{|c|c|c|c|c|c|c|}
\hline \multicolumn{7}{|c|}{$\begin{array}{l}\text { Table 24. Cation Compositions of SR1, SR2, SR3 Before and After Salt Recycle } \\
\text { (Dry Basis) }\end{array}$} \\
\hline & SRI & SR1 & SR2 & SR2 & SR3 & SR3 \\
\hline & Bcfore & After & Before & After & Before & After \\
\hline & ppm & $\mathrm{ppm}$ & $\mathrm{ppm}$ & $\mathrm{ppm}$ & ppm & $\mathrm{ppm}$ \\
\hline & & & & & & \\
\hline $\mathrm{Ag}$ & ND & ND & $\mathrm{ND}$ & ND & $\mathrm{ND}$ & $\mathrm{ND}$ \\
\hline$\Lambda \mathrm{s}$ & $\overline{\mathrm{ND}}$ & $\overline{N D}$ & $\overline{\mathrm{ND}}$ & $\overline{N D}$ & $\overline{\mathrm{ND}}$ & ND \\
\hline $\mathrm{Ba}$ & 1 & 1 & 37 & 7.7 & 2.4 & 5.7 \\
\hline$\overline{\mathrm{Be}}$ & $\overline{\mathrm{ND}}$ & ND & ND & $\mathrm{ND}$ & $\overline{\mathrm{ND}}$ & ND \\
\hline $\mathrm{Cd}$ & $\overline{3}$ & ND & $\overline{N D}$ & $\mathrm{ND}$ & $\mathrm{ND}$ & 0.9 \\
\hline $\mathrm{Co}$ & 2 & 0.3 & 5.7 & $\mathrm{ND}$ & 4 & 0.4 \\
\hline $\mathrm{Cr}$ & 2900 & 150 & 1300 & 57 & 500 & 50 \\
\hline $\mathrm{Cu}$ & 3 & $\mathrm{ND}$ & 6 & ND & 2 & $\mathrm{ND}$ \\
\hline Mo & 16 & 16 & 5 & 7.7 & 4 & 5.6 \\
\hline$\overline{\mathrm{Hg}}$ & $\overline{\mathrm{ND}}$ & $\overline{N D}$ & ND & ND & $\overline{\mathrm{ND}}$ & $\overline{\mathrm{ND}}$ \\
\hline$\overline{\mathrm{Ni}}$ & 53 & 1 & 710 & 1.4 & 670 & 1.3 \\
\hline $\mathrm{Pb}$ & 2 & 2 & 20 & 20 & 5 & 2.5 \\
\hline $\mathrm{Sb}$ & 7 & $\mathrm{ND}$ & 10 & 7.7 & 6 & 2 \\
\hline $\mathrm{Se}$ & 5 & ND & 7 & $\mathrm{ND}$ & $\overline{\mathrm{ND}}$ & ND \\
\hline $\mathrm{T1}$ & $\mathrm{ND}$ & ND & ND & ND & $\overline{\mathrm{ND}}$ & $\overline{\mathrm{ND}}$ \\
\hline $\bar{V}$ & $\overline{N D}$ & ND & 3 & ND & $\overline{N D}$ & $\overline{\mathrm{ND}}$ \\
\hline$\overline{\mathrm{Zn}}$ & ND & ND & 220 & ND & 4 & ND \\
\hline & & & & & & \\
\hline & & & & & & \\
\hline alt & $\overline{f m}$ & $\overline{\text { iur }}$ & $\overline{\text { nate }}$ & & & \\
\hline
\end{tabular}




\begin{tabular}{|c|c|c|c|c|}
\hline \multicolumn{5}{|c|}{$\begin{array}{l}\text { Table 25. Cation Compositions of SR5 and SR6 Before and After } \\
\text { Salt Recycle (Dry Basis) }\end{array}$} \\
\hline & & & & \\
\hline & SR5 & SR5 & SR6 & SR6 \\
\hline & Before & After & Before & After \\
\hline & ppm & ppm & ppm & $\mathrm{ppm}$ \\
\hline & & & & \\
\hline $\mathrm{Ag}$ & ND & $\mathrm{ND}$ & ND & ND \\
\hline As & ND & ND & ND & ND \\
\hline $\mathrm{Ba}$ & 1 & 0.5 & 8.2 & 1.1 \\
\hline$\overline{\mathrm{Be}}$ & 0.4 & $\mathrm{ND}$ & $\mathrm{ND}$ & ND \\
\hline$\overline{\mathrm{Cd}}$ & $\mathrm{ND}$ & $\mathrm{ND}$ & 15 & ND \\
\hline Co & 0.7 & ND & 3 & ND \\
\hline $\mathrm{Cr}$ & 420 & 32 & 980 & 15 \\
\hline$\overline{\mathrm{Cu}}$ & 3 & ND & 7 & ND \\
\hline Mo & 1 & 2 & 4 & $\overline{2}$ \\
\hline$\overline{\mathrm{Hg}}$ & $\mathrm{ND}$ & ND & ND & ND \\
\hline $\mathrm{Ni}$ & 230 & ND & 840 & ND \\
\hline$\overline{\mathrm{Pb}}$ & ND & ND & 10 & ND \\
\hline$\overline{\mathrm{Sb}}$ & $\overline{\mathrm{ND}}$ & ND & ND & ND \\
\hline $\mathrm{Se}$ & ND & ND & ND & ND \\
\hline T1 & ND & ND & ND & $\mathrm{ND}$ \\
\hline$\overline{\mathrm{V}}$ & ND & $\overline{N D}$ & ND & ND \\
\hline $\mathrm{Zn}$ & 1 & ND & 66 & ND \\
\hline$\overline{\mathrm{U}}$ & 11 & 9.4 & 0.63 & 0.6 \\
\hline & & & & \\
\hline & $2 x$ & & & \\
\hline
\end{tabular}


For spent salts with low carbonate content (SR4), salt recycle removed ash, metals, and radionuclides from the salts and generated clean brine (sodium chloride) solution which is not considered hazardous. Table 26 shows the cations (excluding sodium and potassium) and radionuclide (uranium) in the starting spent salt and clean salt after the salt recycle. Initial concentrations of $\mathrm{Cr}, \mathrm{Ni}$ and $\mathrm{U}$ in the spent salt were over $100 \mathrm{ppm}$. Salt recycle successfully reduced $\mathrm{Cr}, \mathrm{Ni}$, and $\mathrm{U}$ to $0.45 \mathrm{ppm}, 2 \mathrm{ppm}$, and $0.1 \mathrm{ppm}$, respectively.

Because the chromium concentration in the high carbonate salts (SR1, SR2, SR3, SR5, SR6) did not drop to less than $20 \mathrm{ppm}$, these salts were not considered for direct disposal. They were reused in the MSO vessel until the chloride contents built up to the level at which the salt could be recycled as "low carbonate," e.g. SR4.

A more comprehensive description of the results of the salt recycle demonstration will be furnished as part of FY99 report.

\section{Results of the Ceramic Final Forms Demonstration}

No Final Forms demonstrations were done in FY1998, nor were any pellets fabricated from surrogate residues. Equipment functional testing was completed satisfactorily. Practice operations of the batching, milling and calcining were done, using innocuous material.

\section{Lessons Learned}

A number of lessons were learned in the first years' operation of the MSO processor and offgas system in the Expedited Technology Demonstration (ETD). These lessons and suggestions for improved operation are summarized below:

* Early practice was to allow the salt to freeze with the injector fully immersed in the melt. To prevent plugging in the injector, air flow was maintained through the injector both during freezing and during melting. During one of the melt cycles, the air flow caused the salt to foam up and some passed over into the off-gas pipe. This occurred with salt with a high ash content, and apparently when salt containing certain - as yet undefined - compositions of ash is first melted, its viscosity and surface tension are conducive to foaming. The operational procedure was changed to require the injector be lifted out of the melt every time the salt was allowed to cool.

* The present processor has a salt drainpipe that extends horizontally from the bottom of the processor and drains the hot, molten salt into a pan located beside the processor. At the end of a draining operation, small quantities of salt could wick back into the heater around the drainpipe, thus causing failure of the heater. In addition, relatively small pieces of debris in the salt could plug the pipe. A larger diameter drainpipe pointing down into a drain pan directly under the processor would improve the salt flow and prevent wicking of the salt into the heater. In addition, the processor top cover should be redesigned so that, if necessary, the drainpipe could be cleared while hot with a long rod from the top of the processor. The design must also recognize that the drainpipe and drain pan will likely distort due to temperature cycling. A spare drain pan is thus necessary to support processor operation while salt is being removed from the first pan. 
Table 26. Cation Composition in SR4 Salt Before and After Salt Recycle (Dry Basis

\begin{tabular}{|c|c|c|}
\hline & $\begin{array}{c}\text { Starting spent salt } \\
\text { (Before) } \\
\text { ppm }\end{array}$ & $\begin{array}{c}\text { Final clean salt } \\
\text { ppm }\end{array}$ \\
\hline & & ND \\
\hline $\mathrm{Ag}$ & $\mathrm{ND}$ & $\mathrm{ND}$ \\
\hline $\mathrm{As}$ & 3 & 1.1 \\
\hline $\mathrm{Ba}$ & $\mathrm{ND}$ & $\mathrm{ND}$ \\
\hline $\mathrm{Be}$ & 3 & 1.5 \\
\hline $\mathrm{Cd}$ & 1 & $\mathrm{ND}$ \\
\hline $\mathrm{Co}$ & 820 & 0.45 \\
\hline $\mathrm{Cr}$ & 1 & 0.5 \\
\hline $\mathrm{Cu}$ & 2 & 2 \\
\hline $\mathrm{Mo}$ & $\mathrm{ND}$ & $\mathrm{ND}$ \\
\hline $\mathrm{Hg}$ & 100 & 2 \\
\hline $\mathrm{Ni}$ & 7 & $\mathrm{ND}$ \\
\hline $\mathrm{Pb}$ & 10 & $\mathrm{ND}$ \\
\hline $\mathrm{Sb}$ & $\mathrm{ND}$ & $\mathrm{ND}$ \\
\hline $\mathrm{Se}$ & $\mathrm{ND}$ & $\mathrm{ND}$ \\
\hline $\mathrm{Tl}$ & $\mathrm{ND}$ & $\mathrm{ND}$ \\
\hline $\mathrm{V}$ & 2 & $\mathrm{ND}$ \\
\hline $\mathrm{Zn}$ & & 0.1 \\
\hline & 200 & \\
\hline $\mathrm{U}$ & & \\
\hline
\end{tabular}

Note: The clean salt consists over $99 \mathrm{wt} . \%$ sodium chloride with trace of sodium sulfate. 
* The processor was built with a cooling air blower capable of blowing air underneath the heater assembly, along the vessel wall, to remove excess heat. Since the blower was pushing air into the heater assembly, hot air leaked out through seams and electrical penetrations. On one occasion during activation, this superheated air damaged insulation on the electrical leads to the heaters. The processor also incorporated fins on the outside surface along the lower, melt-containing zone to assist in heat removal. For the feed rates and materials used in the ETD, overheating of the processor never occurred, thus neither the fins nor the cooling air blower proved necessary. However, if forced air cooling is needed in the future, the cooling air blower should be redesigned to pull air through the furnace assembly rather than pushing air through it. The cooling air duct should also include automatic shut-off dampers to prevent heat loss due to free convection when the blower is not being used.

* The injector assembly for injecting the feed material into the molten salt proved to be very robust and was not prone to plugging. However, to simplify the operation and maintenance and possibly to improve efficiency, the following issues should be considered: a) if internal thermocouples are used, they should be replaceable, b) the hoses that feed the injector needed better support with more compact configuration of hose connections at the top of the injector, c) the injector needs a clamping design to hold it in operating position that will tolerate heat and will be easy to operate, and d) the injector should be self-supporting when raised clear of the molten salt.

* The off-gas system design demonstrated that a simple length of bare pipe with its attendant free convection is sufficient to cool the offgas to a temperature that is compatible with the ceramic filter. No active cooling is required. A trap in front of the GSS filter proved very valuable in the ETD. If molten salt is blown (or foams) out of the processor, the trap will prevent damage to the ceramic filter elements. In addition, the only cooling necded after the ceramic filter is the condenser.

* The off-gas system included a steel wire brush in the pipe section exiting the processor to prevent salt plugging of this line. This salt brush proved invaluable. However, the brush could be morc "robust" (i.c., better able to unstick itself) and should enter the top of the main processor vessel. If the brush encounters some molten salt at the vessel end of the stroke, it must be able to push this aside or tolerate some salt build up on the wall without getting stuck. The brush is less likely to get stuck or abort its stroke if the system is thoroughly hot when the brush is activated.

* In the present design, the feed system to the reactor could potentially expose the operator to hazardous vapors. The feed station should be in a full fume hood to minimize exposure hazards from the feed material. Additionally, the feed system should be optimized to accept multiple phase liquids and liquids containing suspended particulates without allowing significant phase or particle separation or plugging of the pumps and feed lines.

* In the present design, all of the salt was loaded manually into the reaction vessel using a barrel turner hanging from an overhead hoist. The salt was poured out of a funnel attached to the drum, through a plastic tube and into the processor. This design could potentially cause an exposure risk to the operator. A solids conveyor that eliminates salt handling on top of the processor and conveys the salt in a more automatic and contained fashion should be considered. 
For the MSO/ETD Salt Recycle system, lessons and recommendations for improved operation are:

* At present, the entire Salt Recycle system is operated manually. For production use, more automation should be provided. For example, the brine filter should have an easier, perhaps entirely automatic, system for applying the precoat material. The filter should also discharge its filter cake automatically. In addition to filter-related concerns, the valve sequencing for the most common brine transfers should be automated.

* Ground salt is presently conveyed to the dissolution tank using a screw conveyor. Hold-up of salt in this conveyor proved to be excessive, and migration of moisture from the tank into the conveyor caked this remaining salt. A pneumatic type of conveyor would seem to be a better choice since it would have negligible salt hold-up. The conveyor should be isolated from the moist atmosphere in the dissolution tank.

* Significant amounts of non-soluble mineral residue were found in the spent salt. The dissolver tank needs some provision to handle the slurry that results when this salt is introduced. This would include a mixer in the tank plus piping and pumps that can move these solids and pump them into the filter.

* Spray drying of treated brines proved to require expert set-up and operation. Several features of the ETD spray drier should be improved upon for the next-generation system. The wet scrubber should receive more design attention in the following areas: water carryover from the scrubber into the exhaust piping, and algae growth in the scrubber water.

\section{Cost Analysis}

Ecology and Environment, Inc. was contracted by the DOE Oakland Operations Office to prepare an innovative technology summary report for the molten salt oxidation project [11]. The report includes a cost analysis for various feeds. The capital cost for a three vessels system with salt recycle and ceramic final forms was estimated at $\$ 3.3 \mathrm{M}$. Without salt recycle and ceramic final form, the capital cost drops to $\$ 1.8 \mathrm{M}$. Unit costs for several feeds are listed in Table 27.

Table 27: Unit Costs for Various Radioactive Feeds Based on 3-Vessel System (in $\$ / \mathrm{kg}$ )

Feeds $\mathrm{MSO}^{(\mathrm{a}) \quad \text { Incineration }}$

Halogenated organic liquid
32

27

44 $338^{(b)}$

Non-halogenated organic liquid

Ion Exchange resins $20^{\text {(b) }}$

N/A

(a) 3-vessel system, plus operating cost

(b) estimates from LLNL-HWM

\section{Conclusion}

An integrated MSO pilot-scale facility has been built and demonstrations conducted since December 1997. The facility has becn demonstrated with over 20 surrogates and real waste streams. Chlorinated solvents and PCB-contaminated oils, two of the difficult low-level 
mixed waste streams at LLNL, were successfully treated in the facility last August with good results. The MSO technology appears ready to be fielded and implemented with a variety of superfund and DOE low-level mixed wastes. 
References

1. Martyn Adamson and Peter C. Hsu, "Test Plan for Expedited Technology Demonstration Project,", Rev. 1, Lawrence Livermore National Laboratory, August 1998.

2. Martyn Adamson, Peter C. Hsu, David Hipple, Ken Foster, Robert Hopper, and Tim Ford, "Organic Waste Processing using Molten Salt Oxidation," UCRL-JC-129946, presented at 1998 Euchem Conference on Molten Salt Oxidation, France, June 1998.

3. Peter C. Hsu, David Hipple, Dwight Squire, Erica von Holtz, Robert Hopper, and Martyn Adamson, "Integrated Demonstration of Molten Salt Oxidation with Salt Recycle for Mixed Waste Treatment," UCRL-JC-128143, Proceedings of Waste Management ‘98, Tucson, AZ, March 1998.

4. Peter C. Hsu, David H. Hipple, and Martyn Adamson, "MSO Salt Recycle System Operation Manual," Lawrence Livermore National Laboratory, 1998.

5. Cesar O. Pruneda, Bruce E. Watkins, and Ravindra S. Upadhye, "Recent Advances in the Molten Salt Destruction of Energetic Materials," URCL-JC-125250, September 1996.

6. Peter C. Hsu and Martyn G. Adamson, "Treatment of Activated Carbon with Molten Salt Oxidation," unpublished report, LLNL, September 1988.

7. J.C. Rudolph, P.A. Hass, J.T. Bell, S.M. Crosley, Cl. Calhoun, Jr., A.H. Gorin, and L.E. Nulf, "Molten Salt Oxidation of Chloro-organic Compounds: Experimental Results for Products Gas Compositions and Final Forms Studies," ORNL/TM129412, Oak Ridge National Laboratory, April 1995.

8. "Demonstration Testing for Mixed Waste Thermal Treatment Technologies," by Energy and Environmental Research Corporation, available from the website, wastenot.inel.gov/mwfa/ntw/roadmap/compliance/trd/dt.pdt, July 1997.

9. Oscar H. Krikorian, "Selection of Molten Salt Composition for Bench-Scale Molten Salt Processor Tests," UCRL-ID-107081, LLNL, April 1991.

10. Peter C. Hsu, Leslie Summers, Erica von Holtz,David Hipple, Francis Wang, and Martyn Adamson, "Removal of Uranium from MSO Spent Salts," UCRL-126857, Lawrence Livermore National Laboratory, 1998.

11. Denise M Toombs, "Molten Salt Oxidation: Innovative Technology Summary Report," Ecology and Environment, Inc., December 1998.

12. R. A. Van Konynenburg, R. W. Hopper, J. A. Rard, F. J. Ryerson, D. L. Phinney, L. D. Hutcheon \& P. G. Curtis, "Ceramic Waste Form for Residues from Molten Salt Oxidation of Mixed Waste," in Scientific Basis for Nuclear Waste Management XIX, edited by Dieter Knecht \& William M. Murphy (Materials Research Society, Symposium Proceedings 412, Pittsburgh, 1996) pp. 321-328.

13. Operational Safety Procedure 292.19, "ETDP Final Forms System Operation" (effective 12/98). 
Prepared for:

Peter C. Hsu

Lawrence Livermore National Laboratory

P.O. Box 808, L-276

Livermore, CA 94551

\section{SOURCE TEST REPORT}

Hazardous Waste Emissions Testing

Lawrence Livermore National Laboratories

Molten Salt Oxidation Pilot Plant

Test Date(s): August 18, $19 \& 261998$

Prepared by:

BEST ENVIRONMENTAL Inc.

15890 Foothill Blvd.

San Leandro, CA 94578-2101

Phone (510) 278-4011

Fax (510) 278-4018 


\section{TABLE OF CONTENTS}

1.0 Test Results Summary

pg.2

2.0 Introduction \& General Information

pg.3

3.0 Process Description

pg.4

4.0 Test Program

pg.5

5.0 Test Methods

pg.6

6.0 Test Results

pg.9

7.0 Comments

pg.9

Tabulated Data

pg.11-46

Appendix A-Calculations \& Nomenclature

pg.47

Appendix B- Laboratory Reports

pg.69

Appendix C-Field Data Sheets

pg.158

Appendix F- Equipment Calibration Records

pg. 187

Appendix E- Process Data

$\mathrm{pg} .209$

Appendix F-Stack Diagram

pg.215

Appendix G-Sampling System Diagrams

pg.219 
1.0 Test Results Summary: The average emission rate and destruction efficiency test results for the LLNL Bldg. 292 MSO process test program performed on August 18, 19 \& 26, 1998 are presented below:

\section{MSO PROCESS RTS \#1 WASTE FEED EMISSIONS SUMMARY TABLE}

\begin{tabular}{|c|c|c|c|}
\hline Test Parameter & $\begin{array}{c}\text { MSO Inlet Feed } \\
\text { Rate }\end{array}$ & $\begin{array}{c}\text { MSO Outlet } \\
\text { Emission Rate }\end{array}$ & $\begin{array}{c}\text { Destruction } \\
\text { Efficiency }\end{array}$ \\
\hline MCM (1,1,1 trichloroethane) & $24.98 \mathrm{~g} / \mathrm{min}$ & $<0.542 \mathrm{ug} / \mathrm{min}$ & $>99.999998$ \\
\hline 1,1 -dichloroethene & $0.41 \mathrm{~g} / \mathrm{min}$ & $1.067 \mathrm{ug} / \mathrm{min}$ & 99.99974 \\
\hline Tetrachloroethene & $0.81 \mathrm{~g} / \mathrm{min}$ & $<0.175 \mathrm{ug} / \mathrm{min}$ & $>99.999978$ \\
\hline Trichloroethene & $0.20 \mathrm{~g} / \mathrm{min}$ & $<0.197 \mathrm{ug} / \mathrm{min}$ & $>99.999980$ \\
\hline Trichloro-trifluoroethane & $0.57 \mathrm{~g} / \mathrm{min}$ & $<4.372 \mathrm{ug} / \mathrm{min}$ & $>99.999233$ \\
\hline Toluene & $14.69 \mathrm{~g} / \mathrm{min}$ & $3.775 \mathrm{ug} / \mathrm{min}$ & 99.999974 \\
\hline Total PCB & N.A. & N.A. & N.A. \\
\hline Total Dioxin/Furan & N.A. & $56.061 \mathrm{pg} / \mathrm{min}$ & N.A. \\
\hline VOST Volatiles & N.A. & $<31.568 \mathrm{ug} / \mathrm{min}$ & N.A. \\
\hline Total MM5 Semi-volatiles & N.A. & $<91.376 \mathrm{ug} / \mathrm{min}$ & N.A. \\
\hline Particulate & N.A. & $0.00011 \mathrm{lbs} / \mathrm{hr}$ & N.A. \\
\hline Gross Alpha & $9,000 \mathrm{pCi} / \mathrm{hr}$ & $28.55 \mathrm{pCi} / \mathrm{hr}$ & N.A. \\
\hline Gross Beta & $14,100 \mathrm{pCi} / \mathrm{hr}$ & $16.73 \mathrm{pCi} / \mathrm{hr}$ & N.A. \\
\hline Tritium & $41,070 \mathrm{pCi} / \mathrm{hr}$ & $7687.7 \mathrm{pCi} / \mathrm{hr}$ & N.A. \\
\hline HCl & N.A. & $<0.0016 \mathrm{~g} / \mathrm{hr}$ & N.A. \\
\hline
\end{tabular}

\section{MSO PROCESS RTS \#2 WASTE FEED EMISSIONS SUMMARY TABLE}

\begin{tabular}{|c|c|c|c|}
\hline Test Parameter & $\begin{array}{c}\text { MSO Inlet Feed } \\
\text { Rate }\end{array}$ & $\begin{array}{c}\text { MSO Outlet } \\
\text { Emission Rate }\end{array}$ & $\begin{array}{c}\text { Destruction } \\
\text { Efficiency }\end{array}$ \\
\hline MCM (1,1,1 trichloroethane) & $0.168 \mathrm{~g} / \mathrm{min}$ & $<0.291 \mathrm{ug} / \mathrm{min}$ & $>99.999827$ \\
\hline 1,1 -dichloroethene & $0.025 \mathrm{~g} / \mathrm{min}$ & $1.073 \mathrm{ug} / \mathrm{min}$ & 99.99571 \\
\hline Tetrachloroethene & N.A. & $<0.166 \mathrm{ug} / \mathrm{min}$ & N.A. \\
\hline Trichloroethene & N.A. & $<0.187 \mathrm{ug} / \mathrm{min}$ & N.A. \\
\hline Trichloro-trifluoroethane & $0.213 \mathrm{~g} / \mathrm{min}$ & $<4.151 \mathrm{ug} / \mathrm{min}$ & $>99.99805$ \\
\hline Toluene & $2.78 \mathrm{~g} / \mathrm{min}$ & $1.069 \mathrm{ug} / \mathrm{min}$ & 99.999962 \\
\hline Total PCB & $0.0233 \mathrm{~g} / \mathrm{min}$ & $<0.0414 \mathrm{ug} / \mathrm{min}$ & $>99.99982$ \\
\hline Total Dioxin/Furan & N.A. & $108.860 \mathrm{pg} / \mathrm{min}$ & N.A. \\
\hline VOST Volatiles & N.A. & $<17.820 \mathrm{ug} / \mathrm{min}$ & N.A. \\
\hline Total MM5 Semi-volatiles & N.A. & $<95.854 \mathrm{ug} / \mathrm{min}$ & N.A. \\
\hline Particulate & N.A. & $0.000034 \mathrm{lbs} / \mathrm{hr}$ & N.A. \\
\hline Gross Alpha & $8.140 \mathrm{pCi} / \mathrm{hr}$ & $15.53 \mathrm{pCi} / \mathrm{hr}$ & N.A. \\
\hline Gross Beta & $890 \mathrm{pCi} / \mathrm{hr}$ & $0.961 \mathrm{pCi} / \mathrm{hr}$ & N.A. \\
\hline Tritium & $30.700 \mathrm{pCi} / \mathrm{hr}$ & $3.564 .582 \mathrm{pCi} / \mathrm{hr}$ & N.A. \\
\hline HCl & $\mathrm{N} . \mathrm{A}$. & $<0.0015 \mathrm{~g} / \mathrm{hr}$ & N.A. \\
\hline
\end{tabular}




\subsection{Introduction \& General Information:}

Test Date: August 18, $19 \& 26,1998$.

Report Date: November 12, 1998.

Source Facility: Lawrence Livermore National Laboratory (LLNL), Bldg. 292 on Vasco Road in Livermore, California.

Facility Representative: Mr. Peter Hsu, (925) 422-0317.

Subject: Best Environmental Inc. (BEI) was contracted to provide (in-house) emissions testing services on the Molten Salt Oxidation (MSO) pilot plant located at Lawrence Livermore National Laboratory (LLNL), Bldg. 292 on Vasco Road in Livermore, California.

Sampling Locations: Sampling was conducted from the sampling ports located on the 1.375" i.d. inlet and outlet of the GSS (Gas/Solid Separation) filter and from the catalytic converter 4" i.d. outlet stack venting emissions from the MSO process. The sampling ports were located to meet EPA criteria (8 duct diameter downstream and 2 duct diameter upstream from any points of flow disturbance). For more information on the test locations please refer to the Appendix FStack Diagrams section in the Appendices.

Sampling Personnel \& Test Firm: Regan Best, Dan Cartner, Jeff Mesloh, Phil Romando and Mike Wiley of Best Environmental, Inc., (BEI) 15890 Foothill Blvd., San Leandro, CA, 94578.

Observing Personnel: No representatives from the Bay Area Air Quality Management District (BAAQMD) were notified or present during the test days as the test program was not for compliance purposes. Peter Hsu, David Hipple and Tim Ford of LLNL coordinated operation of the MSO process during testing.

Analytical Laboratories: The following analytical laboratories performed analytical work for this project:

\begin{tabular}{|c|c|}
\hline EPA M23 & Philip Services Corporation \\
\hline EPA M0030 & 5555 North Service Road \\
\hline EPA M0050 & Burlington, Ontario, Canada $\mathrm{L} 7 \mathrm{~L} 5 \mathrm{H} 7$ \\
\hline EPA MO010 & Contact: Ron McLeod (905) 332-8788 \\
\hline EPA M114 & $\begin{array}{l}\text { FGL } \\
\text { P.O. Box } 272 \\
\text { Santa Paula. CA } 93601-0272 \\
\text { Contact: Nichel M. Franco ( } 805 \text { ) 525-3824 }\end{array}$ \\
\hline EPA M17 & $\begin{array}{l}\text { BEST ENVIRONIENTAL, NC } \\
15890 \text { Foothill BLVD } \\
\text { San Leandro. CA } 94578 \\
\text { Contact: Wichael Wiley }(510) 2784011\end{array}$ \\
\hline
\end{tabular}


3.0 Process Description: Molten Salt Oxidation (MSO) is a thermal process being demonstrated on a pilot scale for treating low level mixed wastes and energetic materials as an alternative to incineration. The MSO process involves the oxidation and vaporization of organic liquid and solid waste feeds at high temperature in the presence of molten alkali to destroy organic compounds, which produces $\mathrm{CO}_{2}$ and $\mathrm{H}_{2} \mathrm{O}$ vapors while retaining inorganic components such as metals, radionuclides and acid gases in the salt.

The MSO reactor vessel is approximately $9 \mathrm{ft}$. tall, measuring 11.75 " i.d. at the base and 15 " i.d. at the top. The vessel is surrounded by an electric furnace and equipped with waste feed, air and carbonate makeup injection lines. Associated activities include operation of the waste feed system, off-gas system, spent salt freeze pan and salt recycle system.

The process begins with the introduction of salt to the reactor and slowly raising the temperature to $950^{\circ} \mathrm{C}$. The air and dispersing gas flows are started and raised to normal operating conditions. The waste feed flow is then started and brought to the desired level. The injector then sprays the liquid and gases into the molten salt where the organics are oxidized and retained in the salt matrix. The off-gasses and any particulate are passed to the gas solid separator filter (GSS), condenser, HEPA filter, and a NOx/CO catalytic converter before being vented to atmosphere outside the building.

For more detail please refer to the process schematics located in the Process Data section of the Appendices. 
4.0 Test Program: The source test methods and test locations used for each waste feed test series are summarized below:

\section{RTS \#1 WASTE FEED}

\begin{tabular}{lllll} 
Test Location & Parameters & Test Method & Runs & Duration \\
\hline \multirow{3}{*}{ GSS Filter Outlet } & & & & \\
& Filterable Particulate & EPA Method 17 & 3 & $60 \mathrm{~min}$ \\
& Radionuclides & EPA Method 114 & 3 & $60 \mathrm{~min}$ \\
& Volatiles (VOST) & EPA Method 0030 & 9 & $20 \mathrm{~min}$ \\
& HCl & EPA Method 0050 & 3 & $60 \mathrm{~min}$ \\
& DSCFM & EPA Methods 1-4 & 3 & $60 \mathrm{~min}$ \\
GSS Filter Inlet & Dioxins/Furans & EPA Method 23 & 3 & $180 \mathrm{~min}$ \\
& Semi-Volatiles (MM5) & EPA Method 0010 & 3 & $180 \mathrm{~min}$ \\
Catalyst Outlet & & & & \\
& Dioxins/Furans & EPA Method 23 & 1 & $180 \mathrm{~min}$ \\
& Semi-Volatiles (MM5) & EPA Method 0010 & 1 & $180 \mathrm{~min}$ \\
& Volatiles (VOST) & EPA Method 0030 & 3 & $20 \mathrm{~min}$ \\
& Radionuclides & EPA Method 114 & 1 & $60 \mathrm{~min}$
\end{tabular}

\section{RTS \#2 WASTE FEED}

\begin{tabular}{lllll} 
Test Location & Parameters & Test Method & Runs & Duration \\
\hline \multirow{3}{*}{ GSS Filter Outlet } & Filterable Particulate & EPA Method 17 & 3 & \\
& Radionuclides & EPA Method 114 & 3 & $60 \mathrm{~min}$ \\
& Volatiles (VOST) & EPA Method 0030 & 9 & $60 \mathrm{~min}$ \\
& HCl & EPA Method 0050 & 3 & $20 \mathrm{~min}$ \\
& DSCFM & EPA Methods 1-4 & 3 & $60 \mathrm{~min}$ \\
& & & & $60 \mathrm{~min}$ \\
GSS Filter Inlet & Dioxins/Furans. PCB & EPA Method 23 & 3 & $180 \mathrm{~min}$ \\
& Semi-Volatiles (MM5) & EPA Method 0010 & 3 & $180 \mathrm{~min}$ \\
Catalyst Outlet & & & \\
& Dioxins/Furans. PCB & EPA Method 23 & 1 & $180 \mathrm{~min}$ \\
& Semi-Volatiles (MM5) & EPA Method 0010 & 1 & $180 \mathrm{~min}$ \\
& Volatiles (VOST) & EPA Method 0030 & 3 & $20 \mathrm{~min}$ \\
& Radionuclides & EPA Method 114 & 1 & $60 \mathrm{~min}$
\end{tabular}

5.0 Test Methods: This section is intended to provide an overview of the sampling methods and does not attempt to summarize the sampling procedures that are described in detail in the reference methods.

Volumetric flow rate and moisture determination (EP.A Methods $1-4$ ) were pertormed in conjunction with Methods 5 \& 23 to determine mass emissions. Anaivsis for dioxins/furans. PCB's and semi-volatile compounds were performed on a single combined sample train.

Method 1 is used to determine the duct or stack area and appropriate traverse points that represent equal areas of the duct for sampling and velocity measurements. Sampling at the GSS 
inlet and outlet locations were performed at a single point, because of the small duct diameter and the use of a relatively large diameter nozzle.

Method 2 is used to determine stack gas velocity using a standard or S-type pitot tube and inclined manometer. Temperature is monitored using a K-type thermocouple and calibrated Omega temperature meter. Leak checks are performed before and after each traverse to validate the results.

Method 2 QA/QC: Pitot leak checks are performed by pressurizing each leg of the pitot separately to a pressure greater than $3^{\prime \prime} \mathrm{H}_{2} \mathrm{O}$. The leak check is passed when no movement in the manometer fluid occurs over 15 seconds. Thermometer calibrations are performed using an Omega Model CL-300 calibrator. Geometric calibrations of S-type pitots are performed every 6months or following any repairs or modifications, according to guidelines in the CARB QA/QC Volume VI, Table 3. The pitot is visually inspected for damage before each test.

Method 3A is used to determine the molecular weight of the stack gas. Measurements of gas constituents $\% \mathrm{O}_{2}$ and $\% \mathrm{CO}_{2}$ were continuously monitored by facility emission analyzers.

Method 4 is used to determine the moisture content in the gas stream by extracting a sample and condensing the moisture in impingers containing reagents solutions followed by an impinger containing silica gel desiccant. The set-up may vary depending on the primary method it is combined with. e.g., EPA Method 23,0010, 17. The impingers are immersed in an ice-bath controlled to maintain an outlet sample temperature of less than $68^{\circ} \mathrm{F}$. The moisture gained is determined volumetrically and gravimetrically. QA/QC: Results are recorded on the field data sheet. A minimum of 21 cubic feet of sample is pulled using a leak tight pump. Gas sample volume is measured with a calibrated dry gas meter. Sampling system leak checks are performed by capping the nozzle and pulling a vacuum greater than 15 inches of mercury, and observing the meter rate. The leak check is ok if the leak rate is less than 0.02 CFM or $4 \%$ of the average sample rate, whichever is less. The final leak check is performed at a vacuum at least as high as the highest vacuum pulled during the run. If the final leak check exceeds the criteria, then the volume will be corrected based on the leak rate at the average rate (or vacuum), or the test will be voided, according to the method.

EPA Method 23 is used to determine emissions of Dioxin and Furans. The sampling equipment consists of a heated glass-lined probe with pitot and thermocouples, heated filter box, umbilical connected to a XAD-2 resin trap, a series of four Greenburg-Smith impingers and a meter control module. Front and back half fractions will be analyzed separately using high resolution GC/MS following soxhlet extraction. All resin traps are pre-spiked as part of the method QAVQC. Toluene is used in place of methylene chloride as a recovery solvent. The XAD-2 trap inlet gas temperature will be monitored and recorded every ten minutes by sampling personnel. QA/QC: consists of performing sampling system leak checks before and after each test run. Field blanks and reagent blanks are collected. All the sampling equipment is calibrated. (See method 5). Analytical QA/QC consists of field train blanks, reagent blank, and laboratory blanks, duplicates and spikes. 
EPA Method 0010 (Modified Method 5) is used to determine the emissions of semi-volatile (b.p. $>100{ }^{\circ} \mathrm{C}$ ) compounds. The sampling equipment consists of a heat-controlled probe, filter box, an XAD adsorbing resin trap, four Greenburg-Smith impingers, and a meter control module. Isokinetics are maintained by using a programmed $\mathrm{HP}$ calculator. All mandatory data is recorded on a BEI data sheet. Organic emissions that pass through the heated filter are adsorbed in the $\mathrm{XAD}$ resin. The sample train components are recovered and extracted. The extracts are combined and analyzed using gas chromatography/mass spectrometry (GC/MS) according to EPA Method 8270 procedures (SW-846). Sampling QA/QC: Same as Method 5. Analytical QA/QC consisted of a field train blank, laboratory blanks, duplicates and spikes.

EPA Method 0030 (VOST) is used to determine the emissions of volatile (b.p. $<100{ }^{\circ} \mathrm{C}$ ) compounds. The sampling equipment consists of heat-controlled glass probe, water cooled condenser, a pair of resin traps (tenax \& tenax/charcoal), an impinger between the traps to collect liquid condensate. The sampling is non-isokinetic and collects a 20 liter sample at sampling rates of 0.5 to 1 liter per minute depending on the boiling points of the compounds of interest. Three pairs of traps constitute one test run. All mandatory data is recorded on a BEI data sheet. The resin traps are thermally desorbed and analyzed using gas chromatography/mass spectrometry (GC/MS) according to EPA Method 8240 procedures (SW-846). Sampling QA/QC: Same as Method 5. Analytical QA/QC consisted of a field train blank, laboratory blanks, duplicates and spikes.

EPA Method 0050 ( equivalent to CARB Method 421) is used to determine the emissions of Hydrogen Chloride that pass through the probe/filter assembly maintained at $248 \pm 25^{\circ} \mathrm{F}$. The sampling equipment consists of heat-controlled probe, filter box (if required), umbilical, four Greenburg-Smith impingers, and a meter control module. Isokinetics (if required) are maintained by using a programmed HP calculator. All mandatory data is recorded on a BEI data sheet. Condensible gaseous emissions that pass through the filter (rated at $99.95 \%$ efficient for $0.3 \mu \mathrm{m}$ particles) are collected and recovered from the sample line and back-half of the filter holder. The two impingers (containing a solution of $0.1 \mathrm{~N}$ sodium hydroxide), the third impinger that is left empty and the forth impinger containing silica gel desiccant. The impinger solution is analyzed using ion chromatography for any of the following; $\mathrm{HCl}, \mathrm{HNO}_{3}, \mathrm{HBr}, \mathrm{HF}, \mathrm{H}_{3} \mathrm{PO}_{4}$, or $\mathrm{H}_{2} \mathrm{SO}_{4}$. The impingers are immersed in an ice-bath controlled to maintain an outlet sample temperature of less than $68^{\circ} \mathrm{F}$. EPA Method $0050 \mathrm{QA} / \mathrm{QC}$ : Same as Method 5.

EPA Method 114 is used to measure radionuclides. Radionuclides differ in the chemical and physical forms, half-lives and type of radiation emitted. No single method for sample collection and analysis is applicable to all types of facilities. For this test program the sample train would be in the Method 5 configuration with the filter analyzed for alpha and beta radionuclides and the condensed water analyzed for tritium. The precise analytical procedure is determined by the laboratory after examination of the sample matrix.

EPA Method 17 is used to determine the filterable particulate emissions. The sampling equipment consists of a stainless steel nozzle. an in-stack $47 \mathrm{~mm}$ Gelman filter holder with glass fiber filter, followed by a stainless steel, teflon lined probe. Teflon® transfer line and umbilical to four Greenburg-Smith impingers. a pump and a meter control module. The first two impingers each contain $100 \mathrm{ml}$ of de-ionized water. At third impinger is left empty and the fourth impinger contains silica gel desiccant to dry the gas before the pump and gas meter 
Filterable particulate is determined gravimetrically from the acetone rinse of the nozzle and the filter housing and the filter. The acetone is evaporated and desiccated in a tared beaker or tin, then it is weighed to $0.01 \mathrm{mg}$. The filter is desiccated and weighed to $0.01 \mathrm{mg}$. The volume gain in the impinger contents and the weight gain in the silica gel are measured and used to determine the moisture content of the gas stream.

Isokinetic sampling is maintained by using a programmed HP calculator and the numbers are calculated and checked following each run. All mandatory data is recorded on a BEST ENVIRONMENTAL, INC (BEI) data sheet. The dry gas meter, pitot, thermocouples, gauges and nozzles are all calibrated every 6 to 12 months as specified in CARB QA/QC Volume VI, Table 3. Nozzles are calibrated to within 0.001 " diameter and are inspected for damage prior to each test. Pitot leak checks are performed by pressurizing each leg of the pitot separately to a pressure greater than $3 " \mathrm{H}_{2} \mathrm{O}$. The leak check is passed when no movement in the manometer fluid occurs over 15 seconds. Sampling system leak checks are performed before and after each test run. The sampling system is leak checked by sealing the nozzle, pulling a vacuum greater than 15 inches of mercury, and observing the meter rate. If the leak rate is less than 0.02 CFM or $4 \%$ of the average sample rate, whichever is less, the leak check passes. The final leak check is performed at a vacuum at least as high as the highest vacuum pulled during the run.

For sampling system configurations please refer to the diagrams in the Sampling System Diagram section of the appendix of this report. 
6.0 Test Results: Tables 1 through 11 on the following pages present the emission results for the MSO process at the GSS inlet, GSS outlet and catalytic converter outlet locations. Results are shown in micrograms or picograms per dry standard cubic meter concentration and ppt, ppb or ppm concentration. Emission rates are shown in picograms or micrograms per minute for ease of comparison with the waste feed rates. Emission rates were calculated from flow rates measured during the Method 23 or Method 17 test periods. Specific compound removal efficiencies were calculated using the waste feed rates as reported by LLNL personnel.

\section{TABULATED DATA}

PARAMETER RTS \#1 WASTE FEED

RTS \#2 WASTE FEED

Dioxin/Furan

PCB

Semi-Volatiles

Volatiles

Particulate/Radionuclide

$\mathrm{HCl}$
Table 1

N.A.

Table 4

Table 6

Table 8

Table 10
Table 2

Table 3

Table 5

Table 7

Table 9

Calculations, laboratory reports, field data sheets, equipment calibrations, process data, stack diagrams and sampling system diagrams are appended to this report. The contents of each appendix section are arranged in the same order as the tabulated data (i.e. laboratory section begins with dioxin/furan lab results and ends with $\mathrm{HCl}$ results).

7.0 Comments: The GSS inlet location contained high levels of particulate which clogged the sample filter and made it difficult to maintain perfect isokinetic sampling rates. A single run from each test series was outside the $90 \%-110 \%$ range. This would theoretically bias test results somewhat higher, although results from these runs do not appear to differ from the others.

Acetone and methylene chloride blanks for Method 23 were mistakenly shipped to the analytical laboratory in the same coolers as the VOST tube samples. In the opinion of the laboratory this almost certainly resulted in contamination of the sample tubes with these compounds as the trip blanks are comparable with the sample blanks. The results are shown in the tables but were not included in the summaries.

Results from the triplicate sets of VOST tube paifs for each run were combined to calculate a single result for each compound. 
Reporting of average values for triplicate test run series when test results for individual compounds showed both non-detects $(<)$ and detects was decided by majority. That is if two of three test results were non-detect than the average was reported as a non-detect.

With the exception of radionuclides and particulate, test results were not corrected for blank values. California Air Resources Board procedures for toxic emissions calculations generally does not allow blank correction unless the detected compounds are five times greater than the blank values.

The flow measurements at the catalyst outlet were generally higher than at the GSS filter outlet. However these measurements are suspect due to the inherent difficulty in measuring such a low flow in a relatively large duct area.

The details and results contained within this report are to the best of BEI's knowledge an authentic and accurate representation of the test program. If this report is submitted for Compliance purposes it should only be reproduced in its entirety.

If you have any questions concerning this report, or if Best Environmental, Inc. can be of any further assistance, please contact Regan Best, Guy Worthington or Craig Thiry at (510) 2784011 .

Submitted by,

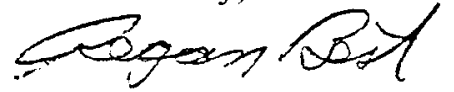

Regan Best

Source Test Manager
Reviewed, by,

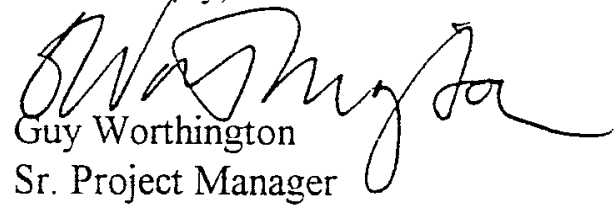




\section{TABLE 1 \\ RTS \#1 Waste Feed \\ LLNL Bldg. 292 MSO \\ GSS Inlet \& Catalytic Converter Outlet \\ EPA Method 23 Dioxin / Furan Emission Results}

\begin{tabular}{|c|c|c|c|c|c|}
\hline TEST\# & 1-GSS Inlet & 2-GSS Inlet & 3-GSS Inlet & AVERAGE & 1-Cat. Out \\
\hline TEST DATE & $8 / 18 / 98$ & $8 / 18 / 98$ & $8 / 19 / 98$ & & $8 / 18 / 98$ \\
\hline TEST TIME & $1016-1326$ & $1413-1707$ & $0918-1308$ & & $1428-1726$ \\
\hline SAMPLE VOLUME (DSCF) & 104.476 & 116.462 & 113.493 & 111.477 & 151.684 \\
\hline SAMPLE VOLUME (DSCM) & 2.959 & 3.298 & 3.214 & 3.157 & 4.296 \\
\hline FLOW RATE (DSCFM) & 13.67 & 13.34 & 13.32 & 13.45 & 16.48 \\
\hline STACK GAS TEMP. ${ }^{\circ} \mathrm{F}$ & 293 & 351 & 318 & 320 & \\
\hline $\mathrm{O}_{2}, \%$ vol. dry & 12.4 & 10.0 & 9.3 & 10.6 & \\
\hline $\mathrm{H}_{2} \mathrm{O}, \% \mathrm{vol}$ & 5.1 & 5.1 & 4.5 & 4.9 & 椾 \\
\hline
\end{tabular}

Total C14-Dibenzofurans (TCDF)

\begin{tabular}{|l|c|c|c|c|c|c|}
\hline \hline total pg & 34 & 35 & 31 & 33.3 & 49 \\
\hline$(\mathrm{pg} / \mathrm{dscm})$ & 11.491 & 10.612 & 9.645 & 10.583 & 11.407 \\
\hline $\mathrm{pg} / \mathrm{min})$ & & 4.449 & 4.010 & 3.639 & $\mathbf{4 . 0 3 3}$ & 5.325 \\
\hline $\mathrm{ppt}$ & $\mathrm{MW}=304$ & 0.0009 & 0.0008 & 0.0008 & 0.0008 & 0.0009 \\
\hline
\end{tabular}

Total C15-Dibenzofurans (PeCDF)

\begin{tabular}{|l|c|c|c|c|c|c|}
\hline \hline total pg & 58 & 68 & 56 & 60.7 & 94 \\
\hline (pg/dscm) & 19.603 & 20.617 & 17.423 & 19.214 & 21.882 \\
\hline (pg/min) & 7.590 & 7.791 & 6.573 & 7.318 & 10.216 \\
\hline $\mathrm{ppt}$ & $\mathrm{MW}=340$ & 0.0014 & 0.0015 & 0.0012 & 0.0014 & 0.0015 \\
\hline
\end{tabular}

Total C16-Dibenzofurans (HxCDF)

\begin{tabular}{|c|c|c|c|c|c|c|}
\hline total pg & & 16 & 23 & 20 & 19.7 & 22 \\
\hline$(\mathrm{pg} / \mathrm{dscm})$ & & 5.408 & 6.974 & 6.223 & 6.201 & 5.121 \\
\hline$(\mathrm{pg} / \mathrm{min})$ & & 2.094 & 2.635 & 2.348 & 2.359 & 2.391 \\
\hline ppt & $M W=374$ & 0.0003 & 0.0004 & 0.0004 & 0.0004 & 0.0003 \\
\hline
\end{tabular}

Total C17-Dibenzofurans (HpCDF)

\begin{tabular}{|l|c|c|c|c|c|}
\hline \hline total pg & $<4.2$ & $<6.0$ & 9.2 & $<6.5$ & $<11.0$ \\
\hline$(\mathrm{pg} / \mathrm{dscm})$ & $<1.420$ & $<1.819$ & 2.862 & $<2.0337$ & $<2.561$ \\
\hline$(\mathrm{pg} / \mathrm{min})$ & $<0.550$ & $<0.687$ & 1.080 & $<0.772$ & $<1.195$ \\
\hline $\mathrm{ppt}$ & $\mathrm{MW}=408$ & $<0.0001$ & $<0.0001$ & 0.0002 & $<0.0001$ \\
\hline
\end{tabular}

C18-Dibenzofurans (OCDF)

\begin{tabular}{|l|c|c|c|c|c|}
\hline \hline total pg & 7.6 & 9.0 & 22 & 12.9 & $<8.9$ \\
\hline$(\mathrm{pg} / \mathrm{dscm})$ & 2.569 & 2.729 & 6.845 & 4.047 & $<2.072$ \\
\hline$(\mathrm{pg} / \mathrm{min})$ & & 0.995 & 1.031 & 2.582 & 1.536 \\
\hline $\mathrm{ppt} \quad \mathrm{MW}=442$ & 0.0001 & 0.0001 & 0.0004 & 0.0002 & $<0.0001$ \\
\hline
\end{tabular}

Total C14-Dibenzo-p-dioxins (TCDD)

\begin{tabular}{|c|c|c|c|c|c|c|}
\hline total og & & 39 & 50 & 34 & 41.0 & 47 \\
\hline$(\mathrm{pg} / \mathrm{dscm})$ & & 13.181 & 15.160 & 10.578 & 12.973 & 10.041 \\
\hline$(\mathrm{pg} / \mathrm{min})$ & & 5.104 & 5.728 & 3.991 & 4.941 & 5.108 \\
\hline ppt & $M W=320$ & 0.0010 & 0.0011 & 0.0008 & 0.0010 & 0.0008 \\
\hline
\end{tabular}


TABLE 1 Continued...

(page 2 of 2)

LLNL Bldg. 292 MSO

GSS Inlet \& Catalytic Converter Outlet

Total C15-Dibenzo-p-dioxins (PeCDD)

\begin{tabular}{|c|c|c|c|c|c|c|}
\hline total pg & & 14 & 21 & 13 & 16.0 & 27 \\
\hline$(\mathrm{pg} / \mathrm{dscm})$ & & 4.732 & 6.367 & 4.045 & 5.048 & 6.285 \\
\hline$(\mathrm{pg} / \mathrm{min})$ & & 1.832 & 2.406 & 1.526 & 1.921 & 2.934 \\
\hline
\end{tabular}

Total C16-Dibenzo-p-dioxins (HxCDD)

\begin{tabular}{|l|c|c|c|c|c|c|}
\hline \hline total pg & $<4.1$ & 11 & $<7.5$ & $<7.5$ & $<8.1$ \\
\hline (pg/dscm) & $<1.386$ & 3.335 & $<2.333$ & $<2.351$ & $<1.886$ \\
\hline$(\mathrm{pg} / \mathrm{min})$ & & $<0.537$ & 1.260 & $<0.880$ & $<0.892$ & $<0.880$ \\
\hline $\mathrm{ppt}$ & $\mathrm{MW}=390$ & $<0.0001$ & 0.0002 & $<0.0001$ & $<0.0001$ & $<0.0001$ \\
\hline
\end{tabular}

Total C17-Dibenzo-p-dioxins (HpCDD)

\begin{tabular}{|l|c|c|c|c|c|c|}
\hline total pg & 8.2 & 18 & 30 & 18.7 & 10 \\
\hline$(\mathrm{pg} / \mathrm{dscm})$ & 2.771 & 5.458 & 9.334 & 5.854 & 2.328 \\
\hline$(\mathrm{pg} / \mathrm{min})$ & 1.073 & 2.062 & 3.521 & 2.219 & 1.087 \\
\hline $\mathrm{ppt}$ & $\mathrm{MW}=424$ & 0.0002 & 0.0003 & 0.0005 & 0.0003 & 0.0001 \\
\hline
\end{tabular}

C18-Dibenzo-p-dioxins (OCDD)

\begin{tabular}{|c|c|c|c|c|c|c|c|}
\hline total pg & & & 22 & 250 & 500 & 257.3 & 97 \\
\hline$(\mathrm{pg} / \mathrm{dscm})$ & & & 7.436 & 75.799 & 155.564 & 79.599 & 22.581 \\
\hline$(\mathrm{pg} / \mathrm{min})$ & & & 2.879 & 28.642 & 58.689 & 30.070 & 10.542 \\
\hline
\end{tabular}

Where,

DSCFM = Dry Standard Cubic Feet per Minute $\mathrm{pg} / \mathrm{dscm}=$ picograms per dry standard cubic meter $\mathrm{pg} / \mathrm{min}=$ Emission rate, picograms per $\mathrm{min}$ ppt $=$ part per trillion

Tstd $=$ Standard Temperature, ${ }^{\circ} \mathrm{F}=$
Calculations, $\mathrm{pg} / \mathrm{min}=0.02832 * \mathrm{DSCFM}^{*}(\mathrm{pg} / \mathrm{dscm})$ $\mathrm{pg} / \mathrm{dscm}=$ total $\mathrm{pg} /$ sample vol, $\mathrm{dscm}$ $\mathrm{ppt}=\mathrm{pg} / \mathrm{dscm} * 0.0224 *(\mathrm{Tstd}+460) / 492 / \mathrm{MW}$ 
TABLE 2

RTS \#2 Waste Feed

LLNL Bldg. 292 MSO

GSS Inlet \& Catalytic Converter Outlet

EPA Method 23 Dioxin / Furan Emission Results

\begin{tabular}{|c|c|c|c|c|c|}
\hline TESTH & 1-GSS Inlet & 2-GSS Inlet & 3-GSS Inlet & AVERAGE & 1-Cat. Out \\
\hline TEST DATE & $8 / 26 / 98$ & $8 / 26 / 98$ & $8 / 26 / 98$ & & $8 / 26 / 98$ \\
\hline TEST TIME & $0903-1216$ & $1309-1616$ & $1636-2002$ & & $1210-1510$ \\
\hline SAMPLE VOLUME (DSCF) & 158.170 & 126.098 & 112.188 & 132.152 & 132.838 \\
\hline SAMPLE VOLUME (DSCM) & 4.479 & 3.571 & 3.177 & 3.743 & 3.762 \\
\hline FLOW RATE (DSCFM) & 14.45 & 12.99 & 13.96 & 13.80 & 16.27 \\
\hline STACK GAS TEMP. ${ }^{\circ} \mathrm{F}$ & 321 & 341 & 292 & 318 & 390 \\
\hline $\mathrm{O}_{2}, \%$ vol. dry & 10.4 & 10.0 & 10.0 & 10.1 & \\
\hline $\mathrm{H}_{2} \mathrm{O}, \%$ vol & 3.2 & 5.4 & 5.4 & 4.7 & \\
\hline
\end{tabular}

Total C14-Dibenzofurans (TCDF)

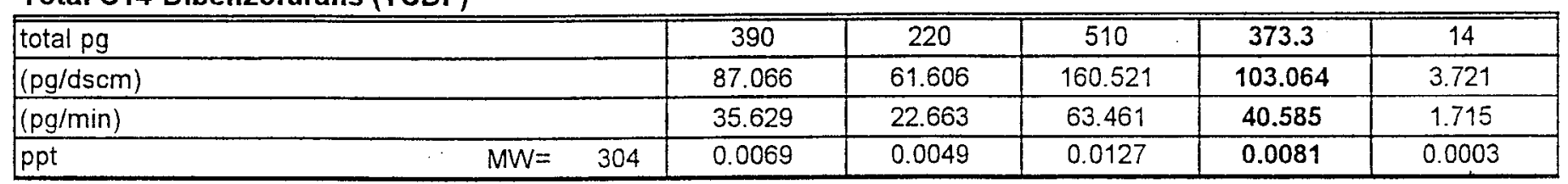

Total C15-Dibenzofurans (PeCDF)

\begin{tabular}{|c|c|c|c|c|c|c|c|}
\hline total pg & & & 66 & 120 & 360 & 182.0 & 22 \\
\hline$(\mathrm{pg} / \mathrm{dscm})$ & & & 14.734 & 33.603 & 113.309 & 53.882 & 5.848 \\
\hline $\mid(\mathrm{pg} / \mathrm{min})$ & & & 6.030 & 12.362 & 44.796 & 21.063 & 2.695 \\
\hline ppt & $\mathrm{MW}=$ & 340 & 0.0010 & 0.0024 & 0.0080 & 0.0038 & 0.0004 \\
\hline
\end{tabular}

Total C16-Dibenzofurans (HXCDF)

\begin{tabular}{|c|c|c|c|c|c|c|}
\hline total pg & & 18 & 31 & 79 & 42.7 & 6 \\
\hline$(\mathrm{pg} / \mathrm{dscm})$ & & 4.018 & 8.681 & 24.865 & 12.521 & 1.515 \\
\hline$(\mathrm{pg} / \mathrm{min})$ & & 1.644 & 3.193 & 9.830 & 4.889 & 0.698 \\
\hline ppt & $M W=\quad 374$ & 0.0003 & 0.0006 & 0.0016 & 0.0008 & 0.0001 \\
\hline
\end{tabular}

Total C17-Dibenzofurans (HPCDF)

\begin{tabular}{|c|c|c|c|c|c|c|}
\hline total pg & & 6.5 & 14.0 & 23.0 & 14.5 & $<4.2$ \\
\hline$(\mathrm{pg} / \mathrm{dscm})$ & & 1.451 & 3.920 & 7.239 & 4.204 & $<1.116$ \\
\hline$(\mathrm{pg} / \mathrm{min})$ & & 0.594 & 1.442 & 2.862 & 1.633 & $<0.514$ \\
\hline$p p t$ & $M W=408$ & 0.0001 & 0.0002 & 0.0004 & 0.0002 & $<0.0001$ \\
\hline
\end{tabular}

C18-Dibenzofurans (OCDF)

\begin{tabular}{|c|c|c|c|c|c|c|}
\hline total pg & & 13.0 & 8.9 & 9 & 10.3 & $<7.1$ \\
\hline$(\mathrm{pg} / \mathrm{dscm})$ & & 2.902 & 2.492 & 2.833 & 2.742 & $<1.887$ \\
\hline$(\mathrm{pg} / \mathrm{min})$ & & 1.188 & 0.917 & 1.120 & 1.075 & $<0.870$ \\
\hline ppt & $M W=442$ & 0.0002 & 0.0001 & 0.0002 & 0.0001 & $<0.0001$ \\
\hline
\end{tabular}

Total C14-Dibenzo-p-dioxins (TCDD)

\begin{tabular}{|c|c|c|c|c|c|c|}
\hline total pg & & 100 & 94 & 58 & 84.0 & 30 \\
\hline (pg/dscm) & & 22.325 & 26.322 & 18.255 & 22.301 & 7.975 \\
\hline$(\mathrm{pg} / \mathrm{min})$ & & 9.136 & 9.683 & 7.217 & 8.679 & 3.674 \\
\hline pot & $M W=320$ & 0.0017 & 0.0020 & 0.0014 & 0.0017 & 0.0006 \\
\hline
\end{tabular}


TABLE 2 Continued...

(page 2 of 2)

RTS \#2 Waste Feed

LLNL BIdg. 292 MSO

GSS Inlet \& Catalytic Converter Outlet

EPA Method 23 Dioxin / Furan Emission Results

Total C15-Dibenzo-p-dioxins (PeCDD)

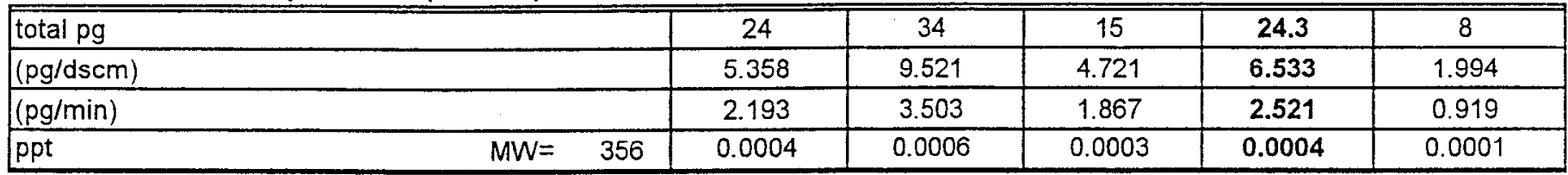

Total C16-Dibenzo-p-dioxins (HxCDD)

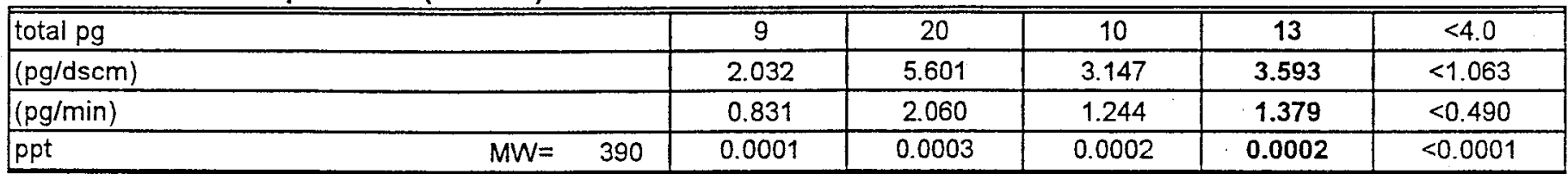

Total C17-Dibenzo-p-dioxins (HpCDD)

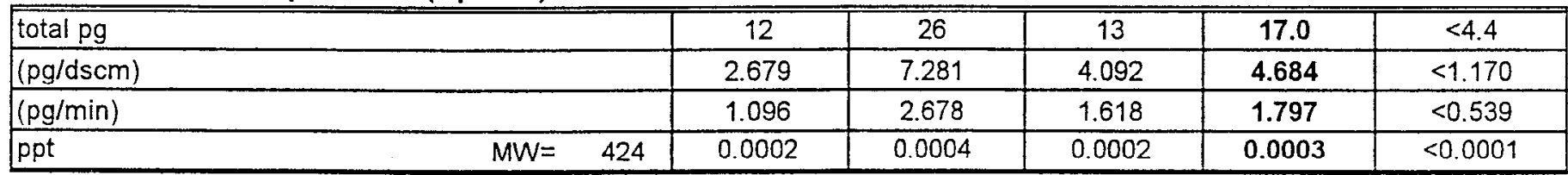

C18-Dibenzo-p-dioxins (OCDD)

\begin{tabular}{|l|c|c|c|c|c|c|}
\hline \hline total $\mathrm{pg}$ & 290 & 200 & 230 & $\mathbf{2 4 0 . 0}$ & 9 \\
\hline$(\mathrm{pg} / \mathrm{dscm})$ & 64.741 & 56.005 & 72.392 & 64.379 & 2.392 \\
\hline$(\mathrm{pg} / \mathrm{min})$ & & 26.494 & 20.603 & 28.620 & $\mathbf{2 5 . 2 3 9}$ & 1.102 \\
\hline $\mathrm{ppt}$ & $\mathrm{MW}=458$ & 0.0034 & 0.0029 & 0.0038 & 0.0034 & 0.0001 \\
\hline
\end{tabular}

Where,

DSCFM $=$ Dry Standard Cubic Feet per Minute $\mathrm{pg} / \mathrm{dscm}=$ picograms per $\mathrm{dry}$ standard cubic meter $\mathrm{pg} / \mathrm{min}=$ Emission rate, picograms per $\mathrm{min}$ $\mathrm{ppt}=$ part per trillion

Tstd $=$ Standard Temperature,${ }^{\circ} \mathrm{F}=$
Calculations,

$\mathrm{pg} / \mathrm{min}=0.02832 * \mathrm{DSCFM} *(\mathrm{pg} / \mathrm{dscm})$

$\mathrm{pg} / \mathrm{dscm}=$ total $\mathrm{pg} /$ sample vol, $\mathrm{dscm}$

$\mathrm{ppt}=\mathrm{pg} / \mathrm{dscm} * 0.0224 *($ Tstd +460$) / 492 / \mathrm{MW}$ 
TABLE 3

RTS \#2 Waste Feed

LLNL BIdg. 292 MSO

GSS Inlet \& Catalytic Converter Outlet

EPA Method 23 PCB Emission Results

\begin{tabular}{|c|c|c|c|c|c|}
\hline TEST\# & 1-GSS Inlet & 2-GSS Inlet & 3-GSS Inlet & AVERAGE & 1-Cat. Out \\
\hline TEST DATE & $8 / 26 / 98$ & $8 / 26 / 98$ & $8 / 26 / 98$ & & $8 / 26 / 98$ \\
\hline TEST TIME & $0903-1216$ & $1309-1616$ & $1636-2002$ & & $1210-1510$ \\
\hline SAMPLE VOLUME (DSCF) & 158.170 & 126.098 & 112.188 & 132.152 & 132.838 \\
\hline SAMPLE VOLUME (DSCM) & 4.479 & 3.571 & 3.177 & 3.743 & 3.762 \\
\hline FLOW RATE (DSCFM) & 14.45 & 12.99 & 13.96 & 13.80 & 16.27 \\
\hline STACK GAS TEMP. ${ }^{\circ} \mathrm{F}$ & 321 & 341 & 292 & 318 & 390 \\
\hline $\mathrm{O}_{2}, \%$ vol. dry & 10.4 & 10.0 & 10.0 & 10.1 & \\
\hline $\mathrm{H}_{2} \mathrm{O}, \%$ vol & 3.2 & 5.4 & 5.4 & 4.7 & 新 \\
\hline
\end{tabular}

\section{Chlorobiphenyls $\left(\mathrm{C}_{12} \mathrm{H}_{9} \mathrm{Cl}\right)$}

\begin{tabular}{|l|c|c|c|c|c|}
\hline \hline total ug & $<0.073$ & $<0.040$ & $<0.021$ & $<0.045$ & $<0.017$ \\
\hline$(\mu \mathrm{g} / \mathrm{dscm})$ & $<0.0163$ & $<0.0112$ & $<0.0066$ & $<0.0114$ & $<0.0045$ \\
\hline$(\mu \mathrm{g} / \mathrm{min})$ & $<0.0067$ & $<0.0041$ & $<0.0026$ & $<0.0045$ & $<0.0021$ \\
\hline $\mathrm{ppb}$ & $\mathrm{MW}=188.7$ & $<0.0021$ & $<0.0014$ & $<0.0008$ & $<0.0014$ \\
\hline
\end{tabular}

Dichlorobiphenyls $\left(\mathrm{C}_{12} \mathrm{H}_{8} \mathrm{Cl}_{2}\right)$

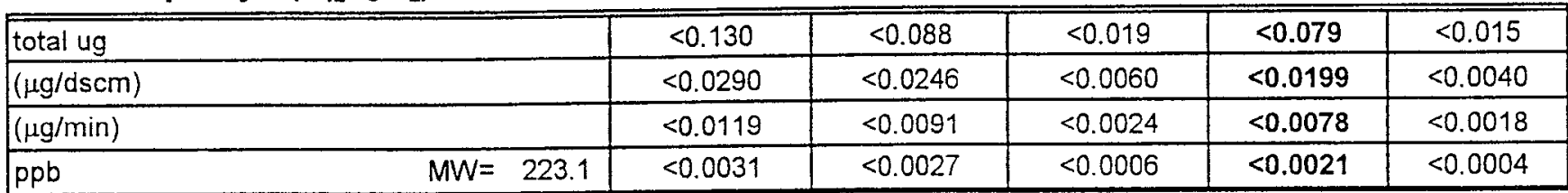

Trichlorobiphenyls $\left(\mathrm{C}_{12} \mathrm{H}_{7} \mathrm{Cl}_{3}\right)$

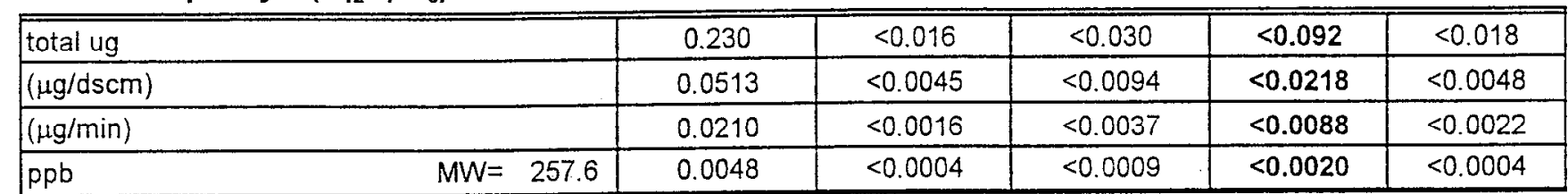

Tetrachlorobiphenyls $\left(\mathrm{C}_{12} \mathrm{H}_{6} \mathrm{Cl}_{4}\right)$

\begin{tabular}{|l|c|c|c|c|c|}
\hline \hline total ug & 0.760 & $<0.053$ & $<0.035$ & $<0.283$ & $<0.054$ \\
\hline$(\mu \mathrm{g} / \mathrm{dscm})$ & 0.1697 & $<0.0148$ & $<0.0110$ & $<0.0652$ & $<0.0144$ \\
\hline$(\mu \mathrm{g} / \mathrm{min})$ & 0.0694 & $<0.0055$ & $<0.0044$ & $<0.0264$ & $<0.0066$ \\
\hline $\mathrm{ppb}$ & $\mathrm{MW}=292.0$ & 0.0140 & $<0.0012$ & $<0.0009$ & $<0.0054$ \\
\hline
\end{tabular}

Pentachlorobiphenyls $\left(\mathrm{C}_{12} \mathrm{H}_{5} \mathrm{Cl}_{5}\right)$

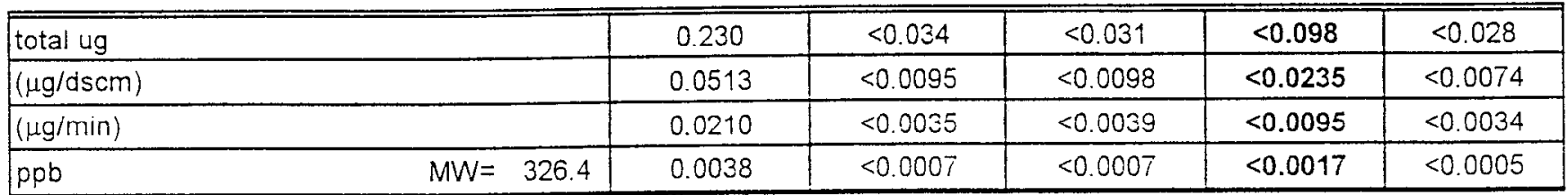

Hexachlorobiphenyls $\left(\mathrm{C}_{12} \mathrm{H}_{4} \mathrm{Cl}_{6}\right)$

\begin{tabular}{|l|c|c|c|c|c|c|}
\hline \hline total ug & $<0.038$ & 0.030 & $<0.031$ & $<0.033$ & $<0.021$ \\
\hline$(\mu \mathrm{g} / \mathrm{dscm})$ & $<0.0085$ & 0.0084 & $<0.0098$ & $<0.0089$ & $<0.0056$ \\
\hline$(\mu \mathrm{g} / \mathrm{min})$ & & $<0.0035$ & 0.0031 & $<0.0039$ & $<0.0035$ & $<0.0026$ \\
\hline $\mathrm{ppb}$ & $\mathrm{MW}=360.9$ & $<0.0006$ & 0.0006 & $<0.0006$ & $<0.0006$ & $<0.0004$ \\
\hline
\end{tabular}


TABLE 3 Continued... (page 2 of 2)

RTS \#2 Waste Feed

LLNL Bldg. 292 MSO

GSS Inlet \& Catalytic Converter Outlet

EPA Method 23 PCB Emission Results

Heptachlorobiphenyis $\left(\mathrm{C}_{12} \mathrm{H}_{3} \mathrm{Cl}_{7}\right)$

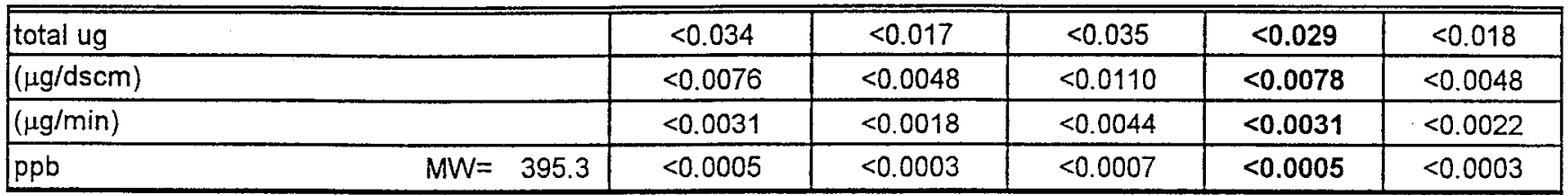

Octachlorobiphenyls $\left(\mathrm{C}_{12} \mathrm{H}_{2} \mathrm{Cl}_{8}\right)$

\begin{tabular}{|c|c|c|c|c|c|c|}
\hline total ug & & $<0.048$ & $<0.110$ & $<0.043$ & $<0.067$ & $<0.066$ \\
\hline$(\mu \mathrm{g} / \mathrm{dscm})$ & & $<0.0107$ & $<0.0308$ & $<0.0135$ & $<0.0184$ & $<0.0175$ \\
\hline$(\mu \mathrm{g} / \mathrm{min})$ & & $<0.0044$ & $<0.0113$ & $<0.0054$ & $<0.0070$ & $<0.0081$ \\
\hline ppb & $M W=429.8$ & $<0.0006$ & $<0.0017$ & $<0.0008$ & $<0.0010$ & $<0.0010$ \\
\hline
\end{tabular}

Nonachlorobiphenyls $\left(\mathrm{C}_{12} \mathrm{HCl}_{9}\right)$

\begin{tabular}{|c|c|c|c|c|c|c|}
\hline total ug & & $<0.018$ & $<0.038$ & $<0.021$ & $<0.026$ & $<<0.027$ \\
\hline$(\mu \mathrm{g} / \mathrm{dscm})$ & & $<0.0040$ & $<0.0106$ & $<0.0066$ & $<0.0071$ & $<0.0072$ \\
\hline$(\mu \mathrm{g} / \mathrm{min})$ & & $<0.0016$ & $<0.0039$ & $<0.0026$ & $<0.0027$ & $<0.0033$ \\
\hline $\mathrm{ppb}$ & $M W=464.2$ & $<0.0002$ & $<0.0006$ & $<0.0003$ & $<0.0004$ & $<0.0004$ \\
\hline
\end{tabular}

Decachlorobiphenyls $\left(\mathrm{C}_{12} \mathrm{Cl}_{10}\right)$

\begin{tabular}{|c|c|c|c|c|c|c|}
\hline total ug & & $<0.022$ & $<0.022$ & $<0.021$ & $<0.022$ & $<0.023$ \\
\hline$(\mu \mathrm{g} / \mathrm{dscm})$ & & $<0.0049$ & $<0.0062$ & $<0.0066$ & $<0.0059$ & $<0.0061$ \\
\hline$(\mu \mathrm{g} / \mathrm{min})$ & & $<0.0020$ & $<0.0023$ & $<0.0026$ & $<0.0023$ & $<0.0028$ \\
\hline$p p b$ & $M W=498.7$ & $<0.0002$ & $<0.0003$ & $<0.0003$ & $<0.0003$ & $<0.0003$ \\
\hline
\end{tabular}

Total PCB's

\begin{tabular}{|l|c|c|c|c|c|}
\hline \hline total ug & 1.20 & 0.12 & $<0.019$ & 0.446 & $<0.015$ \\
\hline$(\mu \mathrm{g} / \mathrm{dscm})$ & 0.2679 & 0.0336 & $<0.0060$ & 0.1025 & $<0.0040$ \\
\hline$(\mu \mathrm{g} / \mathrm{min})$ & 0.1096 & 0.0124 & $<0.0024$ & 0.0414 & $<0.0018$ \\
\hline
\end{tabular}

Where,

DSCFM = Dry Standard Cubic Feet per Minute $\mu \mathrm{g} / \mathrm{ds} \mathrm{cm}=$ micrograms per dry standard cubic meter $\mu \mathrm{g} / \mathrm{min}=$ Emission rate, micrograms per minute $\mathrm{ppb}=$ part per billion

Tstd $=$ Standard Temperature $^{\circ} \mathrm{F} 68$
Calculations,

$\mu \mathrm{g} / \mathrm{min}=0.02832 * \mathrm{DSCFM} *(\mu \mathrm{g} / \mathrm{dscm})$

$\mu \mathrm{g} / \mathrm{dscm}=$ total $\mu \mathrm{g} /$ sample vol, $\mathrm{dscm}$

$\mathrm{ppb}=\mu \mathrm{g} / \mathrm{dscm} * 22.4 *($ Tstd +460$) / 492 / \mathrm{MW}$ 


\section{TABLE 4}

RTS \#1 WASTE FEED

\section{LLNL Bldg. 292 MSO}

GSS Inlet \& Catalytic Converter Outlet

EPA Test Method 0010 - Modified Method 5

\begin{tabular}{|c|c|c|c|c|c|}
\hline TEST\# & 1 1-GSS Iniet & 2-GSS Inlet & 3-GSS Inlet & AVERAGE & 1-Cat. Out \\
\hline TEST DATE & $8 / 18 / 98$ & $8 / 18 / 98$ & $8 / 19 / 98$ & & $8 / 18 / 98$ \\
\hline TEST TIME & $1016-1326$ & $1413-1707$ & $0918-1308$ & & $1428-1726$ \\
\hline SAMPLE VOLUME (DSCF) & 104.476 & 116.462 & 113.493 & 111.477 & 151.684 \\
\hline SAMPLE VOLUME (DSCM) & 2.959 & 3.298 & 3.214 & 3.157 & 4.296 \\
\hline FLOW RATE (DSCFM) & 13.67 & 13.34 & 13.32 & 13.45 & 16.48 \\
\hline STACK GAS TEMP. ${ }^{\circ} \mathrm{F}$ & 292.5 & 351.0 & 317.9 & 320.5 & \\
\hline $\mathrm{O}_{2}, \%$ vol. dry & 12.4 & 10.0 & 9.3 & 10.6 & 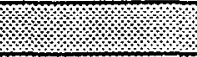 \\
\hline $\mathrm{H}_{2} \mathrm{O}, \%$ vol & 5.1 & 5.1 & 4.5 & 4.9 & \\
\hline
\end{tabular}

\section{Aniline}

\begin{tabular}{|c|c|c|c|c|c|c|}
\hline total ug & & $<40$ & $<40$ & $<40$ & $<40$ & $<40$ \\
\hline$(\mathrm{ug} / \mathrm{dscm})$ & & $<13.519$ & $<12.128$ & $<12.445$ & $<12.697$ & $<9.311$ \\
\hline$(\mathrm{ug} / \mathrm{min})$ & & $<5.234$ & $<4.583$ & $<4.695$ & $<4.837$ & $<4.346$ \\
\hline ppb & MW 93.0 & $<3.494$ & $<3.135$ & $<3.217$ & $<3.282$ & $<2.407$ \\
\hline
\end{tabular}

Phenol

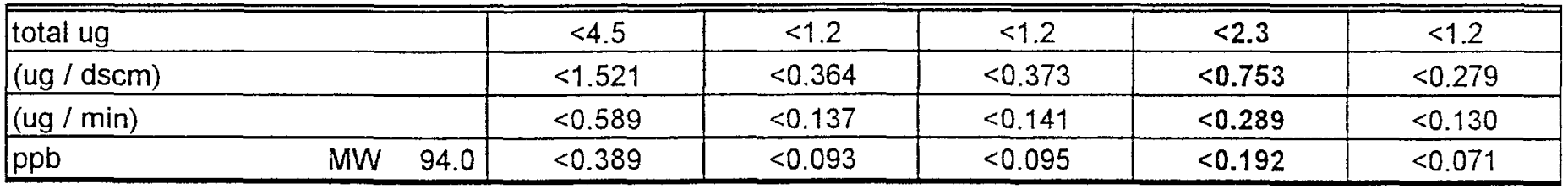

\section{Bis(2-chloroethyl)ether}

\begin{tabular}{|c|c|c|c|c|c|c|}
\hline total ug & & $<3.2$ & $<3.2$ & $<3.2$ & $<3.2$ & $<3.2$ \\
\hline (ug / dscm) & & $<1.082$ & $<0.970$ & $<0.996$ & $<1.016$ & $<0.745$ \\
\hline (ug / min) & & $<0.419$ & $<0.367$ & $<0.376$ & $<0.387$ & $<0.348$ \\
\hline $\mathrm{ppb}$ & MW 143.0 & $<0.182$ & $<0.163$ & $<0.167$ & $<0.171$ & $<0.125$ \\
\hline
\end{tabular}

\section{2-Chlorophenol}

\begin{tabular}{|c|c|c|c|c|c|c|}
\hline total ug & & $<2.0$ & $<2.0$ & $<2.0$ & $<2.0$ & $<2.0$ \\
\hline (ug / dscm) & & $<0.676$ & $<0.606$ & $<0.622$ & $<0.635$ & $<0.466$ \\
\hline (ug / min) & & $<0.262$ & $<0.229$ & $<0.235$ & $<0.242$ & $<0.217$ \\
\hline ppb & MW 128.6 & $<0.126$ & $<0.113$ & $<0.116$ & $<0.119$ & $<0.087$ \\
\hline
\end{tabular}

1,3-Dichlorobenzene

\begin{tabular}{|c|c|c|c|c|c|c|}
\hline total ug & & $<6.0$ & $<6.0$ & $<6.0$ & $<6.0$ & $<6.0$ \\
\hline$(\mathrm{ug} / \mathrm{dscm})$ & & $<2.028$ & $<1.819$ & $<1.867$ & $<1.905$ & $<1.397$ \\
\hline (ug/min) & & $<0.785$ & $<0.687$ & $<0.704$ & $<0.726$ & $<0.652$ \\
\hline $\mathrm{ppb}$ & MW 147.0 & $<0.332$ & $<0.297$ & $<0.305$ & $<0.311$ & $<0.228$ \\
\hline
\end{tabular}


TABLE 4 Continued...

(page 2 of 9 )

RTS \#1 WASTE FEED

EPA Test Method 0010 - Modified Method 5

\section{1-4-Dichlorobenzene}

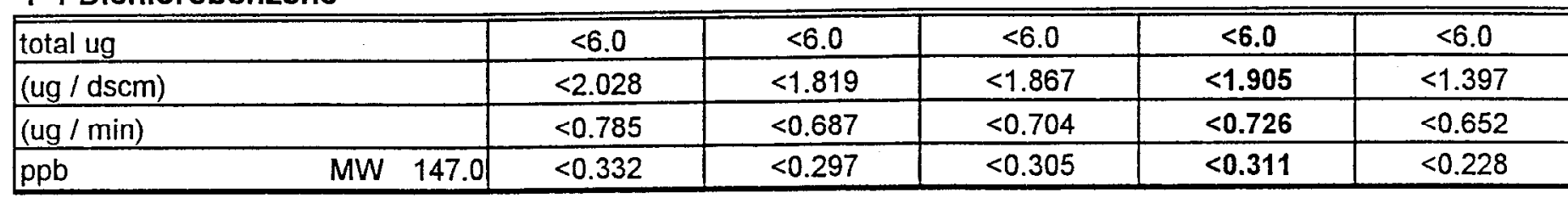

1,2-Dichlorobenzene

\begin{tabular}{|c|c|c|c|c|c|c|}
\hline total ug & & $<6.8$ & $<6.8$ & $<6.8$ & $<6.8$ & $<6.8$ \\
\hline (ug / dscm) & & $<2.298$ & $<2.062$ & $<2.116$ & $<2.159$ & $<1.583$ \\
\hline (ug / min) & & $<0.890$ & $<0.779$ & $<0.798$ & $<0.822$ & $<0.739$ \\
\hline $\mathrm{ppb}$ & MW 147.0 & $<0.376$ & $<0.337$ & $<0.346$ & $<0.353$ & $<0.259$ \\
\hline
\end{tabular}

2-Methylphenol

\begin{tabular}{|c|c|c|c|c|c|c|}
\hline total ug & & $<4.8$ & $<4.8$ & $<4.8$ & $<4.8$ & $<4.8$ \\
\hline (ug / dscm) & & $<1.622$ & $<1.455$ & $<1.493$ & $<1.524$ & $<1.117$ \\
\hline (ug/min) & & $<0.628$ & $<0.550$ & $<0.563$ & $<0.580$ & $<0.521$ \\
\hline ppb & MW 104.1 & $<0.375$ & $<0.336$ & $<0.345$ & $<0.352$ & $<0.258$ \\
\hline
\end{tabular}

Bis(2-chloroisopropyl)ether

\begin{tabular}{|c|c|c|c|c|c|c|}
\hline total ug & & $<4.4$ & $<4.4$ & $<4.4$ & $<4.4$ & $<4.4$ \\
\hline (ug / dscm) & & $<1.487$ & $<1.334$ & $<1.369$ & $<1.397$ & $<1.024$ \\
\hline (ug / min) & & $<0.576$ & $<0.504$ & $<0.516$ & $<0.532$ & $<0.478$ \\
\hline $\mathrm{ppb}$ & MW 132.1 & $<0.271$ & $<0.243$ & $<0.249$ & $<0.254$ & $<0.186$ \\
\hline
\end{tabular}

4-Methylphenol

\begin{tabular}{|c|c|c|c|c|c|}
\hline total ug & $<6.4$ & $<6.4$ & $<6.4$ & $<6.4$ & $<6.4$ \\
\hline (ug / dscm) & $<2.163$ & $<1.940$ & $<1.991$ & $<2.032$ & $<1.490$ \\
\hline (ug / min) & $<0.838$ & $<0.733$ & $<0.751$ & $<0.774$ & $<0.695$ \\
\hline MW 104.1 & $<0.500$ & $<0.448$ & $<0.460$ & $"<0.469$ & $<0.344$ \\
\hline
\end{tabular}

N-Nitroso-di-N-Propylamine

\begin{tabular}{|c|c|c|c|c|c|c|}
\hline total ug & & $<4.4$ & $<4.4$ & $<4.4$ & $<4.4$ & $<4.4$ \\
\hline$(\mathrm{ug} / \mathrm{dscm})$ & & $<1.487$ & $<1.334$ & $<1.369$ & $<1.397$ & $<1.024$ \\
\hline (ug/min) & & $<0.576$ & $<0.504$ & $<0.516$ & $<0.532$ & $<0.478$ \\
\hline $\mathrm{ppb}$ & MW 130.0 & $<0.275$ & $<0.247$ & $<0.253$ & $<0.258$ & $<0.189$ \\
\hline
\end{tabular}

Hexachloroethane

\begin{tabular}{|c|c|c|c|c|c|c|}
\hline total ug & & $<4.4$ & $<4.4$ & $<4.4$ & $<4.4$ & $<4.4$ \\
\hline$(u g / d s c m)$ & & $<1.487$ & $<1.334$ & $<1.369$ & $<1.397$ & $<1.024$ \\
\hline (ug / min) & & $<0.576$ & $<0.504$ & $<0.516$ & $<0.532$ & $<0.478$ \\
\hline ppb & MW 236.7 & $<0.151$ & $<0.135$ & $<0.139$ & $<0.142$ & $<0.104$ \\
\hline
\end{tabular}

\section{Nitrobenzene}

\begin{tabular}{|c|c|c|c|c|c|c|}
\hline total ug & & $<3.2$ & $<3.2$ & $<3.2$ & $<3.2$ & $<3.2$ \\
\hline$(\mathrm{ug} / \mathrm{dscm})$ & & $<1.082$ & $<0.970$ & $<0.996$ & $<1.016$ & $<0.745$ \\
\hline$(\mathrm{ug} / \mathrm{min})$ & & $<0.419$ & $<0.367$ & $<0.376$ & $<0.387$ & $<0.348$ \\
\hline ppb & MW 123.1 & $<0.211$ & $<0.189$ & $<0.194$ & $<0.198$ & $<0.145$ \\
\hline
\end{tabular}


TABLE 4 Continued...

(page 3 of 9)

RTS \#1 WASTE FEED

EPA Test Method 0010 - Modified Method 5

Isophorone

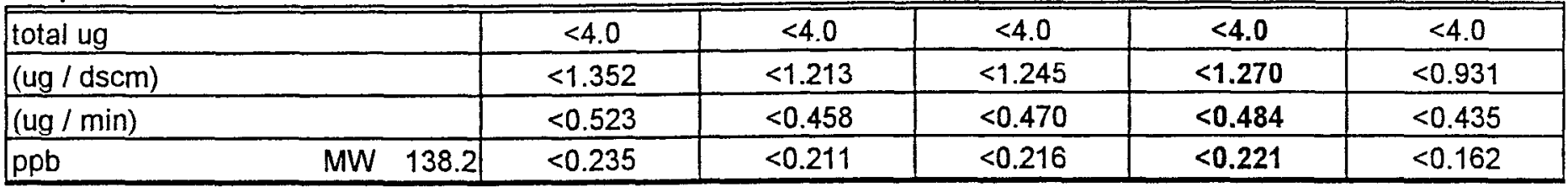

2-Nitrophenol

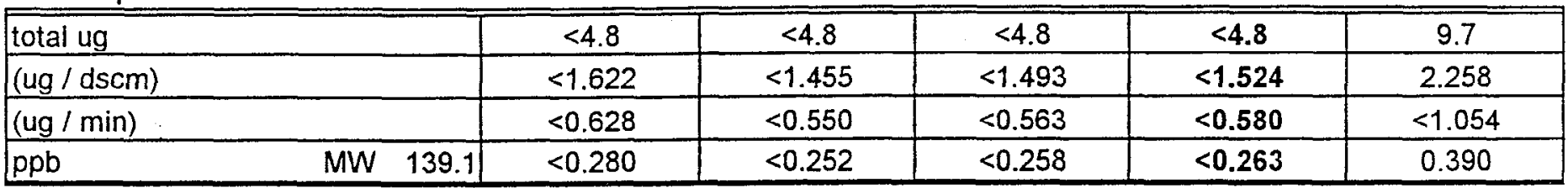

2,4-Dimethylphenol

\begin{tabular}{|c|c|c|c|c|c|c|}
\hline total ug & & $<40.0$ & $<40.0$ & $<40.0$ & $<40.0$ & $<40.0$ \\
\hline (ug / dscm) & & $<13.519$ & $<12.128$ & $<12.445$ & $<12.697$ & $<9.311$ \\
\hline (ug/min) & & $<5.234$ & $<4.583$ & $<4.695$ & $<4.837$ & $<4.346$ \\
\hline$p p b$ & MW 122.2 & $<2.659$ & $<2.386$ & $<2.448$ & $<2.498$ & $<1.832$ \\
\hline
\end{tabular}

\section{Bis(2-chloroethoxy)methane}

\begin{tabular}{|c|c|c|c|c|c|c|}
\hline total ug & & $<4.8$ & $<4.8$ & $<4.8$ & $<4.8$ & $<4.8$ \\
\hline$(\mathrm{ug} / \mathrm{dscm})$ & & $<1.622$ & $<1.455$ & $<1.493$ & $<1.524$ & $<1.117$ \\
\hline (ug / min) & & $<0.628$ & $<0.550$ & $<0.563$ & $<0.580$ & $<0.521$ \\
\hline$p p b$ & MW 173.0 & $<0.225$ & $<0.202$ & $<0.208$ & $<0.212$ & $<0.155$ \\
\hline
\end{tabular}

2,4-Dichlorophenol

\begin{tabular}{|c|c|c|c|c|c|c|}
\hline total ug & & $<4.8$ & $<4.8$ & $<4.8$ & $<4.8$ & $<4.8$ \\
\hline (ug / dscm) & & $<1.622$ & $<1.455$ & $<1.493$ & $<1.524$ & $<1.117$ \\
\hline (ug / min) & & $<0.628$ & $<0.550$ & $<0.563$ & $<0.580$ & $<0.521$ \\
\hline$p p b$ & MW 163.0 & $<0.239$ & $<0.215$ & $<0.220$ & $<0.225$ & $<0.165$ \\
\hline
\end{tabular}

\section{1,2,4-Trichlorobenzene}

\begin{tabular}{|c|c|c|c|c|c|c|}
\hline total ug & & $<8.8$ & $<8.8$ & $<8.8$ & $<8.8$ & $<8.8$ \\
\hline (ug/dscm) & & $<2.974$ & $<2.668$ & $<2.738$ & $<2.793$ & $<2.048$ \\
\hline (ug / min) & & $<1.152$ & $<1.008$ & $<1.033$ & $<1.064$ & $<0.956$ \\
\hline ppb & MW 181.5 & $<0.394$ & $<0.353$ & $<0.363$ & $<0.370$ & $<0.271$ \\
\hline
\end{tabular}

Napthalene

\begin{tabular}{|l|c|c|c|c|c|}
\hline \hline total ug & $<7.6$ & $<7.6$ & $<7.6$ & $<7.6$ & $<7.6$ \\
\hline (ug / dscm) & $<2.569$ & $<2.304$ & $<2.365$ & $<2.413$ & $<1.769$ \\
\hline (ug / min) & $<0.995$ & $<0.871$ & $<0.892$ & $<0.919$ & $<0.826$ \\
\hline $\mathrm{ppb}$ & & $<0.436$ & $<0.444$ & $<0.453$ & $<0.332$ \\
\hline
\end{tabular}

4-Chloroaniline

\begin{tabular}{|c|c|c|c|c|c|c|}
\hline total ug & & $<40.0$ & $<40.0$ & $<40.0$ & $<40.0$ & $<40.0$ \\
\hline (ug / dscm) & & $<13.519$ & $<12.128$ & $<12.445$ & $<12.697$ & $<9.311$ \\
\hline (ug/min) & & $<5.234$ & $<4.583$ & $<4.695$ & $<4.837$ & $<4.346$ \\
\hline ppb & MW 127.6 & $<2.547$ & $<2.285$ & $<2.345$ & $<2.392$ & $<1.754$ \\
\hline
\end{tabular}


TABLE 4 Continued...

(page 4 of 9)

RTS \#1 WASTE FEED

EPA Test Method 0010 - Modified Method 5

Hexachlorobutadiene

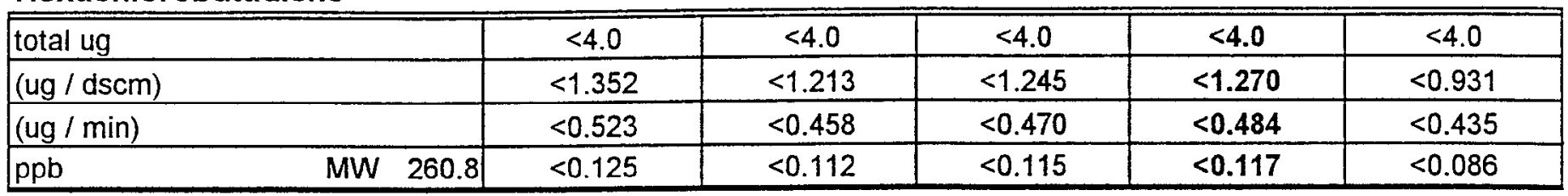

4-Chloro-3-Methylphenol

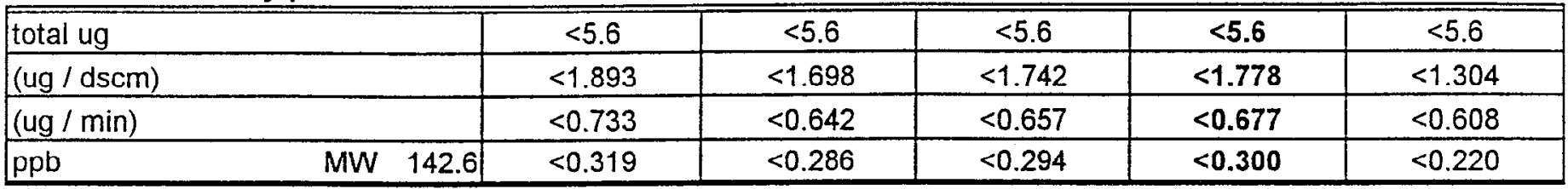

\section{2-Methylnaphthalene}

\begin{tabular}{|c|c|c|c|c|c|c|}
\hline total ug & & $<7.2$ & $<7.2$ & $<7.2$ & $<7.2$ & $<7.2$ \\
\hline (ug / dscm) & & $<2.433$ & $<2.183$ & $<2.240$ & $<2.286$ & $<1.676$ \\
\hline (ug / $\mathrm{min})$ & & $<0.942$ & $<0.825$ & $<0.845$ & $<0.871$ & $<0.782$ \\
\hline$p p b$ & MW 142.0 & $<0.412$ & $<0.370$ & $<0.379$ & $<0.387$ & $<0.284$ \\
\hline
\end{tabular}

\section{Hexachlorocyclopentadiene}

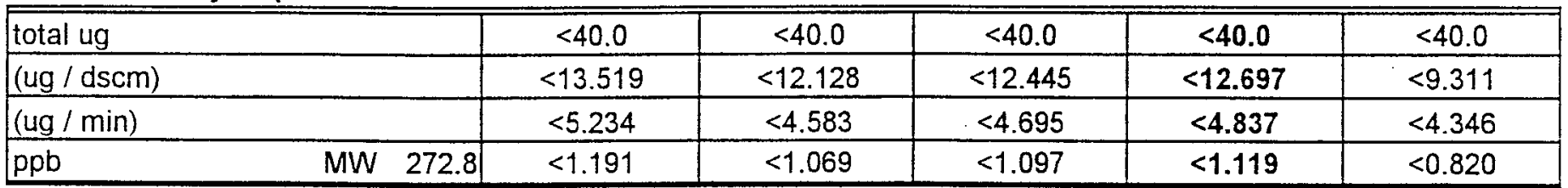

2,4,6-Trichlorophenol

\begin{tabular}{|l|c|c|c|c|c|}
\hline \hline total ug & $<4.8$ & $<4.8$ & $<4.8$ & $<4.8$ & $<4.8$ \\
\hline (ug / dscm) & $<1.622$ & $<1.455$ & $<1.493$ & $<1.524$ & $<1.117$ \\
\hline (ug/min) & $<0.628$ & $<0.550$ & $<0.563$ & $<0.580$ & $<0.521$ \\
\hline $\mathrm{ppb}$ MW 197.5 & $<0.197$ & $<0.177$ & $<0.182$ & $<0.185$ & $<0.136$ \\
\hline
\end{tabular}

2,4,5-Trichlorophenol

\begin{tabular}{|c|c|c|c|c|c|c|}
\hline total ug & & $<6.8$ & $<6.8$ & $<6.8$ & $<6.8$ & $<6.8$ \\
\hline (ug / dscm) & & $<2.298$ & $<2.062$ & $<2.116$ & $<2.159$ & $<1.583$ \\
\hline (ug / min) & & $<0.890$ & $<0.779$ & $<0.798$ & $<0.822$ & $<0.739$ \\
\hline ppb & MW 197.5 & $<0.280$ & $<0.251$ & $<0.258$ & $<0.263$ & $<0.193$ \\
\hline
\end{tabular}

\section{2-Chloronaphthalene}

\begin{tabular}{|c|c|c|c|c|c|c|}
\hline \begin{tabular}{|l|} 
total ug \\
\end{tabular} & & $<8.8$ & $<8.8$ & $<8.8$ & $<8.8$ & $<8.8$ \\
\hline$(\mathrm{ug} / \mathrm{dscm})$ & & $<2.974$ & $<2.668$ & $<2.738$ & $<2.793$ & $<2.048$ \\
\hline (ug / min) & & $<1.152$ & $<1.008$ & $<1.033$ & $<1.064$ & $<0.956$ \\
\hline $\mathrm{ppb}$ & MW 162.6 & $<0.440$ & $<0.394$ & $<0.405$ & $<0.413$ & $<0.303$ \\
\hline
\end{tabular}

2-Nitroaniline

\begin{tabular}{|c|c|c|c|c|c|c|}
\hline total ug & & $<40.0$ & $<40.0$ & $<40.0$ & $<40.0$ & $<40.0$ \\
\hline (ug / dscm) & & $<13.519$ & $<12.128$ & $<12.445$ & $<12.697$ & $<9.311$ \\
\hline$(\mathrm{ug} / \mathrm{min})$ & & $<5.234$ & $<4.583$ & $<4.695$ & $<4.837$ & $<4.346$ \\
\hline$p p b$ & MW 138.1 & $<2.353$ & $<2.111$ & $<2.166$ & $<2.210$ & $<1.621$ \\
\hline
\end{tabular}


TABLE 4 Continued...

(page 5 of 9)

RTS \#1 WASTE FEED

EPA Test Method 0010 - Modified Method 5

Dimethylphthalate

\begin{tabular}{|c|c|c|c|c|c|c|}
\hline total ug & & $<2.8$ & $<2.8$ & $<2.8$ & $<2.8$ & $<2.8$ \\
\hline (ug / dscm) & & $<0.946$ & $<0.849$ & $<0.871$ & $<0.889$ & $<0.652$ \\
\hline (ug / min) & & $<0.366$ & $<0.321$ & $<0.329$ & $<0.339$ & $<0.304$ \\
\hline $\mathrm{ppb}$ & MW 194.2 & $<0.117$ & $<0.105$ & $<0.108$ & $<0.110$ & $<0.081$ \\
\hline
\end{tabular}

Acenaphthylene

\begin{tabular}{|c|c|c|c|c|c|c|}
\hline total ug & & $<6.4$ & $<6.4$ & $<6.4$ & $<6.4$ & $<6.4$ \\
\hline (ug / dscm) & & $<2.163$ & $<1.940$ & $<1.991$ & $<2.032$ & $<1.490$ \\
\hline$(\mathrm{ug} / \mathrm{min})$ & & $<0.838$ & $<0.733$ & $<0.751$ & $<0.774$ & $<0.695$ \\
\hline $\mathrm{ppb}$ & MW 152.0 & $<0.342$ & $<0.307$ & $<0.315$ & $<0.321$ & $<0.236$ \\
\hline
\end{tabular}

2,6-Dinitrotoluene

\begin{tabular}{|c|c|c|c|c|c|c|}
\hline total ug & & $<4.0$ & $<4.0$ & $<4.0$ & $<4.0$ & $<4.0$ \\
\hline (ug / dscm) & & $<1.352$ & $<1.213$ & $<1.245$ & $<1.270$ & $<0.931$ \\
\hline (ug / min) & $\cdots$ & $<0.523$ & $<0.458$ & $<0.470$ & $<0.484$ & $<0.435$ \\
\hline $\mathrm{ppb}$ & MW 182.1 & $<0.178$ & $<0.160$ & $<0.164$ & $<0.168$ & $<0.123$ \\
\hline
\end{tabular}

3-Nitroaniline

\begin{tabular}{|c|c|c|c|c|c|c|}
\hline total ug & & $<40.0$ & $<40.0$ & $<40.0$ & $<40.0$ & $<40.0$ \\
\hline$(\mathrm{ug} / \mathrm{dscm})$ & & $<13.519$ & $<12.128$ & $<12.445$ & $<12.697$ & $<9.311$ \\
\hline (ug / min) & & $<5.234$ & $<4.583$ & $<4.695$ & $<4.837$ & $<4.346$ \\
\hline ppb & MW 138.1 & $<2.353$ & $<2.111$ & $<2.166$ & $<2.210$ & $<1.621$ \\
\hline
\end{tabular}

Acenaphthene

\begin{tabular}{|c|c|c|c|c|c|c|}
\hline total ug & & $<8.0$ & $<8.0$ & $<8.0$ & $<8.0$ & $<8.0$ \\
\hline (ug / dscm) & & $<2.704$ & $<2.426$ & $<2.489$ & $<2.539$ & $<1.862$ \\
\hline$(\mathrm{ug} / \mathrm{min})$ & & $<1.047$ & $<0.917$ & $<0.939$ & $<0.967$ & $<0.869$ \\
\hline$p p b$ & MW 154.0 & $<0.422$ & $<0.379$ & $<0.389$ & $<0.396$ & $<0.291$ \\
\hline \multicolumn{7}{|c|}{ 2,4-Dinitrophenol } \\
\hline total ug & & $<40.0$ & $<40.0$ & $<40.0$ & $<40.0$ & $<40.0$ \\
\hline$(\mathrm{ug} / \mathrm{dscm})$ & & $<13.519$ & $<12.128$ & $<12.445$ & $<12.697$ & $<9.311$ \\
\hline (ug / $\mathrm{min})$ & & $<5.234$ & $<4.583$ & $<4.695$ & $<4.837$ & $<4.346$ \\
\hline $\mathrm{ppb}$ & MW 184.1 & $<1.765$ & $<1.584$ & $<1.625$ & $<1.658$ & $<1.216$ \\
\hline
\end{tabular}

\section{4-Nitrophenol}

\begin{tabular}{|c|c|c|c|c|c|c|}
\hline total ug & & $<40.0$ & $<40.0$ & $<40.0$ & $<40.0$ & $<40.0$ \\
\hline$(\mathrm{ug} / \mathrm{dscm})$ & & $<13.519$ & $<12.128$ & $<12.445$ & $<12.697$ & $<9.311$ \\
\hline$(\mathrm{ug} / \mathrm{min})$ & & $<5.234$ & $<4.583$ & $<4.695$ & $<4.837$ & $<4.346$ \\
\hline $\mathrm{ppb}$ & MW 139.1 & $<2.336$ & $<2.096$ & $<2.151$ & $<2.194$ & $<1.609$ \\
\hline
\end{tabular}

Dibenzofuran

\begin{tabular}{|l|c|c|c|c|c|c|}
\hline \hline total ug & & $<40.0$ & $<40.0$ & $<40.0$ & $<40.0$ & $<40.0$ \\
\hline (ug / dscm) & & $<13.519$ & $<12.128$ & $<12.445$ & $<12.697$ & $<9.311$ \\
\hline (ug / min) & & $<5.234$ & $<4.583$ & $<4.695$ & $<4.837$ & $<4.346$ \\
\hline $\mathrm{ppb}$ & MW 168.2 & $<1.932$ & $<1.733$ & $<1.779$ & $<1.815$ & $<1.331$ \\
\hline
\end{tabular}


TABLE 4 Continued...

(page 6 of 9)

RTS \#1 WASTE FEED

EPA Test Method 0010 - Modified Method 5

\section{2,4-Dinitrotoluene}

\begin{tabular}{|ll|c|c|c|c|c|}
\hline \hline total ug & $<4.4$ & $<4.4$ & $<4.4$ & $<4.4$ & $<4.4$ \\
\hline (ug / dscm) & $<1.487$ & $<1.334$ & $<1.369$ & $<1.397$ & $<1.024$ \\
\hline (ug / min) & & $<0.576$ & $<0.504$ & $<0.516$ & $<0.532$ & $<0.478$ \\
\hline $\mathrm{ppb}$ & $\mathrm{MW} 182.1$ & $<0.196$ & $<0.176$ & $<0.181$ & $<0.184$ & $<0.135$ \\
\hline
\end{tabular}

Diethyl phthalate

\begin{tabular}{|c|c|c|c|c|c|c|}
\hline total ug & & 9.9 & 13 & 3.1 & 8.667 & $<1.6$ \\
\hline (ug / dscm) & & 3.346 & 3.942 & 0.964 & 2.751 & $<0.372$ \\
\hline (ug / min) & & 1.296 & 1.489 & 0.364 & 1.050 & 0.174 \\
\hline$\overline{p p b}$ & MW 222.2 & 0.362 & 0.426 & 0.104 & 0.298 & $<0.040$ \\
\hline
\end{tabular}

4-Chlorophenylphenylether

\begin{tabular}{|c|c|c|c|c|c|c|}
\hline total ug & & $<7.2$ & $<7.2$ & $<7.2$ & $<7.2$ & $<7.2$ \\
\hline (ug / dscm) & & $<2.433$ & $<2.183$ & $<2.240$ & $<2.286$ & $<1.676$ \\
\hline (ug / min) & & $<0.942$ & $<0.825$ & $<0.845$ & $<0.871$ & $<0.782$ \\
\hline $\mathrm{ppb}$ & MW 204.7 & $<0.286$ & $<0.256$ & $<0.263$ & $<0.268$ & $<0.197$ \\
\hline
\end{tabular}

\section{Fluorene}

\begin{tabular}{|c|c|c|c|c|c|c|}
\hline total ug & & $<5.2$ & $<5.2$ & $<5.2$ & $<5.2$ & $<5.2$ \\
\hline (ug / dscm) & & $<1.757$ & $<1.577$ & $<1.618$ & $<1.651$ & $<1.210$ \\
\hline (ug / min) & & $<0.680$ & $<0.596$ & $<0.610$ & $<0.629$ & $<0.565$ \\
\hline $\mathrm{ppb}$ & MW 166.0 & $<0.255$ & $<0.228$ & $<0.234$ & $<0.239$ & $<0.175$ \\
\hline
\end{tabular}

4-Nitroaniline

\begin{tabular}{|ll|c|c|c|c|c|}
\hline \hline total ug & $<40.0$ & $<40.0$ & $<40.0$ & $<40.0$ & $<40.0$ \\
\hline$(\mathrm{ug} / \mathrm{dscm})$ & & $<13.519$ & $<12.128$ & $<12.445$ & $<12.697$ & $<9.311$ \\
\hline (ug / min) & $<5.234$ & $<4.583$ & $<4.695$ & $<4.837$ & $<4.346$ \\
\hline $\mathrm{ppb}$ & MW 138.1 & $<2.353$ & $<2.111$ & $<2.166$ & $<2.210$ & $<1.621$ \\
\hline
\end{tabular}

4,6-Dintro-2-methylphenol

\begin{tabular}{|c|c|c|c|c|c|c|}
\hline total ug & & $<4.8$ & $<4.8$ & $<4.8$ & $<4.8$ & $<4.8$ \\
\hline (ug / dscm) & & $<1.622$ & $<1.455$ & $<1.493$ & $<1.524$ & $<1.117$ \\
\hline (ug / min) & & $<0.628$ & $<0.550$ & $<0.563$ & $<0.580$ & $<0.521$ \\
\hline ppb & MW 198.1 & $<0.197$ & $<0.177$ & $<0.181$ & $<0.185$ & $<0.136$ \\
\hline
\end{tabular}

N-Nitrosodiphenylamine

\begin{tabular}{|c|c|c|c|c|c|c|}
\hline total ug & & $<14.0$ & $<14.0$ & $<14.0$ & $<14.0$ & $<14.0$ \\
\hline$(\mathrm{ug} / \mathrm{dscm})$ & & $<4.732$ & $<4.245$ & $<4.356$ & $<4.444$ & $<3.259$ \\
\hline (ug / min) & & $<1.832$ & $<1.604$ & $<1.643$ & $<1.693$ & $<1.521$ \\
\hline$p p b$ & MW 198.2 & $<0.574$ & $<0.515$ & $<0.528$ & $<0.539$ & $<0.395$ \\
\hline
\end{tabular}

4-Bromophenylphenylether

\begin{tabular}{|c|c|c|c|c|c|c|}
\hline total ug & & $<6.4$ & $<5.4$ & $<6.4$ & $<6.4$ & $<6.4$ \\
\hline (ug/dscm) & & $<2.163$ & $<1.940$ & $<1.991$ & $<2.032$ & $<1.490$ \\
\hline (ug / min) & & $<0.838$ & $<0.733$ & $<0.751$ & $<0.774$ & $<0.695$ \\
\hline $\mathrm{ppb}$ & MW 221.5 & $<0.235$ & $<0.211$ & $<0.216$ & $<0.220$ & $<0.162$ \\
\hline
\end{tabular}




\section{TABLE 4 Continued...}

(page 7 of 9)

RTS \#1 WASTE FEED

EPA Test Method 0010 - Modified Method 5

Hexachlorobenzene

\begin{tabular}{|c|c|c|c|c|c|c|}
\hline total ug & & $<4.0$ & $<4.0$ & $<4.0$ & $<4.0$ & $<4.0$ \\
\hline (ug / dscm) & & $<1.352$ & $<1.213$ & $<1.245$ & $<1.270$ & $<0.931$ \\
\hline (ug / min) & & $<0.523$ & $<0.458$ & $<0.470$ & $<0.484$ & $<0.435$ \\
\hline $\mathrm{ppb}$ & $\mathrm{MW} \quad 284.8$ & $<0.114$ & $<0.102$ & $<0.105$ & $<0.107$ & $<0.079$ \\
\hline
\end{tabular}

\section{Pentachlorophenol}

\begin{tabular}{|c|c|c|c|c|c|c|}
\hline total ug & & $<6.0$ & $<6.0$ & $<6.0$ & $<6.0$ & $<6.0$ \\
\hline$(\mathrm{ug} / \mathrm{dscm})$ & & $<2.028$ & $<1.819$ & $<1.867$ & $<1.905$ & $<1.397$ \\
\hline (ug / min) & & $<0.785$ & $<0.687$ & $<0.704$ & $<0.726$ & $<0.652$ \\
\hline $\mathrm{ppb}$ & MW 266.3 & $<0.183$ & $<0.164$ & $<0.169$ & $<0.172$ & $<0.126$ \\
\hline
\end{tabular}

\section{Phenanthrene}

\begin{tabular}{|c|c|c|c|c|c|c|}
\hline total ug & & 19 & 3.7 & 4.0 & 8.9 & $<2.4$ \\
\hline (ug / dscm) & & 6.422 & 1.122 & 1.245 & 2.929 & $<0.559$ \\
\hline$(\mathrm{ug} / \mathrm{min})$ & & 2.486 & 0.424 & 0.470 & 1.127 & 0.261 \\
\hline $\mathrm{ppb}$ & MW 176.0 & 0.877 & 0.153 & 0.170 & 0.400 & $<0.076$ \\
\hline
\end{tabular}

\section{Anthracene}

\begin{tabular}{|c|c|c|c|c|c|c|}
\hline total ug & & $<4.4$ & $<4.4$ & $<4.4$ & $<4.4$ & $<4.4$ \\
\hline$(\mathrm{ug} / \mathrm{dscm})$ & & $<1.487$ & $<1.334$ & $<1.369$ & $<1.397$ & $<1.024$ \\
\hline (ug/min) & & $<0.576$ & $<0.504$ & $<0.516$ & $<0.532$ & $<0.478$ \\
\hline $\mathrm{ppb}$ & MW 176.0 & $<0.203$ & $<0.182$ & $<0.187$ & $<0.191$ & $<0.140$ \\
\hline
\end{tabular}

\section{Carbazole}

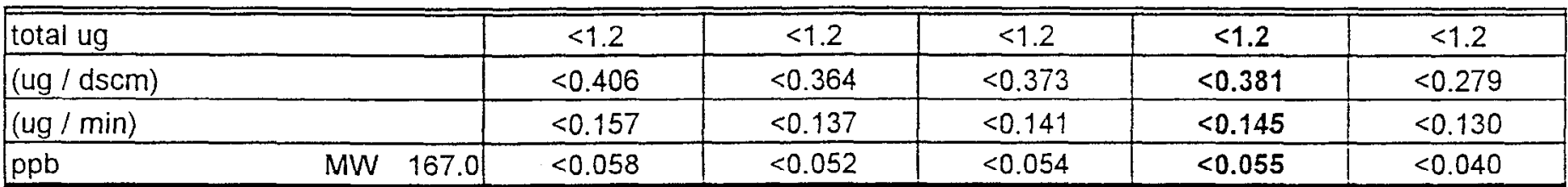

Di-n-butyl phthalate

\begin{tabular}{|c|c|c|c|c|c|}
\hline total ug & 31 & 21 & 9.8 & 20.6 & $<4.0$ \\
\hline$(\mathrm{ug} / \mathrm{dscm})$ & 10.477 & 6.367 & 3.049 & 6.631 & $<0.931$ \\
\hline (ug / min) & 4.057 & 2.406 & 1.150 & 2.538 & 0.435 \\
\hline $\mathrm{ppb}$ & 0.905 & 0.550 & 0.263 & 0.573 & $<0.080$ \\
\hline
\end{tabular}

Fluoranthene

\begin{tabular}{|c|c|c|c|c|c|c|}
\hline total ug & & 16 & $<4.0$ & $<4.0$ & $<8.0$ & $<4.0$ \\
\hline$(\mathrm{ug} / \mathrm{dscm})$ & & 5.408 & $<1.213$ & $<1.245$ & $<2.622$ & $<0.931$ \\
\hline (ug / min) & & 2.094 & $<0.458$ & $<0.470$ & $<1.007$ & $<0.435$ \\
\hline $\mathrm{ppb}$ & MW 202.0 & 0.644 & $<0.144$ & $<0.148$ & $<0.312$ & $<0.111$ \\
\hline \multicolumn{7}{|l|}{ Pyrene } \\
\hline total ug & & 9.3 & $<2.0$ & $<2.0$ & $<4.4$ & $<2.0$ \\
\hline$(\mathrm{ug} / \mathrm{dscm})$ & & 3.143 & $<0.606$ & $<0.622$ & $<1.457$ & $<0.466$ \\
\hline$(\mathrm{ug} / \mathrm{min})$ & & 1.217 & $<0.229$ & $<0.235$ & $<0.560$ & $<0.217$ \\
\hline $\mathrm{ppb}$ & MW 202.0 & 0.374 & $<0.072$ & $<0.074$ & $<0.173$ & $<0.055$ \\
\hline
\end{tabular}


TABLE 4 Continued...

(page 8 of 9)

RTS \#1 WASTE FEED

EPA Test Method 0010 - Modified Method 5

Benzyl butyl phthalate

\begin{tabular}{|c|c|c|c|c|c|c|}
\hline total ug & & $<5.2$ & $<5.2$ & $<5.2$ & $<5.2$ & $<5.2$ \\
\hline$(\mathrm{ug} / \mathrm{dscm})$ & & $<1.757$ & $<1.577$ & $<1.618$ & $<1.651$ & $<1.210$ \\
\hline (ug / min) & & $<0.680$ & $<0.596$ & $<0.610$ & $<0.629$ & $<0.565$ \\
\hline $\mathrm{ppb}$ & MW 312.4 & $<0.135$ & $<0.121$ & $<0.124$ & $<0.127$ & $<0.093$ \\
\hline
\end{tabular}

\section{3,3-Dichlorobenzidine}

\begin{tabular}{|c|c|c|c|c|c|c|}
\hline total ug & & $<40.0$ & $<40.0$ & $<40.0$ & $<40.0$ & $<40.0$ \\
\hline (ug / dscm) & & $<13.519$ & $<12.128$ & $<12.445$ & $<12.697$ & $<9.311$ \\
\hline (ug / min) & & $<5.234$ & $<4.583$ & $<4.695$ & $<4.837$ & $<4.346$ \\
\hline $\mathrm{ppb}$ & MW 253.1 & $<1.284$ & $<1.152$ & $<1.182$ & $<1.206$ & $<0.884$ \\
\hline
\end{tabular}

Benzo(a)anthracene

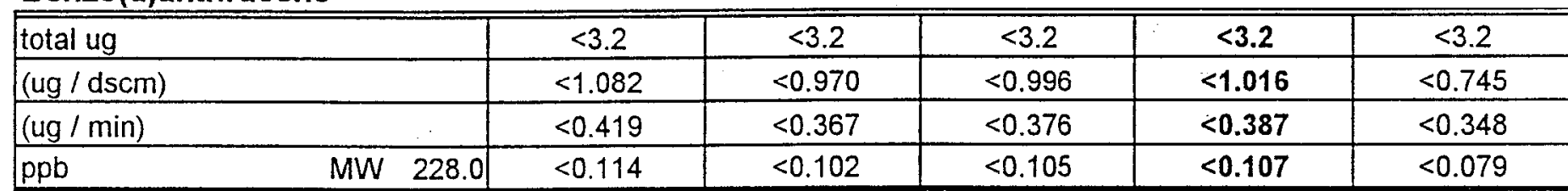

\section{Chrysene}

\begin{tabular}{|l|c|c|c|c|c|}
\hline \hline total ug & 2.0 & $<2.0$ & $<2.0$ & $<2.0$ & $<2.0$ \\
\hline$(\mathrm{ug} / \mathrm{dscm})$ & 0.676 & $<0.606$ & $<0.622$ & $<0.635$ & $<0.466$ \\
\hline (ug / min) & 0.262 & $<0.229$ & $<0.235$ & $<0.242$ & $<0.217$ \\
\hline $\mathrm{ppb}$ & 0.071 & $<0.064$ & $<0.066$ & $<0.067$ & $<0.049$ \\
\hline
\end{tabular}

Bis(2-ethylhexyl)phthalate

\begin{tabular}{|c|c|c|c|c|c|c|}
\hline total ug & & 21.0 & 19.0 & 25.0 & 21.7 & 11.0 \\
\hline (ug / dscm) & & 7.098 & 5.761 & 7.778 & 6.879 & 2.561 \\
\hline$(\mathrm{ug} / \mathrm{min})$ & & 2.748 & 2.177 & 2.934 & 2.620 & 1.195 \\
\hline $\mathrm{ppb}$ & MW 390.6 & 0.437 & 0.355 & 0.479 & 0.423 & 0.158 \\
\hline
\end{tabular}

\section{Di-n-octyl phthalate}

\begin{tabular}{|c|c|c|c|c|c|c|}
\hline total ug & & $<5.2$ & $<5.2$ & $<5.2$ & $<5.2$ & $<5.2$ \\
\hline$(\mathrm{ug} / \mathrm{dscm})$ & & $<1.757$ & $<1.577$ & $<1.618$ & $<1.651$ & $<1.210$ \\
\hline$(\mathrm{ug} / \mathrm{min})$ & & $<0.680$ & $<0.596$ & $<0.610$ & $<0.629$ & $<0.565$ \\
\hline $\mathrm{ppb}$ & MW 390.6 & $<0.108$ & $<0.097$ & $<0.100$ & $<0.102$ & $<0.074$ \\
\hline
\end{tabular}

Benzo(b)fluoranthene

\begin{tabular}{|c|c|c|c|c|c|c|}
\hline total ug & & $<4.0$ & $<4.0$ & $<4.0$ & $<4.0$ & $<4.0$ \\
\hline (ug / dscm) & & $<1.352$ & $<1.213$ & $<1.245$ & $<1.270$ & $<0.931$ \\
\hline (ug / $\min )$ & & $<0.523$ & $<0.458$ & $<0.470$ & $<0.484$ & $<0.435$ \\
\hline$p p b$ & MW 252.0 & $<0.129$ & $<0.116$ & $<0.119$ & $<0.121$ & $<0.089$ \\
\hline
\end{tabular}

Benzo(k)fluoranthene

\begin{tabular}{|c|c|c|c|c|c|c|}
\hline total ug & & $<4.4$ & $<4.4$ & $<4.4$ & $<4.4$ & $<4.4$ \\
\hline (ug / dscm) & & $<1.487$ & $<1.334$ & $<1.369$ & $<1.397$ & $<1.024$ \\
\hline (ug / min) & & $<0.576$ & $<0.504$ & $<0.516$ & $<0.532$ & $<0.478$ \\
\hline $\mathrm{ppb}$ & MW 252.0 & $<0.142$ & $<0.127$ & $<0.131$ & $<0.133$ & $<0.098$ \\
\hline
\end{tabular}


TABLE 4 Continued...

(page 9 of 9)

RTS \#1 WASTE FEED

EPA Test Method 0010 - Modified Method 5

Benzo(a)pyrene

\begin{tabular}{|c|c|c|c|c|c|c|}
\hline total ug & & $<3.2$ & $<3.2$ & $<3.2$ & $<3.2$ & $<3.2$ \\
\hline$(\mathrm{ug} / \mathrm{dscm})$ & & $<1.082$ & $<0.970$ & $<0.996$ & $<1.016$ & $<0.745$ \\
\hline$(\mathrm{ug} / \mathrm{min})$ & & $<0.419$ & $<0.367$ & $<0.376$ & $<0.387$ & $<0.348$ \\
\hline ppb & MW 252.0 & $<0.103$ & $<0.093$ & $<0.095$ & $<0.097$ & $<0.071$ \\
\hline
\end{tabular}

Indeno(1,2,3-cd)pyrene

\begin{tabular}{|l|c|c|c|c|c|}
\hline \hline total ug & $<2.4$ & $<2.4$ & $<2.4$ & $<2.4$ & $<2.4$ \\
\hline (ug / dscm) & $<0.811$ & $<0.728$ & $<0.747$ & $<0.762$ & $<0.559$ \\
\hline (ug / min) & $<0.314$ & $<0.275$ & $<0.282$ & $<0.290$ & $<0.261$ \\
\hline $\mathrm{ppb}$ & & $<0.063$ & $<0.065$ & $<0.066$ & $<0.049$ \\
\hline
\end{tabular}

Dibenzo(a,h)anthracene

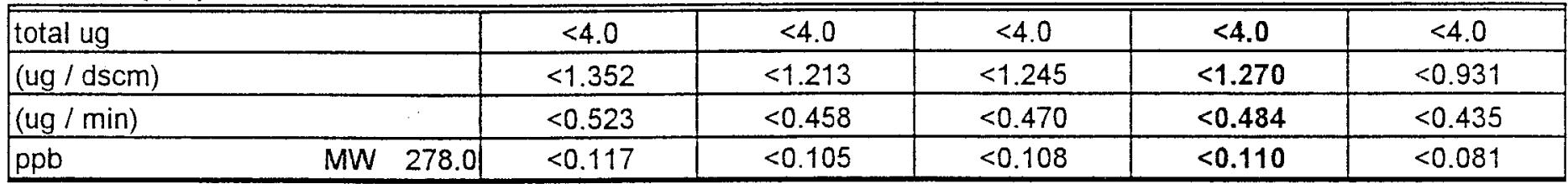

Benzo(ghi)perylene

\begin{tabular}{|c|c|c|c|c|c|c|}
\hline total ug & & $<2.8$ & $<2.8$ & $<2.8$ & $<2.8$ & $<2.8$ \\
\hline (ug / dscm) & & $<0.946$ & $<0.849$ & $<0.871$ & $<0.889$ & $<0.652$ \\
\hline (ug / min) & & $<0.366$ & $<0.321$ & $<0.329$ & $<0.339$ & $<0.304$ \\
\hline $\mathrm{ppb}$ & MW 276.0 & $<0.082$ & $<0.074$ & $<0.076$ & $<0.077$ & $<0.057$ \\
\hline
\end{tabular}

Definitions:

DSCFM $=$ Dry Standard Cubic Feet per Minute

$\mathrm{ug} / \mathrm{dscm}=$ microgram per $\mathrm{dry}$ standard cubic meter $\mathrm{ug} / \mathrm{min}=$ emission rate, micrograms per minute $\mathrm{ppb}=$ parts per billion

T std. = Standard Temerature, ${ }^{\circ} \mathrm{F}=68$
Calculations:

$\mathrm{DSCM}=\mathrm{DSCF} * 0.02832$

ug $/ \mathrm{min}=0.02832{ }^{*} \mathrm{DSCFM}$ * (ug $\left./ \mathrm{dscm}\right)$

$\mathrm{ug} / \mathrm{dscm}=$ total ug / sample vol., $\mathrm{dscm}$

$\mathrm{ppb}=u g / \mathrm{dscm} * 22.4 *(\mathrm{~T}$ std. +460$) / 492 /$ M.W. 
TABLE 5

RTS \#2 WASTE FEED

LLNL BIdg. 292 MSO

GSS Inlet \& Catalytic Converter Outlet

EPA Test Method 0010 - Modified Method 5

\begin{tabular}{|c|c|c|c|c|c|}
\hline TEST\# & 1GSS -Inlet & 2-GSS Inlet & 3-GSS Inlet & AVERAGE & 1-Cat. Out \\
\hline TEST DATE & $8 / 26 / 98$ & $8 / 26 / 98$ & $8 / 26 / 98$ & & $8 / 26 / 98$ \\
\hline TEST TIME & 0903-1216 & $1309-1616$ & 1636-2002 & & $1210-1510$ \\
\hline SAMPLE VOLUME (DSCF) & 158.170 & 126.098 & 112.188 & 111.477 & 132.838 \\
\hline SAMPLE VOLUME (DSCM) & 2.959 & 3.298 & 3.214 & 3.157 & 3.762 \\
\hline FLOW RATE (DSCFM) & 14.45 & 12.99 & 13.96 & 13.45 & 16.27 \\
\hline STACK GAS TEMP. ${ }^{\circ} \mathrm{F}$ & 320.6 & 340.5 & 292.1 & 320.5 & 390 \\
\hline $\mathrm{O}_{2}, \%$ vol. dry & 10.4 & 10.0 & 9.3 & 10.6 & \\
\hline $\mathrm{H}_{2} \mathrm{O}, \%$ vol & 3.2 & 5.4 & 4.5 & 4.9 & \\
\hline
\end{tabular}

Aniline

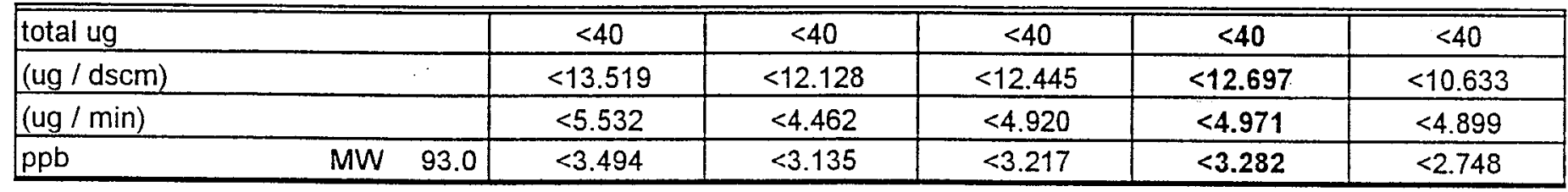

Phenol

\begin{tabular}{|c|c|c|c|c|c|c|}
\hline total ug & & $<1.2$ & $<1.2$ & $<1.2$ & $<1.2$ & $<1.2$ \\
\hline (ug / dscm) & & $<0.406$ & $<0.364$ & $<0.373$ & $<0.381$ & $<0.319$ \\
\hline (ug / $\mathrm{min})$ & & $<0.166$ & $<0.134$ & $<0.148$ & $<0.149$ & $<0.147$ \\
\hline $\mathrm{ppb}$ & MW 94.0 & $<0.104$ & $<0.093$ & $<0.095$ & $<0.097$ & $<0.082$ \\
\hline
\end{tabular}

Bis(2-chloroethyl)ether

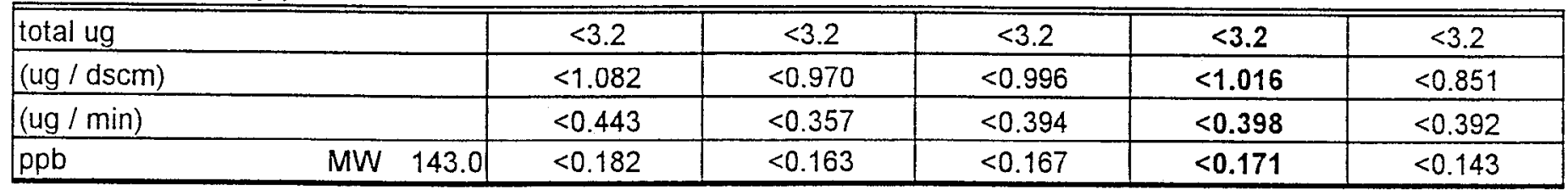

\section{2-Chlorophenol}

\begin{tabular}{|c|c|c|c|c|c|c|}
\hline total ug & & $<2.0$ & $<2.0$ & $<2.0$ & $<2.0$ & $<2.0$ \\
\hline$(\mathrm{ug} / \mathrm{dscm})$ & & $<0.676$ & $<0.606$ & $<0.622$ & $<0.635$ & $<0.532$ \\
\hline$(\mathrm{ug} / \mathrm{min})$ & & $<0.277$ & $<0.223$ & $<0.246$ & $<0.249$ & $<0.245$ \\
\hline $\mathrm{ppb}$ & MW 128.6 & $<0.126$ & $<0.113$ & $<0.116$ & $<0.119$ & $<0.099$ \\
\hline
\end{tabular}

1,3-Dichlorobenzene

\begin{tabular}{|c|c|c|c|c|c|c|}
\hline total ug & & $<6.0$ & $<6.0$ & $<6.0$ & $<6.0$ & $<6.0$ \\
\hline (ug / dscm) & & $<2.028$ & $<1.819$ & $<1.867$ & $<1.905$ & $<1.595$ \\
\hline (ug / min) & & $<0.830$ & $<0.669$ & $<0.738$ & $<0.746$ & $<0.735$ \\
\hline$p p b$ & MW 147.0 & $<0.332$ & $<0.297$ & $<0.305$ & $<0.311$ & $<0.261$ \\
\hline
\end{tabular}


TABLE 5 Continued...

(page 2 of 9 )

RTS \#2 WASTE FEED

EPA Test Method 0010 - Modified Method 5

\section{1-4-Dichlorobenzene}

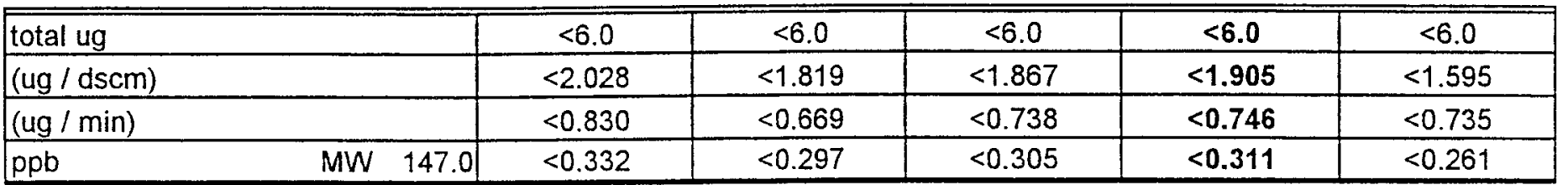

\section{1,2-Dichlorobenzene}

\begin{tabular}{|c|c|c|c|c|c|c|}
\hline total ug & & $<6.8$ & $<6.8$ & $<6.8$ & $<6.8$ & $<6.8$ \\
\hline$(\mathrm{ug} / \mathrm{dscm})$ & & $<2.298$ & $<2.062$ & $<2.116$ & $<2.159$ & $<1.808$ \\
\hline (ug / min) & & $<0.941$ & $<0.758$ & $<0.836$ & $<0.845$ & $<0.833$ \\
\hline $\mathrm{ppb}$ & MW 147.0 & $<0.376$ & $<0.337$ & $<0.346$ & $<0.353$ & $<0.296$ \\
\hline
\end{tabular}

2-Methylphenol

\begin{tabular}{|c|c|c|c|c|c|c|}
\hline total ug & & $<4.8$ & $<4.8$ & $<4.8$ & $<4.8$ & $<4.8$ \\
\hline (ug / dscm) & . & $<1.622$ & $<1.455$ & $<1.493$ & $<1.524$ & $<1.276$ \\
\hline$(\mathrm{ug} / \mathrm{min})$ & & $<0.664$ & $<0.535$ & $<0.590$ & $<0.597$ & $<0.588$ \\
\hline$\overline{p p b}$ & MW 104.1 & $<0.375$ & $<0.336$ & $<0.345$ & $<0.352$ & $<0.295$ \\
\hline
\end{tabular}

Bis(2-chloroisopropyl)ether

\begin{tabular}{|c|c|c|c|c|c|c|}
\hline total ug & & $<4.4$ & $<4.4$ & $<4.4$ & $<4.4$ & $<4.4$ \\
\hline$(\mathrm{ug} / \mathrm{dscm})$ & & $<1.487$ & $<1.334$ & $<1.369$ & $<1.397$ & $<1.170$ \\
\hline (ug / $\mathrm{min})$ & & $<0.609$ & $<0.491$ & $<0.541$ & $<0.547$ & $<0.539$ \\
\hline$p p b$ & MW 132.1 & $<0.271$ & $<0.243$ & $<0.249$ & $<0.254$ & $<0.213$ \\
\hline
\end{tabular}

\section{4-Methylphenol}

\begin{tabular}{|l|c|c|c|c|c|}
\hline \hline total ug & $<6.4$ & $<6.4$ & $<6.4$ & $<6.4$ & $<6.4$ \\
\hline (ug / dscm) & $<2.163$ & $<1.940$ & $<1.991$ & $<2.032$ & $<1.701$ \\
\hline$(\mathrm{ug} / \mathrm{min})$ & & $<0.885$ & $<0.714$ & $<0.787$ & $<0.795$ \\
\hline $\mathrm{ppb}$ & MW 104.1 & $<0.500$ & $<0.448$ & $<0.460$ & $<0.784$ \\
\hline
\end{tabular}

$\mathrm{N}$-Nitroso-di-N-Propylamine

\begin{tabular}{|c|c|c|c|c|c|}
\hline total ug & $<4.4$ & $<4.4$ & $<4.4$ & $<4.4$ & $<4.4$ \\
\hline (ug/dscm) & $<1.487$ & $<1.334$ & $<1.369$ & $<1.397$ & $<1.170$ \\
\hline (ug / $\mathrm{min}$ ) & $<0.609$ & $<0.491$ & $<0.541$ & $<0.547$ & $<0.539$ \\
\hline MW 130.0 & $<0.275$ & $<0.247$ & $<0.253$ & $<0.258$ & $<0.216$ \\
\hline
\end{tabular}

Hexachloroethane

\begin{tabular}{|c|c|c|c|c|c|c|}
\hline total ug & & $<4.4$ & $<4.4$ & $<4.4$ & $<4.4$ & $<4.4$ \\
\hline$(\mathrm{ug} / \mathrm{dscm})$ & & $<1.487$ & $<1.334$ & $<1.369$ & $<1.397$ & $<1.170$ \\
\hline (ug / min) & & $<0.609$ & $<0.491$ & $<0.541$ & $<0.547$ & $<0.539$ \\
\hline ppo & MW 236.7 & $<0.151$ & $<0.135$ & $<0.139$ & $<0.142$ & $<0.119$ \\
\hline
\end{tabular}

Nitrobenzene

\begin{tabular}{|c|c|c|c|c|c|c|}
\hline total ug & & $<3.2$ & $<3.2$ & $<3.2$ & $<3.2$ & $<3.2$ \\
\hline$(\mathrm{ug} / \mathrm{dscm})$ & & $<1.082$ & $<0.970$ & $<0.996$ & $<1.016$ & $<0.851$ \\
\hline$(\mathrm{ug} / \mathrm{min})$ & & $<0.443$ & $<0.357$ & $<0.394$ & $<0.398$ & $<0.392$ \\
\hline$p p b$ & MW 123.1 & $<0.211$ & $<0.189$ & $<0.194$ & $<0.198$ & $<0.160$ \\
\hline
\end{tabular}




\section{TABLE 5 Continued...}

\section{(page 3 of 9) \\ RTS \#2 WASTE FEED \\ EPA Test Method 0010 - Modified Method 5}

Isophorone

\begin{tabular}{|c|c|c|c|c|c|c|}
\hline total ug & & $<4.0$ & $<4.0$ & $<4.0$ & $<4.0$ & $<4.0$ \\
\hline (ug / dscm) & & $<1.352$ & $<1.213$ & $<1.245$ & $<1.270$ & $<1.063$ \\
\hline (ug / min) & & $<0.553$ & $<0.446$ & $<0.492$ & $<0.497$ & $<0.490$ \\
\hline ppb & MW 138.2 & $<0.235$ & $<0.211$ & $<0.216$ & $<0.221$ & $<0.185$ \\
\hline
\end{tabular}

\section{2-Nitrophenol}

\begin{tabular}{|c|c|c|c|c|c|}
\hline total ug & $<4.8$ & $<4.8$ & $<4.8$ & $<4.8$ & 9.7 \\
\hline (ug / dscm) & $<1.622$ & $<1.455$ & $<1.493$ & $<1.524$ & 2.578 \\
\hline (ug / min) & $<0.664$ & $<0.535$ & $<0.590$ & $<0.597$ & $<1.188$ \\
\hline MW 139.1 & $<0.280$ & $<0.252$ & $<0.258$ & $<0.263$ & 0.446 \\
\hline
\end{tabular}

\section{2,4-Dimethylphenol}

\begin{tabular}{|l|c|c|c|c|c|}
\hline \hline total ug & $<40.0$ & $<40.0$ & $<40.0$ & $<40.0$ & $<40.0$ \\
\hline (ug / dscm) & $<13.519$ & $<12.128$ & $<12.445$ & $<12.697$ & $<10.633$ \\
\hline (ug / min) & $<5.532$ & $<4.462$ & $<4.920$ & $<4.971$ & $<4.899$ \\
\hline ppb & $<2.659$ & $<2.386$ & $<2.448$ & $<2.498$ & $<2.092$ \\
\hline
\end{tabular}

\section{Bis(2-chloroethoxy)methane}

\begin{tabular}{|c|c|c|c|c|c|c|}
\hline total ug & & $<4.8$ & $<4.8$ & $<4.8$ & $<4.8$ & $<4.8$ \\
\hline (ug / dscm) & & $<1.622$ & $<1.455$ & $<1.493$ & $<1.524$ & $<1.276$ \\
\hline (ug / min) & & $<0.664$ & $<0.535$ & $<0.590$ & $<0.597$ & $<0.588$ \\
\hline $\mathrm{ppb}$ & MW 173.0 & $<0.225$ & $<0.202$ & $<0.208$ & $<0.212$ & $<0.177$ \\
\hline
\end{tabular}

\section{2,4-Dichlorophenol}

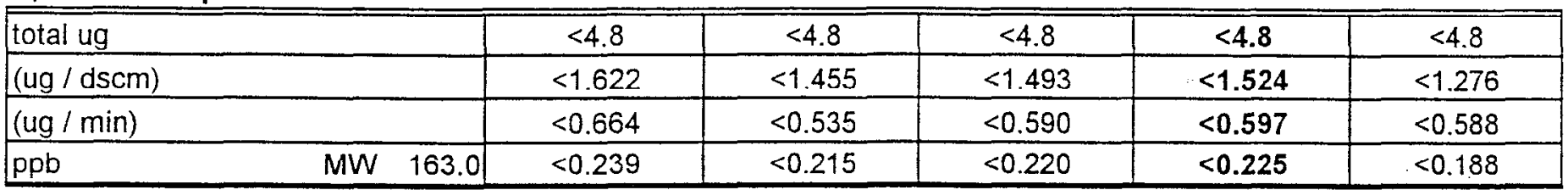

\section{1,2,4-Trichlorobenzene}

\begin{tabular}{|c|c|c|c|c|c|}
\hline total ug & $<8.8$ & $<8.8$ & $<8.8$ & $<8.8$ & $<8.8$ \\
\hline (ug / $\mathrm{min}$ ) & $<1.217$ & $<0.982$ & $<1.082$ & $<1.094$ & $<1.078$ \\
\hline
\end{tabular}

\section{Napthalene}

\begin{tabular}{|l|c|c|c|c|c|}
\hline \hline total ug & $<7.6$ & $<7.6$ & $<7.6$ & $<7.6$ & $<7.6$ \\
\hline (ug/ dscm) & $<2.569$ & $<2.304$ & $<2.365$ & $<2.413$ & $<2.020$ \\
\hline (ug / min) & $<1.051$ & $<0.848$ & $<0.935$ & $<0.945$ & $<0.931$ \\
\hline ppb & $<0.482$ & $<0.433$ & $<0.444$ & $<0.453$ & $<0.379$ \\
\hline
\end{tabular}

4-Chloroaniline

\begin{tabular}{|c|c|c|c|c|c|c|}
\hline total ug & & $<40.0$ & $<40.0$ & $<40.0$ & $<40.0$ & $<40.0$ \\
\hline (ug / dscm) & & $<13.519$ & $<12.128$ & $<12.445$ & $<12.697$ & $<10.633$ \\
\hline (ug / min) & & $<5.532$ & $<4.462$ & $<4.920$ & $<4.971$ & $<4.399$ \\
\hline $\mathrm{ppb}$ & MW 127.6 & $<2.547$ & $<2.285$ & $<2.345$ & $<2.392$ & $<2.003$ \\
\hline
\end{tabular}




\section{TABLE 5 Continued... \\ (page 4 of 9 ) \\ RTS \#2 WASTE FEED}

EPA Test Method 0010 - Modified Method 5

Hexachlorobutadiene

\begin{tabular}{|c|c|c|c|c|c|c|}
\hline total ug & & $<4.0$ & $<4.0$ & $<4.0$ & $<4.0$ & $<4.0$ \\
\hline (ug / dscm) & & $<1.352$ & $<1.213$ & $<1.245$ & $<1.270$ & $<1.063$ \\
\hline$(\mathrm{ug} / \mathrm{min})$ & & $<0.553$ & $<0.446$ & $<0.492$ & $<0.497$ & $<0.490$ \\
\hline ppb & MW 260.8 & $<0.125$ & $<0.112$ & $<0.115$ & $<0.117$ & $<0.098$ \\
\hline
\end{tabular}

4-Chloro-3-Methylphenol

total ug

(ug / dscm)

(ug / min)

$\mathrm{ppb}$

MW 142.6

$<5.6$
$<1.893$
$<0.775$
$<0.319$

\begin{tabular}{|c|c|}
\hline$<5.6$ & $<5.6$ \\
\hline$<1.698$ & $<1.742$ \\
\hline$<0.625$ & $<0.689$ \\
\hline$<0.286$ & $<0.294$ \\
\hline
\end{tabular}

\begin{tabular}{|l|r|}
\hline & $<1$ \\
\hline & $<0$ \\
\hline
\end{tabular}

$<5.6$
$<1.778$
$<0.696$
$<0.300$

$<5.6$

$<1.489$

$<0.686$

2-Methylnaphthalene

\begin{tabular}{|c|c|c|c|c|c|c|}
\hline \begin{tabular}{|l} 
total ug \\
\end{tabular} & & $<7.2$ & $<7.2$ & $<7.2$ & $<7.2$ & $<7.2$ \\
\hline (ug / dscm) & & $<2.433$ & $<2.183$ & $<2.240$ & $<2.286$ & $<1.914$ \\
\hline (ug/min) & $\cdot$ & $<0.996$ & $<0.803$ & $<0.886$ & $<0.895$ & $<0.882$ \\
\hline ppb & MW 142.0 & $<0.412$ & $<0.370$ & $<0.379$ & $<0.387$ & $<0.324$ \\
\hline
\end{tabular}

Hexachlorocyclopentadiene

\begin{tabular}{|c|c|c|c|c|c|}
\hline total ug & $<40.0$ & $<40.0$ & $<40.0$ & $<40.0$ & $<40.0$ \\
\hline (ug / dscm) & $<13.519$ & $<12.128$ & $<12.445$ & $<12.697$ & $<10.633$ \\
\hline (ug / min) & $<5.532$ & $<4.462$ & $<4.920$ & $<4.971$ & $<4.899$ \\
\hline MW 272.8 & $<1.191$ & $<1.069$ & $<1.097$ & $<1.119$ & $<0.937$ \\
\hline \multicolumn{6}{|l|}{ 2,4,6-Trichlorophenol } \\
\hline total ug & $<4.8$ & $<4.8$ & $<4.8$ & $<4.8$ & $<4.8$ \\
\hline$(\mathrm{ug} / \mathrm{dscm})$ & $<1.622$ & $<1.455$ & $<1.493$ & $<1.524$ & $<1.276$ \\
\hline$(\mathrm{ug} / \mathrm{min})$ & $<0.664$ & $<0.535$ & $<0.590$ & $<0.597$ & $<0.588$ \\
\hline MW 197.5 & $<0.197$ & $<0.177$ & $<0.182$ & $<0.185$ & $<0.155$ \\
\hline
\end{tabular}

2,4,5-Trichlorophenol

\begin{tabular}{|c|c|c|c|c|c|c|}
\hline total ug & & $<6.8$ & $<6.8$ & $<6.8$ & $<6.8$ & $<6.8$ \\
\hline (ug/dscm) & & $<2.298$ & $<2.062$ & $<2.116$ & $<2.159$ & $<1.808$ \\
\hline (ug / min) & & $<0.941$ & $<0.758$ & $<0.836$ & $<0.845$ & $<0.833$ \\
\hline$p p b$ & MW 197.5 & $<0.280$ & $<0.251$ & $<0.258$ & $<0.263$ & $<0.220$ \\
\hline
\end{tabular}

2-Chloronaphthalene

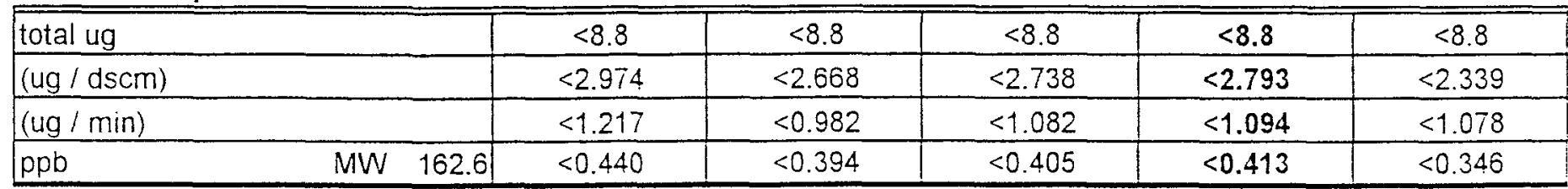

2-Nitroaniline

\begin{tabular}{|l|c|c|c|c|c|c|}
\hline \hline total ug & $<40.0$ & $<40.0$ & $<40.0$ & $<40.0$ & $<40.0$ \\
\hline (ug/dscm) & $<13.519$ & $<12.128$ & $<12.445$ & $<12.697$ & $<10.633$ \\
\hline (ug / min) & $<5.532$ & $<4.462$ & $<4.920$ & $<4.971$ & $<4.899$ \\
\hline $\mathrm{ppb}$ & MW 138.1 & $<2.353$ & $<2.111$ & $<2.166$ & $<2.210$ & $<1.351$ \\
\hline
\end{tabular}


TABLE 5 Continued...

(page 5 of 9)

RTS \#2 WASTE FEED

EPA Test Method 0010 - Modified Method 5

Dimethylphthalate

\begin{tabular}{|c|c|c|c|c|c|c|}
\hline total ug & & $<2.8$ & $<2.8$ & $<2.8$ & $<2.8$ & $<2.8$ \\
\hline (ug / dscm) & & $<0.946$ & $<0.849$ & $<0.871$ & $<0.889$ & $<0.744$ \\
\hline$(\mathrm{ug} / \mathrm{min})$ & & $<0.387$ & $<0.312$ & $<0.344$ & $<0.348$ & $<0.343$ \\
\hline $\mathrm{ppb}$ & MW 194.2 & $<0.117$ & $<0.105$ & $<0.108$ & $<0.110$ & $<0.092$ \\
\hline
\end{tabular}

\section{Acenaphthylene}

\begin{tabular}{|c|c|c|c|c|c|c|}
\hline total ug & & $<6.4$ & $<6.4$ & $<6.4$ & $<6.4$ & $<6.4$ \\
\hline (ug / dscm) & & $<2.163$ & $<1.940$ & $<1.991$ & $<2.032$ & $<1.701$ \\
\hline$(\mathrm{ug} / \mathrm{min})$ & & $<0.885$ & $<0.714$ & $<0.787$ & $<0.795$ & $<0.784$ \\
\hline ppb & MW 152.0 & $<0.342$ & $<0.307$ & $<0.315$ & $<0.321$ & $<0.269$ \\
\hline
\end{tabular}

2,6-Dinitrotoluene

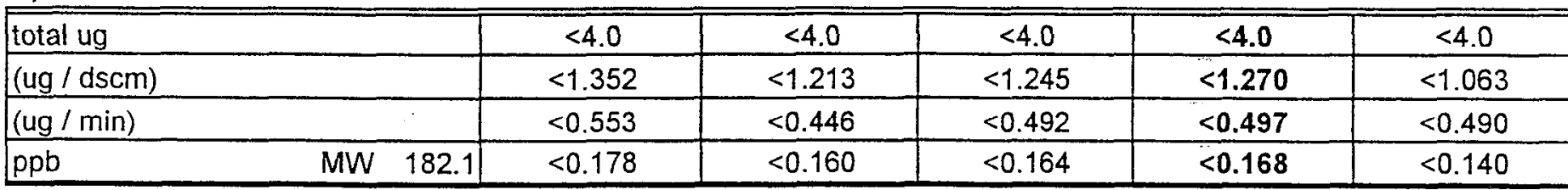

3-Nitroaniline

\begin{tabular}{|c|c|c|c|c|c|c|}
\hline total ug & & $<40.0$ & $<40.0$ & $<40.0$ & $<40.0$ & $<40.0$ \\
\hline$(\mathrm{ug} / \mathrm{dscm})$ & & $<13.519$ & $<12.128$ & $<12.445$ & $<12.697$ & $<10.633$ \\
\hline (ug/min) & & $<5.532$ & $<4.462$ & $<4.920$ & $<4.971$ & $<4.899$ \\
\hline $\mathrm{ppb}$ & MW 138.1 & $<2.353$ & $<2.111$ & $<2.166$ & $<2.210$ & $<1.851$ \\
\hline
\end{tabular}

\section{Acenaphthene}

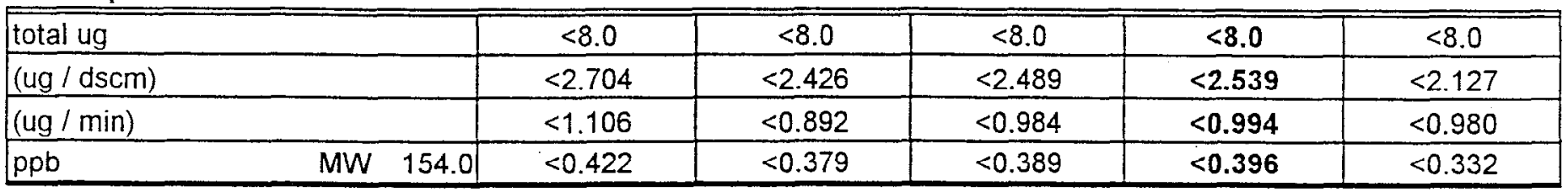

\section{2,4-Dinitrophenol}

\begin{tabular}{|c|c|c|c|c|c|c|}
\hline total ug & & $<40.0$ & $<40.0$ & $<40.0$ & $<40.0$ & $<40.0$ \\
\hline (ug / dscm) & & $<13.519$ & $<12.128$ & $<12.445$ & $<12.697$ & $<10.633$ \\
\hline (ug/min) & & $<5.532$ & $<4.462$ & $<4.920$ & $<4.971$ & $<4.899$ \\
\hline $\mathrm{ppb}$ & MW 184.1 & $<1.765$ & $<1.584$ & $<1.625$ & $<1.658$ & $<1.388$ \\
\hline
\end{tabular}

\section{4-Nitrophenol}

\begin{tabular}{|c|c|c|c|c|c|c|}
\hline total ug & & $<40.0$ & $<40.0$ & $<40.0$ & $<40.0$ & $<40.0$ \\
\hline (ug / dscm) & & $<13.519$ & $<12.128$ & $<12.445$ & $<12.697$ & $<10.633$ \\
\hline$(\mathrm{ug} / \mathrm{min})$ & & $<5.532$ & $<4.462$ & $<4.920$ & $<4.971$ & $<4.899$ \\
\hline$p p b$ & MW 139.1 & $<2.336$ & $<2.096$ & $<2.151$ & $<2.194$ & $<1.838$ \\
\hline
\end{tabular}

\section{Dibenzofuran}

\begin{tabular}{|c|c|c|c|c|c|c|}
\hline total ug & & $<40.0$ & $<40.0$ & $<40.0$ & $<40.0$ & $<40.0$ \\
\hline (ug/dscm) & & $<13.519$ & $<12.128$ & $<12.445$ & $<12.697$ & $<10.633$ \\
\hline (ug / $\mathrm{min})$ & & $<5.532$ & $<4.462$ & $<4.920$ & $<4.971$ & $<4.899^{\circ}$ \\
\hline$p p b$ & MW 168.2 & $<1.932$ & $<1.733$ & $<1.779$ & $<1.815$ & $<1.520$ \\
\hline
\end{tabular}


TABLE 5 Continued...

(page 6 of 9)

RTS \#2 WASTE FEED

EPA Test Method 0010 - Modified Method 5

\section{2,4-Dinitrotoluene}

\begin{tabular}{|c|c|c|c|c|c|c|}
\hline total ug & & $<4.4$ & $<4.4$ & $<4.4$ & $<4.4$ & $<4.4$ \\
\hline (ug / dscm) & & $<1.487$ & $<1.334$ & $<1.369$ & $<1.397$ & $<1.170$ \\
\hline$(\mathrm{ug} / \mathrm{min})$ & & $<0.609$ & $<0.491$ & $<0.541$ & $<0.547$ & $<0.539$ \\
\hline $\mathrm{ppb}$ & MW 182.1 & $<0.196$ & $<0.176$ & $<0.181$ & $<0.184$ & $<0.154$ \\
\hline
\end{tabular}

Diethyl phthalate

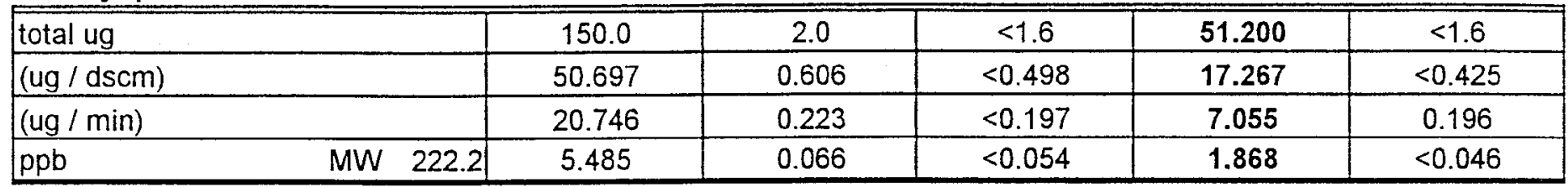

4-Chlorophenylphenylether

\begin{tabular}{|c|c|c|c|c|c|c|}
\hline total ug & & $<7.2$ & $<7.2$ & $<7.2$ & $<7.2$ & $<7.2$ \\
\hline (ug / dscm) & & $<2.433$ & $<2.183$ & $<2.240$ & $<2.286$ & $<1.914$ \\
\hline$(\mathrm{ug} / \mathrm{min})$ & & $<0.996$ & $<0.803$ & $<0.886$ & $<0.895$ & $<0.882$ \\
\hline$p p b$ & MW 204.7 & $<0.286$ & $<0.256$ & $<0.263$ & $<0.268$ & $<0.225$ \\
\hline
\end{tabular}

Fluorene

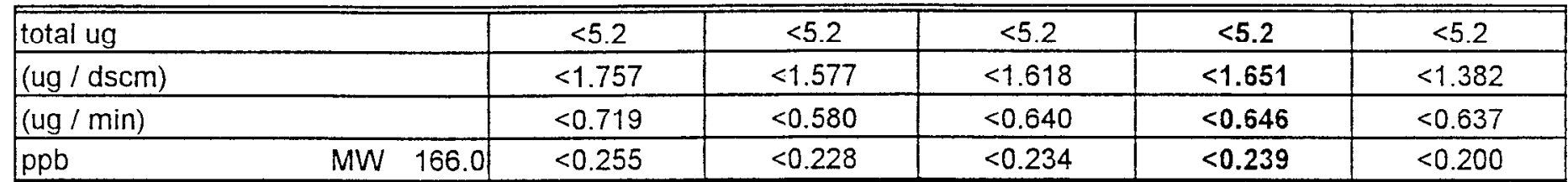

4-Nitroaniline

\begin{tabular}{|c|c|c|c|c|c|c|}
\hline total ug & & $<40.0$ & $<40.0$ & $<40.0$ & $<40.0$ & $<40.0$ \\
\hline (ug / dscm) & & $<13.519$ & $<12.128$ & $<12.445$ & $<12.697$ & $<10.633$ \\
\hline$(\mathrm{ug} / \mathrm{min})$ & & $<5.532$ & $<4.462$ & $<4.920$ & $<4.971$ & $<4.899$ \\
\hline $\mathrm{ppb}$ & MW 138.1 & $<2.353$ & $<2.111$ & $<2.166$ & $<2.210$ & $<1.851$ \\
\hline
\end{tabular}

4,6-Dintro-2-methylphenol

\begin{tabular}{|c|c|c|c|c|c|c|}
\hline total ug & & $<4.8$ & $<4.8$ & $<4.8$ & $<4.8$ & $<4.8$ \\
\hline$(\mathrm{ug} / \mathrm{dscm})$ & & $<1.622$ & $<1.455$ & $<1.493$ & $<1.524$ & $<1.276$ \\
\hline (ug / min) & & $<0.664$ & $<0.535$ & $<0.590$ & $<0.597$ & $<0.588$ \\
\hline$p p b$ & MW 198.1 & $<0.197$ & $<0.177$ & $<0.181$ & $<0.185$ & $<0.155$ \\
\hline
\end{tabular}

$\mathrm{N}$-Nitrosodiphenylamine

\begin{tabular}{|c|c|c|c|c|c|c|}
\hline total ug & & $<14.0$ & $<14.0$ & $<14.0$ & $<14.0$ & $<14.0$ \\
\hline (ug/dscm) & & $<4.732$ & $<4.245$ & $<4.356$ & $<4.444$ & $<3.721$ \\
\hline (ug / min) & & $<1.936$ & $<1.562$ & $<1.722$ & $<1.740$ & $<1.715$ \\
\hline$\overline{p p b}$ & MW 198.2 & $<0.574$ & $<0.515$ & $<0.528$ & $<0.539$ & $<0.451$ \\
\hline
\end{tabular}

4-Bromophenylphenylether

\begin{tabular}{|c|c|c|c|c|c|c|}
\hline total ug & & $<6.4$ & $<6.4$ & $<6.4$ & $<6.4$ & $<6.4$ \\
\hline$(\mathrm{ug} / \mathrm{dscm})$ & & $<2.163$ & $<1.940$ & $<1.991$ & $<2.032$ & $<1.701$ \\
\hline$(\mathrm{ug} / \mathrm{min})$ & & $<0.885$ & $<0.714$ & $<0.787$ & $<0.795$ & $<0.784$ \\
\hline$p p b$ & MW 221.5 & $<0.235$ & $<0.211$ & $<0.216$ & $<0.220$ & $<0.185$ \\
\hline
\end{tabular}


TABLE 5 Continued...

(page 7 of 9)

RTS \#2 WASTE FEED

EPA Test Method 0010 - Modified Method 5

Hexachlorobenzene

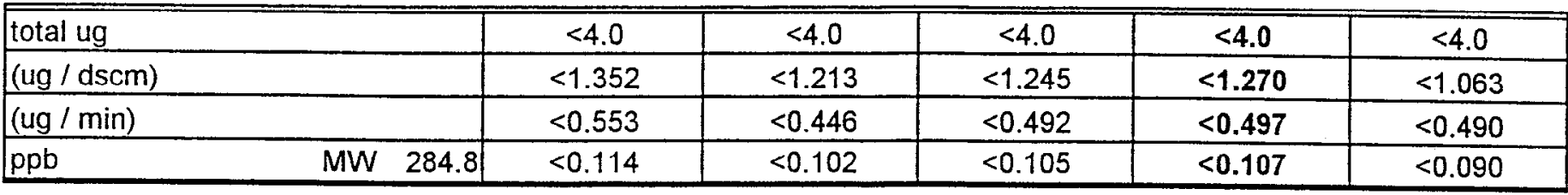

Pentachlorophenol

\begin{tabular}{|c|c|c|c|c|c|c|}
\hline total ug & & $<6.0$ & $<6.0$ & $<6.0$ & $<6.0$ & $<6.0$ \\
\hline (ug / dscm) & & $<2.028$ & $<1.819$ & $<1.867$ & $<1.905$ & $<1.595$ \\
\hline (ug / min) & & $<0.830$ & $<0.669$ & $<0.738$ & $<0.746$ & $<0.735$ \\
\hline $\mathrm{ppb}$ & MW 266.3 & $<0.183$ & $<0.164$ & $<0.169$ & $<0.172$ & $<0.144$ \\
\hline
\end{tabular}

\section{Phenanthrene}

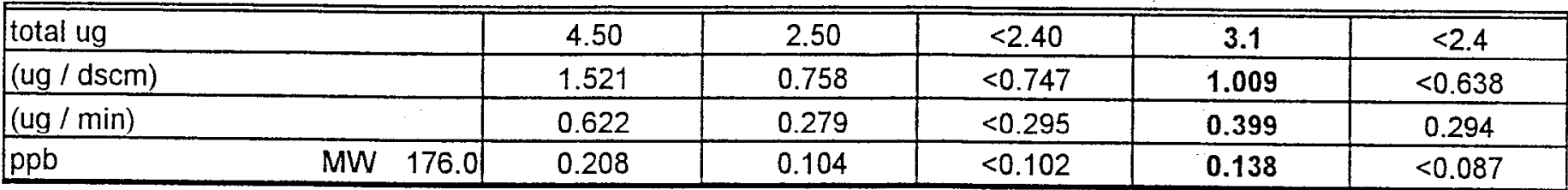

Anthracene

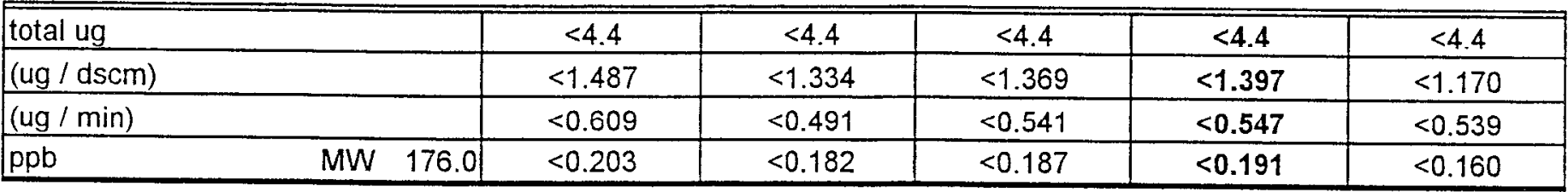

Carbazole

\begin{tabular}{|c|c|c|c|c|c|c|}
\hline total ug & & $<1.2$ & $<1.2$ & $<1.2$ & $<1.2$ & $<1.2$ \\
\hline$(u g / d s c m)$ & & $<0.406$ & $<0.364$ & $<0.373$ & $<0.381$ & $<0.319$ \\
\hline (ug / min) & & $<0.166$ & $<0.134$ & $<0.148$ & $<0.149$ & $<0.147$ \\
\hline $\mathrm{ppb}$ & MW 167.0 & $<0.058$ & $<0.052$ & $<0.054$ & $<0.055$ & $<0.046$ \\
\hline
\end{tabular}

Di-n-butyl phthalate

\begin{tabular}{|ll|c|c|c|c|c|}
\hline \hline total ug & 18 & 4 & $<4.0$ & 8.7 & $<4.0$ \\
\hline (ug / dscm) & & 6.084 & 1.213 & $<1.245$ & 2.847 & $<1.063$ \\
\hline (ug / min) & & 2.490 & 0.446 & $<0.492$ & 1.143 & 0.490 \\
\hline $\mathrm{ppb}$ & MW 278.4 & 0.525 & 0.105 & $<0.107$ & 0.246 & $<0.092$ \\
\hline
\end{tabular}

\section{Fluoranthene}

\begin{tabular}{|c|c|c|c|c|c|c|}
\hline total ug & & $<4.0$ & $<4.0$ & $<4.0$ & $<4.0$ & $<4.0$ \\
\hline$(\mathrm{ug} / \mathrm{dscm})$ & & $<1.352$ & $<1.213$ & $<1.245$ & $<1.270$ & $<1.063$ \\
\hline (ug / min) & & $<0.553$ & $<0.446$ & $<0.492$ & $<0.497$ & $<0.490$ \\
\hline$p p b$ & MW 202.0 & $<0.161$ & $<0.144$ & $<0.148$ & $<0.151$ & $<0.127$ \\
\hline
\end{tabular}

\section{Pyrene}

\begin{tabular}{|c|c|c|c|c|c|c|}
\hline total ug & & $<2.0$ & $<2.0$ & $<2.0$ & $<2.0$ & $<2.0$ \\
\hline$(\mathrm{ug} / \mathrm{dscm})$ & & $<0.676$ & $<0.606$ & $<0.622$ & $<0.635$ & $<0.532$ \\
\hline$(\mathrm{ug} / \mathrm{min})$ & & $<0.277$ & $<0.223$ & $<0.246$ & $<0.249$ & $<0.245$ \\
\hline $\mathrm{ppb}$ & MW 202.0 & $<0.080$ & $<0.072$ & $<0.074$ & $<0.076$ & $<0.063$ \\
\hline
\end{tabular}


TABLE 5 Continued...

(page 8 of 9 )

RTS \#2 WASTE FEED

EPA Test Method 0010 - Modified Method 5

Benzyl butyl phthalate

\begin{tabular}{|c|c|c|c|c|c|c|}
\hline total ug & & $<5.2$ & $<5.2$ & $<5.2$ & $<5.2$ & $<5.2$ \\
\hline (ug / dscm) & & $<1.757$ & $<1.577$ & $<1.618$ & $<1.651$ & $<1.382$ \\
\hline (ug/min) & & $<0.719$ & $<0.580$ & $<0.640$ & $<0.646$ & $<0.637$ \\
\hline $\mathrm{ppb}$ & MW 312.4 & $<0.135$ & $<0.121$ & $<0.124$ & $<0.127$ & $<0.106$ \\
\hline
\end{tabular}

3,3-Dichlorobenzidine

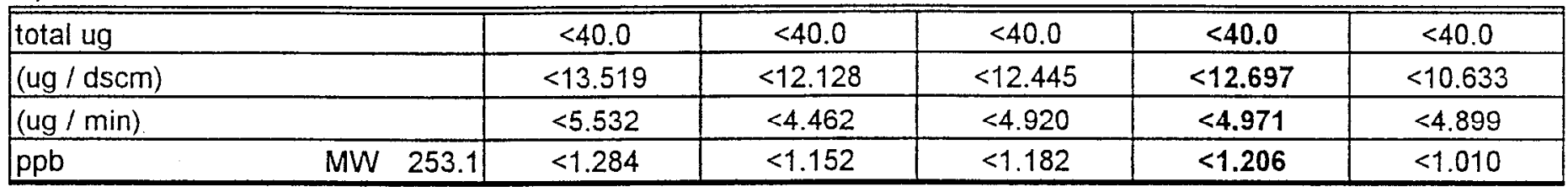

Benzo(a)anthracene

\begin{tabular}{|c|c|c|c|c|c|c|}
\hline total ug & & $<3.2$ & $<3.2$ & $<3.2$ & $<3.2$ & $<3.2$ \\
\hline (ug / dscm) & & $<1.082$ & $<0.970$ & $<0.996$ & $<1.016$ & $<0.851$ \\
\hline (ug / $\mathrm{min})$ & & $<0.443$ & $<0.357$ & $<0.394$ & $<0.398$ & $<0.392$ \\
\hline $\mathrm{ppb}$ & MW 228.0 & $<0.114$ & $<0.102$ & $<0.105$ & $<0.107$ & $<0.090$ \\
\hline
\end{tabular}

Chrysene

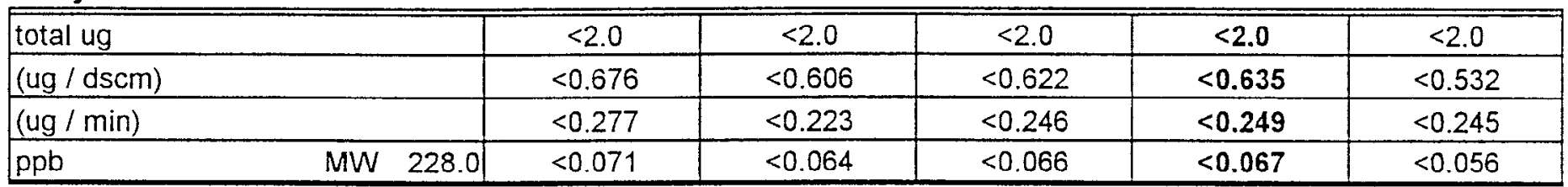

Bis(2-ethylhexyl)phthalate

\begin{tabular}{|c|c|c|c|c|c|c|}
\hline total ug & & 15.0 & 23.0 & 11.0 & 16.3 & $<8.0$ \\
\hline$(\mathrm{ug} / \mathrm{dscm})$ & & 5.070 & 6.974 & 3.422 & 5.155 & $<2.127$ \\
\hline$(u g / \min )$ & & 2.075 & 2.565 & 1.353 & 1.998 & $<0.980$ \\
\hline $\mathrm{ppb}$ & MW 390.6 & 0.312 & 0.429 & 0.211 & 0.317 & $<0.131$ \\
\hline \multicolumn{7}{|c|}{ Di-n-octyl phthalate } \\
\hline total ug & & $<5.2$ & $<5.2$ & $<5.2$ & $<5.2$ & $<5.2$ \\
\hline (ug / dscm) & & $<1.757$ & $<1.577$ & $<1.618$ & $<1.651$ & $<1.382$ \\
\hline$(\mathrm{ug} / \mathrm{min})$ & & $<0.719$ & $<0.580$ & $<0.640$ & $<0.646$ & $<0.637$ \\
\hline $\mathrm{ppb}$ & MW 390.6 & $<0.108$ & $<0.097$ & $<0.100$ & $<0.102$ & $<0.085$ \\
\hline
\end{tabular}

Benzo(b)fluoranthene

\begin{tabular}{|l|c|c|c|c|c|}
\hline \hline total ug & $<4.0$ & $<4.0$ & $<4.0$ & $<4.0$ & $<4.0$ \\
\hline (ug/dscm) & $<1.352$ & $<1.213$ & $<1.245$ & $<1.270$ & $<1.063$ \\
\hline (ug/min) & $<0.553$ & $<0.446$ & $<0.492$ & $<0.497$ & $<0.490$ \\
\hline $\mathrm{ppb}$ MW 252.0 & $<0.129$ & $<0.116$ & $<0.119$ & $<0.121$ & $<0.101$ \\
\hline Benzo(k)fluoranthene & & & & \\
\hline \hline total ug & $<4.4$ & $<4.4$ & $<4.4$ & $<4.4$ & $<4.4$ \\
\hline (ug / dscm) & $<1.487$ & $<1.334$ & $<1.369$ & $<1.397$ & $<1.170$ \\
\hline (ug/min) & $<0.509$ & $<0.491$ & $<0.541$ & $<0.547$ & $<0.539$ \\
\hline ppb & $<0.142$ & $<0.127$ & $<0.131$ & $<0.133$ & $<0.112$ \\
\hline
\end{tabular}


TABLE 5 Continued... (page 9 of 9)

RTS \#2 WASTE FEED

EPA Test Method 0010 - Modified Method 5

Benzo(a)pyrene

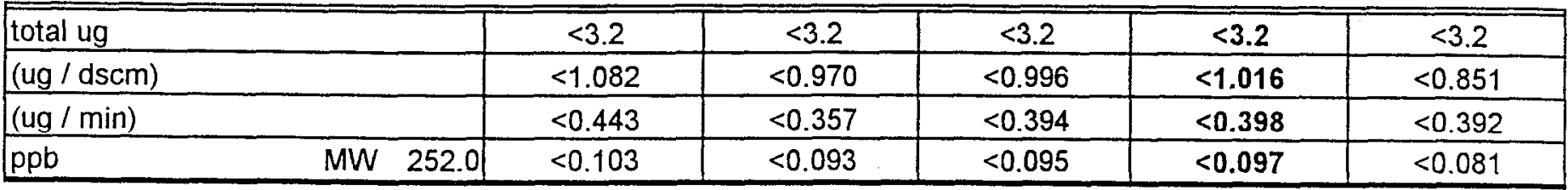

Indeno(1,2,3-cd)pyrene

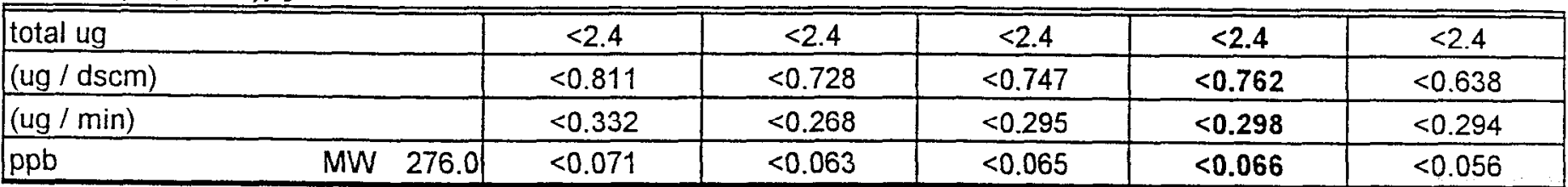

Dibenzo(a,h)anthracene

\begin{tabular}{|c|c|c|c|c|c|c|}
\hline total ug & & $<4.0$ & $<4.0$ & $<4.0$ & $<4.0$ & $<4.0$ \\
\hline (ug/dscm) & & $<1.352$ & $<1.213$ & $<1.245$ & $<1.270$ & $<1.063$ \\
\hline (ug / min) & & $<0.553$ & $<0.446$ & $<0.492$ & $<0.497$ & $<0.490$ \\
\hline
\end{tabular}

\section{Benzo(ghi)perylene}

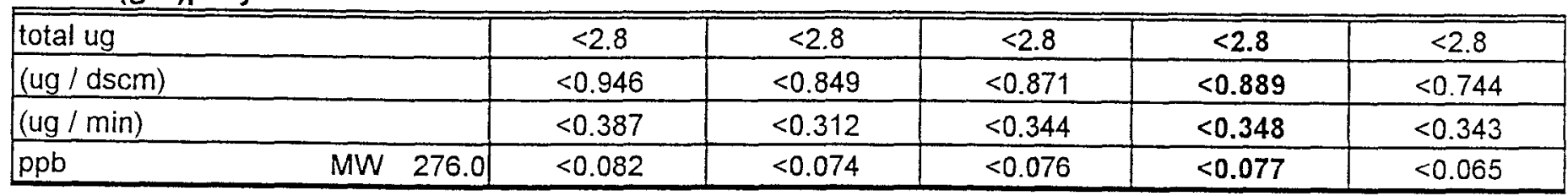

Definitions:

DSCFM = Dry Standard Cubic Feet per Minute $\mathrm{ug} / \mathrm{dscm}=$ microgram per dry standard cubic meter ug / sec = emission rate, micrograms per second $\mathrm{ppb}=$ parts per billion

$\mathrm{T}$ std. $=$ Standard Temerature $^{\circ}{ }^{\circ} \mathrm{F}=68$
Calculations:

$\mathrm{DSCM}=\mathrm{DSCF} * 0.02832$

ug $/ \mathrm{min}=0.02832 * D S C F M *(\mathrm{ug} / \mathrm{dscm})$

ug $/ \mathrm{dscm}=$ total ug $/$ sample vol., dscm

$\mathrm{ppb}=\mathrm{ug} / \mathrm{dscm} * 22.4 *(T$ std. +460$) / 492 / \mathrm{M} . \mathrm{W}$. 


\section{TABLE 6}

\section{LLNL BIdg. 292 MSO} GSS Filter\& Catalytic Converter Outlets - RTS \#1 Waste Feed Volatile Emissions
EPA Test Method 0030 - VOST

\begin{tabular}{|c|c|c|c|c|c|}
\hline TEST \# & 1-GSS Out & 2-GSS Out & 3-GSS Out & AVERAGE & Cat. Out \\
\hline TEST DATE & $8 / 18 / 98$ & $8 / 18 / 98$ & $8 / 18 / 98$ & & 8/18/98 \\
\hline TEST TIME & $1059-1215$ & $1234-1350$ & $1424-1546$ & & $1614-1740$ \\
\hline SAMPLE VOLUME (Std. liters) & 57.020 & 53.690 & 54.309 & 55.006 & 58.688 \\
\hline SAMPLE VOLUME (DSCM) & 0.057 & 0.054 & 0.054 & 0.055 & 0.059 \\
\hline FLOW RATE (DSCFM) & 14.66 & 14.27 & 13.52 & 14.15 & 16.48 \\
\hline
\end{tabular}

\section{Chloromethane}

\begin{tabular}{|c|c|c|c|c|c|c|c|}
\hline total $\mu \mathrm{g}$ & & & $1: 120$ & 0.330 & 3.940 & 1.797 & 0.178 \\
\hline$(\mu \mathrm{g} / \mathrm{dscm})$ & & & 19.642 & 6.146 & 72.548 & 32.779 & 3.033 \\
\hline$(\mu \mathrm{g} / \mathrm{min})$ & & & 8.155 & 2.484 & 27.778 & 12.805 & 1.416 \\
\hline $\mathrm{ppb}$ & MW = & 50.5 & 9.350 & 2.926 & 34.534 & 15.603 & 1.444 \\
\hline \multicolumn{8}{|c|}{ Bromomethane } \\
\hline total $\mu \mathrm{g}$ & & & 0.191 & 0.029 & 0.096 & 0.105 & 0.172 \\
\hline$(\mu \mathrm{g} / \mathrm{dscm})$ & & & 3.350 & 0.540 & 1.768 & 1.886 & 2.931 \\
\hline$(\mu \mathrm{g} / \min )$ & & & 1.391 & 0.218 & 0.677 & 0.762 & 1.368 \\
\hline $\mathrm{ppb}$ & $\mathrm{MW}=$ & 95.0 & 0.848 & 0.137 & 0.447 & 0.477 & 0.742 \\
\hline \multicolumn{8}{|c|}{ Vinyl Chloride } \\
\hline total $\mu \mathrm{g}$ & & & $<0.039$ & $<0.039$ & $<0.039$ & $<0.039$ & $<0.039$ \\
\hline$(\mu \mathrm{g} / \mathrm{dscm})$ & & & $<0.684$ & $<0.726$ & $<0.718$ & $<0.709$ & $<0.665$ \\
\hline$(\mu \mathrm{g} / \mathrm{min})$ & & & $<0.284$ & $<0.294$ & $<0.275$ & $<0.284$ & $<0.310$ \\
\hline $\mathrm{ppb}$ & $\mathrm{MW}=$ & 62.5 & $<0.263$ & $<0.279$ & $<0.276$ & $<0.273$ & $<0.256$ \\
\hline \multicolumn{8}{|c|}{ Chloroethane } \\
\hline total $\mu \mathrm{g}$ & & & $<0.0210$ & $<0.0210$ & $<0.0210$ & $<0.0210$ & $<0.0210$ \\
\hline$(\mu \mathrm{g} / \mathrm{dscm})$ & & & $<0.3683$ & $<0.3911$ & $<0.3867$ & $<0.3820$ & $<0.3578$ \\
\hline$(\mu \mathrm{g} / \mathrm{min})$ & & & $<0.1529$ & $<0.1581$ & $<0.1481$ & $<0.1530$ & $<0.1670$ \\
\hline $\mathrm{ppb}$ & $\mathrm{MW}=$ & 64.5 & $<0.1372$ & $<0.1457$ & $<0.1441$ & $<0.1423$ & $<0.1333$ \\
\hline \multicolumn{8}{|c|}{ Methylene Chloride } \\
\hline total $\mu \mathrm{g}$ & & & 9.900 & 6.600 & 4.210 & 6.903 & 3.700 \\
\hline$(\mu \mathrm{g} / \mathrm{dscm})$ & & & 173.624 & 122.927 & 77.519 & 124.690 & 63.045 \\
\hline$(\mu \mathrm{g} / \min )$ & & & 72.084 & 49.678 & 29.681 & 50.481 & 29.424 \\
\hline $\mathrm{ppb}$ & MW $=$ & 84.9 & 49.161 & 34.806 & 21.949 & 35.305 & 17.851 \\
\hline \multicolumn{8}{|l|}{ Acetone } \\
\hline total $\mu \mathrm{g}$ & & & 7.400 & 11.800 & 1.550 & 6.917 & 0.830 \\
\hline$(\mu \mathrm{g} / \mathrm{dscm})$ & & & 129.780 & 219.779 & 28.540 & 126.033 & 14.143 \\
\hline$(\mu \mathrm{g} / \mathrm{min})$ & & & 53.881 & 88.819 & 10.928 & 51.209 & 6.601 \\
\hline $\mathrm{ppb}$ & $\mathrm{MW}=$ & 58.1 & 53.715 & 90.966 & 11.813 & 52.165 & 5.854 \\
\hline \multicolumn{8}{|c|}{ Carbon Disulfide } \\
\hline total $\mu \mathrm{g}$ & & & $<0.054$ & $<0.054$ & $<0.054$ & $<0.054$ & $<0.054$ \\
\hline$(\mu \mathrm{g} / \mathrm{dscm})$ & & & $<0.947$ & $<1.006$ & $<0.994$ & $<0.982$ & $<0.920$ \\
\hline$(\mu \mathrm{g} / \min )$ & & & $<0.393$ & $<0.406$ & $<0.381$ & $<0.393$ & $<0.429$ \\
\hline $\mathrm{ppb}$ & $\mathrm{MW}=$ & 76.1 & $<0.299$ & $<0.318$ & $<0.314$ & $<0.310$ & $<0.291$ \\
\hline
\end{tabular}


TABLE 6 - cont. (page 2 of 4)

\section{GSS Filter Outlet - RTS \#1 Waste Feed Volatile Emissions \\ EPA Test Method 0030 - VOST}

1,1-Dichloroethene

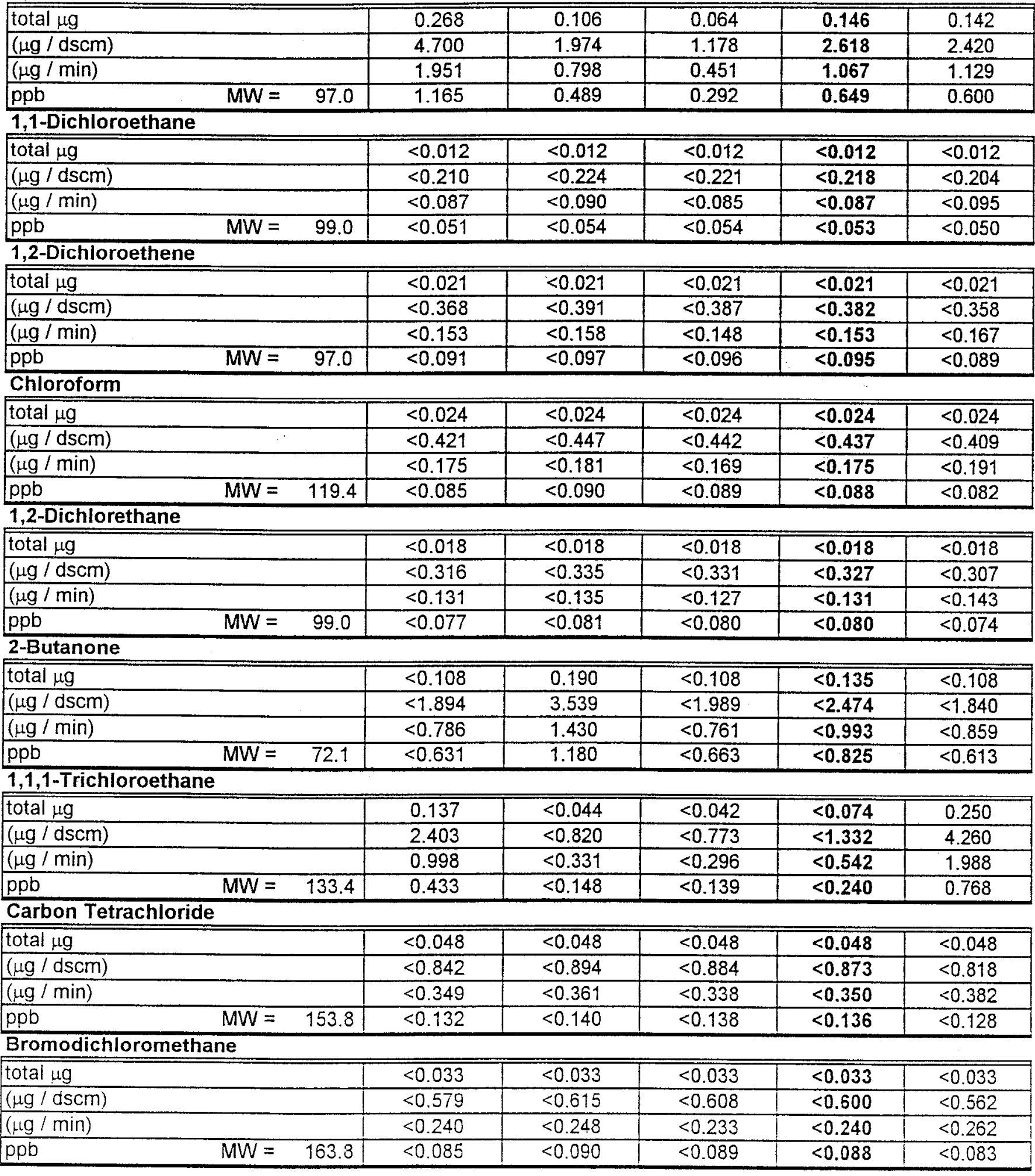


TABLE 6 - cont. (page 3 of 4)

GSS Filter Outlet - RTS \#1 Waste Feed Volatile Emissions

EPA Test Method 0030 - VOST

\section{1,2-Dichloropropane}

\begin{tabular}{|l|l|}
\hline total $\mu \mathrm{g}$ & $<0.02$ \\
\hline$(\mu \mathrm{g} / \mathrm{dscm})$ & $<0.42$ \\
\hline$(\mu \mathrm{g} / \mathrm{min})$ & $<0.17$ \\
\hline $\mathrm{ppb}$ & $<0.090$ \\
\hline
\end{tabular}

cis-1,3-Dichloropropene

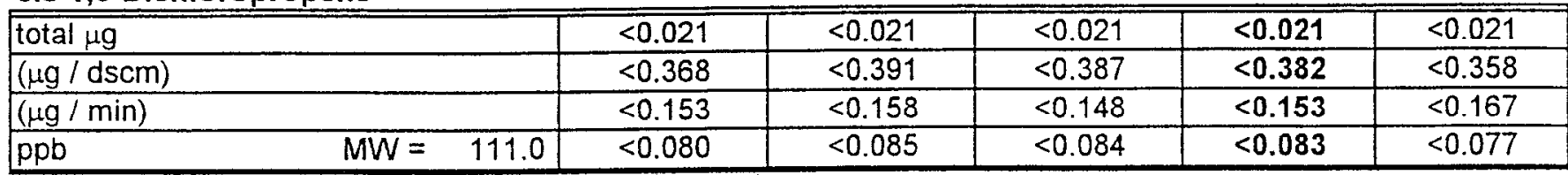

Trichloroethene

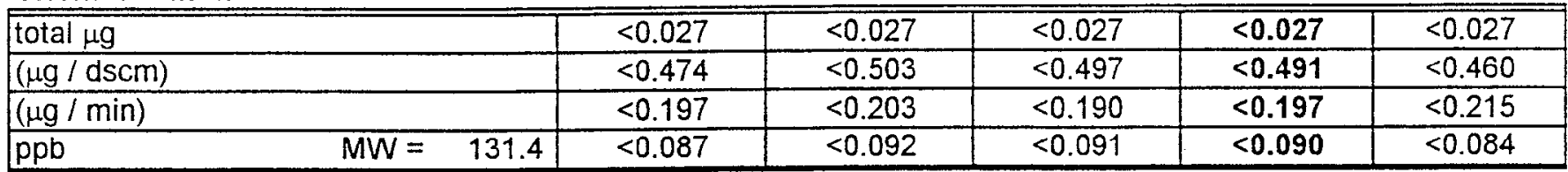

\section{Dibromochloromethane}

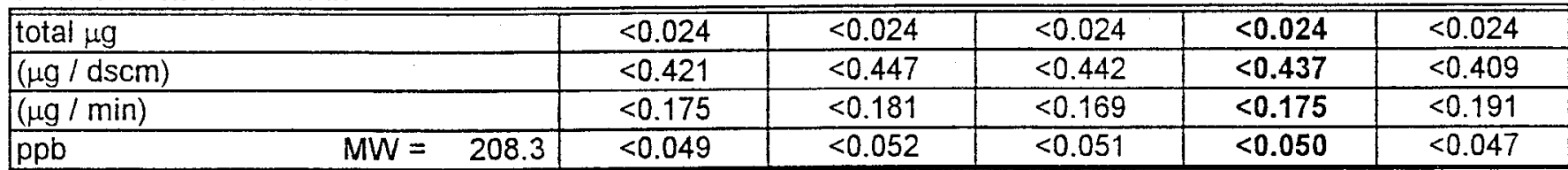

\section{1,1,2-Trichloroethane}

\begin{tabular}{|c|c|}
\hline total $\mu g$ & $<0.048$ \\
\hline$\sqrt{(\mu \mathrm{g} / \mathrm{dscm})}$ & $<0.818$ \\
\hline$(\mu \mathrm{g} / \mathrm{min})$ & $<0.382$ \\
\hline$p p b$ & $<0.147$ \\
\hline
\end{tabular}

\section{Benzene}

\begin{tabular}{|c|c|c|c|c|c|}
\hline total $\mu \mathrm{g}$ & 0.124 & 0.107 & 0.092 & 0.108 & 0.320 \\
\hline$(\mu \mathrm{g} / \mathrm{dscm})$ & 2.175 & 1.993 & 1.694 & 1.954 & 5.453 \\
\hline$(\mu \mathrm{g} / \mathrm{min})$ & 0.903 & 0.805 & 0.649 & 0.786 & 2.545 \\
\hline $\mathrm{MW}=78.1$ & 0.669 & 0.613 & 0.521 & 0.601 & 1.678 \\
\hline
\end{tabular}

trans-1,3-Dichloropropene

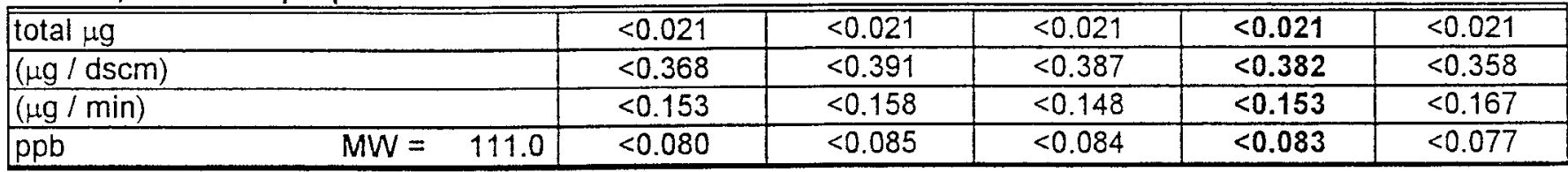

\section{Bromoform}

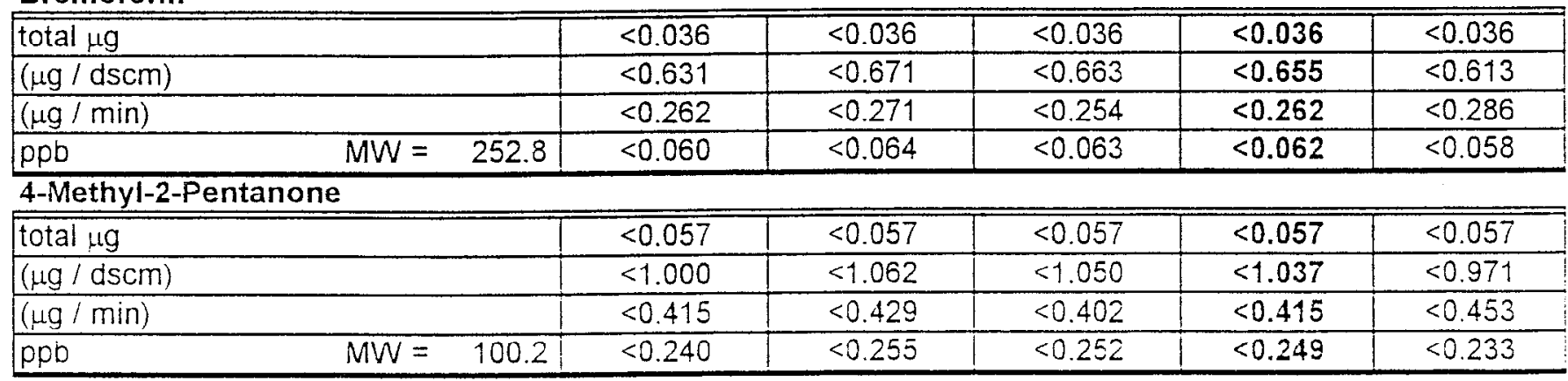


TABLE 6 - cont. (page 4 of 4)

GSS Filter Outlet - RTS \#1 Waste Feed Volatile Emissions

EPA Test Method 0030 - VOST

2-Hexanone

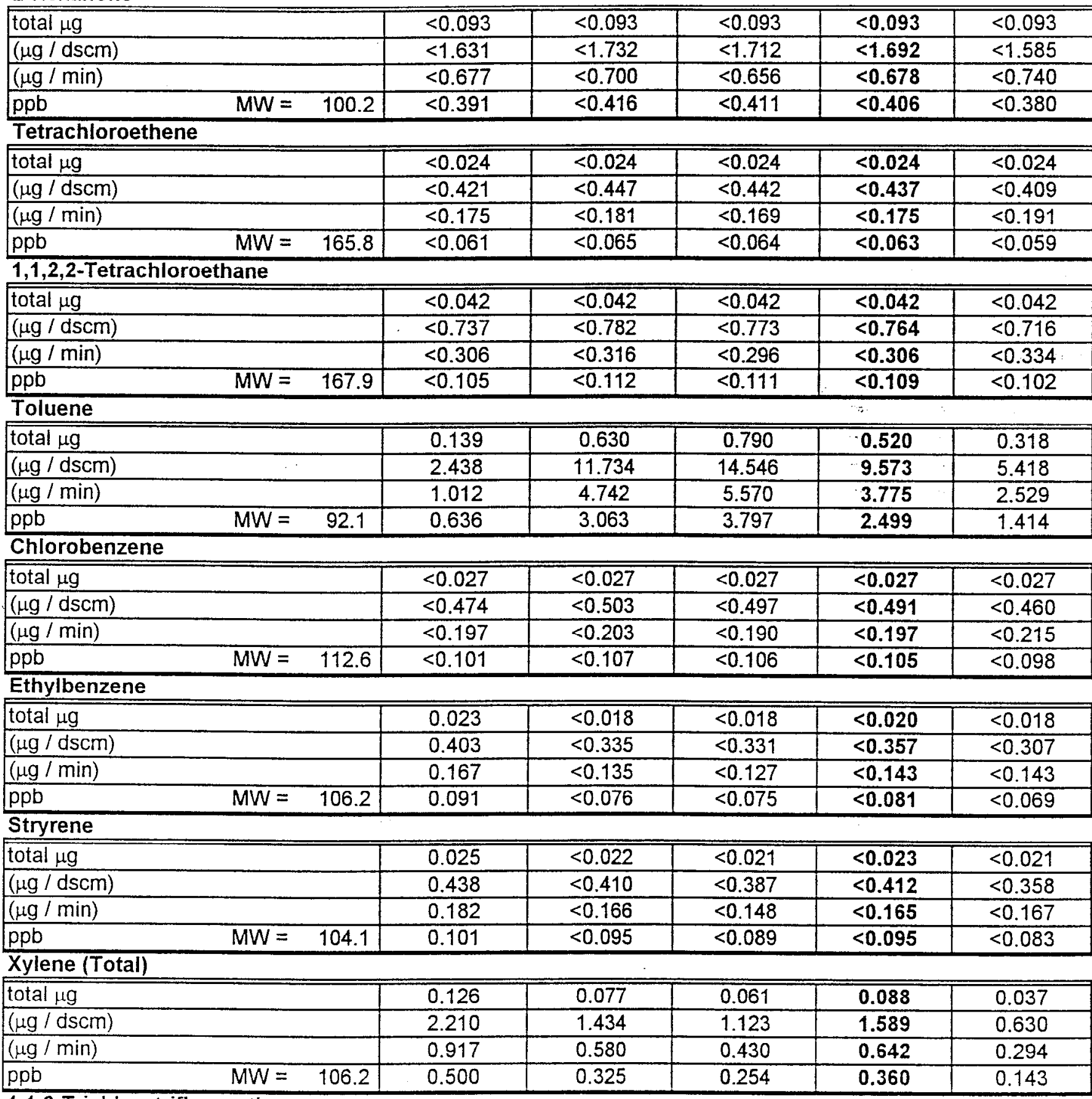

1,1,2-Trichlorotrifluoroethane

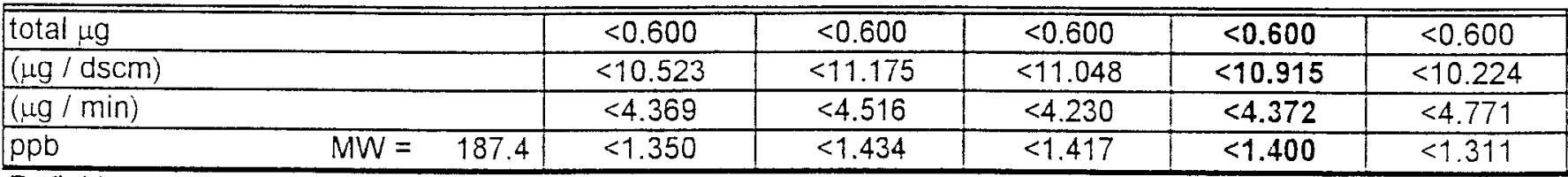

Definitions:

Calculations:

DSCFM = Dry Standard Cubic Feet per Minute

$\mu \mathrm{g} / \mathrm{min}=0.02832 * \mathrm{DSCFM} *(\mu \mathrm{g} / \mathrm{dscm})$

!.g $/ \mathrm{dscm}=$ microgram per dry standard cubic meter

$\mathrm{Lg} / \mathrm{dscm}=$ total $\mathrm{\mu g} /$ sample vol.. dscm

ug $i \min =$ emission rate, micrograms per minute

$\mathrm{ppo}=$. $\mathrm{ug} i \mathrm{dscm} * 22.4 *(T$ std. +460$)+492 / \mathrm{M.N}$

ppo = parts per billion

$\mathrm{T}$ std. = Standard Temperature, $^{\circ} \mathrm{F}=\varepsilon 8$ 


\section{TABLE 7}

\section{LLNL BIdg. 292 MSO \\ GSS Filter \& Catalytic Converter Outlet - RTS \#2 Waste Feed Volatile Emissions EPA Test Method 0030 - VOST}

\begin{tabular}{|c|c|c|c|c|c|}
\hline TEST \# & 1-GSS Out & 2-GSS Out & 3-GSS Out & AVERAGE & Cat. Out \\
\hline TEST DATE & $8 / 26 / 98$ & $8 / 26 / 98$ & $8 / 26 / 98$ & & $8 / 26 / 98$ \\
\hline TEST TIME & $0903-1024$ & $1048-1210$ & $1229-1348$ & & $1410-1530$ \\
\hline SAMPLE VOLUME (Std. liters) & 54.288 & 57.824 & 58.668 & 56.927 & 57.301 \\
\hline SAMPLE VOLUME (DSCM) & 0.054 & 0.058 & 0.059 & 0.057 & 0.057 \\
\hline FLOW RATE (DSCFM) & 13.31 & 14.90 & 13.50 & 13.90 & 16.27 \\
\hline
\end{tabular}

\section{Chloromethane}

\begin{tabular}{|c|c|c|c|c|c|c|}
\hline total $\mu \mathrm{g}$ & & $<0.021$ & $<0.021$ & $<0.021$ & $<0.021$ & 7.89 \\
\hline$(\mu \mathrm{g} / \mathrm{dscm})$ & & $<0.387$ & $<0.363$ & $<0.358$ & $<0.369$ & 137.694 \\
\hline$(\mu \mathrm{g} / \mathrm{min})$ & & $<0.146$ & $<0.153$ & $<0.137$ & $<0.145$ & 63.445 \\
\hline ppb & $\mathrm{MW}=$ & $<0.184$ & $<0.173$ & $<0.170$ & $<0.176$ & 65.545 \\
\hline \multicolumn{7}{|c|}{ Bromomethane } \\
\hline total $\mu \mathrm{g}$ & & 0.855 & 0.103 & 0.242 & 0.400 & 0.175 \\
\hline$(\mu \mathrm{g} / \mathrm{dscm})$ & & 15.749 & 1.781 & 4.125 & 7.219 & 3.054 \\
\hline$(\mu \mathrm{g} / \mathrm{min})$ & & 5.937 & 0.752 & 1.577 & 2.755 & 1.407 \\
\hline $\mathrm{ppb}$ & $M W=$ & 3.985 & 0.451 & 1.044 & 1.827 & 0.773 \\
\hline \multicolumn{7}{|c|}{ Vinyl Chloride } \\
\hline total $\mu \mathrm{g}$ & & $<0.039$ & $<0.039$ & $<0.039$ & $<0.039$ & $<0.039$ \\
\hline$(\mu \mathrm{g} / \mathrm{dscm})$ & & $<0.718$ & $<0.674$ & $<0.665$ & $<0.686$ & $<0.681$ \\
\hline$(\mu \mathrm{g} / \mathrm{min})$ & & $<0.271$ & $<0.285$ & $<0.254$ & $<0.270$ & $<0.314$ \\
\hline $\mathrm{ppb}$ & $M W=$ & $<0.276$ & $<0.259$ & $<0.256$ & $<0.264$ & $<0.262$ \\
\hline \multicolumn{7}{|c|}{ Chioroethane } \\
\hline total $\mu \mathrm{g}$ & & $<0.0210$ & $<0.0210$ & $<0.0210$ & $<0.0210$ & $<0.0210$ \\
\hline$(\mu \mathrm{g} / \mathrm{dscm})$ & & $<0.3868$ & $<0.3632$ & $<0.3579$ & $<0.3693$ & $<0.3665$ \\
\hline$(\mu \mathrm{g} / \mathrm{min})$ & & $<0.1458$ & $<0.1532$ & $<0.1368$ & $<0.1453$ & $<0.1689$ \\
\hline $\mathrm{ppb}$ & $\mathrm{MW}=$ & $<0.1441$ & $<0.1353$ & $<0.1334$ & $<0.1376$ & $<0.1365$ \\
\hline \multicolumn{7}{|c|}{ Methylene Chloride } \\
\hline total $\mu \mathrm{g}$ & & 3.930 & 4.700 & 9.000 & 5.877 & 8.400 \\
\hline$(\mu \mathrm{g} / \mathrm{dscm})$ & & 72.392 & 81.281 & 153.405 & 102.360 & 146.595 \\
\hline$(\mu \mathrm{g} / \mathrm{min})$ & & 27.287 & 34.298 & 58.650 & 40.078 & 67.546 \\
\hline $\mathrm{ppb}$ & $\mathrm{MW}=$ & 20.497 & 23.014 & 43.436 & 28.983 & 41.508 \\
\hline \multicolumn{7}{|l|}{ Acetone } \\
\hline total $\mu \mathrm{g}$ & & 6.860 & 9.700 & 8.900 & 8.487 & 2.210 \\
\hline$(\mu \mathrm{g} / \mathrm{dscm})$ & & 126.364 & 167.751 & 151.701 & 148.605 & 38.568 \\
\hline$(\mu \mathrm{g} / \mathrm{min})$ & & 47.631 & 70.785 & 57.998 & 58.805 & 17.771 \\
\hline $\mathrm{ppb}$ & $\mathrm{MW}=$ & 52.301 & 69.431 & 62.788 & 61.507 & 15.963 \\
\hline \multicolumn{7}{|c|}{ Carbon Disulfide } \\
\hline total $\mu \mathrm{g}$ & & $<0.054$ & $<0.054$ & $<0.054$ & $<0.054$ & $<0.054$ \\
\hline$(\mu \mathrm{g} / \mathrm{dscm})$ & & $<0.995$ & $<0.934$ & $<0.920$ & $<0.950$ & $<0.942$ \\
\hline$(\mathrm{ug} / \mathrm{min})$ & & $<0.375$ & $<0.394$ & $<0.352$ & $<0.374$ & $<0.434$ \\
\hline$p p b$ & $\mathrm{MW}=$ & $<0.314$ & $<0.295$ & $<0.291$ & $<0.300$ & $<0.298$ \\
\hline
\end{tabular}


TABLE 7 - cont. (page 2 of 4)

GSS Filter \& Catalytic Converter Outlet - RTS \#2 Waste Feed Volatile Emissions EPA Test Method 0030 - VOST

1,1-Dichloroethene

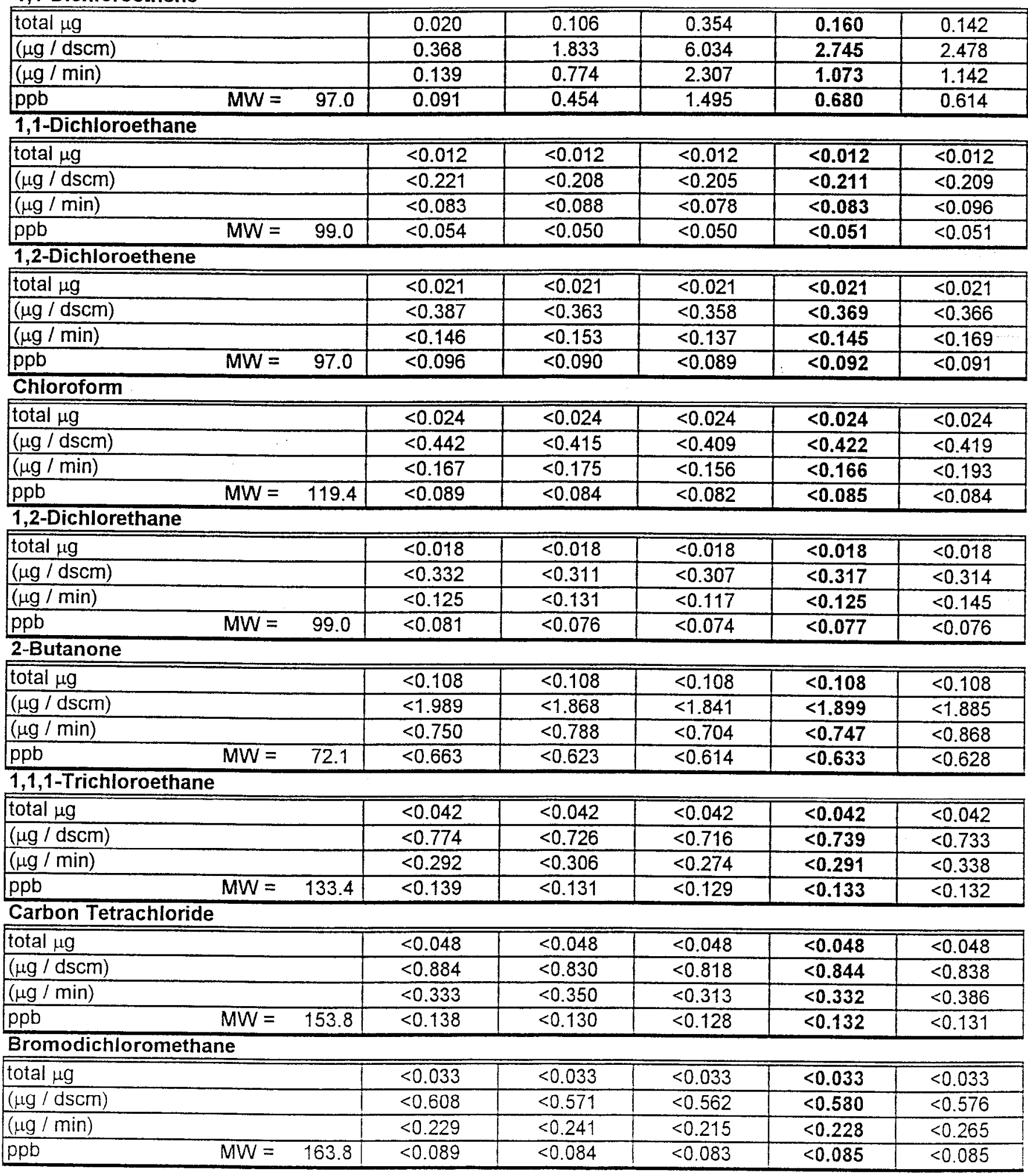


TABLE 7 - cont. (page 3 of 4)

GSS Filter \& Catalytic Converter Outlet - RTS \#2 Waste Feed Volatile Emissions EPA Test Method 0030 - VOST

\section{1,2-Dichloropropane}

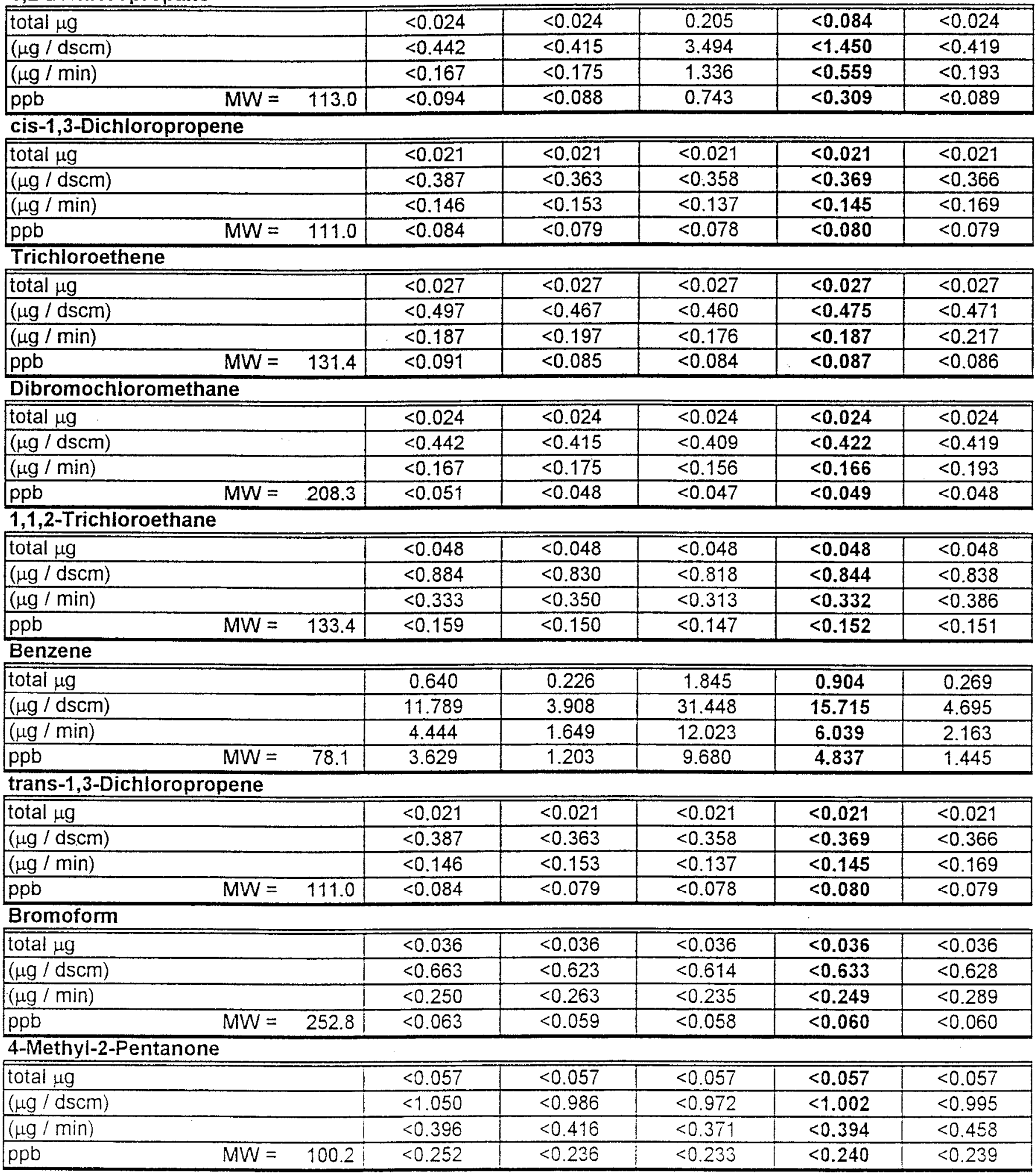


TABLE 7 - cont. (page 4 of 4)

GSS Filter \& Catalytic Converter Outlet - RTS \#2 Waste Feed Volatile Emissions EPA Test Method 0030 - VOST

2-Hexanone

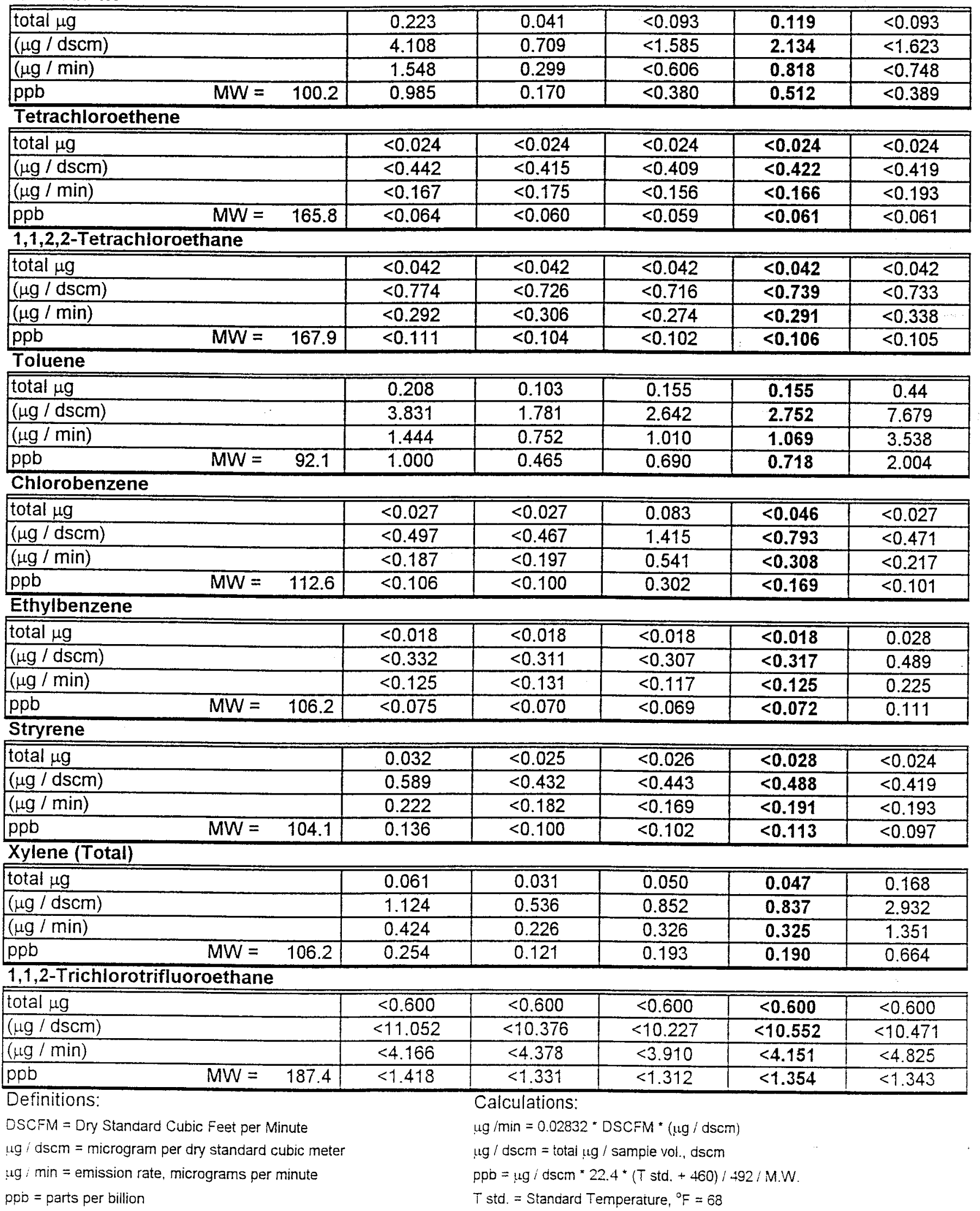


TABLE 8

RTS \#1 Waste Feed

LLNL Bldg. 292 MSO

GSS Filter \& Catalytic Converter Outlets

PARTICULATE\& RADIONUCLIDE EMISSIONS TEST RESULTS

\begin{tabular}{|l|c|c|c|c|c|}
\hline RUN\# & $\mathbf{1}$ & $\mathbf{2}$ & $\mathbf{3}$ & AVERAGE & Catalyst 1 \\
\hline TEST DATE & $8 / 18 / 98$ & $8 / 18 / 98$ & $8 / 18 / 98$ & & $08 / 19 / 98$ \\
\hline TEST TIME & $1027-1127$ & $1245-1345$ & $1500-1600$ & & $0933-1033$ \\
\hline SAMPLE VOLUME (DSCF) & 63.313 & 64.459 & 62.461 & & 36.296 \\
\hline ISOKINETIC (\%) & 92.4 & 96.6 & 98.8 & & 102.7 \\
\hline DUCT TEMP., ('F) & 199.4 & 236.6 & 262.8 & 232.9 & 401.5 \\
\hline VELOCITY (ft/sec) & 32.52 & 33.61 & 33.00 & 33.04 & 5.28 \\
\hline FLOW RATE (ACFM) & 19.51 & 20.17 & 19.80 & 19.83 & 27.54 \\
\hline FLOW RATE (DSCFM) & 14.66 & 14.27 & 13.52 & 14.15 & 16.61 \\
\hline H2O (volume \%) & 3.38 & 3.89 & 3.73 & 3.67 & 0.90 \\
\hline Gross Alpha (pCi/sample) & 5.30 & 0.24 & 0.68 & 2.07 & 0.55 \\
\hline Gross Beta (pCi/sample) & 1.52 & 1.70 & 0.50 & 1.24 & 0.66 \\
\hline Tritium (pCi/sample) & 660.80 & 540.00 & 516.60 & 572.47 & 75.20 \\
\hline F.H. Particulate Conc. (gr/DSCF) & $\mathbf{0 . 0 0 0 0 3}$ & $\mathbf{0 . 0 0 2 2}$ & $\mathbf{0 . 0 0 0 4}$ & $\mathbf{0 . 0 0 0 9}$ & $\mathbf{0 . 0 0 0 3}$ \\
\hline F.H. Particulate Emissions (Lbs/hr) & $\mathbf{0 . 0 0 0 0 0 3}$ & $\mathbf{0 . 0 0 0 2 7}$ & $\mathbf{0 . 0 0 0 0 4}$ & $\mathbf{0 . 0 0 0 1 1}$ & $\mathbf{0 . 0 0 0 0 4}$ \\
\hline Gross Alpha (pCi/DSCF) & 0.084 & 0.004 & 0.011 & 0.03 & 0.015 \\
\hline Gross Beta (pCi/DSCF) & $\mathbf{0 . 0 2 4}$ & 0.026 & 0.008 & 0.02 & 0.018 \\
\hline Tritium (pCi/DSCF) & 10.44 & 8.38 & 8.27 & 9.03 & 2.07 \\
\hline Tot. Alpha Emissions (pCi/hr) & $\mathbf{7 3 . 6 3}$ & $\mathbf{3 . 1 9}$ & $\mathbf{8 . 8 3}$ & $\mathbf{2 8 . 5 4 9}$ & 15.11 \\
\hline Tot. Beta Emissions (pCi/hr) & $\mathbf{2 1 . 1 2}$ & $\mathbf{2 2 . 5 8}$ & $\mathbf{6 . 4 9}$ & $\mathbf{1 6 . 7 2 8}$ & $\mathbf{1 8 . 1 3}$ \\
\hline Tot. Tritium Emissions (pCi/hr) & $\mathbf{9 1 7 9 . 8}$ & $\mathbf{7 1 7 1 . 2}$ & $\mathbf{6 7 0 9 . 1}$ & $\mathbf{7 6 8 6 . 7}$ & $\mathbf{2 0 6 5 . 4}$ \\
\hline
\end{tabular}

WHERE

DSCF $=$ Sample Volume in Dry Standard Cubic Feet

$\mathrm{ACFM}=$ Actual Cubic Feet per Minute

DSCFM = Dry Standard Cubic Feet per Minute

$\mathrm{H}_{2} \mathrm{O}$, volume $\%=$ Stack gas percent water vapor

gr/DSCF $=$ Particulate concentration in grains per DSCF

$\mathrm{lbsihr}=$ Particulate emission rate

pCihr $=$ Pico Curies per hour emission rate

CALCULATIONS

wriDSCF $=0.01543 *$ Sample Wt. $/$ Sample Volume

lbsihr Emission Rate $=0.00857 *$ gri DSCF * DSCFM

pCihr $=$ pCi/DSCF * DSCEM * 60 
TABLE 9

RTS \#2 Waste Feed

LLNL Bldg. 292 MSO

GSS Filter Outlet \& Catalytic Converter Outlet

PARTICULATE\& RADIONUCLIDE EMISSIONS TEST RESULTS

\begin{tabular}{|l|c|c|c|c|c|}
\hline RUN \# & 1 & 2 & 3 & AVERAGE & Catalyst 1 \\
\hline TEST DATE & $8 / 26 / 98$ & $8 / 26 / 98$ & $8 / 26 / 98$ & & $08 / 26 / 98$ \\
\hline TEST TIME & $0910-1010$ & $1100-1200$ & $1245-1345$ & & $1040-1140$ \\
\hline SAMPLE VOLUME (DSCF) & 42.872 & 46.501 & 42.664 & & 33.371 \\
\hline ISOKINETIC (\%) & 103.1 & 99.9 & 101.2 & & 93.4 \\
\hline DUCT TEMP., ('F) & 308.4 & 327.4 & 335.3 & 323.7 & 390.8 \\
\hline VELOCITY (ft/sec) & 35.12 & 39.34 & 36.31 & 36.92 & 5.27 \\
\hline FLOW RATE (ACFM) & 21.1 & 23.6 & 21.8 & 22.2 & 27.5 \\
\hline FLOW RATE (DSCFM) & 13.3 & 14.9 & 13.5 & 13.9 & 16.8 \\
\hline H.O (volume \%) & 5.66 & 3.42 & 4.26 & 4.44 & 0.98 \\
\hline Gross Alpha (pCi/sample) & 0.00 & 0.33 & 2.12 & 0.82 & 0.20 \\
\hline Gross Beta (pCi/sample) & 0.00 & 0.15 & 0.00 & 0.05 & 0.00 \\
\hline Tritium (pCi/sample) & 198,764 & 177,266 & 188,680 & 188.237 & 11.260 \\
\hline F.H. Particulate Conc. (gr/DSCF) & $\mathbf{0 . 0 0 0 1 5}$ & $\mathbf{0 . 0 0 0 1 7}$ & $\mathbf{0 . 0 0 0 5 4}$ & $\mathbf{0 . 0 0 0 2 9}$ & $\mathbf{0 . 0 0 0 0 7}$ \\
\hline F.H. Particulate Emissions (Lbs/hr) & $\mathbf{0 . 0 0 0 0 1 7}$ & $\mathbf{0 . 0 0 0 0 2 2}$ & $\mathbf{0 . 0 0 0 0 6 3}$ & $\mathbf{0 . 0 0 0 0 3 4}$ & $\mathbf{0 . 0 0 0 0 1}$ \\
\hline Gross Alpha (pCi/DSCF) & 0.000 & 0.007 & 0.050 & 0.02 & 0.006 \\
\hline Gross Beta (pCi/DSCF) & 0.000 & 0.003 & 0.000 & 0.001 & 0.000 \\
\hline Tritium (pCi/DSCF) & 4636.17 & 3812.06 & 4422.41 & 4290.22 & 337.42 \\
\hline Tot. Alpha Emissions (pCi/hr) & $\mathbf{0 . 0 0 0}$ & $\mathbf{6 . 3 4 5}$ & $\mathbf{4 0 . 2 4 2}$ & $\mathbf{1 5 . 5 2 9}$ & $\mathbf{6 . 0 4}$ \\
\hline Tot. Beta Emissions (pCi/hr) & $\mathbf{0 . 0 0 0}$ & $\mathbf{2 . 8 8 4}$ & $\mathbf{0 . 0 0 0}$ & $\mathbf{0 . 9 6 1}$ & $\mathbf{0 . 0 0 0}$ \\
\hline Tot. Tritium Emissions (pCi/hr) & $\mathbf{3 , 7 0 3 , 7 5 9}$ & $\mathbf{3 , 4 0 8 , 4 7 2}$ & $\mathbf{3 , 5 8 1 , 5 1 5}$ & $\mathbf{3 , 5 6 4 , 5 8 2}$ & $\mathbf{3 4 0 , 1 2 4}$ \\
\hline
\end{tabular}

\section{WHERE}

DSCF $=$ Sample Volume in Dry Standard Cubic Feet

ACFM = Actual Cubic Feet per Minute

DSCFM $=$ Dry Standard Cubic Feet per Minute

$\mathrm{H}_{2} \mathrm{O}$, volume $\%=$ Stack gas percent water vapor

gr/DSCF $=$ Particulate concentration in grains per DSCF

$\mathrm{lbs} / \mathrm{hr}=$ Particulate emission rate

$\mathrm{pCi} / \mathrm{hr}=$ Pico Curies per hour emission rate

CALCULATIONS

gr/DSCF $=0.015+3 *$ Sample Wt. / Sample Volume

lbshr Emission Rate $=0.00857 *$ gr $r$ DSCF * DSCFM

$\mathrm{pCi} / \mathrm{hr}=\mathrm{pCi} / \mathrm{DSCF} *$ DSCFM $* 60$ 


\section{TABLE 10}

RTS \#1 Waste Feed

\section{LLNL BIdg. 292 MSO}

GSS Filter Outlet Method $0051 \mathrm{HCl}$ Test Results

\begin{tabular}{|l|c|c|c|c|}
\hline Test & Run 1 & Run 2 & Run 3 & AVERAGE \\
\hline Test Date & $8 / 19 / 98$ & $8 / 19 / 98$ & $8 / 19 / 98$ & \\
\hline Test Time & $0915-1015$ & $1025-1125$ & $1131-1231$ & \\
\hline Flow Rate (DSCFM) & 13.32 & 13.32 & 13.32 & 13.32 \\
\hline Sample Volume (DSCF) & 4.024 & 3.981 & 3.966 & 3.990 \\
\hline Sample Volume (DSCM) & 0.1139 & 0.1127 & 0.1123 & 0.1130 \\
\hline $\mathrm{HCl},($ total $\mu \mathrm{g})$ & $<8.00$ & $<8.00$ & $<8.00$ & $<8.00$ \\
\hline $\mathrm{HCl},(\mathrm{ppm})$ & $<0.046$ & $<0.047$ & $<0.047$ & $<0.047$ \\
\hline $\mathrm{HCl},(\mathrm{gm} / \mathrm{hr})$ & $<0.0016$ & $<0.0016$ & $<0.0016$ & $<0.0016$ \\
\hline
\end{tabular}

\section{WHERE:}

$\mathrm{HCl}=$ Hydrogen Chloride $\quad \mathrm{MW}=36.5$

DSCM = Dry Standard Cubic Meter

DSCF $=$ Dry Standard Cubic Foot

ppm $=$ Parts Per Million

$\mu g=$ microgram,$=.001 \mathrm{mg}$ (milligram)

$\mathrm{gm} / \mathrm{hr}=$ Grams per Hour Emission Rate

$<=$ Less Than the Reporting Limit

Std. Temperature, $\operatorname{Tstd}^{\circ} \mathrm{F}=68$

\section{CALCULATIONS:}

$\mathrm{ppm}=\mathrm{ug} /$ sample $^{*} 1.61 *($ Tstd +460$) /\left(\mathrm{MW}^{*} \mathrm{DSCF}^{*} 1000\right)$

$\mathrm{gm} / \mathrm{hr}=453.6 * \mathrm{ppm} * \mathrm{M} . \mathrm{W} .{ }^{*} \mathrm{DSCFM} * 8.223 \mathrm{E}-5 /(\mathrm{Tstd}+460)$ 


\section{TABLE 11}

RTS \#2 Waste Feed

LLNL Bldg. 292 MSO

GSS Filter Outlet

Method $0051 \mathrm{HCl}$ Test Results

\begin{tabular}{|l|c|c|c|c|}
\hline Test & Run 1 & Run 2 & Run 3 & AVERAGE \\
\hline Test Date & $8 / 26 / 98$ & $8 / 26 / 98$ & $8 / 26 / 98$ & \\
\hline Test Time & $1519-1619$ & $1637-1747$ & $1808-1908$ & \\
\hline Flow Rate (DSCFM) & 12.99 & 13.96 & 13.96 & 13.64 \\
\hline Sample Volume (DSCF) & 4.225 & 4.896 & 4.066 & 4.396 \\
\hline Sample Volume (DSCM) & 0.1196 & 0.1386 & 0.1151 & 0.1245 \\
\hline $\mathrm{HCl},($ total $\mu \mathrm{g})$ & $<8.00$ & $<8.00$ & $<8.00$ & $<8.00$ \\
\hline $\mathrm{HCl},(\mathrm{ppm})$ & $<0.044$ & $<0.038$ & $<0.046$ & $<0.043$ \\
\hline $\mathrm{HCl},(\mathrm{gm} / \mathrm{hr})$ & $<0.0015$ & $<0.0014$ & $<0.0016$ & $<0.0015$ \\
\hline
\end{tabular}

\section{WHERE:}

$\mathrm{HCl}=$ Hydrogen Chloride $\quad \mathrm{MW}=36.5$

DSCM $=$ Dry Standard Cubic Meter

DSCF $=$ Dry Standard Cubic Foot

$\mathrm{ppm}=$ Parts Per Million

$\mu \mathrm{g}=$ microgram, $=.001 \mathrm{mg}$ (milligram)

$\mathrm{gm} / \mathrm{hr}=$ Grams per Hour Emission Rate

$<=$ Less Than the Reporting Limit

Standard Temperature, $\operatorname{Tstd}^{\circ} \mathrm{F} \quad 68$

\section{CALCULATIONS:}

$\mathrm{ppm}=\mathrm{ug} /$ sample $* 1.61 *($ Tstd +460$) /\left(\mathrm{MW}^{*} \mathrm{DSCF}^{*} 1000\right)$

$\mathrm{gm} / \mathrm{hr}=453.6 *{ }^{*} \mathrm{ppm} * \mathrm{M} . \mathrm{W} .{ }^{*}$ DSCFM $* 8.223 \mathrm{E}-5 /(\mathrm{Tstd}+460)$ 


\section{APPENDICES}

APPENDIX A - CALCULATIONS \& NOMENCLATURE

APPENDIX B - LABORATORY REPORTS

APPENDIX C - FIELD DATA SHEETS

APPENDIX D- EQUIPMENT CALIBRATION RECORDS

APPENDIX E - PROCESS DATA

APPENDIX F - STACK DIAGRAMS

APPENDIX G - SAMPLING SYSTEM DIAGRAMS 


\section{APPENDIX A \\ CALCULATIONS \& NOMENCLATURE}

000048 



\section{Standard Abbreviations for Reports}

\begin{tabular}{|ll|ll|}
\hline Unit & Abbreviation & Unit & Abbreviation \\
billion & $\mathrm{G}$ & microgram & $\mu \mathrm{g}$ \\
Brake horsepower & $\mathrm{bhp}$ & milligram & $\mathrm{mg}$ \\
Brake horsepower hour & $\mathrm{bhp-hr}$ & milliliter & $\mathrm{ml}$ \\
British Thermal Unit & $\mathrm{Btu}$ & million & $\mathrm{MM}$ \\
capture efficiency & $\mathrm{CE}$ & minute & $\mathrm{min}$ \\
destruction efficiency & $\mathrm{DE}$ & Molecular Weight & $\mathrm{MW}$ \\
Dry Standard Cubic Feet & $\mathrm{DSCF}$ & nanogram & $\mathrm{ng}$ \\
Dry Standard Cubic Feet per Minute & $\mathrm{DSCFM}$ & Parts per Billion & $\mathrm{ppb}$ \\
Dry Standard Cubic Meter & $\mathrm{DSCM}$ & Parts per Million & $\mathrm{ppm}$ \\
Dry Standard Cubic Meter per Minute & $\mathrm{DSCMM}$ & pennyweight per firkin & $\mathrm{pw} / \mathrm{fkn}$ \\
grains per dry standard cubic foot & gr/DSCF & pound & $\mathrm{lb}$ \\
gram & $\mathrm{g}$ & pounds per hour & $\mathrm{lbs} / \mathrm{hr}$ \\
grams per Brake horsepower hour & $\mathrm{g} / \mathrm{bhp}-\mathrm{hr}$ & pounds per million Btu & $\mathrm{lbs} / \mathrm{MMBtu}$ \\
kilowatt & $\mathrm{kw}$ & second & $\mathrm{sec}$ \\
liter & $\mathrm{m}$ & thousand & $\mathrm{k}$ \\
Megawatts & $\mathrm{mw}$ & watt & $\mathrm{w}$ \\
meter & $\mathrm{m}$ & & \\
\hline
\end{tabular}

\section{Common Conversions / Calculations / Constants}

1 gram $=15.432$ grains

1 pound $=7000$ grains

grams per pound $=453.6$

$\mathrm{bhp}=\mathrm{kw} * 1.34$

2.59E-9 = Conversion factor for ppm to lbs/scf; EPA 40CFR60.45

dscf $/$ MMBTU $=8710$ for Natural gas; EPA Method 19

$\mathrm{Btu} / \mathrm{ft}^{3}=1040$ for Naural Gas; EPA Method 19

$\mathrm{lb} / \mathrm{hr}$ Part. Emission Rate $=0.00857^{*} \mathrm{gr} / \mathrm{dscf} * \mathrm{dscfm} ;$ EPA Method 5

$\mathrm{g} / \mathrm{bhp}-\mathrm{hr}=\mathrm{lbs} / \mathrm{hr} * 453.6 / \mathrm{bhp}$

$\mathrm{lbs} / \mathrm{hr}=\mathrm{ppm} / 385 \mathrm{E}^{6} \mathrm{x} \mathrm{dscfm} \times \mathrm{MW} * 60 ; \mathrm{CARB}$ Method 100

Correction to $12 \% \mathrm{CO}_{2}=$ gr/dscf * $12 \% /$ stack $\mathrm{CO}_{2} \%$; EPA Method 5

Correction to $3 \% \mathrm{O}_{2}=$ ppm $* 17.9 /\left(20.9-\right.$ stack $\left.\mathrm{O}_{2} \%\right)$; CARB Method 100

dscfm $=$ Gas Fd * MMBtu/min * 20.9/(20.9 - stack $\left.\mathrm{O}_{2} \%\right)$; EPA Method 19

$\mathrm{lb} / \mathrm{MMBtu}=\mathrm{Fd}^{*} \mathrm{MW}^{*} \mathrm{ppm}^{*} 2.59 \mathrm{E}-9 * 20.9 /\left(20.9-\right.$ stack $\left.\mathrm{O}_{2} \%\right) ;$ EPA Method 19

Standard Temperatures by District

$\begin{array}{llll}\text { EPA } & 68^{\circ} \mathrm{F} & \text { NSAPCD - Northern Sonoma } & 68^{\circ} \mathrm{F} \\ \text { CARB } & 68^{\circ} \mathrm{F} & \text { PCAPCD - Placer } & 68^{\circ} \mathrm{F} \\ \text { BAAQMD - Bay Area } & 70^{\circ} \mathrm{F} & \text { SLOCAPCD - San Luis Obispo } & 60^{\circ} \mathrm{F} \\ \text { SJVUAPCD - San Joaquin } & 60^{\circ} \mathrm{F} & \text { SMAPCD - Sacramento } & 59^{\circ} \mathrm{F} \rightarrow 68^{\circ} \mathrm{F} \\ \text { SCAQMD - South Coast } & 60^{\circ} \mathrm{F} & \text { SCAQMD - Shasta County } & 68^{\circ} \mathrm{F} \\ \text { MBUAPCD - Monterey Bay } & 60^{\circ} \mathrm{F} & \text { YSAPCD - Yolo-Solano } & 68^{\circ} \mathrm{F}\end{array}$




\section{EPA 23 EMISSION CALCULATIONS}

FACILITY:

UNIT:

LLNL Bldg. 292

DATE:

TIME:

CONDITION:

GSS Filter Inlet

TEST NO.:

$8 / 18 / 98$

$1016-1326$

l
METER BOX NO. PROBE NO.: NOZZLE NO:
LSI-2

N.A.

\begin{tabular}{|c|c|c|c|c|c|c|c|c|}
\hline Pitot Factor, & $\mathrm{C}_{\mathrm{p}}$ & 0.990 & Meter Temperature, & $T_{m}$ & 85.6 & Total $\mathrm{H}_{2} \mathrm{O}$ Condensed, & $V_{w}$ & 119.0 \\
\hline Barometric Pressure, & $P_{b}$ & 30.00 & Meter Pressure, & $\Delta \mathrm{H}$ & 1.70 & & & \\
\hline Static Pressure, & $P_{\text {stax }}$ & -11.50 & Average $\sqrt{\Delta P_{2}}$ & $\sqrt{\Delta P}$ & 0.441 & & & \\
\hline Stack Pressure, & $\mathrm{P}_{8}$ & 29.15 & Stack Area, & $A_{3}$ & 0.010 & & & \\
\hline Stack Temperature, & $T_{s}$ & 292.5 & Nozdle Diameter, & $D_{n}$ & 0.309 & Stack Gas $\mathrm{O}_{2}$ & $\%$ & 12.4 \\
\hline Sample Time, & $\Theta$ & 180.0 & Meter Factor, & $Y_{d}$ & 1.0089 & Stack Gas $\mathrm{CO}_{2}$ & $\%$ & 7.90 \\
\hline Std. Temperature, & $T_{\text {sdd }}$ & 68 & Sample Volume, & $\mathrm{V}_{\mathrm{m}}$ & 106.278 & Stack Gas $\mathrm{N}_{2}$ & $\%$ & 79.7 \\
\hline
\end{tabular}

A) Gas Volume $\left(\mathrm{V}_{\mathrm{m}}\right)_{\mathrm{sd}}=\left(\mathrm{T}_{\mathrm{zdd}}+460\right)^{*} \mathrm{~V}_{\mathrm{m}}{ }^{*} \mathrm{Y}_{\mathrm{d}} *\left(\mathrm{P}_{\mathrm{b}}+\Delta \mathrm{H} / 13.6\right) /\left(\left(\mathrm{T}_{\mathrm{m}}+460\right)^{*} 29.92\right)=$

104.476 DSCF

B) Volume $\mathrm{H}_{2} \mathrm{O}$ collected $\left(\mathrm{V}_{\mathrm{w}}\right)_{\mathrm{sd}}=8.9148 \mathrm{E}-5^{*}\left(\mathrm{~T}_{\mathrm{sed}}+460\right)^{*} \mathrm{~V}_{\mathrm{s}}=$

$5.601 \mathrm{SCF}$

C) Total Sample Volume $\left(V_{v_{s d}}=\left(V_{m}\right)_{s d}+\left(V_{w}\right)_{x d}=\right.$

110.077 SCF

D) Moisture Content $\left(\% \mathrm{H}_{2} \mathrm{O}\right)=100 *\left(\mathrm{~V}_{\mathrm{w}}\right)_{s \mathrm{~d}} /\left(\mathrm{V}_{\mathrm{Ldd}}=\right.$

$5.089 \%$

E) Stack Gas Velocity $\left(V_{s}\right)=85.49 C_{p} V(\Delta P)\left(T_{s}+460 / M W_{s} P_{s}\right)=$

$35.114 \mathrm{ft} / \mathrm{sec}$

F) Stack Gas Molecular Wt. $=\left(\left(\mathrm{CO}_{2} \% * 0.44+\mathrm{O}_{2} \% * 0.32+\mathrm{N}_{2} \% * 0.28\right)\left(1-\mathrm{H}_{2} \mathrm{O} \% / 100\right)\right)+18\left(\mathrm{H}_{2} \mathrm{O} \% / 100\right)=$

$29.162 \mathrm{~g} / \mathrm{g}$-mole

G) \% Isokinetic (I) $=9142.88\left(V_{t}\right)\left(T_{s}+460\right) /\left(\left(D_{n}^{2}\right)(\Theta)\left(P_{s}\right)\left(V_{s}\right)\left(T_{s d}+460\right)\right)=$

$81.52 \%$

H) $\quad A C F M=\left(V_{s}\right)\left(A_{s}\right) \times 60=$

21.07 ACFM

I) Stack Gas Vol. Flow Rate, DSCFM $=\left(\mathrm{V}_{s}\right)\left(\mathrm{A}_{s}\right)\left(\left(\mathrm{T}_{\mathrm{sud}}+460\right)\left(\mathrm{T}_{\mathrm{s}} \div 460\right)\right)\left(\mathrm{P}_{s}\right)\left(1-\% \mathrm{H}_{2} \mathrm{O} / 100\right)^{*} 2.005=$

13.67 DSCFM 


\section{EPA 23 EMISSION CALCULATIONS}

\begin{tabular}{|c|c|c|c|c|c|}
\hline FACILITY: & LLNL Bldg. 292 & DATE: & $8 / 18 / 98$ & METER BOX NO.: & $\underline{L S I}-2$ \\
\hline UNIT: & GSS Filter Inlet & TIME: & $1413-1707$ & PROBE NO.: & $\mathrm{N} . \mathrm{A}$. \\
\hline CONDITION: & RTS \#1 Waste Feed & TEST NO.: & 2 & NOZZLE NO:: & $5 \mathrm{E}$ \\
\hline
\end{tabular}

\begin{tabular}{|c|c|c|c|c|c|c|c|c|}
\hline Pitot Factor, & $C_{p}$ & 0.990 & Meter Temperature, & $T_{\mathrm{m}}$ & 88.7 & Total $\mathrm{H}_{2} \mathrm{O}$ Condensed, & $V_{w}$ & 132.0 \\
\hline Barometric Pressure, & $P_{b}$ & 30.00 & Meter Pressure, & $\Delta \mathrm{H}$ & 1.62 & & & \\
\hline Static Pressure, & $P_{\text {sax }}$ & -11.50 & Average $\sqrt{\Delta P}$., & $\sqrt{\Delta P}$ & 0.448 & & & \\
\hline Stack Pressure, & $\mathrm{P}_{\mathrm{s}}$ & 29.15 & Stack Area, & $A_{1}$ & 0.010 & & & \\
\hline Stack Temperature, & $T_{3}$ & 351.0 & Nozzle Diameter. & $\mathrm{D}_{\mathrm{n}}$ & 0.309 & Stack Gas $\mathrm{O}_{2}$ & $\%$ & 10.0 \\
\hline Sample Time, & $\Theta$ & 180.0 & Meter Factor, & $Y_{d}$ & 1.0089 & Stack Gas $\mathrm{CO}_{2}$ & $\%$ & 9.60 \\
\hline Std. Temperature, & $T_{\text {sdd }}$ & 68 & Sample Volume, & $V_{m}$ & 119.167 & Stack Gas $\mathrm{N}_{2}$ & $\%$ & 80.4 \\
\hline
\end{tabular}
A) Gas Volume $\left(V_{m}\right)_{s t d}-\left(T_{\text {std }}{ }^{1460}\right)^{*} V_{m} * Y_{d}^{*}\left(P_{b}+\Delta H / 13.6\right) /\left(\left(T_{m}+460\right) * 29.92\right)=$
116.462 DSCF
B) Volume $\mathrm{H}_{2} \mathrm{O}$ collected $\left(\mathrm{V}_{\mathrm{w}}\right)_{\text {sdd }}=8.9148 \mathrm{E}-5 *\left(\mathrm{~T}_{\mathrm{sd}}+460\right) * \mathrm{~V}_{\mathrm{w}}=$
$6.213 \mathrm{SCF}$
C) Total Sample Volume $\left(V_{\nu_{s d}}=\left(V_{m}\right)_{s d}+\left(V_{w}\right)_{s e d}=\right.$
$122.675 \mathrm{SCF}$
D) Moisture Content $\left(\% \mathrm{H}_{2} \mathrm{O}\right)=100 *\left(\mathrm{~V}_{\mathrm{w}}\right)_{\text {sed }} /\left(\mathrm{V}_{\mathrm{s}}\right)_{\text {sd }}=$
$5.065 \%$
E) Stack Gas Velocity $(\mathrm{Vs})=85.49 \mathrm{C}_{\mathrm{p}} \sqrt{ }(\Delta \mathrm{P})\left(\mathrm{T}_{\mathrm{s}}+460 / \mathrm{MW}_{\mathrm{s}} \mathrm{P}_{\mathrm{s}}\right)=$
$36.925 \mathrm{ft} / \mathrm{sec}$
I) Stack Gas Molecular Wt. $=\left(\left(\mathrm{CO}_{2} \% * 0.44+\mathrm{O}_{2} \% * 0.32+\mathrm{N}_{2} \% * 0.28\right)\left(1-\mathrm{H}_{2} \mathrm{O} \% / 100\right)\right)+18\left(\mathrm{H}_{2} \mathrm{O} \%\right.$ \% 100$)=$
$29.331 \mathrm{~g} / \mathrm{g}$-mole
G) \% Isokinetic $(\mathrm{I})=9142.88\left(\mathrm{~V}_{\mathrm{V}}\right)\left(\mathrm{T}_{\mathrm{s}}+460\right) /\left(\left(\mathrm{D}_{\mathrm{II}}{ }^{2}\right)(\Theta)\left(\mathrm{P}_{\mathrm{s}}\right)\left(\mathrm{V}_{\mathrm{s}}\right)\left(\mathrm{T}_{\mathrm{stul}}+460\right)\right)=$
$93.11 \%$
H) $\mathrm{ACFM}=\left(\mathrm{V}_{s}\right)\left(A_{s}\right) \times 60=$
22.15 ACFM
1) Stack Gas Vol. Flow Rate, DSCFM $=\left(\mathrm{V}_{\mathrm{s}}\right)\left(\mathrm{A}_{\mathrm{s}}\right)\left(\left(\mathrm{T}_{\mathrm{sd}}+460\right) /\left(\mathrm{T}_{\mathrm{s}}+460\right)\right)\left(\mathrm{P}_{\mathrm{s}}\right)\left(1-\% \mathrm{H}_{2} \mathrm{O} / 100\right) * 2.005=$
13.34 DSCFM 
EPA 23 EMISSION CALCULATIONS

\begin{tabular}{|c|c|c|c|c|c|}
\hline FACILITY: & LLNL Bldg. 292 & DATE: & $8 / 19 / 98$ & METER BOX NO.: & LSI-2 \\
\hline UNIT: & GSS Filter Inlet & TIME: & $0918-1308$ & PROBE NO: & N.A. \\
\hline CONDITION: & RTS \#1 Waste Feed & TEST NO: & 3 & NOZZLE NO.: & $S E$ \\
\hline
\end{tabular}

\begin{tabular}{|c|c|c|c|c|c|c|c|c|}
\hline Pitot Factor, & $\mathrm{C}_{\mathrm{p}}$ & 0.990 & Meter Temperature, & $\overline{T_{\mathrm{m}}}$ & 81.4 & Total $\mathrm{H}_{2} \mathrm{O}$ Condensed, & $\overline{V_{w}}$ & 112.5 \\
\hline Barometric Pressure, & $\mathrm{P}_{\mathrm{b}}$ & 29.90 & Meter Pressure, & $\Delta H$ & 1.86 & & & \\
\hline Static Pressure, & $P_{\text {stax }}$ & -11.50 & Average $\sqrt{\Delta P}$, & $\sqrt{\Delta P}$ & 0.437 & & & \\
\hline Stack Pressure, & $P_{s}$ & 29.05 & Stack Area, & $\mathrm{A}_{8}$ & 0.010 & & & \\
\hline Stack Temperature, & $T_{s}$ & 317.9 & Nozzle Diameter, & $\mathrm{D}_{\mathrm{n}}$ & 0.309 & Stack Gas $\mathrm{O}_{2}$ & $\%$ & 9.34 \\
\hline Sample Time, & $\Theta$ & 180.0 & Meter Factor, & $Y_{d}$ & 1.0089 & Stack Gas $\mathrm{CO}_{2}$ & $\%$ & 10.15 \\
\hline Std. Temperature, & $T_{\text {sdd }}$ & 68 & Sample Volume, & $\mathrm{V}_{\mathrm{m}}$ & 114.898 & Stack Gas $\mathrm{N}_{2}$ & $\%$ & 80.5 \\
\hline
\end{tabular}
A) Gas Volume $\left(V_{m}\right)_{\text {sed }}=\left(T_{x d d}+460\right) * V_{m} * Y_{d} *\left(P_{b}+\Delta H / 13.6\right)\left(\left(T_{m}+460\right) * 29.92\right)=$
113.493 DSCF
B) Volume $\mathrm{H}_{2} \mathrm{O}$ collected $\left(\mathrm{V}_{\mathrm{w}}\right)_{\mathrm{sdd}}=8.9148 \mathrm{E}-5^{*}\left(\mathrm{~T}_{\mathrm{sdd}}+460\right)^{*} \mathrm{~V}_{\mathrm{w}}=$
$5.295 \mathrm{SCF}$
C) Total Sample Volume $\left(V_{D_{\text {sd }}}=\left(\mathrm{V}_{\mathrm{m}}\right)_{\mathrm{sdd}}+\left(\mathrm{V}_{\mathrm{w}}\right)_{\mathrm{gdd}}=\ldots\right.$
$118.788 \mathrm{SCF}$
D) Moisture Content $\left(\% \mathrm{H}_{2} \mathrm{O}\right)=100 *\left(\mathrm{~V}_{\mathrm{w}}\right)_{\text {sdd }} /(\mathrm{V})_{\text {std }}=$
$4.458 \%$
E) Stack Gas Velocity $(\mathrm{Vs})=85.49 \mathrm{C}_{\mathrm{p}} \sqrt{ }(\Delta \mathrm{P})\left(\mathrm{T}_{\mathrm{s}}+460 / \mathrm{MW}_{3} \mathrm{P}_{\mathrm{s}}\right)=$
$35.257 \mathrm{ft} / \mathrm{sec}$
F) Stack Gas Molccular Wt. $=\left(\left(\mathrm{CO}_{2} \% * 0.44+\mathrm{O}_{2} \% * 0.32+\mathrm{N}_{2} \% * 0.28\right)\left(1-\mathrm{H}_{2} \mathrm{O} \% / 100\right)\right)+18\left(\mathrm{H}_{2} \mathrm{O} \% / 100\right)=$
$29.463 \mathrm{~g} / \mathrm{g}$-mole
G) \% Isokinetic $(I)=9142.88\left(V_{\nu}\right)\left(T_{3}+460\right) /\left(\left(D_{n}^{2}\right)(\Theta)\left(P_{3}\right)\left(V_{s}\right)\left(T_{s d}+460\right)\right)=$
$90.89 \%$
H) $\mathrm{ACFM}=\left(\mathrm{V}_{\mathrm{s}}\right)\left(\mathrm{A}_{\mathrm{s}}\right) \times 60=$
21.15 ACFM
I) Stack Gas Vol. Flow Rate, DSCFM $=\left(\mathrm{V}_{3}\right)\left(\mathrm{A}_{3}\right)\left(\left(\mathrm{T}_{\mathrm{std}}+460\right) /\left(\mathrm{T}_{3}+460\right)\right)\left(\mathrm{P}_{3}\right)\left(1-\% \mathrm{H}_{2} \mathrm{O} / 100\right)^{*} 2.005=$
13.32 DSCFM 


\section{EPA 23 EMISSION CALCULATIONS}

FACILITY:

UNIT:

LLNL Bldg 292

DATE:

Catalyst Outlet

TIME:

RTS \#1 Waste Feed TFST NO.

\section{$8 / 18 / 98$}

$1428-1726$

1
METER BOX NO:

PROBE NO.:

NOZZLE NO:
LSI-I

N.A.

\begin{tabular}{|c|c|c|c|c|c|c|c|c|}
\hline Pitot Factor, & $\mathrm{C}_{p}$ & 0.990 & Meter Temperature, & $T_{m}$ & 104.4 & Total $\mathrm{H}_{2} \mathrm{O}$ Condensed, & $\mathrm{V}_{\mathrm{W}}$ & 80.0 \\
\hline Barometric Pressure, & $P_{b}$ & 29.90 & Meter Pressure, & $\Delta \mathrm{H}$ & 3.00 & & & \\
\hline Static Pressure, & $P_{\text {stat }}$ & -2.50 & Average $\sqrt{\Delta \mathrm{P}}$, & $\sqrt{\Delta P}$ & 0.063 & & & \\
\hline Stack Pressure, & $P_{s}$ & 29.72 & Stack Area, & $A_{s}$ & 0.087 & & & \\
\hline Stack Temperature, & $T_{s}$ & 390.0 & Nozzle Diameter, & $D_{n}$ & 0.971 & Stack Gas $\mathrm{O}_{2}$ & $\%$ & 8.8 \\
\hline Sample Time, & $\Theta$ & 180.0 & Meter Factor, & $Y_{d}$ & 1.0039 & Stack Gas $\mathrm{CO}_{2}$ & $\%$ & 10.50 \\
\hline Std. Temperature, & $\mathrm{T}_{\text {std }}$ & 68 & Sample Volume, & $\mathrm{V}_{\mathrm{m}}$ & 160.435 & Stack Gas $\mathrm{N}_{2}$ & $\%$ & 80.7 \\
\hline
\end{tabular}
A) Gas Volume $\left(V_{m}\right)_{s t d}=\left(T_{s t d}+460\right)^{*} V_{m} * Y_{d} *\left(P_{b}+\Delta H / 13.6\right)\left(\left(T_{m s}+460\right) * 29.92\right)=$
B) Volume $\mathrm{H}_{2} \mathrm{O}$ collected $\left(\mathrm{V}_{\mathrm{w}}\right)_{\text {std }}=8.9148 \mathrm{E}-5^{*}\left(\mathrm{~T}_{\mathrm{std}}+460\right)^{*} \mathrm{~V}_{\mathrm{w}}=$
C) Total Sample Volume $\left(V_{t}\right)_{s t d}=\left(V_{m}\right)_{s t d}+\left(V_{w}\right)_{s t d}=$
D) Moisture Content $\left(\% \mathrm{H}_{2} \mathrm{O}\right)=100 *\left(\mathrm{~V}_{\mathrm{w}}\right)_{\text {std }} /\left(\mathrm{V}_{\mathrm{t}}\right)_{\mathrm{std}}=$
E) Stack Gas Velocity $(\mathrm{Vs})=85.49 \mathrm{C}_{\mathrm{p}} \sqrt{ }(\Delta \mathrm{P})\left(\mathrm{T}_{s}+460 / \mathrm{MW}_{s} \mathrm{P}_{s}\right)=$
F) Stack Gas Molecular Wt. $=\left(\left(\mathrm{CO}_{2} \% * 0.44+\mathrm{O}_{2} \% * 0.32+\mathrm{N}_{2} \% * 0.28\right)\left(1-\mathrm{H}_{2} \mathrm{O} \% / 100\right)\right)+18\left(\mathrm{H}_{2} \mathrm{O} \% / 100\right)=$
G) \% Isokinetic $(\mathrm{I})=9142.88\left(\mathrm{~V}_{\mathrm{t}}\right)\left(\mathrm{T}_{\mathrm{s}}+460\right) /\left(\left(\mathrm{D}_{\mathrm{n}}^{2}\right)(\Theta)\left(\mathrm{P}_{\mathrm{s}}\right)\left(\mathrm{V}_{\mathrm{s}}\right)\left(\mathrm{T}_{\mathrm{std}}+460\right)\right)=$
H) $\mathrm{ACFM}=\left(\mathrm{V}_{5}\right)\left(\mathrm{A}_{3}\right) \times 60=$
I) Stack Gas Vol. Flow Rate, DSCFM $=\left(\mathrm{V}_{s}\right)\left(\mathrm{A}_{3}\right)\left(\left(\mathrm{T}_{s t d}+460\right)\left(\mathrm{T}_{s}+460\right)\right)\left(\mathrm{P}_{5}\right)\left(1-\% \mathrm{H}_{2} \mathrm{O} / 100\right) * 2.005=$

$151.684 \mathrm{DSCF}$

$3.766 \mathrm{SCF}$

155.449 SCF

$2.422 \%$

$5.246 \mathrm{ft} / \mathrm{sec}$

$29.741 \mathrm{~g} / \mathrm{g}-\mathrm{mole}$

$86.49 \%$

27.38 ACFM

16.48 DSCFM 


\section{EPA 23 EMISSION CALCULATIONS}

\begin{tabular}{|c|c|c|c|c|c|}
\hline FACILITY: & LLNL Bldg. 292 & DATE: & $8 / 26 / 98$ & METER BOX NO.: & LSI-2 \\
\hline UNIT: & GSS Filter Inlet & TIME: & $0903-1216$ & PROBE NO.: & N.A. \\
\hline CONDITION: & RTSH2 Waste Feed & TEST NO.: & 1 & NOZZLE NO:: & $\overline{\mathrm{Q} 5 \mathrm{~A}}$ \\
\hline
\end{tabular}

\begin{tabular}{|c|c|c|c|c|c|c|c|c|}
\hline Pitot Factor, & $\mathrm{C}_{\mathrm{p}}$ & 0.990 & Meter Temperature, & $\mathrm{T}_{\text {m }}$ & 84.4 & Total $\mathrm{H}_{2} \mathrm{O}$ Condensed, & $V_{w}$ & 112.5 \\
\hline Barometric Pressure, & $\mathrm{P}_{\mathrm{b}}$ & 29.90 & Meter Pressure, & $\Delta H$ & 2.77 & & & \\
\hline Static Pressure, & $P_{\text {sxt }}$ & -10.00 & Average $\sqrt{\Delta P}$. & $\sqrt{\Delta P}$ & 0.466 & & & \\
\hline Stack Pressure, & $\mathrm{P}=$ & 29.16 & Stack Area & $A_{z}$ & 0.010 & & & \\
\hline Stack Temperature, & $T_{s}$ & 320.6 & Nozzle Diameter, & $D_{\mathrm{a}}$ & 0.326 & Stack Gas $\mathrm{O}_{2}$ & $\%$ & 10.36 \\
\hline Sample Time, & $\Theta$ & 180.0 & Meter Factor, & $Y_{d}$ & 1.0089 & Stack Gas $\mathrm{CO}_{2}$ & $\%$ & 7.46 \\
\hline Std. Temperature, & $\mathrm{T}_{\text {sdd }}$ & 68 & Sample Volume, & $\mathrm{V}_{\mathrm{m}}$ & 160.670 & Stack Gas $N_{2}$ & $\%$ & 82.2 \\
\hline
\end{tabular}

A) Gas Volume $\left(\mathrm{V}_{\mathrm{m}}\right)_{\mathrm{sdd}}=\left(\mathrm{T}_{\mathrm{sd}}+460\right)^{*} \mathrm{~V}_{\mathrm{m}} * \mathrm{Y}_{\mathrm{d}} *\left(\mathrm{P}_{\mathrm{b}}+\Delta H / 13.6\right) /\left(\left(\mathrm{T}_{\mathrm{m}}+460\right) * 29.92\right)=$

158.170 DSCF

B) Volume $\mathrm{H}_{2} \mathrm{O}$ collected $\left(\mathrm{V}_{\mathrm{w}}\right)_{\mathrm{sd}}=8.9148 \mathrm{E}-5^{*}\left(\mathrm{~T}_{\mathrm{sd}}+460\right)^{*} \mathrm{~V}_{\mathrm{w}}=$ $5.295 \mathrm{SCF}$

C) Total Sample Volume $\left(V_{L}\right)_{s d}=\left(V_{m}\right)_{s d}+\left(V_{w}\right)_{s d}=$

$163.466 \mathrm{SCF}$

D) Moisture Content $\left(\% \mathrm{H}_{2} \mathrm{O}\right)=100 *\left(\mathrm{~V}_{\mathrm{w}}\right)_{\mathrm{sdd}} /(\mathrm{V})_{\mathrm{sdd}}=$

$3.239 \%$

E) Stack Gas Velocity $(\mathrm{Vs})=85.49 \cdot \mathrm{C}_{\mathrm{p}} \sqrt{ }(\Delta \mathrm{P})\left(\mathrm{T}_{\mathrm{s}}+460 / \mathrm{MW}_{\mathrm{s}} \mathrm{P}_{\mathrm{s}}\right)=$

$37.739 \mathrm{ft}$ 'sec

F) Stack Gas Molecular Wt. $=\left(\left(\mathrm{CO}_{2} \% * 0.44+\mathrm{O}_{2} \% * 0.32+\mathrm{N}_{2} \% * 0.28\right)\left(1-\mathrm{H}_{2} \mathrm{O} \% / 100\right)\right)+18\left(\mathrm{H}_{2} \mathrm{O} \% / 100\right)=$

$29.232 \mathrm{~g} \mathrm{~g}-\mathrm{mole}$

G) \% Isokinetic $(\mathrm{I})=9142.88\left(\mathrm{~V}_{2}\right)\left(\mathrm{T}_{\mathrm{s}}+460\right)\left(\left(\mathrm{D}_{\mathrm{n}}{ }^{2}\right)(\Theta)\left(\mathrm{P}_{\mathrm{s}}\right)\left(\mathrm{V}_{\mathrm{s}}\right)\left(\mathrm{T}_{\mathrm{sd}}+460\right)\right)=$

$104.94 \%$

H) $\mathrm{ACFM}=\left(\mathrm{V}_{\mathrm{s}}\right)\left(\mathrm{A}_{\mathrm{s}}\right) \times 60=$

22.64 ACFM

D) Stack Gas Vol. Flow Rate, DSCFM $\left.=\left(\mathrm{V}_{\mathrm{s}}\right)\left(\mathrm{A}_{5}\right)\left(\mathrm{T}_{\mathrm{sdd}}+460\right) /\left(\mathrm{T}_{\mathrm{s}}+460\right)\right)\left(\mathrm{P}_{\mathrm{s}}\right)\left(1-\% \mathrm{H}_{2} \mathrm{O} / 100\right)^{\star} 2.005=$

14.45 DSCFM 


\section{EPA 23 EMISSION CALCULATIONS}

\begin{tabular}{|c|c|c|c|c|c|c|c|}
\hline FACILITY: & LL.NL Bldg. 292 & DATE: & $8 / 26 / 98$ & & METER BOX NO:: & LSI-2 & \\
\hline UNIT: & GSS Filter Indet & TIME: & $1309-1616$ & & PROBE NO: & N.A. & \\
\hline CONDITION: & RTS $\# 2$ Waste Feed & TEST NO:: & 2 & & NOZZLE NO:: & $5 \mathrm{~B}$ & \\
\hline Pitot Factor, & 0.990 & Meter Temperature, & $T_{m}$ & 86.4 & Total $\mathrm{H}_{2} \mathrm{O}$ Condensed, & $V_{w}$ & 154.0 \\
\hline Barometric Pressure, & 29.90 & Meter Pressure, & $\Delta \mathrm{H}$ & 1.97 & & & \\
\hline Static Pressure, & -10.00 & Average $\sqrt{\Delta} \mathrm{P}$. , & $\sqrt{\Delta P}$ & 0.432 & & & \\
\hline Stack Pressure, & 29.16 & Stack Area, & $A_{s}$ & 0.010 & & & \\
\hline Stack Temperature. & 340.5 & Nozzle Diameter, & $D_{n}$ & 0.304 & Stack Gas $\mathrm{O}_{2}$ & $\%$ & 10.0 \\
\hline Sample Time, & 180.0 & Meter Factor, & $Y_{d}$ & 1.0089 & Stack Gas $\mathrm{CO}_{2}$ & $\%$ & 7.30 \\
\hline Std. Temperature, & $T_{\text {sd }}$ & Sample Volume, & $\mathrm{V}_{\mathrm{m}}$ & 128.801 & Stack Gas $N_{2}$ & $\%$ & 82.7 \\
\hline
\end{tabular}
A) Gas Volume $\left(V_{m}\right)_{\text {sd }}=\left(T_{\text {sdd }}+460\right) * V_{m} * Y_{d}^{*}\left(P_{b}+\Delta H / 13.6\right) /\left(\left(T_{m}+460\right) * 29.92\right)=$
126.098 DSCF
B) Volume $\mathrm{H}_{2} \mathrm{O}$ collected $\left(\mathrm{V}_{\mathrm{w}}\right)_{\mathrm{sdd}}=8.9148 \mathrm{E}-5^{*}\left(\mathrm{~T}_{\mathrm{std}}+460\right)^{*} \mathrm{~V}_{\mathrm{w}}=$
$7.249 \mathrm{SCF}$
C) Total Sample Volume $\left(V_{s t d}=\left(V_{m}\right)_{s d}+\left(V_{w}\right)_{s t d}=\right.$
133.346 SCF
D) Moisture Content $\left(\% \mathrm{H}_{2} \mathrm{O}\right)=100 *\left(\mathrm{~V}_{\mathrm{w}}\right)_{\text {std }} /\left(\mathrm{V}_{\mathrm{tsd}}=\right.$
$5.436 \%$
E) Stack Gas Velocity $(\mathrm{Vs})=85.49 \mathrm{C}_{\mathrm{p}} \sqrt{ }(\Delta \mathrm{P})\left(\mathrm{T}_{\mathrm{s}}+460 / \mathrm{MN} \mathrm{W}_{\mathrm{s}} \mathrm{P}_{\mathrm{s}}\right)=$
$35.608 \mathrm{ft} / \mathrm{sec}$
F) Stack Gas Molecular Wt. $=\left(\left(\mathrm{CO}_{2} \% * 0.44+\mathrm{O}_{2} \% * 0.32+\mathrm{N}_{2} \% * 0.28\right)\left(1-\mathrm{H}_{2} \mathrm{O} \% / 100\right)\right)+18\left(\mathrm{H}_{2} \mathrm{O} \% / 100\right)=$
28.939 g'g-mole
G) \% Isokinetic $(\mathrm{I})=9142.88\left(\mathrm{~V}_{\mathrm{U}}\right)\left(\mathrm{T}_{\mathrm{s}}+460\right) /\left(\left(\mathrm{D}_{\mathrm{n}}{ }^{2}\right)(\Theta)\left(\mathrm{P}_{\mathrm{s}}\right)\left(\mathrm{V}_{\mathrm{s}}\right)\left(\mathrm{T}_{\mathrm{sd}}+460\right)\right)=$
$107.00 \%$
H) $\quad \mathrm{ACFM}=\left(\mathrm{V}_{\mathrm{s}}\right)\left(\mathrm{A}_{\mathrm{s}}\right) \times 60=$
21.36 ACFM
I) Stack Gas Vol. Flow Rate, DSCFM $=\left(\mathrm{V}_{\mathrm{s}}\right)\left(\mathrm{A}_{\mathrm{s}}\right)\left(\left(\mathrm{T}_{\mathrm{std}}+460\right) /\left(\mathrm{T}_{\mathrm{s}}+460\right)\right)\left(\mathrm{P}_{\mathrm{s}}\right)\left(1-\% \mathrm{H}_{2} \mathrm{O} / 100\right) * 2.005=$
12.99 DSCFM 
ON

FACILITY:

UNIT:

CONDITION:

\section{EPA 23 EMISSION CALCULATIONS}

\begin{tabular}{|c|c|c|c|c|c|c|c|c|}
\hline Pitor Factor, & $\overline{C_{p}}$ & 0.990 & Meter Temperature, & $T_{m}$ & 84.1 & Total $\mathrm{H}_{2} \mathrm{O}$ Condensed, & $V_{w}$ & 136.0 \\
\hline Barometric Pressure, & $\mathrm{P}_{\mathrm{b}}$ & 29.90 & Meter Pressure, & $\Delta \mathrm{H}$ & 1.93 & & & \\
\hline Static Pressurc, & $P_{s x t}$ & -10.00 & Average $\sqrt{\Delta P_{\text {, }}}$ & $\sqrt{\Delta P}$ & 0.450 & & & \\
\hline Stack Pressure, & $P_{s}$ & 29.16 & Stack Area, & $A_{4}$ & 0.010 & & & \\
\hline Stack Temperature, & $T_{\mathrm{I}}$ & 292.1 & Nozzle Diameter, & $\mathrm{D}_{\mathrm{n}}$ & 0.304 & Stack Gas $\mathrm{O}_{2}$ & $\%$ & 10.01 \\
\hline Sample Time, & $\Theta$ & 180.0 & Meter Factor, & $Y_{d}$ & 1.0089 & Stack Gas $\mathrm{CO}_{2}$ & $\%$ & 7.29 \\
\hline Std. Temperature, & $T_{\text {sad }}$ & 68 & Sample Volume, & $\mathrm{V}_{\mathrm{m}}$ & 114.124 & Stack Gas $\mathrm{N}_{2}$ & $\%$ & 82.7 \\
\hline
\end{tabular}

A) Gas Volume $\left(\mathrm{V}_{\mathrm{m}}\right)_{\mathrm{sdd}}=\left(\mathrm{T}_{\mathrm{sd}}+460\right)^{*} \mathrm{~V}_{\mathrm{m}} * \mathrm{Y}_{\mathrm{d}}^{*}\left(\mathrm{P}_{\mathrm{b}}+\Delta \mathrm{H} / 13.6\right)\left(\left(\mathrm{T}_{\mathrm{m}}+460\right) * 29.92\right)=$

112.188 DSCF

B) Volume $\mathrm{H}_{2} \mathrm{O}$ collected $\left(\mathrm{V}_{\mathrm{w}}\right)_{\mathrm{sdd}}=8.9148 \mathrm{E}-5 *\left(\mathrm{~T}_{* d}+460\right) * \mathrm{~V}_{\mathrm{w}}=$

$6.402 \mathrm{SCF}$

C) Total Sample Volume $\left(V_{v_{s t d}}=\left(V_{m}\right)_{s d}+\left(V_{w}\right)_{x d d}=\right.$

$118.589 \mathrm{SCF}$

D) Moisture Content $\left(\% \mathrm{H}_{2} \mathrm{O}\right)=100 *\left(\mathrm{~V}_{w}\right)_{\text {ad }} /\left(\mathrm{V}_{\text {sed }}=\right.$

$5.398 \%$

E) Stack Gas Velocity $(\mathrm{Vs})=85.49 \mathrm{C}_{\mathrm{p}} \sqrt{ }(\Delta \mathrm{P})\left(\mathrm{T}_{\mathrm{s}}+460 / \mathrm{MW}_{\mathrm{s}} \mathrm{P}_{\mathrm{s}}\right)=$

$35.950 \mathrm{f} / \mathrm{sec}$

F) Stack Gas Molecular Wt. $=\left(\left(\mathrm{CO}_{2} \% * 0.44+\mathrm{O}_{2} \% * 0.32+\mathrm{N}_{2} \% * 0.28\right)\left(1-\mathrm{H}_{2} \mathrm{O} \% 1100\right)\right)+18\left(\mathrm{H}_{2} \mathrm{O} \% / 100\right)=$

$28.942 \mathrm{~g} / \mathrm{g}$-mole

G) \% isokinetic $(\mathrm{I})=9142.88\left(V_{v}\right)\left(T_{s}+460\right) /\left(\left(D_{n}^{2}\right)(\Theta)\left(P_{3}\right)\left(V_{s}\right)\left(T_{s d d}+460\right)\right)=$

$88.55 \%$

H) $A C F M=\left(V_{s}\right)\left(A_{s}\right) \times 60=$

21.57 ACFM

I) Stack Gas Vol. Flow Rate, DSCFM $\left.=\left(\mathrm{V}_{s}\right)\left(\mathrm{A}_{s}\right)\left(\mathrm{T}_{s d}+460\right) /\left(\mathrm{T}_{\mathrm{s}}+460\right)\right)\left(\mathrm{P}_{3}\right)\left(1-\% \mathrm{H}_{2} \mathrm{O} / 100\right)^{* 2.005}=$
13.96 DSCFM 


\section{EPA 23 EMISSION CALCULATIONS}

FACILITY:

UNIT:

LLNL Bldg. 292

Catalyst Outlet

RTS \#2 Waste Feed TEST NO:
$8 / 26 / 98$

$1210-1510$

1
METER BOX NO: PROBE NO: NOZZLE NO.:
LSI-1

N.A.

1

\begin{tabular}{|c|c|c|c|c|c|c|c|c|}
\hline Pitot Factor, & $\mathrm{C}_{\mathrm{p}}$ & 0.990 & Meter Temperature, & $\mathrm{T}_{\mathrm{m}}$ & 108.6 & Total $\mathrm{H}_{2} \mathrm{O}$ Condensed, & $\overline{V_{w}}$ & 123.0 \\
\hline Barometric Pressure, & $P_{b}$ & 29.99 & Meter Pressure, & $\Delta \mathrm{H}$ & 3.00 & & & \\
\hline Static Pressure, & $P_{\text {sat }}$ & -2.50 & Average $\sqrt{\Delta P}$. & $\sqrt{\Delta P}$ & 0.063 & & & \\
\hline Stack Pressure, & $\mathrm{P}_{\mathrm{s}}$ & 29.81 & Stack Area, & $A_{s}$ & 0.087 & & & \\
\hline Stack Temperature, & $T_{3}$ & 390.0 & Nozzle Diameter, & $D_{n}$ & 0.971 & Stack Gas $\mathrm{O}_{3}$ & $\%$ & 8.8 \\
\hline Sample Time, & $\Theta$ & 180.0 & Meter Factor, & $\overline{Y_{d}}$ & 1.0039 & Stack Gas $\mathrm{CO}_{2}$ & $\%$ & 10.50 \\
\hline Std. Temperature, & $T_{\text {std }}$ & 68 & Sample Volume, & $\mathrm{V}_{\mathrm{m}}$ & 141.126 & Stack Gas $N_{2}$ & $\%$ & 80.7 \\
\hline
\end{tabular}
A) Gas Volume $\left(V_{m}\right)_{s t d}=\left(T_{s t o}+460\right) * V_{m} * Y_{d}^{*}\left(P_{b}+\Delta H / 13.6\right) /\left(\left(T_{m}+460\right) * 29.92\right)=$
132.838 DSCF
B) ... Volume $\mathrm{H}_{2} \mathrm{O}$ collected $\left(\mathrm{V}_{\mathrm{w}}\right)_{\text {std }}=8.9148 \mathrm{E}-5^{*}\left(\mathrm{~T}_{\mathrm{std}}+460\right)^{*} \mathrm{~V}_{\mathrm{w}}=$
$5.790 \mathrm{SCF}$
C) Total Sample Volume $\left(\mathrm{V}_{\mathrm{t}}\right)_{\text {std }}=\left(\mathrm{V}_{\mathrm{m}}\right)_{\mathrm{sta}}+\left(\mathrm{V}_{\mathrm{w}}\right)_{\text {std }}=$
138.628 SCF
D) Moisture Content $\left(\% \mathrm{H}_{2} \mathrm{O}\right)=100 *\left(\mathrm{~V}_{\mathrm{w}}\right)_{\text {std }} /\left(\mathrm{V}_{\mathrm{t}}\right)_{\mathrm{sd}}=$
$4.176 \%$
E) Stack Gas Velocity $(\mathrm{Vs})=85.49 \mathrm{C}_{\mathrm{p}} \sqrt{ }(\Delta \mathrm{P})\left(\mathrm{T}_{\mathrm{s}}+460 / \mathrm{MW}_{\mathrm{s}} \mathrm{P}_{\mathrm{s}}\right)=$
$5.256 \mathrm{ft} / \mathrm{sec}$
F) Stack Gas Molecular Wt. $=\left(\left(\mathrm{CO}_{2} \% * 0.44+\mathrm{O}_{2} \% * 0.32+\mathrm{N}_{2} \% * 0.28\right)\left(1-\mathrm{H}_{2} \mathrm{O} \% / 100\right)\right)+18\left(\mathrm{H}_{2} \mathrm{O} \% / 100\right)=$
$29.529 \mathrm{~g} / \mathrm{g}-\mathrm{mole}$
G) \% Isokinetic $(I)=9142.88\left(\mathrm{~V}_{t}\right)\left(T_{s}+460\right) /\left(\left(D_{n}^{2}\right)(\odot)\left(P_{s}\right)\left(V_{s}\right)\left(T_{s t d}+460\right)\right)=$
$76.74 \%$
H) $\mathrm{ACFM}=\left(\mathrm{V}_{s}\right)\left(\mathrm{A}_{s}\right) \times 60=$
27.44 ACFM
I) Stack Gas Vol. Flow Rate, DSCFM $\left.=\left(\mathrm{V}_{s}\right)\left(\mathrm{A}_{s}\right)\left(\mathrm{T}_{\mathrm{std}}+460\right)\left(\mathrm{T}_{\mathrm{s}}+460\right)\right)\left(\mathrm{P}_{3}\right)\left(1-\% \mathrm{H}_{2} \mathrm{O} / 100\right) * 2.005=$
16.27 DSCFM 


\section{Volume Correction Calculations EPA Method 0030-VOST}
Meter \# :
2400
Meter factor
0.9818

RTS \#1 Waste Feed

\begin{tabular}{|l|c|c|c|c|}
\hline Run \# & \#1-GSS Out & \#2-GSS Out & \#3-GSS Out & \#1-Cat. Out \\
\hline Date & $8 / 18 / 98$ & $8 / 18 / 98$ & $8 / 18 / 98$ & $8 / 18 / 98$ \\
\hline Time & $1059-1215$ & $1234-1350$ & $1424-1546$ & $1614-1740$ \\
\hline Barometric Pressure & 29.9 & 29.9 & 29.9 & 29.9 \\
\hline Raw Sample Volume, liters & 59.0 & 55.7 & 56.3 & 61.1 \\
\hline Meter Temp, ${ }^{\circ} \mathrm{F}$ (avg) & 76.30 & 77.70 & 77.30 & -79.60 \\
\hline Corrected Volume, liters & 57.02 & 53.69 & 54.31 & 58.69 \\
\hline Corrected Volume, meters & 0.057 & 0.054 & 0.054 & 0.059 \\
\hline
\end{tabular}




\section{Volume Correction Calculations \\ EPA Method 0030-VOST}
Meter \# :
2400
Meter factor
0.9818

\section{RTS \#2 Waste Feed}

\begin{tabular}{|l|c|c|c|c|}
\hline Run \# & $\# 1$-GSS Out & $\# 2$-GSS Out & $\# 3$-GSS Out & \#1-Cat. Out \\
\hline Date & $8 / 26 / 98$ & $8 / 26 / 98$ & $8 / 26 / 98$ & $8 / 26 / 98$ \\
\hline Time & $0903-1024$ & $1048-1210$ & $1229-1348$ & $1410-1530$ \\
\hline Barometric Pressure & 29.9 & 29.9 & 29.9 & 29.9 \\
\hline Raw Sample Volume, liters & 56.1 & 60.1 & 61 & 59.7 \\
\hline Meter Temp, ${ }^{\circ} \mathrm{F}$ (avg) & 75.60 & 78.70 & 78.90 & 80.00 \\
\hline Corrected Volume, liters & 54.29 & 57.82 & 58.67 & 57.30 \\
\hline Corrected Volume, meters & 0.054 & 0.058 & 0.059 & 0.057 \\
\hline
\end{tabular}




\section{EPA 17/114 PARTICULATE \& RADIONUCLIDE EMISSION CALCULATIONS}

FACILITY:

UNIT:

CONDITION:

$\begin{array}{ll}\text { LLNL Bldg, } 292 \text { MSO } & \text { DATE: } \\ \text { GSS Filter Outlet } & \text { TIME: } \\ \text { RTS \#1 Waste Feed } & \text { TEST NO: }\end{array}$

\begin{tabular}{ll}
$\frac{8 / 18 / 98}{1027-1127}$ & METER BOX NO: \\
\hline 1 & PROBE NO.: \\
\hline & NOZZLE NO:
\end{tabular}

ASI 8 N.A. $6 \mathrm{~A}$

\begin{tabular}{|c|c|c|c|c|c|c|c|c|}
\hline Pitot Factor, & $\mathrm{C}_{\mathrm{p}}$ & 0.990 & Meter Temp., ${ }^{\circ} \mathrm{F}$ & $\mathrm{T}_{\mathrm{m}}$ & 81.1 & Total $\mathrm{H}_{2} \mathrm{O}$ Condensed, & $V_{w}$ & 47.1 \\
\hline Barometric Press., "Hg & $P_{b}$ & 29.90 & Meter Press., $" \mathrm{H}_{2} \mathrm{O}$ & $\Delta \mathrm{H}$ & 3.660 & Total F.H. Particulate, & $\mathrm{mg}$ & 0.11 \\
\hline Static Pressure, $" \mathrm{H}_{2} \mathrm{O}$ & $P_{\text {stat }}$ & -11.50 & Average $\sqrt{\Delta \mathrm{P}},{ }^{n} \mathrm{H}_{2} \mathrm{O}$ & $\sqrt{\Delta \mathrm{P}}$ & 0.437 & B.H. Organics, & $\mathrm{mg}$ & N.A. \\
\hline Stack Pressure, "Hg & $P$, & 29.05 & Stack Area, $\mathrm{Ft}^{2}$ & $A_{2}$ & 0.010 & B.H. Inorganics, & $\mathrm{mg}$ & N.A. \\
\hline Stack Temp., ${ }^{\circ} \mathrm{F}$ & $T_{8}$ & 199.4 & Nozzle Dia., Inches & $\mathrm{D}_{\mathrm{n}}$ & 0.378 & Stack Gas $\mathrm{O}_{2}$ & $\mathrm{O}_{2} \%$ & 11.8 \\
\hline Sample Time, mins & $\Theta$ & 60 & Meter Factor, & $Y_{d}$ & 0.9593 & Stack Gas $\mathrm{CO}_{2}$ & $\mathrm{CO}_{2} \%$ & 8.00 \\
\hline Std. Temp., ${ }^{\circ} \mathrm{F}$ & $T_{\text {rtd }}$ & 68 & Sample Volume, $\mathrm{Ft}^{3}$ & $\mathrm{~V}_{\mathrm{m}}$ & 67.078 & Stack Gas $\mathrm{N}_{2}$ & $\mathrm{~N}_{2} \%$ & 80.2 \\
\hline
\end{tabular}
A) Sample Volume $\left(V_{m}\right)_{s t d}=\left(T_{s t d}+460\right) * V_{m} * Y_{d}^{*}\left(P_{b}+\Delta H / 13.6\right) /\left(\left(T_{m}+460\right) * 29.92\right)=$
63.313 DSCF
B) Volume $\mathrm{H}_{2} \mathrm{O}$ collected $\left(\mathrm{V}_{w}\right)_{s t d}=8.9148 \mathrm{E}-5^{*}\left(\mathrm{~T}_{\mathrm{std}}+460\right)^{*} \mathrm{~V}_{w}=$
$2.217 \mathrm{SCF}$
C) Total Sample Volume $(V)_{s t d}=\left(V_{m}\right)_{\text {std }}+\left(V_{w}\right)_{\text {std }}=$
$65.530 \mathrm{SCF}$
D) Moisture Content $\left(\% \mathrm{H}_{2} \mathrm{O}\right)=100 *\left(\mathrm{~V}_{\mathrm{w}}\right)_{\text {std }} /\left(\mathrm{V}_{\mathrm{t}}\right)_{\mathrm{std}}=$
$3.4 \%$
E) Stack Gas Velocity. $(\mathrm{Vs})=85.49 \mathrm{C}_{\mathrm{p}} \mathrm{V}(\Delta \mathrm{P})\left(\mathrm{T}_{\mathrm{s}}+460 \mathrm{MW}, \mathrm{P}_{\mathrm{s}}\right)=$
$32.52 \mathrm{ft} / \mathrm{sec}$
F) Stack Gas Molecular Wt $=\left(\left(\mathrm{CO}_{2} \% * 0.44+\mathrm{O}_{2} \% * 0.32+\mathrm{N}_{2} \% * 0.28\right)\left(1-\mathrm{H}_{2} \mathrm{O} \% / 100\right)\right)+18\left(\mathrm{H}_{2} \mathrm{O} \% / 100\right)=$
$29.35 \mathrm{~g} / \mathrm{gm}-\mathrm{mole}$
G) \% Isokinetic $(\mathrm{I})=9142.88\left(\mathrm{~V}_{t}\right)\left(\mathrm{T}_{\mathrm{s}}+460\right) /\left(\left(\mathrm{D}_{\mathrm{n}}{ }^{2}\right)(\Theta)\left(\mathrm{P}_{\mathrm{s}}\right)\left(\mathrm{V}_{\mathrm{s}}\right)\left(\mathrm{T}_{\mathrm{std}}+460\right)\right)=$
$92.37 \%$
H) $\mathrm{ACFM}=\left(\mathrm{V}_{3}\right)\left(\mathrm{A}_{3}\right) 60=$
19.51 ACFM
D) Stack Gas Vol. Flow Rate, DSCFM $=\left(\mathrm{V}_{3}\right)\left(\mathrm{A}_{3}\right)\left(\left(\mathrm{T}_{\mathrm{sed}}+460\right) /\left(\mathrm{T}_{3}+460\right)\right)\left(\mathrm{P}_{3}\right)\left(1-\% \mathrm{H}_{2} \mathrm{O} / 100\right)^{*} 2.005=$
14.66 DSCFM
J) F.H. Particulate Concentration (gr $/ \mathrm{DSCF})=\mathrm{mg} / \mathrm{Vmstd} * 0.01543=$
0.00003 gr/DSCF
K) F.H. Particulate Emission Rate $=0.00857 * \mathrm{gr} / \mathrm{DSCF} * \mathrm{DSCFM}=$
$0.000003 \mathrm{lbs} / \mathrm{hr}$ 
EPA 17/114 PARTICULATE \& RADIONUCLIDE EMISSION CALCULATIONS

FACILITY:

UNIT:

CONDITION:

LLNL Bldg. 292 MSO DATE:
$\begin{aligned} & \text { GSS Filter Outlet } \\ & \text { RTS } \# 1 \text { Waste Feed }\end{aligned}$ TEST NO:

$8 / 18 / 98$

$$
1245-1345
$$

2
METER BOX NO:: PROBE NO.: NOZZLE NO.:
ASI 8

N.A

$6 \mathrm{~A}$

\begin{tabular}{|c|c|c|c|c|c|c|c|c|}
\hline Pitot Factor, & $\mathrm{C}_{\mathrm{p}}$ & 0.99 & Meter Temp., ${ }^{\circ} \mathrm{F}$ & $T_{m}$ & 85.5 & Total $\mathrm{H}_{2} \mathrm{O}$ Condensed, & $\mathrm{V}_{\mathrm{w}}$ & 55.4 \\
\hline Barometric Press., " $\mathrm{Hg}$ & $\mathrm{P}_{\mathrm{b}}$ & 29.90 & Meter Press., ${ }^{\mathrm{H}} \mathrm{H}_{2} \mathrm{O}$ & $\Delta \mathrm{H}$ & 3.820 & Total F.H. Particulate, & $\mathrm{mg}$ & 9.20 \\
\hline Static Pressure, " $\mathrm{H}_{2} \mathrm{O}$ & $P_{\text {sat }}$ & -11.50 & Average $\sqrt{ } \triangle \mathrm{P},{ }^{\prime} \mathrm{H}_{2} \mathrm{O}$ & $\sqrt{\Delta P}$ & 0.439 & B.H. Organics, & $\mathrm{mg}$ & N.A. \\
\hline Stack Pressure, " $\mathrm{Hg}$ & $P_{s}$ & 29.05 & Stack Area, $\mathrm{Ft}^{2}$ & $A_{3}$ & 0.010 & B.H. Inorganics, & $\mathrm{mg}$ & N.A. \\
\hline Stack Temp.. ${ }^{\circ} \mathrm{F}$ & $T_{3}$ & 236.6 & Nozzle Dia., Inches & $D_{n}$ & 0.378 & Stack Gas $\mathrm{O}_{2}$ & $\mathrm{O}_{2} \%$ & 11.8 \\
\hline Sample Time, mins & $\Theta$ & 60.0 & Meter Factor, & $Y_{d}$ & 0.9593 & Stack Gas $\mathrm{CO}_{2}$ & $\mathrm{CO}_{2} \%$ & 8.00 \\
\hline Std. Temp., ${ }^{\circ} \mathrm{F}$ & $T_{\text {sd }}$ & 68 & Sample Volume, $\mathrm{Ft}^{3}$ & $V_{m}$ & 68.821 & Stack Gas $\mathrm{N}_{2}$ & $\mathrm{~N}_{2} \%$ & 80.2 \\
\hline
\end{tabular}

A) Sample Volume $\left(V_{m}\right)_{s d}=\left(T_{s c d}+460\right) * V_{m} * Y_{d}^{*}\left(P_{b}+\Delta H / 13.6\right)\left(\left(T_{m}+460\right) * 29.92\right)=$

64.459 DSCF

B) Volume $\mathrm{H}_{2} \mathrm{O}$ collected $\left(\mathrm{V}_{\mathrm{w}}\right)_{\text {sdd }}=8.9148 \mathrm{E}-5 *\left(\mathrm{~T}_{x d}+460\right)^{*} \mathrm{~V}_{\mathrm{w}}=$

$2.608 \mathrm{SCF}$

C) Total Sample Volume $\left(V_{D}\right)_{s d}=\left(V_{m a d}\right)_{s d}+\left(V_{w}\right)_{a d}=$

$67.067 \mathrm{SCF}$

D) Moisture Content $\left(\% \mathrm{H}_{2} \mathrm{O}\right)=100 *\left(\mathrm{~V}_{\mathrm{w}}\right)_{\text {sed }} /\left(\mathrm{V}_{\mathrm{t}_{\mathrm{sdd}}}\right.$ -

$3.9 \%$

E) Stack Gas Velocity $(\mathrm{Vs})=85.49 \mathrm{C}_{\mathrm{p}} \sqrt{ }(\Delta \mathrm{P})\left(\mathrm{T}_{\mathrm{s}}+460 / \mathrm{MW}_{\mathrm{s}} \mathrm{P}_{\mathrm{s}}\right)=$

$33.61 \mathrm{ft} / \mathrm{sec}$

F) Stack Gas Molecular Wt. $=\left(\left(\mathrm{CO}_{2} \% * 0.44+\mathrm{O}_{2} \% * 0.32+\mathrm{N}_{2} \% * 0.28\right)\left(1-\mathrm{H}_{2} \mathrm{O} \% / 100\right)\right)+18\left(\mathrm{H}_{2} \mathrm{O} \% / 100\right)=$

$29.30 \mathrm{~g} / \mathrm{gm}$-mole

G) \% Isokinetic $(I)=9142.88\left(V_{D}\right)\left(T_{s}+460\right) /\left(\left(D_{n}^{2}\right)(\Theta)\left(P_{s}\right)\left(V_{s}\right)\left(T_{s d}+460\right)\right)=$

$96.63 \%$

H) $\mathrm{ACFM}=\left(\mathrm{V}_{s}\right)\left(\mathrm{A}_{s}\right) 60=$

20.17 ACFM

1) Stack Gas Vol. Flow Rate, DSCFM $=\left(\mathrm{V}_{\mathrm{s}}\right)\left(\mathrm{A}_{3}\right)\left(\left(\mathrm{T}_{\mathrm{std}}+460\right)\left(\mathrm{T}_{\mathrm{s}}+460\right)\right)\left(\mathrm{P}_{\mathrm{s}}\right)\left(1-\% \mathrm{H}_{2} \mathrm{O} / 100\right) * 2.005=$

14.27 DSCFM

J) F.H. Particulate Concentration (gr/DSCF) $=\mathrm{mg} / \mathrm{Vmstd}^{\prime} * 0.01543=$

$0.0022 \mathrm{gr} / \mathrm{DSCF}$

K) F.H. Particulate Emission Rate $=0.00857 * \mathrm{gr} / \mathrm{DSCF} * \mathrm{DSCFM}=$

$0.000269 \mathrm{Lbs} / \mathrm{hr}$ 


\section{EPA 17/114 PARTICULATE \& RADIONUCLIDE EMISSION CALCULATIONS}

FACILITY:

UNIT:

CONDITION:

\begin{tabular}{|c|c|}
\hline LLNL Bldg. 292 MSO & \\
\hline GSS Filter Outlet & \\
\hline RTS \#1 Waste Feed & \\
\hline
\end{tabular}

\begin{tabular}{ll}
$\frac{8 / 18 / 98}{1500-1600}$ & METER BOX NO.: \\
\hline 3 & PROBE NO.: \\
\hline & NOZZLE NO.:
\end{tabular}

$\frac{\mathrm{ASI} 8}{\mathrm{NA}}$

\begin{tabular}{|c|c|c|c|c|c|c|c|c|}
\hline Pitot Factor, & $C_{p}$ & 0.990 & Meter Temp., ${ }^{\circ} \mathrm{F}$ & $T_{m}$ & 85.6 & Total $\mathrm{H}_{2} \mathrm{O}$ Condensed, & $\overline{V_{w}}$ & 51.4 \\
\hline Barometric Press., "Hg & $\mathrm{P}_{\mathrm{b}}$ & 29.90 & Meter Press.," $\mathrm{H}_{2} \mathrm{O}$ & $\Delta \mathrm{H}$ & 3.500 & Total F.H. Particulate, & $\mathrm{mg}$ & 1.50 \\
\hline Static Pressure, " $\mathrm{H}_{2} \mathrm{O}$ & $P_{s x}$ & -11.50 & Average $\sqrt{ } \Delta \mathrm{P} ., " \mathrm{H}_{2} \mathrm{O}$ & $\sqrt{\Delta \mathrm{P}}$ & 0.423 & B.H. Organics, & $\mathrm{mg}$ & N.A. \\
\hline Stack Pressure, "Hg & $P_{8}$ & 29.05 & Stack Area, $\mathrm{Ft}^{2}$ & $A_{s}$ & 0.010 & B.H. Inorganics, & $\mathrm{mg}$ & N.A. \\
\hline Stack Temp., ${ }^{\circ} \mathrm{F}$ & $T_{3}$ & 262.8 & Nozale Dia., Inches & $D_{n}$ & 0.378 & Stack Gas $\mathrm{O}_{2}$ & $\mathrm{O}_{2} \%$ & 11.9 \\
\hline Sample Time, mins & $\Theta$ & 60.0 & Meter Factor, & $Y_{d}$ & 0.9593 & Stack Gas $\mathrm{CO}_{2}$ & $\mathrm{CO}_{2} \%$ & 7.80 \\
\hline Std. Temp. ${ }^{\circ} \mathrm{F}$ & $T_{\text {scd }}$ & 68 & Sample Volume, $\mathrm{Ft}^{3}$ & $\mathrm{~V}_{\mathrm{m}}$ & 66.752 & Stack Gas $N_{2}$ & $\mathrm{~N}_{2} \%$ & 80.3 \\
\hline
\end{tabular}

A) Gas Volume $\left(V_{m}\right)_{s d}=\left(T_{s d}+460\right)^{*} V_{m}^{*} Y_{d}^{*}\left(P_{b}+\Delta H / 13.6\right)\left(\left(T_{m}+460\right)^{* 29.92)}\right)=$

62.461 DSCF

B) Volume $\mathrm{H}_{2} \mathrm{O}$ collected $\left(\mathrm{V}_{\mathrm{w}}\right)_{\text {std }}=8.9148 \mathrm{E}-5^{*}\left(\mathrm{~T}_{\mathrm{xdd}}+460\right)^{*} \mathrm{~V}_{\mathrm{w}}=$

$2.419 \mathrm{SCF}$

C) Total Sample Volume $\left(V_{v_{s d d}}=\left(V_{m}\right)_{x d}+\left(V_{v}\right)_{s d}=\right.$

$64.881 \mathrm{SCF}$

D) Moisture Content $\left(\% \mathrm{H}_{2} \mathrm{O}\right)=100 *\left(\mathrm{~V}_{\mathrm{w}}\right)_{\text {sed }} /\left(\mathrm{V}_{2}\right)_{\text {sd }}=$

$3.7 \%$

E) Stack Gas Velocity $(\mathrm{Vs})=85.49 \mathrm{C}_{\mathrm{p}} \sqrt{ }(\Delta \mathrm{P})\left(\mathrm{T}_{\mathrm{s}}+460 / \mathrm{MW}_{\mathrm{s}} \mathrm{P}_{\mathrm{s}}\right)=$

F) Stack Gas Molecular Wt $=\left(\left(\mathrm{CO}_{2} \% * 0.44+\mathrm{O}_{2} \% * 0.32+\mathrm{N}_{2} \% * 0.28\right)\left(1-\mathrm{H}_{2} \mathrm{O} \% / 100\right)\right)+18\left(\mathrm{H}_{2} \mathrm{O} \% / 100\right)=$

G) \% Isokinetic $(\mathrm{I})=9142.88\left(\mathrm{~V}_{\mathrm{u}}\right)\left(\mathrm{T}_{\mathrm{s}}+460\right) /\left(\left(\mathrm{D}_{\mathrm{n}}{ }^{2}\right)(\Theta)\left(\mathrm{P}_{\mathrm{s}}\right)\left(\mathrm{V}_{\mathrm{s}}\right)\left(\mathrm{T}_{\mathrm{sd}}+460\right)\right)=$

H) $\mathrm{ACFM}=\left(\mathrm{V}_{3}\right)\left(\mathrm{A}_{3}\right) 60=$

I) Stack Gas Vol. Flow Rate, DSCFM $\left.=\left(\mathrm{V}_{s}\right)\left(\mathrm{A}_{3}\right)\left(\mathrm{T}_{\text {xdd }}+460\right)\left(\mathrm{T}_{\mathrm{s}}-460\right)\right)\left(\mathrm{P}_{3}\right)\left(1-\% \mathrm{H}_{2} \mathrm{O} / 100\right) * 2.005=$

$33.00 \mathrm{ft} / \mathrm{sec}$

$29.29 \mathrm{~g} / \mathrm{gm}-\mathrm{mole}$

$98.80 \%$

19.80 ACFM

13.52 DSCFM

J) F.H. Particulate Concentration (gr/DSCF) $=\mathrm{mg} / \mathrm{Vmstd} * 0.01543=$

$0.0004 \mathrm{gI} / \mathrm{DSCF}$

K) F.H. Particulate Emission Rate $=0.00857 *$ gr $/ \mathrm{DSCF} *$ DSCFM $=$ 


\section{EPA 17/114 PARTICULATE \& RADIONUCLIDE EMISSION CALCULATIONS}

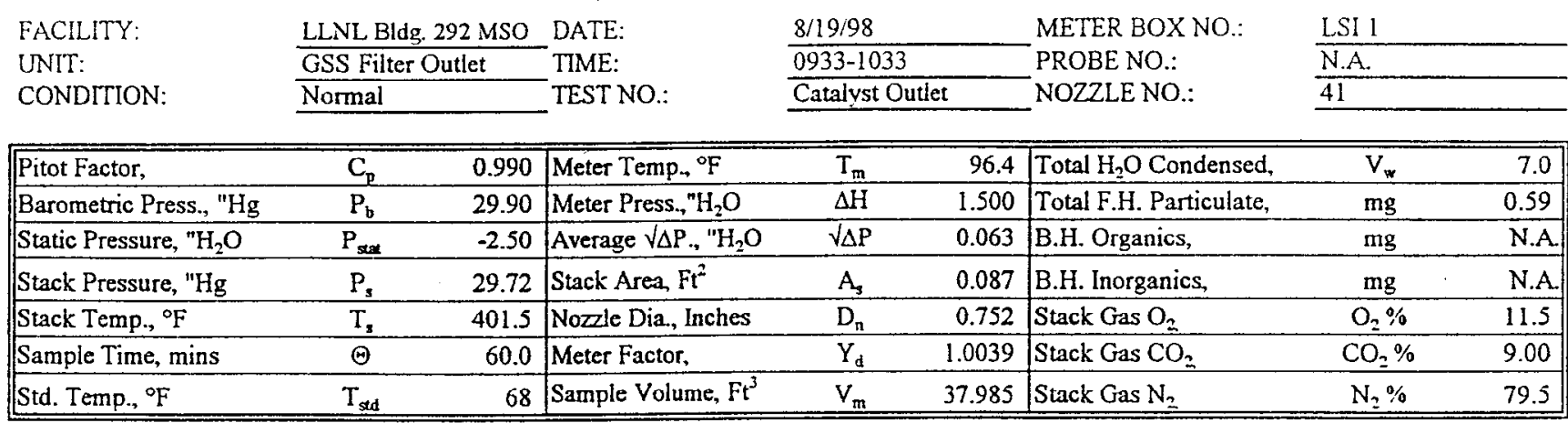
A) Gas Volume $\left(\mathrm{V}_{\mathrm{m}}\right)_{s d}=\left(\mathrm{T}_{\mathrm{std}}+460\right)^{*} \mathrm{~V}_{\mathrm{m}} * \mathrm{Y}_{\mathrm{d}}^{*}\left(\mathrm{P}_{\mathrm{b}}+\Delta \mathrm{H} / 13.6\right) /\left(\left(\mathrm{T}_{\mathrm{m}}+460\right)^{*} 29.92\right)=$
36.296 DSCF
B) Volume $\mathrm{H}_{2} \mathrm{O}$ collected $\left(\mathrm{V}_{\mathrm{w}}\right)_{\mathrm{sdd}}=8.9148 \mathrm{E}-5^{*}\left(\mathrm{~T}_{\mathrm{sd}}+460\right)^{*} \mathrm{~V}_{\mathrm{w}}=$
0.329 SCF
C) Total Sample Volume $\left(V_{t}\right)_{s d}=\left(V_{m}\right)_{s d}+\left(V_{x}\right)_{s d}=$
36.625 SCF
D) Moisture Content $\left(\% \mathrm{H}_{2} \mathrm{O}\right)=100 *\left(\mathrm{~V}_{\mathrm{w}}\right)_{\mathrm{sd}}:\left(\mathrm{V}_{\mathrm{v}}\right)_{\mathrm{sd}}$ -
$0.9 \%$
E) Stack Gas Velocity $(V s)=85.49 C_{p} \sqrt{ }(\Delta P)\left(T_{s}-460 / M W_{s} P_{s}\right)=$
$5.28 \mathrm{ft} / \mathrm{sec}$
F) Stack Gas Molecular Wt. $=\left(\left(\mathrm{CO}_{2} \% * 0.44+\mathrm{O}_{2} \% * 0.32+\mathrm{N}_{2} \% * 0.28\right)\left(1-\mathrm{H}_{2} \mathrm{O} \% / 100\right)\right)+18\left(\mathrm{H}_{2} \mathrm{O} \% / 100\right)=$
$29.79 \mathrm{~g} / \mathrm{gm}-\mathrm{mole}$
G) \% Isokinetic $(\mathrm{I})=9142.88\left(\mathrm{~V}_{t}\right)\left(\mathrm{T}_{\mathrm{s}}+460\right)\left(\left(\mathrm{D}_{\mathrm{n}}^{2}\right)(\Theta)\left(\mathrm{P}_{\mathrm{s}}\right)\left(\mathrm{V}_{\mathrm{s}}\right)\left(\mathrm{T}_{\mathrm{std}}+460\right)\right)=$
$102.70 \%$
H) $A C F M=\left(V_{s}\right)\left(A_{s}\right) 60=$
27.54 ACFM
I) Stack Gas Vol. Flow Rate, DSCFM $\left.=\left(\mathrm{V}_{\mathrm{s}}\right)\left(\mathrm{A}_{\mathrm{s}}\right)\left(\mathrm{T}_{\mathrm{sdd}}+460\right)\left(\mathrm{T}_{\mathrm{s}}+460\right)\right)\left(\mathrm{P}_{\mathrm{s}}\right)\left(1-\% \mathrm{H}_{2} \mathrm{O} / 100\right)^{* 2.005}=$
16.61 DSCFM
D F.H. Particulate Concentration $(\mathrm{gr} / \mathrm{DSCF})=\mathrm{mg} / \mathrm{Vmstd} * 0.01543=$
$0.0003 \mathrm{gr} / \mathrm{DSCF}$
K) F.H. Particulate Emission Rate $=0.00857^{*} \mathrm{gr} / \mathrm{DSCF} * \mathrm{DSCFM}=$
$0.000036 \mathrm{Lbs} / \mathrm{hr}$ 


\section{EPA 17/114 PARTICULATE \& RADIONUCLIDE EMISSION CALCULATIONS}

FACILITY:

UNIT:

CONDITION:
LLNL Bldg. 292

GSS Filter Oudlet RTS \#2 Waste Feed
DATE: TIME: TEST NO.:

\begin{tabular}{ll}
$8 / 26 / 98$ & METER BOX NO.: \\
\hline $0910-1010$ & PROBE NO.: \\
1 & NOZZLE NO.:
\end{tabular}

ASI 8

N.A.

SE

\begin{tabular}{|c|c|c|c|c|c|c|c|c|}
\hline Pitot Factor, & $\mathrm{C}_{\mathrm{p}}$ & 0.990 & Meter Temp., ${ }^{\circ} \mathrm{F}$ & $T_{m}$ & 79.5 & Total $\mathrm{H}_{2} \mathrm{O}$ Condensed, & $\mathrm{V}_{\mathrm{w}}$ & 54.6 \\
\hline Barometric Press., " $\mathrm{Hg}$ & $P_{b}$ & 29.90 & Meter Press. " ${ } \mathrm{H}_{2} \mathrm{O}$ & $\Delta \mathrm{H}$ & 1.530 & Total F.H. Particulate, & $\mathrm{mg}$ & 0.42 \\
\hline Static Pressure, " $\mathrm{H}_{2} \mathrm{O}$ & $P_{\text {stat }}$ & -10.00 & Average $\sqrt{\Delta P} ., "{ }^{n}{ }_{2} \mathrm{O}$ & $\sqrt{\Delta} \mathrm{P}$ & 0.436 & B.H. Organics, & $\overline{\mathrm{mg}}$ & NA. \\
\hline Stack Pressure, "Hg & $\mathrm{P}_{3}$ & 29.16 & Stack Area, $\mathrm{Ft}^{2}$ & $A_{1}$ & 0.010 & B.H. Inorganics, & $\mathrm{mg}$ & N.A. \\
\hline Stack Temp., ${ }^{\circ} \mathrm{F}$ & $T_{3}$ & 308.4 & Nozzle Dia., Inches & $D_{a}$ & 0.309 & Stack Gas $\mathrm{O}_{2}$ & $\mathrm{O}_{2} \%$ & 9.9 \\
\hline Sample Time, mins & $\Theta$ & 60 & Meter Factor, & $Y_{d}$ & 0.9593 & Stack Gas $\mathrm{CO}_{2}$ & $\mathrm{CO}_{2} \%$ & 8.50 \\
\hline Std. Temp., of & $T_{\text {std }}$ & 68 & Sample Volume, $\mathrm{Ft}^{3}$ & $\mathrm{~V}_{\mathrm{m}}$ & 45.524 & Stack Gas $\mathrm{N}_{2}$ & $\mathrm{~N}_{2} \%$ & 81.6 \\
\hline
\end{tabular}
A) Sample Volume $\left(\mathrm{V}_{\mathrm{ra}}\right)_{\mathrm{std}}=\left(\mathrm{T}_{\mathrm{std}}+460\right) * \mathrm{~V}_{\mathrm{m}} * \mathrm{Y}_{\mathrm{d}}^{*}\left(\mathrm{P}_{\mathrm{b}}+\lambda H / 13.6\right) /\left(\left(\mathrm{T}_{\mathrm{m}}+460\right) * 29.92\right)=$
42.872 DSCF
B) Volume $\mathrm{H}_{2} \mathrm{O}$ collected $\left(\mathrm{V}_{\mathrm{w}}\right)_{\mathrm{rdd}}=8.9148 \mathrm{E}-5 *\left(\mathrm{~T}_{\mathrm{rtd}}+460\right)^{*} \mathrm{~V}_{\mathrm{w}}=$
$2.570 \mathrm{SCF}$
C) Total Sample Volume $\left(V_{v_{\text {rdd }}}=\left(V_{m}\right)_{\text {rd }}+\left(V_{w}\right)_{\text {rd }}=\right.$
45.442 SCF
D) Moisture Content $\left(\% \mathrm{H}_{2} \mathrm{O}\right)=100 *\left(\mathrm{~V}_{\mathrm{w}}\right)_{\text {sdd }} /\left(\mathrm{V}_{\mathrm{std}}=\right.$
$5.7 \%$
E) Stack Gas Velocity $(V s)=85.49 \mathrm{C}_{\mathrm{p}} \sqrt{ }(\Delta \mathrm{P})\left(\mathrm{T}_{\mathrm{s}}+460 / \mathrm{MW}_{\mathrm{s}} \mathrm{P}_{\mathrm{s}}\right)=$
$35.12 \mathrm{ft} / \mathrm{sec}$
F) Stack Gas Molecular Wt. $=\left(\left(\mathrm{CO}_{2} \% * 0.44+\mathrm{O}_{2} \% * 0.32+\mathrm{N}_{2} \% * 0.28\right)\left(1-\mathrm{H}_{2} \mathrm{O} \% / 100\right)\right)+18\left(\mathrm{H}_{2} \mathrm{O} \% / 100\right)=$
$29.09 \mathrm{~g} / \mathrm{gm}-\mathrm{mole}$
G) \% Isokinetic $(\mathrm{I})=9142.88\left(V_{t}\right)\left(T_{s}+460\right) /\left(\left(D_{n}^{2}\right)(\Theta)\left(P_{s}\right)\left(V_{s}\right)\left(T_{s t d}+460\right)\right)=$
$103.05 \%$
H) $\mathrm{ACFM}=\left(\mathrm{V}_{3}\right)\left(\mathrm{A}_{8}\right) 60=$
21.07 ACFM
D) Stack Gas Vol. Flow Rate, DSCFM $=\left(\mathrm{V}_{s}\right)\left(\mathrm{A}_{8}\right)\left(\left(\mathrm{T}_{\text {std }}+460\right) /\left(\mathrm{T}_{\mathrm{s}}+460\right)\right)\left(\mathrm{P}_{\mathrm{s}}\right)\left(1-\% \mathrm{H}_{2} \mathrm{O} / 100\right) * 2.005=$
13.31 DSCFM
J) F.H. Particulate Concentration $(\mathrm{gr} / \mathrm{DSCF})=\mathrm{mg} / \mathrm{Vmstd} * 0.01543=$
0.0002 gr/DSCF
k) F.H. Particulate Emission Rate $=0.00857^{*} \mathrm{gr} / \mathrm{DSCF} * \mathrm{DSCFM}=$
$0.000 \mathrm{lbs} / \mathrm{hr}$ 


\section{EPA 17/114 PARTICULATE \& RADIONUCLIDE EMISSION CALCULATIONS}

FACILITY:

UNIT:
CONDITION:
LLNL Bldg. 292

GSS Filter Outlet

DATE:

TIME:

RTS H2 Waste Feed TEST NO:

$8 / 26 / 98$

$1100-1200$

2
METER BOX NO.:

PROBE NO.:

NOZZLE NO.:
$\frac{\mathrm{ASI} 8}{\mathrm{~N} . \mathrm{A} .}$

\begin{tabular}{|c|c|c|c|c|c|c|c|c|}
\hline Pitot Factor, & $C_{p}$ & 0.99 & Meter Temp., ${ }^{\circ} \mathrm{F}$ & $T_{m}$ & 80.6 & Total $\mathrm{H}_{2} \mathrm{O}$ Condensed, & $V_{w}$ & 35.0 \\
\hline Barometric Press, "Hg & $P_{b}$ & 29.90 & Meter Press. ${ }^{\mathrm{H}} \mathrm{H}_{2} \mathrm{O}$ & $\Delta \mathrm{H}$ & 1.820 & Total F.H. Particulate, & $\mathrm{mg}$ & 0.52 \\
\hline Static Pressure, ${ }^{n} \mathrm{H}_{2} \mathrm{O}$ & $P_{\text {stat }}$ & -10.00 & Average $\sqrt{ } \Delta \mathrm{P} .,{ }^{n} \mathrm{H}_{2} \mathrm{O}$ & $\sqrt{\triangle P}$ & 0.483 & B.H. Organics, & $\mathrm{mg}$ & N.A \\
\hline Stack Pressure, "Hg & $P_{8}$ & 29.16 & Stack Area, $\mathrm{Ft}^{2}$ & $\mathrm{~A}_{3}$ & 0.010 & B.H. Inorganics, & $\mathrm{mg}$ & N.A. \\
\hline Stack Tcmp., ${ }^{\circ} \mathrm{F}$ & $T_{3}$ & 327.4 & Nozzle Dia., Inches & $\mathrm{D}_{\mathrm{n}}$ & 0.309 & Stack Gas $\mathrm{O}_{2}$ & $\mathrm{O}_{2} \%$ & 10.5 \\
\hline Sample Time, mins & $\Theta$ & 60.0 & Meter Factor, & $Y_{d}$ & 0.9593 & Stack Gas $\mathrm{CO}_{2}$ & $\mathrm{CO}_{2} \%$ & 7.00 \\
\hline Std. Tcmp., ${ }^{\circ}$ & $T_{\text {sdd }}$ & 68 & Samplo Volume, $\mathrm{Ft}^{3}$ & $V_{m}$ & 49.443 & Stack Gas $\mathrm{N}_{2}$ & $\mathrm{~N}_{2} \%$ & 82.5 \\
\hline
\end{tabular}

A) Sample Volume $\left(\mathrm{V}_{\mathrm{m}}\right)_{s d d}=\left(\mathrm{T}_{z \mathrm{dc}}+460\right) * \mathrm{~V}_{\mathrm{m}}^{*} \mathrm{Y}_{\mathrm{d}}^{*}\left(\mathrm{P}_{\mathrm{b}}+\Delta \mathrm{H} / 13.6\right) /\left(\left(\mathrm{T}_{\mathrm{m}}+460\right) * 29.92\right)=$

46.501 DSCF

B) Volume $\mathrm{H}_{2} \mathrm{O}$ collected $\left(\mathrm{V}_{\mathrm{w}}\right)_{\mathrm{xd}}=8.9148 \mathrm{E}-5^{*}\left(\mathrm{~T}_{\mathrm{xd}}+460\right)^{*} \mathrm{~V}_{\mathrm{w}}=$

$1.647 \mathrm{SCF}$

C) Total Sample Volume $\left(V_{1}\right)_{\text {sdd }}=\left(V_{m}\right)_{\text {sdd }}+\left(V_{w}\right)_{s d}=$

48.149 SCF

D) Moisture Content $\left(\% \mathrm{H}_{2} \mathrm{O}\right)=100 *\left(\mathrm{~V}_{\mathrm{w}}\right)_{\mathrm{sed}} /(\mathrm{V})_{\mathrm{sed}}=$

$3.4 \%$

E) Stack Gas Velocity $(V s)=85.49 \mathrm{C}_{\mathrm{p}} \mathrm{V}(\Delta \mathrm{P})\left(\mathrm{T}_{\mathrm{s}}+460 / \mathrm{MW}, \mathrm{P}_{\mathrm{s}}\right)=$

$39.34 \mathrm{ft} / \mathrm{sec}$

F) Stack Gas Molecular Wt. $=\left(\left(\mathrm{CO}_{2} \% * 0.44+\mathrm{O}_{2} \% * 0.32+\mathrm{N}_{2} \% * 0.28\right)\left(1-\mathrm{H}_{2} \mathrm{O} \% / 100\right)\right)+18\left(\mathrm{H}_{2} \mathrm{O} \% / 100\right)=$

$29.15 \mathrm{~g} / \mathrm{gm}-\mathrm{mole}$

G) \% Isokinetic $(\mathrm{I})=9142.88\left(\mathrm{~V}_{\mathrm{L}}\right)\left(\mathrm{T}_{\mathrm{s}}+460\right) /\left(\left(\mathrm{D}_{\mathrm{n}}{ }^{2}\right)(\odot)\left(\mathrm{P}_{\mathrm{s}}\right)\left(\mathrm{V}_{\mathrm{s}}\right)\left(\mathrm{T}_{\mathrm{scd}}+460\right)\right)=$

$99.87 \%$

H) $A C F M=\left(V_{s}\right)\left(A_{s}\right) 60=$

$23.61 \mathrm{ACFM}$

I) Stack Gas Vol. Flow Rate, DSCFM $=\left(\mathrm{V}_{\mathrm{s}}\right)\left(\mathrm{A}_{\mathrm{s}}\right)\left(\left(\mathrm{T}_{\mathrm{sad}}+460\right) /\left(\mathrm{T}_{\mathrm{s}}+460\right)\right)\left(\mathrm{P}_{\mathrm{s}}\right)\left(1-\% \mathrm{H}_{2} \mathrm{O} / 100\right) * 2.005=$

14.90 DSCFM

J) F.H. Particulate Concentration $(\mathrm{gr} / \mathrm{DSCF})=\mathrm{mg} / \mathrm{Vmstd} * 0.01543=$

$0.0002 \mathrm{gr} / \mathrm{DSCF}$

K) F.H. Particulate Emission Rate $=0.00857 * \mathrm{gr} / \mathrm{DSCF} * \mathrm{DSCFM}=$ 
EPA 17/114 PARTICULATE \& RADIONUCLIDE EMISSION CALCULATIONS

\begin{tabular}{|c|c|c|c|c|c|}
\hline FACILITY: & LLNL BIdg. 292 & DATE: & $8 / 26 / 98$ & METER BOX NO.: & ASI 8 \\
\hline UNTT: & GSS Filter Outlet & TIME: & $1245-1345$ & PROBE NO.: & N.A. \\
\hline CONDITION: & RTS \#2 Waste Feed & TEST NO.: & 3 & NOZZLE NO: & SE \\
\hline
\end{tabular}

\begin{tabular}{|c|c|c|c|c|c|c|c|c|}
\hline Pitot Factor, & $\overline{C_{p}}$ & 0.990 & Meter Temp., ${ }^{\circ} \mathrm{F}$ & $\mathrm{T}_{\mathrm{m}}$ & 81.6 & Total $\mathrm{H}_{2} \mathrm{O}$ Condensed, & $V_{w}$ & 40.3 \\
\hline Barometric Press., " $\mathrm{Hg}$ & $P_{b}$ & 29.90 & Meter Press., ${ }^{n} \mathrm{H}_{2} \mathrm{O}$ & $\Delta \mathrm{H}$ & 1.490 & Total F.H. Particulate, & $\mathrm{mg}$ & 1.50 \\
\hline Static Pressure, " $\mathrm{H}_{2} \mathrm{O}$ & $P_{\text {stat }}$ & -10.00 & Average $\sqrt{\Delta} \mathrm{P},{ }^{n}$ " $\mathrm{H}_{2} \mathrm{O}$ & $\sqrt{\Delta P}$ & 0.443 & B.H. Organics, & $\mathrm{mg}$ & N.A. \\
\hline Stack Pressure, "Hg & $P_{3}$ & 29.16 & Stack Area, $\mathrm{Ft}^{2}$ & $A_{3}$ & 0.010 & B.H. Inorganics, & $\mathrm{mg}$ & N.A. \\
\hline Stack Temp., ${ }^{\circ} \mathrm{F}$ & $\mathrm{T}_{3}$ & 335.3 & Nozzle Dia., Inches & $D_{n}$ & 0.309 & Stack Gas $\mathrm{O}_{2}$ & $\mathrm{O}_{2} \%$ & 10.1 \\
\hline Sample Time, mins & $\Theta$ & 60.0 & Meter Factor, & $Y_{d}$ & 0.9593 & Stack Gas $\mathrm{CO}_{2}$ & $\mathrm{CO}_{2} \%$ & 7.30 \\
\hline Std. Temp., ${ }^{\circ} \mathrm{F}$ & $\mathrm{T}_{\text {sdd }}$ & 68 & Sample Volume, $\mathrm{Ft}^{3}$ & $\mathrm{~V}_{\mathrm{m}}$ & 45.484 & Stack Gas $\mathrm{N}_{2}$ & $\mathrm{~N}_{2} \%$ & 82.6 \\
\hline
\end{tabular}
A) Gas Volume $\left(V_{m}\right)_{s d}=\left(T_{s t d}+460\right)^{*} V_{m}^{*} Y_{d d}^{*}\left(P_{b}+\Delta H / 13.6\right) /\left(\left(T_{m}+460\right) * 29.92\right)=$
42.664 DSCF
B) Volume $\mathrm{H}_{2} \mathrm{O}$ collected $\left(\mathrm{V}_{\mathrm{w}}\right)_{\mathrm{sdd}}=8.9148 \mathrm{E}-5^{*}\left(\mathrm{~T}_{\mathrm{sd}}+460\right)^{*} \mathrm{~V}_{\mathrm{w}}=$
$1.897 \mathrm{SCF}$
C) Total Sample Volume $\left(V_{v}\right)_{s d}=\left(V_{m}\right)_{r d}+\left(V_{w}\right)_{x d}=$
44.561 SCF
D) Moisture Content $\left(\% \mathrm{H}_{2} \mathrm{O}\right)=100 *\left(\mathrm{~V}_{\mathrm{w}}\right)_{\mathrm{std}} /\left(\mathrm{V}_{\mathrm{sdd}}=\right.$
$4.3 \%$

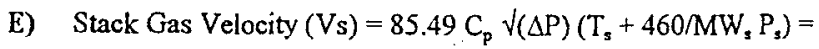
$36.31 \mathrm{ft} / \mathrm{sec}$
F) Stack Gas Molecular Wt. $=\left(\left(\mathrm{CO}_{2} \% * 0.44+\mathrm{O}_{2} \% * 0.32+\mathrm{N}_{2} \% * 0.28\right)\left(1-\mathrm{H}_{2} \mathrm{O} \% / 100\right)\right)+18\left(\mathrm{H}_{2} \mathrm{O} \% / 100\right)=$
$29.08 \mathrm{~g} / \mathrm{gm}-\mathrm{mole}$
G) \% Isokinetic $(\mathrm{I})=9142.88\left(\mathrm{~V}_{\mathrm{V}}\right)\left(\mathrm{T}_{\mathrm{s}}+460\right)\left(\left(\mathrm{D}_{\mathrm{n}}^{2}\right)(\Theta)\left(\mathrm{P}_{\mathrm{s}}\right)\left(\mathrm{V}_{\mathrm{s}}\right)\left(\mathrm{T}_{\mathrm{xd}}+460\right)\right)=$
$101.16 \%$
I) $\mathrm{ACFM}=\left(\mathrm{V}_{\mathrm{s}}\right)\left(\mathrm{A}_{\mathrm{s}}\right) 60=$
21.78 ACFM
I) Stack Gas Vol. Flow Rate, DSCFM $=\left(\mathrm{V}_{\mathrm{s}}\right)\left(\mathrm{A}_{3}\right)\left(\left(\mathrm{T}_{\mathrm{std}}+460\right)\left(\mathrm{T}_{\mathrm{s}}+460\right)\right)\left(\mathrm{P}_{\mathrm{s}}\right)\left(1-\% \mathrm{H}_{2} \mathrm{O} / 100\right) * 2.005=$
13.50 DSCFM
J) F.H. Particulate Concentration (gr/DSCF) $=\mathrm{mg} / \mathrm{Vmstd} * 0.01543=$
0.0005 gr/DSCF
K) F.H. Particulate Fmission Rate $=0.00857 * \mathrm{gr} / \mathrm{DSCF} * \mathrm{DSCFM}=$
$0.000 \mathrm{Lbs} / \mathrm{hr}$ 
EPA 17/114 PARTICULATE \& RADIONUCLIDE EMISSION CALCULATIONS

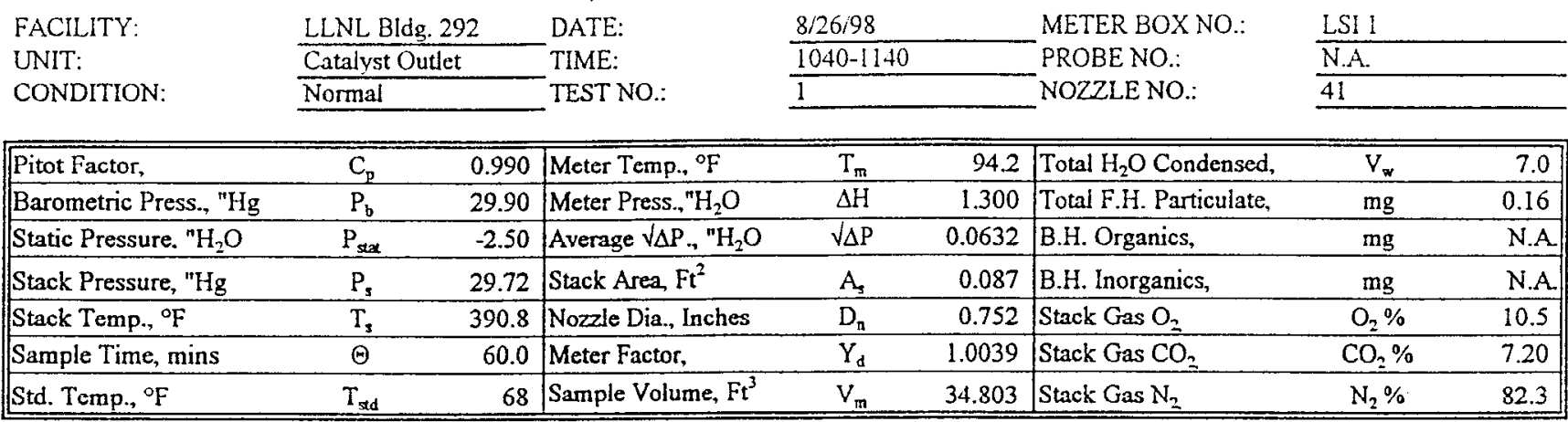
A) Gas Volume $\left(V_{m}\right)_{s d}=\left(T_{s d d}+460\right)^{*} V_{m}^{*} Y_{d}^{*}\left(P_{b}+\Delta H / 13.6\right) /\left(\left(T_{m}+460\right)^{* 29.92)}=\right.$
33.371 DSCF
B) Volume $\mathrm{H}_{2} \mathrm{O}$ collected $\left(\mathrm{V}_{\mathrm{w}}\right)_{\mathrm{sd}}=8.9148 \mathrm{E}-5^{*}\left(\mathrm{~T}_{\mathrm{sd}}+460\right) * \mathrm{~V}_{\mathrm{w}}=$
$0.329 \mathrm{SCF}$
C) Total Sample Volume $\left(V_{t}\right)_{s c d}=\left(V_{m}\right)_{s d}+\left(V_{w}\right)_{s d}=$
$33.701 \mathrm{SCF}$
D) Moisture Content $\left(\% \mathrm{H}_{2} \mathrm{O}\right)=100 *\left(\mathrm{~V}_{\mathrm{w}}\right)_{\mathrm{sdd}} /\left(\mathrm{V}_{\mathrm{t}}\right)_{\mathrm{std}}=$
$1.0 \%$
E) Stack Gas Velocity $(\mathrm{Vs})=85.49 \mathrm{C}_{\mathrm{p}} \sqrt{ }(\Delta \mathrm{P})\left(\mathrm{T}_{\mathrm{s}}+460 / \mathrm{MW}, \mathrm{P}_{\mathrm{s}}\right)=$
$5.27 \mathrm{ft} / \mathrm{sec}$
F) Stack Gas Molecular Wt. $=\left(\left(\mathrm{CO}_{2} \% * 0.44+\mathrm{O}_{2} \% * 0.32+\mathrm{N}_{2} \% * 0.28\right)\left(1-\mathrm{H}_{2} \mathrm{O} \% / 100\right)\right)+18\left(\mathrm{H}_{2} \mathrm{O} \% / 100\right)=$
$29.46 \mathrm{~g} / \mathrm{gm}-\mathrm{mole}$
G) \% Isokinetic $(\mathrm{I})=9142.88\left(\mathrm{~V}_{\mathrm{t}}\right)\left(\mathrm{T}_{\mathrm{s}}+460\right)\left(\left(\mathrm{D}_{\mathrm{n}}{ }^{2}\right)(\Theta)\left(\mathrm{P}_{\mathrm{s}}\right)\left(\mathrm{V}_{\mathrm{s}}\right)\left(\mathrm{T}_{\mathrm{sd}}+460\right)\right)=$
$93.38 \%$
H) $\mathrm{ACFM}=\left(\mathrm{V}_{\mathrm{s}}\right)\left(\mathrm{A}_{\mathrm{s}}\right) 60=$
27.53 ACFM
D) Stack Gas Vol. Flow Rate, DSCFM $=\left(\mathrm{V}_{\mathrm{s}}\right)\left(\mathrm{A}_{\mathrm{s}}\right)\left(\left(\mathrm{T}_{\mathrm{sdd}}+460\right) /\left(\mathrm{T}_{\mathrm{s}}+460\right)\right)\left(\mathrm{P}_{\mathrm{s}}\right)\left(1-\%_{\mathrm{H}} \mathrm{O} / 100\right)^{*} 2.005=$
16.80 DSCFM
J) F.H. Particulate Concentration $(\mathrm{gr} / \mathrm{DSCF})=\mathrm{mg} / \mathrm{Vmstd} * 0.01543=$
0.0001 gr/DSCF
K) F.H. Particulate Emission Rate $=0.00857^{*} \mathrm{gr} / \mathrm{DSCF} * \mathrm{DSCFM}=$
$0.000 \mathrm{Lbs} / \mathrm{hr}$ 


\section{HCl Sample Train Meter Volume}

Facility: $\quad$ LLNL BIdg. 292

Unit: $\quad$ GSS Filter Outlet

Condition: $\quad$ RTS \#1 Waste Feed

Date: $\quad 8 / 19 / 98$

Time:

Run $1 \quad$ Run $2 \quad$ Run 3

1a. Uncorrected Meter Volume (Vm)

lb. Uncorrected Meter Volume (Vm)

2. Meter Factor (Yd)

3. Barometric Pressure (Pb)

4. Meter Pressure $(\Delta H)$

5. Meter Temperature (Tm)

6. Std. Temperature (Tstd)

7. Impinger $\mathrm{H}_{2} \mathrm{O}$ Gain ( $\mathrm{Vw}$ imp)

8. Silica Gel Wt. Gain (Vw sg)

9. Total $\mathrm{H}_{2} \mathrm{O}$ Gain ( $\mathrm{Vw}$ )

10. Moisture Vapor (Vw std)

\begin{tabular}{|c|c|c|}
\hline 0.1185 & 0.1183 & 0.1181 \\
\hline 4.185 & 4.178 & 4.171 \\
\hline 0.9818 & 0.9818 & 0.9818 \\
\hline 29.90 & 29.90 & 29.90 \\
\hline 0.00 & 0.00 & 0.00 \\
\hline 78.8 & 83.6 & 84.8 \\
\hline 68 & 68 & 68 \\
\hline 0.0 & 0.0 & 0.0 \\
\hline 0.0 & 0.0 & 0.0 \\
\hline 0.0 & 0.0 & 0.0 \\
\hline 0.0 & 0.0 & 0.0 \\
\hline
\end{tabular}

Std. Meter Volume (Vm std)

Std. Meter Volume (Vm std)

\begin{tabular}{|c|c|c|c|}
\hline 4.024 & 3.981 & 3.966 & \\
\hline 0.1139 & 0.1127 & 0.1123 & \\
\hline
\end{tabular}

WHERE:

$$
\begin{aligned}
& \mathrm{ft}^{3}=\text { Cubic Feet } \\
& \mathrm{H}_{2} \mathrm{O}=\text { Water } \\
& \mathrm{Hg}=\text { Mercury } \\
& { }^{\circ} \mathrm{F}=\text { Fahrenheit } \\
& \mathrm{ml}=\text { milliliters } \\
& \mathrm{g}=\text { grams } \\
& \%=\text { Percent }
\end{aligned}
$$

DSCF $=$ Dry Standard Cubic Foot

DSCM $=$ Dry Standard Cubic Meter

\section{CALCULATIONS:}

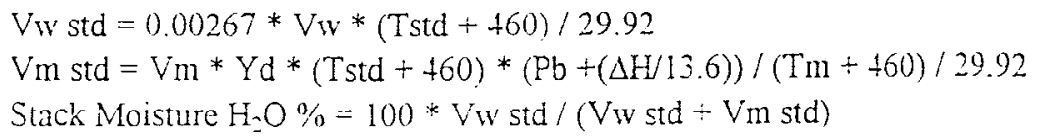




\section{HCI Sample Train Meter Volume}

Facility: $\quad$ LLNL Bldg. 292

Unit: GSS Filter Outlet

Condition: $\quad$ RTS \#2 Waste Feed

Date: $\quad 8 / 26 / 98$

Time:

Run 1 Run 2 Run 3

1a. Uncorrected Meter Volume (Vm)

Ib. Uncorrected Meter Volume (Vm)

2. Meter Factor (Yd)

3. Barometric Pressure $(\mathrm{Pb})$

4. Meter Pressure $(\Delta \mathrm{H})$

5. Meter Temperature ( $\mathrm{Tm})$

6. Std. Temperature (Tstd)

7. Impinger $\mathrm{H}_{2} \mathrm{O}$ Gain ( $\mathrm{Vw}$ imp)

8. Silica Gel Wt. Gain (Vw sg)

9. Total $\mathrm{H}_{2} \mathrm{O}$ Gain (Vw)

10. Moisture Vapor (Vw std)

\begin{tabular}{|c|c|c|}
\hline 0.1247 & 0.1450 & 0.1208 \\
\hline 4.404 & 5.121 & 4.266 \\
\hline 0.9818 & 0.9818 & 0.9818 \\
\hline 29.90 & 29.90 & 29.90 \\
\hline 0.00 & 0.00 & 0.00 \\
\hline 80.0 & 81.8 & 83.6 \\
\hline 68 & 68 & 68 \\
\hline 0.0 & 0.0 & 0.0 \\
\hline 0.0 & 0.0 & 0.0 \\
\hline 0.0 & 0.0 & 0.0 \\
\hline 0.0 & 0.0 & 0.0 \\
\hline
\end{tabular}

Std. Meter Volume (Vm std)

Std. Meter Volume (Vm std)

\begin{tabular}{|c|c|c|l|l}
\hline 4.225 & 4.896 & 4.066 & DSCF \\
\cline { 1 - 3 } 0.1196 & 0.1386 & 0.1151 & DSCM \\
\hline
\end{tabular}

\section{WHERE:}

$$
\begin{aligned}
& \mathrm{ft}^{3}=\text { Cubic Feet } \\
& \mathrm{H}_{2} \mathrm{O}=\text { Water } \\
& \mathrm{Hg}=\text { Mercury } \\
& { }^{\circ} \mathrm{F}=\text { Fahrenheit } \\
& \mathrm{ml}=\text { milliliters } \\
& \mathrm{g}=\text { grams } \\
& \%=\text { Percent }
\end{aligned}
$$

$$
\begin{aligned}
& \text { DSCF = Dry Standard Cubic Foot } \\
& \text { DSCM = Dry Standard Cubic Meter }
\end{aligned}
$$

\section{CALCULATIONS:}

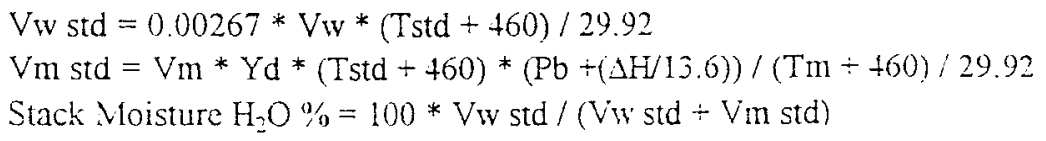




\section{APPENDIX B LAB REPORTS}




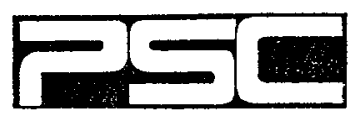

PHILIP SERVICES

\section{ORGANIC DATA PACKAGE FOR BEST ENVIRONMENTAL INC. \\ Project: Livermore}

Philip Analytical Services Corporation

5555 North Service Road

Burlington, Ontario L7L 5H7

Submission $\pi$ I00998

Prepared by: Ancy Sebastian - CSR

Approved by: Dr. Ron McLeod - Principal Scientist

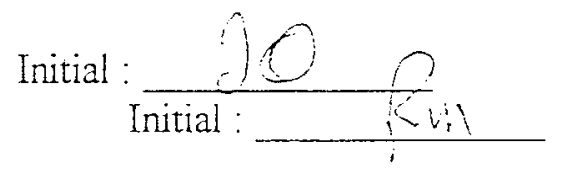




\section{PROJECT NARRATIVE}

PHILIP Analytical Services (Burlington ON)

Philip Project: AN980845

Philip Submission \#:810098

Client: Best Environmental Inc.

Client Project: Livermore

\section{SAMPLE RECEIPT/ANALYSIS}

a) Sample Listing

Philip D $\begin{gathered}\text { Client } \\ \text { Sample D }\end{gathered}$

Date
Sampled

Date
Received

Date

Run

Date

\section{Polychlorinated Biphenyls via CARB 428 Method}

04315698 Method Blank

04315798

04315898

R4M23-TB

$98 / 08 / 26$

04315998

04316098

R1M23 Baghouse Inlet

$98 / 08 / 26$

R2M23 Baghouse Inlet

R3M23 Baghouse Inlet

04316198

R1M23 Cot Outlet

$98 / 08 / 26$

$98 / 08 / 26$

$98 / 08 / 26$

Semi-Volatiles via SW846 Method 8270

$\begin{array}{ll}04315698 & \text { Method Blank } \\ 04315798 & \text { R4M23-TB } \\ 04315898 & \text { R1M23 Baghouse Inlet } \\ 04315998 & \text { R2M23 Baghouse Inlet } \\ 04316098 & \text { R3M23 Baghouse Inlet } \\ 04316198 & \text { R1M23 Cot Outlet } \\ 04316398 & \text { R1M429 BaghouseInlet } \\ \text { 04316498 } & \text { R2M429 BaghouseInlet } \\ 04316598 & \text { R3M429 BaghouseInlet } \\ \text { )4316698 } & \text { R1M429 Cat Outlet }\end{array}$

VOST via SW846 Method 5041A/8260B

- $04318798 \quad$ LLNL Field Blank

04318898 LLNL Trip Blank

04318998 RTS\#1/R1/0030 15a/b

04319098 RTS\#1/R1/0030 2a/b

04319198 RTS\#I/R1/0030 3a/b

()4319298 RTS\#1/R2/0030 4a/b

$014319398 \quad$ RTS\#1/R2/0030 5a/b

(1)4319498 RTS\#1/R2/0030 6a/b

04319598 RTS\#1/R3/0030 8a/b

J4319698 RTSH H/R3/0030 9ab

1)4319798 RTSH $1 / R 3 / 003010 \mathrm{a} / \mathrm{b}$

04319898 RTSHI/RICAT 1lab

1) 4319998 RTS\#1/RICAT 13a/b

$\begin{array}{llll}98 / 08 / 26 & 98 / 08 / 28 & 98 / 09 / 27 & 98 / 10 / 05 \\ 98 / 08 / 26 & 98 / 08 / 28 & 98 / 09 / 27 & 98 / 10 / 05 \\ 98 / 08 / 26 & 98 / 08 / 28 & 98 / 09 / 27 & 98 / 10 / 05 \\ 98 / 08 / 26 & 98 / 08 / 28 & 98 / 09 / 27 & 98 / 10 / 05 \\ 98 / 08 / 26 & 98 / 08 / 28 & 98 / 09 / 27 & 98 / 10 / 05 \\ 98 / 08 / 26 & 98 / 08 / 28 & 98 / 09 / 27 & 98 / 10 / 05 \\ 98 / 08 / 18 & 98 / 08 / 28 & 98 / 09 / 27 & 98 / 10 / 05 \\ 98 / 08 / 18 & 98 / 08 / 28 & 98 / 09 / 27 & 98 / 10 / 05 \\ 98 / 08 / 19 & 98 / 08 / 28 & 98 / 09 / 27 & 98 / 10 / 05 \\ 98 / 08 / 18 & 98 / 08 / 28 & 98 / 09 / 27 & 98 / 10 / 05\end{array}$

$\begin{array}{llll}98 / 08 / 18 & 98 / 08 / 28 & 98 / 09 / 04 & 98 / 09 / 04 \\ 98 / 08 / 18 & 98 / 08 / 28 & 98 / 09 / 04 & 98 / 09 / 04 \\ 98 / 08 / 18 & 98 / 08 / 28 & 98 / 09 / 04 & 98 / 09 / 04 \\ 98 / 08 / 18 & 98 / 08 / 28 & 98 / 09 / 04 & 98 / 09 / 04 \\ 98 / 08 / 18 & 98 / 08 / 28 & 98 / 09 / 04 & 98 / 09 / 04 \\ 98 / 08 / 18 & 98 / 08 / 28 & 98 / 09 / 04 & 98 / 09 / 04 \\ 98 / 08 / 18 & 98 / 08 / 28 & 98 / 09 / 04 & 98 / 09 / 04 \\ 98 / 08 / 18 & 98 / 08 / 28 & 98 / 09 / 04 & 98 / 09 / 04 \\ 98 / 08 / 18 & 98 / 08 / 28 & 98 / 09 / 04 & 98 / 09 / 04 \\ 98 / 08 / 18 & 98 / 08 / 28 & 98 / 09 / 04 & 98 / 09 / 04 \\ 98 / 08 / 18 & 98 / 08 / 28 & 98 / 09 / 04 & 98 / 09 / 04 \\ 98 / 08 / 18 & 98 / 08 / 28 & 98 / 09 / 09 & 98 / 09 / 09 \\ 98 / 08 / 18 & 98 / 08 / 28 & 98 / 09 / 09 & 98 / 09 / 09\end{array}$

$98 / 10 / 05$

$98 / 10 / 05$

$98 / 10 / 05$

$98 / 10 / 05$

98/10/05

$98 / 09 / 27 \quad 98 / 10 / 05$ 


$\begin{array}{llllll}04320098 & \text { RTS\#1/R1CAT 14a/b } & 98 / 08 / 18 & 98 / 08 / 28 & 98 / 09 / 09 & 98 / 09 / 09 \\ 04320198 & \text { LINL Field Blank } & 98 / 08 / 18 & 98 / 08 / 28 & 98 / 09 / 09 & 98 / 09 / 09 \\ 04320298 & \text { RTS\#2/R1/0030 23a/b } & 98 / 08 / 26 & 98 / 08 / 28 & 98 / 09 / 08 & 98 / 09 / 08 \\ 04320398 & \text { RTS\#2/R1/0030 22a/b } & 98 / 08 / 26 & 98 / 08 / 28 & 98 / 09 / 08 & 98 / 09 / 08 \\ 04320498 & \text { RTS\#2/R1/0030 21a/b } & 98 / 08 / 26 & 98 / 08 / 28 & 98 / 09 / 08 & 98 / 09 / 08 \\ 04320598 & \text { RTS\#2/R2/0030 20a/b } & 98 / 08 / 26 & 98 / 08 / 28 & 98 / 09 / 08 & 98 / 09 / 08 \\ 04320698 & \text { RTS\#2/R2/003019a/b } & 98 / 08 / 26 & 98 / 08 / 28 & 98 / 09 / 08 & 98 / 09 / 08 \\ 04320798 & \text { RTS\#2/R2/0030 18a/b } & 98 / 08 / 26 & 98 / 08 / 28 & 98 / 09 / 08 & 98 / 09 / 08 \\ 04320898 & \text { RTS\#2/R3/0030 17a/b } & 98 / 08 / 26 & 98 / 08 / 28 & 98 / 09 / 08 & 98 / 09 / 08 \\ 04320998 & \text { RTS\#2/R3/0030 16a/b } & 98 / 08 / 26 & 98 / 08 / 28 & 98 / 09 / 09 & 98 / 09 / 09 \\ 04321098 & \text { RTS\#2/R3/0030 1a/b } & 98 / 08 / 26 & 98 / 08 / 28 & 98 / 09 / 09 & 98 / 09 / 09 \\ 04321198 & \text { RTS\#2/R1CAT 2a/b } & 98 / 08 / 26 & 98 / 08 / 28 & 98 / 09 / 09 & 98 / 09 / 09 \\ 04321298 & \text { RTS\#2/R1CAT 3a/b } & 98 / 08 / 26 & 98 / 08 / 28 & 98 / 09 / 09 & 98 / 09 / 09 \\ 04321398 & \text { RTS\#2/R1CAT 4a/b } & 98 / 08 / 26 & 98 / 08 / 28 & 98 / 09 / 09 & 98 / 09 / 09\end{array}$

\section{PCDD/F(DB5) via EPA Method 23-Primary Column Analysis}

$\begin{array}{llllll}04315698 & \text { Method Blank } & 98 / 08 / 26 & 98 / 08 / 28 & 98 / 09 / 27 & 98 / 10 / 05 \\ 04315798 & \text { R4M23-TB } & 98 / 08 / 26 & 98 / 08 / 28 & 98 / 09 / 27 & 98 / 10 / 02 \\ 04315898 & \text { RIM23 Baghouse Inlet } & 98 / 08 / 26 & 98 / 08 / 28 & 98 / 09 / 27 & 98 / 10 / 04 \\ 04315998 & \text { R2M23 Baghouse Inlet } & 98 / 08 / 26 & 98 / 08 / 28 & 98 / 09 / 27 & 98 / 10 / 04 \\ 04316098 & \text { R3M23 Baghouse Inlet } & 98 / 08 / 26 & 98 / 08 / 28 & 98 / 09 / 27 & 98 / 10 / 04 \\ \text { J4316198 } & \text { R1M23 Cot Outlet } & 98 / 08 / 26 & 98 / 08 / 28 & 98 / 09 / 27 & 98 / 10 / 07 \\ 04316398 & \text { RIM429 BaghouseInlet } & 98 / 08 / 18 & 98 / 08 / 28 & 98 / 09 / 27 & 98 / 10 / 04 \\ \text { 04316498 } & \text { R2M429 BaghouseInlet } & 98 / 08 / 18 & 98 / 08 / 28 & 98 / 09 / 27 & 98 / 10 / 04 \\ 04316598 & \text { R3M429 BaghouseInlet } & 98 / 08 / 19 & 98 / 08 / 28 & 98 / 09 / 27 & 98 / 10 / 04 \\ 04316698 & \text { R1M429 Cat Outlet } & 98 / 08 / 18 & 98 / 08 / 28 & 98 / 09 / 27 & 98 / 10 / 04\end{array}$

\section{PCDD/F(DB225) via EPA Method 23-Confirmational Analysis}

\begin{tabular}{|c|c|c|c|c|c|}
\hline 04315698 & Method Blank & $98 / 08 / 26$ & $98 / 08 / 28$ & $98 / 09 / 27$ & $98 / 10 / 20$ \\
\hline 04315798 & $\mathrm{R} 4 \mathrm{M} 23-\mathrm{TB}$ & $98 / 08 / 26$ & $98 / 08 / 28$ & $98 / 09 / 27$ & $98 / 10 / 20$ \\
\hline 04315898 & R1M23 Baghouse Inlet & $98 / 08 / 26$ & $98 / 08 / 28$ & $98 / 09 / 27$ & $98 / 10 / 20$ \\
\hline 04315998 & R2M23 Baghouse Inlet & $98 / 08 / 26$ & $98 / 08 / 28$ & $98 / 09 / 27$ & $98 / 10 / 20$ \\
\hline 1)4316098 & R3M23 Baghouse Inlet & $98 / 08 / 26$ & $98 / 08 / 28$ & $98 / 09 / 27$ & $98 / 10 / 20$ \\
\hline 04316198 & R1M23 Cot Outlet & $98 / 08 / 26$ & $98 / 08 / 28$ & $98 / 09 / 27$ & $98 / 10 / 20$ \\
\hline 04316398 & R1M429 BaghouseInlet & $98 / 08 / 18$ & $98 / 08 / 28$ & $98 / 09 / 27$ & $98 / 10 / 20$ \\
\hline$) 4316498$ & R2M429 BaghouseInlet & $98 / 08 / 18$ & $98 / 08 / 28$ & $98 / 09 / 27$ & $98 / 10 / 20$ \\
\hline 04316598 & R3M429 Baghouselnlet & $98 / 08 / 19$ & $98 / 08 / 28$ & $98 / 09 / 27$ & $98 / 10 / 20$ \\
\hline 4316698 & R1M429 Cat Outlet & $98 / 08 / 18$ & $98 / 08 / 2 S$ & $98 / 09 / 27$ & $98 / 10 / 20$ \\
\hline
\end{tabular}

Run Date is defined as the date of injection of the last calibration standard (12 hour or less) prior to the samples analyzed within that run sequence. Therefore the time of calibration injection that defines the I un date is always within 12 hours of the time of sample injection.

b) Shipping Problems: none encountered

vOST Samples were shipped in the same container as the SV solvents. Therefore significant background of recovery solvents were observed in the VOST sampies during analysis.

c) Documentation Problems: none encountered 


\section{Certificate of Analysis}

\section{CLIENT INFORMATION}

$\begin{array}{ll}\text { Attention: } & \text { Dan Cartner } \\ \text { Client Name: } & \text { Best Environmental Inc. } \\ \text { Project: } & \text { Livermore } \\ \text { Project Desc: } & \text { Stack Emissions }\end{array}$

Address:

\author{
15890 Foothill Blvd \\ San Leandro, CA \\ CA 94578
}

Fax Number: 5102784018

Phone Number: 5102784011

\section{LABORATORY INFORMATION}

$\begin{array}{ll}\text { Contact: } & \text { Ron McLeod } \\ \text { Project: } & \text { AN980845 } \\ \text { Date Received: } & 98 / 08 / 28 \\ \text { Date Reported: } & 98 / 10 / 09 \\ & \\ \text { Submission No.: } & 810098 \\ \text { Sample No.: } & 043156\end{array}$

NOTES: $\quad$ " - -'=not analysed ' $<$ ' $=$ less than Method Derection Limit (MDL) 'NA' = no data available LOQ can by determined for all analytes by multiplying the appropriate $M D L X 3.33$ Solids uluta is based on dry weight except for biota analyses. Organic analyses are not corrected for extraction recovery standards except for isotope dilution methods. (ie CAKB $\$ 29$ PAH, all PCDD/F and DBD/DBF analyses)

Methods used by PASC are based upon those found in 'Standard Methods for the Examination of Water and Wastewater', Nineteenth Edition. Other methods are based on the principles of MSA or EPA methodologies. New York State: ELAP Identification Number 10756.

All work recorded herein has been done in accordance with normal professional standards using accepted testing methodologies, quality assurance and quality control procedures except where otherwise agreed to by the client and testing company in writing. Any and all use of these test results shall be limited to the actual cost of the pertinent analysis done. There is no other warranty expressed or implied. Your samples will be retained at PASC for a period of three weeks from receipt of data or as per contract.

COMMENTS: Revision 98/10/23: Confirmation Data

Certified by: 


\begin{tabular}{|c|c|c|c|c|c|c|}
\hline $\begin{array}{r}\text { Client ID: } \\
\text { Lab No.: } \\
\text { Date Sampled: }\end{array}$ & & $\begin{array}{l}\text { Method } \\
\text { Blank } \\
04315698 \\
98 / 08 / 26\end{array}$ & $\begin{array}{c}\text { Blank } \\
\text { Spike \# } 1 \\
04315698 \\
98 / 08 / 26\end{array}$ & $\begin{array}{c}\text { Blank } \\
\text { Spike \#1 } \\
04315698 \\
98 / 08 / 26\end{array}$ & $\begin{array}{c}\text { Blank } \\
\text { Spike } \# 2 \\
04315698 \\
98 / 08 / 26\end{array}$ & $\begin{array}{c}\text { Blank } \\
\text { Spike \#2 } \\
04315698 \\
98 / 08 / 26\end{array}$ \\
\hline Component & Units & & & $\%$ Recoveries & & \% Recoveries \\
\hline Total Cl4-Dibenzofurans & $\mathrm{pg}$ & 19 & 5300 & 107 & 4900 & 99 \\
\hline Total C15-Dibenzofurans & $"$ & $<24$ & 11000 & 110 & 11000 & 113 \\
\hline Total Cl6-Dibenzofurans & $"$ & $<22$ & 23000 & 112 & 23000 & 118 \\
\hline Total C17-Dibenzofurans & $"$ & $<6.3$ & 11000 & 110 & 11000 & 105 \\
\hline 18-Dibenzofuran & $"$ & $<7.1$ & 11000 & 110 & 12000 & 117 \\
\hline Total C14-Dibenzo-p-dioxins & $"$ & $<19$ & 6400 & 127 & 6500 & 130 \\
\hline i otal C15-Dibenzo-p-dioxins & $"$ & 62 & 6200 & 124 & 6200 & 124 \\
\hline Total Cl6-Dibenzo-p-dioxins & $"$ & $<8.9$ & 19000 & 125 & 19000 & 122 \\
\hline Fotal C17-Dibenzo-p-dioxins & $"$ & $<9.8$ & 6000 & 120 & 6300 & 125 \\
\hline C18-Dibenzo-p-dioxin & $"$ & 9.6 & 11000 & 110 & 12000 & 116 \\
\hline Liternal Recoveries & $\%$ & & & & & \\
\hline $2,3,7,8-\mathrm{T} 4 \mathrm{CDF}-13 \mathrm{C}-12$ & & 68 & 72 & 72 & 70 & 70 \\
\hline $2,3,7,8-\mathrm{T} 4 \mathrm{CDD}-13 \mathrm{C}-12$ & & 70 & 71 & 71 & 69 & 69 \\
\hline $1.2,3,7,8-P 5 C D F-13 C-12$ & & 81 & 88 & 88 & 74 & 74 \\
\hline 2,3,7,8-P5CDD-13C-12 & & 89 & 95 & 95 & 79 & 79 \\
\hline $1.2,3,6,7,8-\mathrm{H} 6 \mathrm{CDF}-13 \mathrm{C}-12$ & & 87 & 92 & 92 & 89 & 89 \\
\hline $1,2,3,6,7,8-\mathrm{H} 6 \mathrm{CDD}-13 \mathrm{C}-12$ & & 95 & 96 & 96 & 94 & 94 \\
\hline $1.2,3,4,6,7,8-\mathrm{H} 7 \mathrm{CDF}-13 \mathrm{C}-12$ & & 88 & 89 & 89 & 82 & 82 \\
\hline ᄂ $2,3,4,6,7,8-\mathrm{H} 7 \mathrm{CDD}-13 \mathrm{C}-12$ & & 93 & 93 & 93 & 87 & 87 \\
\hline$O C D D-13 \mathrm{C}-12$ & & 87 & 89 & 89 & 78 & 78 \\
\hline Siurrogate Recoveries & $\%$ & & & & & \\
\hline $2.3,7,8-\mathrm{T} 4 \mathrm{CDD}-37 \mathrm{Cl} 4$ & & NS & NS & NS & NS & NS \\
\hline$\therefore 3,4,7,8-\mathrm{P} 5 \mathrm{CDF}-13 \mathrm{C}-12$ & & NS & NS & NS & NS & NS \\
\hline $1,2,3,4,7,8-\mathrm{H} 6 \mathrm{CDF}-13 \mathrm{C}-12$ & & NS & NS & NS & NS & NS \\
\hline$, 2,3,4,7,8-\mathrm{H} 6 \mathrm{CDD}-13 \mathrm{C}-12$ & & NS & NS & NS & NS & NS \\
\hline $2,3,4,7,8,9-\mathrm{H} 7 \mathrm{CDF}-13 \mathrm{C}-12$ & & NS & NS & NS & NS & NS \\
\hline Aternate & $\%$ & & & & & \\
\hline $.2,3,7,8,9-\mathrm{H} 6 \mathrm{CDF}-13 \mathrm{C}-12$ & & $10 \Sigma$ & 102 & 102 & 106 & 106 \\
\hline$\therefore 3,7,8-C 14-$ Dibenzofuran (DB5) & $\mathrm{pg}$ & 19 & 5300 & 107 & 4900 & 98 \\
\hline 2,3,7,8-Cl4-Dibenzo-p-dioxin & $"$ & $<19$ & 6400 & 127 & 6500 & 130 \\
\hline 2,3,7,8-C15-Dibenzofuran & $"$ & $<6.9$ & 5500 & 109 & 5300 & 106 \\
\hline 2.3,4,7,8-Cl5-Dibenzofuran & $"$ & $<25$ & 5500 & 111 & 5900 & 119 \\
\hline 1 2,3,7,8-C15-Dibenzo-p-dioxin & $"$ & $<6.5$ & 6200 & 124 & 6200 & 124 \\
\hline $1,2,3,4,7,8-C l 6$-Dibenzofuran & $"$ & $<8.1$ & 5100 & 102 & 5600 & 112 \\
\hline $12,3,6,7,8-C 16-D i b e n z o f u r a n$ & $"$ & $<7.2$ & 6200 & 125 & 5900 & $11 \overline{9}$ \\
\hline $23,4,6,7,8$-Cl6-Dibenzofuran & $"$ & $<9.2$ & 5700 & 115 & 6500 & 129 \\
\hline $3,2,3,7,8,9-C 16-$ Dibenzofuran & $"$ & $<9.6$ & 5300 & 107 & 5500 & 110 \\
\hline i $\hat{2}, 3,4,7,8-C 16-D i b e n z o-p-d i o x i n$ & $"$ & $<9.2$ & 6000 & 120 & 5500 & 110 \\
\hline 2,3,6,7,8-C16-Dibenzo-p-dioxin & $"$ & $<9.6$ & 6400 & 129 & 6400 & 129 \\
\hline i $2,3,7,3,9-C 16-$ Dibenzo-p-dioxin & $"$ & $<3.9$ & 6200 & 125 & 6400 & 128 \\
\hline $1.2,3,4,6,7,8-\mathrm{Cl} 7$-Dibenzofuran & $"$ & $<5.9$ & 6000 & 120 & 5400 & 108 \\
\hline $1,2,3,4,7,8,9-\mathrm{Cl} 7$-Dibenzofuran & $"$ & $<6.6$ & 5300 & 106 & 5100 & 102 \\
\hline $2,3,4,6,7,8-C 17-D i b e n z o-p-d i o x i n$ & $"$ & $<9.8$ & 6000 & 120 & 6300 & 125 \\
\hline ! 2,3,4,6,7,8,9-C18-Dibenzoruran & $"$ & $<i$. & $\$ 1000$ & 110 & 12000 & $11 \%$ \\
\hline 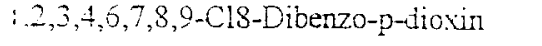 & $"$ & 0.6 & 11000 & 110 & 12000 & 110 \\
\hline
\end{tabular}




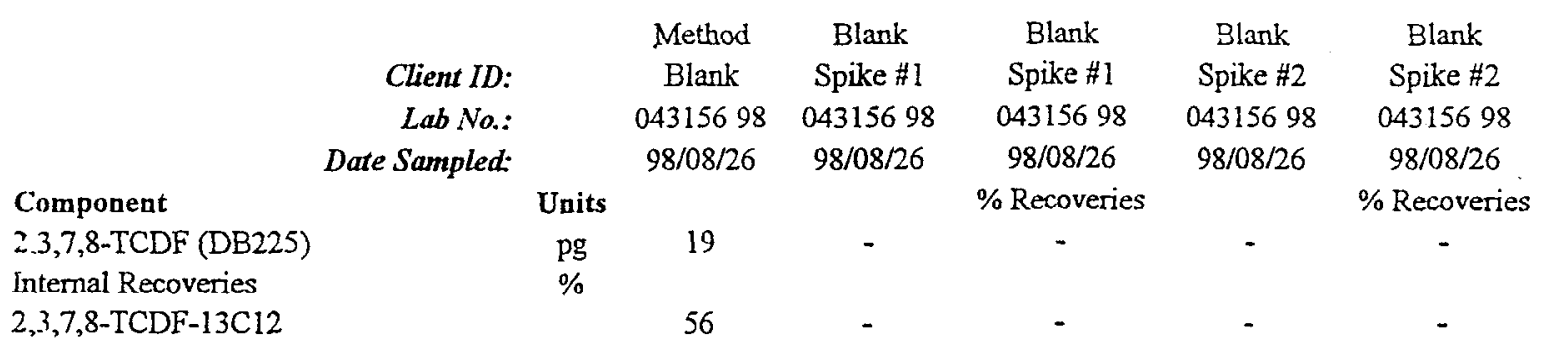




\begin{tabular}{|c|c|c|c|c|c|}
\hline $\begin{array}{r}\text { Client ID: } \\
\text { Lab No.: } \\
\text { Date Sampled: }\end{array}$ & & $\begin{array}{c}\text { R4M23-TB } \\
04315798 \\
98 / 08 / 26\end{array}$ & $\begin{array}{c}\text { R1M23 Baghouse } \\
\text { Inlet } \\
04315898 \\
98 / 08 / 26\end{array}$ & $\begin{array}{c}\text { R2M23 Baghouse } \\
\text { Inlet } \\
04315998 \\
98 / 08 / 26\end{array}$ & $\begin{array}{c}\text { R3M23 Baghouse } \\
\text { Inlet } \\
04316098 \\
98 / 08 / 26\end{array}$ \\
\hline Component & Units & & & & \\
\hline otal Cl4-Dibenzofurans & $\mathrm{pg}$ & 31 & 390 & 220 & 510 \\
\hline Fotal C15-Dibenzofurans & $n$ & 34 & 66 & 120 & 360 \\
\hline Total Cl6-Dibenzofurans & $n$ & $<14$ & 18 & 31 & 79 \\
\hline Total C17-Dibenzofurans & $"$ & $<14$ & 6.5 & 14 & 23 \\
\hline C18-Dibenzofuran & $n$ & $<36$ & 13 & 8.9 & 9.0 \\
\hline Total Cl4-Dibenzo-p-dioxins & $"$ & 31 & 100 & 94 & 58 \\
\hline Total Cl5-Dibenzo-p-dioxins & $n$ & 40 & 24 & 34 & 15 \\
\hline Total Cl6-Dibenzo-p-dioxins & $"$ & $<44$ & 9.1 & 20 & 10 \\
\hline Total C17-Dibenzo-p-dioxins & $"$ & $<23$ & 12 & 26 & 13 \\
\hline Cl8-Dibenzo-p-dioxin & $"$ & $<52$ & 290 & 200 & 230 \\
\hline Internal Recoveries & $\%$ & & & & \\
\hline$\therefore 3,7,8-\mathrm{T} 4 \mathrm{CDF}-13 \mathrm{C}-12$ & & 85 & 86 & 84 & 87 \\
\hline $23,7,8-\mathrm{T} 4 \mathrm{CDD}-13 \mathrm{C}-12$ & & 74 & 82 & 79 & 77 \\
\hline $1.2,3,7,8-P 5 C D F-13 C-12$ & & 80 & 76 & 82 & 76 \\
\hline $1,2,3,7,8-P 5 C D D-13 \mathrm{C}-12$ & & 85 & 76 & 84 & 74 \\
\hline $1,2,3,6,7,8-\mathrm{H} 6 \mathrm{CDF}-13 \mathrm{C}-12$ & & 129 & 114 & 125 & 130 \\
\hline $.2,3,6,7,8-H 6 C D D-13 C-12$ & & 129 & 110 & 104 & 104. \\
\hline , 2,3,4,6,7,8-H7CDF-13C-12 & & 98 & 88 & 98 & 95 \\
\hline$: 2,3,4,6,7,8-H 7 C D D-13 C-12$ & & 86 & 79 & 90 & 86 \\
\hline ()CDD-13C-12 & & 87 & 76 & 87 & 83 \\
\hline Surrogate Recoveries & $\%$ & & & & \\
\hline . . 3,7,8-T4CDD-37C14 & & 95 & 102 & 100 & 98 \\
\hline$-3,4,7,8-\mathrm{P} 5 \mathrm{CDF}-13 \mathrm{C}-12$ & & 108 & 107 & 106 & 104 \\
\hline i. $2,3,4,7,8-\mathrm{H} 6 \mathrm{CDF}-13 \mathrm{C}-12$ & & 77 & 85 & 82 & 82 \\
\hline $1,2,3,4,7,8-H 6 C D D-13 \mathrm{C}-12$ & & 73 & 85 & 104 & 104 \\
\hline$: 2,3,4,7,8,9-\mathrm{H} 7 \mathrm{CDF}-13 \mathrm{C}-12$ & & 88 & 90 & 91 & 88 \\
\hline Altemate & $\%$ & & & & \\
\hline I $2,3,7,8,9-\mathrm{H} 6 \mathrm{CDF}-13 \mathrm{C}-12$ & & 99 & 100 & 101 & 106 \\
\hline $2,3,7,8$-Cl4-Dibenzofuran (DB5) & $\mathrm{pg}$ & 31 & 60 & 65 & 81 \\
\hline $2,3,7,8$-Cl4-Dibenzo-p-dioxin & $"$ & 31 & 44 & 54 & 45 \\
\hline i 2,3,7,8-C15-Dibenzofuran & $"$ & $<22$ & 12 & 19 & 52 \\
\hline $2,7,4,7,8-C 15-$ Dibenzofuran & $"$ & 35 & 36 & 51 & 52 \\
\hline $12,3,7,8-C 15$-Dibenzo-p-dioxin & $"$ & $<33$ & 15 & 23 & 15 \\
\hline i.2,3,4,7,8-Cl6-Dibenzofuran & $"$ & $<13$ & 7.5 & 8.1 & 14 \\
\hline : 2,3,6,7,8-Cl6-Dibenzofuran & $"$ & $<12$ & 4.6 & 4.5 & 12 \\
\hline $23,4,6,7,8-C 16$-Dibenzofuran & $"$ & $<15$ & 5.8 & 6.4 & 12 \\
\hline : 2,3,7,8,9-Cl6-Dibenzofuran & $"$ & $<15$ & $<5.1$ & 1.4 & 6.7 \\
\hline 1.2,3,4,7,8-Cl6-Dibenzo-p-dioxin & $"$ & $<45$ & $<4.2$ & 4.5 & $<4.6$ \\
\hline 2,3,6,7,8-Cl6-Dibenzo-p-dioxin & $"$ & $<42$ & 4.3 & 5.1 & 5.7 \\
\hline 2,3,7,8,9-Cl6-Dibenzo-p-dioxin & $"$ & $<14$ & 4.7 & 5.1 & 4.5 \\
\hline $2,3,4,6,7,8$-Cl7-Dibenzofuran & $"$ & $<14$ & 6.2 & 6.1 & 9.9 \\
\hline $2,3.4,7,8,9-C 17-D i b e n z o f u r a n$ & $"$ & $<15$ & $<5.0$ & $<5.1$ & 6.2 \\
\hline : $2,3,4,6,7,8-C l 7-D i b e n z o-p-d i o x i n$ & $"$ & 23 & $<14$ & 15 & 13 \\
\hline $2,3,4,6,7,3,9-\mathrm{Cl}$-Dibenzofuran & $"$ & $<36$ & 13 & 8.9 & 90 \\
\hline$\therefore, 3,4,5,7,8,9-C 18-D i o e n z o-p-d i o x i n$ & $"$ & $<2$ & 290 & 200 & 230 \\
\hline
\end{tabular}




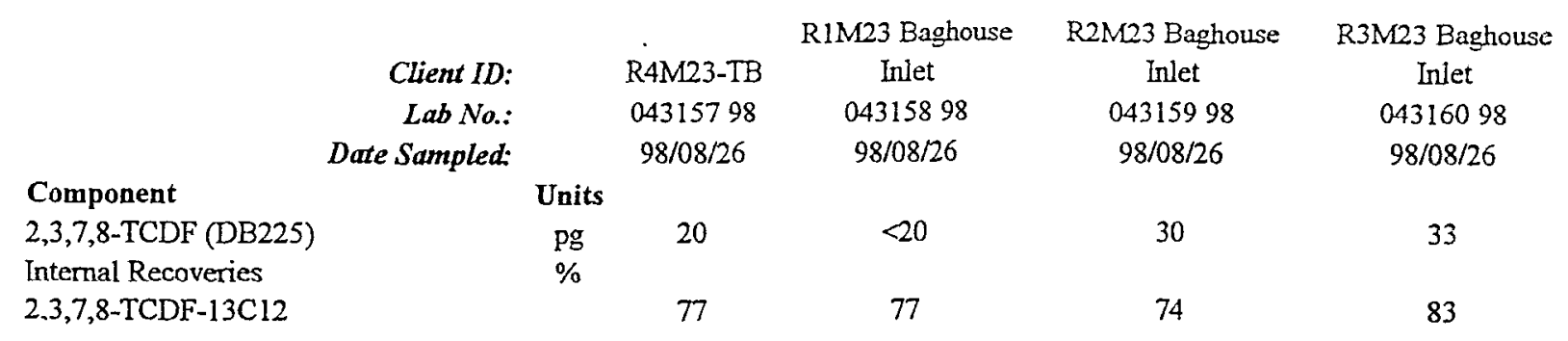




\begin{tabular}{|c|c|c|c|c|c|c|}
\hline $\begin{array}{r}\text { Client ID: } \\
\text { Lab No.: } \\
\text { Date Sampled: }\end{array}$ & & $\begin{array}{c}\text { RIM23 Cot } \\
\text { Outlet } \\
04316198 \\
98 / 08 / 26\end{array}$ & $\begin{array}{c}\text { R1M429 } \\
\text { BaghouseInlet } \\
04316398 \\
98 / 08 / 18\end{array}$ & $\begin{array}{c}\text { R2M429 } \\
\text { BaghouseIniet } \\
04316498 \\
98 / 08 / 18\end{array}$ & $\begin{array}{c}\text { R3M429 } \\
\text { BaghouseInlet } \\
04316598 \\
98 / 08 / 19\end{array}$ & $\begin{array}{c}\text { R1M429 Cat } \\
\text { Outlet } \\
04316698 \\
98 / 08 / 18\end{array}$ \\
\hline romponent & Units & & & & & \\
\hline Total Cl4-Dibenzofurans & pg & 14 & 34 & 35 & 31 & 49 \\
\hline Total Cl5-Dibenzofurans & $\pi$ & 22 & 58 & 68 & 56 & 94 \\
\hline Total Cl6-Dibenzofurans & $n$ & 5.7 & 16 & 23 & 20 & 22 \\
\hline Total C17-Dibenzofurans & $n$ & $<4.2$ & $<4.2$ & $<6.0$ & 9.2 & $<11$ \\
\hline C18-Dibenzofuran & $n$ & $<7.1$ & 7.6 & 9.0 & 22 & $<8.9$ \\
\hline Total Cl4-Dibenzo-p-dioxins & $n$ & 30 & 39 & 50 & 34 & 47 \\
\hline Total Cl5-Dibenzo-p-dioxins & $n$ & 7.5 & 14 & 21 & 13 & 27 \\
\hline Total Cl6-Dibenzo-p-dioxins & $n$ & $<4.0$ & $<4.1$ & 11 & $<7.5$ & $<8.1$ \\
\hline Total C17-Dibenzo-p-dioxins & $n$ & $<4.4$ & 8.2 & 18 & 30 & 10 \\
\hline C18-Dibenzo-p-dioxin & " & 9.4 & 22 & 250 & 500 & 97 \\
\hline Internal Recoveries & $\%$ & & & & & \\
\hline$\therefore 3,7,8-\mathrm{T} 4 \mathrm{CDF}-13 \mathrm{C}-12$ & & 93 & 82 & 84 & 80 & 68 \\
\hline$\therefore 3,7,8-T 4 C D D-13 C-12$ & & 80 & 74 & 76 & 71 & 60 \\
\hline $.2,3,7,8-P 5 C D F-13 C-12$ & & 84 & 82 & 81 & 80 & 70 \\
\hline $2,3,7,8-P 5 C D D-13 C-12$ & & 87 & 84 & 82 & 81 & 72 \\
\hline $2,3,6,7,8-\mathrm{H} 6 \mathrm{CDF}-13 \mathrm{C}-12$ & & 109 & 113 & 107 & 100 & 101 \\
\hline $2,3,6,7,8-H 6 C D D-13 C-12$ & & 98 & 105 & 102 & 104 & 99 \\
\hline $.2,3,4,6,7,8-\mathrm{H} 7 \mathrm{CDF}-13 \mathrm{C}-12$ & & 99 & 98 & 95 & 96 & 88 \\
\hline ' $2,3,4,6,7,8-H 7 C D D-13 C-12$ & & 93 & 90 & 86 & 89 & 86 \\
\hline DCDD-13C-12 & & 86 & 88 & 85 & 88 & 82 \\
\hline Bilnogate Recoveries & $\%$ & & & & & \\
\hline $23,7,8-T 4 C D D-37 \mathrm{Cl} 4$ & & 98 & 97 & 99 & 96 & 97 \\
\hline $2,3,4,7,8-\mathrm{P} 5 \mathrm{CDF}-13 \mathrm{C}-12$ & & 105 & 105 & 105 & 106 & 106 \\
\hline 1. $2,3,4,7,8-\mathrm{H}^{2} \mathrm{CDF}-13 \mathrm{C}-12$ & & 95 & 95 & 93 & 98 & 93 \\
\hline $1.2,3,4,7,8-\mathrm{H} 6 \mathrm{CDD}-13 \mathrm{C}-12$ & & 107 & 102 & 102 & 101 & 95 \\
\hline$: 2,3,4,7,8,9-\mathrm{H} 7 \mathrm{CDF}-13 \mathrm{C}-12$ & & 93 & 93 & 94 & 98 & 93 \\
\hline i itemate & $\%$ & & & & & \\
\hline i $2,3,7,8,9-\mathrm{H} 6 \mathrm{CDF}-13 \mathrm{C}-12$ & & 102 & 103 & 100 & 99 & 97 \\
\hline 2,3,7,8-Cl4-Dibenzofuran (DB5) & pg & 14 & 34 & 35 & 31 & 49 \\
\hline 2,3,7,8-Cl4-Dibenzo-p-dioxin & $"$ & 30 & 39 & 50 & 34 & 47 \\
\hline $2,3,7,8-C l 5-D i b e n z o f u r a n$ & $"$ & 5.0 & 12 & 18 & 13 & 22 \\
\hline $2.3,4,7,8$-Cl5-Dibenzofuran & $"$ & 18 & 41 & 51 & 37 & 58 \\
\hline : $2,3,7,8-C 15-$ Dibenzo-p-dioxin & $"$ & 7.5 & 14 & 21 & 13 & 27 \\
\hline $.2,3,4,7,8-C 16-$ Dibenzofuran & $"$ & 5.5 & 6.3 & 8.7 & 8.8 & 8.3 \\
\hline$\cdot 2,3,6,7,8-C 16-$ Dibenzofuran & $"$ & $<4.0$ & 3.5 & 5.9 & 4.7 & 5.9 \\
\hline $2.3,4,6,7,8$-Cl6-Dibenzofuran & $\pi$ & $<5.0$ & 6.3 & 7.4 & 6.1 & 7.5 \\
\hline $2,3,7,8,9-C 16-$ Dibenzofuran & $"$ & $<5.2$ & $<4.5$ & $<4.6$ & $<4.9$ & $<1.2$ \\
\hline $2,3,4,7,8$-C16-Dibenzo-p-dioxin & $"$ & $<7.2$ & $<1.2$ & $6 . \hat{3}$ & $<7.7$ & $<8.4$ \\
\hline 2,3,6,7,8-Cl6-Dibenzo-p-dioxin & $"$ & $<30$ & $<4.0$ & 5.0 & $<7.2$ & $<7.8$ \\
\hline - $2,3,7,8,9-C l 6-D i b e n z o-p-d i o x i n$ & $"$ & $<+0$ & $<4.1$ & $<3.6$ & $<7.5$ & $<8.1$ \\
\hline$\therefore 2,3,4,6,7,8-\mathrm{Cl} 7$-Dibenzofuran & $"$ & $<3.9$ & $<4.0$ & $<5.5$ & 8.7 & $<10$ \\
\hline ' $2,3,4,7,8,9-C 17$-Dibenzofuran & $"$ & $<4.4$ & $<4.4$ & $<6.3$ & $<5.4$ & $<12$ \\
\hline 1. $2,3,4,6,7,8-C 17-D i b e n z 0-p-d i o x i n$ & $"$ & $<4.4$ & 8.2 & $1 !$ & 17 & 10 \\
\hline $12.3,4,6,7,8,9-C ! 9-D i b e n z o t u r a n$ & $"$ & $<i .1$ & 7.6 & 9.0 & 22 & $<3.9$ \\
\hline : $, 2,3,4,6,7,3,0-C 18$-Dibenzo-p-dioxin & $"$ & 9.4 & 22 & 250 & 500 & $9 ?$ \\
\hline
\end{tabular}




\begin{tabular}{|c|c|c|c|c|c|c|}
\hline $\begin{array}{r}\text { Client ID: } \\
\text { Lab No.: } \\
\text { Date Sampled: }\end{array}$ & & $\begin{array}{c}\text { RIM23 Cot } \\
\text { Outlet } \\
04316198 \\
98 / 08 / 26\end{array}$ & $\begin{array}{c}\text { RIM429 } \\
\text { Baghouseinlet } \\
04316398 \\
98 / 08 / 18\end{array}$ & $\begin{array}{c}\text { R2M429 } \\
\text { BaghouseInlet } \\
04316498 \\
98 / 08 / 18\end{array}$ & $\begin{array}{c}\text { R3M429 } \\
\text { BaghouseInlet } \\
04316598 \\
98 / 08 / 19\end{array}$ & $\begin{array}{c}\text { RIM429 Cat } \\
\text { Outlet } \\
04316698 \\
98 / 08 / 18\end{array}$ \\
\hline Component & Units & & & & & \\
\hline $\begin{array}{l}\text { 2,3,7,8-TCDF (DB225) } \\
\text { internal Recoveries }\end{array}$ & $\begin{array}{l}\mathrm{pg} \\
\%\end{array}$ & 13 & 17 & 29 & 21 & 36 \\
\hline $2,3,7,8-\mathrm{TCDF}-13 \mathrm{Cl} 2$ & & 83 & 84 & 84 & 83 & 69 \\
\hline
\end{tabular}


Satch Code:

$\mathrm{PCDD} / \mathrm{F}$ (DB5)

Run Date

Date of Sample Prep

Batch Code:

2.3,7,8-TCDF (DB225)

Kun Date

Date of Sample Prep

$\begin{array}{lccc}0927 \mathrm{FB} 01 & .0927 \mathrm{FB01} & 0927 \mathrm{FB} 01 & 0927 \mathrm{FB} 01 \\ 04315698 & 04315798 & 04315898 & 04316198 \\ & & 04315998 & \\ & & 04316098 & \\ & & 04316398 & \\ & & 04316498 & \\ & & 04316598 & \\ & & 04316698 & \\ 98 / 10 / 05 & 93 / 10 / 02 & 98 / 10 / 04 & 98 / 10 / 07 \\ 98 / 09 / 27 & 98 / 09 / 27 & 98 / 09 / 27 & 98 / 09 / 27\end{array}$

0927FB01 0927FB01

$04315698 \quad 04315898$

$04315798 \quad 04315998$

04316098

04316398

04316498

04316598

04316698

04316198

$98 / 10 / 20 \quad 98 / 10 / 20$

$98 / 09 / 27 \quad 98 / 09 / 27$ 


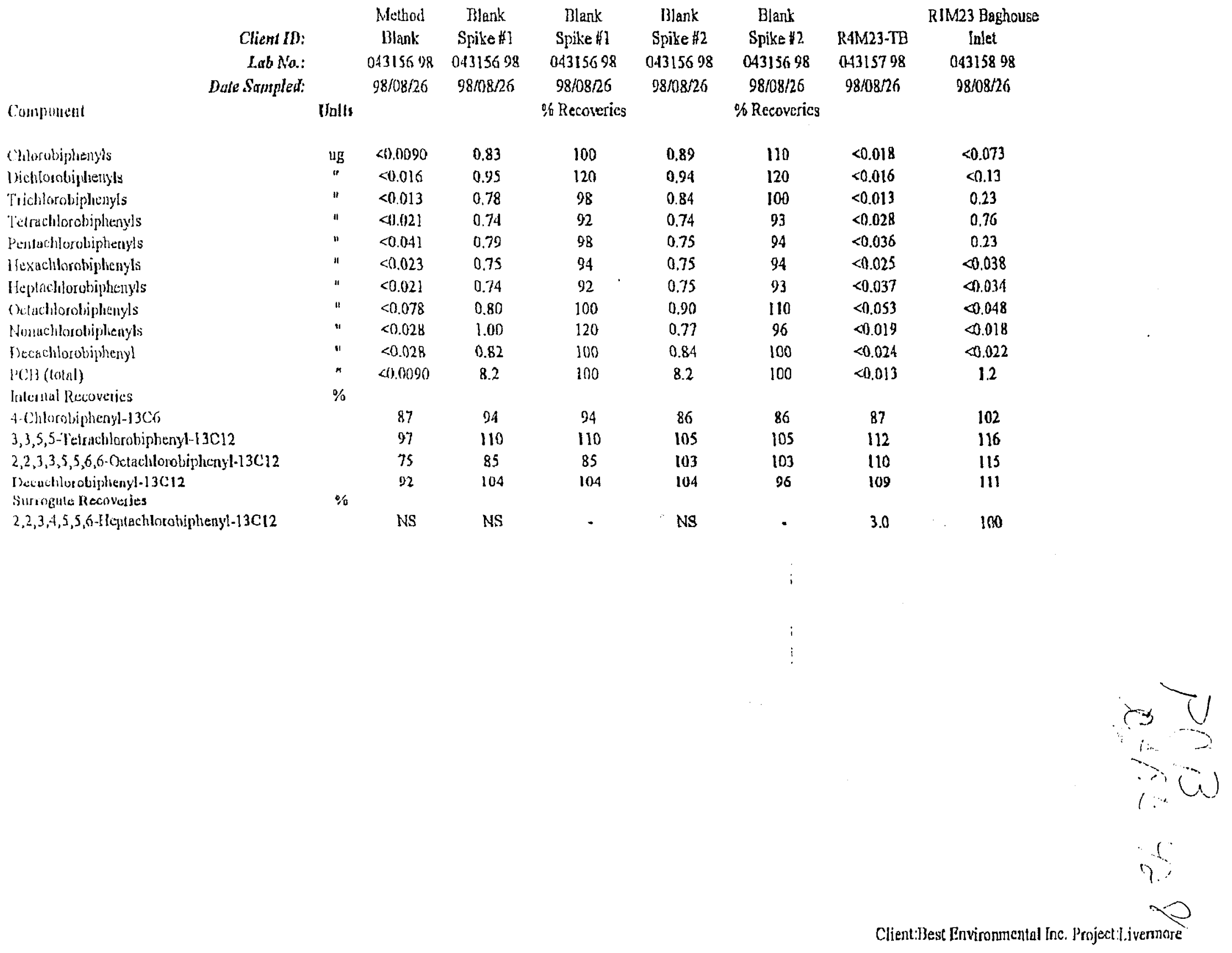




\begin{tabular}{|c|c|c|c|c|}
\hline $\begin{array}{r}\text { Clisut ID: } \\
\text { Lab Na: } \\
\text { Thate Sampled: }\end{array}$ & & $\begin{array}{c}\text { R2M23 Baghouse } \\
\text { Inlet } \\
04715998 \\
9808 / 26\end{array}$ & $\begin{array}{c}\text { R3M23 Baghouse } \\
\text { Inlet } \\
04316098 \\
98 / 08 / 26\end{array}$ & $\begin{array}{c}\text { RIM23 Col } \\
\text { Outlet } \\
04316198 \\
98 / 08 / 26\end{array}$ \\
\hline Conpunent & Units & & & \\
\hline Chenotiphenyls & ug & $<0.0 .10$ & $<0.021$ & $<0.017$ \\
\hline Dichlusubiplenyls & $"$ & 0.088 & $<0.019$ & 40.015 \\
\hline livilorobighenyls & $"$ & $<0.016$ & $<0.030$ & 40.018 \\
\hline Telanchorohiphenyls & " & $<0.053$ & $<0.035$ & 4.054 \\
\hline l'entathlorobiphosyls & $"$ & $<0.034$ & $<0.031$ & 00.028 \\
\hline Hokachlorobjphenyls & $"$ & 0.030 & $<0.031$ & $<0.1121$ \\
\hline 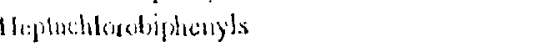 & $"$ & $<0.017$ & $<0.035$ & $<0.018$ \\
\hline ( Ketachilurobipleteryls & $"$ & $<0.11$ & $<0,043$ & $<0.066$ \\
\hline Wonedilorobiphenyls & $=$ & $<0.1038$ & $<0.021$ & $<0.027$ \\
\hline Danchloublipheny'] & $n$ & $<0.0122$ & 40.1121 & $<0.023$ \\
\hline$l^{2} \operatorname{Cls}(\operatorname{tola})$ & $"$ & 0.12 & $\infty, 019$ & $<0.015$ \\
\hline Intenal Recheritos & $\%$ & & & \\
\hline H.Chitrathiphenyl-13CO & & 97 & 91 & 91) \\
\hline 3,3,5,5-l'druclitorobingheny]-13012 & & 117 & 115 & 123 \\
\hline $2,2,3,3,5,5,6$, , (1, Octaciliturobipleny $] \cdot 13<, 12$ & & 84 & 100 & 85 \\
\hline Destathoroldithenyl-13012 & & 115 & 119 & 118 \\
\hline Surngate Recoverjes & $1 / 4$ & & & \\
\hline 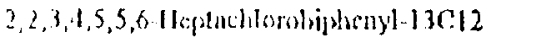 & & [1)! & 10.3 & 5.0 \\
\hline
\end{tabular}




\section{Certificate of Analysis}

CLIENT INFORMATION

Attention:

Client Name:

Project:

Project Desc:

Dan Cartner

Best Environmental Inc.

Livermore

Stack Emissions

Address:

15890 Foothill Blvd

San Leandro, CA

CA 94578

Fax Number: $\quad 5102784018$

Phone Number: 5102784011

\section{LABORATORY INFORMATION}

Contact:

Ron McLeod

Project:

AN980845

Date Received: $\quad 98 / 08 / 28$

Date Reported: $\quad 98 / 10 / 14$

Submission No.: 810098

Sample No.:

$043156-043161$

NOTES: $\quad$ " - ' = not analysed ' $<$ ' = less than Wethod Detection Limit (MDL) ' $N A$ ' = no data available

$L O Q$ can by determined for all analytes by multiplying the appropriate.$T D L X 3.33$

Solids dasa is based on dry weight except for biota analyses.

Organic analyses are not corrected for extraction recovery standards except for isotope

dilution methods, (he CARB $+29 P A H$, all $P C D D / F$ and $D B D / D B F$ analyses)

Methods used by PASC are based upon those found in 'Standard Methods for the Examination of Water and Wastewater, Nineteenth Edition. Other methods are based on the principles of MISA or EPA methodologies. New York State: ELAP Identification Number 10756.

All work recorded herein has been done in accordance with normal professional standards using accepted testing methodologies, quality assurance and quality control procedures except where otherwise agreed to by the client and testing company in writing. Any and all use of these test results shall be limited to the acrual cost of the pertinent analysis done. There is no other warranty expressed or implied. Your samples will be retained at PASC for a period of three weeks from receipt of data or as per contract.

COMMENTS:

NS=Not Spiked

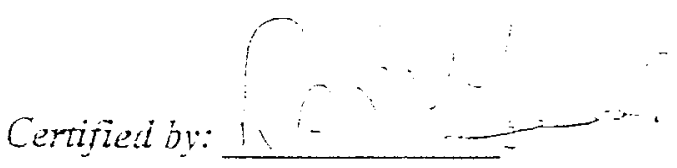




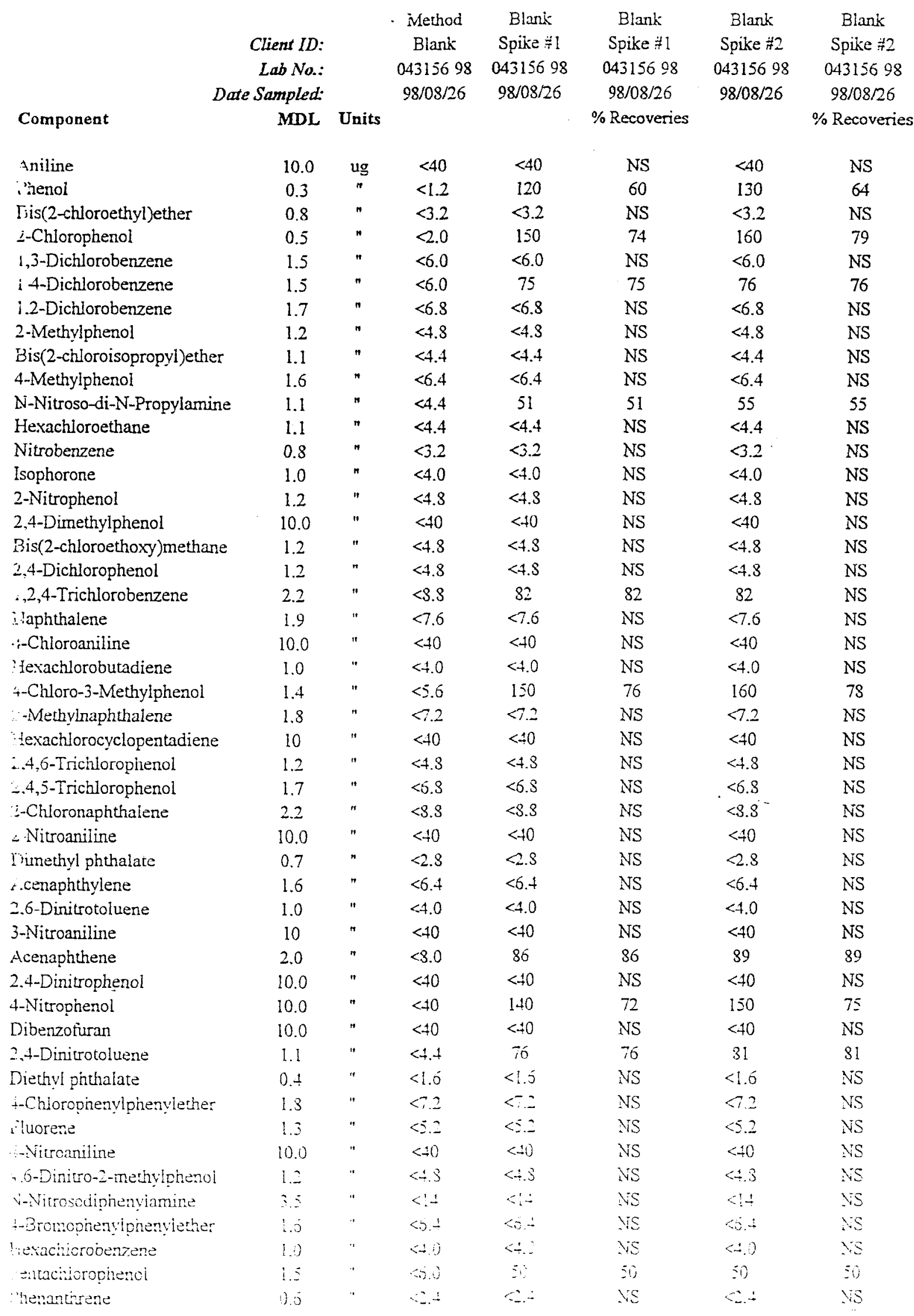




Component
Anthracene
Carhazole
Di-n-butyl phthalate
Fluoranthene
Pyrene
Benzyl butyl phthalate
3,3-Dichlorobenzidine
Benzo(a)anthracene
Chrysene
3is(2-ethylhexyl)phthalate
3i-n-octyl phthalate
Benzo(b)fluoranthene
Benzo(k)fluoranthene
3enzo(a)pyrene
ndeno(1,2,3-cd)pyrene
Dibenzo(a,h)anthracene
E enzo(ghi)perylene
Surrogate Recoveries
2-Fluorophenol
d5-Phenol
d5-Nitrobenzene
2-Fluorobiphenyl
2 4,6-Tribromophenol
d-14-p-Terphenyl
Field Spike
2.6-Dibromo-4-fluorophenol
a10-Pyrcne
B.

\begin{tabular}{|c|c|c|c|c|c|c|}
\hline Client ID: & & $\begin{array}{l}\text { Method } \\
\text { Blank }\end{array}$ & $\begin{array}{c}\text { Blank } \\
\text { Spike \#1 }\end{array}$ & $\begin{array}{c}\text { Blank } \\
\text { Soike }\end{array}$ & $\begin{array}{c}\text { Blank } \\
\text { Snike }\end{array}$ & $\begin{array}{c}\text { Blank } \\
\text { Spike } 42\end{array}$ \\
\hline Lab No: & & 04315698 & 04315698 & 04315698 & 04315698 & 04315698 \\
\hline Date Sampled: & & $98 / 08 / 26$ & $98 / 08 / 26$ & $98 / 08 / 26$ & $98 / 08 / 26$ & $98 / 08 / 26$ \\
\hline MDL & Units & & & $\%$ Recoveries & & $\%$ Recoveries \\
\hline 1.1 & $"$ & $<4.4$ & $<4.4$ & NS & $<4.4$ & NS \\
\hline 0.3 & $"$ & $<1.2$ & $<1.2$ & NS & $<1.2$ & NS \\
\hline 1.0 & $"$ & $<4.0$ & $<4.0$ & NS & $<4.0$ & NS \\
\hline 1.0 & $n$ & $<4.0$ & $<4.0$ & NS & $<4.0$ & NS \\
\hline 0.5 & $"$ & 1.4 & 87 & 87 & 90 & 90 \\
\hline 1.3 & $"$ & $<5.2$ & $<5.2$ & NS & $<5.2$ & NS \\
\hline 10.0 & $"$ & $<40$ & $<40$ & NS & $<40$ & NS \\
\hline 0.8 & $"$ & $<3.2$ & $<3.2$ & NS & $<3.2$ & NS \\
\hline 0.5 & $n$ & $<2.0$ & $<2.0$ & NS & $<2.0$ & NS \\
\hline 2.0 & $n$ & $<8.0$ & $<8.0$ & NS & $<8.0$ & NS \\
\hline 1.3 & $n$ & $<5.2$ & $<5.2$ & NS & $<5.2$ & NS \\
\hline 1.0 & $"$ & $<4.0$ & $<4.0$ & NS & $<4.0$ & NS \\
\hline 1.1 & $n$ & $<4.4$ & $<4.4$ & NS & $<4.4$ & NS \\
\hline 0.8 & $"$ & $<3.2$ & $<3.2$ & NS & $<3.2$ & NS \\
\hline 0.6 & $"$ & $<2.4$ & $<2.4$ & NS & $<2.4$ & NS \\
\hline 1.0 & $"$ & $<4.0$ & $<4.0$ & NS & $<4.0$ & NS \\
\hline \multirow[t]{11}{*}{0.7} & $"$ & $<2.8$ & $<2.8$ & NS & $<2.8$ & NS \\
\hline & $\%$ & & & & & \\
\hline & & 53 & - & 55 & - & 63 \\
\hline & & 64 & - & 68 & - & 75 \\
\hline & & 72 & - & 76 & - & 82 \\
\hline & & 93 & - & 92 & - & 100 \\
\hline & & 81 & - & 83 & - & 92 \\
\hline & & 89 & - & 91 & - & 95 \\
\hline & $\%$ & & & & & \\
\hline & & NS & NS & - & NS & - \\
\hline & & NS & NS & - & NS & - \\
\hline
\end{tabular}




\begin{tabular}{|c|c|c|c|c|c|c|}
\hline Date & $\begin{array}{l}\text { Client ID: } \\
\text { Lab No.: } \\
\text { Sampled: }\end{array}$ & & $\begin{array}{c}\text { R+NE23-TB } \\
04315798 \\
98 / 08 / 26\end{array}$ & $\begin{array}{c}\text { RIM23 Baghouse } \\
\text { Inlet } \\
04315898 \\
98 / 08 / 26\end{array}$ & $\begin{array}{c}\text { R2M23 Baghouse } \\
\text { Inlet } \\
04315998 \\
98 / 08 / 26\end{array}$ & $\begin{array}{c}\text { R3ML3 Baghouse } \\
\text { Inlet } \\
04316099 \\
98 / 08 / 26\end{array}$ \\
\hline Component & $\mathrm{MDL}$ & Units & & & & \\
\hline Aniline & 10.0 & ug & $<40$ & $<40$ & $<40$ & $<40$ \\
\hline ithenol & 0.3 & $\pi$ & $<1.2$ & $<1.2$ & $<1.2$ & $<1.2$ \\
\hline Bis(2-chloroethyl)ether & 0.8 & $n$ & $<3.2$ & $<3.2$ & $<3.2$ & $<3.2$ \\
\hline ¿-Chlorophenol & 0.5 & $"$ & $<2.0$ & 2.0 & $<2.0$ & $<2.0$ \\
\hline 1,3-Dichlorobenzene & 1.5 & $"$ & $<6.0$ & $<6.0$ & $<6.0$ & $<6.0$ \\
\hline 1-4-Dichlorobenzene & 1.5 & $"$ & $<6.0$ & $<6.0$ & $<6.0$ & $<6.0$ \\
\hline 1.2-Dichlorobenzene & 1.7 & $"$ & $<6.8$ & $<6.8$ & $<6.9$ & $<6.8$ \\
\hline 2-Methylphenol & 1.2 & $"$ & $<4.8$ & $<4.8$ & $<4.8$ & $<4.8$ \\
\hline Ejis(2-chloroisopropyl)ether & 1.1 & $n$ & $<4.4$ & $<4.4$ & $<4.4$ & $<4.4$ \\
\hline 4-Methylphenol & 1.6 & $"$ & $<6.4$ & $<6.4$ & $<6.4$ & $<6.4$ \\
\hline N-Nitroso-di-N-Propylamine & 1.1 & $"$ & $<4.4$ & $<4.4$ & $<4.4$ & $<4.4$ \\
\hline Hexachlorocthane & 1.1 & $"$ & $<4.4$ & $<4.4$ & $<4.4$ & $<4.4$ \\
\hline Nitrobenzene & 0.8 & $"$ & $<3.2$ & $<3.2$ & $<3.2$ & $<3.2$ \\
\hline isophorone & 1.0 & $"$ & $<4.0$ & $<4.0$ & $<7.0$ & $<4.0$ \\
\hline 2-Nitrophenol & 1.2 & $"$ & $<7.8$ & $<4.8$ & $<4.8$ & $<4.8$ \\
\hline 2.4-Dimethylphenol & 10.0 & $"$ & $<40$ & $<40$ & $<40$ & $<40$ \\
\hline ;3is(2-chloroethoxy)methane & 1.2 & $"$ & $<4.8$ & $<7.8$ & $<4.8$ & $<4.8$ \\
\hline$\therefore$ 4-Dichlorophenol & 1.2 & $"$ & $<4.8$ & $<4.8$ & $<7.8$ & $<4.8$ \\
\hline i 2,4-Trichlorobenzene & 2.2 & $\pi$ & $<8 . S$ & $<8.8$ & $<8.8$ & $<8.8$ \\
\hline aphthalene & 1.9 & $"$ & $<7.6$ & $<7.6$ & $<7.6$ & $<7.6$ \\
\hline$\therefore$ Chloroaniline & 10.0 & $"$ & $<10$ & $<+0$ & $<40$ & $<40$ \\
\hline l exachlorobutadiene & 1.0 & $"$ & $<4.0$ & $<4.0$ & $<4.0$ & $<4.0$ \\
\hline -Chioro-3-Methylphenol & 1.4 & $"$ & $<5.6$ & $<5.6$ & $<5.6$ & $<5.6$ \\
\hline --Methylnaphthalene & 1.8 & $"$ & $<7.2$ & $<.2$ & $<7.2$ & $<7.2$ \\
\hline i exachlorocyclopentadiene & 10 & $"$ & $<40$ & $<+0$ & $<40$ & $<40$ \\
\hline 24,6-Trichlorophenol & 1.2 & $"$ & $<4.8$ & $<7.8$ & $<4.8$ & $<4.8$ \\
\hline $2,4,5$-Trichlorophenol & 1.7 & $"$ & $<5.8$ & $<6.3$ & $<6.8$ & $<6.8$ \\
\hline 2-Chloronaphthalene & 2.2 & $"$ & $<S . S$ & $<8.9$ & $<8.3$ & $<8.8$ \\
\hline 2-Nitroaniline & 10.0 & $"$ & $<40$ & $<10$ & $<40$ & $<\neq 0$ \\
\hline Limethyl phthalate & 0.7 & $"$ & $<.3$ & $<.8$ & $<.8$ & $<.3$ \\
\hline F.cenaphthylene & 1.6 & $"$ & $<6.4$ & $<6.4$ & $<6.4$ & $<6.4$ \\
\hline 2.6-Dinitrotoluene & 1.0 & $"$ & $<4.0$ & $<4.0$ & $<4.0$ & $<4.0$ \\
\hline 3-Nitroaniline & 10 & $"$ & $<40$ & $<40$ & $<40$ & $<40$ \\
\hline Acenaphthene & 2.0 & $"$ & $<3.0$ & $<8.0$ & $<8.0$ & $<8.0$ \\
\hline 2.t-Dinitropnenol & 10.0 & $"$ & $<40$ & $<40$ & $<40$ & $<+0$ \\
\hline $4-$ Nitrophenol & 10.0 & $"$ & $<40$ & $<40$ & $<40$ & $<40$ \\
\hline Dibenzofuran & 10.0 & $"$ & $<40$ & $<\div 0$ & $<40$ & $<+0$ \\
\hline$\therefore 4$-Dinitrotoluene & 1.1 & $"$ & $<4.4$ & $<4$ & $<4.4$ & $<4$ \\
\hline Qiechỵl phthaiate & 0.4 & $"$ & $<1.5$ & 150 & 1.9 & $<1.5{ }^{\circ}$ \\
\hline Chloropinenylpnenylether & 1.9 & $"$ & $<:=$ & $<.2$ & $<7.2$ & $<7.2$ \\
\hline Oluorene & 1.3 & $"$ & $\because=$ & $<.2$ & $<5.2$ & $<5.2$ \\
\hline $4-$ vitroaniline & 10.0 & $"$ & $< \pm 0$ & $<+1)$ & $<+0$ & $<40$ \\
\hline$\therefore-$-Dinitro-2-nethylphenol & 1.2 & $"$ & $<.3$ & $<1 . s$ & $<+3$ & $\because .3$ \\
\hline$\because$-Vitrosocionenviamine & $\vdots \Sigma$ & $"$ & $\therefore-$ & $<-$ & $<14$ & 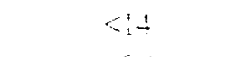 \\
\hline Bromophenyphanyidue & 1.5 & $\cdot$ & $\therefore-$ & - & i.: & $6 . \div$ \\
\hline rexaciolorocenzene & 19 & $\cdot$ & $\because \vdots$ & $\therefore i$ & +3 & $\div 0$ \\
\hline Dentacialoropienci & $1 . \Sigma$ & $"$ & $\therefore$ & $\therefore$ & $<5$ & -5.3 \\
\hline trenanthenes & $\therefore$ & ' & $\therefore-$ & $1 \vdots$ & $2 . \Sigma$ & $\because+$ \\
\hline
\end{tabular}




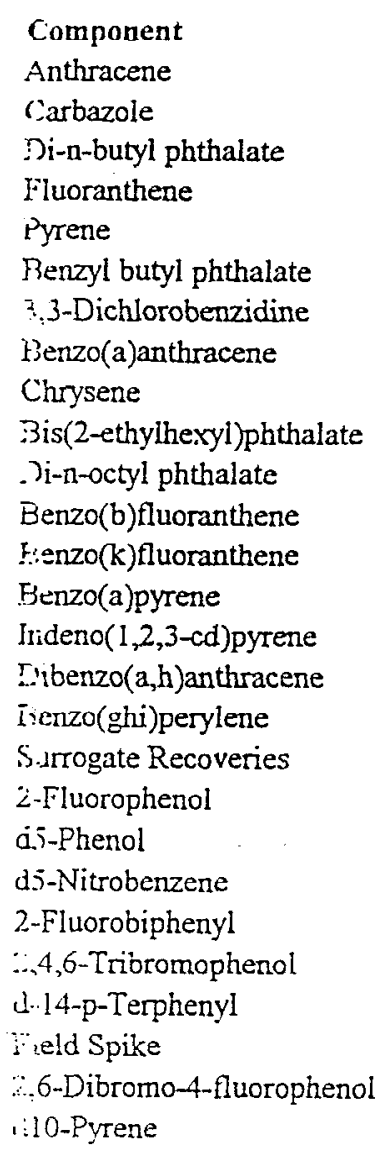

Component

Di-n-butyl phthalate

Fluoranthene

Pyrene

7 3-Dichld

Benzo(a)anthracene

Chrysene

. )i-n-octyl phthalate

Benzo(b)fluoranthene

Irideno( $1,2,3-c d)$ pyrene

Iibenzo(a,h)anthracene

Iienzo(ghi)perylene

¿-Fluorophenol

a.)-Phenol

d.5-Nitrobenzene

2-Fluorobiphenyl

$\because 4,6$-Trioromophenol

d..14-p-Terphenyl

6-Dibromo-4-fluorophenol

:10-Pyrene

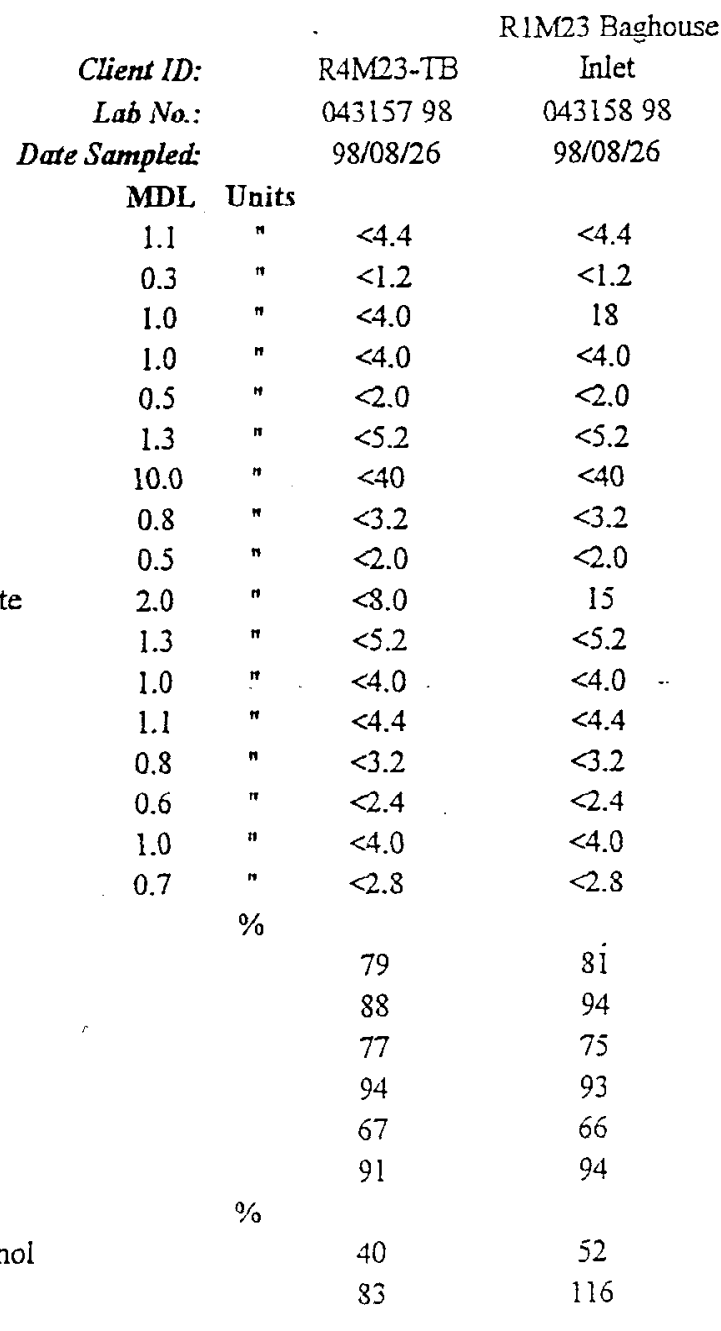

R2M23 Baghouse

Inlet

04315998

$98 / 08 / 26$

$<4.4$

$<1.2$

4.0

$<4.0$

2.0

$<5.2$

$<40$

$<3.2$

$<.0$

23

$<5.2$

$<4.0$

$<4.4$

$<3.2$

$<2.4$

$<4.0$

$<2.8$

85

86

73

91

83

92

92

108
R3M23 Eaghouse

Inlet

04316098

$98 / 08 / 26$

$<4.4$
$<1.2$
$<4.0$
$<4.0$
$<2.0$
$<5.2$
$<40$
$<3.2$
$<2.0$
11
$<5.2$
$<4.0$
$<4.4$
$<3.2$
$<2.4$
$<4.0$
$<2.8$
78
82
69
88
81
91
79
111




\begin{tabular}{|c|c|c|c|c|c|c|c|}
\hline Date & $\begin{array}{l}\text { Client ID: } \\
\text { Lab No.: } \\
\text { Sampled: }\end{array}$ & & $\begin{array}{c}\text { RIM23 Cot } \\
\text { Outlet } \\
04316198 \\
98 / 08 / 26\end{array}$ & $\begin{array}{c}\text { R1M429 } \\
\text { BaghouseInlet } \\
04316398 \\
98 / 08 / 18\end{array}$ & $\begin{array}{c}\text { R2M429 } \\
\text { BaghouseInlet } \\
04316498 \\
98 / 08 / 18\end{array}$ & $\begin{array}{c}\text { R3M429 } \\
\text { Baghouseiniet } \\
04316598 \\
98 / 08 / 19\end{array}$ & $\begin{array}{c}\text { R.M429 Cat } \\
\text { Outlet } \\
04316698 \\
98 / 08 / 18\end{array}$ \\
\hline Component & MDL & Units & & & & & \\
\hline Aniline & 10.0 & ug & $<40$ & $<40$ & $<40$ & $<40$ & $<40$ \\
\hline f'henol & $0 . \overline{3}$ & $"$ & 8.7 & $<4.5$ & $<1.2$ & $<1.2$ & $<1.2$ \\
\hline Eis(2-chloroethyl)ether & 0.8 & $"$ & $<3.2$ & $<3.2$ & $<3.2$ & $<3.2$ & $<3.2$ \\
\hline 2-Chlorophenol & 0.5 & $"$ & $<2.0$ & $<2.0$ & $<2.0$ & $<2.0$ & $<2.0$ \\
\hline 1.3-Dichlorobenzene & 1.5 & $"$ & $<6.0$ & $<6.0$ & $<6.0$ & $<6.0$ & $<6.0$ \\
\hline 14-Dichlorobenzene & 1.5 & $"$ & $<6.0$ & $<6.0$ & $<6.0$ & $<6.0$ & $<6.0$ \\
\hline 1,2-Dichlorobenzene & 1.7 & $"$ & $<6.8$ & $<6.8$ & $<6.8$ & $<6.8$ & $<6.8$ \\
\hline 2-Methylphenol & 1.2 & $"$ & $<4.8$ & $<4.8$ & $<4.8$ & $<4.8$ & $<4.8$ \\
\hline Iis(2-chloroisopropyl)ether & 1.1 & $"$ & $<4.4$ & $<4.4$ & $<7.4$ & $<4.4$ & $<4.4$ \\
\hline 4-Methylphenol & 1.6 & $"$ & $<6.4$ & $<6.4$ & $<6.4$ & $<6.4$ & $<6.4$ \\
\hline N-Nitroso-di-N-Propylamine & 1.1 & $"$ & $<4.4$ & $<4.4$ & $<4.4$ & $<4.4$ & $<4.4$ \\
\hline Hexachloroethane & 1.1 & $"$ & $<4.4$ & $<4.4$ & $<4.4$ & $<4.4$ & $<4.4$ \\
\hline Oitrobenzene & 0.8 & $"$ & $<3.2$ & $<3.2$ & $<3.2$ & $<3.2$ & $<3.2$ \\
\hline ¿sophorone & 1.0 & $"$ & $<4.0$ & $<4.0$ & $<4,0$ & $<4.0$ & $<4.0$ \\
\hline$\because$-Nitrophenol & 1.2 & $"$ & $<4.8$ & $<4.8$ & $<4.8$ & $<4.8$ & $9.7 \cdot$ \\
\hline$\therefore$ 4-Dimethylphenol & 10.0 & $"$ & $<40$ & $<40$ & $<40$ & $<40$ & $<40$ \\
\hline 3is(2-chloroethoxy)methane & 1.2 & $"$ & $<4.8$ & $<4.8$ & $<4.8$ & $<4.8$ & $<4.8$ \\
\hline 34-Dichlorophenol & 1.2 & $"$ & $<4.8$ & $<4.8$ & $<4.8$ & $<4.8$ & $<4.8$. \\
\hline i,2,4-Trichlorobenzene & 2.2 & $"$ & $<8.8$ & $<3.8$ & $<8.8$ & $<8.8$ & $<8.8$ \\
\hline A:aphthalene & 1.9 & $"$ & $<7.6$ & $<7.6$ & $<7.6$ & $<7.6$ & $<7.6$ \\
\hline 4-Chloroaniline & 10.0 & $"$ & $<40$ & $<40$ & $<40$ & $<40$ & $<40$ \\
\hline Hexachlorobutadiene & 1.0 & $"$ & $<4.0$ & $<4.0$ & $<4.0$ & $<4.0$ & $<4.0$ \\
\hline 4-Chloro-3-Methylphenol & 1.4 & $"$ & $<5.6$ & $<5.6$ & $<5.6$ & $<5.6$ & $<5.6$ \\
\hline 2-Methylnaphthalene & 1.8 & $"$ & 7.2 & $<.2$ & $<7.2$ & $<7.2$ & $<.2$ \\
\hline Fexachiorocyclopentadiene & 10 & $"$ & $<40$ & $<40$ & $<40$ & $<40$ & $<40$ \\
\hline 2.4,6-Trichlorophenol & 1.2 & $"$ & $<4.8$ & $<4.8$ & $<4.8$ & $<1.8$ & $<4.8$ \\
\hline 2,4,5-Trichlorophenol & 1.7 & $"$ & $<6.8$ & $<6.8$ & $<5.8$ & $<6.8$ & $<6.8$ \\
\hline 2-Chloronaphthalene & 2.2 & $"$ & $<8.8$ & $<3.9$ & $<8.8$ & $<8.8$ & $<8.8$ \\
\hline 2.Nitroaniline & 10.0 & $"$ & $<40$ & $<40$ & $<40$ & $<40$ & $<40$ \\
\hline "jimethyl phthalate & 0.7 & $"$ & $<2.8$ & 2.8 & $<.8$ & $<.8$ & $<2.8$ \\
\hline$\therefore$ cenaphthylene & 1.6 & $"$ & $<6.4$ & $<5.4$ & $<6.4$ & $<6.4$ & $<6.4$ \\
\hline$\because 6$-Dinitrotoluene & 1.0 & $"$ & $<4.0$ & $<4.0$ & $<4.0$ & $<4.0$ & $<4.0$ \\
\hline$\therefore$-Nitroaniline & 10 & $"$ & $<40$ & $<40$ & $<40$ & $<40$ & $<40$ \\
\hline Acenaphthene & 2.0 & $"$ & $<9.0$ & $<8.0$ & $<8.0$ & $<8.0$ & $<8.0$ \\
\hline : 4-Dinitrophenol & 10.0 & $"$ & $<40$ & $<40$ & $<40$ & $<40$ & $<40$ \\
\hline - Nitrophenol & 10.0 & $"$ & $<40$ & $<40$ & $<40$ & $<40$ & $<40$ \\
\hline abenzofuran & 10.0 & $"$ & $<40$ & $<40$ & $<.0$ & $<40$ & $<40$ \\
\hline$\because 4$-Dinitrotoluene & 1.1 & $"$ & $<4.4$ & $<4.4$ & $<4.4$ & $<4.4$ & $<4.4$ \\
\hline - iechyl phthalate & 0.4 & $"$ & $<1.6$ & 0.9 & 13 & 3.1 & $<1.6 \quad$ \\
\hline 4-Chlorophenylpienylether & 1.8 & $"$ & $<7.2$ & 7.2 & $<.2$ & $<7.2$ & $<7.2$ \\
\hline Ouorene & 1.3 & $"$ & $<5.2$ & 5.2 & $<2$ & $<.2$ & $<5.2$ \\
\hline 4. vitroaniline & 10.0 & $"$ & $<+0$ & $<40$ & $<+0$ & $<+0$ & $<\div 0$ \\
\hline$\therefore$ 5-Dinitro-2-methylpneno: & 1.2 & $"$ & $<+.8$ & $<4.3$ & $<4.8$ & $<4.8$ & $<+8$ \\
\hline$\because$ Yitoscdipnenylamine & 3.5 & $"$ & $<! \div$ & $<:-$ & $<:-$ & $<1 \div$ & $<1+$ \\
\hline$\therefore$ Eromopilenylpinenylether & 1.6 & $"$ & $\therefore \div$ & $<5 \div$ & $<.-$ & 65. & -5. \\
\hline Fvacialorobenzene & 10 & $"$ & $\Leftrightarrow\}$ & $\Leftrightarrow \because$ & $\therefore \therefore$ & $\leftrightarrow \because$ & $<+0$ \\
\hline a smciloropinenol & $1 . \Sigma$ & $"$ & $<.0$ & $<5 . j$ & $<5.2$ & 65 & $<5.0$ \\
\hline -nenonthrene & 1.5 & $"$ & $\because-$ & $\because$ & $3-$ & $\therefore \dot{0}$ & $<. \div$ \\
\hline
\end{tabular}




\section{Component}

Anthracene

Carbazole

Di-n-butyl phthalate

Oluoranthene

Pyrene

Penzyl butyl phthaiate

3,3-Dichlorobenzidine

Benzo(a)anthracene

Chrysene

Bis(2-ethylhexyl)phthalate

Di-n-octyl phthalate

Eenzo(b)fluoranthene

Benzo(k)fluoranthene

Benzo(a)pyrene

Indeno(1,2,3-cd)pyrene

j)ibenzo(a,h)anthracene

Benzo(ghi)perylene

isurrogate Recoveries

2-Fluorophenol

i5-Phenol

15-Nitrobenzene

$\because$-Fluorobiphenyl

$\therefore 4,6$-Tribromophenol

$\therefore$-14-p-Terphenyl

ield Spike

$\therefore$,6-Dibromo-4-fluorophenol

110-Pyrene

\begin{tabular}{|c|c|c|c|c|c|c|}
\hline & \multirow{3}{*}{$\begin{array}{c}\text { R1M23 Cot } \\
\text { Outlet } \\
04316198\end{array}$} & \multirow{3}{*}{$\begin{array}{c}\text { RiM429 } \\
\text { Baghouseinlet } \\
04316398\end{array}$} & \multirow{3}{*}{$\begin{array}{c}\text { R2M429 } \\
\text { Baghouseinlet } \\
04316498\end{array}$} & \multirow{3}{*}{$\begin{array}{c}\text { R3M429 } \\
\text { BaghouseInlet } \\
04316598\end{array}$} & RIM429 Cat \\
\hline & & & & & & Outlet \\
\hline Lab No.: & & & & & & 04316698 \\
\hline Date Sampled: & & $98 / 08 / 26$ & $98 / 08 / 18$ & $98 / 08 / 18$ & $98 / 08 / 19$ & $98 / 08 / 18$ \\
\hline MDL & Units & & & & & \\
\hline 1.1 & $"$ & $<4.4$ & $<4.4$ & $<4.4$ & $<4.4$ & $<4.4$ \\
\hline 0.3 & $n$ & $<1.2$ & $<12$ & $<1.2$ & $<1.2$ & $<1.2$ \\
\hline 1.0 & $"$ & $<4.0$ & 31 & 21 & 9.8 & $<4.0$. \\
\hline 1.0 & $n$ & $<4.0$ & 16 & $<4.0$ & $<4.0$ & $<4.0$. \\
\hline 0.5 & $"$ & $<2.0$ & 9.3 & $<2.0$ & $<2.0$ & $<2.0^{\circ}$ \\
\hline 1.3 & $"$ & $<5.2$ & $<5.2$ & $<5.2$ & $<5.2$ & $<5.2$ \\
\hline 10.0 & $"$ & $<40$ & $<40$ & $<40$ & $<40$ & $<40$ \\
\hline 0.8 & $n$ & $<3.2$ & $<3.2$ & $<3.2$ & $<3.2$ & $<3.2$ \\
\hline 0.5 & $"$ & $<2.0$ & 2.0 & $<2.0$ & $<2.0$ & $<2.0$. \\
\hline 2.0 & $n$ & $<8.0$ & 21 & 19 & 25 & 11. \\
\hline 1.3 & $"$ & $<5.2$ & $<5.2$ & $<5.2$ & $<5.2$ & $<5.2$ \\
\hline 1.0 & $"$ & $<4.0$ & $<4.0$ & $<4.0$ & $<4.0$ & $<4.0$ \\
\hline 1.1 & $"$ & $<4.4$ & $<4.4$ & $<4.4$ & $<4.4$ & $<4.4$ \\
\hline 0.8 & $n$ & $<3.2$ & $<3.2$ & $<3.2$ & $<3.2$ & $<3.2$ \\
\hline 0.6 & $"$ & $<2.4$ & $<2.4$ & $<2.4$ & $<2.4$ & $<2.4$ \\
\hline 1.0 & $"$ & $<4.0$ & $<4.0$ & $<4.0$ & $<4.0$ & $<4.0$ \\
\hline 0.7 & $"$ & $<2.8$ & $<2.8$ & $<2.8$ & $<2.8$ & $<2.8$ \\
\hline & $\%$ & & & & & \\
\hline & & 51 & 88 & 84 & 89 & 69 \\
\hline & & 66 & 90 & 88 & 90 & 92 \\
\hline & & 70 & 80 & 77 & 82 & 78 \\
\hline & & 87 & 95 & 94 & 94 & 88 \\
\hline & & 88 & 90 & 91 & 91 & 83 \\
\hline & & 91 & 89 & 93 & 92 & 84 \\
\hline & $\%$ & & & & & \\
\hline & & 41 & 71 & 75 & 69 & 32 \\
\hline & & 81 & $8 \hat{3}$ & 86 & 85 & 73 \\
\hline
\end{tabular}




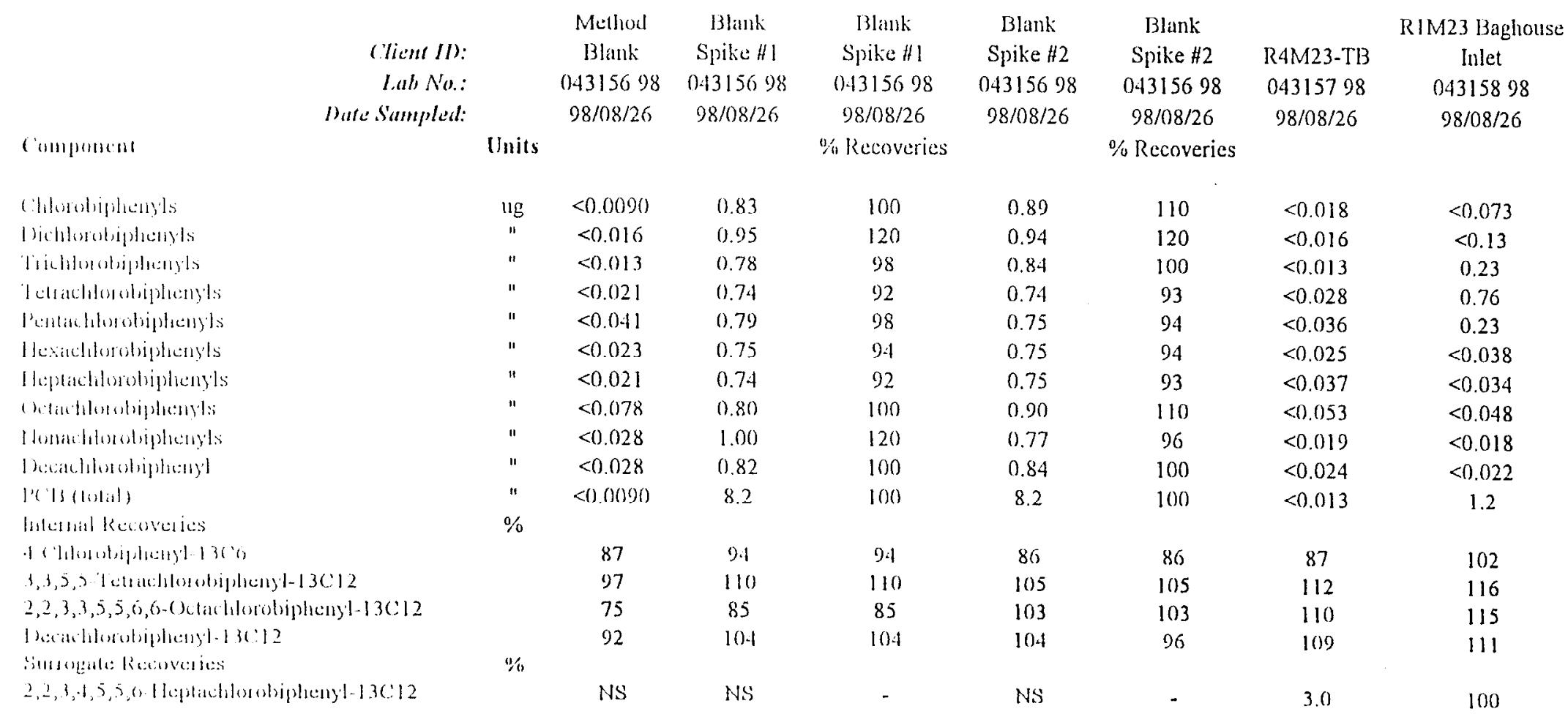




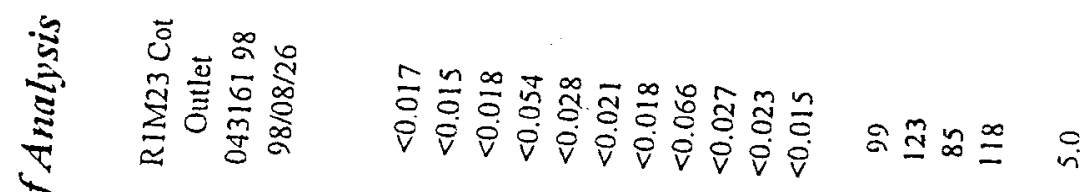

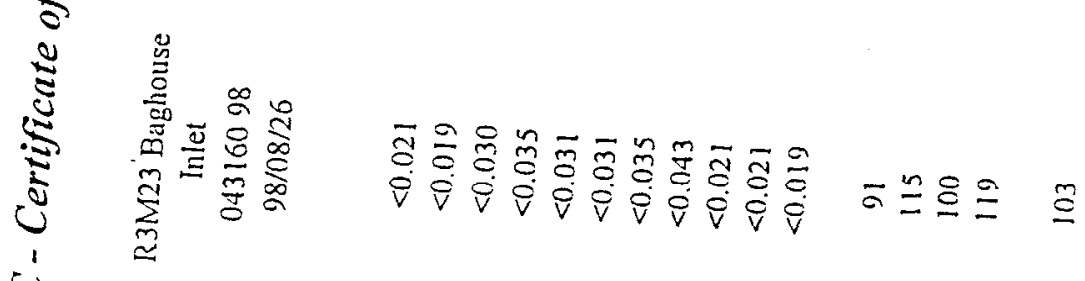

家

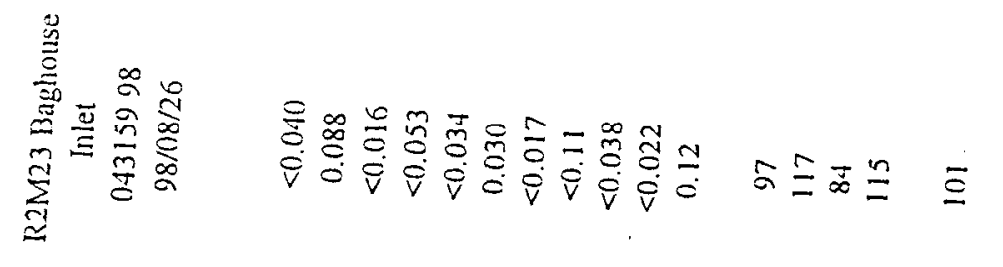

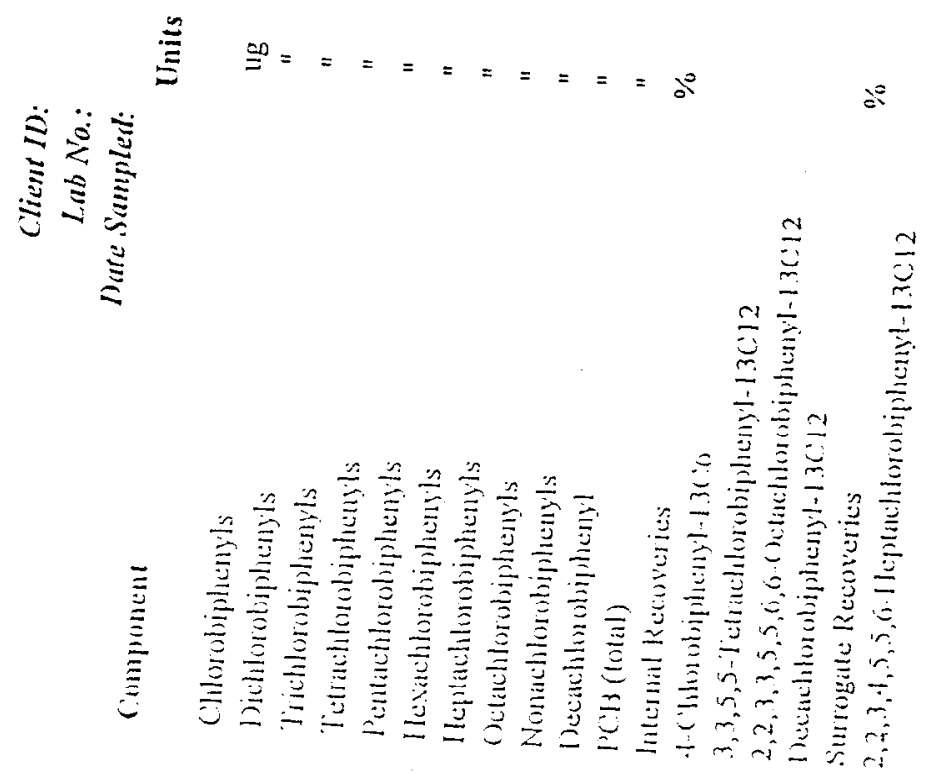


Batch Code:

SVOC

Kun Date

Date of Sample Prep

Batch Code:

PCB

Run Date

Sate of Sample Prop
0927FB01

04315698

04315798

04315898

04315998

04316098

04316198

04316398

04316498

04316598

04316698

$98 / 01 / 05$

$98 / 09 / 27$

0927FB01

04315698

04315798

04315898

04315998

04316098

04316198

98/10/05

98/09/27 


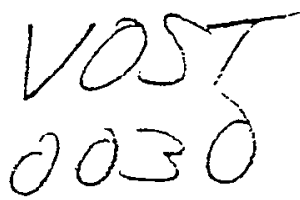

\section{Certificate of Analysis}

\section{CLIENT INFORMATION}

$\begin{array}{ll}\text { Attention: } & \text { Dan Cartner } \\ \text { Client Name: } & \text { Best Environmental Inc. } \\ \text { Project: } & \text { Livermore } \\ \text { Project Desc: } & \text { Stack Emissions }\end{array}$

Address:

15890 Foothill Blvd

San Leandro, CA

CA 94578

Far Number: $\quad 5102784018$

Phone Number: 5102784011

\section{LABORATORY INFORMATION}

$\begin{array}{ll}\text { Contact: } & \text { Ron McLeod } \\ \text { Project: } & \text { AN980845 } \\ \text { Date Received: } & 98 / 08 / 28 \\ \text { Date Reported: } & 98 / 09 / 16\end{array}$

Submission No.: 810098

Sample No.:

NOTES: $\quad$ " $-1=$ not analysed ' $<$ '= less than Wethod Detection Limit (MDL) ' $N A$ '= no data available

LOQ can by determined for all analytes by multiplying the appropriate. $M D L X 3.33$

Sulids data is based on dy weigitt except for biota analyses.

Organic analyses are not corrected for exraction recovery standards except for isotope

dilution methods. (i.e CARB $429 P .4 H$, all $P C D D / F$ and $D B D / D B F$ anadyses)

Methods used by PASC are based upon those found in 'Standard Methods for the Examination of Water and Wastewater', Nineteenth Edition. Other methods are based on the principles of MISA or EPA mechodologies. New York State: ELAP Identification Number 10756.

All work recorded herein has been done in accordance with nommal professional standards using accepted testing methodologies, quality assurance and qualiry control procedures except where othervise agreed to by the client and testing company in writing. Any and all use of these test results shall be limited to the actual cost of the pertinent analysis done. There is no other warranty expressed or implied. Your samples will be retained at PASC for a period of three weeks from receipt of data or as per contract.

\section{COMMENTS: $\quad$ Revised Report: 981001}

*Estimated value, data above the instrument calibration range. Sample contamination with dichloromethane and acetone is almost certainly related to cross-contamination of the traps with SVOC train solvents shipped in the same container as the VOST samples. Most of the response from these analytes is likely not from the stack source.

**Data uncorrected for recovery of the first internal standard (bromochloromethane. BCM) because of interierence from a cyclic C -5 hydrocarion (likely methyleyclopentane) the BCM peak being suppressed from interierence from this peak. ***Data uncorrected for recovery of the first internal standard because of poor recovery of this internal standard.

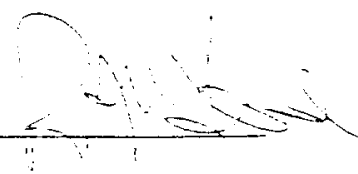




\section{Component}

Chloromethane

Bromomethane

Vinyl Chloride

Chloroethane

Methylene Chloride

Acetone

Carbon Disulfide

i. 1-Dichloroethene

1.1-Dichloroethane

I.2-Dichloroethene(total)

Chloroform

2-Dichloroethane

2-Butanone

1,1-Trichloroethane

arbon Tetrachloride

1. romodichloromethane

i.2-Diciloropropane

is-1,3-Dichloropropene

I richloroethene

ribromochlormethane

1.1,2-Trichloroethane

Eenzene

t:ans-1,3-Dichloropropene

tromoform

$\therefore$ Methyl-2-Pentanone

2.-Hexanone

"etrachloroethene

1.1.2.2-Tetrachloroethane

?oluene

Shlorobenzene

ithylbenzene

ityrene

sylene(total)

$\therefore$ 1.2-Trichlorotrifluorcethane

: rrogate Recoveries

1+-1.2-Dichloroerhane

(.)-Toluene

bromolluorobenzene

Field Spike

(1)-Erhyibenzena
LLNL Field LLVI Trip RTSت̈l/R1/0030 RTS:1/R1/0030

Client ID:

Blank

Blank

$04318798 \quad 04318898$

$15 \mathrm{a} / \mathrm{b}$

$2 \mathrm{ab}$

$98 / 08 / 18 \quad 98 / 08 / 18$

04318998

$98 / 08 / 18$

04319098

$98 / 08 / 18$

Date Sampled:
MDL Units

\begin{tabular}{|c|c|c|c|c|c|}
\hline 0.007 & ug & 0.053 & $<$ & $<$ & 0.23 \\
\hline 0.005 & $"$ & 0.042 & $<$ & 0.039 & 0.10 \\
\hline 0.013 & " & $<$ & $<$ & $<$ & $<$ \\
\hline 0.007 & $"$ & $<$ & $<$ & $<$ & $<$ \\
\hline 0.019 & $"$ & $3.2^{*}$ & 0.54 & $3.5 *$ & $3.3^{*}$ \\
\hline 0.045 & $"$ & 0.41 & $<$ & $1.5 *$ & $2.4^{*}$ \\
\hline 0.018 & " & $<$ & $<$ & $<$ & $<$ \\
\hline 0.007 & $"$ & 0.036 & $<$ & 0.14 & 0.082 \\
\hline 0.004 & $"$ & $<$ & $<$ & $<$ & $<$ \\
\hline 0.007 & $"$ & $<$ & $<$ & $<$ & $<$ \\
\hline 0.008 & 18 & $<$ & $<$ & $<$ & $<$ \\
\hline 0.006 & $"$ & $<$ & $<$ & $<$ & $<$ \\
\hline 0.036 & " & $<$ & $<$ & $<$ & $<$ \\
\hline 0.014 & $"$ & $<$ & $<$ & 0.083 & 0.035 \\
\hline 0.016 & $1 "$ & $<$ & $<$ & $<$ & $<$ \\
\hline 0.011 & " & $<$ & $<$ & $<$ & $<$ \\
\hline 0.008 & $"$ & $<$ & $<$ & $<$ & $<$ \\
\hline 0.007 & $"$ & $<$ & $<$ & $<$ & $<$ \\
\hline 0.009 & $"$ & $<$ & $<$ & $<$ & $<$ \\
\hline 0.008 & $"$ & $<$ & $<$ & $<$ & $<$ \\
\hline 0.016 & $"$ & $<$ & $<$ & $<$ & $<$ \\
\hline 0.009 & $"$ & 0.018 & 0.009 & 0.034 & 0.057 \\
\hline 0.007 & " & $<$ & $<$ & $<$ & $<$ \\
\hline 0.012 & $"$ & $<$ & $<$ & $<$ & $<$ \\
\hline 0.019 & " & $<$ & $<$ & $<$ & $<$ \\
\hline 0.031 & " & $<$ & $<$ & $<$ & $<$ \\
\hline 0.008 & " & $<$ & $<$ & 0.008 & $<$ \\
\hline 0.014 & $"$ & $<$ & $<$ & $<$ & $<$ \\
\hline 0.009 & " & 0.019 & $<$ & 0.17 & 0.089 \\
\hline 0.009 & $"$ & $<$ & $<$ & $<$ & $<$ \\
\hline 0.006 & $"$ & $<$ & $<$ & 0.010 & 0.007 \\
\hline 0.007 & $"$ & $<$ & $<$ & 0.018 & 0.007 \\
\hline 0.015 & 11 & $<$ & $<$ & 0.049 & $0.04+$ \\
\hline \multirow[t]{7}{*}{0.020} & $"$ & $<$ & $<$ & $<$ & $<$ \\
\hline & 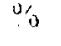 & & & & \\
\hline & & 107 & $0 \Xi$ & 105 & 109 \\
\hline & & 99 & 100 & Qs & 29 \\
\hline & & 109 & $1: 2$ & 114 & 105 \\
\hline & 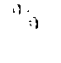 & & & & \\
\hline & & 90 & $\because-$ & 38 & $y y$ \\
\hline
\end{tabular}




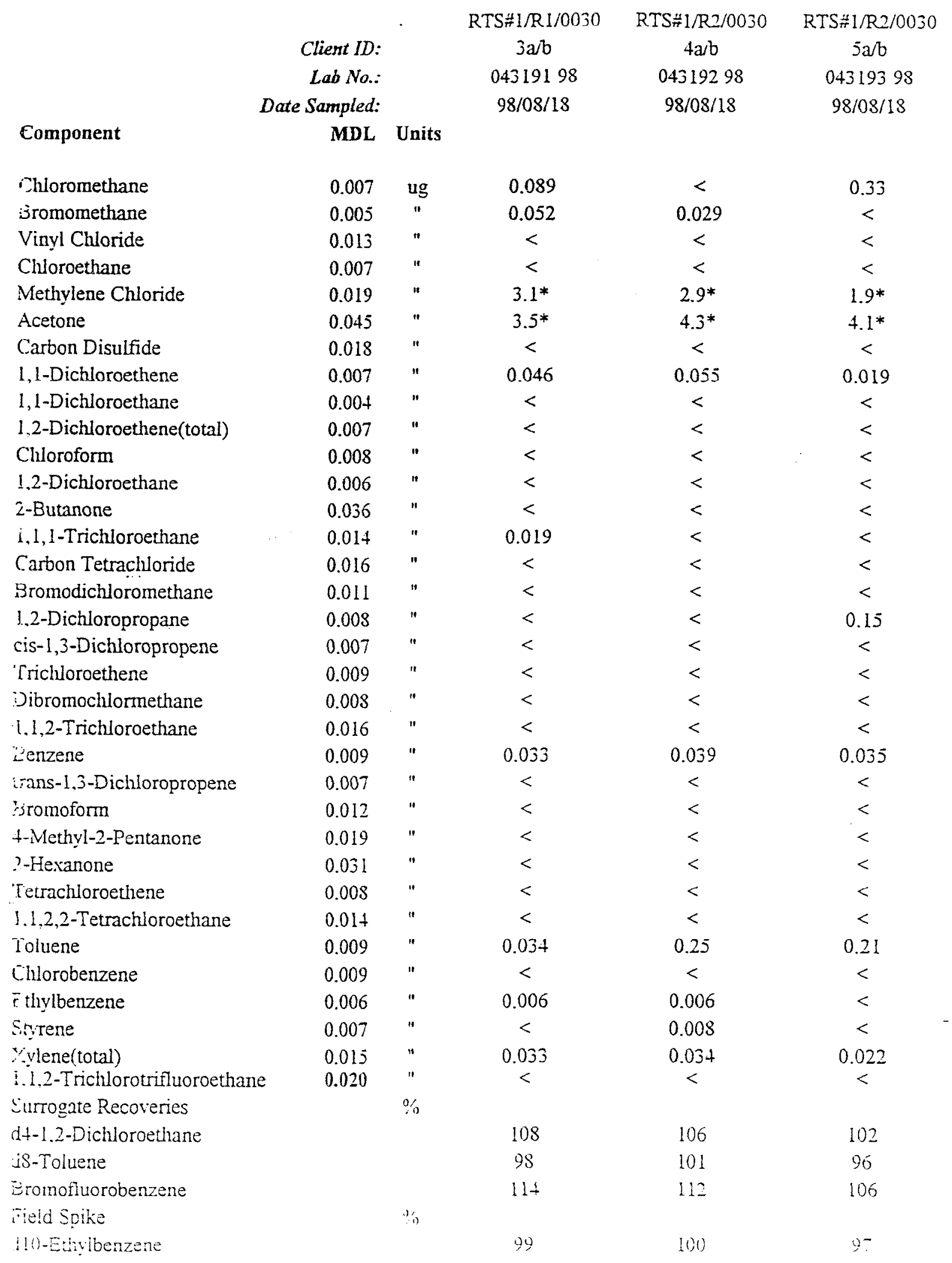




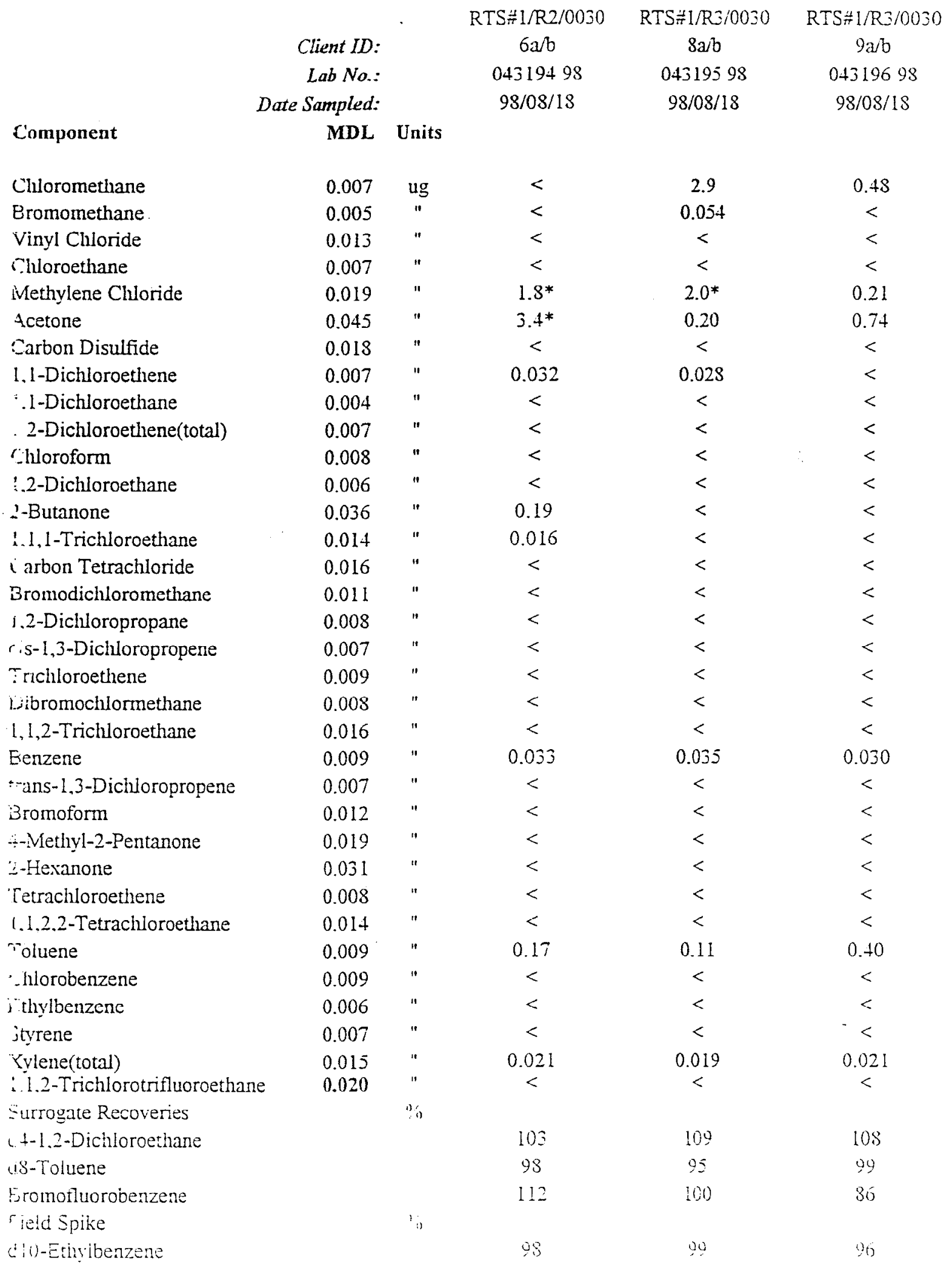




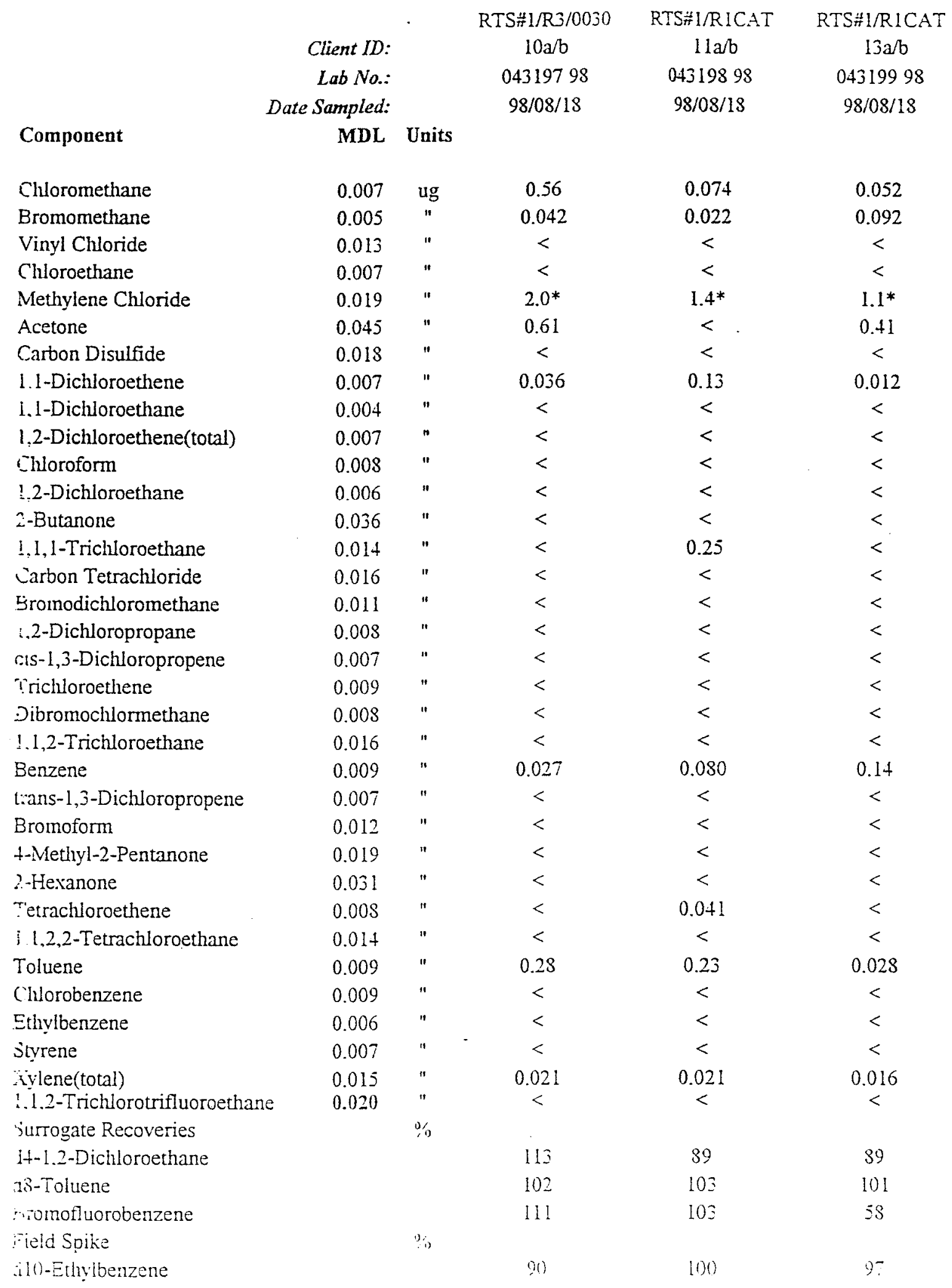




\section{Component}

Shloromethane

3 romomethane

Vinyl Chloride

- Thloroethane

vethylene Chloride

icetone

Carbon Disulfide

1,1-Dichloroethene

1,1-Dichloroethane

1,2-Dichloroethene(total)

Chloroform

1,2-Dichloroethane

?.-Butanone

! 1,1-Trichloroethane

Carbon Tetrachloride

Eromodichloromethane

1.2-Dichloropropane

cis-1,3-Dichloropropene

'I richloroethene

sibromochlormethane

i. 1,2-Trichloroethane

Benzene

irans-1.3-Dichloropropene

Eromoform

$\therefore$-Methyl-2-Pentanone

2-Hexanone

Tetrachloroethene

..1,2.2-Tetraciloroethane

:oluene

:hlorodenzene

Ithylbenzene

sivrene

Aylene (total)

1.2-Trichlorotrifluoroethane

Surrogate Recoveries

i+-1.2-Dichloroethane

d.3-Toilune

Gromoluorobenene

Held Solke

110-Erivibenzente

$\begin{array}{ccc}\text { RTSḦlRICAT } & \text { LLiNL Field } & \text { RTS\#̈2/RIO030 } \\ 1+a / b & \text { Blank } & 23 \mathrm{a} / \mathrm{b} \\ 04320098 & 04320198 & 04320298 \\ 98 / 08 / 18 & 98 / 08 / 18 & 98 / 08 / 26\end{array}$

0.052

0.058

$<$

$<$

$1.2 *$

0.42

$<$

0.018

0.007

0.004

0.007

0.008

0.006

0.036

0.014

0.016

0.011

0.008

0.007

0.009

0.008

0.016

0.009

0.007

0.012

0.019

0.031

0.008

0.014

0.009

0.009

0.006

0.007

0.015

0.020
0.0

0.21

$<$

$<$

$<$

$<$

$<$

$<$

$<$

$<$

$<$

$<$

$<$

$<$

$<$

$<$

$<$

$<$

$<$

0.015

$<$

$<$

$<$

$<$

$<$

$<$

$<$

$<$

$<$

$<$

$<$

$<$

$<$

92

104

103
$<$

$0.035 * *$

$<$

$<$

$1.0^{* * *}$

$0.56 * *$

$<$

$<$

$<$

$<$

$<$

$<$

$<$

$<$

$<$

$<$

$<$

$<$

$<$

$<$

$<$

0.29

$<$

$<$

$<$

0.076

$<$

$<$

0.11

$<$

$<$

0.007

0.027

$<$

7

93

107 


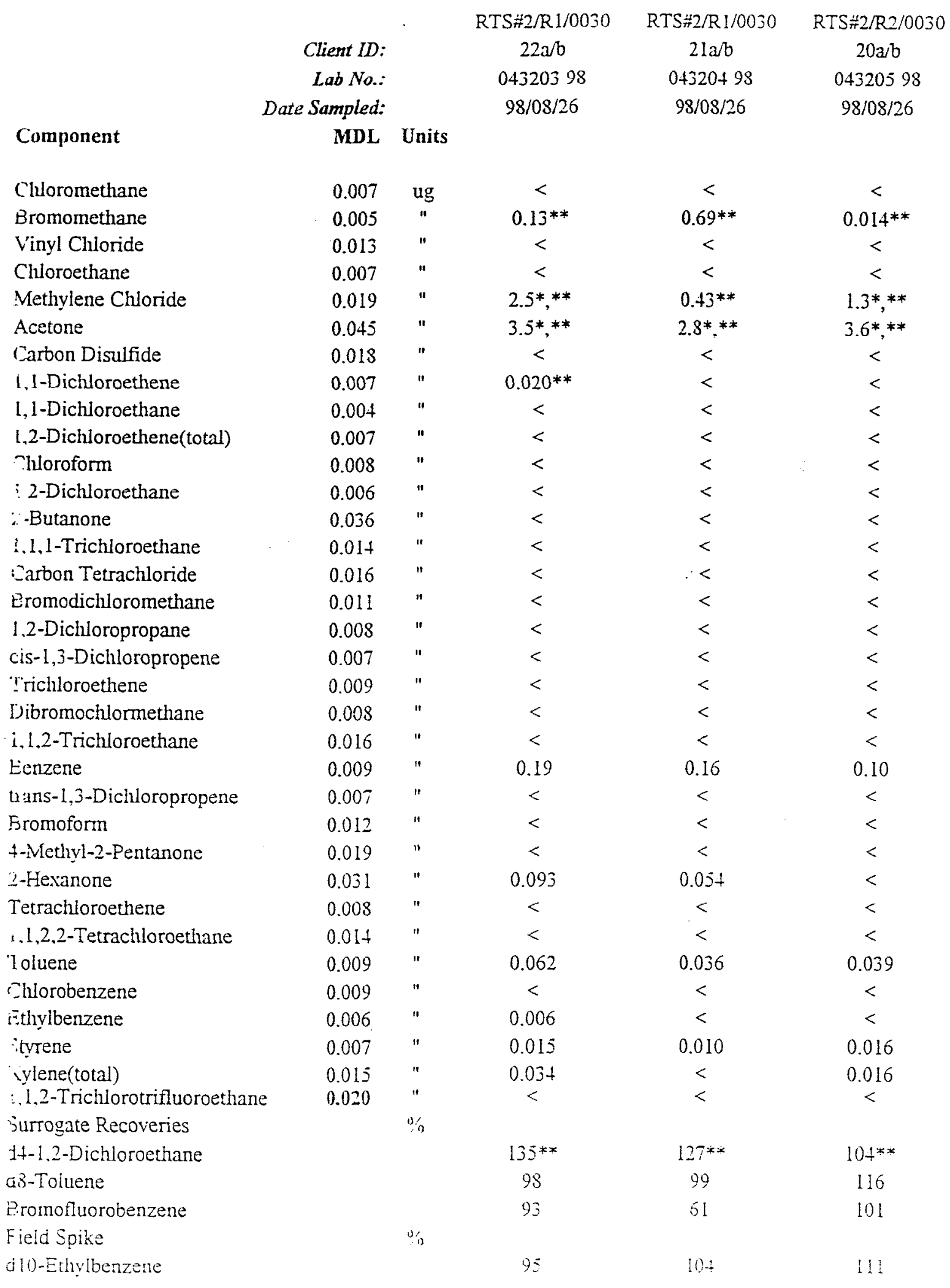




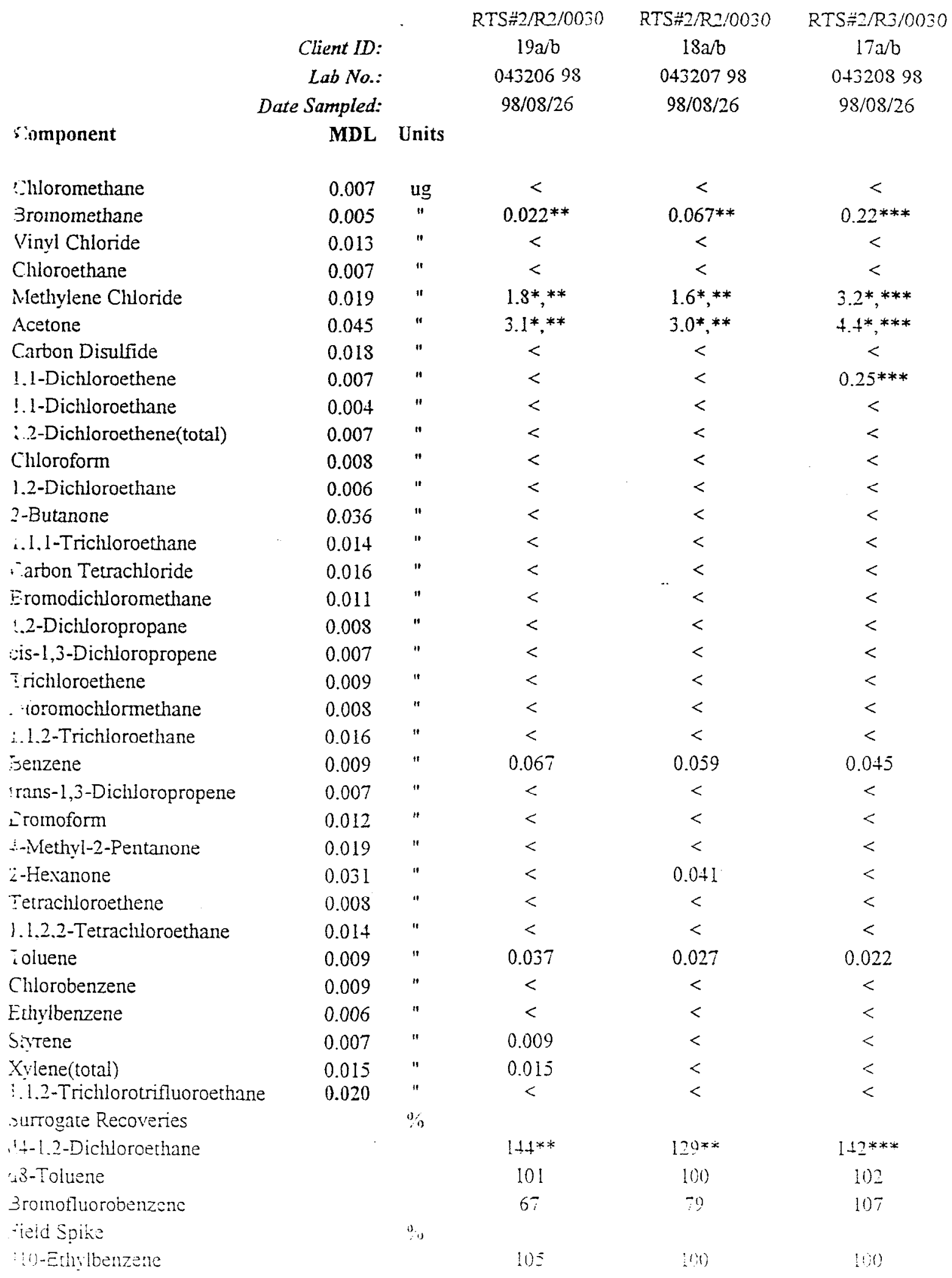




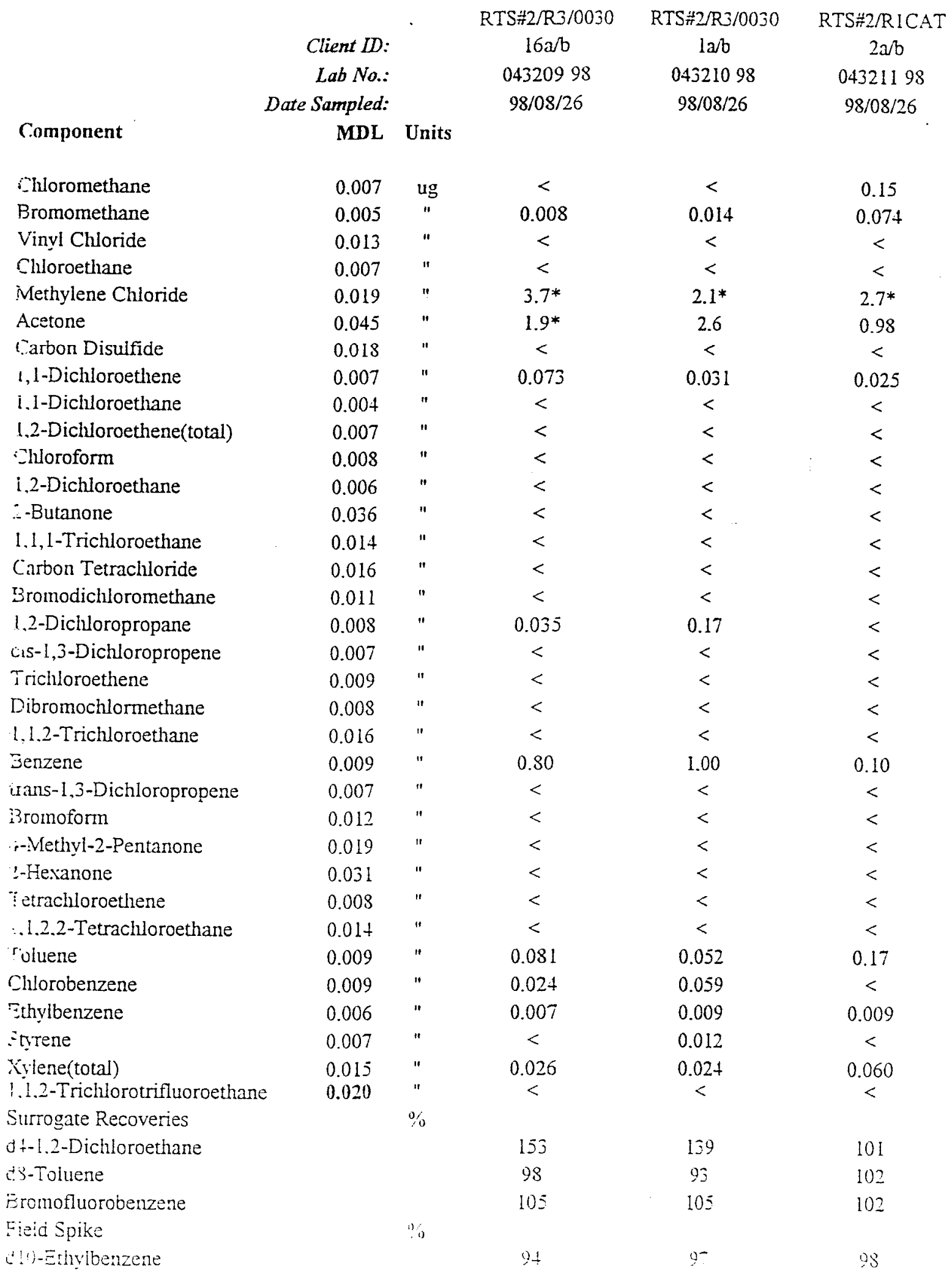




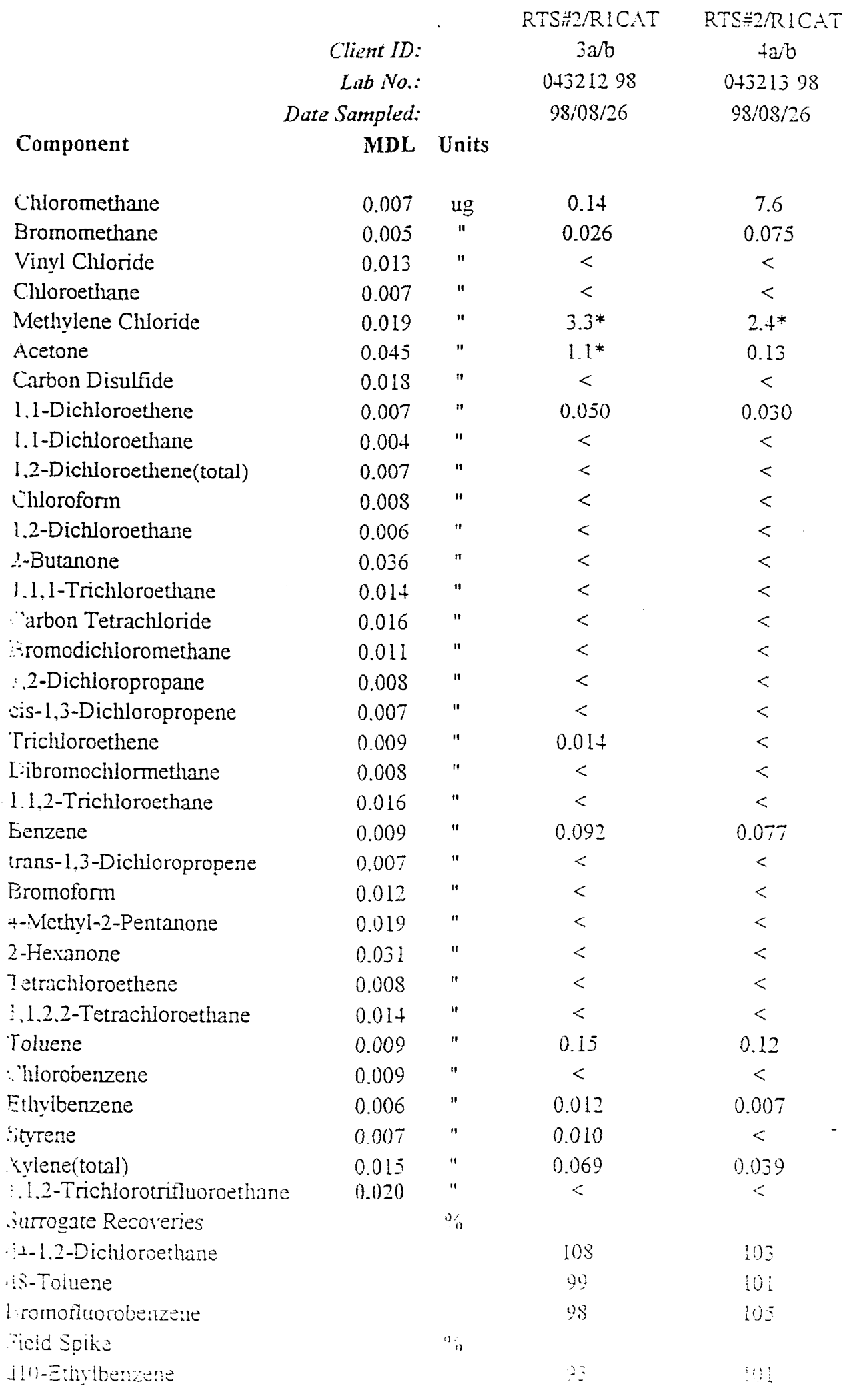




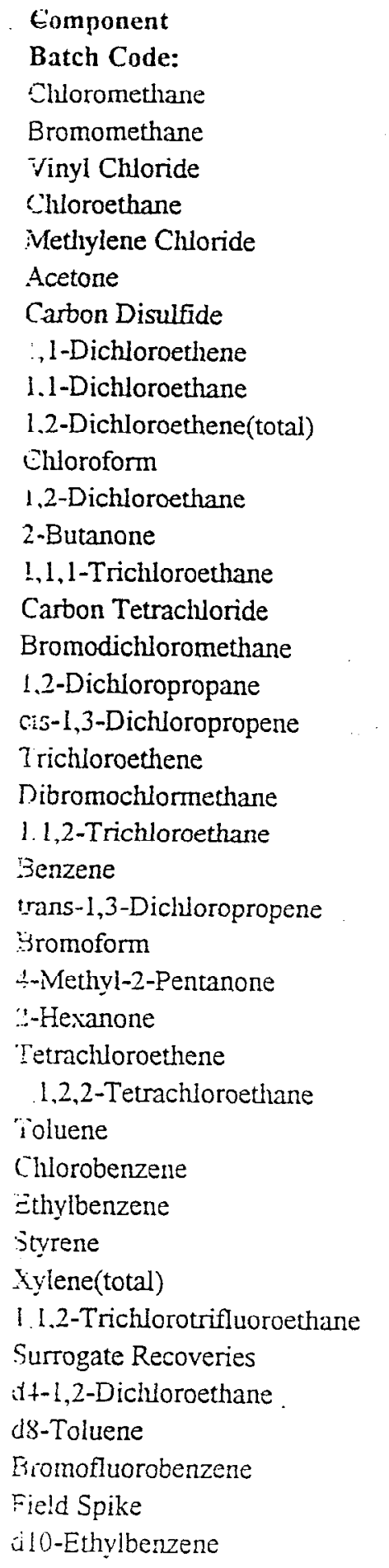

\section{Units}

\begin{tabular}{|c|c|c|c|c|}
\hline & & $0904 \mathrm{EG} 01$ & $0909 \mathrm{EG} 01$ & 0908EG01 \\
\hline 0.007 & ug & $<$ & $<$ & $<$ \\
\hline 0.005 & $"$ & 0.014 & $<$ & 0.006 \\
\hline 0.013 & $"$ & $<$ & $<$ & $<$ \\
\hline 0.007 & $"$ & $<$ & $<$ & $<$ \\
\hline 0.019 & $"$ & $<$ & 0.059 & 0.027 \\
\hline 0.045 & $"$ & 0.072 & $<$ & $<$ \\
\hline 0.018 & $"$ & $<$ & $<$ & $<$ \\
\hline 0.007 & $"$ & $<$ & $<$ & $<$ \\
\hline 0.004 & $"$ & $<$ & $<$ & $<$ \\
\hline 0.007 & $"$ & $<$ & $<$ & $<$ \\
\hline 0.008 & $"$ & $<$ & $<$ & $<$ \\
\hline 0.006 & $"$ & $<$ & $<$ & $<$ \\
\hline 0.036 & $"$ & $<$ & $<$ & $<$ \\
\hline 0.014 & $"$ & $<$ & $<$ & $<$ \\
\hline 0.016 & $"$ & $<$ & $<$ & $<$ \\
\hline 0.011 & $"$ & $<$ & $<$ & $<$ \\
\hline 0.008 & $"$ & $<$ & $<$ & $<$ \\
\hline 0.007 & $"$ & $<$ & $<$ & $<$ \\
\hline 0.009 & $"$ & $<$ & $<$ & $<$ \\
\hline 0.008 & $"$ & $<$ & $<$ & $<$ \\
\hline 0.016 & $"$ & $<$ & $<$ & $<$ \\
\hline 0.009 & $"$ & 0.012 & 0.013 & 0.012 \\
\hline 0.007 & $"$ & $<$ & $<$ & $<$ \\
\hline 0.012 & $"$ & $<$ & $<$ & $<$ \\
\hline 0.019 & $"$ & $<$ & $<$ & $<$ \\
\hline 0.031 & $"$ & $<$ & $<$ & $<$ \\
\hline 0.008 & $"$ & $<$ & $<$ & $<$ \\
\hline 0.014 & $"$ & $<$ & $<$ & $<$ \\
\hline 0.009 & $"$ & $<$ & $<$ & $<$ \\
\hline 0.009 & $"$ & $<$ & $<$ & $<$ \\
\hline 0.006 & $\because$ & $<$ & $<$ & $<$ \\
\hline 0.007 & $"$ & $<$ & $<$ & $<$ \\
\hline 0.015 & $"$ & $<$ & $<$ & $<$ \\
\hline \multirow[t]{7}{*}{0.020} & $"$ & $<$ & $<$ & $<$ \\
\hline & $\%$ & & & \\
\hline & & 105 & 90 & 86 \\
\hline & & 98 & 103 & 104 \\
\hline & & 107 & 107 & 110 \\
\hline & $\%$ & & & \\
\hline & & 103 & 104 & 97 \\
\hline
\end{tabular}


Analytical report

$\begin{array}{ll}\text { Job Name: } & \text { LLNL } \\ \text { Sample Date: } & 8 / 18 / 98 \\ \text { Request by: } & \text { R Bcst } 7 \\ \text { Analytical Method: } & \text { Method EPA } \\ \text { Date of Anaysis: } & 8 / 31 / 98 \text { to } 9 / 17 / 98 \\ \text { Source: } & \text { Pagkouse oullet }\end{array}$

\begin{tabular}{|c|c|c|c|c|c|}
\hline Lab ID Number & $\begin{array}{c}\text { Sample } \\
(\mathrm{ml})\end{array}$ & $\begin{array}{c}\text { Aliquot } \\
(\mathrm{ml})\end{array}$ & Parameter & $\begin{array}{l}\text { Net Weight } \\
\text { gain, (mg) }\end{array}$ & $\begin{array}{c}\text { Result } \\
\text { Blank Corrected }\end{array}$ \\
\hline $\begin{array}{l}\text { R1M5 (ProberNozzle rinsc) } \\
\text { RIM5 (Filter) }\end{array}$ & $\begin{array}{l}56.0 \mathrm{ml} \\
\mathrm{N} / \mathrm{A}\end{array}$ & $\begin{array}{l}56.0 \mathrm{ml} \\
\mathrm{N} / \mathrm{A}\end{array}$ & $\begin{array}{l}\text { Particulatc } \\
\text { Particulate }\end{array}$ & $\begin{array}{l}0.71 \mathrm{mg} \\
-1.18 \mathrm{mg}\end{array}$ & $\begin{array}{c}0.11 \mathrm{mg} \\
<0.05 \mathrm{mg}\end{array}$ \\
\hline $\begin{array}{l}\text { R2M5 (Probe/Nozzle rinse) } \\
\text { R2M5 (Filter) }\end{array}$ & $\begin{array}{l}69.0 \mathrm{ml} \\
\mathrm{N} / \mathrm{A}\end{array}$ & $\begin{array}{l}69.0 \mathrm{ml} \\
\mathrm{N} / \mathrm{A}\end{array}$ & $\begin{array}{l}\text { Particulate } \\
\text { Particulate }\end{array}$ & $\begin{array}{l}9.95 \mathrm{mg} \\
-0.76 \mathrm{mg}\end{array}$ & $\begin{array}{l}9.20 \mathrm{mg} \\
<0.05 \mathrm{mg}\end{array}$ \\
\hline $\begin{array}{l}\text { R3M5 (ProberNozzle rinsc) } \\
\text { R3M5 (Filter) }\end{array}$ & $\begin{array}{l}67.0 \mathrm{ml} \\
\mathrm{N} / \mathrm{A}\end{array}$ & $\begin{array}{l}67.0 \mathrm{ml} \\
\mathrm{N} / \mathrm{A}\end{array}$ & $\begin{array}{l}\text { Particulate } \\
\text { Particulate }\end{array}$ & $\begin{array}{l}1.70 \mathrm{mg} \\
0.52 \mathrm{mg}\end{array}$ & $\begin{array}{l}0.98 \mathrm{ing} \\
0.52 \mathrm{mg} g\end{array}$ \\
\hline $\begin{array}{l}\text { R4M5 (Acetone blank) } \\
\text { R4M5 (Filter blank) }\end{array}$ & $\begin{array}{l}50.0 \mathrm{mi} \\
\mathrm{N} / \mathrm{A}\end{array}$ & $\begin{array}{l}50.0 \mathrm{ml} \\
\mathrm{N} / \mathrm{A}\end{array}$ & $\begin{array}{l}\text { Particulatc } \\
\text { Pariculate }\end{array}$ & $\begin{array}{l}0.5+\mathrm{mg} \\
0.00 \mathrm{mg}\end{array}$ & \\
\hline
\end{tabular}

Comments:

$<0.05 \mathrm{mg}=$ Nol detceicd

$\%$ Accionc Residuc $=0.0014 \%$

Calculations:

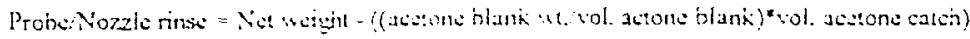

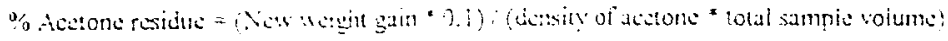

Tolerance Limits: $\%$ tce:ton resiume $=0.00 \%$ s...

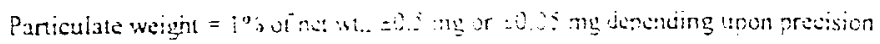




\section{Analytical report}

Job Name: $\quad$ LLNL

Sample Date: $\quad 8 / 19 / 98$

Request by: R Best
Analyst: Michael W. Wiley

Analytical Method: Method 5 EPA

$\begin{array}{ll}\text { Date of Anaysis: } & 8 / 31 / 98 \text { to } 9 / 17 / 98 \\ \text { Source: } & \text { Catalyst outlct RTS }\end{array}$

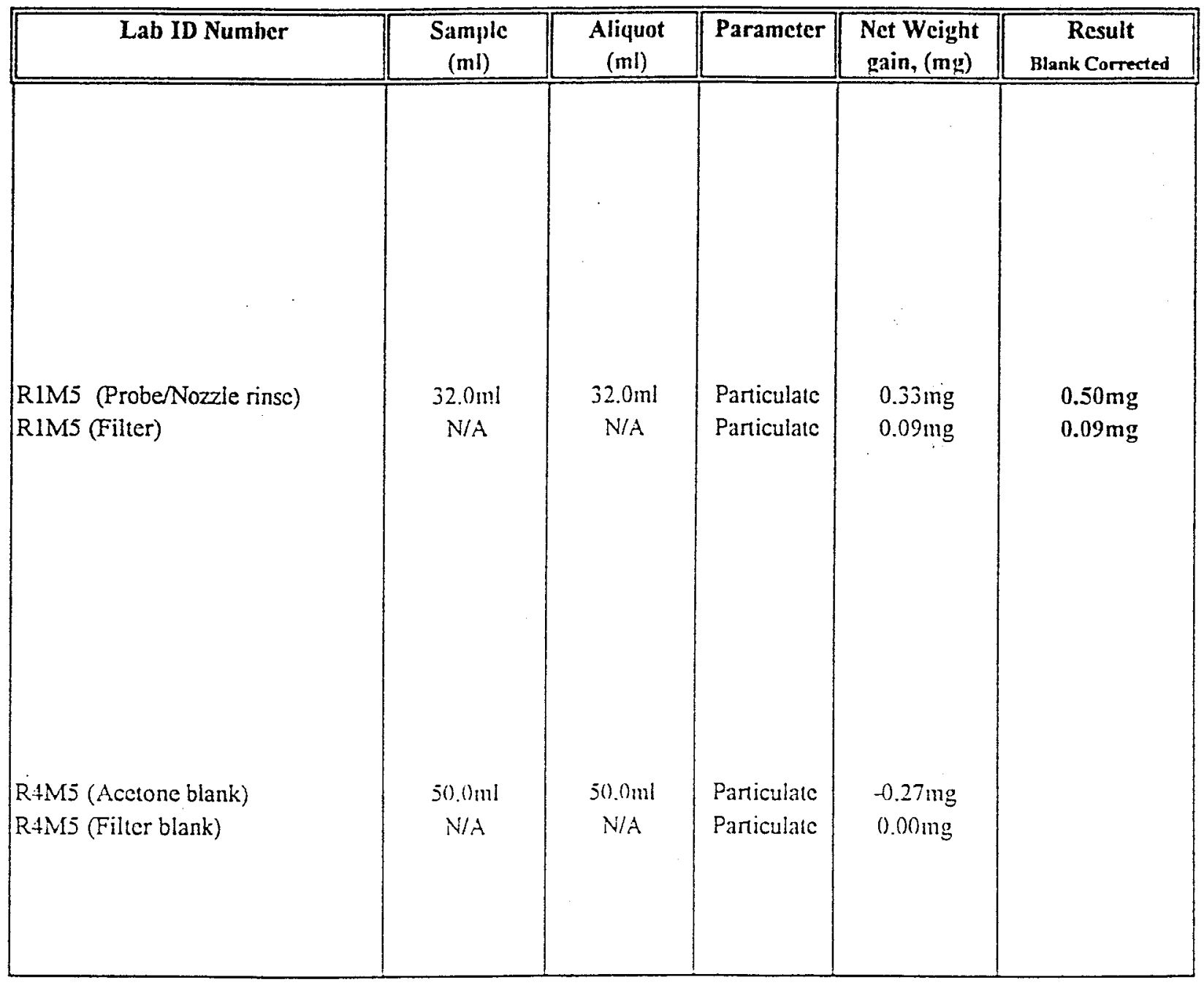

Comments: $\quad \quad \quad 0.05 \mathrm{mg}=$ Not deiccicd

$\%$ Acctonc Residuc $=\quad-0.0007 \%$

Calculations:

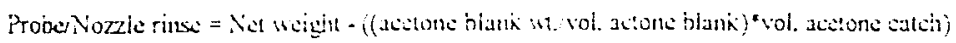

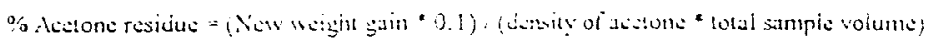

Tolerance Linits: $\%$ Actone resivus = $1.00 ! ", \ldots$.

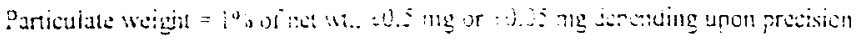


GRAVTMETRIC SAMPLE WORKSHEET

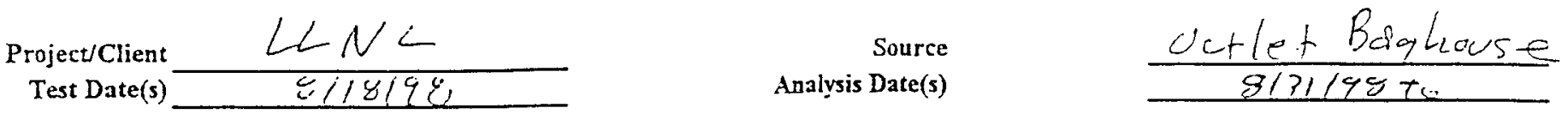

\begin{tabular}{|c|c|c|c|c|c|c|c|}
\hline \multicolumn{8}{|c|}{ Probe/Nozle Weights } \\
\hline Rus * & $\operatorname{Tin} *$ & $\begin{array}{c}\text { Sample Residwe WL } \\
\text { (mg) }\end{array}$ & $\begin{array}{c}\text { Samphe Vol (a) } \\
\text { Van }\end{array}$ & $\begin{array}{c}\text { Acetome Blsok WL } \\
\text { (nos) } \\
\text { Mos }\end{array}$ & $\begin{array}{c}\begin{array}{c}\text { Acetome Blank Vol } \\
\text { (mi) } \\
V_{\mathrm{n}}\end{array} \\
\end{array}$ & $\begin{array}{c}\text { Acetoae Blank } \\
\text { Correction WL (an) } \\
W_{2}\end{array}$ & Net WL gain (-g) \\
\hline Besfureather & 271 & 56 & 071 & 50 & $05 x$ & 0.60 & 0.11 \\
\hline 24 & 272 & 69 & 9.95 & 7 & 0.54 & 0.75 & 9.20 \\
\hline 至 & 276 & 67 & 1.70 & $\sqrt{1}$ & 0.54 & 0.75 & 6.95 \\
\hline Cotout & 2 & & & & & & \\
\hline & 277 & Son & 0.54 & & & & \\
\hline
\end{tabular}

Acetone Blank Correction $W_{L} W_{3}=M_{a} * V_{a} W_{1} / V_{2}$

Net Wt gain $(\mathrm{mg})=$ Sampie Residue Weight - Blank Correction

Filter Weights

\begin{tabular}{|c|c|c|c|c|}
\hline Ran \# & Filter * & Iare Wt (me) & Gross WL (me) & Net Wt gain (mo) \\
\hline & $b_{0} \times 801$ & & & -1.18 \\
\hline & bey $8 c z$ & & & $-0.2 r$ \\
\hline & $b c \times a .45$ & & & 0.52 \\
\hline & & & & \\
\hline & & & & \\
\hline
\end{tabular}

Bach-Haif $\left(\mathrm{H}_{2} \mathrm{O}\right)$ Condeasible Fraction

\begin{tabular}{|c|c|c|c|c|c|c|c|}
\hline Rua * & $\begin{array}{c}\text { Container } \\
\text { Typer\# }\end{array}$ & $\begin{array}{c}\text { Tocal Sample Volume } \\
\text { (mi) } \\
v_{t} \\
\end{array}$ & $\begin{array}{c}\text { Aliquar Yolume (mi) } \\
\text { Y. }\end{array}$ & $\begin{array}{c}\vdots \\
\text { Aliquor Dry Wt (oog) } \\
\text { Yal }\end{array}$ & $\begin{array}{c}\text { Calculated Toul } \\
\text { Sample Dry tht (mg) } \\
\text { ys } \\
\end{array}$ & $\begin{array}{c}\begin{array}{c}\text { Btank Correcdoa Wt } \\
\text { (mg) } \\
\mathrm{Mb}\end{array} \\
\end{array}$ & Net Wt gasin (me) \\
\hline & & & & & & & \\
\hline & & & & & & & \\
\hline & & & & & & & \\
\hline & & & & & & & \\
\hline & & & & & & & \\
\hline
\end{tabular}

Total Sample Dry Weight $(\mathrm{Ms})=(\mathrm{VtVa}) * \mathrm{Mal}$

Blank Correction Wt. (Mb) $=$ Ms(biank)* (Vt/Yit blank)

Net Wright $=\mathrm{Ms}-\mathrm{Mb}$

Back-Ealf : Oraanic) Condeasibie Fraction

\begin{tabular}{|c|c|c|c|c|c|c|c|}
\hline Ren $\#$ & $\begin{array}{l}\text { Concainer } \\
\text { Irpert }\end{array}$ & $\begin{array}{c}\text { Totai Sampigie Volume } \\
\text { (mi) } \\
\text { is }\end{array}$ & 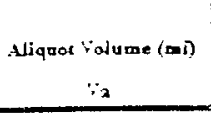 & 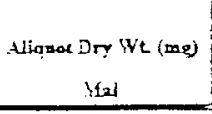 & $\begin{array}{c}\text { Calcuized Total } \\
\text { Sample tre iWh (mos) } \\
316\end{array}$ & $\begin{array}{c}\text { Blank Wh (mp) } \\
31 \mathrm{~b}\end{array}$ & Net $W_{t}$ z̧in (my) \\
\hline & & & & & & & \\
\hline & & & & & 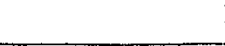 & & \\
\hline & & 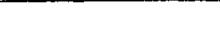 & & & 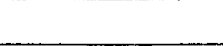 & & \\
\hline & & 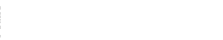 & & & & & \\
\hline & & $\Gamma$ & & & 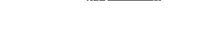 & & \\
\hline
\end{tabular}

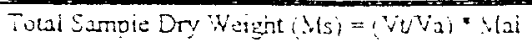

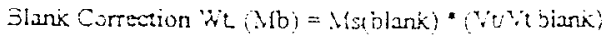

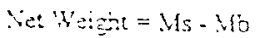


BEST ENVIRONMENTAL, INC.

\section{GRAVIMETRIC SAMPLE RECORD}

Project/Client $L C N L$ Test Date(s) $\varepsilon / 28 / q \varepsilon$
Source Botelecse aut $6 X$ Method

\begin{tabular}{|c|c|c|c|c|c|c|c|}
\hline Project Sample ID & $\begin{array}{l}\text { Lab Container } \\
\text { Type/\# }\end{array}$ & $\begin{array}{c}\text { Tare Wt. (g) from } \\
\text { Tare Sheet }\end{array}$ & Gross Wt. (g) & Date & Time & $\begin{array}{c}\text { Net Wt gain } \\
(\mathrm{mg})\end{array}$ & Initial \\
\hline \multirow[t]{5}{*}{$R M S-F L I$} & $\Rightarrow$ & & 2.32124 & 191.198 & $13: 07$ & & 4 \\
\hline & - & Date & 2.32123 & 1914128 & $16: 59$ & & 2 \\
\hline & T.4 & 2.32051 & & & & & \\
\hline & 271 & $\mathrm{Wt}$ & & & & $0.7,-2$ & \\
\hline & & 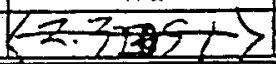 & 23.321234 & & & & \\
\hline \multirow{5}{*}{$R_{2} M S-F / H$} & TIL & & 2.32454 & $19119 \varepsilon$ & $13: 10$ & & $\mathrm{kez}$ \\
\hline & 272 & Date & 232451 & 9/4) & $16: 57$ & & 2 \\
\hline & & & & & & & $\Sigma$ \\
\hline & & Wt. & & & & & \\
\hline & & 22.31456 & $(2.32453$ & & & 925 & \\
\hline \multirow{5}{*}{$R 3 M S-F / A$} & Iif & $\pi$ & 231226 & $91 / 198$ & $13: 12$ & & $\varkappa_{2}$ \\
\hline & 376 & Date & 2.31226 & $9 / 4 / 6$ & 10.55 & & $k$ \\
\hline & & & & & & & \\
\hline & & $\mathrm{Wt}$ & & & & 1.70 & \\
\hline & 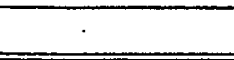 & 2.31056 & $22.31226\rangle$ & & & & \\
\hline \multirow{5}{*}{ RUMS-FIH } & Iin & & $2.35942 \mathrm{k}$ & $91198)$ & $13: 14$ & & Es \\
\hline & 277 & Date & 2.35937 & $4 / 4 / x$ & $16: 53$ & & $2 z_{2}$ \\
\hline & & & & & & & \\
\hline & & $\mathrm{Wt}$ & & & & & \\
\hline & & 1235986 & $x 2.35950 x$ & & & 0.54 & \\
\hline \multirow[t]{5}{*}{$R / M S-F:$ Trer } & $b \circ x$ & & 0.382487 & $9 / 198$ & $13: 16$ & & 165 \\
\hline & $g \varepsilon$ & Date & 0.30245 & $9 / 4196$ & $17: 19$ & & $\mathrm{kz}$ \\
\hline & & & & & & & \\
\hline & & $\mathrm{Wt}$ & & & & & \\
\hline & & 150.38363 & 20.382464 & & & -1.18 & \\
\hline \multirow[t]{5}{*}{$R 2 M S-F / F$} & $b c x$ & & 0.385561 & $9 / 1 / 90$ & $13: 18$ & & Vyes \\
\hline & 882 & Date & 0.385121 & 914198 & $17: 16$ & & \\
\hline & & & 6385121 & 918198 & & & \\
\hline & & $\mathrm{Wt}$ & & & & & \\
\hline & & 60.39588 & $00.385 / 27$ & & & -0.76 & \\
\hline \multirow[t]{5}{*}{ R3MS-F/A } & $b 0 v$ & & 0.36148 & $9 / 1196$ & $\angle 3: 20$ & & $k<$ \\
\hline & 0245 & Date & 0.36166 & $914 / 98$ & $17: 15$ & & $2=2$ \\
\hline & & & $0361 / 6$ & $918 / 48$ & $11 ! 19$ & & 22 \\
\hline & & $\mathrm{Wt}$ & $0 . \overline{3} 662$ & $1 / \times 194$ & $17: 22$ & & $E$ \\
\hline & & 00.360771 & 00.3610 .51 & 41919 & $e: 40$ & & \\
\hline \multirow[t]{5}{*}{ RLyS-Fi:Ter } & & 11 & 0.36146 & $919 / 41$ & $10: 2 !$ & & -72 \\
\hline & & Dare & 10.70057 & जilizell & $10: 46$ & & 2 \\
\hline & & & $60.6124 ?$ & & & 0.521 & \\
\hline & & Wi & $1 !$ & & & 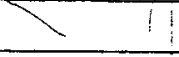 & \\
\hline & & 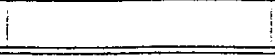 & 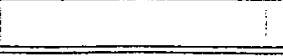 & & $i$ & 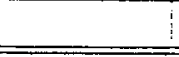 & \\
\hline
\end{tabular}

TARE to $0.0001=5 \Delta$

Final Wt. - either $=0.0005 \Delta$ or $0.005 \Delta$ or $=4 \%$ or vet Wt

z'reporsimwi $97 /$ wtshcer 
BEST ENVIRONMENTAL, INC.

GRAVIMETRIC SAMPLE RECORD

Project/Client $L L N L$

Source Re

Test Date(s) $81 / 9198$ $8 / 19$ Method

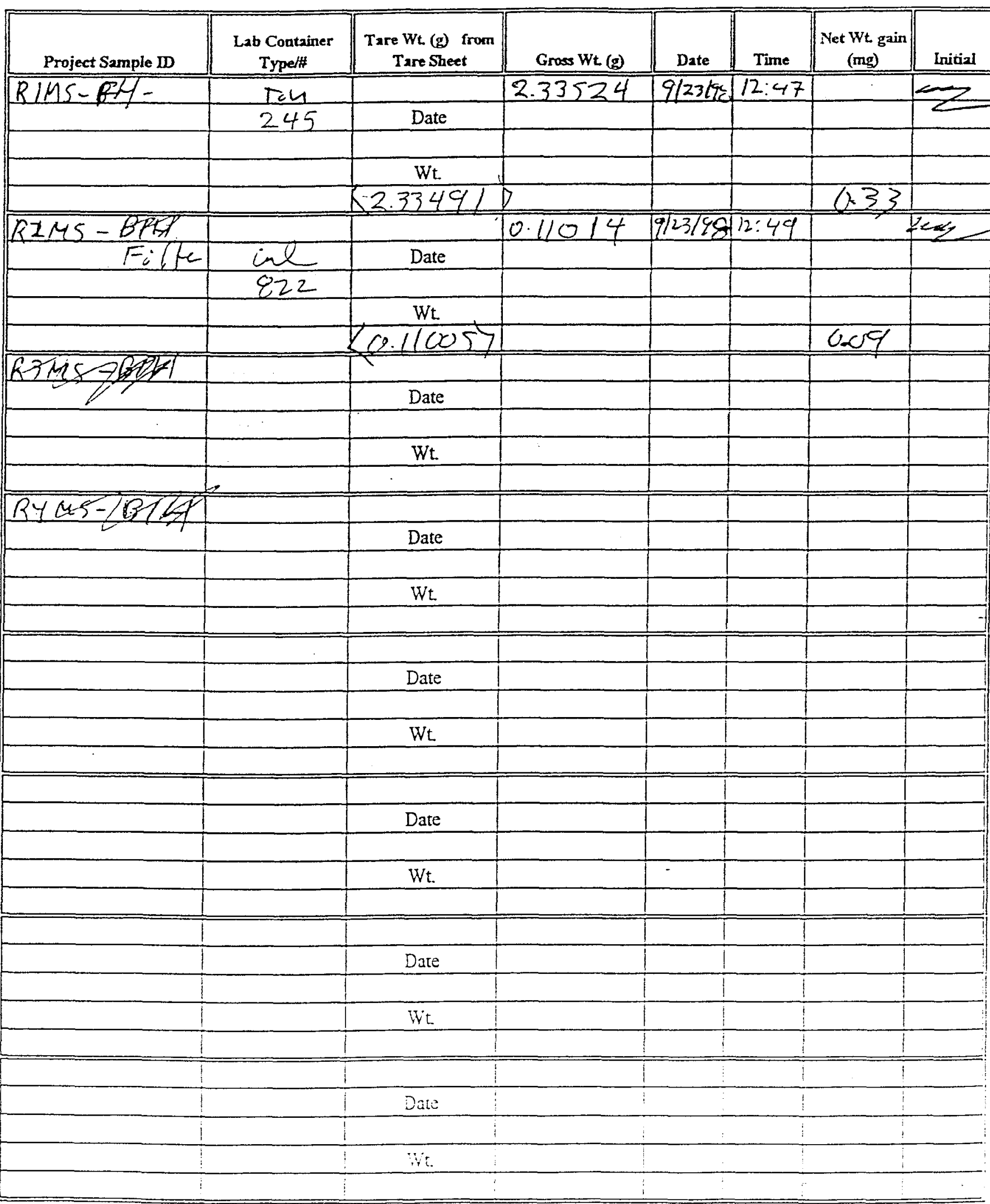

TARE to $0.0001=5 \Delta$

Final Wt, - either $=0.0005 \Delta$ or $0.005 \Delta$ or $=4 \%$ d or Ner Wt

girecorisimwighoutsices 


\section{ANALYTICAL CHEMISTS}

October 22, 1998

Best Environmental, Inc. 15890 Foothill Blvd, San Leandro, CA 94578

Sample Site: LLNL

Description: RIMS/114-F/H-B-OUT

Sampled by:

Type of Sample: Solid
LAB No: SP 807981-1

RE: Radiological Analysis
Sampled : August 18, 1998
Received : September 25, 1998
Completed : October 13, 1998
QA/QC ID $:$ 80798101- A

\section{Analytical Results}

\begin{tabular}{lllll}
\hline & EPA & & & \\
\multicolumn{1}{c}{ CONSTITUENT } & METHOD & UNITS & RESULTS & ERROR \\
\hline \hline Gross Alpha & 9310 & $\mathrm{pCi} / \mathrm{samp}$ & 0.1 & \pm 1 \\
Gross Beta & 9310 & $\mathrm{pCi} / \mathrm{samp}$ & $0.3 \pm \pm 1$ \\
Tritium & $\mathrm{H}-1$ & $\mathrm{pCi} / \mathrm{samp}$ & $0.0 \pm \pm 2$ \\
\hline \hline
\end{tabular}

$\mathrm{pCi} / \mathrm{L}=$ pico Curies per Liter $\mathrm{FCi} / \mathrm{ml}=$ pico Curies per milliliter

Containers: (a) Plastic

If you have any questions, please call.

FGL ENVIRONMENTAL

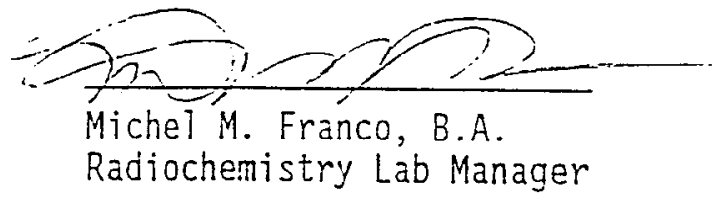

MMF :vt 


\section{ANALYTICAL CHEMISTS}

October 22, 1998

LAB No: SP 807981-5

Best Environmental, Inc.

15890 Foothill Blvd,

San Leandro, CA 94578

RE: Radiological Analysis

Sample Site: LLNL

Description: RIMS/114-FILTER-B-OUT

Sampled : August 18, 1998

Sampled by :

Received : September 25, 1998

Type of Sample: Air Filter

Completed : October 19, 1998

QA/QC ID $\#$ : 80798105- A

\section{Analytical Results}

\begin{tabular}{lllcl}
\hline \hline & EPA & & & \\
CONSTITUENT & METHOD & UNITS & RESULTS & ERROR \\
\hline \hline Gross Alpha & 9310 & $\mathrm{pCi} / \mathrm{samp}$ & $0.00 \pm 0.38$ \\
Gross Beta & 9310 & $\mathrm{pCi} / \mathrm{samp}$ & $0.96 \pm 1.3$ \\
Tritium & $\mathrm{H}-1$ & $\mathrm{pCi} / \mathrm{samp}$ & $2.0 \pm 2$ \\
\hline \hline
\end{tabular}

$\mathrm{pCi} / \mathrm{L}=$ pico Curies per Liter $\mathrm{pCi} / \mathrm{ml}=$ pico Curies per milliliter

Containers: (a) Glass

If you have any questions, please call.

FGL ENVIRONMENTAL

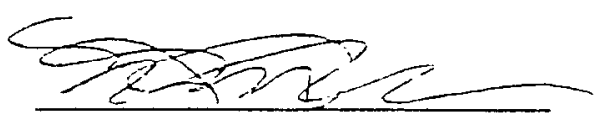

Michel M. Franco, B.A.

Radiochemistry Lab Manager

MMF:vt 


\section{ENVIRONMENTAL}

\section{ANALYTICAL CHEMISTS}

October 21, 1998

LAB No: SP 807981-9

Best Environmental, Inc. 15890 Foothill Blvd,

San Leandro, CA 94578

RE: Radiological Analysis

Sample Site: LLNL

Description: RIMS/114-IMP-B-OUT

Sampled by :

Type of Sample: Non Potable Water

Sampled : August 18, 1998

Received : September 25, 1998

Completed : October 20, 1998

QA/QC ID $\vec{\pi}:$ : 80798109-A

\section{Analytical Results}

\begin{tabular}{|c|c|c|c|c|c|}
\hline CONSTITUENT & $\begin{array}{l}\text { EPA } \\
\text { METHOD }\end{array}$ & UNITS & RESULTS & ERROR & $\begin{array}{l}\text { Piesults } \\
\times 0.200 \mathrm{H}\end{array}$ \\
\hline $\begin{array}{l}\text { Gross Alpha } \\
\text { Gross Beta } \\
\text { Tritium }\end{array}$ & $\begin{array}{r}9310 \\
9310 \\
906.0\end{array}$ & $\begin{array}{l}\mathrm{pCi} / \mathrm{L} \\
\mathrm{pCi} / \mathrm{L} \\
\mathrm{pCi} / \mathrm{L}\end{array}$ & $\begin{array}{r}20 \\
1 \\
3000\end{array}$ & $\begin{array}{r}4 \\
7 \\
00\end{array}$ & $\begin{array}{l}5.2 \\
0.26 \\
780 .\end{array}$ \\
\hline
\end{tabular}

$\mathrm{pCi} / \mathrm{L}=$ pico Curies per Liter $\mathrm{pCi} / \mathrm{ml}=$ pico Curies per milliliter

Containers: (a) Glass

If you have any questions, please call.

FGL ENVIRONMENTAL

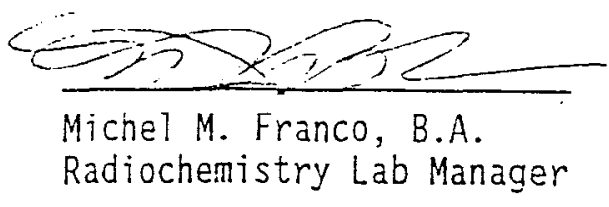

MMF:vt 


\section{ANALYTICAL CHEMISTS}

October 22, 1998

Best Environmental, Inc. 15890 Foothi17 Blvd, San Leandro, CA 94578

Sample Site: LLNL

Description: R2MS/114-F/H-B-OUT

Sampled by :

Type of Sample: Solid
LAB No: SP 807981-2

RE: Radiological Analysis

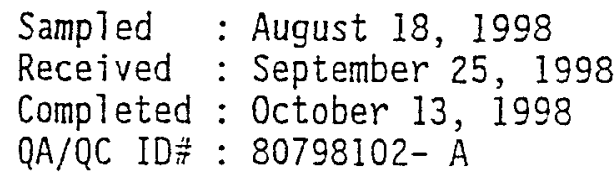

Sampled : August 18, 1998

Received : September 25, 1998

QA/QC ID

\section{Analytical Results}

\begin{tabular}{lllcl}
\hline \hline \multirow{2}{*}{ CONSTITUENT } & EPA & & & \\
& METHOD & UNITS & RESULTS & ERROR \\
\hline \hline Gross Alpha & 9310 & PCi/samp & $0.0 \pm 1$ \\
Gross Beta & 9310 & pCi/samp & $0.6 \pm 1$ \\
Tritium & $H-1$ & pCi/samp & $31 \pm \pm 2$ \\
\hline \hline
\end{tabular}

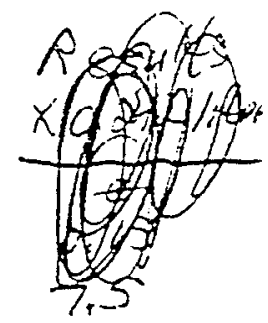

FCi/L = pico Curies per Liter $\mathrm{pCi} / \mathrm{ml}=$ pico Curies per milliliter

Containers: (a) Plastic

If you have any questions, please call.

FGL ENVIRONMENTAL

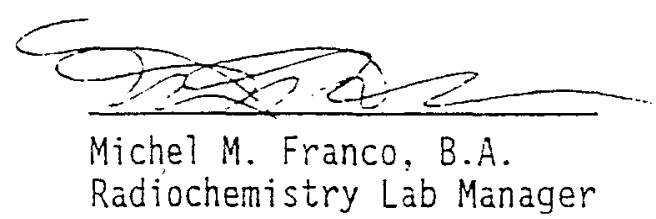

MMF :vt

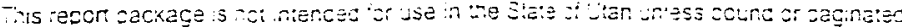




\section{AYALYTICAL CHEMISTS}

October 22, 1998

Best Environmental, Inc. 15890 Foothi71 BTvd, San Leandro, CA 94578

Sample Site: LLNL

Description: R2MS/114-FILTER-B-OUT Sampled by :

Type of Sample: Air Filter
LAB No: SP 807981-б

RE: Radiological Analysis
Sampled : August 18, 1998

Received : September 25, 1998

Completed : October 19, 1998

QA/QC ID $\frac{*}{\pi}:$ 80798106- A

\section{Analytical Results}

\begin{tabular}{lllll}
\hline \hline & EPA & & & \\
\multicolumn{1}{c}{ CONSTITUENT } & METHOD & UNITS & RESULTS & ERROR \\
\hline \hline Gross Alpha & 9310 & $\mathrm{pCi} / \mathrm{samp}$ & $0.00 \pm 0.39$ \\
Gross Beta & 9310 & $\mathrm{pCi} / \mathrm{samp}$ & $0.62 \pm 1.3$ \\
Tritium & $\mathrm{H}-1$ & $\mathrm{pCi} / \mathrm{samp}$ & $1.0 \pm 2$ \\
\hline \hline
\end{tabular}

$\mathrm{pCi} / \mathrm{L}=$ pico Curies per Liter $\mathrm{pCi} / \mathrm{ml}=$ pico Curies per milliliter Containers: (a) Glass

If you have any questions, please call.

FGL ENVIRONMENTAL

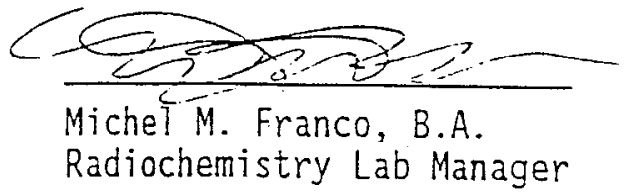

MMF:vt

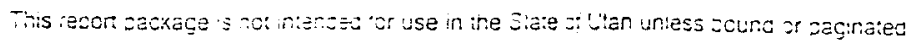




\section{ENVIRONMENTAL}

\section{AYALYTICAL CHEMISTS}

October 21, 1998

Best Environmenta7, Inc. 15890 Foothill BTvd, San Leandro, CA 94578

Sample Site: LLNL

Description: R2MS/114-IMP-B-OUT

Sampled by :

Type of Sample: Non Potable Water
LAB No: SP 807981-10

RE: Radiological Analysis
Sampled : August 18, 1998

Received : September 25, 1998

Completed : October 20, 1998

QA/QQC ID\# : 80798110- A

\section{Analytical Results}

\begin{tabular}{|c|c|c|c|c|c|}
\hline CONSTITUENT & $\begin{array}{c}\text { EPA } \\
\text { METHOD }\end{array}$ & UNITS & RESULTS & ERROR & $\begin{array}{l}\text { Resal te } \\
\times 0.0421 \text { ito }\end{array}$ \\
\hline $\begin{array}{l}\text { Gross Alpha } \\
\text { Gross Beta } \\
\text { Tritium }\end{array}$ & $\begin{array}{r}9310 \\
9310 \\
906.0\end{array}$ & $\begin{array}{l}\mathrm{pCi} / \mathrm{L} \\
\mathrm{pCi} / \mathrm{L} \\
\mathrm{pCi} / \mathrm{L}\end{array}$ & $\begin{array}{r}1 \\
2 \\
2600\end{array}$ & $\begin{array}{r}1 \\
2 \\
00\end{array}$ & $\begin{array}{r}0.48 \\
629.2\end{array}$ \\
\hline
\end{tabular}

$\mathrm{pCi} / \mathrm{L}=$ pico Curies per Liter $\mathrm{FCi} / \mathrm{ml}=$ pico Curies per milliliter

Concainers: (a) Glass

If you have any questions, please call.

FGL ENVIRONMENTAL

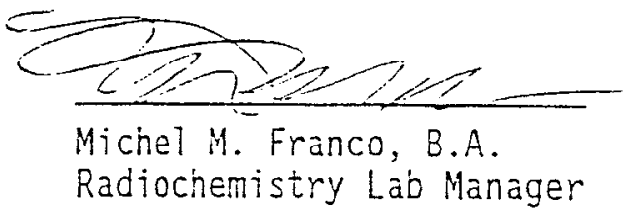

MMF :vt 


\section{ANALYTICAL CHEMISTS}

October 22, 1998

Best Environmental, Inc. 15890 Foothill Blvd,

San Leandro, CA 94578

Sample Site: LLNL

Description: R3MS/114-F/H-B-OUT

Sampled by :

Type of Sample: Solid
LAB No: SP 807981-3

RE: Radiological Analysis
Sampled : August 18, 1998
Received : September 25, 1998
Completed : October 13, 1998
QA/QC ID\# : 80798103-A

\section{Analytical Results}

\begin{tabular}{lllll}
\hline \hline & EPA & & & \\
\multicolumn{1}{c}{ CONSTITUENT } & METHOD & UNITS & RESULTS & ERROR \\
\hline \hline Gross Alpha & 9310 & $\mathrm{pCi} /$ samp & $0.3 \pm 1$ \\
Gross Beta & 9310 & $\mathrm{pCi} /$ samp & $0.5 \pm 1$ \\
Tritium & $\mathrm{H}-1$ & $\mathrm{pCi} /$ samp & $0.0 \pm 2$ \\
\hline \hline
\end{tabular}

pCi/L = pico Curies per Liter $p C i / m l=$ pico Curies per milliliter

Containers: (a) Plastic

If you have any questions, please call.

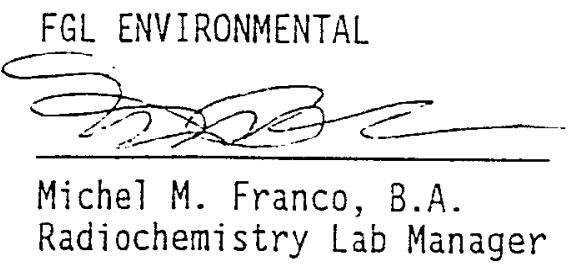

MMF :vt 


\section{AYALYTICAL CHEMISTS}

October 22, 1998

LAB No: SP 807981-7

Best Environmental, Inc.

RE: Radiological Analysis

15890 Foothi17 Blvd,

San Leandro, CA 94578

Sample Site: LLNL

Description: R3MS/114-FILTER-B-OUT

Sampled : August 18, 1998

Sampled by :

Type of Sample: Air Filter

Received : September 25, 1998

Completed : October 19, 1998

QA/QC ID $\#$ : 80798107-A

\section{Analytical Results}

\begin{tabular}{|c|c|c|c|c|}
\hline CONSTITUENT & $\begin{array}{c}\text { EPA } \\
\text { METHOD }\end{array}$ & UNITS & RESULTS & ERROR \\
\hline $\begin{array}{l}\text { Gross Alpha } \\
\text { Gross Beta } \\
\text { Tritium }\end{array}$ & $\begin{array}{l}9310 \\
9310 \\
H-1\end{array}$ & $\begin{array}{l}\mathrm{pCi} / \text { samp } \\
\mathrm{pCi} / \text { samp } \\
\mathrm{pCi} / \text { samp }\end{array}$ & $\begin{array}{l}0.12 \\
0.0 \\
0.6\end{array}$ & $\begin{array}{l} \pm 0.43 \\
\pm \quad 1.2 \\
\pm \quad 2\end{array}$ \\
\hline
\end{tabular}

pCi/L = pico Curies per Liter $p C i / m l=$ pico Curies per milliliter

Containers: (a) Glass

If you have any questions, please call.

FGL ENVIRONMENTAL

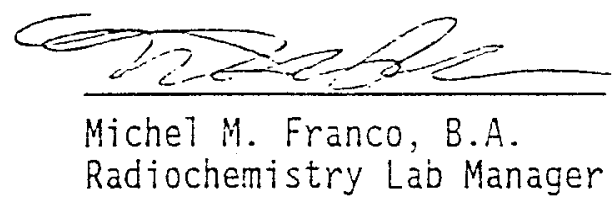

MMF $: v t$ 


\section{AYALYTICAL CHEMISTS}

October 21, 1998

Best Environmental, Inc. 15890 Foothill Blvd, San Leandro, CA 94578

Sample Site: LLNL

Description: R3MS/114-IMP-B-OUT

Sampled by :

Type of Sample: Non Potable Water
LAB No: SP 807981-11

RE: Radiological Analysis

Sampled : August 18, 1998

Received : September 25, 1998

Completed : October 20, 1998

QA/QC ID\# : $80798111-\mathrm{A}$

\section{Analytical Results}

\begin{tabular}{lrlcc}
\hline \multicolumn{1}{c}{ CONSTITUENT } & EPA & & & \\
\hline Gross Alpha & METHOD & UNITS & RESULTS & ERROR \\
Gross Beta & 9310 & $\mathrm{pCi} / \mathrm{L}$ & 1 & 1 \\
Tritium & 9310 & $\mathrm{pCi} / \mathrm{L}$ & $0.0 \pm \pm 2$ \\
\hline \hline
\end{tabular}

Resuths

$\mathrm{pCi} / \mathrm{L}=$ pico Curies per Liter $\mathrm{pCi} / \mathrm{ml}=$ pico Curies per milliliter

Containers: (a) Glass

If you have any questions, please call.

FGL ENVIRONMENTAL

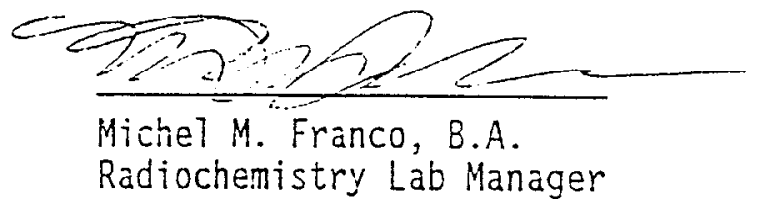

MMF:vt 
GRAVTMETRIC SAMPLE WORKSHEET

Project/Client $2 \angle N C$ Test Date(s) s/20/4\%
Source

Analysis Date(s)
Babinot aut $8 / 31940$

Probe/Nozrle Weights

\begin{tabular}{|c|c|c|c|c|c|c|c|}
\hline Rua * & Tin * & $\begin{array}{c}\text { Semple Residen Wt } \\
\text { (met) }\end{array}$ & $\begin{array}{c}\text { Semplo Vol (mol) } \\
\text { Var }\end{array}$ & $\begin{array}{c}\text { Acetoon Blank Wt } \\
\text { (mo) } \\
\text { Ms }\end{array}$ & $\begin{array}{c}\text { Acetace Blank Vol } \\
(m i) \\
V_{x}\end{array}$ & $\begin{array}{c}\text { Acetome Bhank } \\
\text { Correction WL }(=0) \\
\text { W. }\end{array}$ & Net Wh gain $(-8)$ \\
\hline & 295 & S. & 0.04 & -0.27 & $S c$ & -0.27 & 0.31 \\
\hline & 296 & & 0.25 & -427 & 1 & 9 & 0.52 \\
\hline & $29-7$ & & 3.21 & $-0.2=$ & 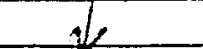 & $y$ & 3.48 \\
\hline & $2 c c$ & & $=0.27$ & & & & \\
\hline
\end{tabular}

Acetone Blank Correction $W_{L} W_{a}=M_{a} * V a w / V_{a}$

Net Wt. gain (mg) = Sample Residue Weight - Blank Correction

Filter Weights

\begin{tabular}{|c|c|c|c|c|}
\hline Rua* & Finter * & Ture Wt (me) & Grose $W_{t}$ (ng) & Net Wt zain (ne) \\
\hline & & & & 0.11 \\
\hline & & & & -008 \\
\hline & & & & -0.04 \\
\hline & & & & \\
\hline & & & & \\
\hline
\end{tabular}

\begin{tabular}{|c|c|c|c|c|c|c|c|}
\hline $\operatorname{Ran} *$ & $\begin{array}{l}\text { Container } \\
\text { Typerk }\end{array}$ & $\begin{array}{c}\text { Tocal Sample Yolamo } \\
\text { (mi) } \\
\text { vt }\end{array}$ & $\begin{array}{c}\text { Aliquas Volume (mal) } \\
y_{2}\end{array}$ & $\begin{array}{c}: \\
\text { Aliquot Dry WL (mo) } \\
\text { MLal }\end{array}$ & $\begin{array}{c}\text { Calcuiated Total } \\
\text { Sample Dry Wt (ang) } \\
\text { Yss }\end{array}$ & $\begin{array}{c}\text { Black Correction Wt } \\
\text { (mg) } \\
\mathbf{M b} \\
\end{array}$ & Net Wh gain $(m g)$ \\
\hline & & & & & & & \\
\hline & & & & & & & \\
\hline & & & & & & & \\
\hline & & & & & & & \\
\hline & & & & & & & \\
\hline
\end{tabular}

Total Sample Dry Weight $(\mathrm{Ms})=\left(\mathrm{V} V \mathrm{~V}_{\mathrm{a}}\right) * \mathrm{Mal}$

Blank Correction Wh (Mb) $=\mathrm{Ms}$ (blanik) $*(V t / \mathrm{t}$ blank)

Net Weight $=\mathrm{Ms}-\mathrm{Mh}$

Back-Haif (Organic) Condensiole Fraction

\begin{tabular}{|c|c|c|c|c|c|c|c|}
\hline Run * & $\begin{array}{l}\text { Container } \\
\text { Trpej* }\end{array}$ & $\begin{array}{c}\text { Total Somple Volume } \\
\text { (mi) } \\
V_{t}\end{array}$ & $\begin{array}{c}\text { Aliquad Voinume (nI) } \\
\text { V. }\end{array}$ & $\begin{array}{c}\text { Aliquor Dry Wt (mg) } \\
\text { MLi }\end{array}$ & $\begin{array}{c}\text { Caiculated Iotal } \\
\text { Sampie Dry Wh (me) } \\
\text { IIs }\end{array}$ & $\begin{array}{c}\text { Blask int (me) } \\
3 \mathrm{~b} \\
\end{array}$ & Net Wt pain (me) \\
\hline & & i & & & & & \\
\hline & & 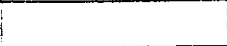 & & 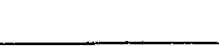 & 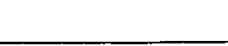 & & \\
\hline & & 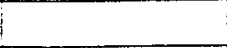 & & & : & & \\
\hline & & 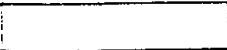 & & & & & \\
\hline & & ! & & & & & \\
\hline
\end{tabular}

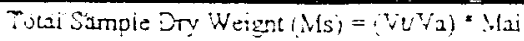

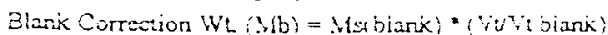

Yet Veight $=\mathrm{Ms}-\mathrm{Mb}$ 
BEST ENVIRONMENTAL, INC.

GRAVIMETRIC SAMPLE RECORD

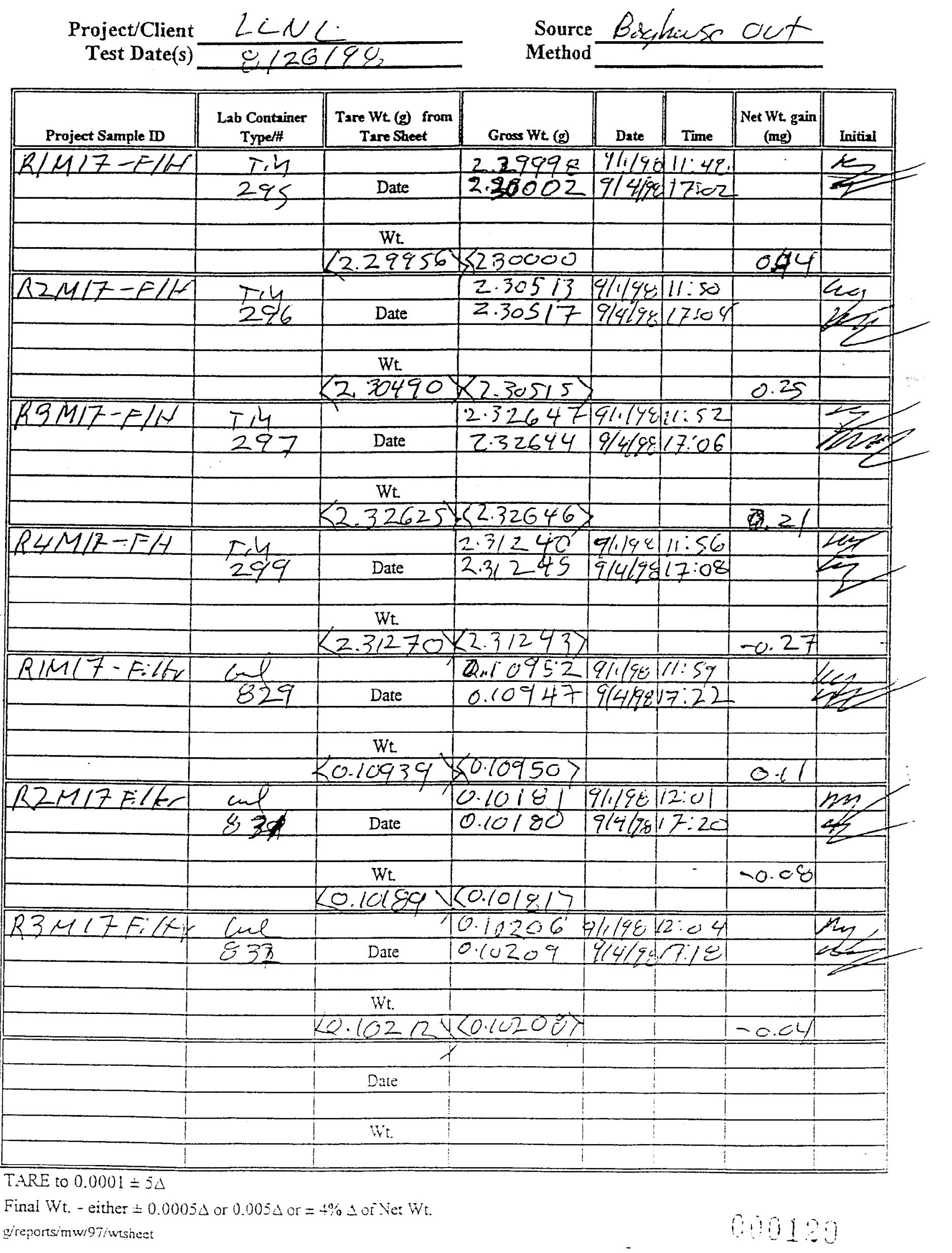




\section{GRAVIMETRIC SAMPLE RECORD}

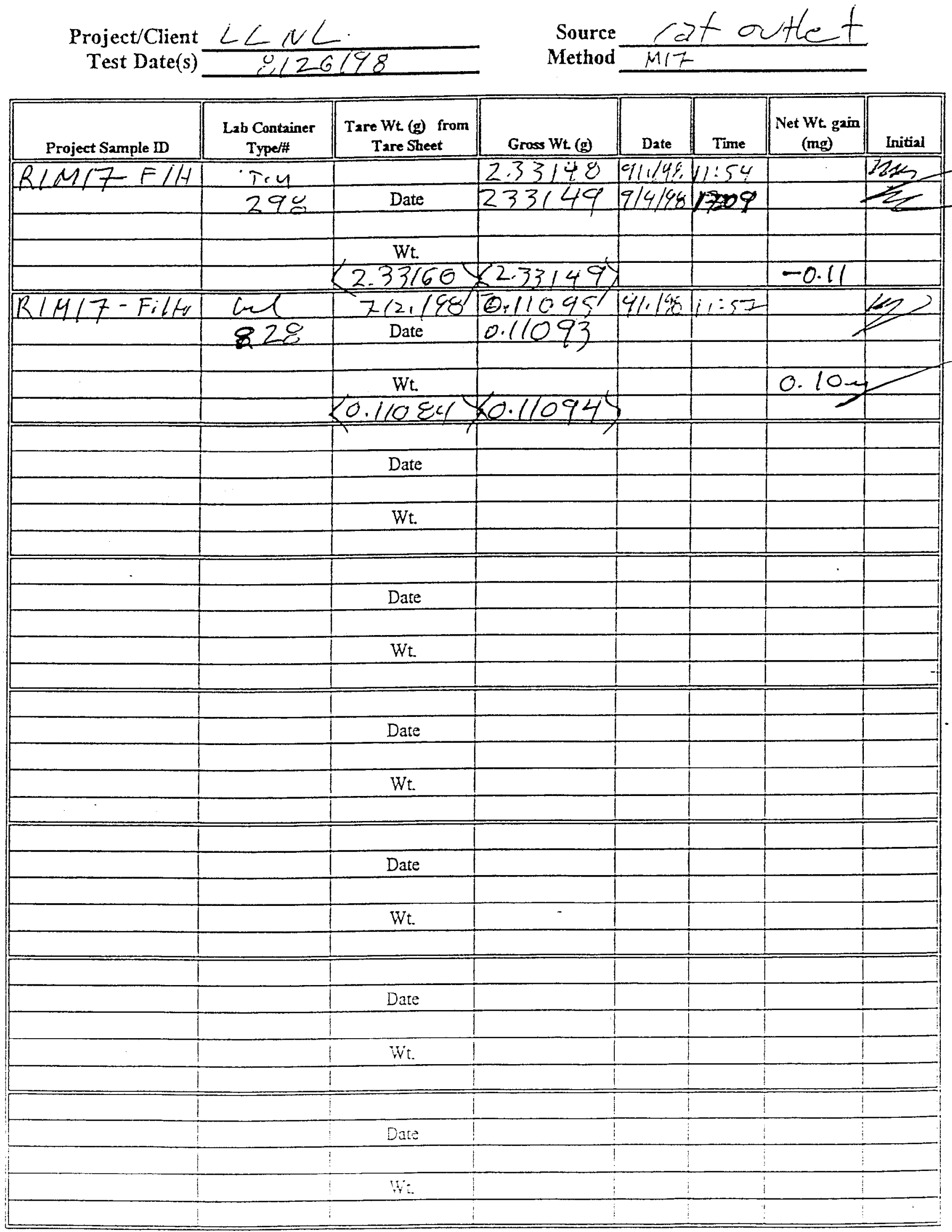

$T A R E$ to $0.0001=52$

Final Wt. - either $=0.0005 \Delta$ or $0.005 \Delta$ or $=4 \%$ of ver $w$. 


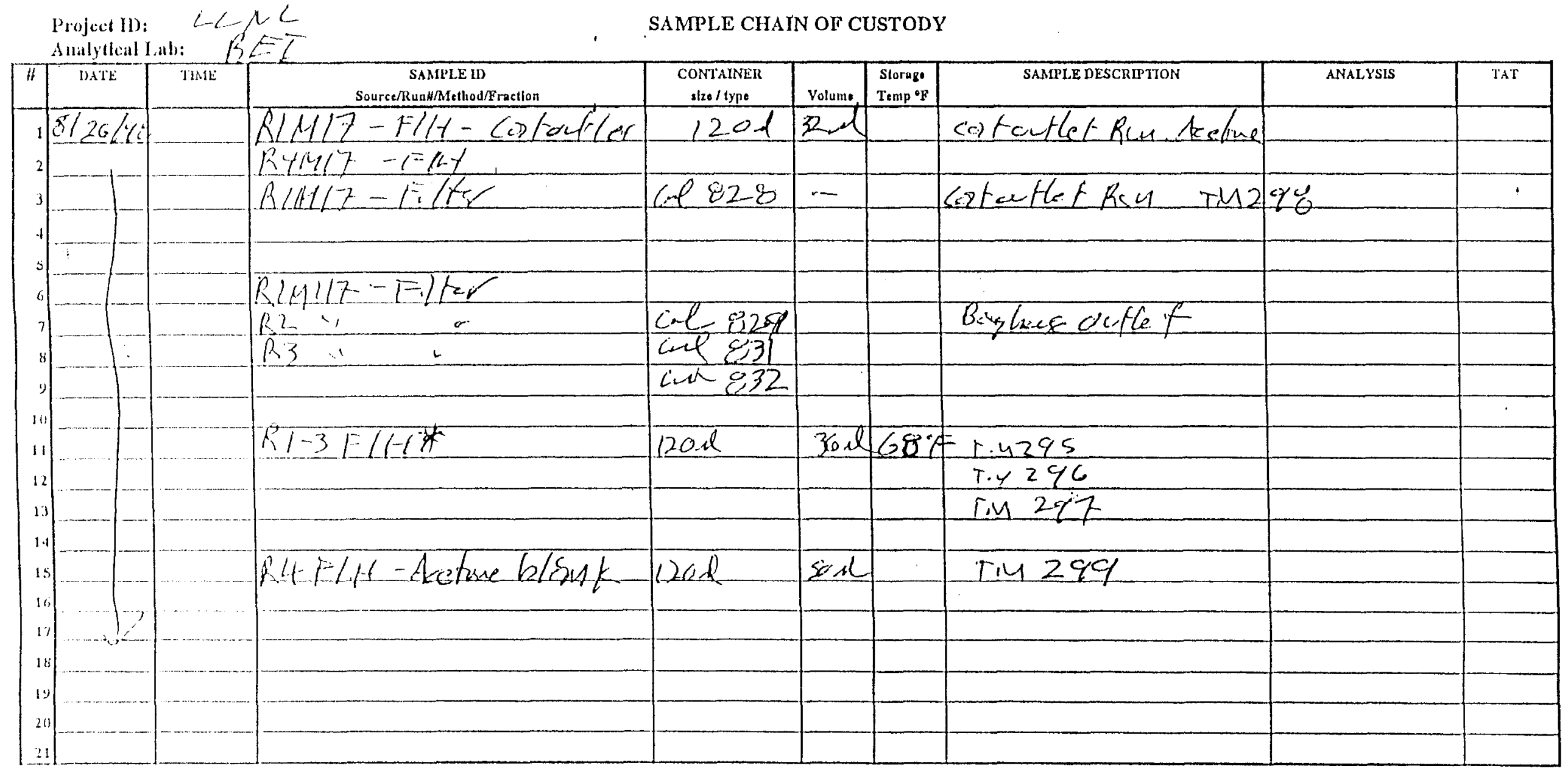

S1' ECAAL INGSTRUCTIONS: Record \& Report all liguld sumple volumes.

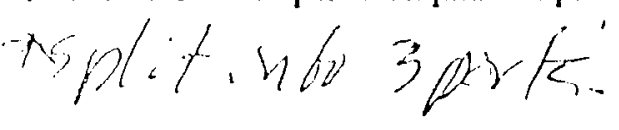

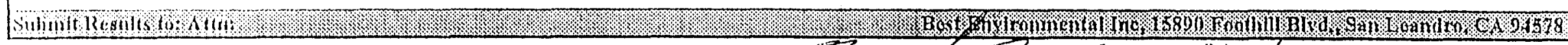

Relinquistical by:

Relinquishod by:

Kelinquisicil by:

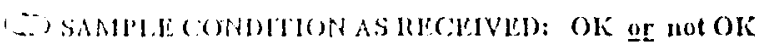

6
Received by Received by: Received by: 22 Date: $9 / 36 / 98$ Time: Date: Date 


\section{AMALYTICAL CHEMISTS}

October 22, 1998

LAB No: SP 807981-16

Best Environmental, Inc. 15890 Foothill Blvd, RE: Radiological Analysis

San Leandro, CA 94578

Sample Site: LLNL

Description: RIMS/114-F/H-B-OUT

Sampled by :

Type of Sample: Solid
Sampled : August 26, 1998
Received : September 25, 1998
Completed : October 13, 1998
QA/QC ID\# : 80798116-A

\section{Analytical Results}

\begin{tabular}{lllll}
\hline \hline & EPA & & & \\
\multicolumn{1}{c}{ CONSTITUENT } & METHOD & UNITS & RESULTS & ERROR \\
\hline \hline Gross Alpha & 9310 & $\mathrm{pCi} /$ samp & $0.0 \pm \pm 1$ \\
Gross Beta & 9310 & $\mathrm{pCi} /$ samp & $0.0 \pm \pm 1$ \\
Tritium & $\mathrm{H}-1$ & $\mathrm{pCi} / \mathrm{samp}$ & $0.0 \pm \pm 2$ \\
\hline \hline
\end{tabular}

$\mathrm{pCi} / \mathrm{L}=$ pico Curies per Liter $\mathrm{pCi} / \mathrm{ml}=$ pico Curies per milliliter

Containers: (a) Glass

If you have any questions, please call.

FGL ENVIRONMENTAL

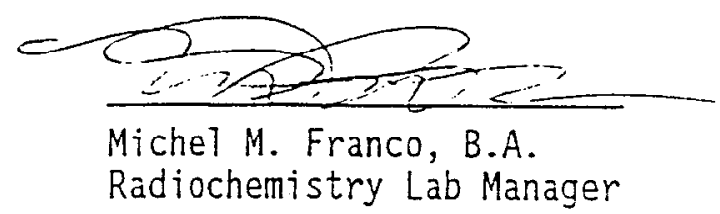

MMF:vt 


\section{AYALYTICAL CHEMISTS}

October 22, 1998

Best Environmental, Inc. 15890 Foothill Blvd, San Leandro, CA 94578

Sample Site: LLNL

Description: RIMS/114-FILTER-B-OUT

Sampled by :

Type of Sample: Air Filter
LAB No: SP 807981-20

RE: Radiological Analysis

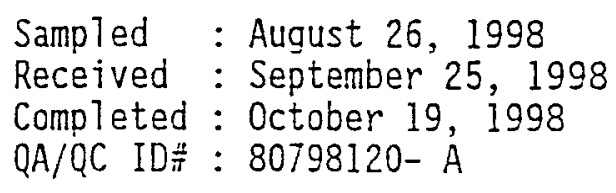

Sampled : August 26, 1998

Received : September 25, 1998

QA/QC ID\#: 80798120-A

\section{Analytical Results}

\begin{tabular}{lllll}
\hline \hline & EPA & & & \\
\multicolumn{1}{c}{ CONSTITUENT } & METHOD & UNITS & RESULTS & ERROR \\
\hline \hline Gross ATpha & 9310 & $\mathrm{pCi} /$ samp & $0.00 \pm 0.37$ \\
Gross Beta & 9310 & $\mathrm{pCi} /$ samp & $0.0 \pm 1.2$ \\
Tritium & $\mathrm{H}-1$ & $\mathrm{pCi} / \mathrm{samp}$ & $0.2 \pm \pm 2$ \\
\hline \hline
\end{tabular}

$\mathrm{pCi} / \mathrm{L}=$ pico Curies per Liter $\mathrm{pCi} / \mathrm{ml}=$ pico Curies per milliliter

Containers: (a) Glass

If you have any questions, please call.

FGL ENVIRONMENTAL

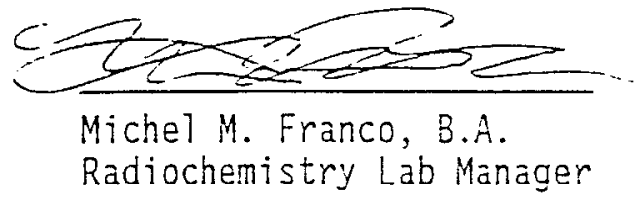

MMF :vt 


\section{AMALYTICAL CHEMISTS}

October 21, 1998

LAB No: SP 807981-24

Best Environmenta], Inc. 15890 Foothi17 Bivd, San Leandro, CA 94578

RE: Radiological Analysis

Sample Site: LLNL

Description: RIMS/114-IMP-B-OUT

Sampled by :

Type of Sample: Non Potable Water

Sampled : August 26, 1998

Received : September 25, 1998

Completed : October 20, 1998

QA/QC ID\# : 80798124- A

\section{Analytical Results}

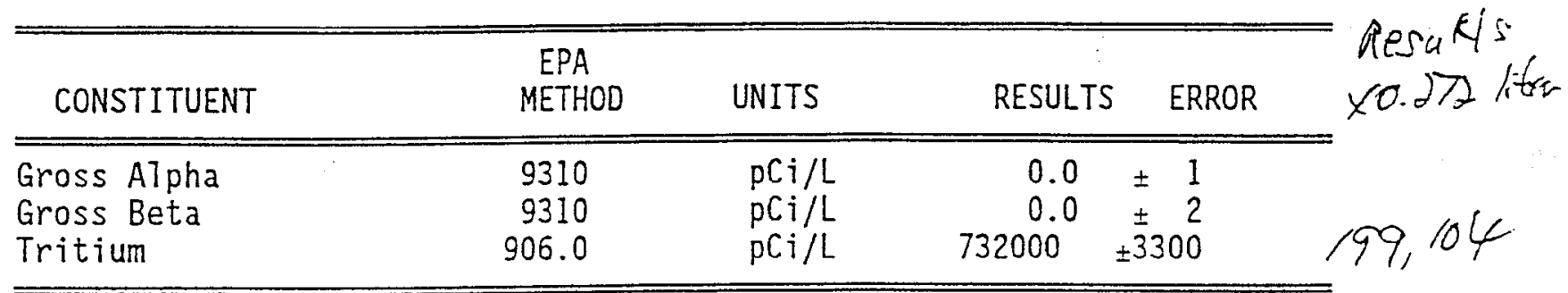

$\mathrm{pCi} / \mathrm{L}=$ pico Curies per Liter pci/ml = pico Curies per milliliter

Containers: (a) Glass

If you have any questions, please calt.

FGL ENVIRONMENTAL

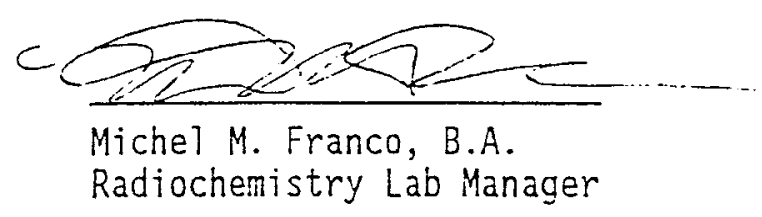

MMF :vt 


\section{ANALYTICAL CHEMISTS}

October 22, 1998

Best Environmental, Inc. 15890 Foothill Blvd, San Leandro, CA 94578

Sample Site: LLNL

Description: R2MS/114-F/H-B-OUT

Sampled by :

Type of Sample: Solid
LAB No: SP 807981-17

RE: Radiological Analysis
Sampled : August 26, 1998

Received : September 25, 1998

Completed : October 13, 1998

QA/QC ID\# : 80798117-A

\section{Analytical Results}

\begin{tabular}{lllll}
\hline \hline & EPA & & & \\
\multicolumn{1}{c}{ CONSTITUENT } & METHOD & UNITS & RESULTS & ERROR \\
\hline \hline Gross ATpha & 9310 & $\mathrm{pCi} /$ samp & $0.4 \pm \pm 1$ \\
Gross Beta & 9310 & $\mathrm{pCi} /$ samp & 0.1 & \pm 1 \\
Tritium & $\mathrm{H}-1$ & $\mathrm{pCi} /$ samp & $0.0 \pm 2$ \\
\hline
\end{tabular}

$\mathrm{pCi} / \mathrm{L}=$ pico Curies per Liter $\mathrm{pCi} / \mathrm{mL}=$ pico Curies per milliliter

Containers: (a) Plastic

If you have any questions, please call.

FGL ENVIRONMENTAL

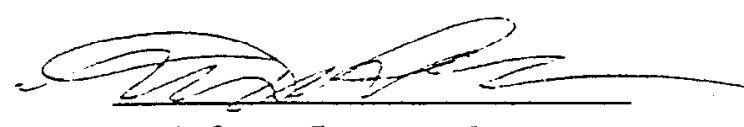

Michel M. Franco, B.A.

Radiochemistry Lab Mänager

MMF :vt 


\section{ANALYTICAL CHEMISTS}

October 22, 1998

LAB No: SP 807981-21

Best Environmental, Inc.

RE: Radiological Analysis

15890 Foothi71 Bivd,

San Leandro, CA 94578

Sample Site: LLNL

Description: R2MS/114-FILTER-B-OUT

Sampled : August 26, 1998

Sampled by :

Type of Sample: Air Filter

Received : September 25, 1998

Completed : October 19, 1998

QA/QC ID

\section{Anaiytical Results}

\begin{tabular}{lllll}
\hline & EPA & & $\vdots$ \\
CONSTITUENT & METHOD & UNITS & RESULTS & ERROR \\
\hline \hline Gross Alpha & 9310 & $\mathrm{pCi} /$ samp & $0.00 \pm 0.34$ \\
Gross Beta & 9310 & $\mathrm{pCi} /$ samp & $0.0 \pm \pm 1.1$ \\
Tritium & $\mathrm{H}-1$ & $\mathrm{pCi} /$ samp & $2 \pm 2$ \\
\hline \hline
\end{tabular}

$\mathrm{pCi} / \mathrm{L}=$ pico Curies per Liter $\mathrm{pci} / \mathrm{ml}=$ pico Curies per milliliter

Containers: (a) Glass

If you have any questions, please call.

FGL ENVIRONMENTAL

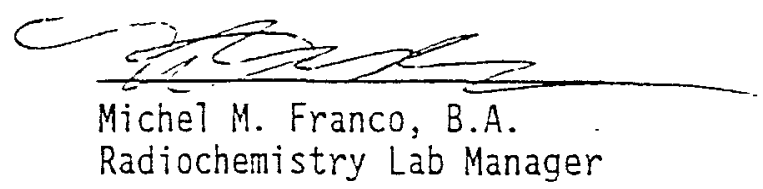

MMF:vt

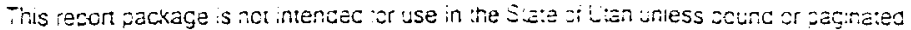




\section{AYALYTICAL CHEMISTS}

October 21, 1998

Best Environmental, Inc. 15890 Foothill Blvd,

San Leandro, CA 94578

Sample Site: LLNL

Description: R2MS/114-IMP-B-OUT

Sampled by :

Type of Sample: Non Potabie Water
LAB No: SP 807981-25

RE: Radiological Analysis

\section{Analytical Results}

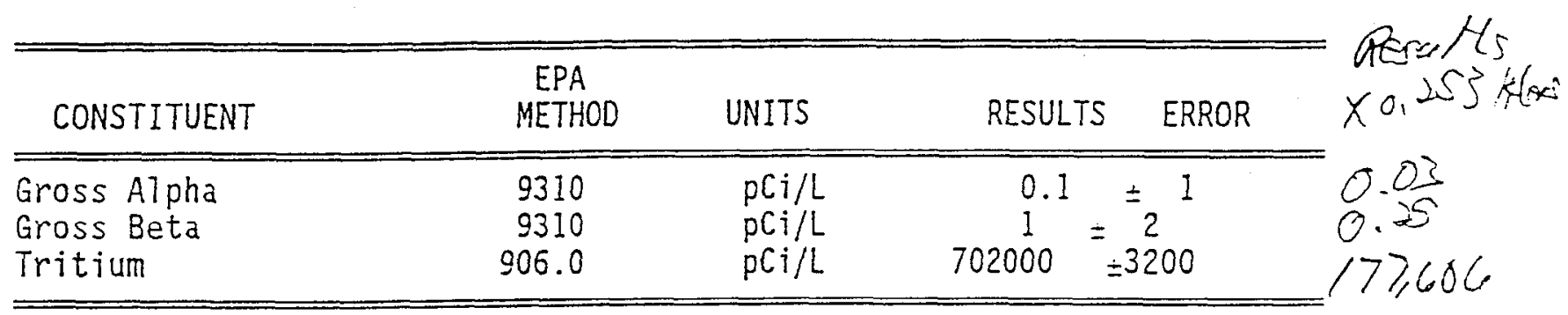

pCi/L = pico Curies per Liter pCi/mi = pico Curies fer milliliter

Containers: (a) Glass

If you have any questions, please call.

FGL ENVIRONMENTAL

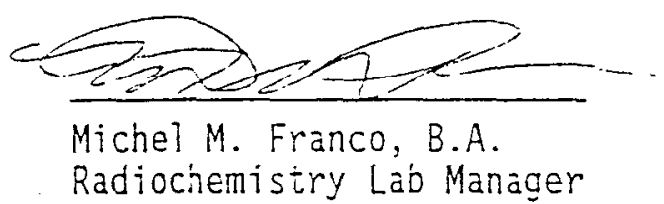

MMF :vt

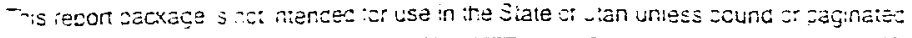




\section{ANALYTICAL CHEMISTS}

October 22, 1998

LAB No: SP 807981-18

Best Environmental, Inc.

15890 Foothi17 B7vd,

RE: Radiological Analysis

San Leandro, CA 94578

Sample Site: LLNL

Description: R3MS/114-F/H-B-OUT

Sampled by :

Type of Sample: Solid

Sampled : August 26, 1998

Received : September 25, 1998

Completed : October 13, 1998

QA/QC ID\# : 80798118- A

\section{Analytical Results}

\begin{tabular}{lllcl}
\hline \hline & EPA & & & \\
\multicolumn{1}{c}{ CONSTITUENT } & METHOD & UNITS & RESULTS & ERROR \\
\hline \hline Gross ATpha & 9310 & $\mathrm{pCi} /$ samp & $0.4 \pm 1$ \\
Gross Beta & 9310 & $\mathrm{pCi} /$ samp & $0.0 \pm \pm 1$ \\
Tritium & $\mathrm{H}-1$ & $\mathrm{pCi} /$ samp & 0.0 & \pm 2 \\
\hline \hline
\end{tabular}

pCi/L = pico Curies per Liter $p C i / m l=$ pico Curies per milliliter

Containers: (a) Plastic

If you have any questions, please call.

FGL ENVIRONMENTAL

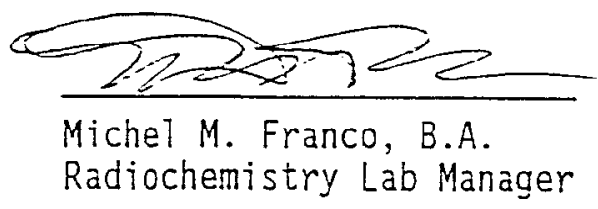

MMF : vt 


\section{ANALYTICAL CHEMISTS}

October 22, 1998

Best Environmenta1, Inc. 15890 Foothill Blvd, San Leandro, CA 94578

Sample Site: LLNL

Description: R3MS/114-FILTER-B-OUT Sampled by :

Type of Sample: Air Filter
LAB No: SP 807981-22

RE: Radiological Analysis
Sampled : August 26, 1998

Received : September 25, 1998

Completed : October 19, 1998

QA/QC ID $\#$ : $80798122-A$

\section{Analytical Results}

\begin{tabular}{|c|c|c|c|}
\hline CONSTITUENT & $\begin{array}{c}\text { EPA } \\
\text { METHOD }\end{array}$ & UNITS & RESULTS \\
\hline $\begin{array}{l}\text { Gross Alpha } \\
\text { Gross Beta } \\
\text { Tritium }\end{array}$ & $\begin{array}{l}9310 \\
9310 \\
\mathrm{H}-1\end{array}$ & $\begin{array}{l}p C i / \text { samp } \\
p C i / \text { samp } \\
p C i / \text { samp }\end{array}$ & $\begin{array}{l}0.00 \pm 0.34 \\
0.0 \pm 1.2 \\
2 \pm 2\end{array}$ \\
\hline
\end{tabular}

pCi $/ L=$ pico Curies per Liter $p$ ci/ml = pico Curies per milliliter Containers: (a) Glass

If you have any questions, please call.

FGL ENVIRONMENTAL

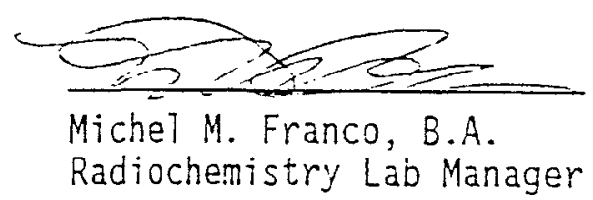

MMF : vt 


\section{ANALYTICAL CHEMISTS}

October 21, 1998

Best Environmental, Inc. 15890 Foothill Blvd, San Leandro, CA 94578

Sample Site: LLNL

Description: R3MS/114-IMP-B-OUT

Sampled by :

Type of Sample: Non Potable Water
LAB No: SP 807981-26

RE: Radiological Analysis

\section{Analytical Results}

\begin{tabular}{|c|c|c|c|c|}
\hline CONSTITUENT & $\begin{array}{c}\text { EPA } \\
\text { METHOD }\end{array}$ & UNITS & RESULTS & $\begin{array}{l}\text { Resalts } \\
\times 0.260 \text { intes }\end{array}$ \\
\hline $\begin{array}{l}\text { Gross Alpha } \\
\text { Gross Beta } \\
\text { Tritium }\end{array}$ & $\begin{array}{r}9310 \\
9310 \\
906.0\end{array}$ & $\begin{array}{l}\mathrm{pCi} / \mathrm{L} \\
\mathrm{pCi} / \mathrm{L} \\
\mathrm{pCi} / \mathrm{L}\end{array}$ & $\begin{array}{c}7 \\
0.6 \pm 1 \\
727000 \pm 3300\end{array}$ & $\begin{array}{l}1.82 \\
0.16 \\
189.020\end{array}$ \\
\hline
\end{tabular}

$\mathrm{pCi} / \mathrm{L}=$ pico Curies per Liter $\mathrm{pCi} / \mathrm{ml}=$ pico Curies per milliliter

Containers: (a) Glass

If you have any questions, please call.

Sampled : August 26, 1998

Received : September 25, 1998

Completed : October 20, 1998

QA/QC ID\# : 80798126- A 


\section{AMALYTICAL CHEMISTS}

October 22, 1998

Best Environmental, Inc. 15890 Foothi11 Blvd, San Leandro, CA 94578

Sample Site: LLNL

Description: RIMS/114-F/H-CAT-OUT

Sampled by:

Type of Sample: Solid
LAB No: SP 807981-28

RE: Radiological Analysis
Sampled : August 26, 1998
Received : September 25, 1998
Completed : October 13, 1998
QA/QC ID $:$ : 80798128- A

\section{Analytical Results}

\begin{tabular}{lllll}
\hline & EPA & & & \\
CONSTITUENT & METHOD & UNITS & RESULTS & ERROR \\
\hline \hline Gross ATpha & 9310 & $\mathrm{pCi} /$ samp & $0.3 \pm 1$ \\
Gross Beta & 9310 & $\mathrm{pCi} /$ samp & $0.0 \pm \pm 1$ \\
Tritium & $\mathrm{H}-1$ & $\mathrm{pCi} /$ samp & $0.0 \pm \pm 2$ \\
\hline
\end{tabular}

pCi/L = pico Curies per Liter $p C i / m L=$ pico Curies per milliliter

Containers: (a) Plastic

If you have any questions, please calll.

FGL ENVIRONMENTAL

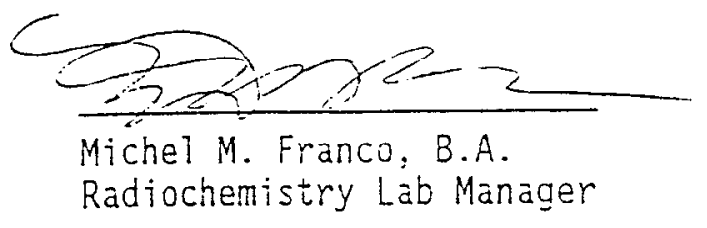

MMF :vt 


\section{ANALYTICAL CHEMISTS}

October 22, 1998

Best Environmental, Inc. 15890 Foothill Blvd, San Leandro, CA 94578

Sample Site: LLNL

Description: RIMS/114-Fi7ter-CAT-OUT Sampled by :

Type of Sample: Air Filter
LAB No: SP 807981-29

RE: Radiological Analysis
Sampled : August 26, 1998

Received : September 25, 1998

Completed : October 19, 1998

QA/QC ID\# : 80798129- A

\section{Analytical Results}

\begin{tabular}{lllll}
\hline \hline & EPA & & & \\
\multicolumn{1}{c}{ CONSTITUENT } & METHOD & UNITS & RESULTS & ERROR \\
\hline \hline Gross Alpha & 9310 & $\mathrm{pCi} /$ samp & $0.00 \pm 0.34$ \\
Gross Beta & 9310 & $\mathrm{pCi} /$ samp & $0.0 \pm 1.1$ \\
Tritium & $\mathrm{H}-1$ & $\mathrm{pCi} /$ samp & $1.2 \pm 2$ \\
\hline \hline
\end{tabular}

$\mathrm{pCi} / \mathrm{L}=$ pico Curies per Liter $\mathrm{pCi/mL}=$ pico Curies per milliliter Containers: (a) Glass

If you have any questions, please call.

FGL ENVIRONMENTAL

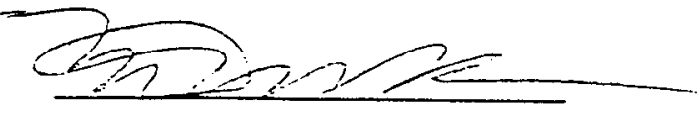

Michel M. Franco, B.A.

Radiochemistry Lab Manager

MMF :vt

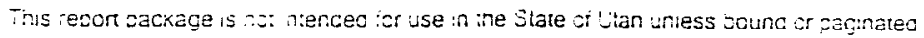




\section{AMALYTICAL CHEMISTS}

October 21, 1998

Best Environmental, Inc. 15890 Foothil1 Bivd, San Leandro, CA 94578

Sample Site: LLNL

Description: RIMS/114-IMP-CAT-OUT Sampled by :

Type of Sample: Non Potable Water
LAB NO: SP 807981-30

RE: Radiological Analysis
Sampled : August 26, 1998

Received : September 25, 1998

Completed : October 20, 1998

QA/QC ID\#̈ : 80798130- A

\section{Analytical Results}

\begin{tabular}{|c|c|c|c|c|}
\hline CONSTITUENT & $\begin{array}{l}\text { EPA } \\
\text { METHOD }\end{array}$ & UNITS & RESULTS & ERROR \\
\hline $\begin{array}{l}\text { Gross Alpha } \\
\text { Gross Beta } \\
\text { Tritium }\end{array}$ & $\begin{array}{r}9310 \\
9310 \\
906.0\end{array}$ & $\begin{array}{l}\mathrm{pCi} / \mathrm{L} \\
\mathrm{pCi} \mathrm{L} \\
\mathrm{pCi} / \mathrm{L}\end{array}$ & $\begin{aligned} 0.0 & = \\
0.3 & \pm \\
46400 & \pm 000\end{aligned}$ & $0^{1}$ \\
\hline
\end{tabular}

pCi/L = pico Curies per Liter $\quad p C i / m l=$ pico Curies per milliliter

Containers: (a) Glass

If you have any questions, piease cail.

FGL ENVIRONMENTAL

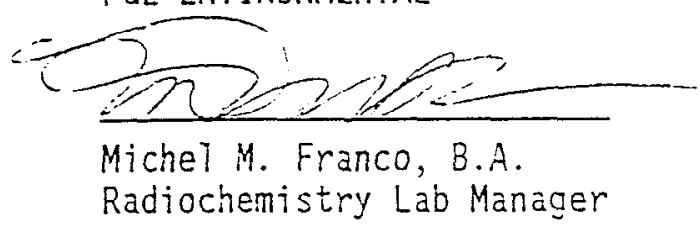

MMF :vt 


\section{AMALYTICAL CHEMISTS}

October 22, 1998

Best Environmental, Inc. 15890 Foothi17 Blvd, San Leandro, CA 94578

Sample Site: LLNL Description: R4MS/114-F/H-B-OUT-BLK Sampled by :

Type of Sample: Solid
LAB No: SP 807981-19

RE: Radiological Analysis
Sampled : August 26, 1998
Received $:$ September 25, 1998
Completed $:$ October 13, 1998
QA/QC ID\# $:$ 80798119- A

\section{Analytical Results}

\begin{tabular}{lcccc}
\hline \hline & EPA & & & \\
\multicolumn{1}{c}{ CONSTITUENT } & METHOD & UNITS & RESULTS & ERROR \\
\hline \hline Gross Alpha & 9310 & $\mathrm{pCi} /$ samp & $0.1 \pm 1$ \\
Gross Beta & 9310 & $\mathrm{pCi} /$ samp & $0.2 \pm 1$ \\
Tritium & $\mathrm{H}-1$ & $\mathrm{pCi} / \mathrm{samp}$ & $0.0 \pm \pm 2$ \\
\hline \hline
\end{tabular}

pCi $/ L=$ pico Curies per Liter pCi/ml = pico Curies per milliliter

Containers: (a) Plastic

If you have any questions, please call.

FGL ENYIRONMENTAL

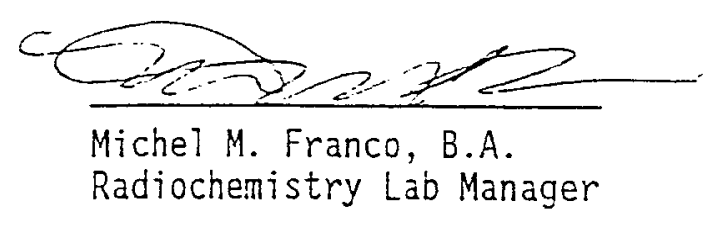

MMF :vt 
AYALYTICAL CHEMISTS

October 22, 1998

LAB No: SP 807981-23

Best Environmental, Inc.

RE: Radiological Analysis

15890 Foothil1 BTvd,

San Leandro, CA 94578

Sample Site: LLNL

Description: R4MS/114-FILTER-8-OUT-BLK Sampled : August 26, 1998

Sampled by:

Type of Sample: Air Filter

Received : September 25, 1998

Completed : October 19, 1998

QA/QC ID\# : 80798123- A

\section{Analytical Results}

\begin{tabular}{|c|c|c|c|c|}
\hline CONSTITUENT & $\begin{array}{c}\text { EPA } \\
\text { METHOD }\end{array}$ & UNITS & RESULTS & ERROR \\
\hline $\begin{array}{l}\text { Gross Alpha } \\
\text { Gross Beta } \\
\text { Tritium }\end{array}$ & $\begin{array}{l}9310 \\
9310 \\
H-1\end{array}$ & $\begin{array}{l}\mathrm{pCi} / \text { samp } \\
\mathrm{pCi} / \text { samp } \\
\mathrm{pCi} / \text { samp }\end{array}$ & $\begin{array}{l}0.00 \\
0.0 \\
1.6\end{array}$ & $\begin{array}{l} \pm 0.37 \\
\pm 1.2 \\
\pm 2\end{array}$ \\
\hline
\end{tabular}

pCi/L = pico Curies per Liter pCi/ml = pico Curies per milliliter

Containers: (a) Glass

If you have any questions, please call.

FGL ENVIRONMENTAL

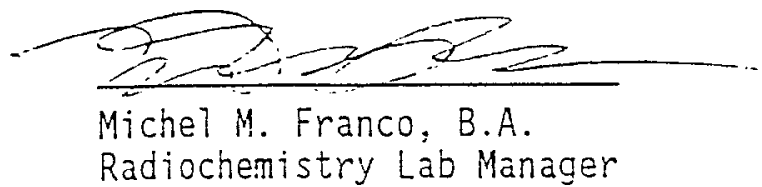

MMF :vt 


\section{ANALYTICAL CHEMISTS}

October 21, 1998

Best Environmental, Inc. 15890 Foothi17 BTvd, San Leandro, CA 94578

Sample Site: LLNL

Description: R4MS/114-IMP-B-OUT

Sampled by :

Type of Sample: Non Potable Water
LAB No: SP 807981-27

RE: Radiological Analysis
Sampled : August 26, 1998

Received : September 25, 1998

Completed : October 20, 1998

QA/QC ID\# : 80798127- A

\section{Analytical Results}

\begin{tabular}{|c|c|c|c|c|}
\hline CONSTITUENT & $\begin{array}{c}\text { EPA } \\
\text { METHOD }\end{array}$ & UNITS & RESULTS & ERROR \\
\hline $\begin{array}{l}\text { Gross Alpha } \\
\text { Gross Beta } \\
\text { Tritium }\end{array}$ & $\begin{array}{r}9310 \\
9310 \\
906.0\end{array}$ & $\begin{array}{l}p C i / L \\
p C i / L \\
p C i / L\end{array}$ & $\frac{0.0 \pm}{0.0 \pm} \pm$ & $\begin{array}{l}1 \\
3\end{array}$ \\
\hline
\end{tabular}

If you have any questions, please call.

FGL ENVIRONMENTAL

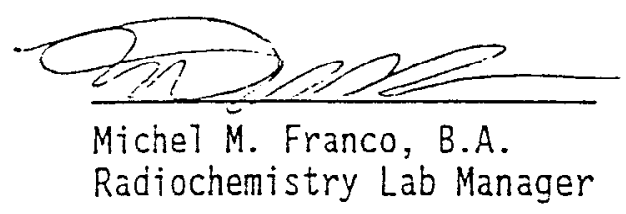

MMF:vt 


\section{ENVIRONMENTAL}

\section{Allalytical Chemists}

culober 21, 1998

Buss tinvirommental, Inc.

15890) Foosthill Blvd,

Sall leandro, (X 9.1578
Radiochemistry Quality Assurance Report for sample: 807981

Actual sample results are contained in the accompanying analytical report(s).

\begin{tabular}{|c|c|c|c|c|c|c|c|c|c|c|c|c|c|c|c|c|c|c|}
\hline \multirow[b]{2}{*}{ Constitust } & \multirow{2}{*}{$\begin{array}{c}\text { BATCII } \\
\text { ID }\end{array}$} & \multirow{2}{*}{$\begin{array}{l}\text { EPA } \\
\text { Method }\end{array}$} & \multirow[b]{2}{*}{ Units } & \multicolumn{3}{|c|}{ BI ALK QA $/$ OC } & \multicolumn{5}{|c|}{ CALIBRAION QA/QC } & \multirow[b]{2}{*}{ Type } & ' & \multirow[b]{2}{*}{$\%$ REC } & \multirow{2}{*}{$\begin{array}{l}\text { METHOD } \\
\% \text { REC }\end{array}$} & \multirow{2}{*}{$\begin{array}{l}Q A / Q C \\
A R\end{array}$} & \multirow{2}{*}{$\% D I F$} & \multirow{2}{*}{ MAV HOTE } \\
\hline & & & & DLR & Result & HOTE & Type & Conc. & $\%$ REC & AR & NOTE & & Conc. & & & & & \\
\hline \multirow[t]{2}{*}{ lis USS Alplis } & $0 A 2 B$ & 900.0 & $\mathrm{pCi} / \mathrm{cm}^{2}$ & 0.03 & ND & & LCS & 25.0 & 81.2 & $75-125$ & & BS & 25.0 & 100 & 95.2 & $75-125$ & 4.9 & 25.0 \\
\hline & $O A 2 C$ & 900.0 & $\mathrm{pCi} / \mathrm{L}$ & 1.0 & 0.3 & & LCS & 7.12 & 123 & $75-125$ & & BS & 20.0 & 78.5 & 95.5 & $70-130$ & 19.2 & 25.0 \\
\hline \multirow{2}{*}{ Gitos $B \in t a$} & $O A 2 B$ & 900.0 & $\mathrm{pCi} / \mathrm{cm} ?$ & 0.05 & HD & & LCS & 86.0 & 98.5 & $75-125$ & & BS & 86.0 & 98.8 & 98.0 & $75-125$ & 0.8 & 20.0 \\
\hline & $0 A 20$ & 900.0 & $\mathrm{pci} / \mathrm{L}$ & 1.0 & ND & & LCS & 106 & 82.4 & $75-125$ & & BS & 22.0 & 95.5 & 85.9 & $75-125$ & 10.5 & 25.0 \\
\hline \multirow[t]{2}{*}{ nitionu } & $O A \quad B$ & 906.0 & $\mathrm{pCi} / \mathrm{L}$ & 200 & HD & & L.CS & 367 & 98.9 & $75-125$ & & BS & 367 & 98.6 & 100 & $75-125$ & 1.6 & 20.0 \\
\hline & OA $2 C$ & 906.0 & $\mathrm{pCi} / \mathrm{L}$ & 200 & ND & & L.CS & 367 & 100 & $75-125$ & & BS & 367 & 102 & 101 & $75-125$ & 0.8 & 20.0 \\
\hline Litosi Alpua & $O A 2 A$ & 900.0 & $\mathrm{pCi} / \mathrm{L}$ & 1.0 & 0.5 & & LCS & 35.6 & 83.7 & $75-125$ & & MS & 400 & 105 & 99.2 & $60-140$ & 5.6 & 30.0 \\
\hline Cirous Beta & $O A 2 A$ & 900.0 & $\mathrm{pCi} / \mathrm{L}$ & 1.0 & HD & & LCS & 535 & 103 & $75-125$ & & MS & 457 & 102 & 93.4 & $60-140$ & 9.1 & 30.0 \\
\hline Ii i inuil & $O A=2 A$ & 906.0 & $\mathrm{pCi} / \mathrm{L}$ & 200 & 110 & & LCS & 4000 & 107 & $75-125$ & & BS & 4000 & 97.5 & 100 & $75-125$ & 2.5 & 20.0 \\
\hline
\end{tabular}

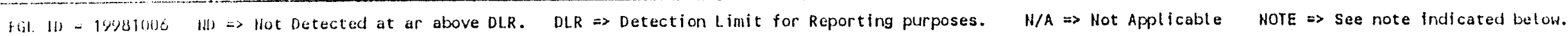
wir explumblion of UA terms is provided on the reverse side of this page.

FGL ENVIRONMENTAL, INC.

$\|H\|:$ vt.

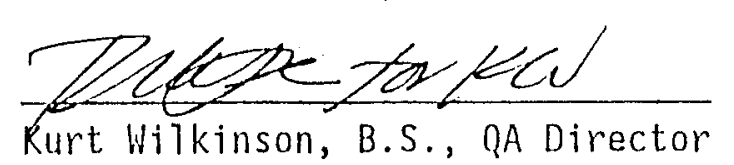


等

Project ID: $\quad$ L.C- $-L$

15890 Foothill Blva San Leandri, $\mathrm{Ca}$
SAMPIE CHAIN OF CUSTODY

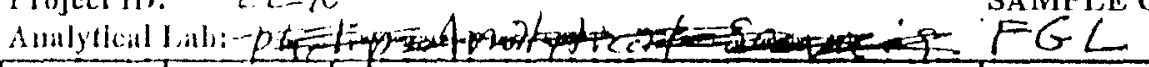

\begin{tabular}{|c|c|c|c|c|c|c|c|c|c|}
\hline$\#$ & DATE & TIANE & $\begin{array}{c}\text { SAMPLE ID } \\
\text { Source/RunHMLethod/8 raction } \\
\end{array}$ & $\begin{array}{c}\text { CONTAINER } \\
\text { slzo/ype } \\
\end{array}$ & Volume & $\begin{array}{ll}\text { Storag: } \\
\text { Temp } \mathrm{F} \\
\end{array}$ & SAMPLE DESCRMTION & ANAIYSIS & TAT \\
\hline 11 & $8 / 18 / 98$ & 9 & $R \mid M 1 S /(14-H) H \cdot B$-out & Alesinguter & 271 & 689 & Acetore ringe Proleqnezzls & & \\
\hline 2.2 & $8 / 10146$ & $S$ & R3MSlIIL-FlH-B-out & Alouilume tiy & 272 & & Acelace nufe prols quezzola & & \\
\hline 33 & & $S$ & $R 3 M S)(14-F \mid H-B-00 t$ & “ & 276 & & 2 & & \\
\hline 4.4. & $\therefore \quad 1$ & $S$ & $|B Y M S| 1|4-1=| 1-\beta-\alpha, 4-\beta \mid K$ & 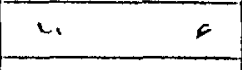 & 277 & & Acetane b/adk & & \\
\hline 5 & & & & & & & & & \\
\hline 50 & $8 / i z / 9 g$ & $A$ & RIMSl114-Filter B-out & $80 z 6-1855$ & & & Glassfiker filtr & & \\
\hline $6 ?$ & $\begin{array}{ll}1 & 4\end{array}$ & $A F$ & $R 2 N S 1114-F \cdot f<, B-U_{0} t$ & II & & & $\because$ & & \\
\hline 28 & 4 & Af & R3MS/114-F / Her B ont & 1 & & & in & & \\
\hline 8,9 & 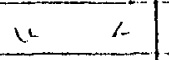 & AF & R4M5lil4-Filfer Bitant BlK & $u$ & & & 6elossfiner filkec blduks & & \\
\hline 101. & & & & & & & & & \\
\hline$\$ 1$ & Q/16/8느. & $(\mathrm{u})$ & $1 R 1 M 5 / 114-T M P$ - $\theta$-out & Soond Gelss & & & Ionpryec DInsfest rinse & & \\
\hline 102 & 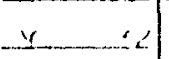 & $w w$ & R2MILIL-IMP-B-aLt & c & & & 4 & & \\
\hline 113 & $\therefore$ & We & $R 3 M S / 114-I M P-B$-ot & 4 & & & $u$ & & \\
\hline$|2|$, & & wow & R4MS/I14-IMP-Bout BIK & ${ }^{\prime}$ & & & DIadfor blduk & & \\
\hline 15 & & & & & & & & & \\
\hline 130. & $g / 14 q$ & 9 & RIMSLU4-Flb-CatoCT & & & & Acekere Probellozzle ausce & & \\
\hline 14. & $E M 14$ LE & $A F$ & 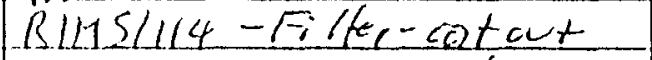 & & & & Goss fiberfiler & & \\
\hline M & $8(14<4 \times$ & $(1, \omega)$ & BlMslly - tup - catat & & & & DFupter mpodzed + vikse. & & \\
\hline 19 & & & & & & & & & \\
\hline 20 & & & & & & & & & \\
\hline 21 & & & & & & & & & \\
\hline
\end{tabular}

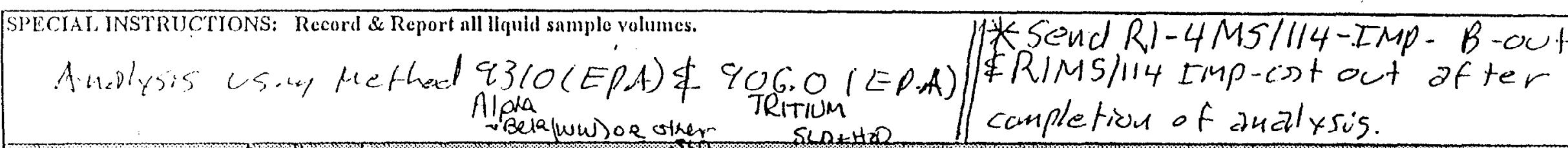

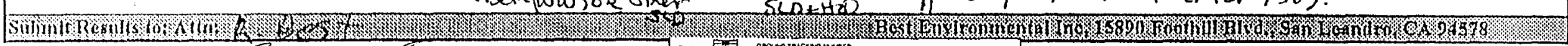
Relinquislical by: . 


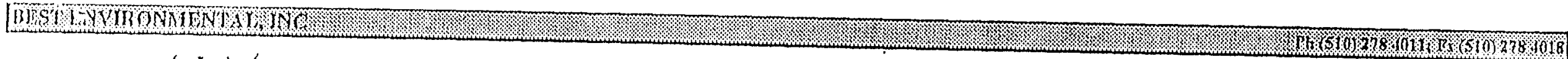

Projectin: $L L L L$

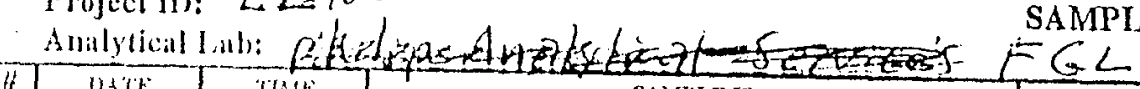

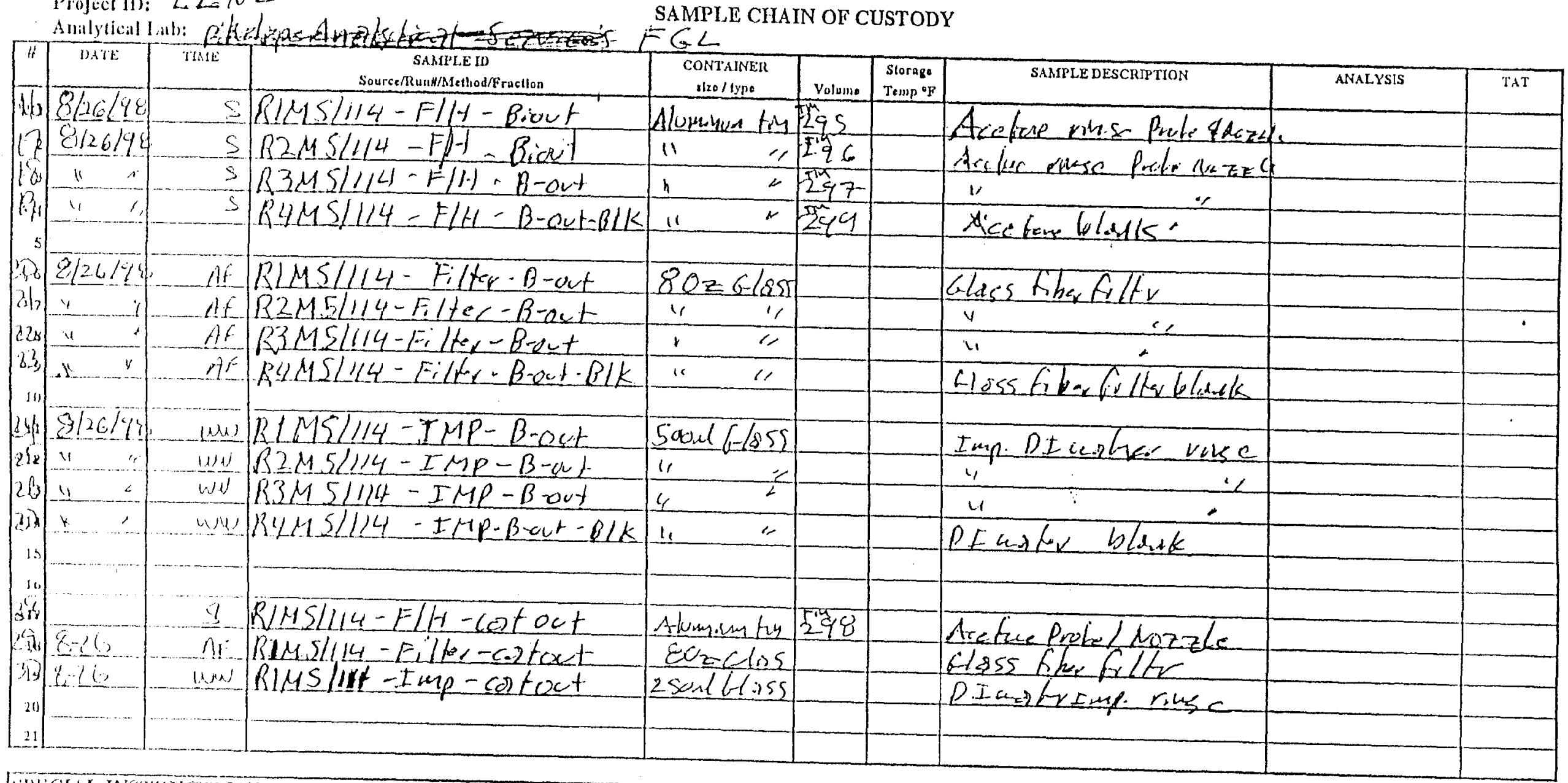

SILCTA INSTRUCTONS: Record \& Report ull liquid smmple volumes.

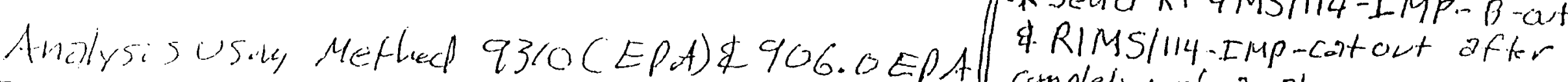

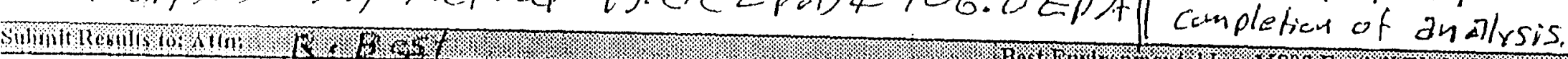

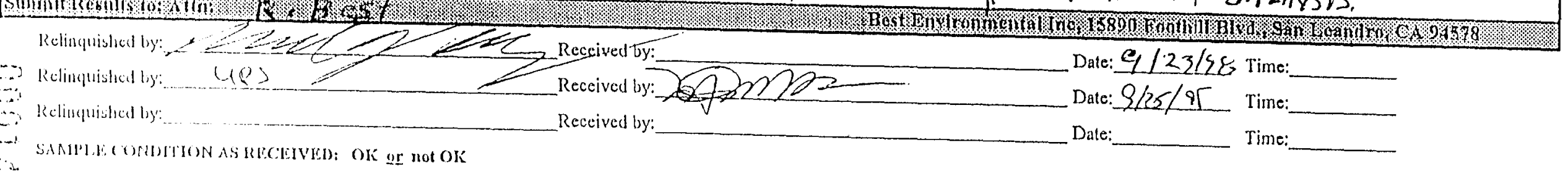
$\int$ 


\section{INORGANIC DATA PACKAGE FOR BEST ENVIRONMENTAL INC. \\ Project: Livermore}

Philip Analytical Services Corporation

5555 North Service Road

Burlington, Ontario LiL 5H7

Submission \#8I0098

Prepared by: Ancy Sebastian - CSR

Approved by: Dr. Ron McLeod - Princinal Scientisi

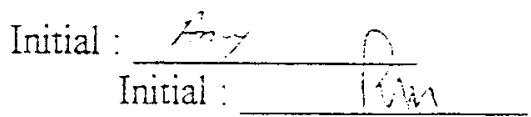


PROJECT NARRATIVE

PHCIP Analytical Services (Burington ON)

Philip Project: AN980845

Philip Submission \#:810098

Client: Best Environmental Inc.

Client Project: Livermore

\section{SAMPLE RECEIPT/ANALYSIS}

a) Sample Listing

\begin{tabular}{cccccc} 
Philip ID & \multicolumn{1}{c}{$\begin{array}{c}\text { Client } \\
\text { Sample ID }\end{array}$} & $\begin{array}{c}\text { Date } \\
\text { Sampled }\end{array}$ & $\begin{array}{c}\text { Date } \\
\text { Received }\end{array}$ & $\begin{array}{c}\text { Date } \\
\text { Prepped }\end{array}$ & $\begin{array}{c}\text { Run } \\
\text { Date }\end{array}$ \\
Hydrogen & Chloride via SW846 Method 26A & & & & \\
04316798 & Method Blank & $98 / 08 / 19$ & $98 / 08 / 28$ & $98 / 09 / 11$ & $98 / 09 / 11$ \\
04316898 & R4M0051-HCl & $98 / 08 / 19$ & $98 / 08 / 28$ & $98 / 09 / 11$ & $98 / 09 / 11$ \\
04316998 & R1M0051-HCl & $98 / 08 / 19$ & $98 / 08 / 28$ & $98 / 09 / 11$ & $98 / 09 / 11$ \\
04317098 & R2M0051-HCl & $98 / 08 / 19$ & $98 / 08 / 28$ & $98 / 09 / 11$ & $98 / 09 / 11$ \\
04317198 & R3M0051-HCl & $98 / 08 / 19$ & $98 / 08 / 23$ & $98 / 09 / 11$ & $98 / 09 / 11$ \\
04317298 & R4M0051-H2SO4 & $98 / 08 / 26$ & $98 / 08 / 28$ & $98 / 09 / 11$ & $98 / 09 / 11$ \\
04317398 & R1M0051-H2SO4 & $98 / 08 / 26$ & $98 / 08 / 28$ & $98 / 09 / 11$ & $98 / 09 / 11$ \\
04317498 & R2M0051-H2SO4 & $98 / 08 / 26$ & $98 / 08 / 28$ & $98 / 09 / 11$ & $98 / 09 / 11$ \\
04317598 & R3M0051-H2SO4 & $98 / 08 / 26$ & $98 / 08 / 28$ & $98 / 09 / 11$ & $98 / 09 / 11$ \\
04317698 & R1CatOut-HC1/CL2 & $98 / 08 / 26$ & $98 / 08 / 28$ & $98 / 09 / 11$ & $98 / 09 / 11$
\end{tabular}

Run Date is defined as the date of injection of the last calibration standard ( 12 hour or less) prior to the samples analyzed within that run sequence. Therefore the time of calibration injection that deñnes the run date is always within 12 bours of the time of sample injection.

b) Shipping Problems: none encountered

c) Documentation Problems: none encountered

II. SAMPLE PREP:

No problems encountered

DI. SAMPLE ANALYSIS:

See also comments within the appropriate Cerifricate of Analysis.

7) Hold Times: all within recommended hoid times

b) Instrument Cailoration: ail within contro tints 
$i$ certify that this data package is in compliance with the terms and conditions of the contract, both technically and for completeness, for other than the conditions detailed above.

In addition, I certify, that to the best of my knowledge and belief, the data as reported are true and accurate. Release of the data contained in this data package has been authorized by the cognizant laboratory official or his/her designee, as verified by this signature.

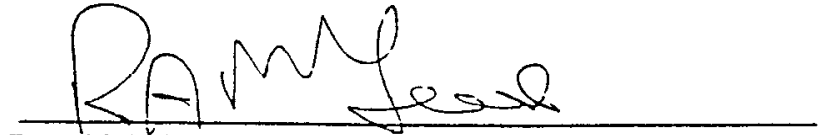

Ronaid A. McLeod, Principal Sci., Ph.D, C.Chem

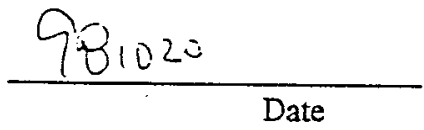




\section{Certificate of Analysis}

\section{CLIENT INFORMATION}

$\begin{array}{ll}\text { Attention: } & \text { Dan Cartner } \\ \text { Client Name: } & \text { Best Environmental Inc. } \\ \text { Project: } & \text { Livermore } \\ \text { Project Desc: } & \text { Stack Emissions }\end{array}$

Address:

15890 Foothill Blvd

San Leandro, CA

CA 94578

Far Number: $\quad 5102784018$

Phone Number: $510278+011$

\section{LABORATORY INFORMATION}

$\begin{array}{ll}\text { Contact: } & \text { Ron McLeod } \\ \text { Project: } & \text { AN980845 } \\ \text { Date Received: } & 98 / 08 / 28 \\ \text { Date Reported: } & 98 / 09 / 15 \\ & \\ \text { Submission No.: } & 810098 \\ \text { Sample No.: } & 043167-043176\end{array}$

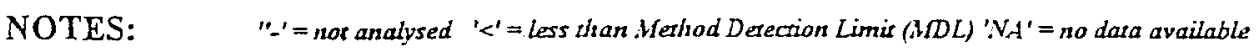
$L O Q$ can by determined for all analytes by mulipilying the appropriate $1 \mathrm{HDL} \times 3.33$ Solids data is based on dy weight except for biota analyses. Organic analyses are not corrected for etraction recovery standards except for isotope dilution methods. (Le CARB +29 PAH. ail PCDD/F and DBD/DBF analyses)

Methods used by PASC are based upon those found in Stancard Methods for the Examination of Water and Wastewater', Nineteenth Edirion. Other methods are based on the principles of MISA or EPA methodologies. New York State: ELAP Identification Number 10756

All work recorded herein has been done in accordance with normal proressional standards using accepted testing methodologies, quality assurance and quality control procedures except where otherwise agreed to by the client and testing company in writing. Any and all use of these test results shail be limited to the acrual cost of the pertinent analysis done. There is no other warranty expressed or implied. Your samples wiil be retained at PASC for a period of three weeks from receipt of data or as per contract.

COMMENTS:

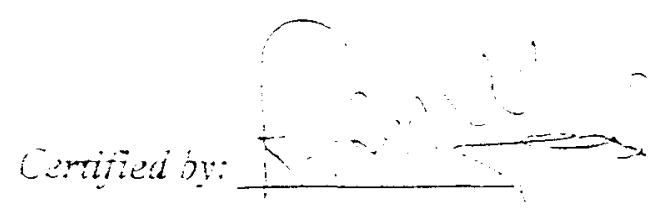
$2=2$ 


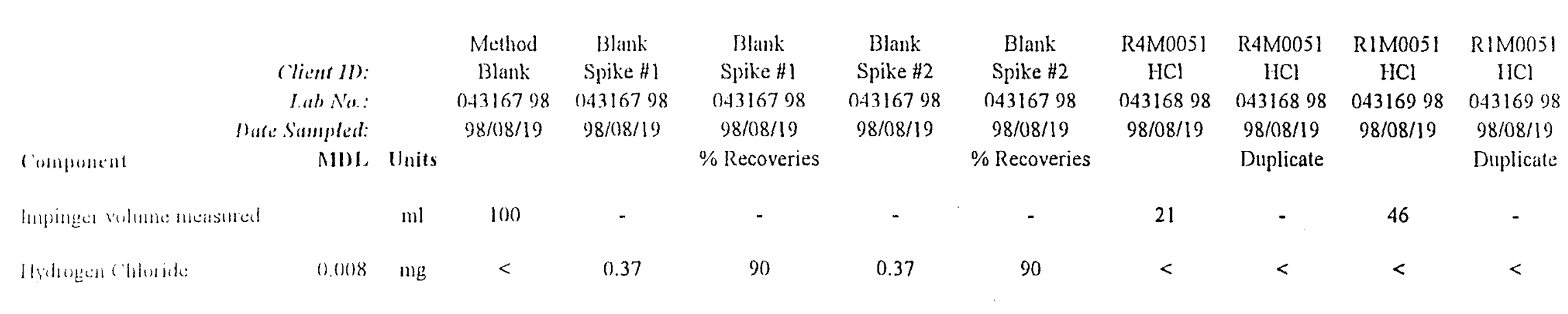




\begin{tabular}{|c|c|c|c|c|c|c|c|c|c|c|c|c|}
\hline & (licul $l l)$ : & & $\begin{array}{c}\text { RIMOOSI } \\
\mathrm{IICl}\end{array}$ & $\begin{array}{c}\text { RIMOO5I } \\
\text { IICl }\end{array}$ & $\begin{array}{c}\text { RIMO05I } \\
\text { IICl }\end{array}$ & $\begin{array}{c}\text { RIM0051 } \\
\mathrm{HCl}\end{array}$ & $\begin{array}{c}\text { R2M0051 } \\
\mathrm{HCl}\end{array}$ & $\begin{array}{c}\mathrm{R} 2 \mathrm{M} 0051 \\
\mathrm{HCl}\end{array}$ & $\begin{array}{c}\text { R3M005I } \\
\mathrm{HCl}\end{array}$ & $\begin{array}{c}\text { R3M005l } \\
\mathrm{HCl}\end{array}$ & $\begin{array}{c}\text { R4M0051 } \\
\text { I12SO4 }\end{array}$ & $\begin{array}{c}\text { RaMoO5l } \\
112904\end{array}$ \\
\hline & I.ab No.: & & 04316998 & 04316998 & 04316998 & 04316998 & 04317098 & 04317098 & 04317198 & 04317198 & 04317298 & 04317298 \\
\hline & He Stampled: & & $98 / 08 / 19$ & $98 / 08 / 19$ & $98 / 08 / 19$ & $98 / 08 / 19$ & $98 / 08 / 19$ & $98 / 08 / 19$ & $98 / 08 / 19$ & $98 / 08 / 19$ & $98 / 08 / 26$ & $98 / 08 / 26$ \\
\hline rimpromsint & M101. & Units & M. Spike & MS\% Rec. & MS Dup & MSD \% Rec. & & Duplicate & & Duplicate & & Duplicate \\
\hline 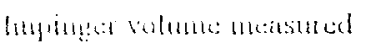 & & ml & - & - & - & - & 48 & - & 48 & - & 13 & - \\
\hline 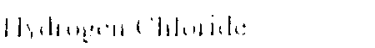 & 0.008 & $m g$ & 0.87 & 91 & 0.86 & 91 & $<$ & $<$ & $<$ & $<$ & $<$ & $<$ \\
\hline
\end{tabular}




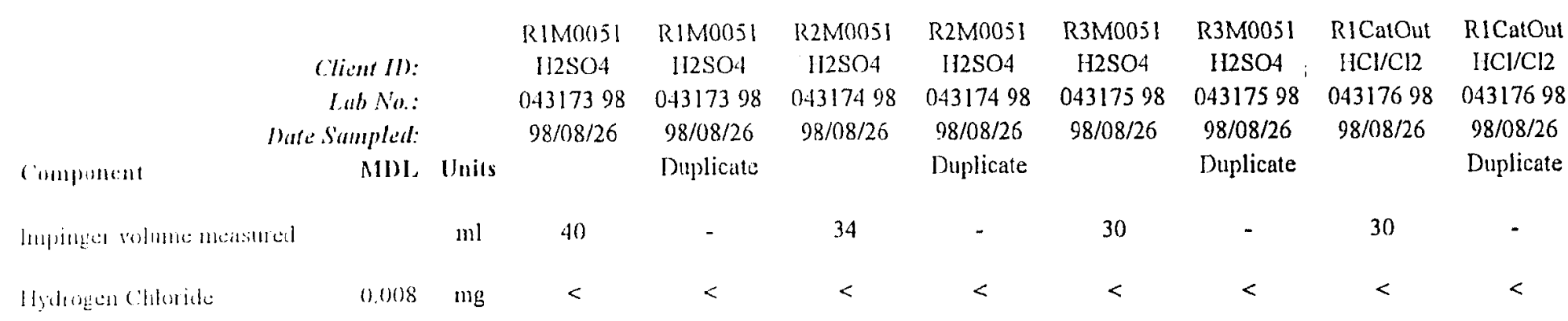




\section{APPENDIX $\mathrm{C}$ \\ FIELD DATA SHEETS}

00100158 
BEST ENVIRONMENTAL, INC.

San Leandra, CA (510)278-4011

$\times 9 \div 5+32$

Isokinetic Sampling Data Sheet (Method 429 )

Facility: $L L N L$ Date: $8 / 18 / 98$ Run 1 Persomed: B.R., $M \omega, J u, R B, D C$ Facility Information Eocation EITES IN/ET RTS F Port Dia: Depth: Fitting: Length: Stack Dia: $\overline{1.375}$ Area: $\overline{6018}$ Upstream from disturbance:

Downstream from disturbance: $\frac{2}{8}$ Equipment Information

Weter: H: 2 is r Pitot H: $\mathrm{Yd} 1.0089$ $\Delta H @: \frac{1.869}{4}$

Filter Box \#

Filter \#: -

Probe \#: $\mathbb{2}^{\prime}$ Umb. \#Pyrometer \#:
HE

$D_{\mathrm{n}}: \overline{309}$

Mag.

(1)

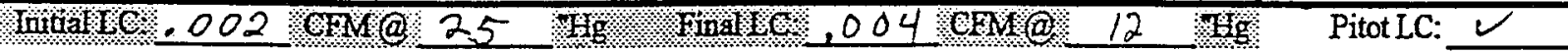
Sampling Information

\begin{tabular}{|c|c|c|c|c|c|c|c|c|c|c|c|c|c|c|}
\hline \multirow{8}{*}{ - } & \multirow{2}{*}{\multicolumn{2}{|c|}{ Point/: ifin: }} & \multirow{2}{*}{ 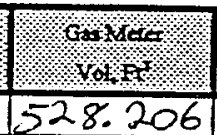 } & \multicolumn{2}{|c|}{ 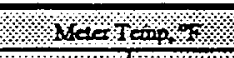 } & $\begin{array}{c}\text { Stact } \\
\text { Temp, TF }\end{array}$ & \multirow[t]{2}{*}{$\Delta P$} & \multirow[t]{2}{*}{$\overline{\Delta H}$} & \multirow{2}{*}{$\begin{array}{l}\text { Mect } \\
\text { ACPM }\end{array}$} & \multirow{2}{*}{$\begin{array}{l}\text { SQRT } \\
\Delta P \\
P\end{array}$} & \multicolumn{2}{|c|}{ | } & W. & Notes \\
\hline & & & & in & $\alpha$ & Temp, $F$ & & & & & & & & \\
\hline & $\bar{I}$ & $10: 16$ & 528.206 & 76 & 78 & 286 & .19 & 1.904 & .794 & .436 & & 92 & 8 & \\
\hline & 2 & $10: 26 \div$ & 535.3 & 81 & 78 & 286 & .19 & 1.648 & .705 & .436 & & 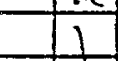 & & \\
\hline & 3 & $10: 36$ & 541.8 & 88 & 80 & 284.4 & .19 & 1.662 & .711 & -736 & & & & \\
\hline & 41 & $10: 582$ & 1547.2 & 89 & 80 & 286.2 & .19 & 1.663 & .712 & .436 & & & & \\
\hline & 5 & 10.56 & 552.5 & 90 & 80 & 290.3 & .24 & 2.091 & .798 &, 490 & & & & \\
\hline & 6 & 11106 & 559.0 & 88 & 80 & 292.1 & .20 & 1.735 & .727 & .447 & & & & \\
\hline 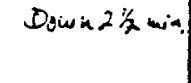 & 7 & $1 / 22$ & 562.7 & 84 & 80 & 290,0 & .20 & 1.733 & .225 & .447 & & & & \\
\hline & 8 & $11: 34:$ & 567.8 & 92 & 82 & 294,4 & .18 & $\sqrt{1.565}$ & 1.692 & .424 & & & & \\
\hline & 9 & iiig & 573.1 & 96 & 82 & 292.1 & .18 & 1,576 & .696 & .424 & & & & \\
\hline & 10 & $11: 912$ & 578.5 & 98 & 84 & 293.2 & .18 & 1,579 & .698 & .424 & & & & \\
\hline $\begin{array}{l}12: 02 \\
2: 12\end{array}$ & 11 & 16 & 583.5 & 98 & 84 & 274.4 & .18 & $|1.5\rangle\rangle$ & .697 & .424 & & & & \\
\hline $\begin{array}{l}2: 12 \\
2: 22\end{array}$ & $\sqrt{21}$ & $12: 19$ & 588.2 & 97 & 86 & 293,7 & .18 & 1.58 & .698 & .424 & & & & \\
\hline $\begin{array}{l}12: 22 \\
12: 32\end{array}$ & 13 & 12,6 & 594.7 & 92 & 84 & 295,7 & .20 & 1.739 & .730 & 2447 & & & & \\
\hline $\begin{array}{l}12: 32 \\
12: 42\end{array}$ & 14 & $12: 36$ & $60 \% 1$ & 88 & 84 & 298.0 & .20 & 1628 & .727 & .447 & & & & \\
\hline $\begin{array}{r}12: 42 \\
12: 52\end{array}$ & 15 & 12.3 & 607.5 & 88 & 84 & 295.5 & .20 & 1.733 & .228 & .2647 & & & & \\
\hline $12: 52$ & 161 & $12, \%$ & 613.6 & 86 & 82 & 298.0 & .20 & 1.721 & .724 & .447 & & & & \\
\hline $13: 02$ & 171 & 22,56 & 1619.6 & 88 & 84 & 297.3 & .20 & 1.729 & .727 & 447 & & & & \\
\hline $3 ; 13$ & 181 & $13: 06$ & 625.9 & 88 & 82 & 298.4 & 20 & 1.724 & .725 & 447 & & & & \\
\hline$|3: 26|$ & 19 & $13: 16$ & 634.484 & & & & & & & & & 1 & & \\
\hline & सह & & & & & & & & & & & I & & \\
\hline & 27 & & & & & & & & & & & I & & \\
\hline & $\$ 21$ & & & & & & & & & & & 1 & & \\
\hline & 33 & & & & & & & & & & & I. & & \\
\hline & 24 & & & & & & & & & & & & & \\
\hline & & & & & & & & & & & & & & \\
\hline & & & & & & & & & & & & & & \\
\hline & & & & & & & & & & & & & & \\
\hline & & & & & & & & & & & & & & \\
\hline & & & 106.278 & 3.5 & & $29,2,54$ & & 1.705 & & 441 & & & & \\
\hline
\end{tabular}

\begin{tabular}{|c|c|c|c|c|}
\hline & Mois & réData & & \\
\hline & Initial & Final & Net & Rinse \\
\hline Impinger & 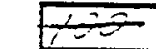 & & & \\
\hline Impinger & 100 & 186 & 86 & \\
\hline impinger(s) & & & & \\
\hline Impinger(s) & & & & \\
\hline Silica Gel: & 200 & $73=$ & 39 & \\
\hline & $\begin{array}{l}\text { Totai } \\
\text { Toral Sam }\end{array}$ & $\begin{array}{l}\text { et/Rinse } \\
\text { Voiume }\end{array}$ & $\sqrt{119}$ & \\
\hline
\end{tabular}

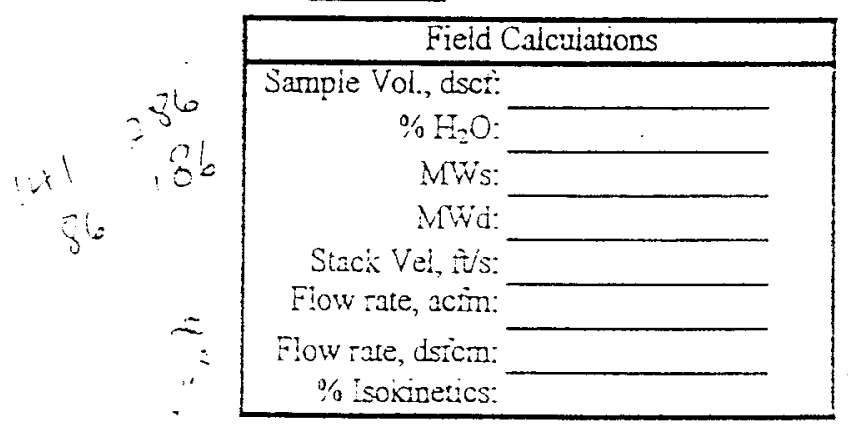


Isokinetic Sampling Data Sheet (Method 429 )

Facility: $\angle L N C$

Date: $8-18-98$ Run \#: 2

Facility Information

Location EilTERInIET RTS?

Port Dia:

Depth:

Fitting:

Length:

Stack Dia: 1,375 Arex:

Upstream from disturbance:

Downstream from disturbance:

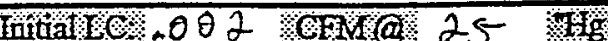

Nete:H 2LSI Pitot \#: -

V.d: 0.0089 Cp: -

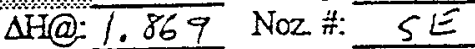

Finter Box \#: $\frac{1}{4} \quad D_{n}: \frac{569}{309}$

Filten: - Mag. \#:-

Probe \#: 2 Umb. \#-

Pyrometer \#: -

Personnei: $D \cdot R, D C J \mu, R B, M$

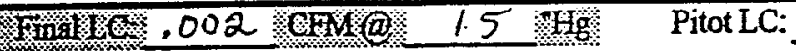

\begin{tabular}{|c|c|c|c|c|c|c|c|c|c|c|c|c|c|}
\hline \multirow{9}{*}{$\begin{array}{l}14: 23 \\
1423\end{array}$} & \multirow{2}{*}{\begin{tabular}{|l} 
Point \\
\\
\end{tabular}} & \multirow{2}{*}{ 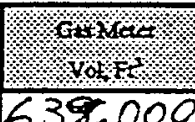 } & \multicolumn{2}{|c|}{ 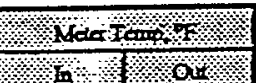 } & 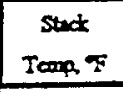 & $\Delta P$ & $\overline{\Delta H}$ & $\begin{array}{l}\text { Medra } \\
\text { ACPM }\end{array}$ & $\begin{array}{l}\text { SQRT } \\
\Delta P \\
\end{array}$ & \multicolumn{3}{|c|}{ (I) } & \multirow[t]{2}{*}{ Nots } \\
\hline & & & & & & & & & & & & & \\
\hline & 7 & 649,3 & 88 & 82 & 297.1 & .20 & 1.588 & .668 & 3.447 & & 12 & 7 & \\
\hline & 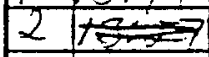 & 655.7 & 98 & 84 & 310.5 & 20 & 1.715 & .727 & 2.447 & & 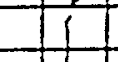 & 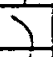 & \\
\hline & $3 \cup 4: 33$ & 662.8 & 98 & 84 & 333.3 & 20 & 1.666 & .717 & 2.444 & & & 1 & \\
\hline & \begin{tabular}{|l|l|l|}
4 & $14: 43$ \\
\end{tabular} & 668.5 & 94 & 84 & 344,3 & .20 & 1.637 & .709 & 9.2147 & & & & \\
\hline & $5114: 53$ & 675.7 & 92 & 82 & 3501 & .20 & 1,619 & .704 & 1.447 & & & 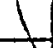 & \\
\hline & $60.5: 04$ & 681.8 & 88 & 84 & 353.7 & 20 & 1,609 & .701 & .447 & & & 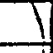 & \\
\hline & $7 / 15: 14$ & 687.5 & 86 & 82 & 356.5 & .20 & 1,598 & .698 & $\mid .447$ & & & & \\
\hline $\sin \lambda \operatorname{se}$ & \begin{tabular}{|l|l|}
$5: 24$ \\
\end{tabular} & 683.0 & 86 & 82 & 358.5 & .20 & $1,594$. & .697 & 2.447 & & & 1 & \\
\hline & $91 / 5: 36$ & 700.2 & 100 & 84 & 360,1 & .20 & 1.614 & .706 & 1.447 & & & 1 & \\
\hline & $101 / 5: 46$ & 708.1 & 100 & 86 & 361.0 & 18 & 0.454 & .671 & .424 & & & $\pi$ & \\
\hline & $11115: 56$ & 714.2 & 100 & 88 & 359.8 & .18 & 1.459. & .673 & .624. & & 1 & 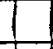 & \\
\hline & 12116.06 & 722.1 & 98 & 88 & 360.0 & .18 & 1.458 & .673 & 3.474 & & I & I & \\
\hline & $13 \mathrm{~V} 6 \mathrm{il6}$ & 779.3 & 92 & 88 & 360.0 & .18 & 0.448 & .668 & 0.424 & & I & I & \\
\hline & $14 / 16: 26$ & 736.1 & 92 & 86 & 360.0 & 18 & $1.445 \mid$ & .667 & 0.424. & & & & \\
\hline & $1516 ; 36$ & 74.8 & 90 & 86 & 362.3 & 23 & 1.8381 & .751 & .480 .1 & & I & L & \\
\hline & $16 \sqrt{16: 46}$ & 747.2 & 88 & 84 & 363.2 & .23 & 1.829 & 747 & 480 & & T & I & \\
\hline & $\angle / 6 i 57$ & 753.1 & 90 & 84 & 3625 & .23 & $|1.834|$ & .749 & .490 .1 & & & 4 & \\
\hline & \begin{tabular}{|l|l|}
15.07 \\
\end{tabular} & 758.167 & 90 & 84 & 364.6 & .23 & V.830 & .748 & 980 & & 4 & 7 & \\
\hline & & & & & & & & & & & & & \\
\hline & & & & & & & & & & & & & \\
\hline & & & & & & & & & & & & & \\
\hline & & & & & & & & & & & & & \\
\hline & & & & & & & & & & & & & \\
\hline & & & & & & & & & & & & & \\
\hline & & & & & & & & & & & & & \\
\hline & & & & & & & & & & & & & \\
\hline & $T$ & & & & & & & & & & 1 & & \\
\hline & & 119.167 & 88 & 67 & 350.97 & & 1.624 & & .448 & & & & \\
\hline & 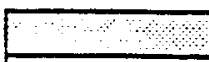 & Y. Moistur & Eata & 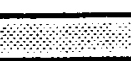 & $=1$ & & & & & ieid C & culation & & \\
\hline & & Initial & Final & Net & Rinse & & & & ample Vol., & dsct: & & & \\
\hline & Inopinger $\# 1$ & 5 & & & & & & & & $\mathrm{H}_{2} \mathrm{O}:$ & & & \\
\hline & inginget & 100 & 197 & $9 \sqrt{3}$ & & & & & & Ws: & & & \\
\hline & Impingeris) $\#$ & & & & & & & & & Wi: & & & \\
\hline & Encinger s) & & & & & & & & Siack tel & & & & \\
\hline & Siitea Cet: & 206 & 239 & 301 & & & & & Fiow rate, ac & & & & \\
\hline & & $\begin{array}{l}\text { Totai } \mathrm{N} \\
\text { Toral Sample }\end{array}$ & $\begin{array}{l}/ \text { Rine } \\
\text { Voluse }\end{array}$ & 132 & & & & & $\begin{array}{l}\text { Fiow rate, ist } \\
\% \text { :sokised }\end{array}$ & & & & \\
\hline
\end{tabular}




\section{Isokinetic Sampling Data Sheet (Method 429}

Facility: CAWRENCE Date: 8-19-98 Run H: S Personnel: MM- SC-RO- me

\begin{tabular}{|c|c|c|c|}
\hline Facility Information & Equipment & Information & Sarmpling Information \\
\hline Tocation BAGASUSE INLET RT & 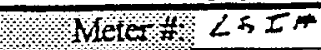 & 2 Pitot $\frac{H}{H}$ MINI STD & Pbar $29-9$ \\
\hline Depth: & $101 / .0089$ & $2=.99$ & Pstatic: -4.0 \\
\hline Length: & $\Delta H(0): 1869$ & Noz \#: $5 E$ & $\% \mathrm{O}_{2}:$ \\
\hline Stack Dia: 1.375 Area: 0.01 & Filter Box \#: & $D_{\mathrm{n}}:=.309$ & $\% \mathrm{CO}_{2}: \frac{8}{8}$ \\
\hline Upstream from disturbance: & Filter \#: $1,2,3$ & Mag \#: & $\% \overline{\mathrm{H}_{2} \mathrm{O}:} \quad 2.0$ \\
\hline Downstream from disturbance: & Probe \#: $2^{\prime}$ & Umb. \# & Rin Mins $/ 80 \mathrm{~m}$ \\
\hline
\end{tabular}

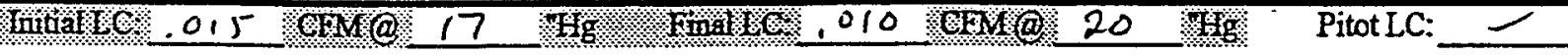

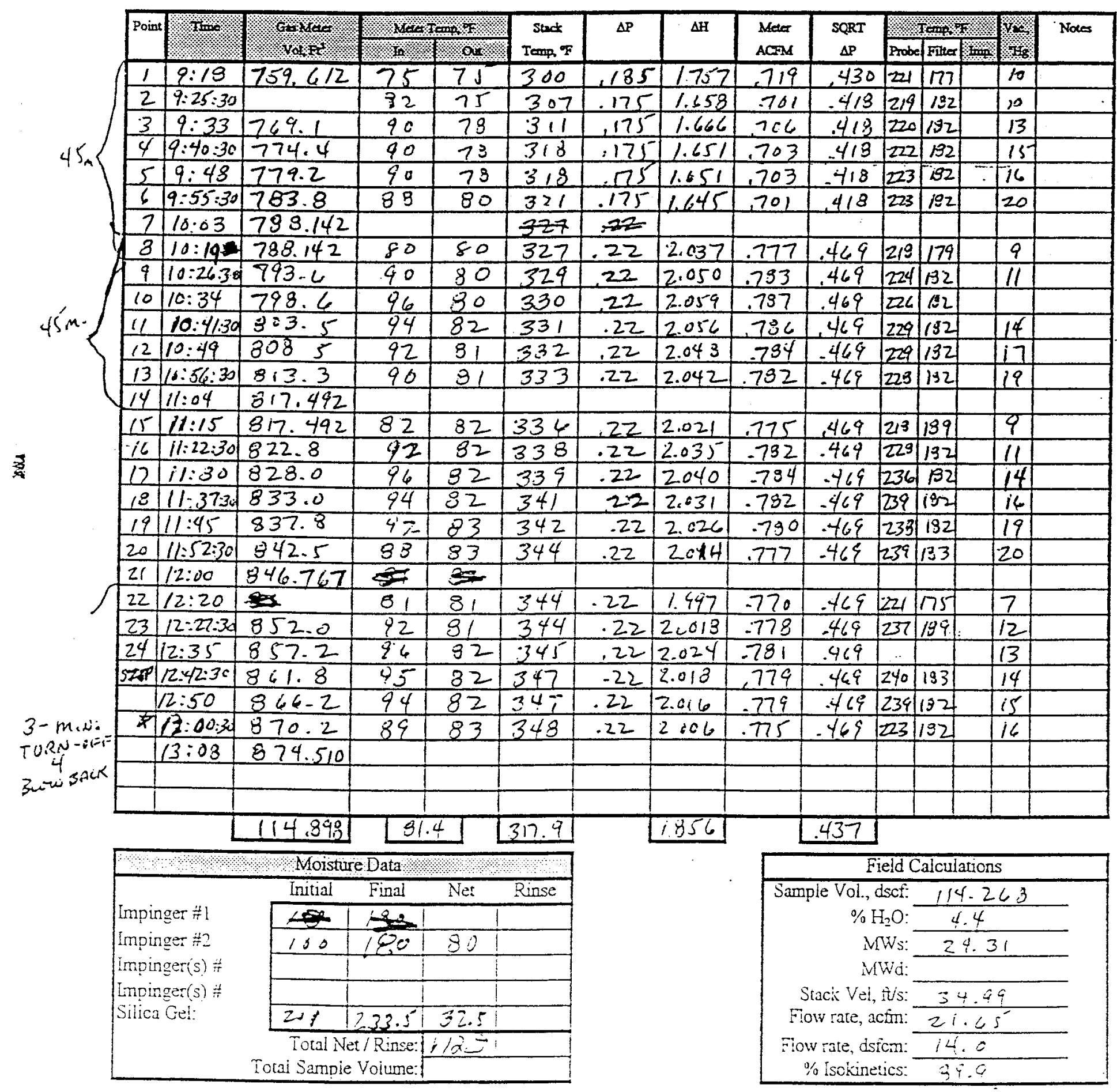

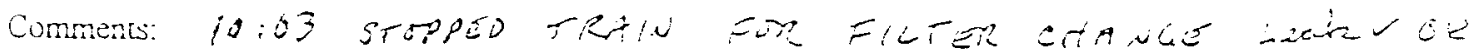


BEST ENVIRONMENTAL, INC.

Isokinetic Sampling Data Sheet (Method $M M 5$ )

Facility: $\angle L N \angle$ Date: $8 / 18 / 98$ Run H: / Personnel: $D C$

\begin{tabular}{|c|c|c|c|}
\hline Facility Information & Equpment & ntormation & Sampling Information \\
\hline Location: Cat, Out RTS & Wetert $<51-1$ & Pitot t: $=$ & $\begin{array}{l}\text { Pbar } 29.9 \\
\text { Pstatic: }-2.5\end{array}$ \\
\hline $\begin{array}{l}\text { Port Dia: } \\
\text { Fitting: }\end{array}$ & $\Delta H @: \frac{1.0037}{2.196}$ & Noz H: & $\% \mathrm{O}_{2}:$ \\
\hline Stack Dia: $\overline{4,0}$ Area: $\overline{, 08}$ & Filter Box \#: & $D_{\mathrm{a}}: .5$ & $\% \mathrm{CO}_{2}$ \\
\hline Upstream from disturbance: & Filter \#: & Mag. \#: & $\% \overline{\mathrm{H}_{2} \mathrm{O}}$ \\
\hline Downstream from disturbance: & $\begin{array}{l}\text { Probe \#: } \\
\text { Pyrometer \#: }\end{array}$ & Umb. \# & Ruin Mllins \\
\hline
\end{tabular}

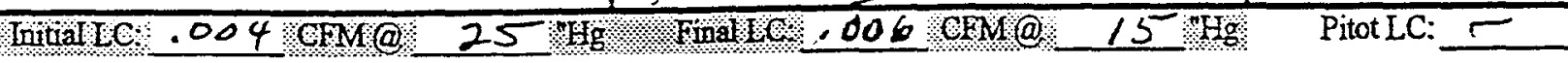

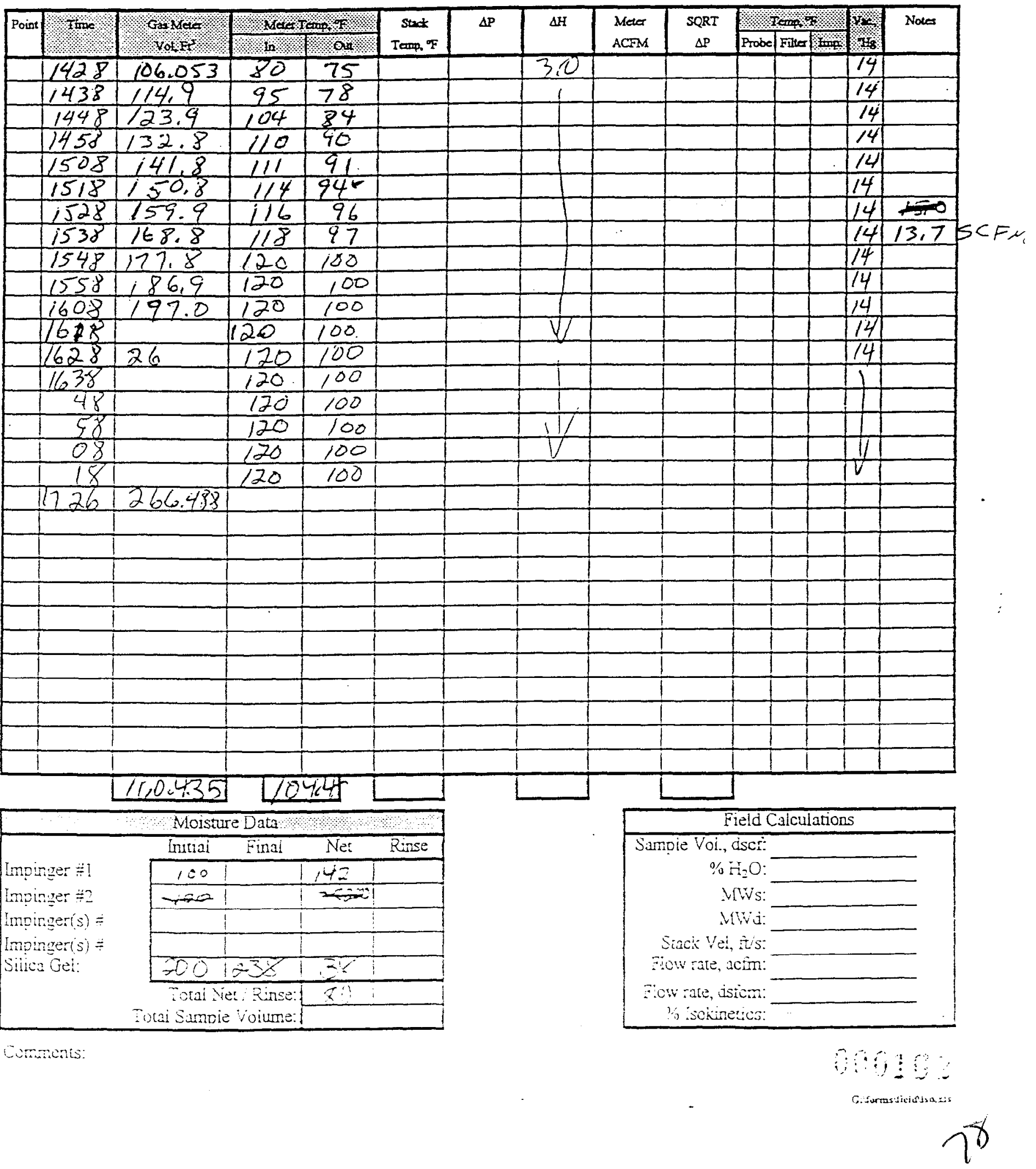




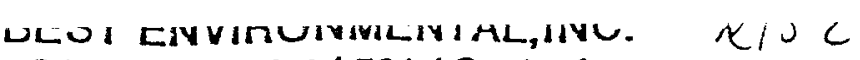

CARB Method 5 / $501 /$ Cyclonic

Facility: $\angle L N L$

Date: 8-26-98 Method: 23

Run \#: /

\begin{tabular}{|c|c|c|c|}
\hline Facility Information & Equipment & \multicolumn{2}{|c|}{ Sampling Data } \\
\hline Location: QSS Inled PST2 & Meter $\# 2$ & PBar 29.9 & P Static: -10.0 \\
\hline Port Dia. & Meter Yd: 1.0089 Pitot $C_{p}: 99$ & $96 \mathrm{O}_{2}$ Ass. & $\mathrm{gO}_{2}$ Actual: \\
\hline Fitting Type: & $\Delta \mathrm{HQ:} 1.869$ & $\mathrm{FCO}_{2}$ Ass. & $96 \mathrm{CO}_{2}$ Actual: \\
\hline Stack Dia $1.37 \mathrm{~S}$ Area: & Noz-Dia.32Ld & $\$ 6 \mathrm{H}_{2} \mathrm{O}$ Ass & Pitot LC: \\
\hline Upstream Dist. 2 & Probe \#: & Test Mins. 180 & Personacl:PR \\
\hline Downstream Dist $\&$ & $\mathrm{LC}$ & .0 & $20 \mathrm{Hg}_{\mathrm{g}}$ \\
\hline
\end{tabular}

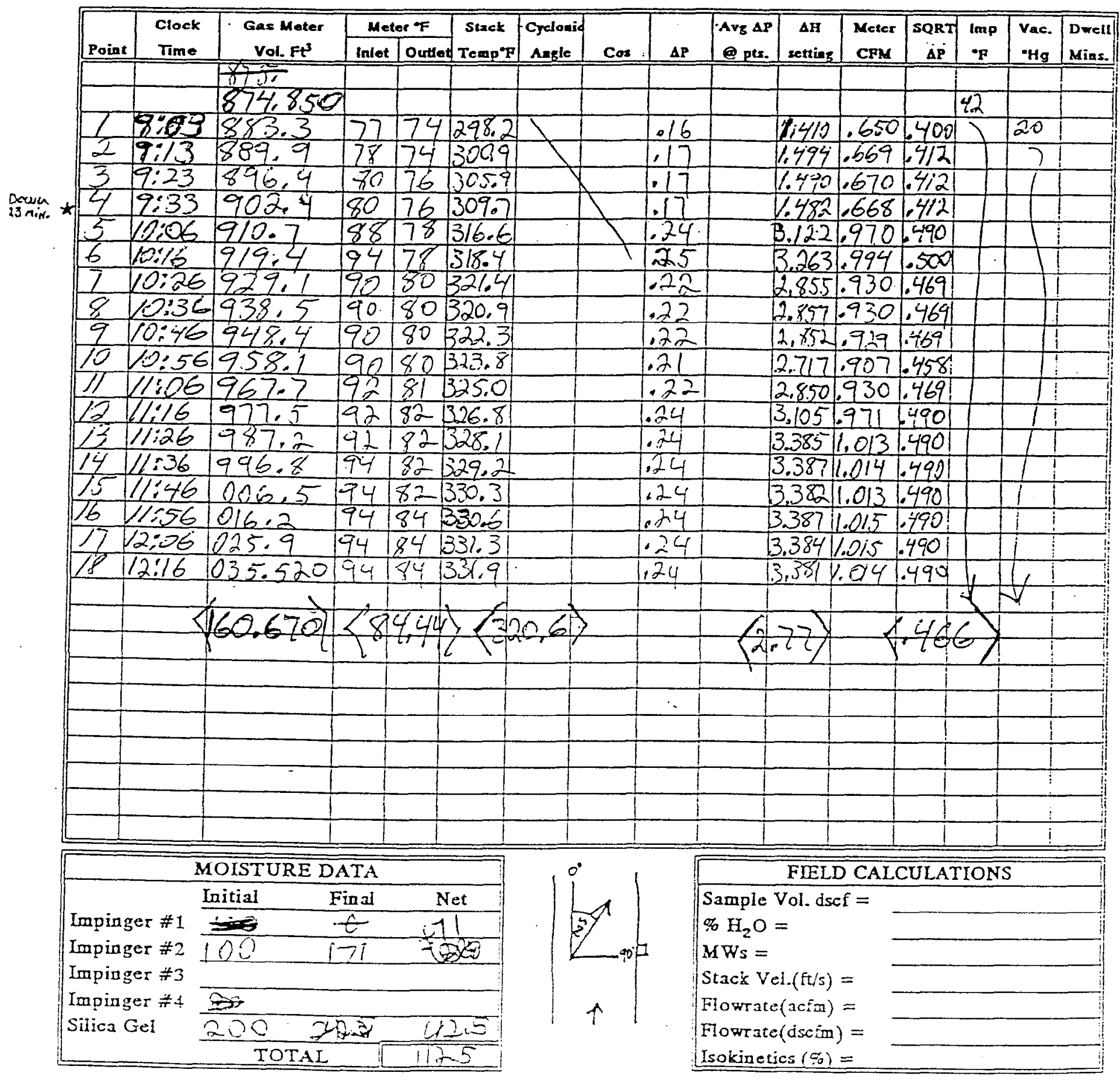

COMMENTS: Cyctonic Dwe!l $=$ Test Duration $\cdot \cos / \operatorname{sti}$ COS

MS01 \& Cylonic DweI = Tes Duration $($ COSiAVG COS $) \cdot$ SQRT dP $/$ TOL SQRT dP @ pLs ampied

WPCE Spiri 


\section{Isokinetic Sampling Data Sheet (Method \$23)}

Facility: $\angle \angle N L$

Date: $8-26-98$ Run \#: 2

Facility Information

Port Dia:

Fitting:

tack Dia: Length:

Ins Area:

Upstream from disturbance:

Downstream from disturbance Equinment Information

Yd: $\overline{1.0089} \quad \mathrm{Cp}: \overline{94}$

$\Delta \mathrm{H} @ 1,1,869$ Noz $\#: 56$

Filter Box $\frac{H}{\pi}$ :

Filter $\#$ :

Probe \#:
Personnel:QR.RLC,JM, RE MW

Meter $\frac{4}{\pi} 2$ Pitot $\frac{4}{\pi:}-5^{2 t u}$

Pyrometer \#:
Samping Information

Pbar 29.9
Pstatic: -10
$\% \mathrm{O}_{2}:-$
$\% \mathrm{CO}_{2}: \overline{\mathrm{H}_{2} \mathrm{O}:}$
$\mathrm{Ram} \mathrm{Mins}=180$

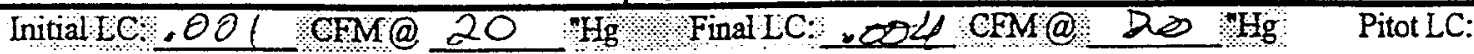

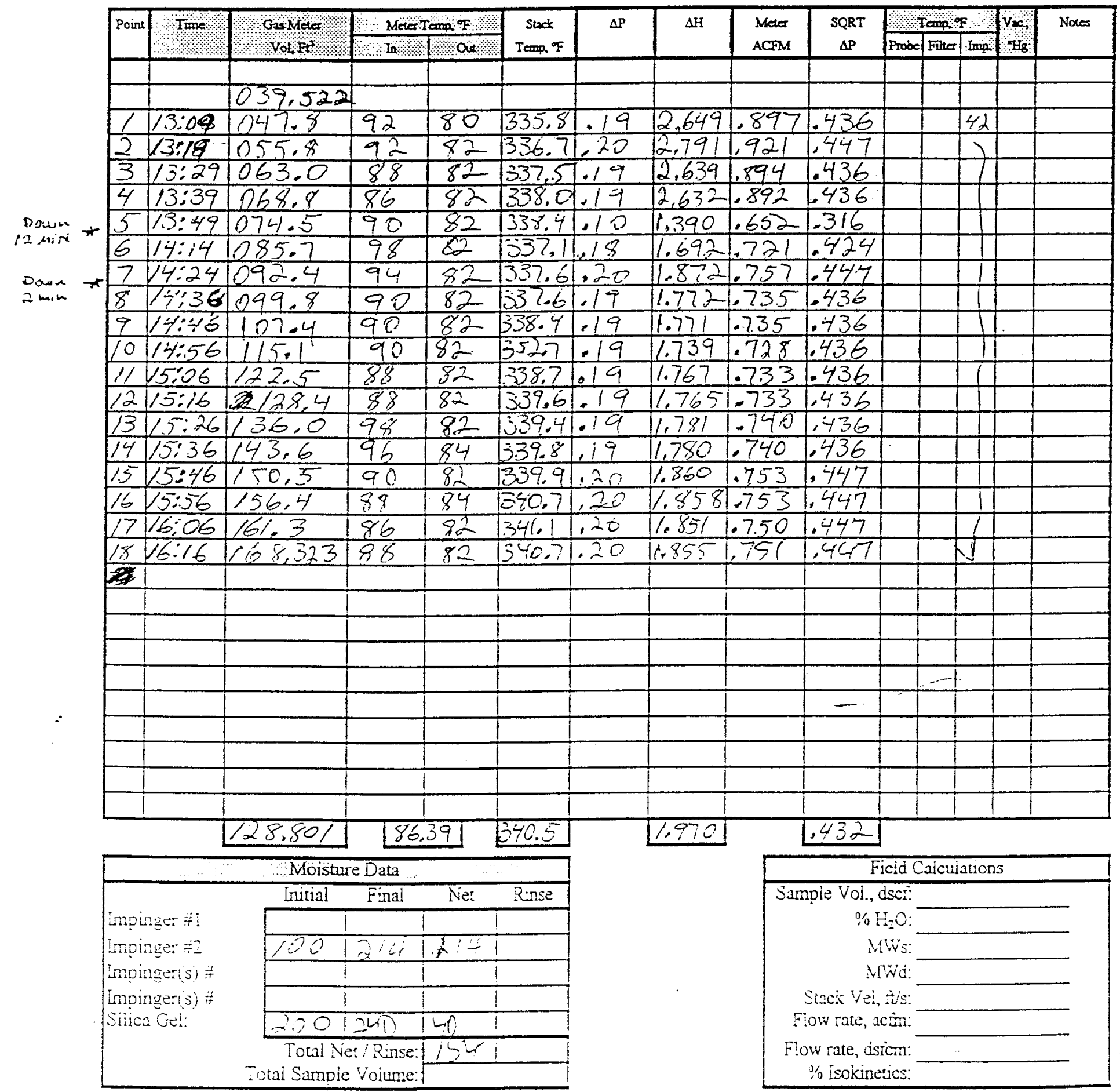




\section{Isokinetic Sampling Data Sheet (Method 423)}

Facility: $L C N L$

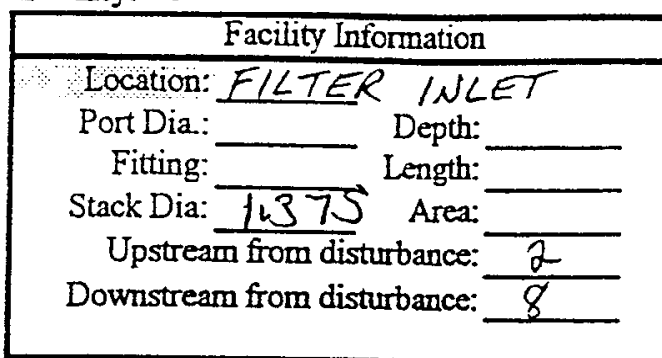

Date: $8-26-88$ Run $\#: 3$ Equipment Information

Meter $\# \angle 5 I \# 2$ Pitot $\#$ :

$\mathrm{Yd} \frac{1.0089}{1.869} \quad \mathrm{Cp}:$

$\Delta H @: 1.869$ Noz: $\$ 5 B$

Filter Box \#:

Filter \#;

Probe \#:

Pyrometer \#:

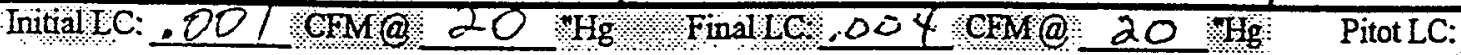

Personnel: DC, $\mu \omega$

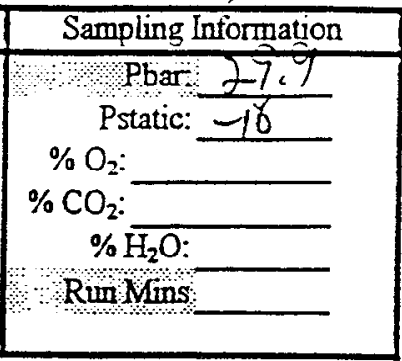

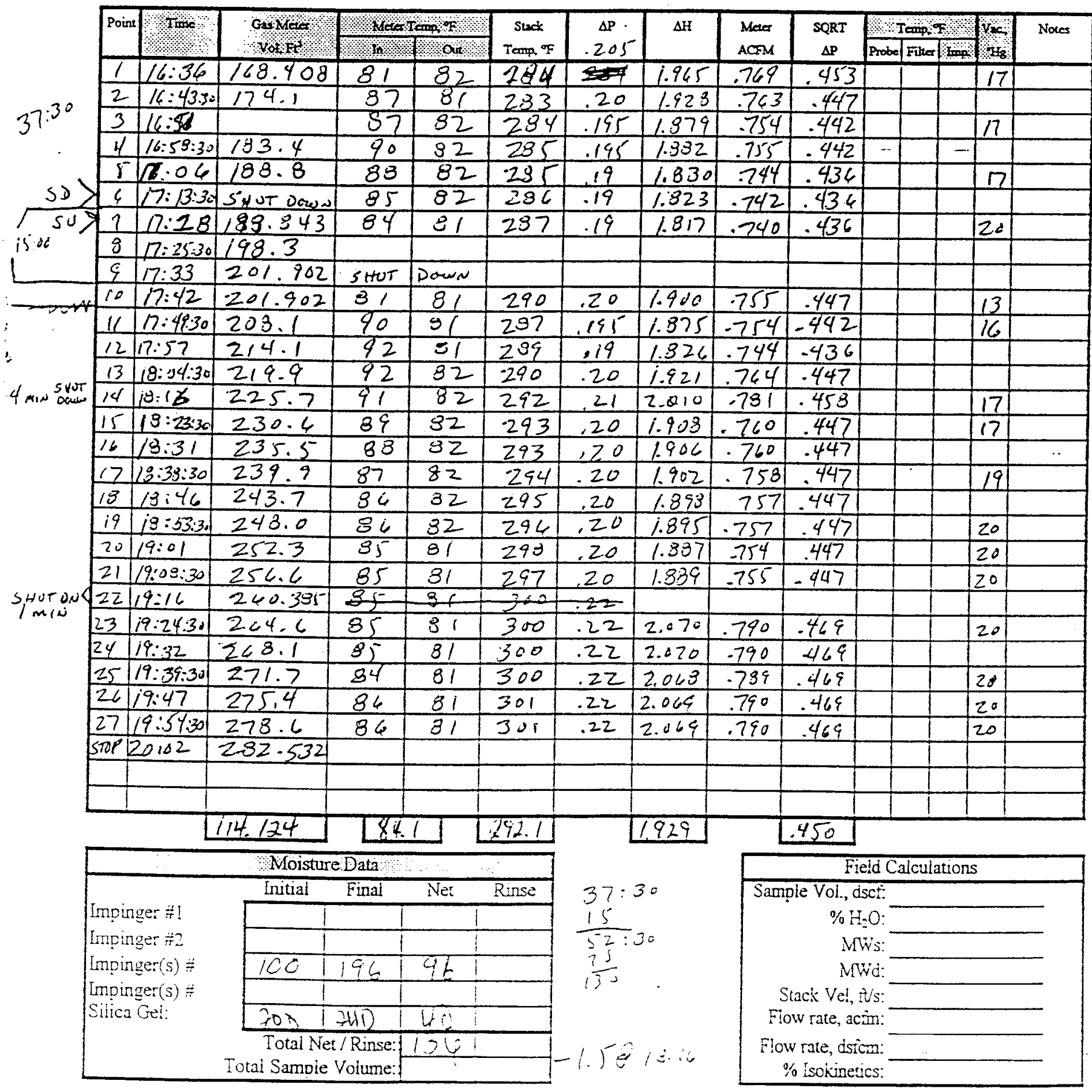

Comments: 
BEST ENVIR ONMENTAL, INC.

San Leandro, CA $(510) 273+011$

\section{Isokinetic Sampling Data Sheet (Method 423 )}

Facility: $L L N L$

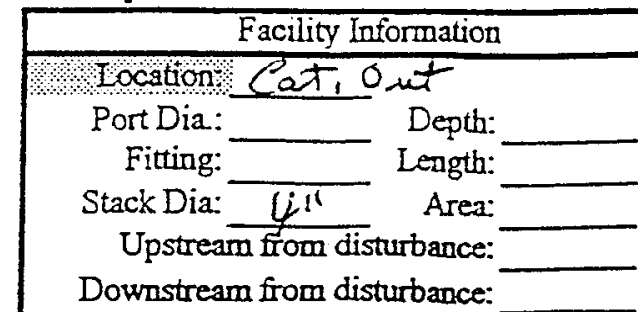

Date: $8 / 24 / 98$ Run \#1

Pitot $\frac{4}{\pi:}$ - $\quad$ - Pbar 2999

Id $\frac{1,0039}{201}=$

$\Delta H @: \frac{1,0196}{2,19 b}$ Noz \#:

Filter Box $\#$ : $\quad D_{\mathrm{n}}: \overline{.471}$

Filter \#:- Mag: \#-

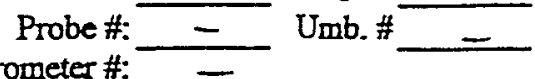

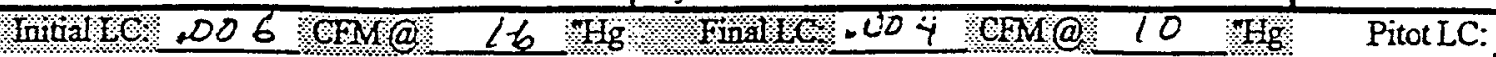

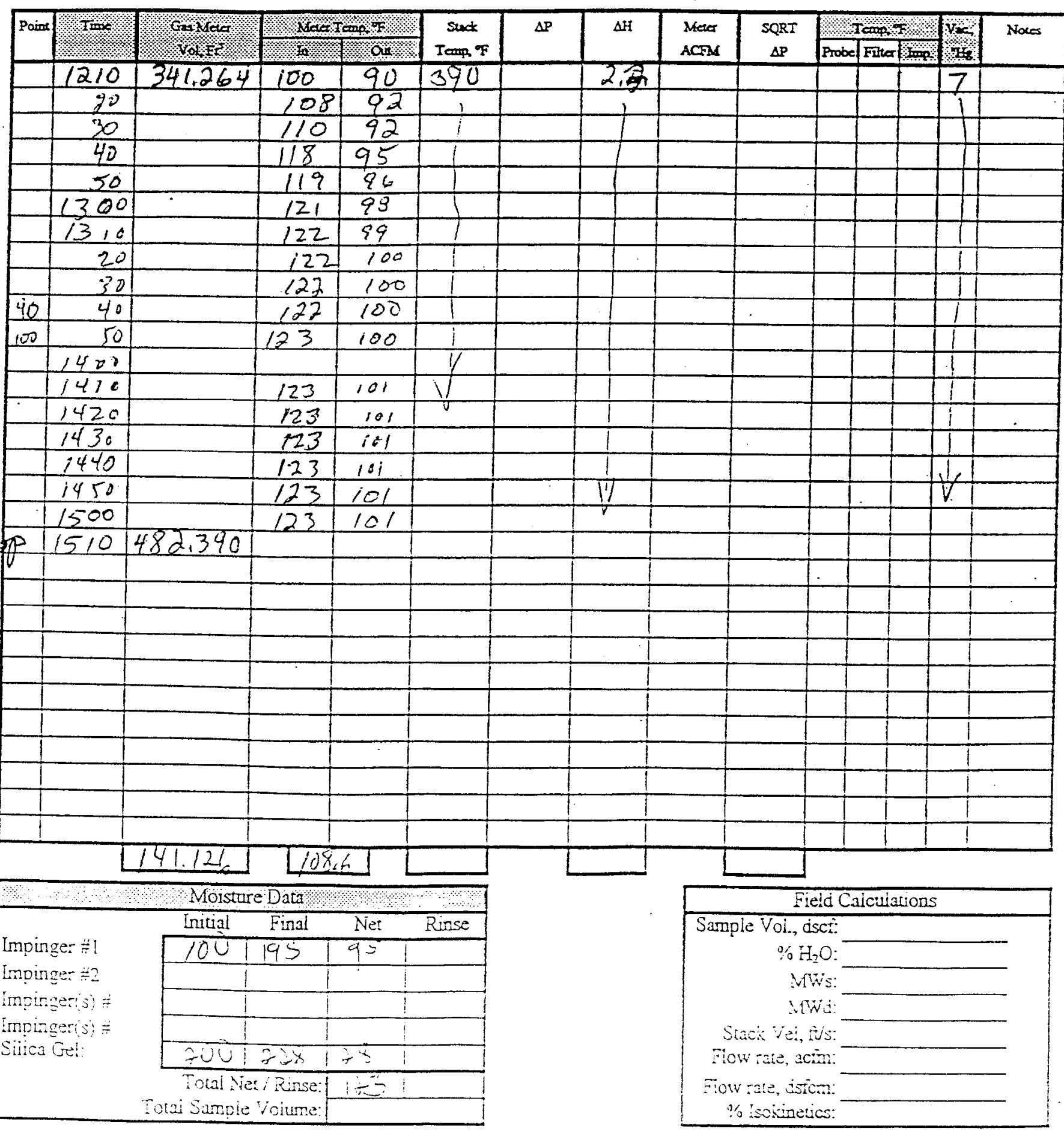


Sampling Data Sheet (Method 0030)

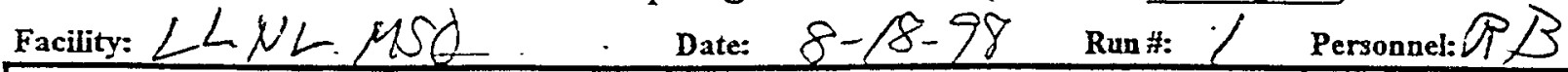

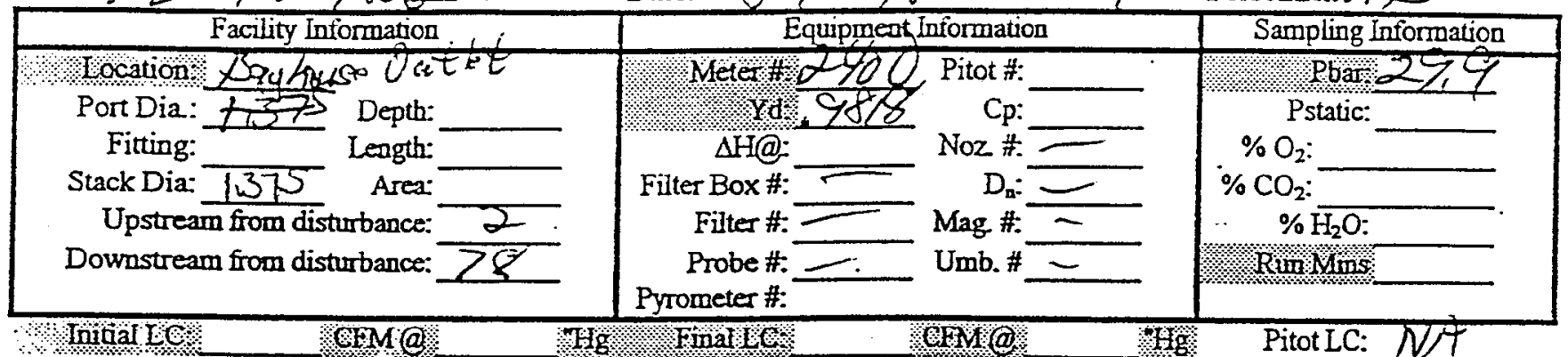

\begin{tabular}{|c|c|c|c|c|c|c|c|c|c|c|c|c|c|c|}
\hline \multirow[t]{2}{*}{ Point } & \multirow{2}{*}{ 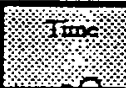 } & \multirow{2}{*}{ Hg } & \multicolumn{2}{|c|}{ H.t. } & \multirow{2}{*}{$\begin{array}{c}\text { Stact } \\
\text { Temp, F }\end{array}$} & \multirow{2}{*}{ exden } & \multirow[t]{2}{*}{$\Delta H$} & \multirow{2}{*}{$\begin{array}{l}\text { Meter } \\
\text { ACPM }\end{array}$} & \multirow{2}{*}{$\begin{array}{c}\text { SQRT } \\
\Delta \mathrm{P}\end{array}$} & \multicolumn{3}{|c|}{ F } & \multirow{2}{*}{ 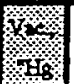 } & \multirow{2}{*}{$\frac{1}{i \pi \times \infty}$} \\
\hline & & & . & & & & & & & Probe F & Finter & In & & \\
\hline ET & 405 & $15: 4$ & $\pi$ & $x$ & & प्रय & & & & & & & & $15 a$ \\
\hline & 11104 & 4,0 & $x$ & 73 & & $5 \%$ & & & & & & & & $i \alpha b$ \\
\hline & 109 & $2010 \ldots$ & 75 & 73 & & 54 & & & & & & & & \\
\hline & 119 & $3 / .2$ & 76 & 73 & & 55 & & & & & & & & \\
\hline 20 & 1119 & 35,2 & & & & & & & & & & . & & \\
\hline & & & & & & & & & & & & & & ZE. \\
\hline & & & & & & & & & & & & & & \\
\hline & 119 & ज्ञाC & 76 & 75 & & 5 & & & & & & & & $2 a$ \\
\hline & 1132 & 10.1 & 78 & 75 & & $5: 2$ & & & & & & & & 26 \\
\hline & 1137 & 45 & 18 & 25 & & 55 & & & & & & & & \\
\hline & 112 & $4 \geq 1$ & 7 & 36 & & 54 & & & & & & & & \\
\hline 8 & iा47 & जप्यंज & & & & & & & & & & & & \\
\hline & & & & 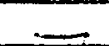 & & & & & & & & & & \\
\hline & 1155 & Stile & 78 & 27 & & 5.5 & & & & & & & & $3 a$ \\
\hline & 500 & $5 \times 45$ & 80 & 72 & & Sit & & & & & & & & 85 \\
\hline & 2205 & 69.4 & 80 & & & 32 & & & & & & & & \\
\hline & $12 / 0$ & 109,3 & 80 & 71 & & 52 & & & & & & & & $\angle C$. \\
\hline (2) & 1215 & 7511 & & & & & E & & & & & & & $\lambda \pi$ \\
\hline
\end{tabular}

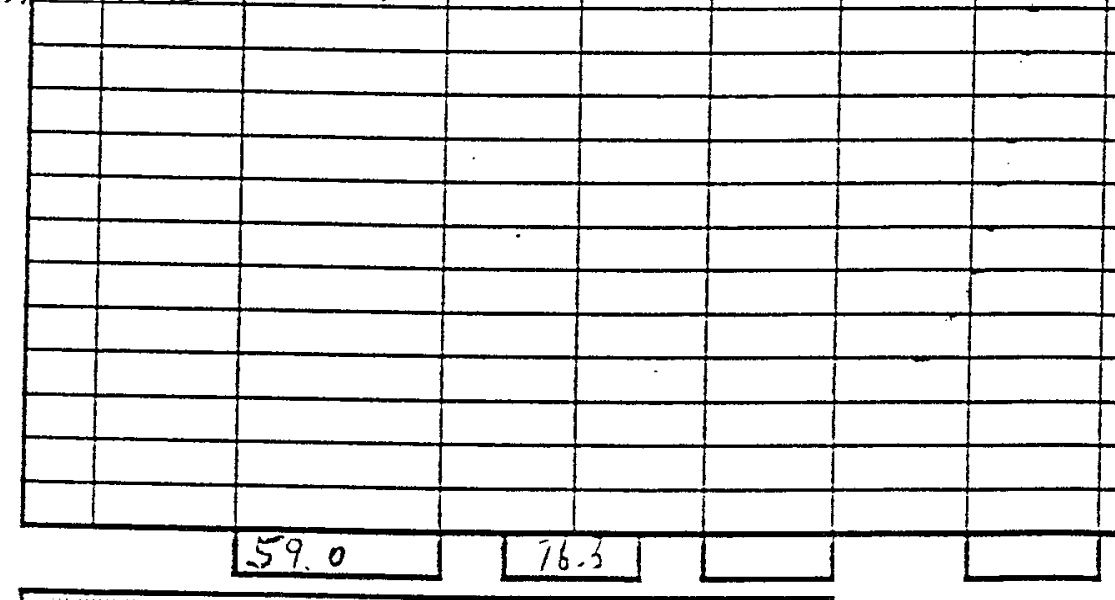

\begin{tabular}{|c|c|c|c|c|}
\hline 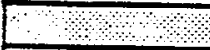 & Moist & Bata & & \\
\hline & Initial & Final & Net & Rinse \\
\hline Impinger 1 & & & & \\
\hline Impinger & & & & \\
\hline Impinger(s) & & & & \\
\hline Impinger(s) & & & & \\
\hline Silica Ge: & & & & \\
\hline & Total & /Rinse: & & \\
\hline
\end{tabular}

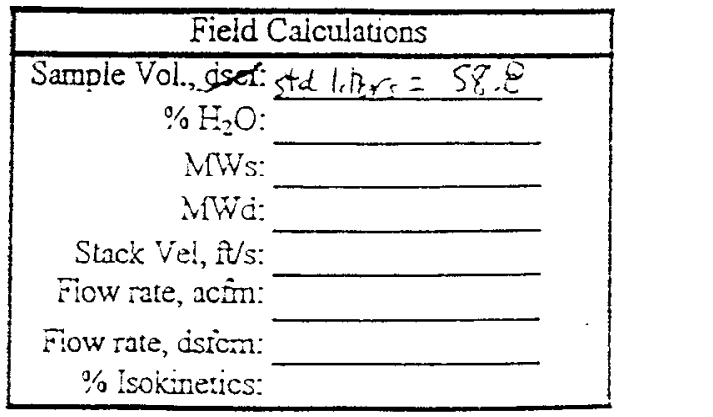

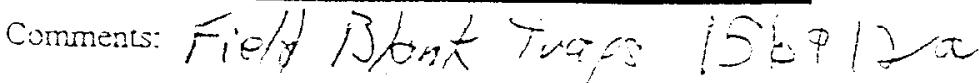


Isokinetic Sampling Data Sheet (Method 0030 )

Facility: LLUL 450 Date: $8-18.99$ Run H: 2 Personnel:PB

\begin{tabular}{|c|c|c|}
\hline Facility Intormation & Equipmeat Intormation & Sampling Information \\
\hline Soction $\$$ Daghasse Uutlel & 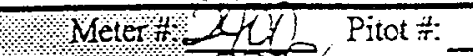 & $\mathrm{Pbar}$ \\
\hline Port Dia: $\quad$ Depth: & $1.9098 \mathrm{cp}$ & Pstatic: \\
\hline Fitting: $\quad$ Length: & $\Delta \mathrm{H} @ \mathrm{~N}: \mathrm{Noz}$ & $\% \mathrm{O}_{2}$ \\
\hline Stack Dia:- & Filter Box\#: & $\% \mathrm{CO}_{2}$ \\
\hline Upstream from disturbance: 2 & Filter \#: & $\% \overline{\mathrm{H}_{2} \mathrm{O}}$ \\
\hline Downstream from disturbance: $\bar{x}$ & $\begin{array}{l}\text { Probe \#: } \\
\text { Pyrometer }\end{array}$ & R Rum Hins \\
\hline
\end{tabular}
Initalle:
GEM@
$\mathrm{Hg}$ Finalo
SEMI.
Pitot IC:

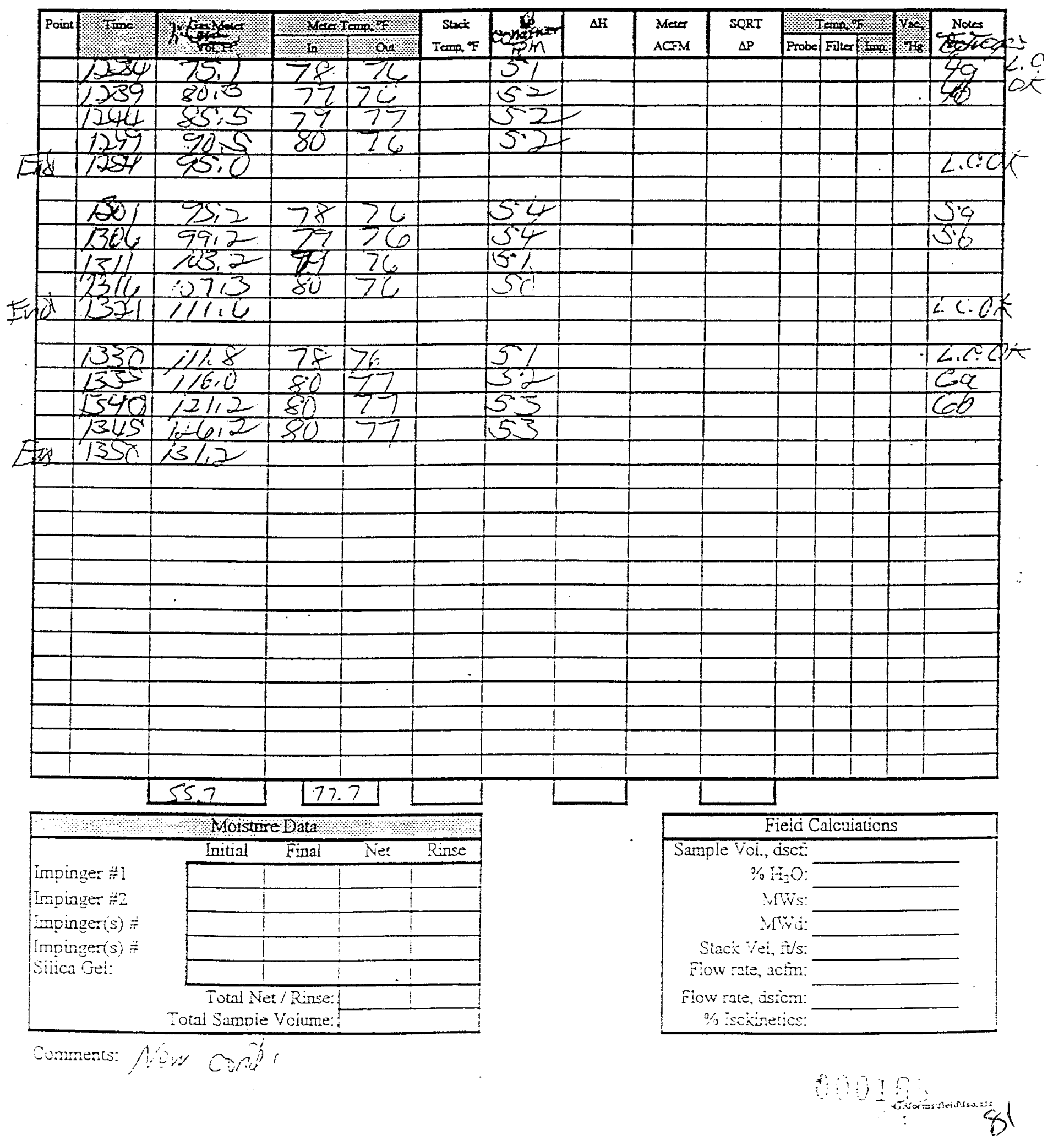


DED I LNV LRUNMLNTAL, INL.

San Leandro, CA (510)273-1011

Facility: $\angle L N L$

Iso ic Sampling Data Sheet (Method 0038 )

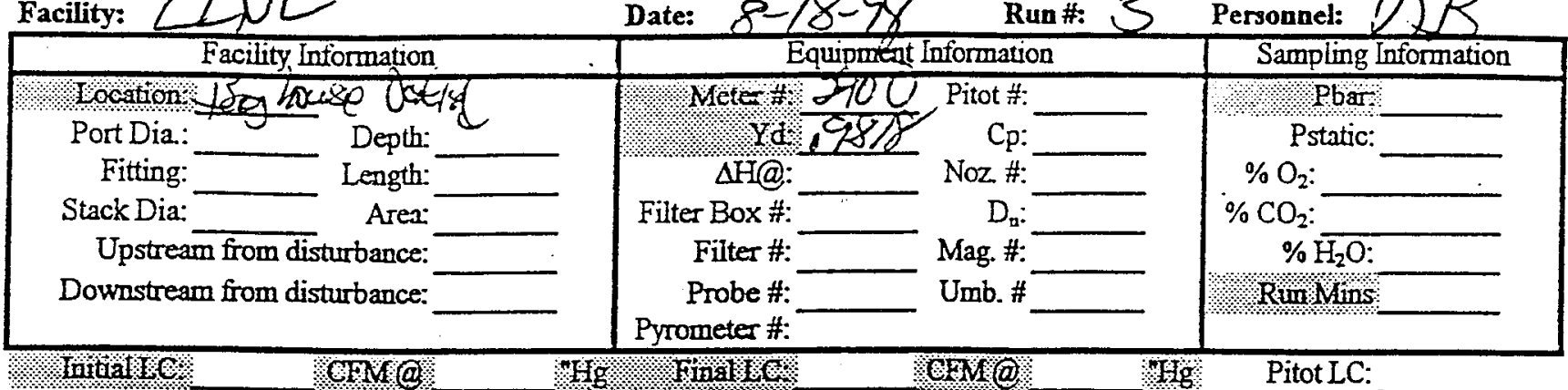

\begin{tabular}{|c|c|c|c|c|c|c|c|c|c|c|c|c|c|}
\hline \multirow{2}{*}{${ }^{P o i n t}$} & \multirow{2}{*}{ H.t. } & \multirow{2}{*}{ (6) } & \multicolumn{2}{|c|}{ 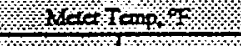 } & \multirow{2}{*}{$\begin{array}{c}\text { Stact } \\
\text { Ietep or }\end{array}$} & \multirow{2}{*}{ costanses } & \multirow[t]{2}{*}{$\Delta H$} & \multirow{2}{*}{$\begin{array}{l}\text { Metre } \\
\text { ACPM }\end{array}$} & \multirow{2}{*}{$\begin{array}{l}\text { SQRT } \\
\Delta P\end{array}$} & \multicolumn{2}{|c|}{ Teupt. } & \multirow{2}{*}{ Fi: } & \multirow{2}{*}{ 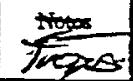 } \\
\hline & & & 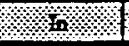 & . & & & & & & \begin{tabular}{l|l|} 
Probe Fiter \\
\end{tabular} & Intan & & \\
\hline E & 924 & $15 A 7$ & 76 & 75 & & 30 & & & & & & & 80 \\
\hline & sy & 136.4 & 77 & 76 & & $4 x$ & & & & & & & 86 \\
\hline & 1404 & 141.1 & 34 & 76 & & 50 & & & & & & & \\
\hline & 1739 & ixs, 6 & 74 & 76 & & 51 & & & & & & & \\
\hline & 1042 & $-50,3$ & & & & & & & & & & & F.ot \\
\hline & & & . & 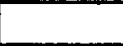 & & & & & & & & & \\
\hline & 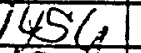 & 15016 & 76 & 21. & & 52 & & & & & & & 4 \\
\hline & 501 & 154.4 & 78 & 76 & & 52 & & & & & & & 99 \\
\hline & SSo6 & $\langle, 5 \%, 2$ & 7 & 76 & & 521 & & & & & & & 96 \\
\hline & 51 & 165,5 & 74 & दE & & $5^{2}$ & & & & & & & \\
\hline & $B / 6$ & 169.0 & & & & & & & & & & & \\
\hline & & & & & & & & & & & & & \\
\hline & & $\cdot$ & & & & & & & & & & & Lot \\
\hline & $15+6$ & 169.2 & 74 & 77 & & $5 \%$ & & & & & & & 719 \\
\hline & 1531 & 174.0 & 77 & 79 & & 51 & & & & & & & 106 \\
\hline & 2536 & 1741 & 80 & 77 & & 52 & & & & & & & \\
\hline & 151 & 18415 & 80 & 72 & & 52 & & & & & & & \\
\hline & $19 / 4$ & $\angle 8815^{\circ}$ & & & & & & & & & & & $L C, 0$ \\
\hline & & & & & & & & & & & & & \\
\hline & & & & & & & & & & & & & \\
\hline & & & & & & & & & & & & & \\
\hline & & & & & & & & & & & & & \\
\hline & & & & & & & & & & & & & \\
\hline & & & & & & & & & & & & & \\
\hline & & & & & & & & & & & & & \\
\hline & & & & & & & & & & & & & \\
\hline & & - & & & & & & & & & & & \\
\hline & & & & & & & & & & & & & \\
\hline & & & & & & & & & & & & & \\
\hline & & & & & & & & & & & & & \\
\hline & & 56.3 & 71 & .3 & & & & & & & & & \\
\hline & & Moistur & Data & 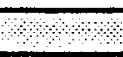 & 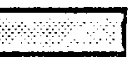 & & & & & ield Calo & culation & & \\
\hline & & Initial & Final & Net & Rinse & & & $\overline{\text { Sarn! }}$ & e Vol., & disct: & & & \\
\hline Imping & ger $\# !$ & 1 & 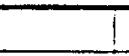 & 1 & & & & & & $\mathrm{H}_{2} \mathrm{O}$ & & & \\
\hline Imping & ger $\div 2$ & 1 & L & I & & & & & & AWs: & & & \\
\hline imping & geris) $\frac{1}{\pi}$ & & 1 & 1 & & & & & & Wd: & & & \\
\hline Imping & $\operatorname{ger}(s)=$ & 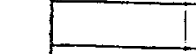 & 1 & 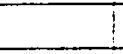 & & & & & ack Ve! & $4 / 5:$ & & & \\
\hline Silica 0 & Ge:: & 1 & $!$ & 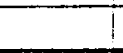 & & & & & vate, ac & $\operatorname{ctin}:$ & & & \\
\hline & & $\begin{array}{l}\text { Total Ne } \\
\text { Total Sampie }\end{array}$ & $\begin{array}{l}\text { Rinse: } \\
\text { Volume: }\end{array}$ & 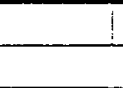 & & & & & $\begin{array}{l}\text { rate, dst } \\
\text { Isokine }\end{array}$ & icin: & & & \\
\hline
\end{tabular}

Comments: 
BESL ENV LKUIVMLNIAL, LYL.

-

\section{Isokinetic Sampling Data Sheet (Method co30)}

Facility: $L L N L M S O$ Date: $8-18=98$ Run \#: 1 Personnel: $\int / 2$

\begin{tabular}{|c|c|c|c|}
\hline Facility Information & \multicolumn{2}{|c|}{ Equipment Information } & Sampling Information \\
\hline Location (a)talvat vatet & Meter & Pitot $\frac{4}{\pi}$ : & Pbar: \\
\hline 7 Depth: & Yot & $\mathrm{Cp}_{\mathrm{p}}$ & Pstatic: \\
\hline Length: & $\Delta \mathrm{H} @:$ & Noz $\frac{\pi}{\pi}$ & $\% \mathrm{O}_{2}:$ \\
\hline Stack Dia: - & Filter Box \#: & $D_{\mathrm{a}}:$ & $\% \mathrm{CO}_{2}:$ \\
\hline Upstream from disturbance: & Filter \#: & Mag. \#: & $\% \overline{\mathrm{H}_{2} \mathrm{O}:}$ \\
\hline Downstream from disturbance: & $\begin{array}{l}\text { Probe \#: } \\
\text { Pyrometer \#- }\end{array}$ & Umb. \# & RainAms \\
\hline
\end{tabular}

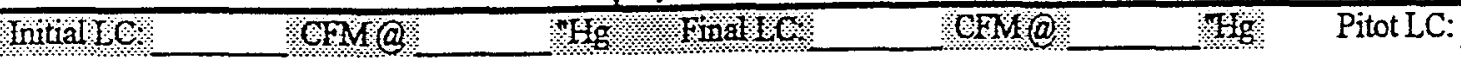

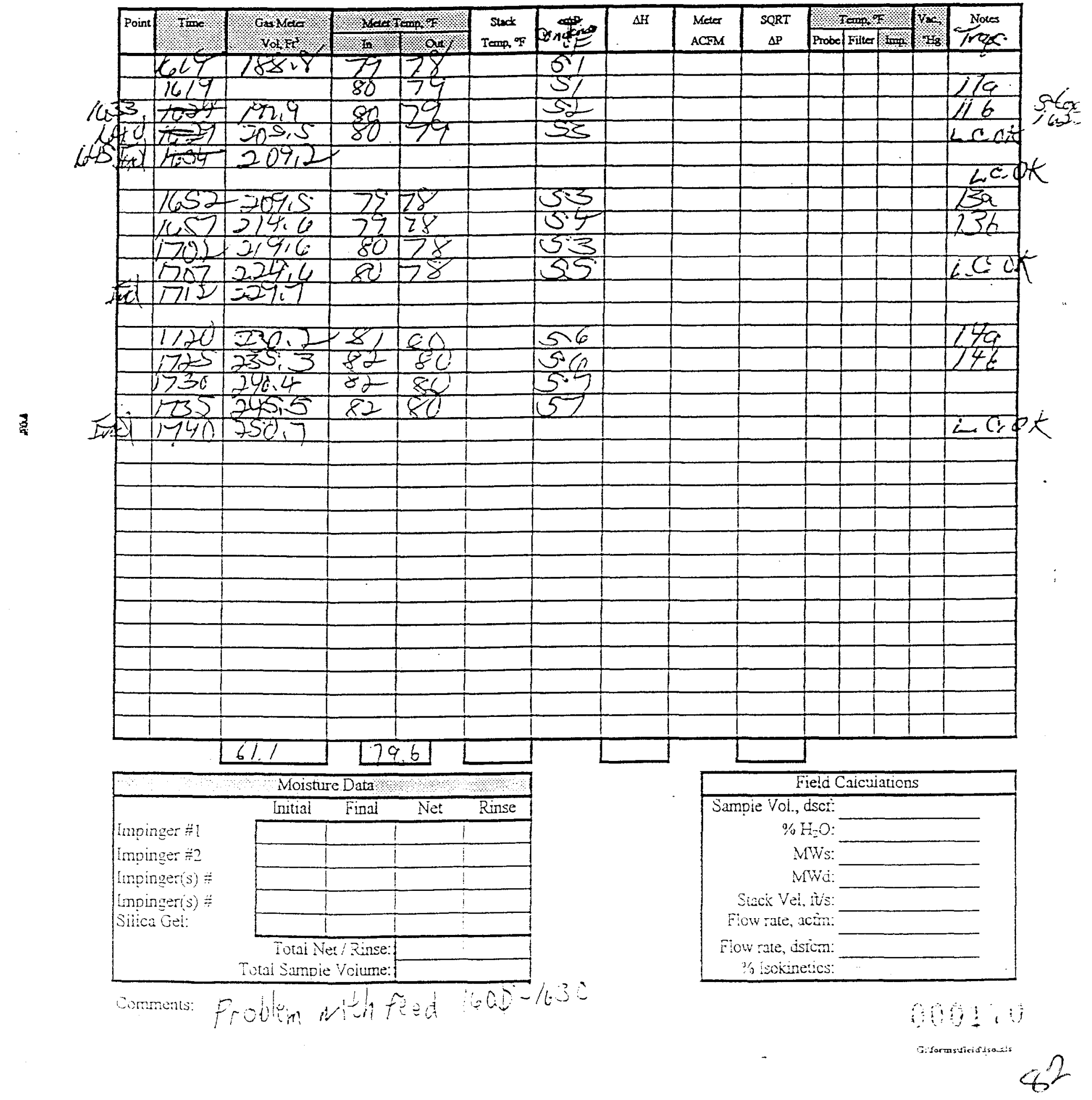



CARB Method 5/501/ Cyclonic

Facility: LLNL MSO

Date: 8.26-99 Method: 0030 Facility Information

Location: Filter Outles

Port Dia. Depth:

Fitting Type: Length:

Stack Dia TSXS Area:

Upstream Dist.

Downstream Dist.

\section{Equipment}

Meter *: 2400 Pitot $\#$ : PBar

Meter Yd: Pitot Cp: $\$ 6 \mathrm{O}_{2}$ Ass.

$\Delta H @:$

Filter \#:

Probe \#:

Initial LC:
Noz \#:

Noz Dia.

$96 \mathrm{CO}_{2}$ Ass.

$\% \mathrm{H}_{2} \mathrm{O}$ Ass.

Test Mins.

CFM @_

Run \#: I

Sampiing Data

P Static:

$\$ 6 \mathrm{O}_{2}$ Actuai:

$\$ 6 \mathrm{CO}_{2}$ Actual:

Pitot LC:

Personnel:

CFM@ $@$

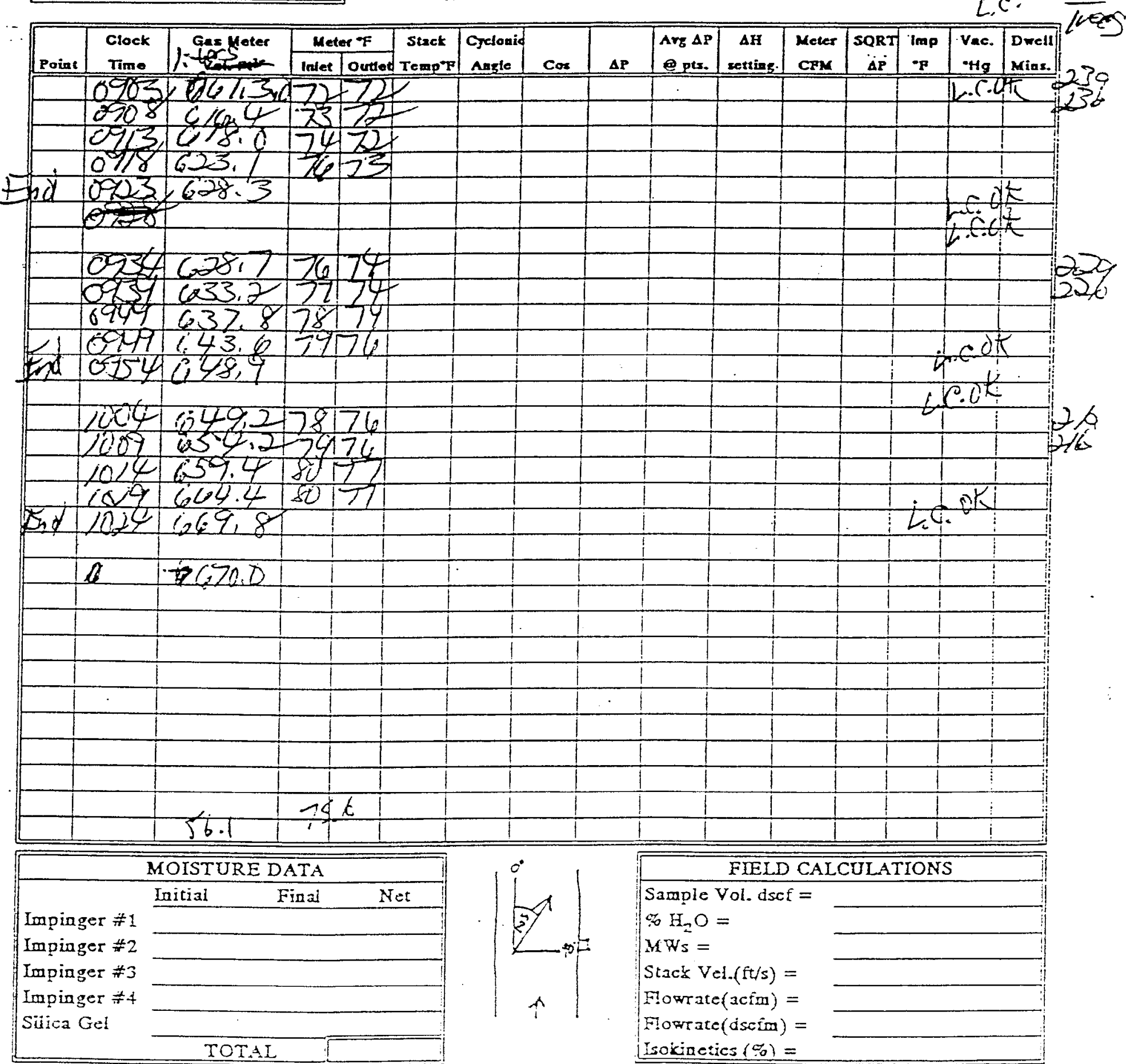

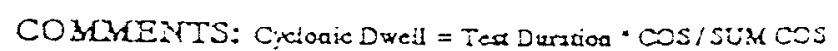

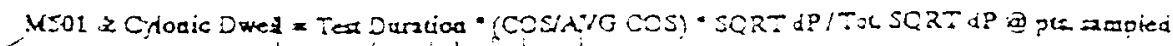

Trops 


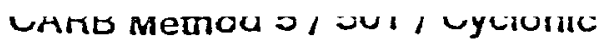

Facility:LLNL MSO Date: $8+26.96$ Method: 0036

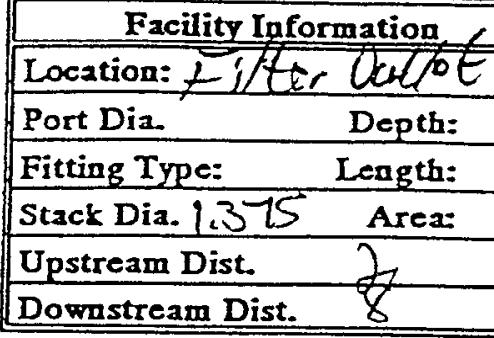

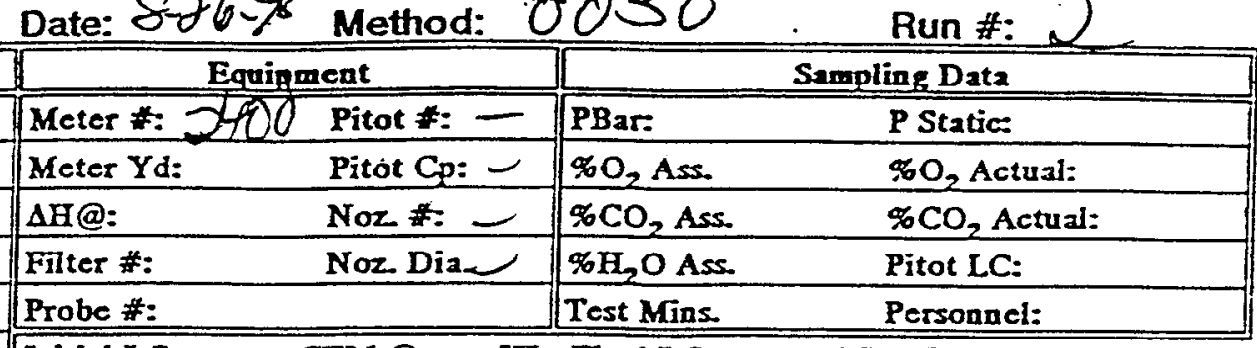
Initial LC: CFM @ _Hg Final LC: CFM @ "Hg

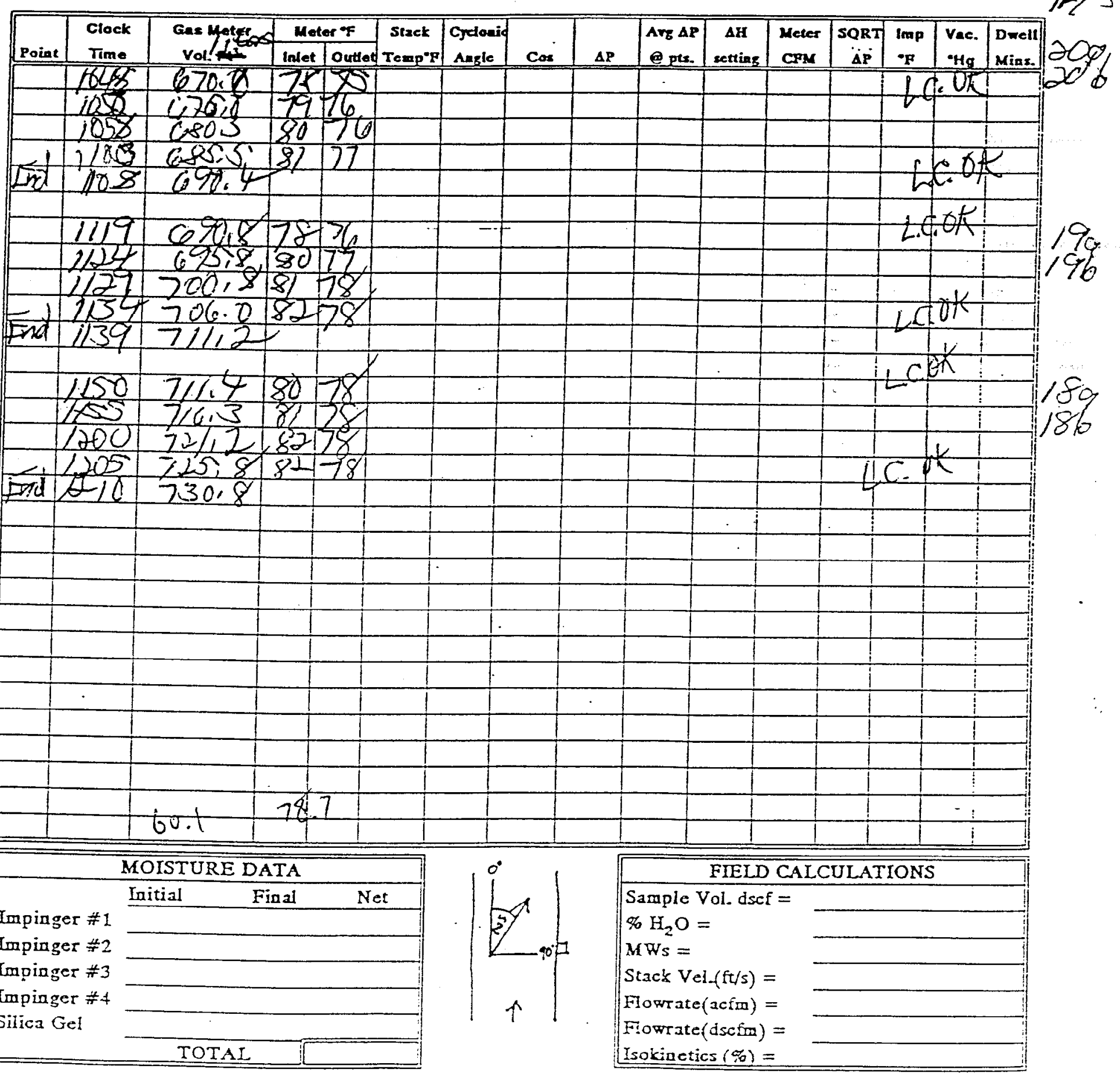

COMARENTS: Cytioaic Dweil $=$ Test Dursion $\cdot$ Cos $/$ SLM COS

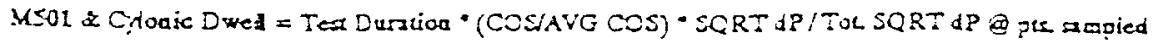


BEST ENVIRONMENTAL, INC.

San Leandra, CA (510)278-4011

Isokinetic Sampling Data Sheet (Method 0030 )

Faciity: LLNL MSO $\frac{\text { Date: } 8 \text { - } 698 \text { Run \#: } 3}{\text { Equipment Information }}$

Location Fifter liutlot

Port Dia:

Fitting:

Depth:

Stack Dia:

Leagth:

Downstream from disturbance:

Intalse_rav@

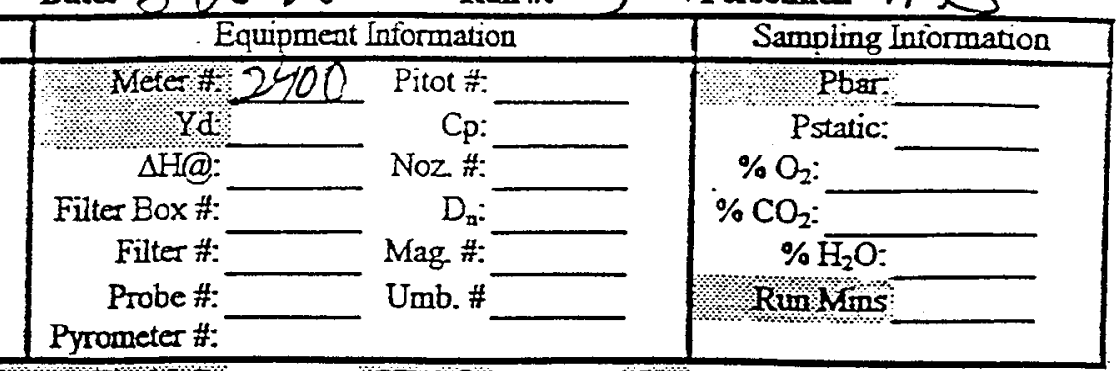

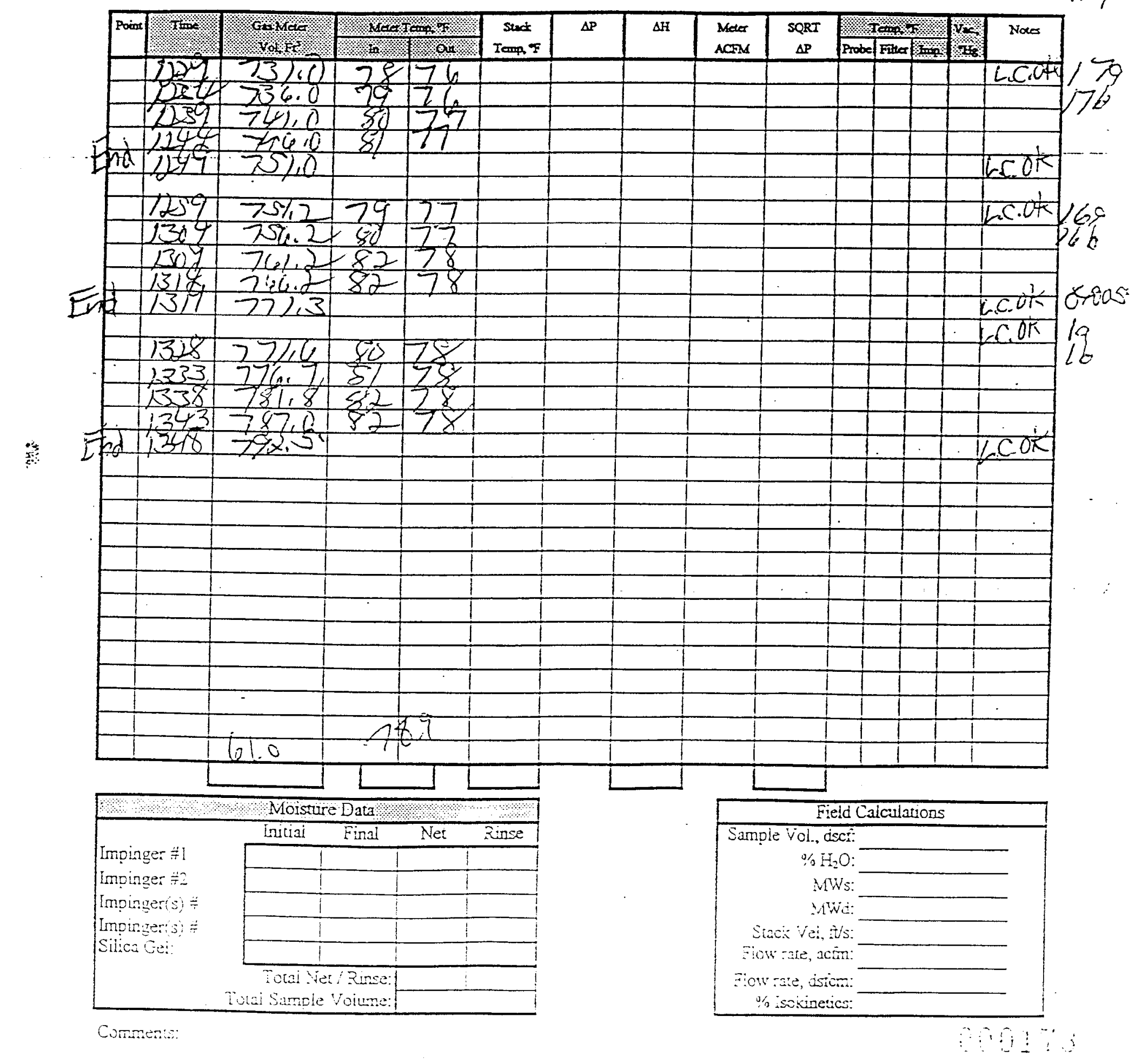




\section{Isokinetic Sampling Data Sheet (Method 0030 )}

Facility: $\angle L N L M S O$

Location (dastyst Datiot)

Port Dia:

Fitting:

Stack Dia:

Upstream Area:

Upstream from disturbance.

Downstream from disturbance:

Tillogls:

ब्रमशू.
Date: $8 \times 1,99$

Equipment Information

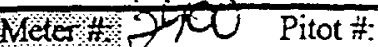

$1 \mathrm{Yd}$

4H@:

Filter Box \#:

Fiiter \#:

Probe \#:

Pyrometer \#:

18 Fing

Noz $\frac{1}{\pi}$

$\mathrm{D}_{\mathrm{a}}$ :

Mag. \#:

Umb. \#

3rata.
Run \#: $\%$

Personncl: OPIS

Sampling Information

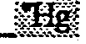

Pbar:

Pstatic:

$\% \mathrm{O}_{2}:$

$\% \mathrm{CO}_{2}:$

$\% \mathrm{H}_{2} \mathrm{O}$ :

Run

Pitot LC:

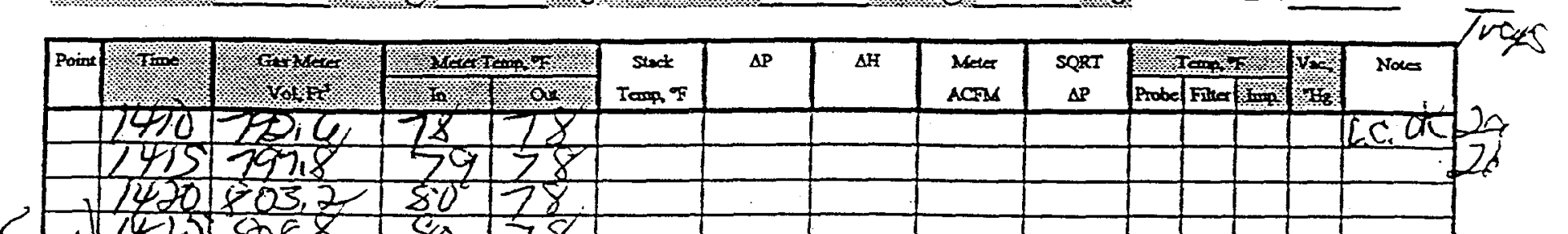

\begin{tabular}{|l|l|l|}
\hline & 1.15 & 505.8 \\
\hline 1430 & 813.7 \\
\hline
\end{tabular}

144005.280

1645

1750.025

सरे

सxal 1500

878.4

8279

$8 \times 80$

$15 \%$ 833\% $80 \quad 50$

\begin{tabular}{c|c|c|c}
\hline $515^{\circ}$ & 838,8 & 82 & 40 \\
15.00 & 843.6 & 82 & 80 \\
\hline 5.5 & 848.5 & 85 & 81
\end{tabular}

7. 1230823,3

82 80

tC.OK

La.0र जक

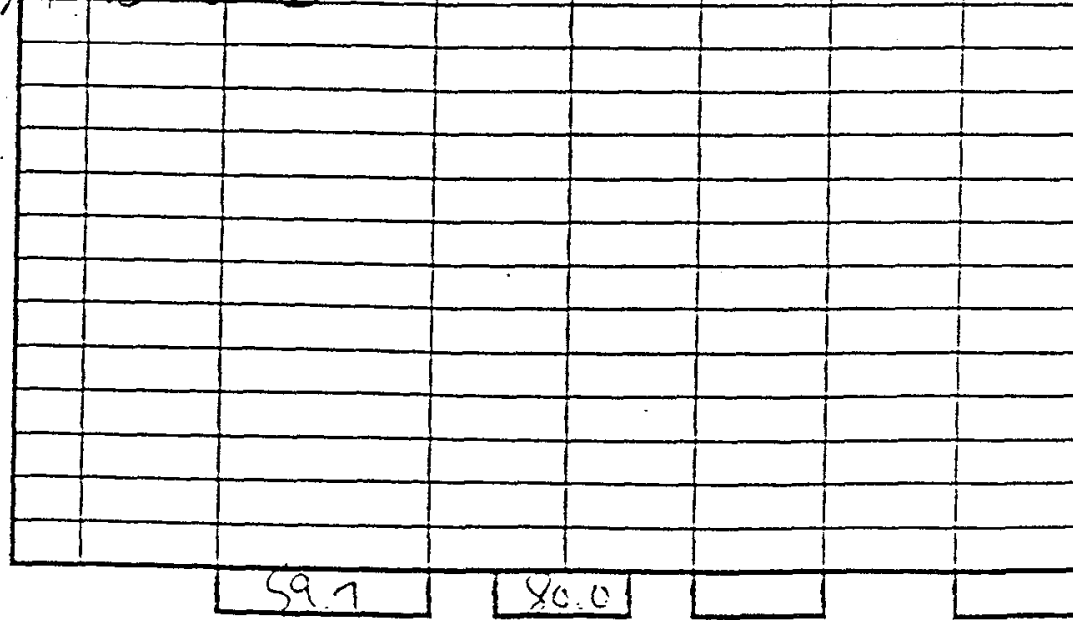

\begin{tabular}{|c|c|c|c|c|}
\hline ॰ & Mois & Data & 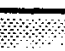 & \\
\hline & Initial & Final & Net & Rinse \\
\hline Impinger $\# 1$ & & & & \\
\hline Impinger $\approx 2$ & & & & \\
\hline Impinger(s) & & & & \\
\hline Lnpinger(s) & & & & \\
\hline Silica Ge!: & & & & \\
\hline & Tocal & TRinse: & & \\
\hline & 1 Samn & Jolume: & & \\
\hline
\end{tabular}

Comments: 


\section{Isokinetic Sampling Data Sheet (Method $5 / 114$ )}

Facility: $\angle L N L$

Date: $8 / / 8 / 98 \quad$ Run \#: $/$

Personnelake, P.R, RB, nw, OC

Facility Intormation

Location: EILTER OUTLET

Port Dia:

Depth:

Fitting:

Length:

Stack Dia: 1.375 Area:

Upstream from disturbance: -.. Equipment Intormation Sampling Information

\section{Pyrometer \#:}

Meter $A S I \pm g$ Pitot $\frac{1}{\pi}$ :

$\mathrm{10} \frac{.9593}{1.684} \mathrm{Cp}: .91$

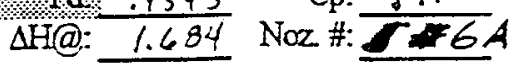

Filter Box \#: $\frac{1.684}{86} \quad D_{n}: \frac{.378}{12}$

Filter \#: 861 Mag \#:

Probe\#:—Umb. \#

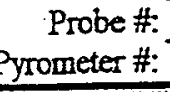

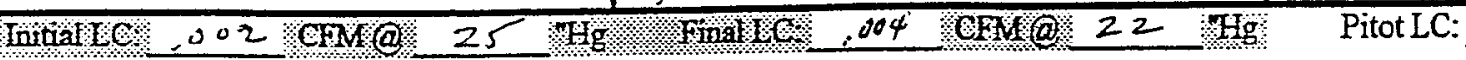

\begin{tabular}{|c|c|c|c|c|c|c|c|c|c|c|c|c|c|c|}
\hline \multirow[t]{2}{*}{ Point } & \multirow{2}{*}{ \%row } & \multirow{2}{*}{$101010=1$} & \multicolumn{2}{|c|}{ atec lomp } & \multirow{2}{*}{$\begin{array}{c}\text { Stack } \\
\text { Toun } \%\end{array}$} & \multirow[t]{2}{*}{$\Delta P$} & \multirow[t]{2}{*}{$\Delta \mathrm{H}$} & \multirow{2}{*}{$\begin{array}{l}\text { Meter } \\
\text { ACIM }\end{array}$} & \multirow{2}{*}{$\begin{array}{c}\text { SQRI } \\
\Delta P \\
\end{array}$} & \multicolumn{3}{|c|}{ Tonow } & \multirow{2}{*}{ Y.: } & \multirow[t]{2}{*}{ Nokes } \\
\hline & & & $8 \mathrm{n}$ & or. & & & & & & Probe & Filter & 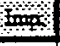 & & \\
\hline 1 & 10.21 & 751.413 & 65 & 6.4 & 106 & .167 & 3.159 & 1.002 & .409 & & & & 10 & \\
\hline 2 & $10: 34: 30$ & 754.0 & 75 & 65 & 194 & 195 & 3.681 & 1.035 & .442 & & & & 12 & \\
\hline 3 & 10.42 & 267.3 & 83 & 70 & 196 & .19 & 3.619 & 1.003 & .436 & & & & 12 & \\
\hline 4 & $15: 49: 36$ & 774.6 & 89. & 75 & 197 & .19 & 3.651 & 1.043 & .436 & & - & $=$ & 12 & \\
\hline 51 & jo: 57 & 793.9 & 92 & 30 & 201 & .18 & 3.463 & 1.064 & .424 & & & $\therefore$ & 11 & \\
\hline 6 & $11: 04: 30$ & 792.4 & 93 & 83 & 203 & .185 & 3.561 & 1.086 & .430 & & & & 11 & \\
\hline 7 & $11: 12$ & 386.7 & 95 & 86 & 207 & .205 & 3.941 & 1.144 & .453 & & & & 125 & \\
\hline 9 & $11: 19: 30$ & $8 \in 9.4$ & 94 & 97 & 210 & .22 & 4.213 & 1.194 & .469 & & & & 13 & \\
\hline $\operatorname{sic} e$ & $11: 27$ & 818.496 & & & & & & & & & & & & \\
\hline & & & & & & & & & & & & & & \\
\hline & & & & & & & & & & & & & & \\
\hline & & & & & & & & & & & & & & \\
\hline & & & & & & & & & & & & & & \\
\hline & & & & & & & & & & & & & & \\
\hline & & & & & & & & & & & & & & \\
\hline & & & & & & & & & & & & & & \\
\hline & & & & & & & & & & & & & & \\
\hline & & & & & & & & & & & & & & \\
\hline & & & & & & & & & & & & & & \\
\hline & & & & & & & & & & & & & & \\
\hline & & & & & & & & & & & & & & \\
\hline & & & & & & & & & & & & & & \\
\hline & & & & & & & & & & & & & & \\
\hline & & & & & & & & & & & & & & \\
\hline & & & & & & & & & & & & & & \\
\hline & & & & & & & & & & & & & & \\
\hline & & & & & & & & & & & & & & \\
\hline & & & & & & & & & & & & & & \\
\hline & & & & & & & & & & 1 & & & & \\
\hline 1 & & 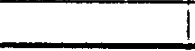 & 1 & & & & & & & $i$ & & & & \\
\hline & & $\dot{47.073}$ & 81 & & 199,1 & & So, 6 & & 37 & & & & & \\
\hline & & Moistur & Data: & 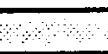 & 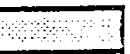 & & & & & ield 0 & Caicili & arion & & \\
\hline & & Enitial & Final & Ne! & Rinse & & & Sam & le vici., & dset: & $\therefore$ & 2.9 & 66 & \\
\hline Impir & nger $\ddot{\# 1}$ & 100 & 1.571 & & & & & & 名年 & $\therefore=0$ & & $E$ & 5 & \\
\hline Inpir & nger $=2$ & 100 & 1031 & & & & & & & Civs: & & & & \\
\hline Linpir & nger $(s)=$ & 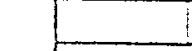 & 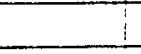 & & & & & & & livid: & & & & \\
\hline Impir & $\operatorname{nger}(s) \div$ & 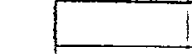 & 1 & & & & & & $a c i$ & : is: & & & & \\
\hline & a Gei: & 01 & 17.1 & & & a 1 & & & vinte gy & acin: & & & & \\
\hline & & Tota & /Rince: & & & & & Fio & tare is & sicm: & 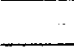 & & & \\
\hline & & Total Samcie & Volume: & Qin & & & & & 6 Schine & exics: & & & & \\
\hline
\end{tabular}

Comments: ille ins ive 
BEST ENVIRONMENTAL, INC.

\section{Isokinetic Sampling Data Sheet (Method $5 / 114$ )}

Facility: LAWREACE LUERmoret Date: 8-18-98 Run \#: 2 Personnel:

\begin{tabular}{|c|c|c|c|c|}
\hline \multicolumn{2}{|l|}{ Facility Information } & \multicolumn{2}{|c|}{ Equipment Information } & Sampling Information \\
\hline Location $B A C$ HO OSE & OUTLET & $\mathrm{Meter}^{\#}$ : A51-48 & Pitot \#: $M I N l$ STD. & Pbas $29-9$ \\
\hline Port Dia: & & $10 \%, 9593$ & $\mathrm{Cp}: .94$ & Pstatic: -11.5 \\
\hline Length: & & $\Delta \mathrm{H} @: 1.684$ & Noz \#: & $\% \mathrm{O}_{2}:$ \\
\hline Stack Dia: 1.375 Area: & 0.01 & Filter Box \#: $\frac{2}{987}$ & 378 & $\% \mathrm{CO}_{2}: \frac{3}{5}$ \\
\hline Upstream from disturbance: & $<8$ & Filter \#: 882 & Mag. \#. & $\% \mathrm{H}_{2} \mathrm{O}: 5.5$ \\
\hline Downstream from disturbance: & $<8$ & $\begin{array}{l}\text { Probe \#: } \\
\text { Pyrometer \#: }\end{array}$ & Umb. \# & Rug Kins \\
\hline
\end{tabular}

\begin{tabular}{|c|c|c|c|c|c|c|c|c|c|c|c|c|}
\hline \multirow[t]{2}{*}{ Point } & \multirow[t]{2}{*}{10} & \multirow{2}{*}{ orsoro } & \multicolumn{2}{|c|}{ Wetch Tenp 1} & \multirow{2}{*}{$\begin{array}{c}\text { Stuct } \\
\text { Temp of }\end{array}$} & \multirow[t]{2}{*}{$\Delta \mathbf{P}$} & \multirow[t]{2}{*}{$\Delta \mathrm{H}$} & \multirow{2}{*}{$\begin{array}{l}\text { Meter } \\
\text { ACSM }\end{array}$} & \multirow{2}{*}{$\begin{array}{l}\text { SQRI } \\
\Delta P\end{array}$} & \multirow{2}{*}{\multicolumn{2}{|c|}{ Probel pithed }} & $\mathrm{Xu}$ \\
\hline & & & Hho & 04 & & & & & & & & 8 \\
\hline
\end{tabular}

\begin{tabular}{|l|l|l|l|l|l|l|l|l|l|}
\hline$i$ & $12: 45$ & 819.745 & 69 & 69 & 223 & .19 & 3.490 & 1.657 & .424 \\
\hline 2 & 13.5230 & 323.0 & 78 & 71 & 231 & .175 & 3.414 & 1.051 & .418 \\
\hline 3 & $13: 00$ & 836.0 & 87 & 74 & 233 & 19 & 3.737 & 1.104 & 436 \\
\hline
\end{tabular}

\begin{tabular}{|l|l|l|l|l|l|l|l|l|l|l|}
\hline 4 & $13: 0.7: 30$ & 844.7 &.-42 & .80 & 235 & .19 & 3.737 & 1.104 & .436 \\
\hline & $13: 15$ & 853.214 & .436 \\
\hline
\end{tabular}

\begin{tabular}{|l|l|l|l|l|l|l|l|l|l|}
5 & $13: 15$ & 853.2 & 90 & 36 & 233 & .195 & 3.332 & 1.136 & 442 \\
\hline & 13.2236 & 361.9 & 93 & 86 & 240 & &
\end{tabular}

\begin{tabular}{|l|l|l|l|l|l|l|l|l|l|}
\hline 6 & $13: 22: 30$ & 361.9 & 98 & 86 & 240 & 19 & 3.779 & 1.122 & .436 \\
\hline
\end{tabular}

\begin{tabular}{|l|l|l|l|l|l|l|l|l|l|}
\hline 7 & $13: 30$ & 876.6 & 100 & 89 & 243 & .221 & 4.476 & 1.222 & .474 \\
\hline
\end{tabular}

\begin{tabular}{|l|l|l|l|l|l|l|l|l|l|}
8 & $13: 37: 36$ & 879.3 & 102 & 91 & 2.15 & .20 & 3.931 & 1.156 & .447 \\
\hline
\end{tabular}

mpinger $\# 1$

inpinger

Lmpinger $(s)=$

impinger (s) $\#$

Silica Gei:
$43.321][95.5][236.6$

\begin{tabular}{|c|c|c|c|}
\hline \multicolumn{4}{|c|}{ Moisture Data: } \\
\hline Initial & Final & Net & Rinse \\
\hline 10 & $163^{x}$ & 33 & \\
\hline 100 & 109 & $\vec{i}$ & \\
\hline & & & \\
\hline & & & \\
\hline 20 & 213.4 & 13. & \\
\hline
\end{tabular}

$13413.61 \quad 100=842$

Total Sample Voiume: $\sigma x^{a} y$

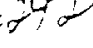

3315

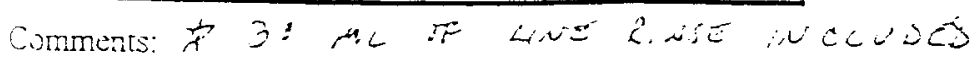

\section{.439}

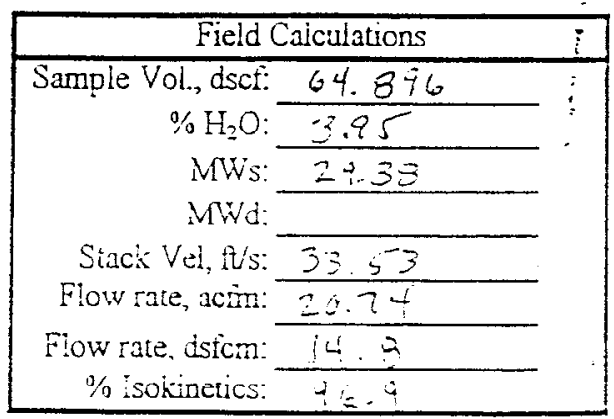




\section{Isokinetic Sampling Data Sheet (Method $5 / 114$ )}

Facility: LAWRENCE LIVERMORE Date: 8-18-93 Run \#: 3

Personnel: $J M-D C-P R-M \omega-\alpha_{i}$ Loation. BAGHOUJE OUTLET

Port Dia:

Depth: Fitting:

Length:

Stack Dia: $\overline{1.375}$ Area: $\overline{0.01}$ Upstream from disturbance: $\frac{0.01}{<9}$

Downstream from disturbance: $<8$

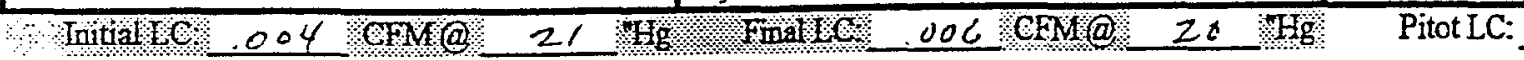

Equipment Intormation

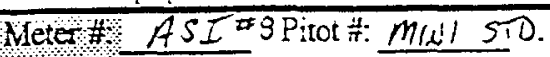

$1 \mathrm{~d} .9593 \quad \mathrm{Cp}: .99$

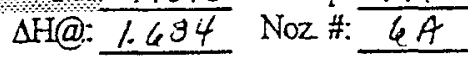

Filter Box \#: $\frac{16}{2} \quad D_{0}: \frac{373}{372}$

Filter \#: 0245 Mag. \#:

Probe \#: Umb. \#

Pyrometer \#:
Sampling Information

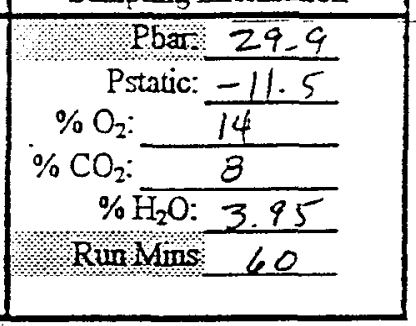

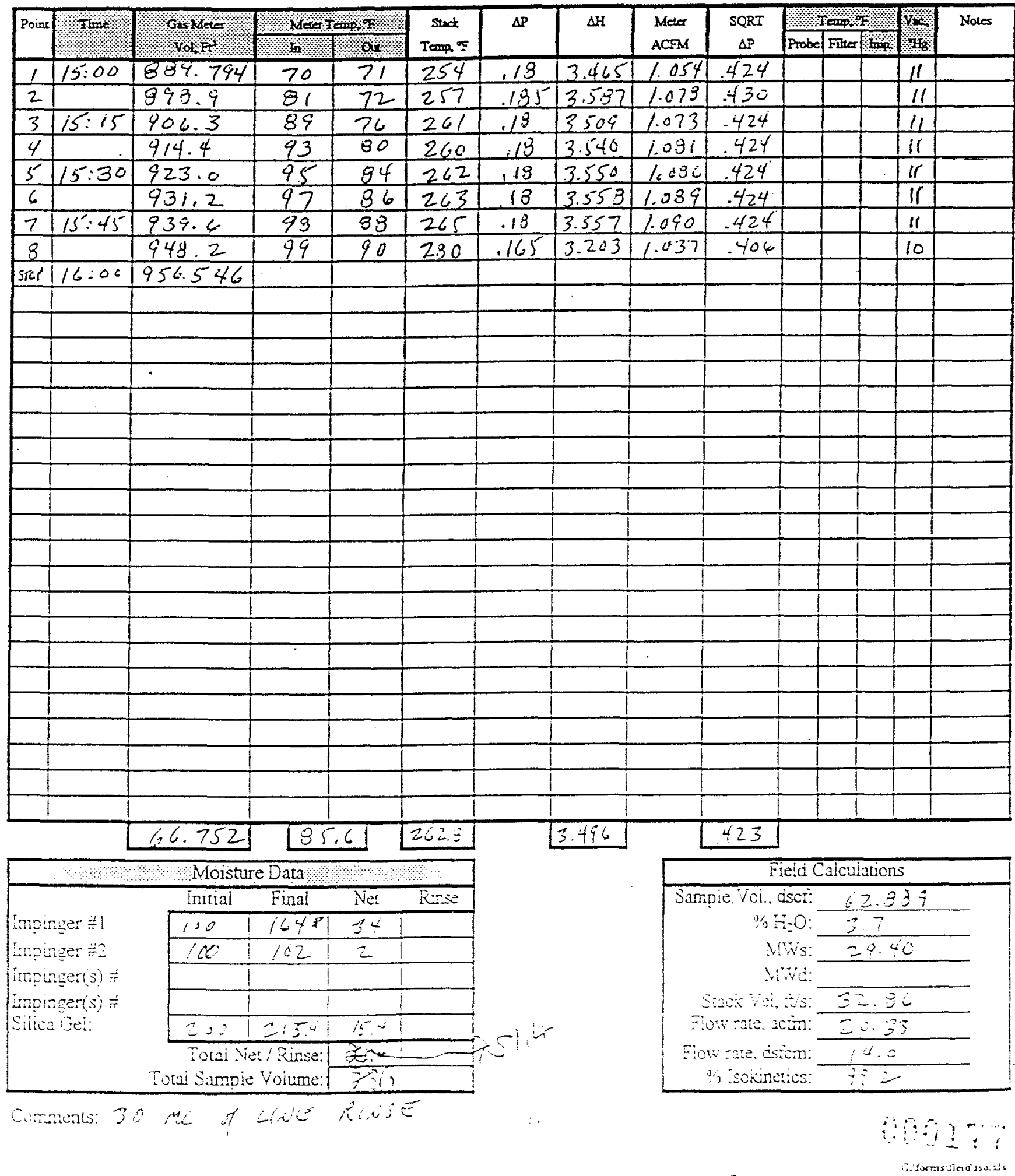


BESI ENVIRONMLENTAL, INC.

Sea Leandro, CA $(510) 278-4011$

\section{Isokinetic Sampling Data Sheet (Method $5 / 114$ )}

Facility: $\angle C N L$

Date: $8 / 19 / 98$ Run \#: $\%$ Personnel: $D C$

Equipment Information

Sampling Information

Port Dia: 1 Depth:

Fitting: $\frac{\theta}{4}$ Length:

Stack Dia: $4^{\prime \prime}$ Area:

Upstream from disturbance:

Downstream from disturbance:

Meles $<51-1$ Pitot $7:$ Sth

1d: 1.0039 cp: $\frac{199}{2.196}$

$\Delta H @: \frac{2196}{2}$ Noz \#: 41

Filter Box $\#: \frac{2}{-} \quad D_{n}: \frac{.752}{.22}$

\& Filter \#: $\overline{822}$ Mag. \#:

Probe \#: - Umb. \#

Pyrometer \#: -

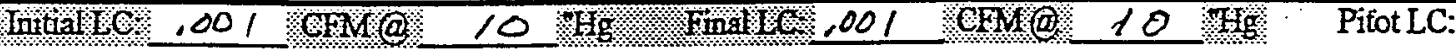

\begin{tabular}{|c|c|c|c|c|c|c|c|c|c|c|c|c|c|c|}
\hline \multirow{2}{*}{ Poimt } & \multirow[t]{2}{*}{ tran } & \multirow{2}{*}{$1041 \%$} & \multicolumn{2}{|c|}{ Nator tonp } & \multirow{2}{*}{$\begin{array}{c}\text { Stact } \\
\text { Temp. F }\end{array}$} & \multirow[t]{2}{*}{$\Delta P$} & \multirow[t]{2}{*}{$\Delta \mathrm{FI}$} & \multirow{2}{*}{$\begin{array}{l}\text { Meter } \\
\text { ACrM }\end{array}$} & \multirow{2}{*}{$\begin{array}{c}S Q R T \\
\triangle P\end{array}$} & \multicolumn{3}{|c|}{ Thong } & \multirow{2}{*}{$1 \%$} & \multirow[t]{2}{*}{ Noles } \\
\hline & & & \% & ax & & & & & & Probe Fi & Fitter & thong & & \\
\hline & 933 & 267.077 & 88 & 74 & 385 & .005 & 1.8 & .69 & & & & & 6 & \\
\hline & & 270.5 & 96 & 78 & 385 & .004 & 1.5 & 62 & & & & & 5 & \\
\hline \multirow[t]{2}{*}{10} & 943 & 273.6 & 48 & 79 & 420 & .004 & 1,4 & .61 & & & & & 5 & \\
\hline & & 276.7 & 100 & 80 & 420 & .004 & 1,4 & 61 & & & & & 5 & \\
\hline \multirow[t]{2}{*}{20} & 953 & 279.8 & 104 & 84 & 401 & .004 & 1.5 & 162 & & & & & 5 & \\
\hline & & 282.9 & 109 & 86 & 401 & .007 & 1.5 & .63 & & & & & 5 & \\
\hline \multirow[t]{2}{*}{20} & 1003 & 286.1 & 112 & 88 & 401 & .004 & 1,5 & 163 & & $\cdots$ & & & 5 & \\
\hline & 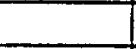 & 289,3 & 112 & 83 & 401 & .004 & 1.5 & .63 & & 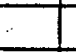 & & & 5 & \\
\hline \multirow[t]{2}{*}{40} & 1013 & 292.4 & 114 & 90 & 401 & 1004 & 1.5 & .63 & & $\cdots$ & & & 5 & \\
\hline & & 295.6 & 116 & 92 & 401 & .004 & 1.5 & 63 & & $\cdots$ & & & & \\
\hline \multirow[t]{2}{*}{501} & 1023 & 298.8 & 178 & 94 & 401 & $\infty 04$ & 1.5 & .64 & & & & & & \\
\hline & & 301.9 & 119 & 95 & 401 & 009 & 1.5 & 164 & & & & & & \\
\hline \multirow[t]{2}{*}{ Exp } & 1033 & 305.062 & & & & & & & & & & & & \\
\hline & & & & & & & & & & & & & & \\
\hline & & & & & & & & & & & & & & \\
\hline & & & & & & & & & & & & & & \\
\hline & & & & & & & & & & & & & & \\
\hline & & & & & & & & & & & & & & \\
\hline & & & & & & & & & & & & & & \\
\hline & & & & & & & & & & & & & & \\
\hline & & & & & & & & & & & & & & \\
\hline & & & & & & & & & & $\cdots$ & & & & \\
\hline & & & & & & & & & & & & & & \\
\hline & & & & & & & & & & $\therefore$ & & & & \\
\hline & & & & & & & & & & & & & & \\
\hline & & & & & & & & & & & & & & \\
\hline & & & & & & & _ & & & & & & & \\
\hline & & & & & & & & & & & & & & \\
\hline & & & & & & & & & & & & & & \\
\hline & & & & & & & & & & & & & & \\
\hline & & 37.925 & 96 & & 015 & & & & & & & & & \\
\hline & & Moistur & Data & & \& & & & & & ield C & alcul & ations & & \\
\hline & & Initial & Final & Ner & Rinse & & & Sam & e Vol, & dsef: & & & & \\
\hline Impin & ger $\left.\frac{4}{t 1}\right]$ & 100 & 98 & -2 & 70 & & & & & $\mathrm{I}_{2} \mathrm{O}:$ & & & & \\
\hline Inpin & 2ger $\frac{\dot{\pi} 2}{\pi}$ & 100 & 100 & & & & & & & LWs: & & & & \\
\hline Impin & $\operatorname{gger}(s) \nRightarrow$ & 1 & & 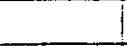 & & & & & & IWd: & & & & \\
\hline Impin & $\operatorname{lger}(s) \ddot{7}$ & 1 & & 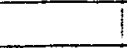 & & & & & $\cos V \mathrm{~V}$ & ids: & & & & \\
\hline Siites & Ge: & 2001 & 2091 & 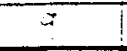 & & & & & $\checkmark$ rate, & $\operatorname{cin}:$ & & & & \\
\hline & & Tolai ive & / Rinse: & 201 & & & & Fo & rale, is & in: & & & & \\
\hline & & Total Sample & Voiune: & $1=19$ & & & & & isokin. & acs: & & & & \\
\hline
\end{tabular}

Comments: 
BEST ENVLRONMDENTAL, INC.

\section{Isokinetic Sampling Data Sheet (Method}

\begin{tabular}{|c|c|c|c|}
\hline Facility: LRWRENLE LVERMORÉ & Date: $8-26-98$ & Run \#: & Personnel: JM-RB \\
\hline Facility Information & Equipment & Information & Sampling Information \\
\hline Eocation / TLTER OUTLET & Meter H ASI 8 & Pitot $\#: M|L|$ STD & Pbar 29.9 \\
\hline $\begin{array}{l}\text { Port Dia: } \\
\text { Fitting: }\end{array}$ & 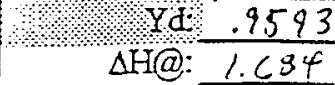 & Noz: $\frac{.99}{5 E}$ & $\begin{array}{l}\text { Pstatic: }-10.0 \\
\% \mathrm{O}_{2}:\end{array}$ \\
\hline $\begin{aligned} \text { Stack Dia: } & \frac{1.375}{3} \\
\text { Upstream from disturbance: } & \frac{0.01}{3}\end{aligned}$ & 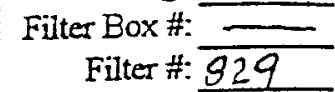 & $\begin{array}{l}D_{n}: 309 \\
\text { Mag. }\end{array}$ & $\begin{array}{l}\% \mathrm{CO}_{2}: \overline{ } \\
\quad \% \overline{\mathrm{H}_{2} \mathrm{O}: 5-0}\end{array}$ \\
\hline Downstream from disturbance: $>8$ & $\begin{array}{r}\text { Probe \#: }=- \\
\text { Pyrometer \#: }\end{array}$ & Umb. \# & Ram Mnns \\
\hline
\end{tabular}

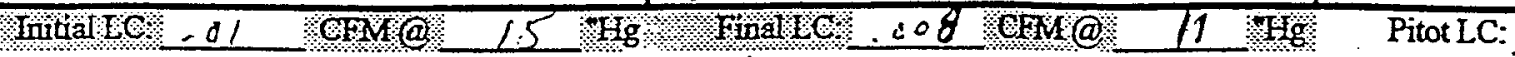

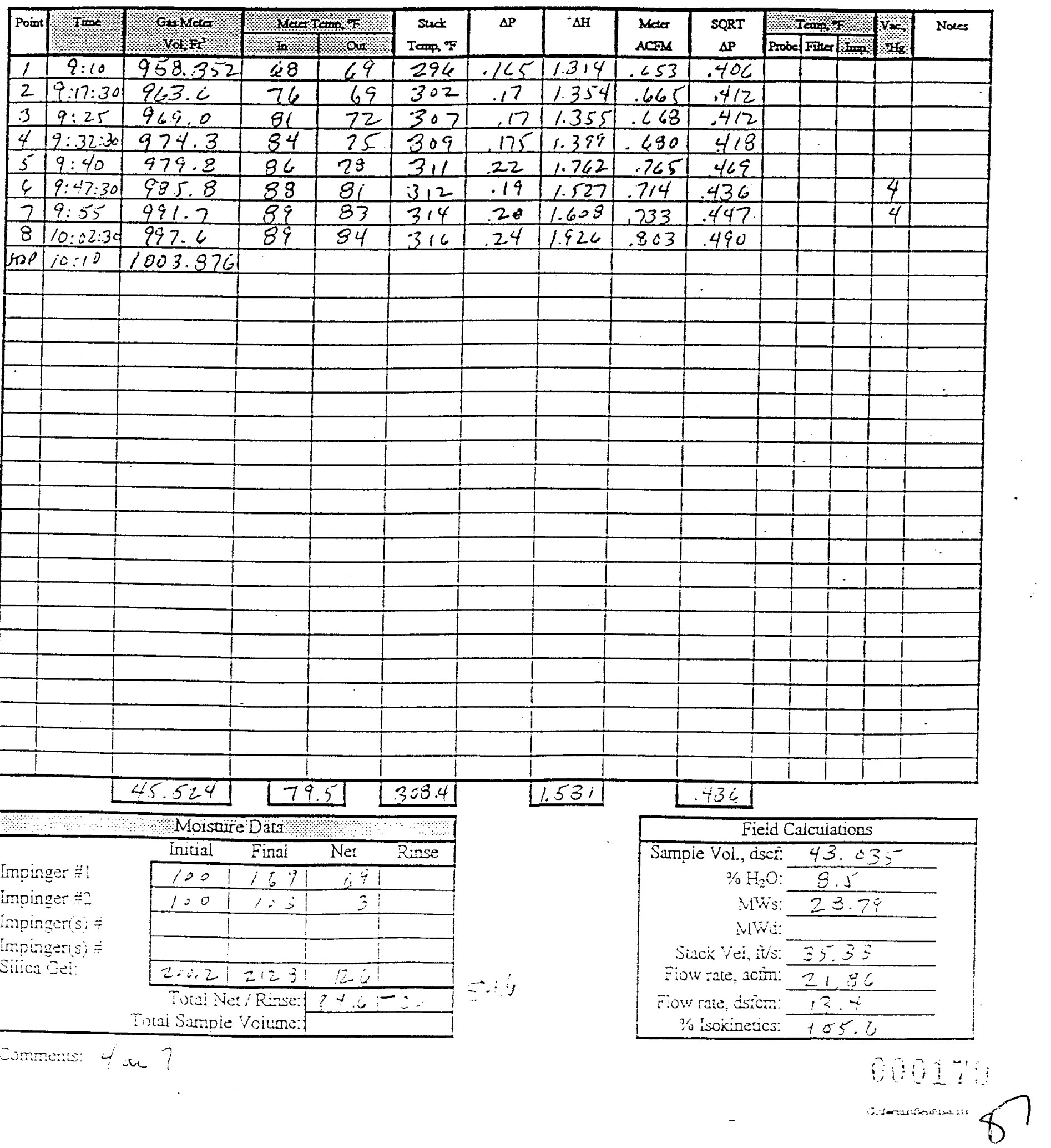




\section{Isokinetic Sampling Data Sheet (Method 17/114)}

Facility: LAWRENCE LIVERMARE Date: 8-26-98 RunH: 2 Personnel: SM-RB-DC-PR

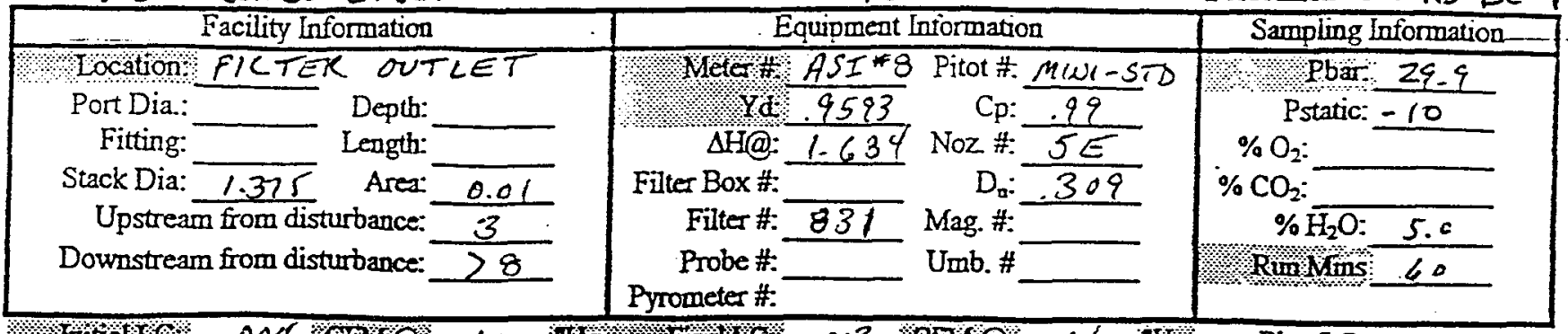

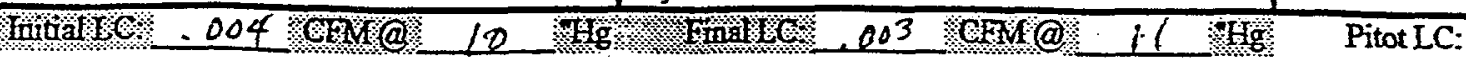

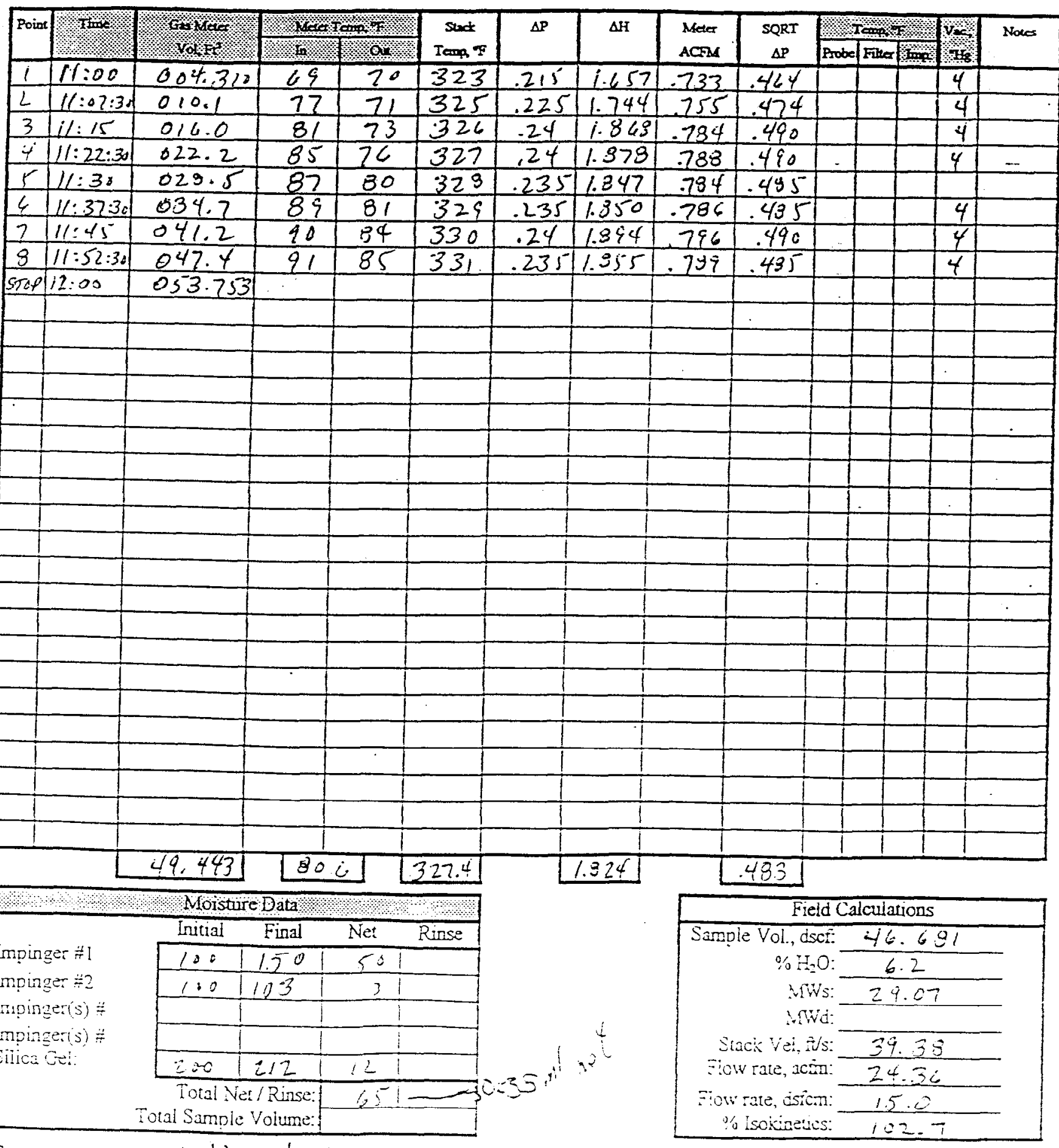

comments: 30 in line rinse 


\section{Isokinetic Sampling Data Sheet (Method $17 / 114$ )}

Facility: LAWRENCE LIVERMOKE Date: 8-24-98 Run H: 3

\begin{tabular}{|c|c|c|c|}
\hline Facility Intormation & Equipment & niormation & Sampling Information \\
\hline Locaton FICTER OUTLET & Meter $45 I \% 3$ & Pitot it: m/Ni STD & Pbar: 29.9 \\
\hline Port Dia: &., $9 d .9593$ & Cp: & Pstatic: -10.0 \\
\hline Length: & $\Delta \mathrm{H} @: 1.634$ & Noz H: & $\% \mathrm{O}_{2}: 9.75$ \\
\hline $\begin{aligned} \text { Stack Dia: } \overline{1.375} & \text { Area: } \\
\text { Upstream from disturbance: } & \frac{0.01}{3}\end{aligned}$ & $\begin{array}{l}\text { Filter Box } \#: \\
\text { Filter } \#=832\end{array}$ & 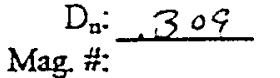 & $\begin{array}{c}\% \mathrm{CO}_{2}: \frac{7.5}{\mathrm{H}_{2} \mathrm{O}:} \\
\end{array}$ \\
\hline Downstream from disturbance: $>8$ & $\begin{array}{r}\text { Probe \#: } \\
\text { Pyrometer \#: }\end{array}$ & Umb. \# & Rur Mors 60 \\
\hline
\end{tabular}

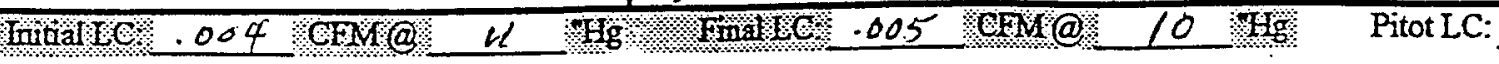

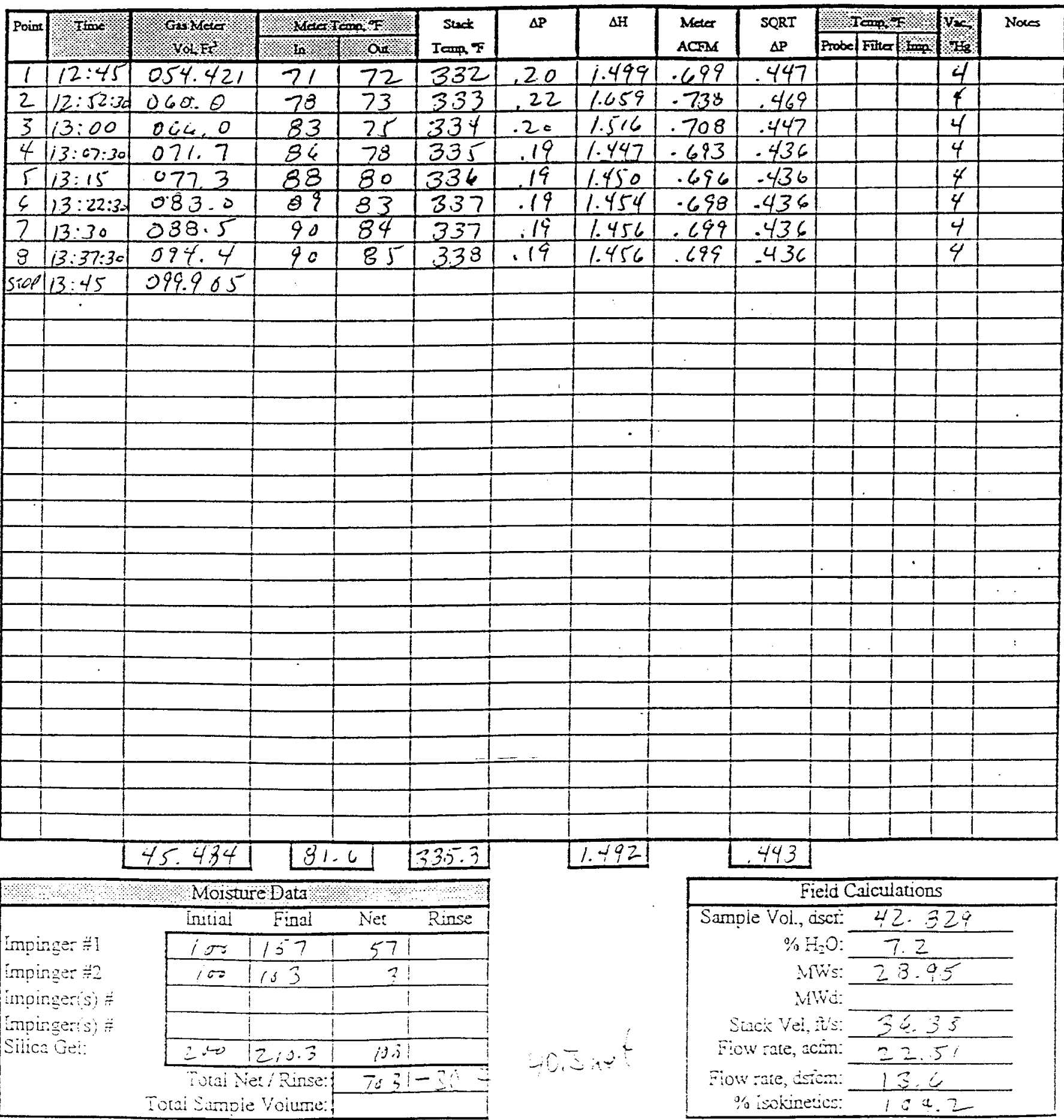




\section{Isokinetic Sampling Data Sheet (Method $M / 7 / 114)$}

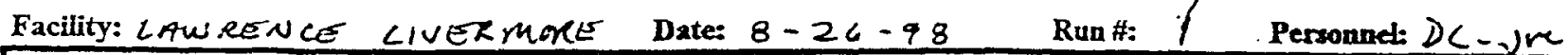

\begin{tabular}{|c|c|c|}
\hline Facility Information & Equipmeat Information & Sampling Information \\
\hline Tocation CATACYST OUTLET & Metor $i S I$ I Pitot & Pbar: \\
\hline Port Dia: $=$ & Yd 1.0039 & Pstatic: -2.2 .5 \\
\hline Leagth: & $\Delta H @: 2.196$ Noz H: & $\% \mathrm{O}_{2}$ \\
\hline Stack Dia: $4^{\prime \prime}$ Area: & Filter Box \#: $\angle S /-1 \quad D_{n}:$ & $\% \mathrm{CO}_{2}:$ \\
\hline Upstream from disturbance: & Filter: 828 & $\% \overline{\mathrm{H}_{2} \mathrm{O}}$ \\
\hline Downstream from disturbance: & $\begin{array}{l}\text { Probe \# - } \\
\text { Pyrometer \#: }\end{array}$ & Rino uns \\
\hline
\end{tabular}

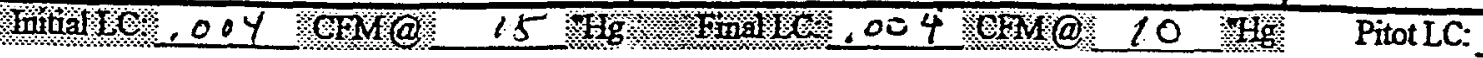

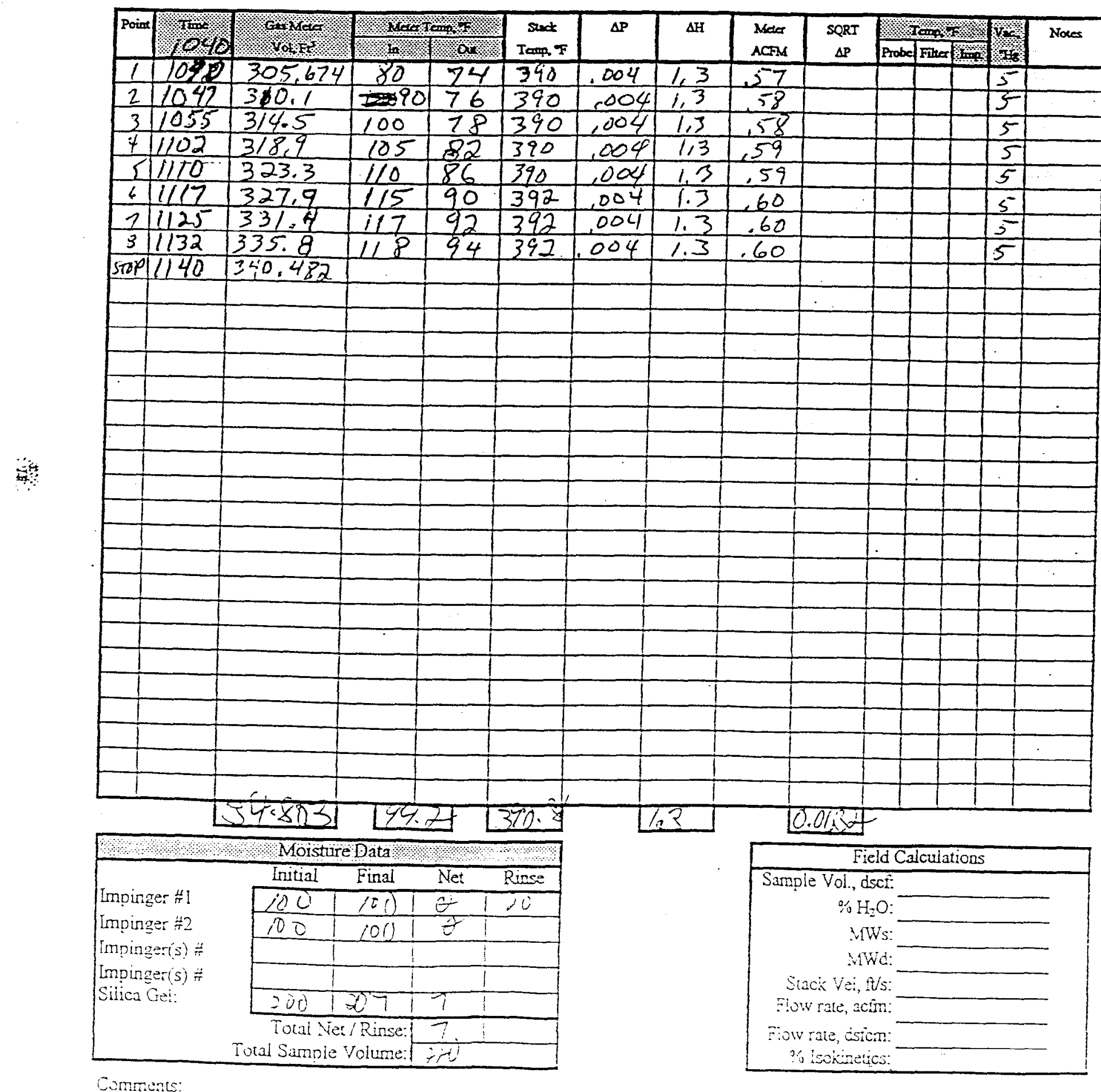

Comments: 


\section{Isokinetic Sampling Data Sheet (Method 26}

Facility: $\angle L N L M 50$ Date: $8-1298$ Run \#: / Personnel: $9 \times 3$

\begin{tabular}{|c|c|c|}
\hline Facility Information & Equipment Information & Sampling Infcrmatio \\
\hline Location Jaahoase catiet & Meter $1290 \mathrm{O}_{0}$ itot & $\mathrm{Pbar} 2 \% 7$ \\
\hline Port Dia: $1^{11}$ Depth: & Yd \&98/8 Cp: & Pstatic: \\
\hline Fitting: Leagth: & - Noz \#: & $\% \mathrm{O}_{2}:$ \\
\hline $\begin{array}{l}\text { Stack Dia: } / 1375 \\
\text { Upstream from disturbance: }\end{array}$ & $\begin{array}{r}\text { Filter Box } \#: \\
\text { Filter } \#:\end{array}$ & $\begin{array}{l}\% \mathrm{CO}_{2}: \\
\quad \% \overline{\mathrm{H}_{2} \mathrm{O}}\end{array}$ \\
\hline Downstream from disturbance: & $\begin{array}{r}\text { Probe \#: } \\
\text { Pyrometer \#: }\end{array}$ & Run Mims 60 \\
\hline
\end{tabular}

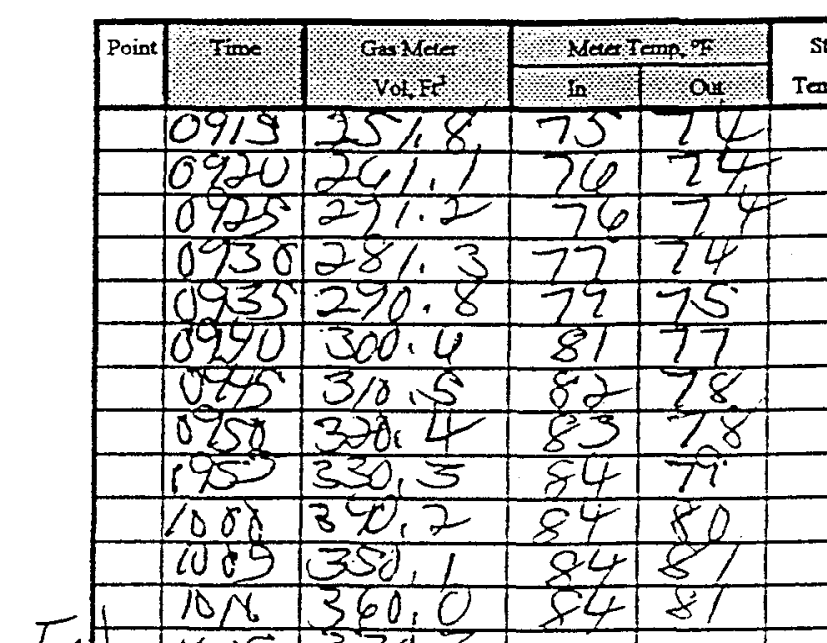

Fis 1015 : 37013

\begin{tabular}{|c|c|c|c|c|}
\hline \\
\hline & & & & \\
\hline & & & & \\
\hline & & & & \\
\hline & & & & i \\
\hline & & & & \\
\hline & & & & \\
\hline & & & & \\
\hline & & & & \\
\hline & & & & 1 \\
\hline & & & & \\
\hline & & & & \\
\hline & & & & 1 \\
\hline & & & & 1 \\
\hline & & & & 1 \\
\hline & & & & 1 \\
\hline & & & & $\div$ \\
\hline & & & & $i$ \\
\hline liters & 118.5 & 78 & 2.8 & - \\
\hline & Moistur & Data: & 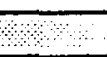 & ?. \\
\hline & Initial & Final & Net & Rinse \\
\hline Impinger $\neq 1$ & 1 & 1 & & 1 \\
\hline impinger & $!$ & 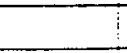 & & \\
\hline Lmpinger(s) \# & 1 & 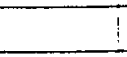 & & \\
\hline Impingers) $=$ & 1 & 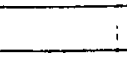 & & \\
\hline Silica Ge!: & 1 & 1 & & \\
\hline & $\begin{array}{l}\text { Totai Ne } \\
\text { Totai Sambie }\end{array}$ & $\begin{array}{l}\text { CRnce: } \\
\text { Yolume: }\end{array}$ & & \\
\hline
\end{tabular}

Comments: T/O conduntion in ine

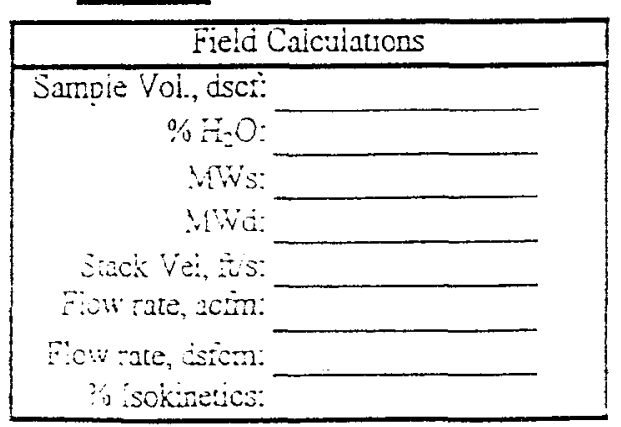


Isokinetic Sampling Data Sheet (Method 26

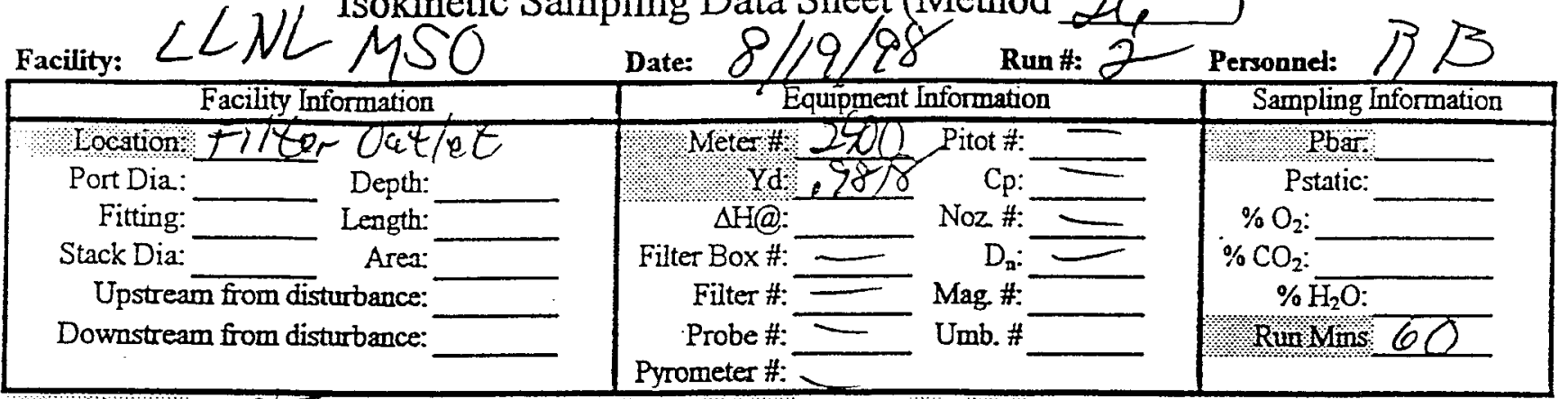

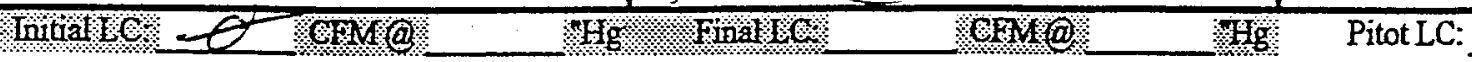

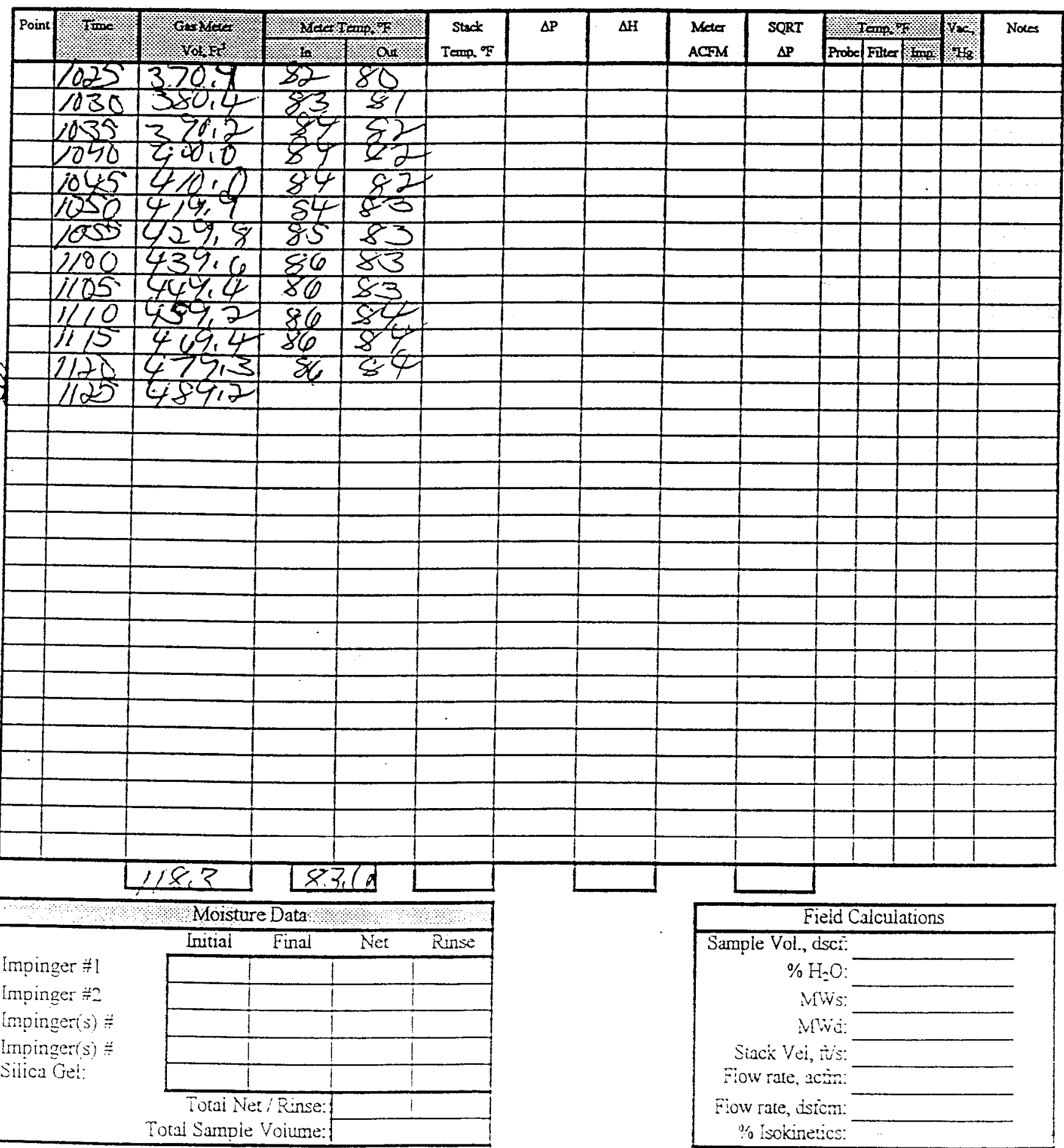

Cumments: 
Isokinetic Sampling Data Sheet (Method 24$)$

Facility: $\angle L U L M 5 O$ Date: 89.98 Run \#: 3 Personnel:

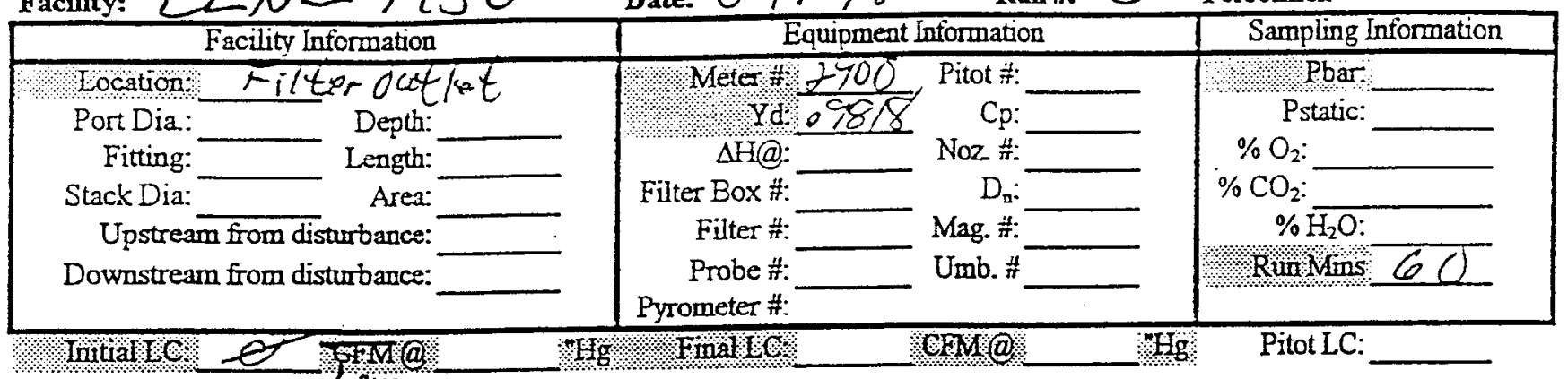

\begin{tabular}{|c|c|c|c|c|c|c|c|c|c|c|c|c|c|}
\hline \multirow{2}{*}{ Poins } & \multirow{2}{*}{ Ting } & \multirow{2}{*}{ oroluch } & \multicolumn{2}{|c|}{ 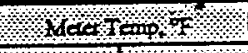 } & \multirow{2}{*}{$\begin{array}{c}\text { Stuck } \\
\text { Temop, of }\end{array}$} & \multirow{2}{*}{$\Delta \mathrm{P}$} & \multirow[t]{2}{*}{$\Delta H$} & \multirow{2}{*}{$\begin{array}{l}\text { Metrer } \\
\text { ACsMs }\end{array}$} & \multirow{2}{*}{$\begin{array}{l}\text { SQRT } \\
\Delta P\end{array}$} & \multicolumn{2}{|c|}{ Fromp $1 \%$} & \multirow{2}{*}{$4:$} & \multirow[t]{2}{*}{ Notes } \\
\hline & & & for & ons & & & & & & \begin{tabular}{|l|l|} 
Probe Filte \\
\end{tabular} & 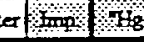 & & \\
\hline & 1131 & 584.8 & 87 & 831 & & & & & & & & & \\
\hline & $1 / 36$ & 994.4 & 85 & 83 & & & & & & & & & \\
\hline & 1,4 & $5.00 \% 2$ & 86 & 83 & & & & & & & & & \\
\hline & $14 c$ & $5,4 /$ & 86 & 83 & & & & & & & & & \\
\hline & 115 & 5200 & 84 & 83 & & & & & & & r & & \\
\hline & 1156 & $5.38^{2} \cdot 8$ & 86 & 84 & & & & & & & & & \\
\hline & 1201 & 548.6 & 86 & 84 & & & & & & & & & \\
\hline & $1) 86$ & 505.5 & 80 & 84 & & & & & & & & & \\
\hline & $2 \times 11$ & $56,8,4$ & 86 & 84 & & & & & & & & & \\
\hline & 1216 & 578,3 & 37 & ह4 & & & & & & & & & \\
\hline & 1121 & 588,3 & 87 & 65 & & & & & & & & & \\
\hline & 126 & 598,1 & 87 & क्रे & & & & & & & & & \\
\hline$x$ & $|2| 3 \mid$ & 607.9 & & & & & & & & & & & \\
\hline & & & & & & & & & & & & & \\
\hline & & & & & & & & & & & & & \\
\hline & & & & & & & & & & & & & \\
\hline & & & & & & & & & & & & & \\
\hline & & & & & & & & & & & & & \\
\hline & & & & & & & & & & & & & \\
\hline & & & & & & & & & & & & & \\
\hline & & & & & & & & & & & & & \\
\hline & & & & & & & & & & & & & \\
\hline & & & & & & & & & & & & & \\
\hline & & & & & & & & & & & & & \\
\hline & & & & & & & & & & & & & \\
\hline & & & & & & & & & & & & & \\
\hline & & & & & & & & & & & & & \\
\hline & & & & & & & & & & & & & \\
\hline & & & & 1 & & & & & & 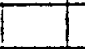 & & & \\
\hline & & & & & & & & & & $T$ & & & \\
\hline & & $118=1$ & E4 & $-\square$ & & & & & & & & & \\
\hline & 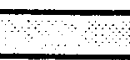 & Moistur & Data: & & 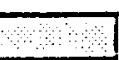 & & & & & Fieid C & alculaucns & & \\
\hline & & Initial & Final & Net & Rinse & & & $\overline{\operatorname{San}}$ & le Voi., & disct: & & & \\
\hline Imp̣in & ager $\ddot{=} !$ & & & $!$ & & & & & & $\mathrm{H}_{2} \mathrm{O}$ & & & \\
\hline Inpin & nger & & & 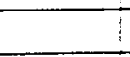 & & & & & & vivs: & & & \\
\hline Impin & lgeris) $=$ & 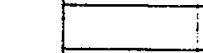 & & 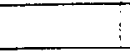 & & & & & & ivi: & & & \\
\hline Impin & 1geris : & 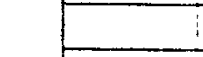 & & $\vdots$ & & & & & $\operatorname{acc} V \mathrm{~V} i$ & iss: & & & \\
\hline Silica & Gei: & 1 & & & & & & & w rate, & acin: & & & \\
\hline & & $\begin{array}{l}\text { Towi No } \\
\text { Totai Samoie }\end{array}$ & $\begin{array}{l}\text { Rinse: } \\
\text { iolume: }\end{array}$ & . & & & & & isate, is & $\begin{array}{l}\text { sicm: } \\
\text { etics: }\end{array}$ & & & \\
\hline
\end{tabular}

Cumments: 
BEST ENVIRONMENTAL, INC.

San Leandro, CA (510)278-4011

Isokinetic Sampling Data Sheet (Method

Facility: Date: $8 / 24 / 98$ Run \#: $1,2 * 3$ Personnel: $O C$

Facility Information

Location: Filtu outtet

Port Dia:

Depth:

Fitting:

Length:

Stack Dia:

Area:

Upstream from disturbance:

Downstream from disturbance:

Meter H: 8314 Pitot :

$\mathrm{Yd} \quad \mathrm{Cp}$ :

$\Delta H @:$

Noz \#:

Filter Box\#: $\longrightarrow \quad D_{\mathrm{n}}$ :

Filter

Probe \#: Umb. \#

Pyrometer \#:

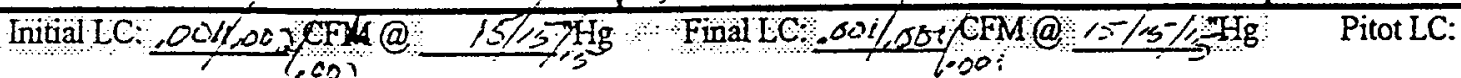

\begin{tabular}{|c|c|c|c|c|c|c|c|c|c|c|c|c|c|}
\hline \multirow{2}{*}{ Point } & \multirow{2}{*}{ Tine: } & \multirow{2}{*}{ rog dom } & \multicolumn{2}{|c|}{ Mech Trm, F } & \multirow{2}{*}{$\begin{array}{l}\text { Slack } \\
\text { Temp, of }\end{array}$} & \multirow{2}{*}{$\Delta P$} & \multirow[t]{2}{*}{$\Delta H$} & \multirow{2}{*}{$\begin{array}{l}\text { Meter } \\
\mathrm{ACPM}\end{array}$} & \multirow{2}{*}{$\begin{array}{l}\text { SQRT } \\
\Delta P\end{array}$} & \multicolumn{2}{|c|}{ Trap, $\%$} & \multirow{2}{*}{ Yos } & \multirow[t]{2}{*}{ Notes } \\
\hline & & & $3 \mathrm{~h}$ & oni & & & & & & Probe $/ \mathrm{FI}$ & Finter Imand & & \\
\hline & 1379 & $2,496.0$ & 78 & 78 & & & 201 & & & & & & \\
\hline & 1524 & & 80 & 78 & & & .1 & & & & & & \\
\hline & 1529 & & 80 & 79 & & & .1 & & & & & & \\
\hline & 1.534 & & 80 & 79 & & & 1 & & & & & & \\
\hline & 1539 & & 81 & 79 & & & & & & & & & \\
\hline & 1544 & & 81 & 79 & & & & & & & & & \\
\hline & 1549 & & 81 & 79 & & & & & & & & & \\
\hline & 1554 & & 81 & 99 & & & & & & & & & \\
\hline & 1559 & & 81 & 79 & & & & & & & & & \\
\hline & 1504 & 2582. & 81 & 79 & & & 1 & & & & & & \\
\hline & 1609 & & 81 & 79 & & & $x y$ & & & & & & \\
\hline & 1614 & & 81 & 79 & & & 4 & & & & & & \\
\hline & 1619 & 2620.7 & 4 & 21 & & & & & & & & & \\
\hline & & & 80 & 01 & & & & & & & & & \\
\hline & & H. 11 & 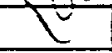 & & & & & & & & & & \\
\hline & & t & & & & & & & & & & & \\
\hline & & $26 x-7$ & & & & & & & & & & & \\
\hline & 1837 & 2633,0 & 80 & 79 & & & 1808 & 27700 & $83 / 83$ & & & & \\
\hline & 16047 & & 80 & 79 & & & 1818 & & $83 / 83$ & & & & \\
\hline & 57 & & 81 & 80 & & & & & & & & & \\
\hline & 07 & & 83 & 82 & & & 1833 & 283001 & $83 / 831$ & & & & \\
\hline & 17 & & 82 & 82 & & & 7848 & & & & & & \\
\hline & 27 & & 83 & 83 & & & 1858 & & 84184 & & & & \\
\hline & $1 \overline{337}$ & & 84 & 84 & & & 1908 & & $34 / 84$ & & & & \\
\hline & 1347 & 27680 & 84 & 84 & & & & 289081 & & & & & \\
\hline & & $\operatorname{Lis} 77$ & & 7 & & & & (1) & 830 & & & & \\
\hline & & & 810 & & & & 1 & & & & & & \\
\hline & & & 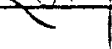 & & & & & - & & & & & \\
\hline & & & & & & & & & & & & & \\
\hline & & & & & & & & & & & & & \\
\hline & & & & & & & & & & & & & \\
\hline & & Moist & Data & & & & & & & ield C & alculation & & \\
\hline & & Initial & Final & Net & Rinse & & & $\overline{S a m}$ & ţie Vol., & dsct: & & & \\
\hline Impin & nger $\#$ ! & & & & & & & & & $=0:$ & & & \\
\hline Impin & nger $\# 2$ & & & & & & & & & W: & & & \\
\hline Impin & nger(s) $\ddot{*}$ & & & & & & & & & Wd: & & & \\
\hline Impin & nger(s) $=$ & & & & & & & & Eirck Vei, & $\mathrm{it} / \mathrm{s}:$ & & & \\
\hline Silica & Ge!: & & & & & & & & cw rate, ac & $\operatorname{cin}:$ & & & \\
\hline & & $\begin{array}{r}\text { Total } \\
\text { Total Samol }\end{array}$ & $\begin{array}{l}\text { Rinse: } \\
\text { Vciume: }\end{array}$ & & & & & & $\begin{array}{l}\text { wate, dst } \\
\% \text { isokine: }\end{array}$ & & & & \\
\hline
\end{tabular}

Comnents:

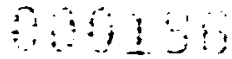

G.'forandeionisiz: 


\section{APPENDLX D \\ EQUIPMENT CALIBRATION RECORDS}

0000187 


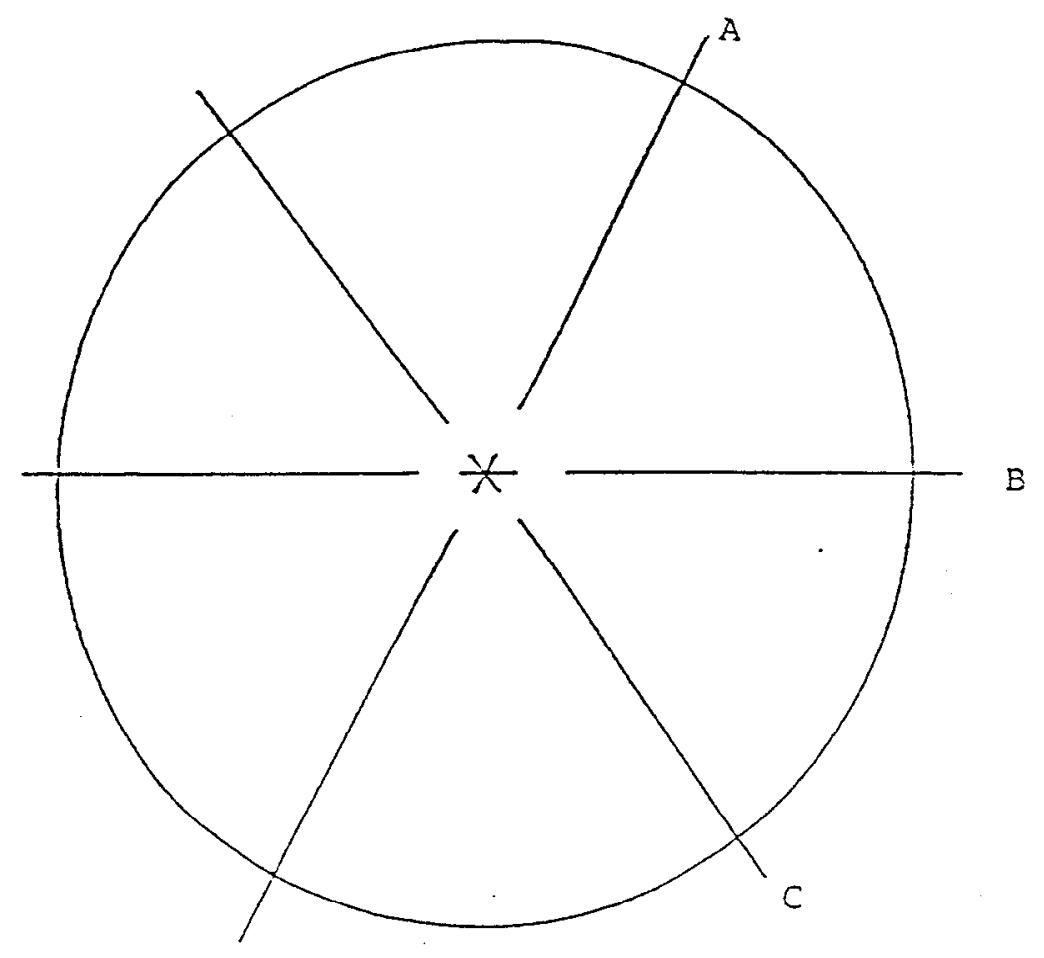

Diameter

Dimension

0,378

$\frac{0.378}{0,378}$

Average

0.378

Range

.000

Reiracos Hetad EPA S (resions)

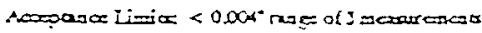

Culitraica Prounecy II hores
Nozzie type: Glass: $6 \mathrm{~A} \mathrm{MS}$ Quart: Stainless Steel: Other:

Date: $\frac{1-16-98}{2 \sqrt{3} \epsilon_{p} l(n)}$

Next Cal due: $1-16-99$ 


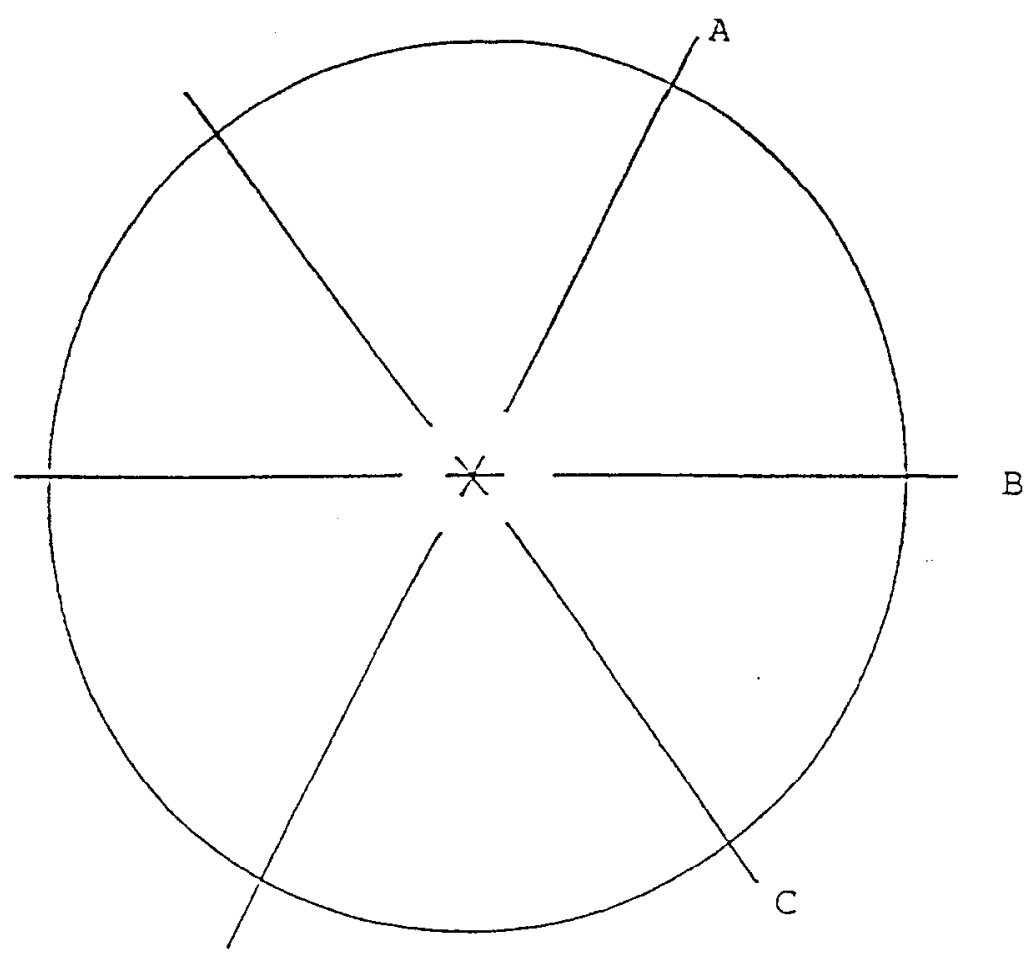

Diameter

Dimension

0.324

$0,32,7$

0.326

Average

0,326

Range

01003

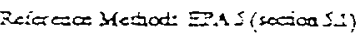

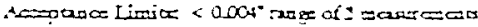

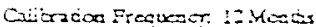

Nozzle type: Glass:

Quart: $15 B$

Stainless Steel:

Other:

Date: $\frac{1-15.98}{\text { Fecorced By. }}$

NexiCal due: $1-15-99$ 


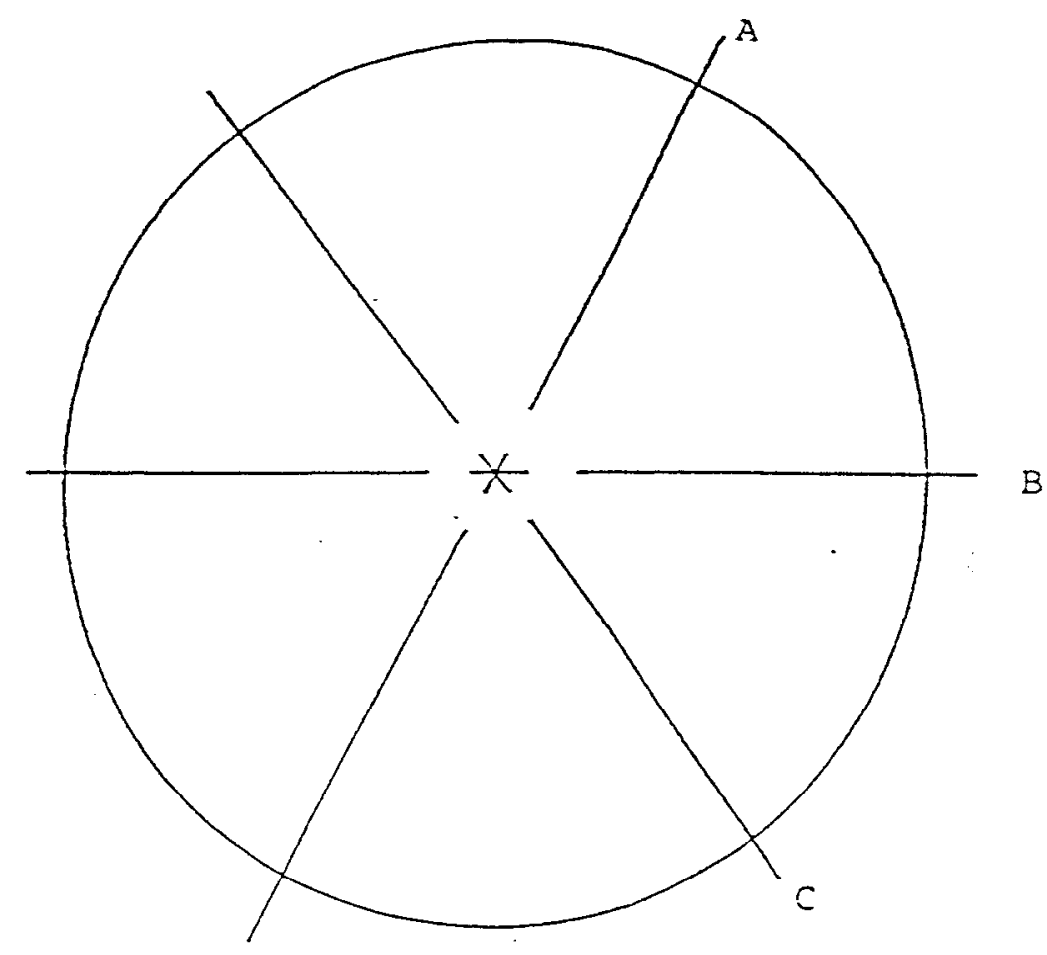

Diameter

Dimension

$0.30 \overline{5}$

0,309 0.310

Average

0,309 .

fange

0.002

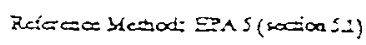

A

Ouisason Froquere :I Hocts
Nozzle type:

Glass: $5 E$ ms

Quart:

Stainless Steel:

Other:

Date: $\frac{1-16-98}{286 \mathrm{~s} / \mathrm{h} /}$

Next Cal due: $1-16-99$ 


\section{BEST ENVIRONMENTAL, INC.}

\section{Nozzle Calibration}

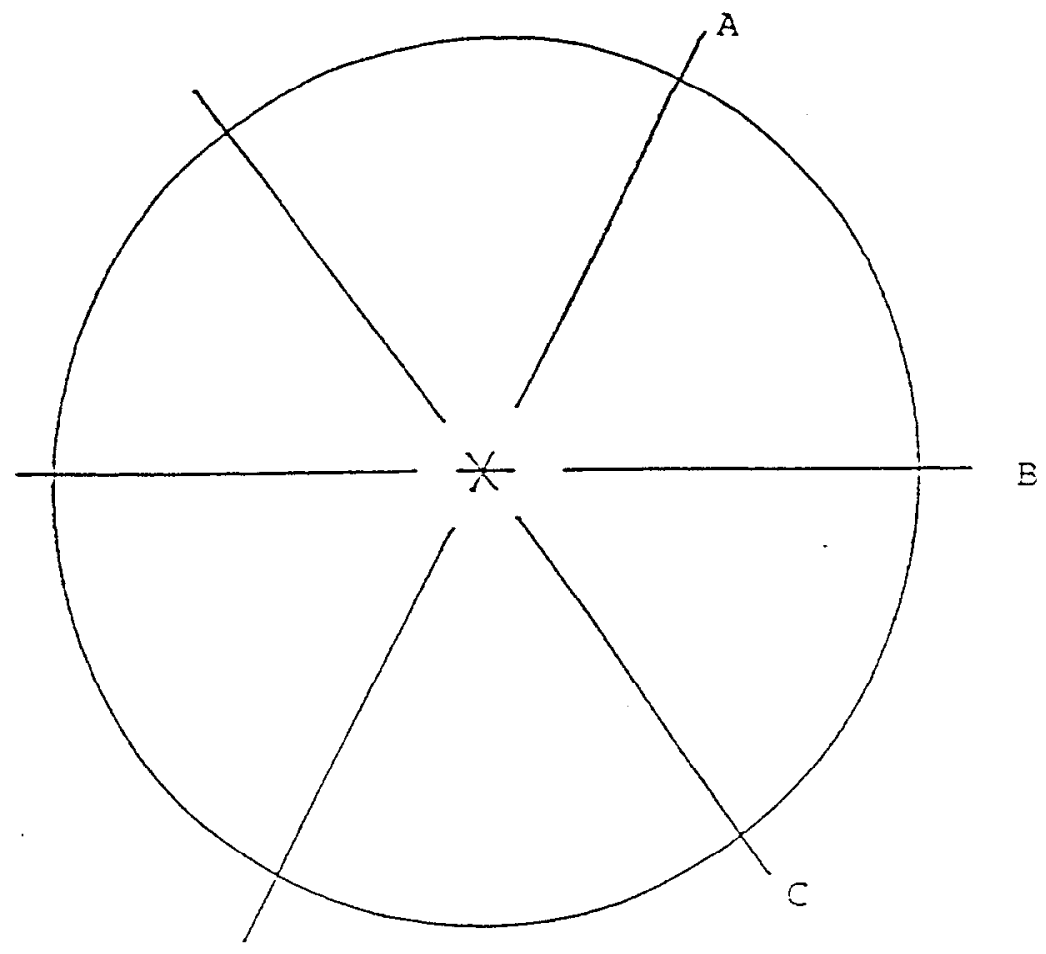

Diameter

Dimension

0305

0,304

0,304

Average

Q. 304 .

hance

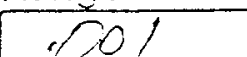

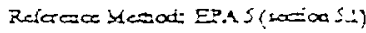

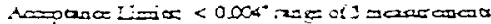

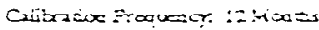

Nozze type:

Glass: 5e ms
Quart:
Stainless Stes:
Other:

Date:

$1-16-98$

Secorced Ey:

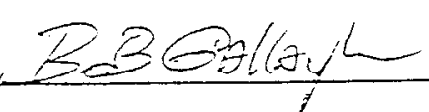

Next Cail due: $x-16-99$ 


\section{BEST ENVIRONMENTAL, INC. \\ Nozzle Calibration}

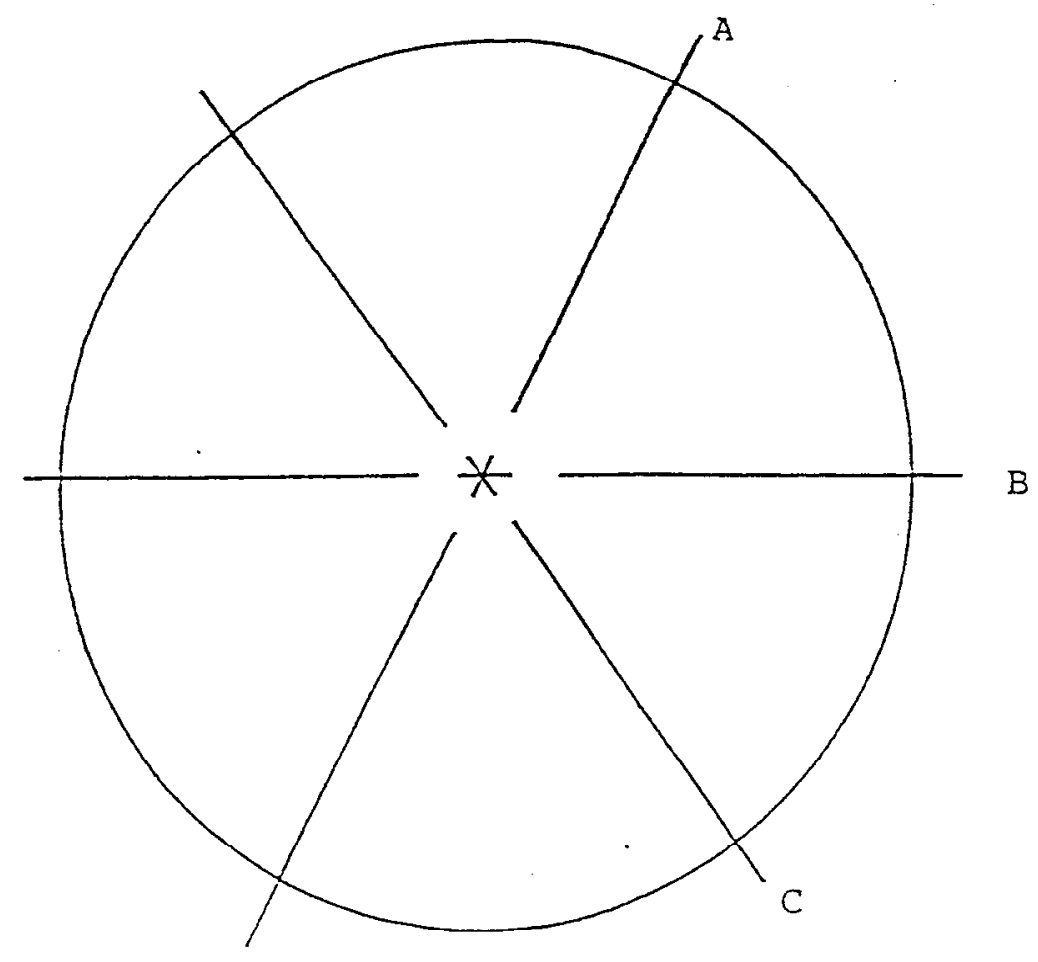

Diameter

Dimension

\begin{tabular}{|c|}
\hline .749 \\
\hline .753 \\
\hline .753 \\
\hline Average \\
\hline .752 \\
\hline Range \\
\hline .004 \\
\hline
\end{tabular}

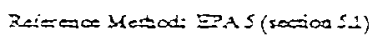

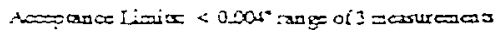

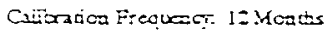

Nozzle type: Glass:

Quart:

Stainless Steel: 4 /

Other:

Date:

$1 / 27 / 98$

Recorded By:

Mi Wiley

Next Cal. due: 


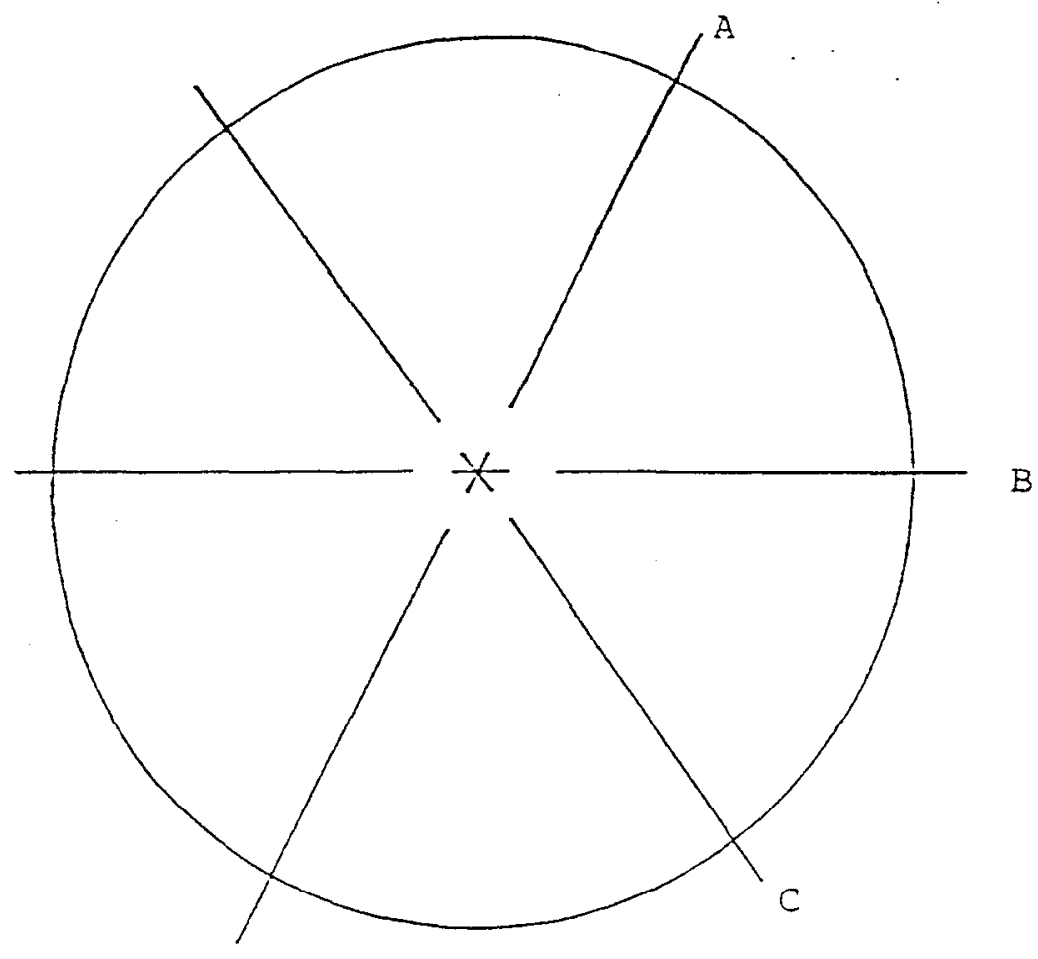

Diameter

Dimension

\begin{tabular}{|c|}
\hline 0.970 \\
\hline 0.971 \\
\hline 0.972 \\
Average \\
\hline 0.971 \\
Range \\
\hline 0.002 \\
\hline
\end{tabular}

Nozzle type: Giass:

Quart:

Stainless Steel:

Other:

Date:

$1 / 27 / 98$

Fecorcied By:

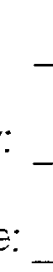

Next Câl. due:

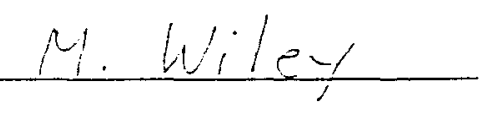

$1 / 27 / 09$

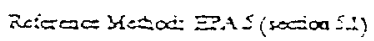

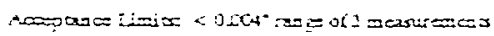

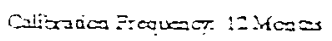


BEST ENVIRONMENTAL, INC.

Nozzle Calibration

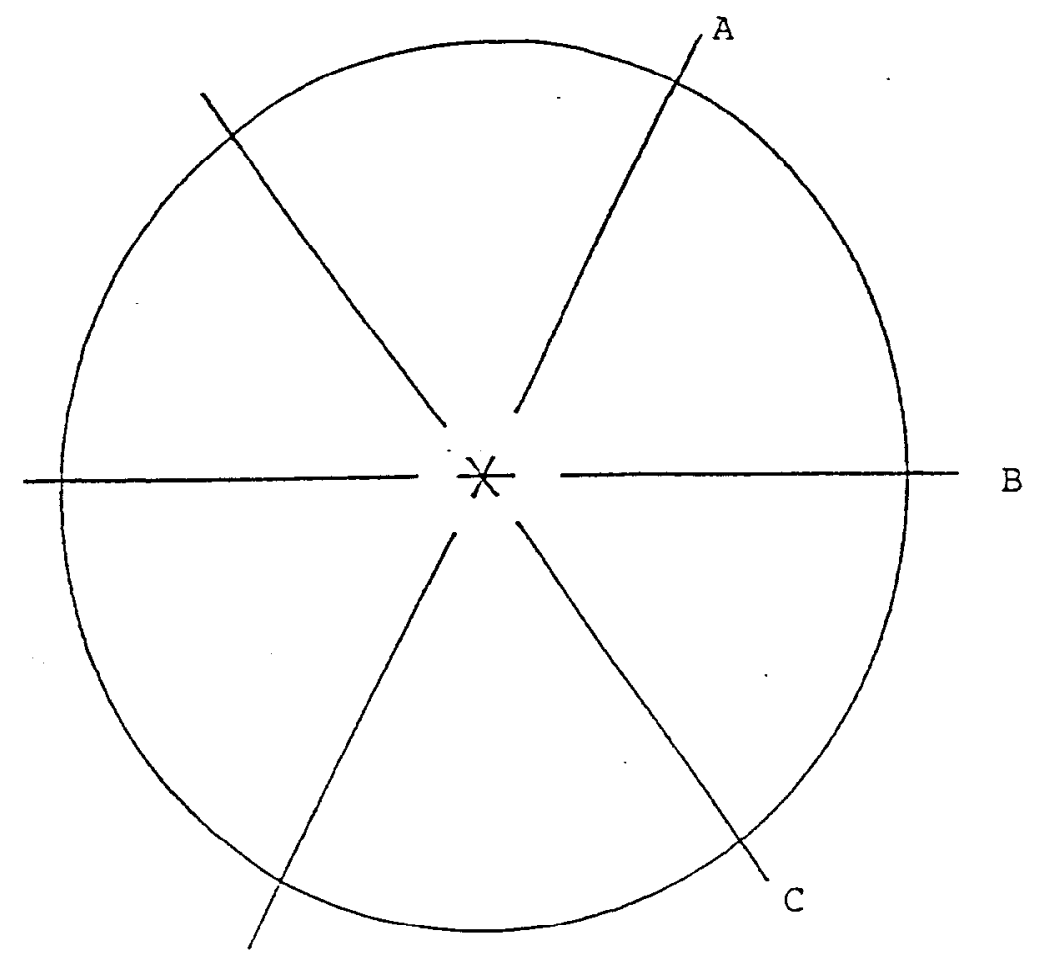

Diameter

Dimension

\begin{tabular}{l}
\hline 0.751 \\
\hline 0.752 \\
\hline 0.750 \\
\hline Average \\
\hline 0.751 \\
\hline Range \\
0.002 \\
\hline
\end{tabular}

Nozzle type: Glass:

Quart:

Stainless Steel: 40

Other:

Date:

$1 / 26 / 98$

Fecorded By: M. Wiley

Next Cal. due: 1/26/99

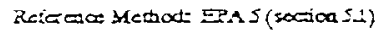

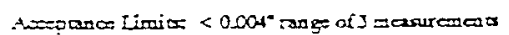

Cuiliostice Frequeace 12Monis 


\section{METER BOX FULL TEST CALIBRATION}

Meter \#: L.S.1. \#I

Dat: $09-10-97$.

Operator: Bob Gallagher

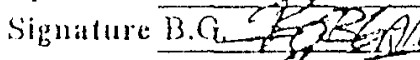

QAge: offices: C.T.
Meter Orifice ID: fixed box orifice

Standard Meter: Wet Gas Meter

Test Vacuum "IIg: n/a

Bar. Pressure (Pb): 29.93

Lenk Checked: Yes (1) 18"Hg.

\begin{tabular}{ccc} 
Current & Yd & $\Delta \mathrm{H} @ \mathrm{G}$ \\
\hline 1.0039 & 2.196 \\
\hline
\end{tabular}

\begin{tabular}{ll|l}
\hline Previous & 0.9886 & 2.091 \\
\hline
\end{tabular}

\begin{tabular}{|c|c|c|c|c|c|c|c|c|c|c|c|c|c|c|c|c|c|c|}
\hline \multirow[b]{2}{*}{$\Delta I I$} & \multirow[b]{2}{*}{$\Delta P^{\prime}$} & \multirow[b]{2}{*}{ Yds } & \multicolumn{3}{|c|}{$\begin{array}{c}\text { Stundard Meter Gas } \\
\text { Volume }\left(\mathrm{Ct}^{3}\right)\end{array}$} & \multicolumn{3}{|c|}{$\begin{array}{l}\text { Mefer Box Giss } \\
\text { Volunte (fi') }\end{array}$} & \multirow{2}{*}{$\begin{array}{l}\text { Sid. } \\
\text { Melcr } \\
\text { Templ). } \\
\left(\mathrm{T}_{\mathrm{u}_{0}}\right) \\
\text { Avg. }\end{array}$} & \multicolumn{5}{|c|}{$\begin{array}{l}\text { Meter Box } \\
\text { Temperature }\end{array}$} & \multirow{2}{*}{$\begin{array}{c}\text { Time } \\
\text { (Min.) }\end{array}$} & \multirow[b]{2}{*}{$\Omega$} & \multirow[b]{2}{*}{$\mathrm{Yd}$} & \multirow[b]{2}{*}{$\Delta I I @$} \\
\hline & & & Inilial & Final & $\mathrm{Net}$ & Initial & Fina! & $\mathrm{Nel}$ & & Init. & End & Inth. & End & Avg. & & & & \\
\hline 0.50 & $0(\%)$ & 1000 & 0.000 & 9.200 & 9.200 & 997.738 & 1007.115 & 9.377 & 76.0 & 22 & 100 & 82 & 84 & 89.5 & 25.38 & 0.357 & 1.0044 & 2.132 \\
\hline 0.50 & -0.100 & 1000 & 9.200 & 15.000 & 5.800 & 7.115 & 13.044 & 5.929 & 76.0 & 95 & 98 & 83 & 84 & 90.0 & 16.05 & 0.356 & 1.0023 & 2.144 \\
\hline 0.50 & .0100 & 1.000 & 15.000 & 21.250 & 6.250 & 13.044 & 19.449 & 6.405 & 76.0 & 98 & 102 & 84 & 86 & 92.5 & 17.32 & 0.356 & 1.0044 & 2.144 \\
\hline 1.50 & 0.122 & 10000 & 0.000 & 10.000 & 10.000 & 19.792 & 29.982 & 10.190 & 77.0 & 99 & 104 & 84 & 85 & 93.0 & 15.98 & 0.615 & 1.0066 & 2.149 \\
\hline 1.50 & .0 .120 & 1.000 & 10.000 & 22.250 & 12.250 & 29.982 & 42.527 & 12.545 & 77.0 & 103 & 104 & 84 & 85 & 94.0 & 19.75 & 0.610 & 1.0034 & 2.187 \\
\hline 1.50 & 0125 & 10000 & 22.250 & 32.250 & 10.000 & 42.527 & 52.815 & 10.288 & 77.0 & 103 & 106 & 85 & 87 & 95.3 & 16.18 & 0.608 & 1.0010 & 2.197 \\
\hline $3(n)$ & -0.155 & 1000 & 0.000 & 10,000 & 10.000 & 53.349 & 63.567 & 10.218 & 78.0 & 105 & 105 & 87 & 88 & 96.3 & 11.62 & 0.845 & 1.0041 & 2.268 \\
\hline 30110 & -0.130 & $10(100)$ & 10.000 & 20.000 & 10.000 & 63.567 & 73.806 & 10.239 & 78.0 & 104 & 108 & 88 & 89 & 97.3 & 11.62 & 0.845 & 1.0038 & 2.264 \\
\hline 300 & -00.155 & 1000 & 20.000 & 30.000 & 10.000 & 73.806 & $B 4.053$ & 10.247 & 78.0 & 106 & 110 & 88 & 90 & 98.5 & 11.66 & 0.842 & 1.0053 & 2.278 \\
\hline
\end{tabular}

Cunnents: This is the Calib. Cent.

Variblites:

(1) - How late (chin)

all- (nifice presure diffential (in. 1120 )

st'- lnfel pressure diffetential standard meter (in. 11,0 )

Y̌ds - Standird meler conrection fuctor (Unilless)

ad- - Actu box contection factor (Unitless)

Alie - Gitice pressure diflecential that gives 0.75 DSCFM of air

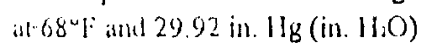

$Y^{\prime} d=\left(Y^{\prime} d s\right)\left(\frac{V d s}{V d}\right)\left(\frac{T d+460}{T d s+460}\right)\left(\frac{P b+\Delta P / 13.6}{P b+\Delta I / 13.6}\right)$

$\Delta H @=\frac{0.0317 \times \Delta H}{P b\left(T_{0}+460\right)}\left[\frac{(T d s+460) 0}{V d s \times Y d s}\right]^{2}$

$Q=\frac{17.64 \times V d s \times P b}{(T d s+460) 0}$ 


\section{METER BOX FULL TEST CALIBRATION}

Meter H: L.S.I.H1

Datc: $09-11-98$ Operator: Bob Gallagher Signature $\mathrm{BG}$ QAQC Office: CTliazbr
Meter Orifice $\mathrm{M}$ : boxes orifice

Stimlard Meter: Wet Gas Meter

Test Vacuum "Ig: 0 "Hg

Bar. Pressure (Pb): 29.79 Leak Checked: Yesat17" $H_{B}$

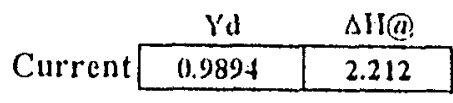

Previous $\quad 1.0039 \quad 2.196$

\begin{tabular}{|c|c|c|c|c|c|c|c|c|c|c|c|c|c|c|c|c|c|c|}
\hline \multirow[b]{2}{*}{$\Delta 11$} & \multirow[b]{2}{*}{$\Delta P^{P}$} & \multirow[b]{2}{*}{ Yols } & \multicolumn{3}{|c|}{$\begin{array}{c}\text { Standard Meter Gas } \\
\text { Volume ( }\left(t^{3}\right)\end{array}$} & \multicolumn{3}{|c|}{$\begin{array}{l}\text { Meter Box Gas } \\
\text { Volume }\left(\mathrm{ft}^{3}\right)\end{array}$} & \multirow{2}{*}{$\begin{array}{c}\text { Std.' } \\
\text { Meter } \\
\text { 'Temp. } \\
\left(T_{d s}\right) \\
\text { Avg. }\end{array}$} & \multicolumn{5}{|c|}{$\begin{array}{c}\text { Meter Box } \\
\text { Temperuture }\end{array}$} & \multirow{2}{*}{$\begin{array}{c}\text { Thine } \\
\text { (Min.) } \\
0 \\
0\end{array}$} & \multirow[b]{2}{*}{$Q$} & \multirow[b]{2}{*}{$\mathrm{Yd}$} & \multirow[b]{2}{*}{$\triangle \mathrm{II} Q$} \\
\hline & & & Initial & Flna! & $\begin{array}{c}\text { (Vols) } \\
\text { Net }\end{array}$ & Initial & Finn! & $\begin{array}{l}\text { (Vid) } \\
\text { Net }\end{array}$ & & $\begin{array}{c}\left(\mathrm{I}_{1}\right) \\
\ln \mathrm{I}_{2} \\
\end{array}$ & & $\begin{array}{l}\left(T_{0}\right) \\
\text { lalt }\end{array}$ & $\begin{array}{l}\text { Dutlet } \\
\text { End } \\
\end{array}$ & $\begin{array}{l}\left(T_{d}\right) \\
\text { Avg. } \\
\end{array}$ & & & & \\
\hline 0.511 & .0 .085 & 1.000 & 10.000 & 16.650 & 6.650 & 5.32 .406 & 5.39 .35 .3 & 6.947 & 82.0 & 110 & 110 & 91 & 24 & 101.3 & 18.03 & 0.358 & 0.9898 & 2.080 \\
\hline 0.50 & -0.090 & 1.000 & 16.650 & 23.150 & 6.500 & 539.353 & 546.171 & 6.818 & 83.0 & 110 & 115 & 94 & 26 & 103.8 & 17.68 & 0.356 & 0.9884 & 2.091 \\
\hline 0.50 & .0 .085 & 1.000 & 23.150 & 31.000 & 7.850 & 546.17 & 554.413 & 8.242 & 83.0 & 112 & 116 & 24 & 96 & 104.5 & 21.30 & 0.357 & 0.9887 & 2.081 \\
\hline 150 & -0.115 & 1.000 & 0.000 & 16000 & 16.000 & 554.587 & 571.387 & 16.800 & 84.0 & 114 & 115 & 94 & 96 & 104.8 & 26.00 & 0.595 & 0.9848 & 2.248 \\
\hline 150 & .0 .120 & 1.000 & 16.000 & 29.773 & 13.773 & 571.387 & 585.791 & 14.404 & 84.0 & 115 & 115 & 96 & 96 & 105.5 & 22.22 & 0.599 & 0.9900 & 2.211 \\
\hline 1.50 & -0.120 & 1.000 & 29.773 & 42.195 & 12.422 & 585.791 & 598.779 & 12.988 & 84.0 & 112 & 116 & 26 & 98 & 105.5 & 20.07 & 0.598 & 0.9903 & 2.213 \\
\hline 3.00 & -0.140 & 1.000 & 0.000 & 19.450 & 19.450 & 599.047 & 619.283 & 20.236 & 84.0 & 111 & 116 & 98 & 99 & 106.0 & 22.60 & 0.832 & 0.9923 & 2.284 \\
\hline 300 & -0.1 .45 & 1000 & 19.450 & 33.250 & 13.800 & 619.283 & 633.675 & 14.392 & 85.0 & 116 & 117 & 98 & 90 & 107.5 & 16.15 & 0.824 & 0.9908 & 2.325 \\
\hline 3.100 & -0.1 .40 & 1.000 & 33.250 & 47.070 & 13.820 & 633.675 & 648.102 & 14.427 & 85.0 & 115 & 117 & 98 & 99 & 107.3 & 16.36 & 0.815 & 0.9894 & 2.379 \\
\hline
\end{tabular}

Comments: Thiy is tho Calib. Cort.

Variables:

(?) - How rate (cfin)

$\mathrm{MI}$ - Oritico pressuro differential (in. $\mathrm{H}_{2} \mathrm{O}$ )

$\Delta \mathrm{P}^{\prime}$ - Inlel pressuro dilierontial standard moter (in. Ho)

Yals . Stimblard meter corsection fuctor (Unitless)

Yal - Melcr box correction fuctor (Unitless)

Allige... () iticu preysure difforontial that givos 0.75 DSCFM of air ut $684 \mathrm{~F}$ and $29.92 \mathrm{in.} 1 \mathrm{gg}$ (in. 11.0)

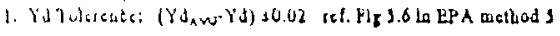

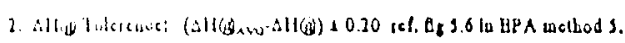

$\gamma d=(Y d s)\left(\frac{V d s}{V d}\right)\left(\frac{T d+4(1)}{T d s+460}\right)\left(\frac{P^{\prime} b+N^{\prime} / 136}{P b+\Delta d / 13.6}\right)$

$\Delta / @=\frac{0.0317 \times \Delta H}{P b\left(T_{0}+460\right)}\left[\frac{(T d s+460) 0}{V d s \times Y d s}\right]^{2}$

$Q=\frac{17.64 \times V d s \times P b}{(T d s+460) 0}$ 
Best Environmental, Inc.

San Leandro, California (510)483-0515

Spring Type Thermometer Calibration

calibrated By: Beferllog L

Date Calibrated: $\quad 5-8-98$

Calibration Due: $11-898$

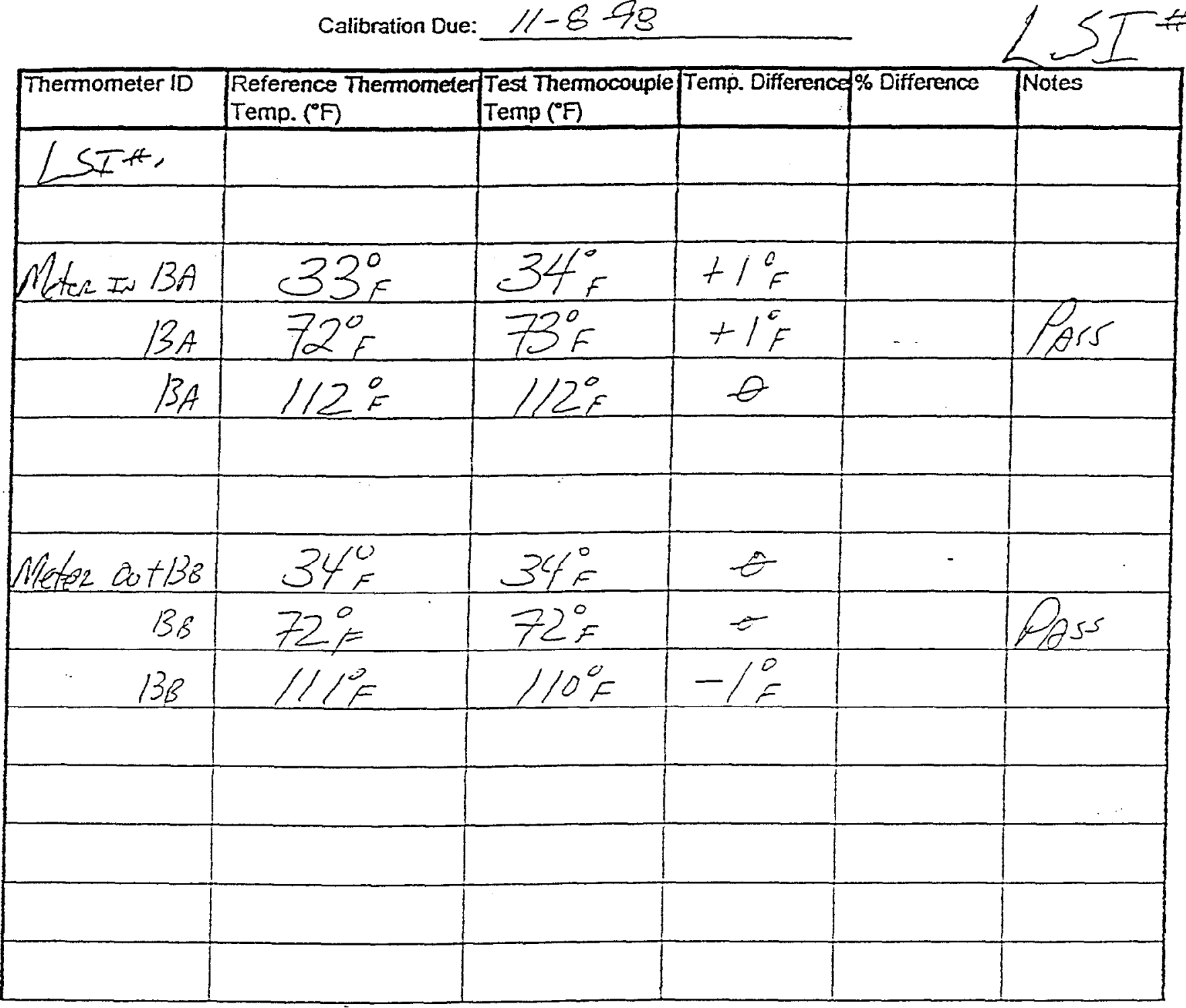

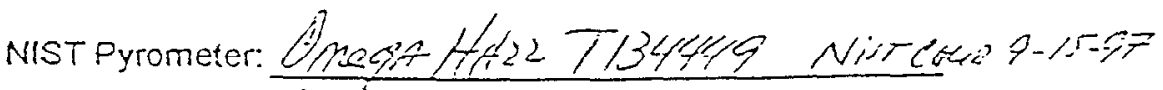

ASTM Thermometer. $61132-00: 6$

Comments:

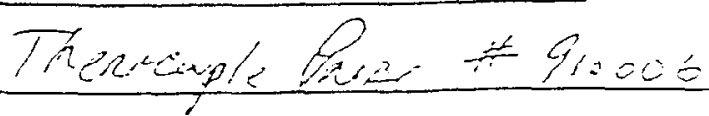

Reference Thermometer ASTM mercury in glass.

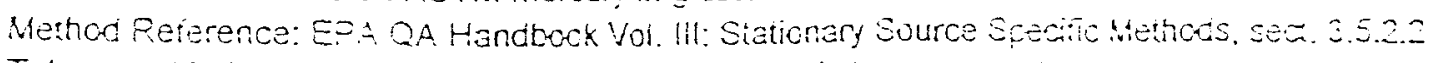

Tolerance Limits: \pm 5.4 "? at ambient temperature and in hot water $s a t h$

$9 \varphi$ 


\section{Pressure \& Vacuum Gauge Calibrations}

Calibration Date: $3-10-98$

Calibrated By: Bobfollogher

Gauge Location: LSI\#1
Gauge Number: $L S I^{\# 1} \triangle P$

ID Number: $\overline{R 8909056931}$

Calibration Frequency: SEmi Awwciec q-10-9:

Magnehelic: $\sqrt{ }$ Vacuum:___ Pressure:

\begin{tabular}{|c|c|c|c|c|}
\hline Gauge Range & $\begin{array}{c}\text { Manometer or } \\
\text { Slack Tube }\end{array}$ & Gauge Reading & Difference \% & $\begin{array}{c}\text { Notes } \\
\text { Pass / Fail }\end{array}$ \\
\hline \multicolumn{5}{|l|}{0 To $3^{\prime \prime}$} \\
\hline & $\therefore .75^{\circ}$ & $+.75^{\prime}-$ & $\theta$ & Poss \\
\hline & $+1.81^{\prime \prime}$ & $+1.82^{\prime \prime}$ & $+.552 \%$ & PASS \\
\hline & $+2.65^{\prime \prime}$ & $+2.70^{\prime \prime}$ & $+1,887 \%$ & Poss \\
\hline & & & & \\
\hline & $-.75^{\prime \prime}$ & $-.75^{\prime \prime}$ & $\theta$ & kass \\
\hline & $-1.68^{\circ}$ & $-1.70^{\circ}$ & $1.190 \%$ & PASS \\
\hline & $-2,77^{4}$ & $-2,80^{\prime \prime}$ & $1.083 \%$ & Pose \\
\hline & & & & \\
\hline & & & & \\
\hline & & & & \\
\hline & & & & \\
\hline & & & & \\
\hline & & & & \\
\hline & & & & \\
\hline & - & & & \\
\hline 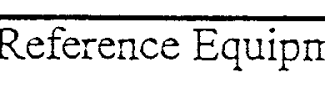 & Used (ID & & & \\
\hline & Gaur & ge Range & & \\
\hline
\end{tabular}

comments: USED Dwuer O to5" Inclue Manometer as Standaro. 


\section{Pressure \& Vacuum Gauge Calibrations}

Calibration Date: $3-10-98$

Calibrated By: Berelechre

Gauge Location: $L S T \# 1$
Gauge Number: LSI\#1 14

ID Number: $R 95188105414$

Calibration Frequency: Semi Anvurer 9-10 4:

Magnehelic: $\sqrt{ } \quad$ Vacuum: ___ Pressure:

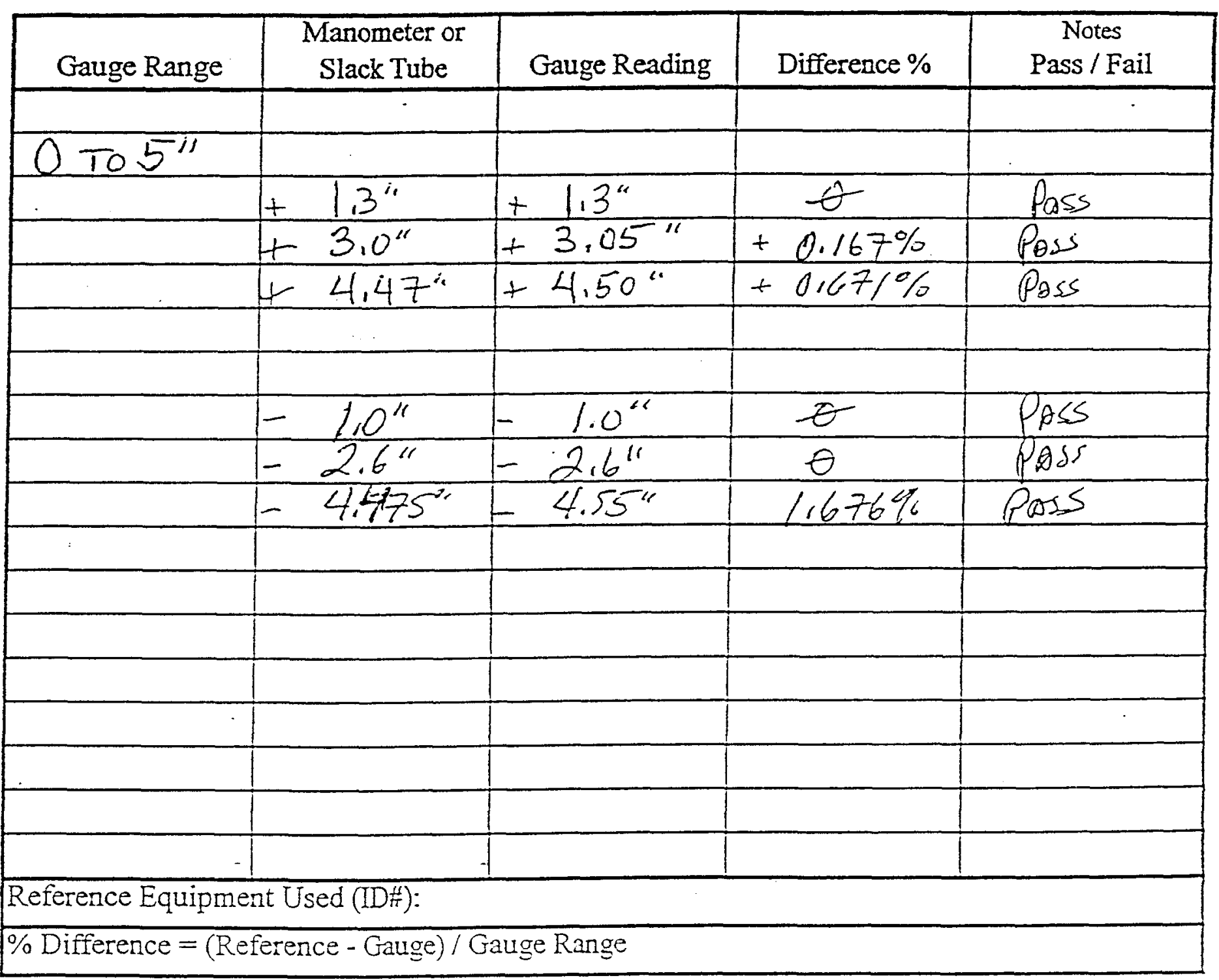

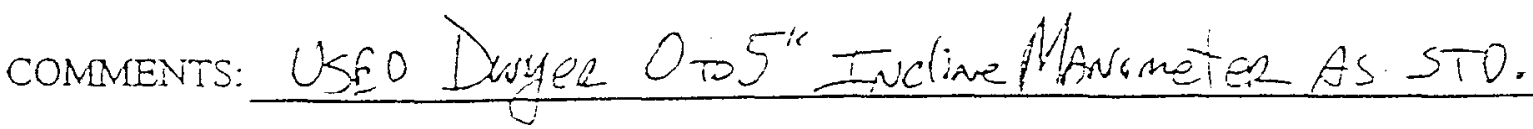




\section{METER BOX FULL TEST CALIBRATION}

Meter H: L.S.IH2

Date: 09-15-97.

Operator: Bob Gallagher

Signalure $\overline{B G}$

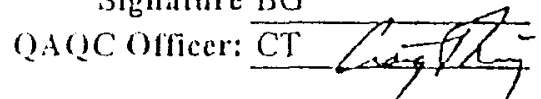

Meter Orifice ID: boxes orifice

Standard Meter: Wet Gas Meter

Test Vacuum "IIg: $\mathrm{O} \mathrm{Hg}$

Bar. Pressure (P'b): 29.83

Leak Checked: Yes at 17"Hg

Current

Previous

\begin{tabular}{|c|c|c|c|c|c|c|c|c|c|c|c|c|c|c|c|}
\hline \multirow[b]{2}{*}{$\Delta H$} & \multirow[b]{2}{*}{$\Delta P$} & \multirow[b]{2}{*}{ Yids } & \multicolumn{3}{|c|}{$\begin{array}{c}\text { Standard Meter Giss } \\
\text { Volume (fit) }\end{array}$} & \multicolumn{3}{|c|}{$\begin{array}{l}\text { Meter Box Gas } \\
\text { Volume }\left(f^{3}\right)\end{array}$} & \multirow{2}{*}{$\begin{array}{l}\text { Std. } \\
\text { Meter } \\
\text { Temp. } \\
\left(T_{d_{1}}\right) \\
\text { Avg. }\end{array}$} & \multicolumn{5}{|c|}{$\begin{array}{c}\text { Metcr Box } \\
\text { Temperature }\end{array}$} & \multirow{2}{*}{$\begin{array}{c}\text { Time } \\
\text { (Min.) } \\
0 \\
0\end{array}$} \\
\hline & & & Initial & Iinal & $\begin{array}{c}\text { V(ls) } \\
\text { Net }\end{array}$ & Initial & Finnl & $\begin{array}{l}(\mathrm{Vd}) \\
\mathrm{Nel}\end{array}$ & & $\begin{array}{c}\left(T_{1}\right) \\
\text { init. }\end{array}$ & & $\begin{array}{l}\left(\mathrm{T}_{.}\right) \\
\text {IniL. }\end{array}$ & & $\begin{array}{l}\left(T_{4}\right) \\
\text { Avg. } \\
\end{array}$ & \\
\hline 0.50 & -0.110 & 10000 & 0.000 & 5.260 & 5.260 & 862.522 & 867.803 & 5.281 & 80.0 & 87 & 87 & 82 & 82 & 84.5 & 13.48 \\
\hline 0.50 & -0.110 & 10000 & 5.260 & 10.520 & 5.260 & 867.803 & 873.087 & 5.284 & 800 & 87 & 87 & 82 & 82 & 84.5 & 13.50 \\
\hline 0.50 & .0 .115 & 1.000 & 10.520 & 17.350 & 6.830 & 873.087 & 879.947 & 6.860 & 80.0 & 87 & 87 & 82 & 82 : & 84.5 & 17.55 \\
\hline $1.50^{\circ}$ & -0140 & 1.000 & 0.000 & 10.100 & 10.100 & 880.074 & 890.102 & 10.028 & 80.0 & 90 & 90 & 83 & 83 & 86.5 & 14.96 \\
\hline 150 & 0) 1.15 & 1000 & 10.100 & 20.200 & 10.100 & 890.102 & 900.140 & 10.038 & 80.0 & 90 & 91 & 83 & 83 & 86.8 & 14.96 \\
\hline 1.50 & -1) 1.10 & 1.000 & 20.200 & 30.250 & 10.050 & 900.140 & 910.208 & 10.068 & 81.0 & 91 & 94 & 83 & 84 & 88.0 & 14.90 \\
\hline 3.00 & -0165 & 1.000 & 0.000 & 10.100 & 10.100 & 911.750 & 921.830 & 10.080 & 81.0 & 96 & 101 & 84 & 85 & 91.5 & 10.50 \\
\hline 300 & .0160 & 1.000 & 10.100 & 20.250 & 10.150 & 921.830 & 931.995 & 10.165 & 81.0 & 101 & 102 & 85 & 85 & 93.3 & 10.52 \\
\hline 3.00 & -0.165 & 1.000 & 20.250 & 37.300 & 17.050 & 931.995 & 949.131 & 17.136 & 81.0 & 101 & 102 & 84 & 85 & 93.0 & 17.68 \\
\hline
\end{tabular}

Commuculs: This is the Calib. Cert

Viatialles:

0 - ligurate (efm)

NII - (silice presinte differential (in. $H_{2} O$ )

$\therefore \quad$ sp-lulet pessinc difleential standard meter (in. $\mathrm{H}_{2} \mathrm{O}$ )

Y.. Y $\quad$ is $=$ Standard meler correction factor (Unitless)

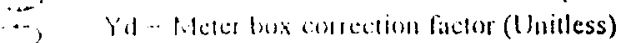

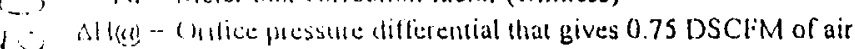

- an $68^{\circ} \mathrm{k}$ and $29.92 \mathrm{in} . \mathrm{Hg}$ (in. $11, \mathrm{O}$ )
$Y d=(Y d s)\left(\frac{V d s}{V d}\right)\left(\frac{T d l+460}{T d d s+460}\right)\left(\frac{m b+\Delta m^{\prime} 1:}{P b+\Delta m / l}\right.$

$\Delta H @=\frac{0.0317 \times \Delta H}{P b\left(T_{s}+460\right)}\left[\frac{(T d s+460) \theta}{V d s \times Y d s}\right]^{2}$

$Q=\frac{17.64 \times V d s \times P b}{(T d s+460) \theta}$

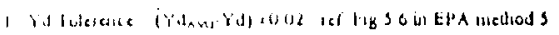

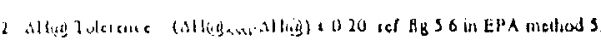




\section{METER BOX FULL TEST CALIBRATION}

Meter \#: L.S.I.H2

Meter Orifice ID: boxes orifice

\begin{tabular}{ccc} 
& Yd & $\Delta 11 @$ \\
\cline { 2 - 2 } Current & 0.9840 & 1.805 \\
\hline
\end{tabular}

(1) prator: Bob Gallagher

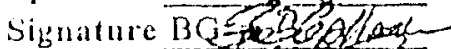

a Aocoficer: CT Cantify

Standard Meter: Wet Gas Meter

Previous $\quad 1.0089 \quad 1.869$

Bar. Pressure (Pl): 30.01

Leak Checked: Yes at 17 "IIg $^{\mathrm{I}}$

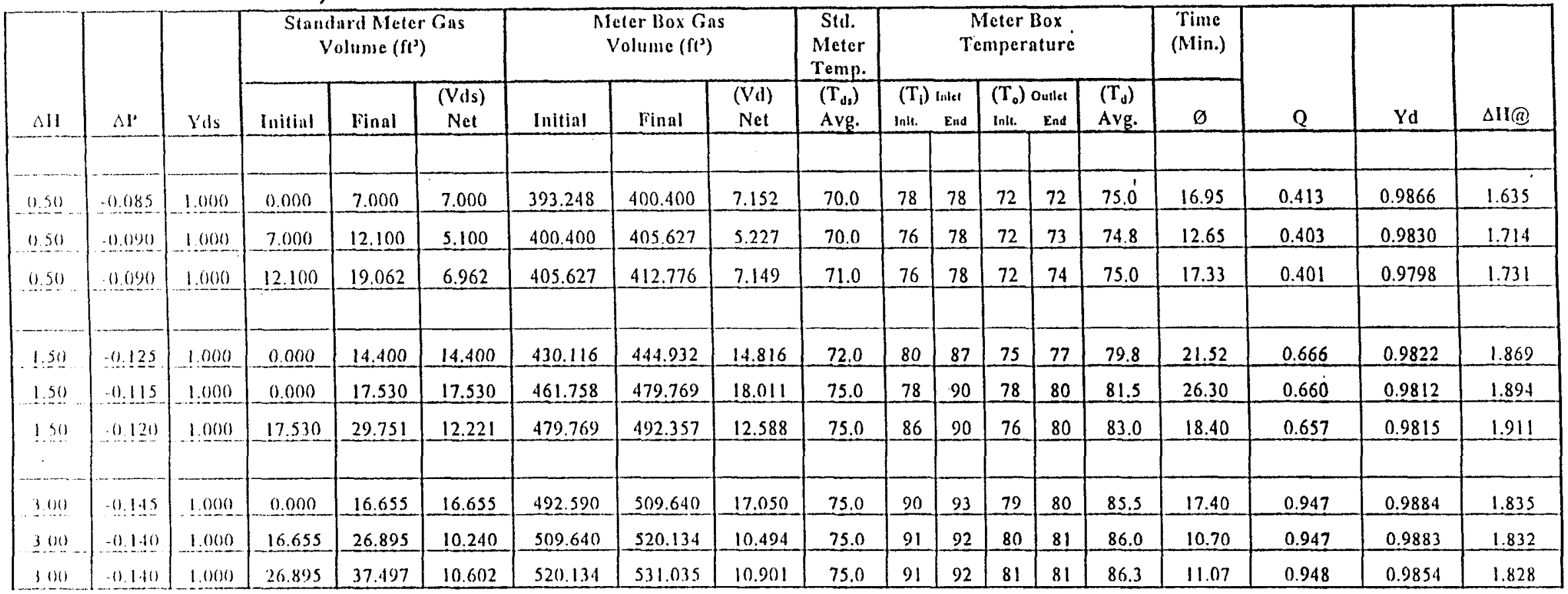

Comments: This is the Calib. Cert.

Vilrialyles:

1) ... Horv ratt: (chin)

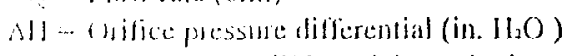

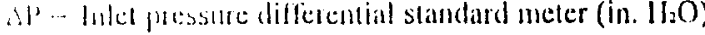

ids - Standard uncter correction factor (Unitless)

Ya- Meter box correction factor (Unitless)

d) Jol - Orifice pressure differential that gives 0.75 DSCFM of air it 6840 and $29.92 \mathrm{ing} 1 \mathrm{Ig}$ (in. 11,0$)$ $\gamma^{\prime} d=\left(\gamma^{\prime} d s\right)\left(\frac{V d s}{V d}\right)\left(\frac{T d+460}{T d s+460}\right)\left(\frac{P b+\Delta l^{\prime} / 13.6}{p b+\Delta l / 13.6}\right)$

$\Delta H @=\frac{0.0317 \times \Delta H}{P b\left(T_{0}+460\right)}\left[\frac{(T d s+460) 0}{V d s \times \gamma d s}\right]^{2}$

$Q=\frac{17.64 \times V d s \times P b}{(T d s+460) 0}$ 


\section{Pressure \& Vacuum Gauge Calibrations}

Calibration Date: $9-2-98$

Calibrated By: Shier Eomando

Gauge Location: $\angle S I^{* Z 2}$
ID Number $k \leqslant \pm 2 \Delta B$

Gauge Type: R10316VR/15

Calibration Frequency: Semi-Annual 3-2-99

Magnehelic:

Vacuum:

Pressure:

\begin{tabular}{|c|c|c|c|c|}
\hline Gange Range & $\begin{array}{l}\text { Manometer or } \\
\text { Slack Tube }\end{array}$ & Gange Reading & Difference \% & $\begin{array}{c}\text { Notes } \\
\text { Pass / Fail }\end{array}$ \\
\hline F/03/6VR/15 & $x / .85$ & +1.82 & $1.648 \%$ & GAS5 \\
\hline \multirow[t]{6}{*}{$2-5^{4}$} & +3.05 & +3.10 & $1.613 \%$ & 0,55 \\
\hline & $\div 4.45$ & +4.55 & $2.198 \%$ & QASS \\
\hline & -1.75 & -1.72 & $1.744 \%$ & DASS \\
\hline & -3.08 & -3.10 & $.645 \%$ & SASS \\
\hline & -4.50 & -4.60 & $2.174 \%$ & P.t5s \\
\hline & & $\because$ & & \\
\hline & & & & \\
\hline & & & $\therefore$ & \\
\hline & & & & \\
\hline$\therefore$ & & & & \\
\hline & & & & \\
\hline & & & & \\
\hline & & & & \\
\hline & & & & \\
\hline- & & & & \\
\hline & & & & \\
\hline Equil & Used (D: $\#):$ & & & \\
\hline
\end{tabular}

COMMENTS: USEd O-to owyer Incline Harometer is sta 


\section{Type K Thermocouple Calibration}

Pitot $\frac{\pi}{\pi:}$
Probe $\frac{\dot{\pi}}{\pi}:$
Probe TyperLength:
Meter \# LSI
Heater Box \#- Other:

\begin{tabular}{|c|c|c|c|c|c|c|c|}
\hline $\begin{array}{c}\begin{array}{c}\text { Calibration } \\
\text { Date }\end{array} \\
\end{array}$ & $\begin{array}{c}\text { Thermocouple } \\
\text { ID }\end{array}$ & $\begin{array}{l}\text { Reference } \\
\text { Temp. }\left({ }^{\circ} \mathrm{F}\right) \\
\end{array}$ & $\begin{array}{c}\text { Test T/C } \\
\text { Termp. }\left({ }^{\circ} \mathrm{F}\right) \\
\end{array}$ & Temp. Difference & $\%$ Difference & Initials & $\begin{array}{c}\text { Notes } \\
\text { Pass/Fail } \\
\end{array}$ \\
\hline $9-1597$ & & & & & & & \\
\hline KeascuT & Plitue & $44{ }^{\circ} \mathrm{F}$ & $399.7^{\circ}$ &,$- 3^{i}=$ & $-0.075 \%$ & $B 6$ & A $A \leq S$ \\
\hline K'Type & 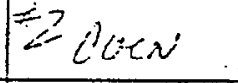 & $\sum 00^{\circ}$ & $201.6{ }^{\circ}$ & $+1,6^{\circ}$ & $\mid+-{ }^{2} C \omega$ & $R$ & ir \\
\hline if & S: STACK & $300^{\circ} F$ & $299.8 \%$ &,$- Z^{\circ}$ & -.067 & $B 0^{\prime}$ & G \\
\hline & F!' $\times$ TR/j & $y^{c} F^{-}$ & $4 \times, 2^{\circ}=$ & $-\pi^{\circ}$ & $1-80 \%$ & Bes & $i !$ \\
\hline & $5 \times 1$ & $500 \%$ & $500.26=$ & $+.2 i$ & $+0.04 \%$ & 30 & \&: \\
\hline & & & & & & & \\
\hline & & & & & & & \\
\hline & & & & & & & \\
\hline & & & & & & & \\
\hline & & & & & & & \\
\hline & & & & & & & \\
\hline
\end{tabular}

NTST Pyrometer: T1 34446

NIST Thermocouple: 600

$$
\text { Comments: } \begin{aligned}
& \text { tes } \\
& \text { Hond }
\end{aligned}
$$

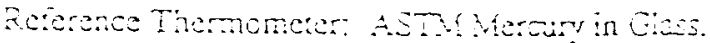

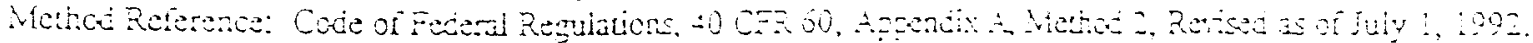

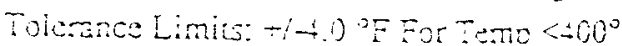

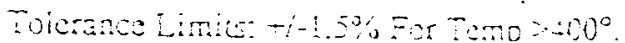




\section{Spring Type Thermometer Calibration}

Calibrated By: Darred M. Lane

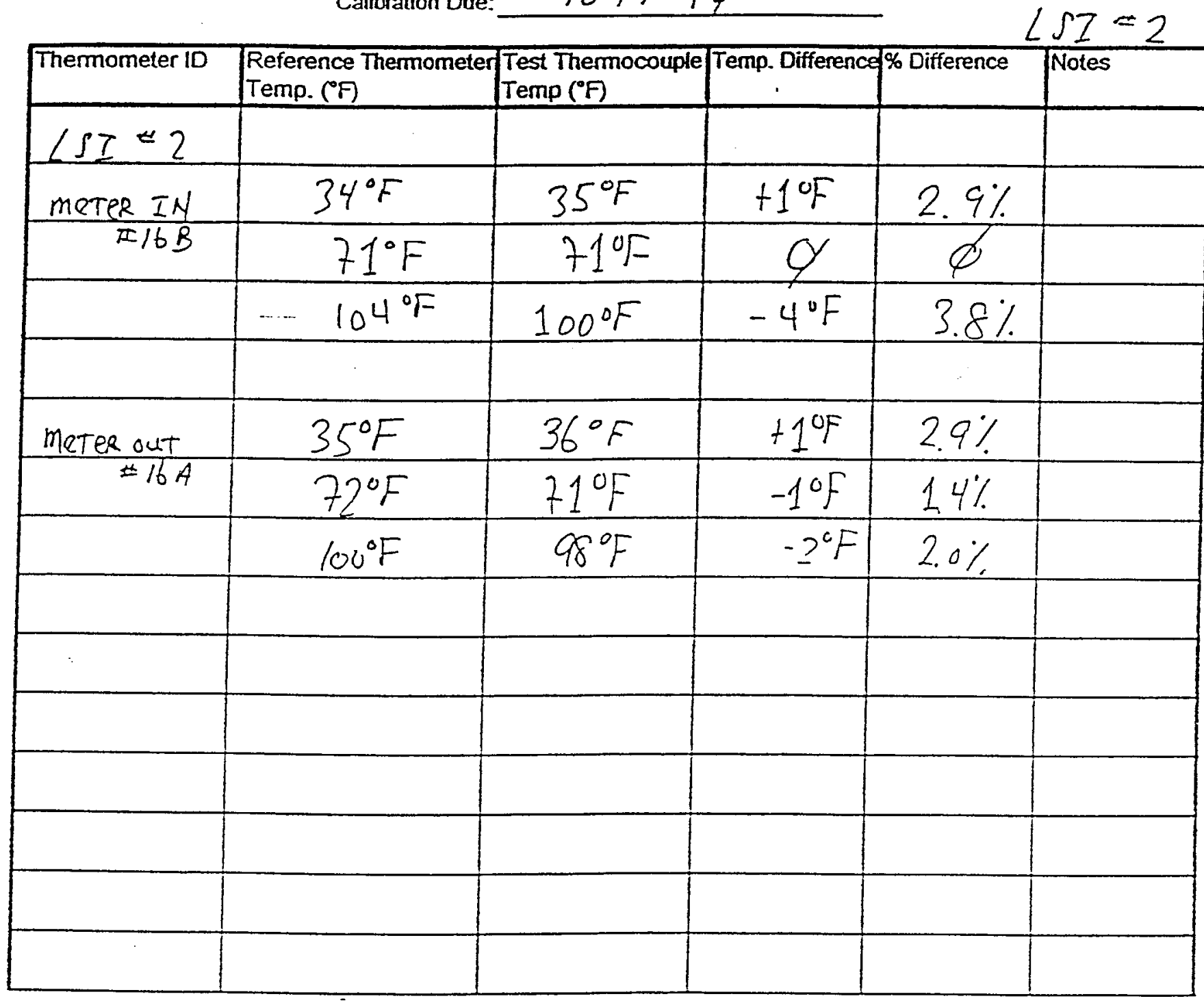

NIST Pyrometer: 134449

ASTM Thermometer. $61132-006$

comments: PAffed

Reference Themometer. ASTM mercury in glass.

Method Rererence: EPA QA Handbook Vol IIt: Stationary Source Scenific Methods, sea. 3.5.2.2

Tolerance Limits: $\pm 5.4^{\circ} \mathrm{F}$ at ambient temperature and in not water bath. 


\section{METER BOX FULL TEST.CAI.IBRATION}

Meter H: A.S.l. 8 , Meter Orifice ID: boxes orilice/.I

Standard Meter: Wet Gas Meter

Date: 02-05-98,

Oparator: Bob Gallagher Signature $B \mathrm{BG}$

Q.AOCorficen: $\overline{C T}$
Test Vacuum "Hg: 0 "Hg Bar: Pressure (P(1)): 29.84'

Leak Checked: Yes at 17"IIG.
Šñ Lemudro, CA (510)278-4011

$\therefore$

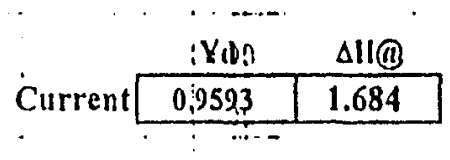

Provious . $099003-1.590$

\begin{tabular}{|c|c|c|c|c|c|c|c|c|c|c|c|c|c|c|c|c|c|c|}
\hline \multirow[b]{2}{*}{$\Delta I I$} & \multirow[b]{2}{*}{$\Delta P^{\prime}$} & \multirow[b]{2}{*}{ Yils } & \multicolumn{3}{|c|}{$\begin{array}{l}\text { Standard Meler Gas } \\
\text { Volume (ft') }\end{array}$} & \multicolumn{3}{|c|}{$\begin{array}{l}\text { Meter llox Gas } \\
\text { Volume (ft })\end{array}$} & \multirow{2}{*}{ 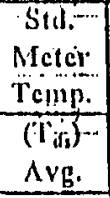 } & \multicolumn{5}{|c|}{$\begin{array}{c}\text { Meter box } \\
\therefore \quad \text { Temperalure } \\
\end{array}$} & \multirow{2}{*}{$\begin{array}{c}\text { Thime } \\
\text { (Min.) } \\
0 \\
\end{array}$} & \multirow{2}{*}{ 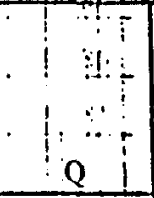 } & \multirow[b]{2}{*}{ Yd } & \multirow[b]{2}{*}{$\Delta \| \cap$} \\
\hline & & & Initial & Final & $\begin{array}{c}(\mathrm{V} d s) \\
\mathrm{Net}\end{array}$ & Initin! & IImal & $\begin{array}{l}\mathrm{Vd}) \\
\mathrm{Nel} \\
\end{array}$ & & $\begin{array}{l}\text { (1i) } \\
\text { luit. }\end{array}$ & Eind & $\begin{array}{l}\left(T_{0}\right) \\
\text { inlt. }\end{array}$ & $\begin{array}{r}\text { Onites } \\
\text { rins } \\
\end{array}$ & $\begin{array}{l}\left(T_{1}\right) \\
A v g . \\
\end{array}$ & & & & \\
\hline & & & & & & & & . & $\cdots+\cdots$ & $\cdots \cdots$ & & $\cdots$ & ... & & & $\cdot \cdots \cdot r \cdot r$ & & \\
\hline 0.50 & .0 .095 & 1.000 & 0.000 & 6.550 & 6.550 & 672.487 & 679.432 & 6.945 & 56.0 & 64 & 69 & 56 & 63. & 63.0 & $16.05^{\circ}$ & 0.416 & 0.9545 & 1.635 \\
\hline 80.50 & $-(10.090$ & 1.000 & 6.550 & 18.345 & 11.795 & 679.432 & 692.146 & 12.714 & 56.0 & 69 & 73 & 63 & 170 & 68.8 & $28.97^{\circ}$ & $\begin{array}{ll}1: \\
1 & 0.415 \\
\end{array}$ & 0.9493 & 1.620 \\
\hline 0.50 & -0.095 & 1.000 & 18.345 & 26.300 & 7.955 & 692.146 & 700.783 & 8.637 & 57.0 & 80 & 80 & 71 & 71 & 75.5 & $19.52^{i}$ & 0.415 & 0.9526 & 1.610 \\
\hline & & & & & & & & & & $\therefore$ & 1 & $\begin{array}{c}1 \\
\vdots \\
\vdots\end{array}$ & $\because$. & & & .11 & & \\
\hline 1.50 & -0.115 & 1.000 & 0.000 & 17.400 & 17.400 & 701.406 & 720.328 & 18.922 & 57.0 & 79 & 88 & 71 & 75 & 78.3 & $25.68^{1 !}$ & 0.690 & 0.9536 & 1.741 \\
\hline 1.511 & -0.110 & 1.000 & 17.400 & 33.305 & 15.905 & 720.328 & 737.708 & 17.380 & 57.0 & 86 & 85 & 75 & \begin{tabular}{|lll}
1 & \\
& $75 i$ \\
\end{tabular} & 80.3 & 23.47: & $0,690 !$ & 0.9525 & 1.734 \\
\hline 150 & -0.115 & 1.000 & 33.305 & 55.710 & 22.405 & 737.708 & 762.223 & 24.515 & 57.0 & 85 & 84 & 75 & 76 & 80.0 & $33.00 !$ & $0,692^{\circ} ;$ & 0.9508 & 1.725 \\
\hline & & & & & & & & & & & & & & & & $\begin{array}{r}1 \\
\end{array}$ & & \\
\hline 3.00 & -0.150 & 1.000 & 0.000 & 19.595 & 19.595 & 537.089 & 557.822 & 20.733 & 58.0 & 81 & 83 & 72 & 75 & 77.8 & $20: 16$ & 0.988 & 0.9736 & 1.697 \\
\hline 3.60 & -0.150 & 1.000 & 19.595 & 29.700 & 10.105 & 557.822 & 568.572 & 10.750 & 58.0 & 83 & 91 & 75 & 78 & $B 1.8$ & $10142 \vdots$ & 0.985 & 0.9755 & 1.695 \\
\hline 3.110 & .0 .150 & 1.000 & 29.700 & 69.000 & 39.300 & 568.572 & 610.642 & 12,070 & 59.0 & 89 & 89 & 77 & 80 & 83.8 & $4063:$ & 0081 & 0.9712 & 1.704 \\
\hline
\end{tabular}

(omments: This is the Calibration Cert.

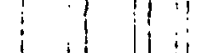

Vuriables:

$Q=$ How rate $(\mathrm{cfm})$

$\Delta I=$ Orifice pressure differential (in. $H, O)$

$\triangle \mathrm{P}^{\mathrm{i}}$ in Inlet pressure differential standard meter (in. $\mathrm{IH}_{2} \mathrm{O}$ )

Yas is Standiril meler correction factor (Unitless)

yil a P.felur box conection factor (Unitless)

All (a) = onitice pressure differential that gives 0.75 DSCFM of air at $68^{\circ} \mathrm{l}$ and $29.92 \mathrm{in}$. Hg (in. H.O)

$Y d=(Y d s)\left(\frac{V d s}{V d}\right)\left(\frac{T d+460}{T d s+460}\right)\left(\frac{P b+\Delta P / 13.6}{P^{\prime} b+\Delta H / 13.6}\right)$

$\Delta H @=\frac{0.0317 \times \Delta H}{P b\left(T_{0}+460\right)}\left[\frac{(T d s+460) 0}{V^{\prime} d s \times \gamma d s}\right]^{2}$,

$Q=\frac{17.64 \times V d s \times P b}{(T d s+460) D}$ 
Pitot H:

Probc \#:

Probe Type:

\section{Type K Thermocouple Calibration}

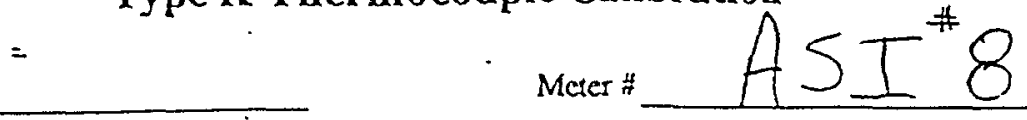

Heates Box

Gher. T/couple ReADovt KTyp-

\begin{tabular}{|c|c|c|c|c|c|c|}
\hline $\begin{array}{c}\text { Calibration } \\
\text { Date }\end{array}$ & $\begin{array}{c}\text { Thermocouple } \\
\text { ID }\end{array}$ & $\begin{array}{l}\text { Reference } \\
\text { Temp ( } F)\end{array}$ & $\begin{array}{l}\text { Test T/C } \\
\text { Temp. (F) }\end{array}$ & $\begin{array}{c}\text { Temp. Difference } \\
<400^{\circ} \mathrm{F}\end{array}$ & $\begin{array}{c}\% \text { Difference } \\
>400^{\circ} \mathrm{F}\end{array}$ & $\begin{array}{c}\text { Notes } \\
\text { Pass / Fail }\end{array}$ \\
\hline \multicolumn{7}{|l|}{$10-7-98$} \\
\hline & STACK & $600.0^{\circ} \mathrm{F}$ & $602^{\circ} \mathrm{F}$ & $+20 \mathrm{~F}$ & $.333 \%$ & Passes \\
\hline & ProBe & $300^{\circ} \mathrm{F}$ & $300^{\circ} \mathrm{F}$ & $\theta$ & & ir \\
\hline & ouen & $300^{\circ} \mathrm{F}$ & $300^{\circ} \mathrm{F}$ & $\theta$ & & ASSES \\
\hline & Aux & $200 \%$ & $20 / \%$ & +10 & & 11 \\
\hline & Meterin & 6.3 & 63 & $\theta$ & & " \\
\hline & Meterar & 63 & 64 & $+1^{0} \mathrm{~F}$ & & ', \\
\hline - & & & & & & \\
\hline & & & & & & \\
\hline & & & & & & \\
\hline & & & & & & \\
\hline & & & & & & \\
\hline & IST Pyrometer. & 13444 & & Cainbrated By: & $F$ & $\operatorname{logh}$ \\
\hline NI & Thermocouple: & 910006 & & bration Frequency. & 6Months & $2-7.98$ \\
\hline
\end{tabular}

ASTM Mercary in Giass Thermometer $\frac{4}{\pi}$ :

Comments: AlsOUSED KTpe themenociple Simuiatce. OmEaA muoefir $5 / N C L 3002100=$

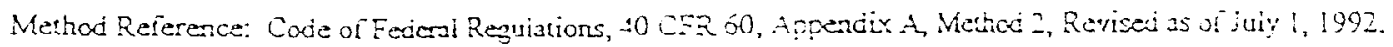

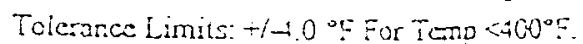

Folexance Limits: $1-1.5 \%$ For Tens $>400 \%$ 


\section{METER BOX FULL TEST CALIBRATION}

Meter H: $24001 \mathrm{f}$

Meter Orifice ID: Calib. 11 13/64

Diale: $4 / 1 / 97$

Standard Meter: Wet Gas Meter

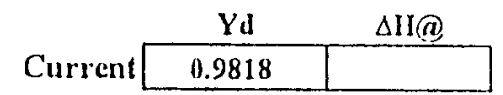

Operator: Michael J. Wiley

Test Vacuum "Hg: $n / a$

signtature

Bar. Pressure (Pl)): 30.04

Leak Checked: Yes

Previous 0.9622

onocontiner: 9

\begin{tabular}{|c|c|c|c|c|c|c|c|c|c|c|c|c|c|c|c|c|c|c|}
\hline \multirow[b]{2}{*}{ int } & \multirow[b]{2}{*}{$\Delta P$} & \multirow[b]{2}{*}{$y^{\prime} d s$} & \multicolumn{3}{|c|}{$\begin{array}{c}\text { Stundard Meter Gas } \\
\left.\text { Volinue (ft }{ }^{3}\right)\end{array}$} & \multicolumn{3}{|c|}{$\begin{array}{l}\text { Meter llox Gas } \\
\text { Volume (L) }\end{array}$} & \multirow{2}{*}{$\begin{array}{c}\text { Std. } \\
\text { Meter } \\
\text { Temp. } \\
\left(T_{u_{1}}\right) \\
\text { Avg. }\end{array}$} & \multicolumn{5}{|c|}{$\begin{array}{l}\text { Meter Box } \\
\text { Temperature }\end{array}$} & \multirow{2}{*}{$\begin{array}{c}\text { Time } \\
\text { (Min.) }\end{array}$} & \multirow[b]{2}{*}{$\begin{array}{c}(\mathrm{I} / \mathrm{Min}) \\
Q \\
\end{array}$} & \multirow[b]{2}{*}{$\mathrm{Yd}$} & \multirow[b]{2}{*}{$\Delta H Q$} \\
\hline & & & Initial & lïinal & $\begin{array}{c}(\mathrm{Vds}) \\
\mathrm{Net}\end{array}$ & $\begin{array}{c}\text { (1.) } \\
\text { Initial }\end{array}$ & $\begin{array}{c}(\mathrm{I}) \\
\text { lininal } \\
\end{array}$ & $\begin{array}{c}(\mathrm{V} d) \\
\mathrm{N} \in \mathrm{t}\left(\mathrm{ft}^{3}\right) \\
\end{array}$ & & \multicolumn{2}{|c|}{$\begin{array}{l}\text { (T) Intet } \\
\text { lnit. } \quad \mathrm{gnd}_{\mathrm{nu}}\end{array}$} & \multicolumn{2}{|c|}{ 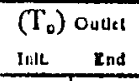 } & $\begin{array}{l}\text { (Td } \\
\text { Avg. }\end{array}$ & & & & \\
\hline & & & & & & & & & & & & & & & & & & \\
\hline & & & & & & & & & & & & & & & & & & . \\
\hline $0(8)+1 !$ & .400 & 10000 & 22320 & 72.640 & 0.320 & 013.200 & 622400 & 0.325 & 62.0 & 66 & 69 & 63 & 66 & 66.0 & 25.8 & 0.357 & 0.9925 & \\
\hline (1) (1) & : & 10001 & 72.640 & 72.960 & 0.320 & 622.400 & 631.600 & 0.325 & 62.0 & 70 & 70 & 66 & 66 & 68.0 & 25.8 & 0.357 & 0.9962 & \\
\hline 0.0012 & -0.090) & 1.000 & 73.000 & 73.500 & 0.500 & 633.000 & 647.500 & 0.512 & 700 & 70 & 71 & 72 & 73 & 715 & 2103 & 0646 & 00701 & \\
\hline "110? & (1) (1,n) & !. 10000 & 73.500 & 74000 & 0.500 & 6.17 .500 & 662.000 & 0.512 & 70.0 & 71 & 74 & 78 & 72 & 72.0 & 21.93 & 0.646 & 0.9800 & \\
\hline & & & & & & & & & & & & & & & & & & \\
\hline $0(0) !$ & 01010 & $\ln (006)$ & 74.200 & 75.100 & 0.900 & 668.000 & 694.500 & 0.936 & 72.0 & 78 & BO & 76 & 77 & 77.8 & 25.08 & 1.013 & 0.9722 & \\
\hline 00014 & -0.010 & $1 .(80)$ & 75.100 & 76.000 & 0.900 & 694.500 & 721.100 & 0.939 & 72.0 & 80 & 81 & 77 & 78 & 79.0 & 25.10 & 1.012 & 0.9708 & \\
\hline & $\cdots$ & & & & & & & & & & & & & & & & & \\
\hline & & & & & & & & & & & & & & & & & & \\
\hline
\end{tabular}

Cummonts: This is the Cullib. Cont slect.

Sintiatil's:

(). - H luw ralc (cfiin)

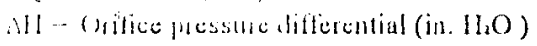

Af - Intcl prisistice dillec contial standard meter (in. IHO)

rits - Stundurd miter conection factor (Unilless)

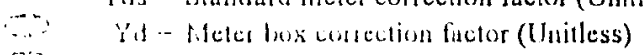

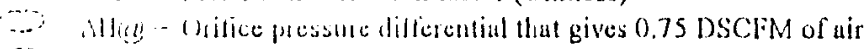

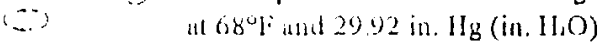

$r^{\prime} d=(Y d s)\left(\frac{V d s}{V d}\right)\left(\frac{T d+460}{T d s+460}\right)\left(\frac{P b+\Delta P / 13.6}{P b+\Delta / / 13.6}\right)$

$\Delta H @=\frac{0.0317 \times \Delta H}{P b\left(T_{0}+460\right)}\left[\frac{(T d s+460) 0}{V d s \times Y d s}\right]^{2}$

$Q=\frac{17.64 \times V d s \times P b}{(T d s+460) 0}$ 


\section{Spring Type Thermometer Calibration}

Calibrated By. Darren. $\mu$ Lane

Date Calibrated: $\quad 10-7-96$

Calibration Due: 6 months 4-7-97

\begin{tabular}{|c|c|c|c|c|c|}
\hline Thermometer ID & $\begin{array}{l}\text { Reference Thermometer } \\
\text { Temp. ( } \mathrm{P})\end{array}$ & $\begin{array}{l}\text { Test Thermocouple } \\
\text { Temp ( } \mathrm{C})\end{array}$ & Temp. Difference & \% Difference & Notes \\
\hline $22 H \quad \not 8383$ & 112 & III & -1 & & \\
\hline $224 \quad I N^{\prime}$ & 78 & 78 & 0 & & \\
\hline $22 A$ & 33 & 34 & +1 & & \\
\hline $18 A$ & $1 ! 1$ & 112 & +1 & & \\
\hline $18 \mathrm{~A} \quad 0 \mathrm{U11}$ & 78 & 79 & +1 & & \\
\hline $18 A$ & 33 & 34 & +1 & & \\
\hline $204^{2 F 2400}$ & 102 & 100 & -2 & & \\
\hline $20 A \quad I N$ & $8+76$ & 75 & -1 & & \\
\hline $2 \pi A$ & 41 & 40 & -1 & & \\
\hline $20 . B$ & $i 04$ & 100 & -4 & & \\
\hline $20 \mathrm{~s}$ out & 84 & 83 & -1 & & \\
\hline $20 B \cdot 1$ & 41 & 40 & -1 & & \\
\hline & & & & & \\
\hline & & & & & \\
\hline 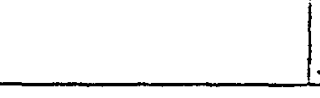 & & & & & \\
\hline
\end{tabular}

NIST Pyrometer. 733449

ASTM Themometer. $61132-006 \quad 76 \mathrm{~mm}$

Comments:

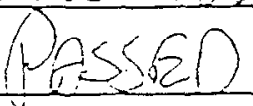

Reference Thermometer ASTM mercury in glass.

Wethod Reference: EPA QA Handbook Vol. Ill: Starionary Source Specific Methcds, sea. 3.5 .2 .2

Tolerance Limits: $\pm 5.4^{\circ} \mathrm{F}$ at ambient temnerature and in hot water bath. 


\section{APPENDIX E \\ PROCESS DATA}

0000209 
Revised Toluenel Addition to RTS til PCH F/it/28

Ken measued RTS I today and found that only! $22.66 . \mathrm{kg} R \mathbb{S}^{*} /$ in the container

1. composition of undiluted RTS 7 1 excluding pantivelte

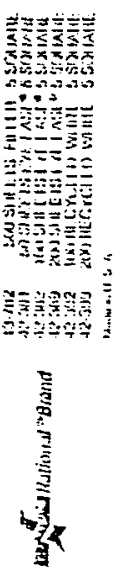

1,1-diclbroethere

Tetraclloroethane $1.57 \%$ 342

Trichlozothene $=3.02 \% \quad 684$ Tricllow-trifluoroethane $\frac{2.11 \%}{100 \%} \frac{478}{22660 \mathrm{~g}}$

Diluted with $12.34 \mathrm{~kg}$ To/uene

2. Couposition diluted RTS

$$
\begin{array}{lll}
M C M & \frac{g}{20983} & \frac{w \div \%}{59.95 \%} \\
\text { Fi-dichlowethe } & 342 & 0.98 \%
\end{array}
$$

Feed rate gim 24.98 0.41

Tetrachlocothere $684 \quad 1.95 \%$

0.81

Trichlowetheve

172

$0.49 \%$

0.20

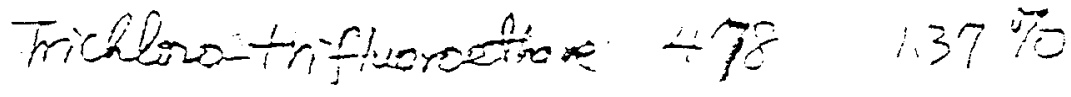

0.57

$\frac{\text { Toluere }}{\quad=340 \quad 3526 \%}$

$\frac{469}{41.6 \div 94 \text { min }}$ 
Actual Ferel Rate for RTS \#/ $P C H i \quad \delta / 24 / 98$ off-Gas Flow \& composition

(1) Average feed rate to the Mso vessel was $38.5 \mathrm{~g} / \mathrm{min} \pm 1.5 \mathrm{~g} / \mathrm{min}$ (or $4.0 \%)$ For individual components

Components wt. \% 1. H Trichroedhence MCM 59.95

1,1 -dicllowethene 0.98

Tetraclbroethene 1.95

Triclbosothere $\quad 0.49$

Triclers-Erepifluarothere 1.37

Toluene

rate, $\mathrm{g} / \mathrm{min}$

23.08

0.38

0.75

0.19

0.53

35.26

(2) Off-gas Fowrate

per FI-OI (Flowmetter in the off-gas system), the off-ganflowrate wer $15 \pm 0.5$ SCFM (which was condirtent with the pitot twate mensuremsents)

(3) 60 . in the off $=$

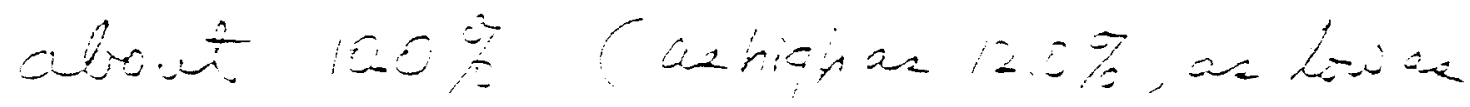

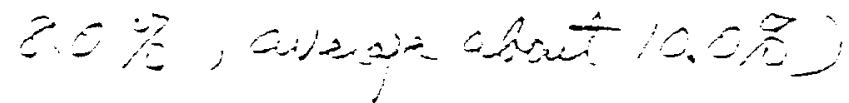

$10^{3}$ 


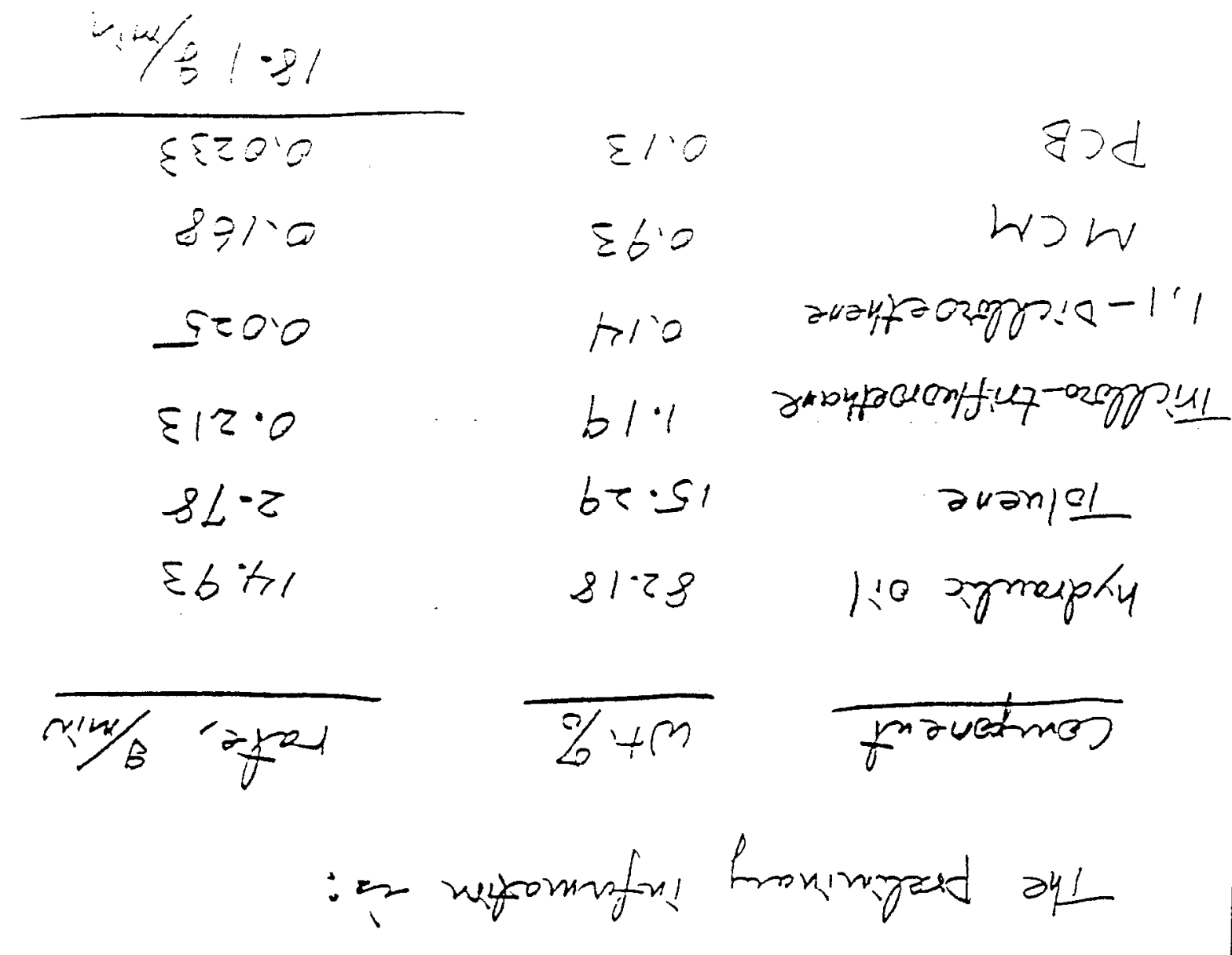

izpol popinut ra lim ayol prat ponpo

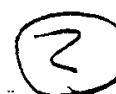

$$
\begin{aligned}
& \text {-...... } \\
& \text { Lo: } 0: 11-2 m+s i a n \\
& \text { gos } \approx{ }^{2} 0 \\
& 20.01 \approx 200
\end{aligned}
$$

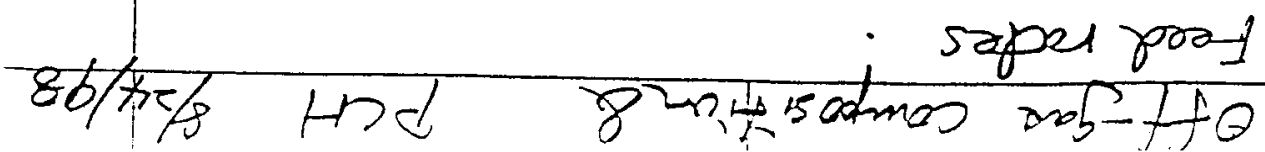




\section{Integrated MSO System}

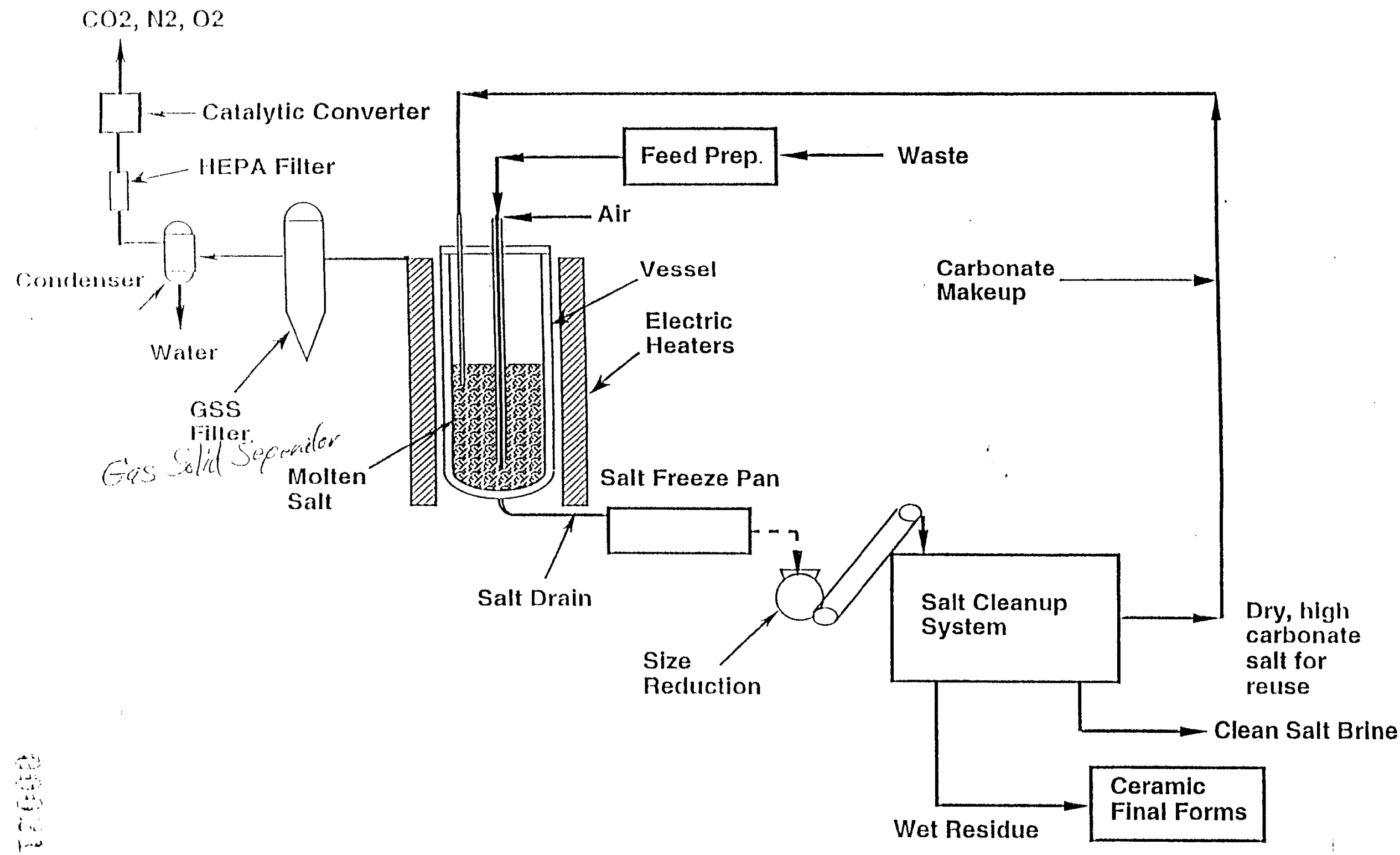


3. toderions

114

Fig. 3 Off-gas System

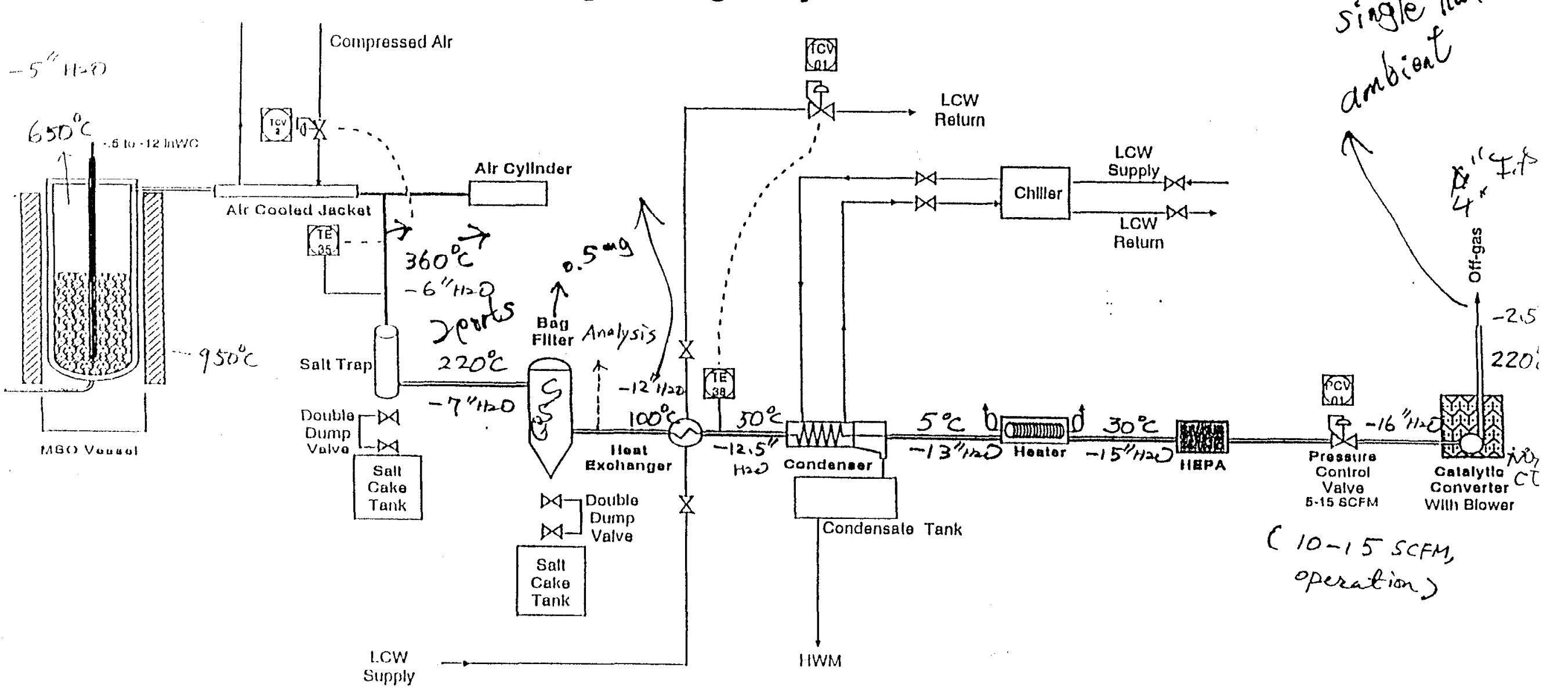




\section{APPENDIX $\mathrm{F}$ STACK DLAGRAMS}

0000215 


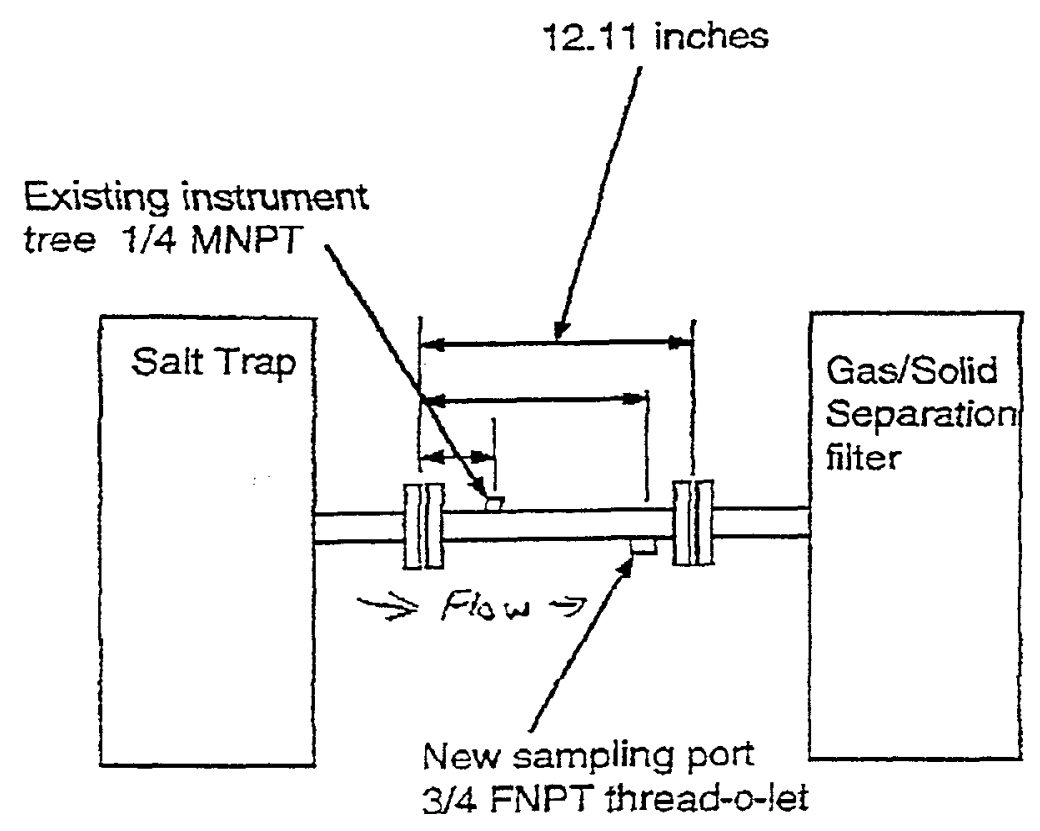

Existing bellows temporarily replaced with rigid pipe. 1.25 pipe, Schedule 40 
For the four sampling ports after the GSS filter

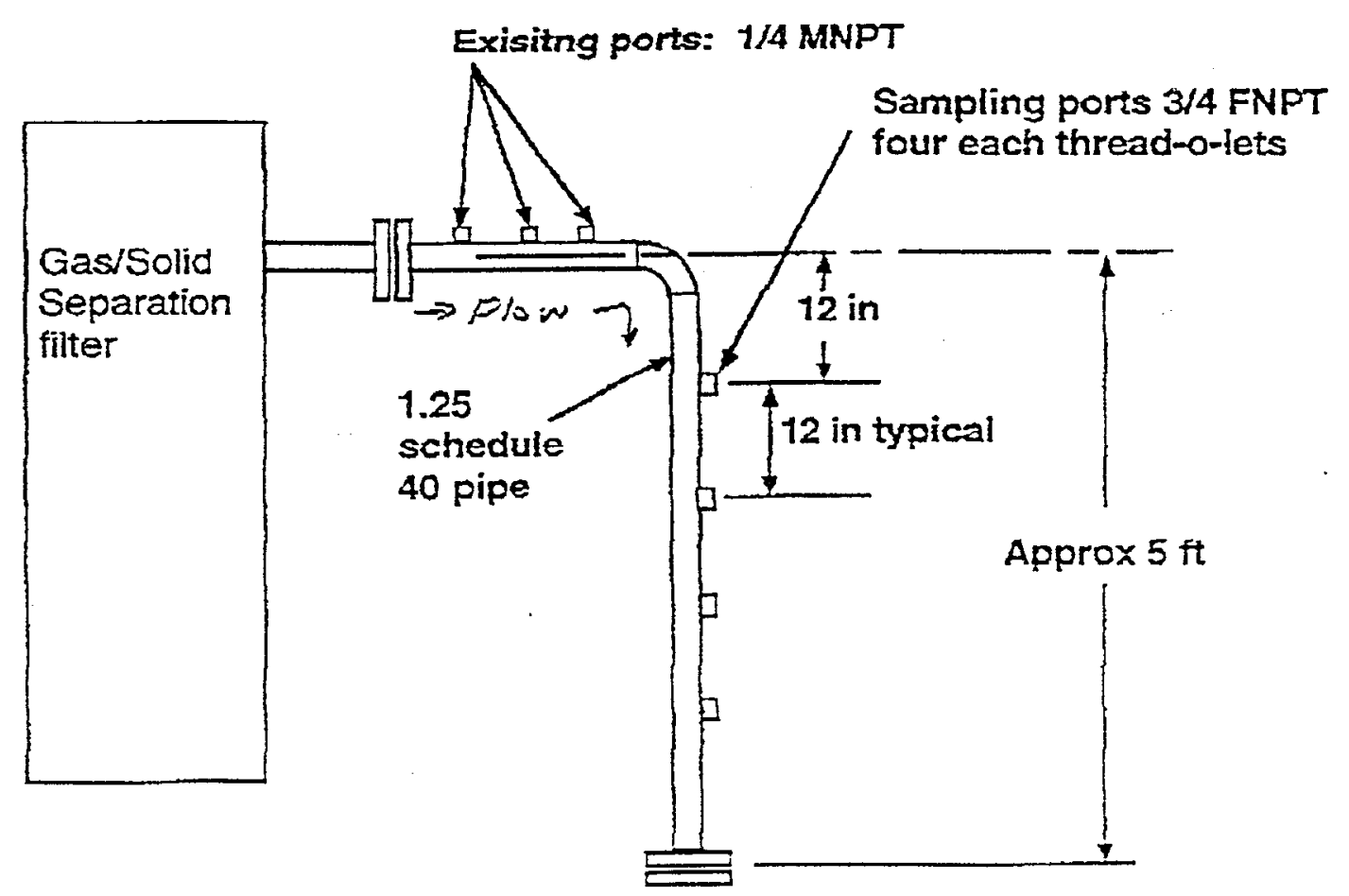


For the two sampling ports after the Catalytic converter

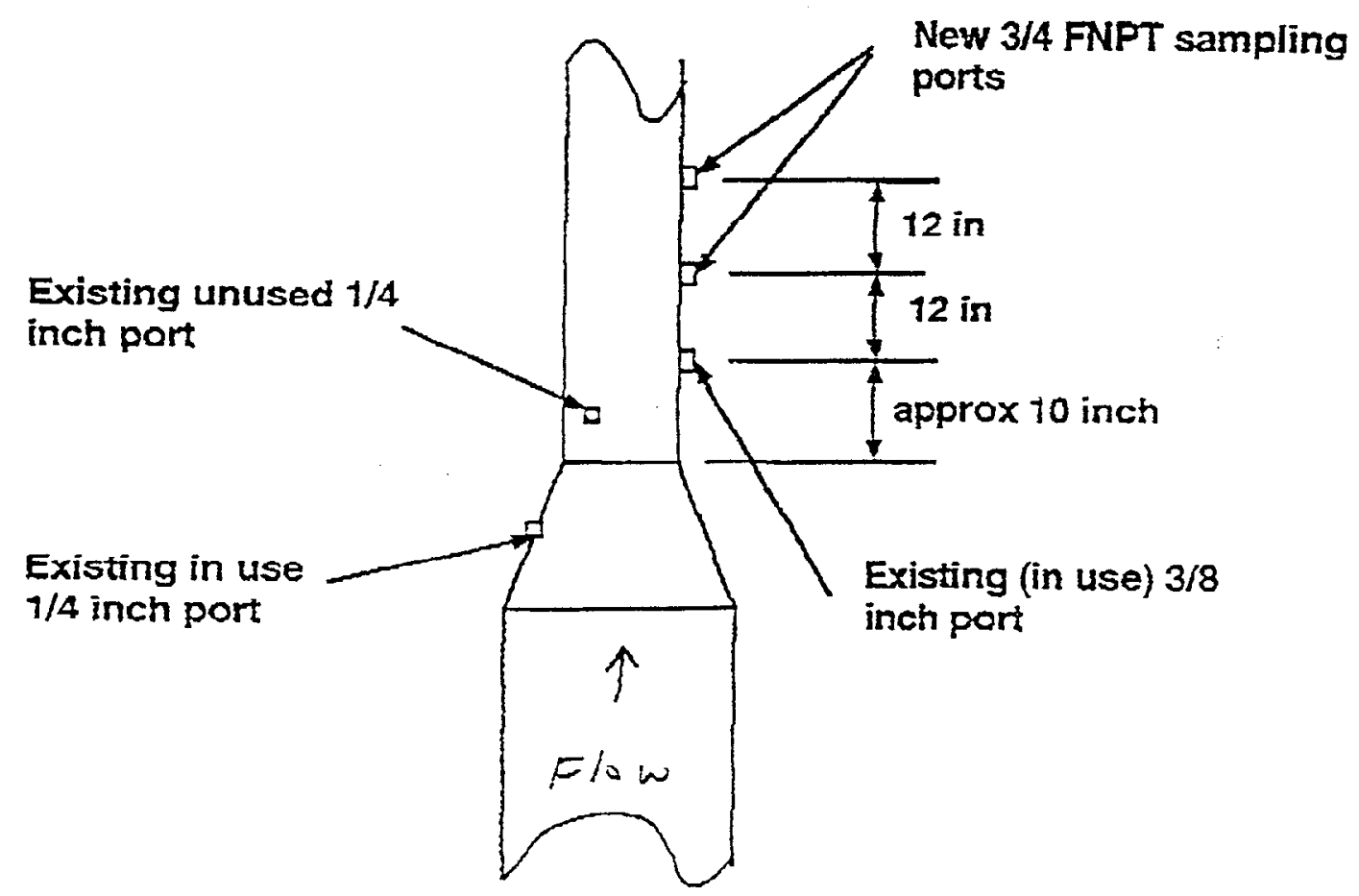




\section{APPENDLX G SAMPLING SYSTEM DIAGRAMS}

0000219 


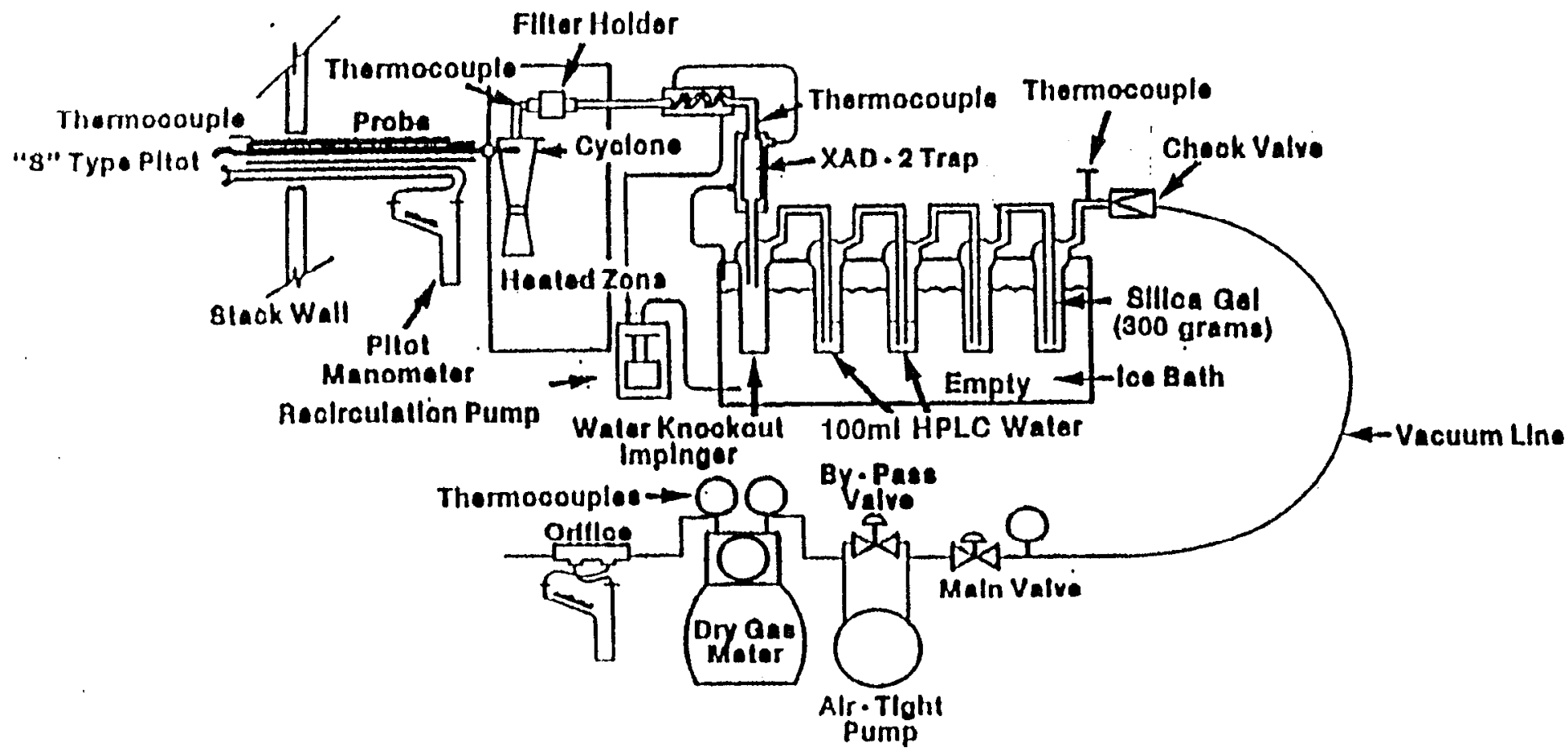

CDD/CDF Sampling Train Configuration 


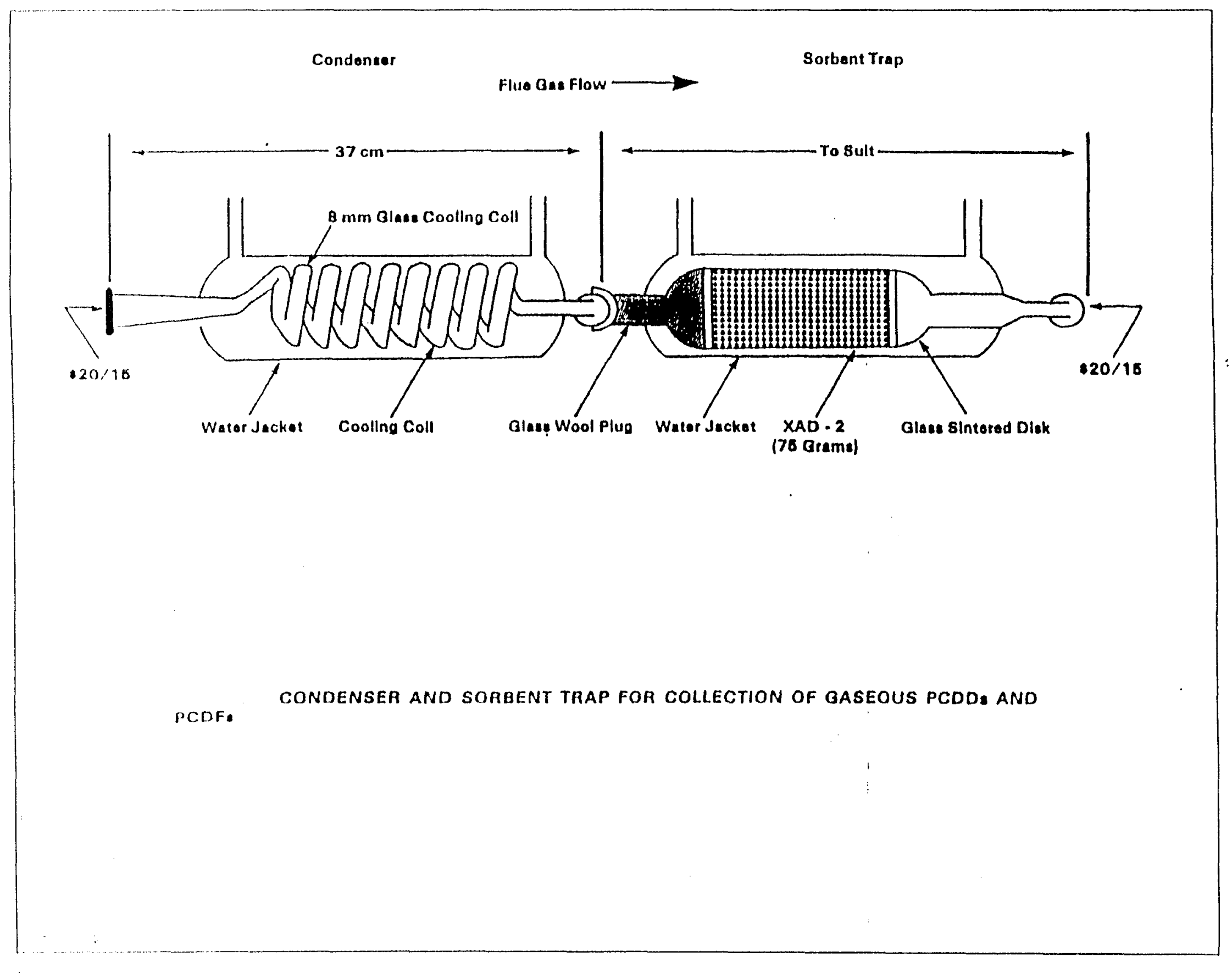




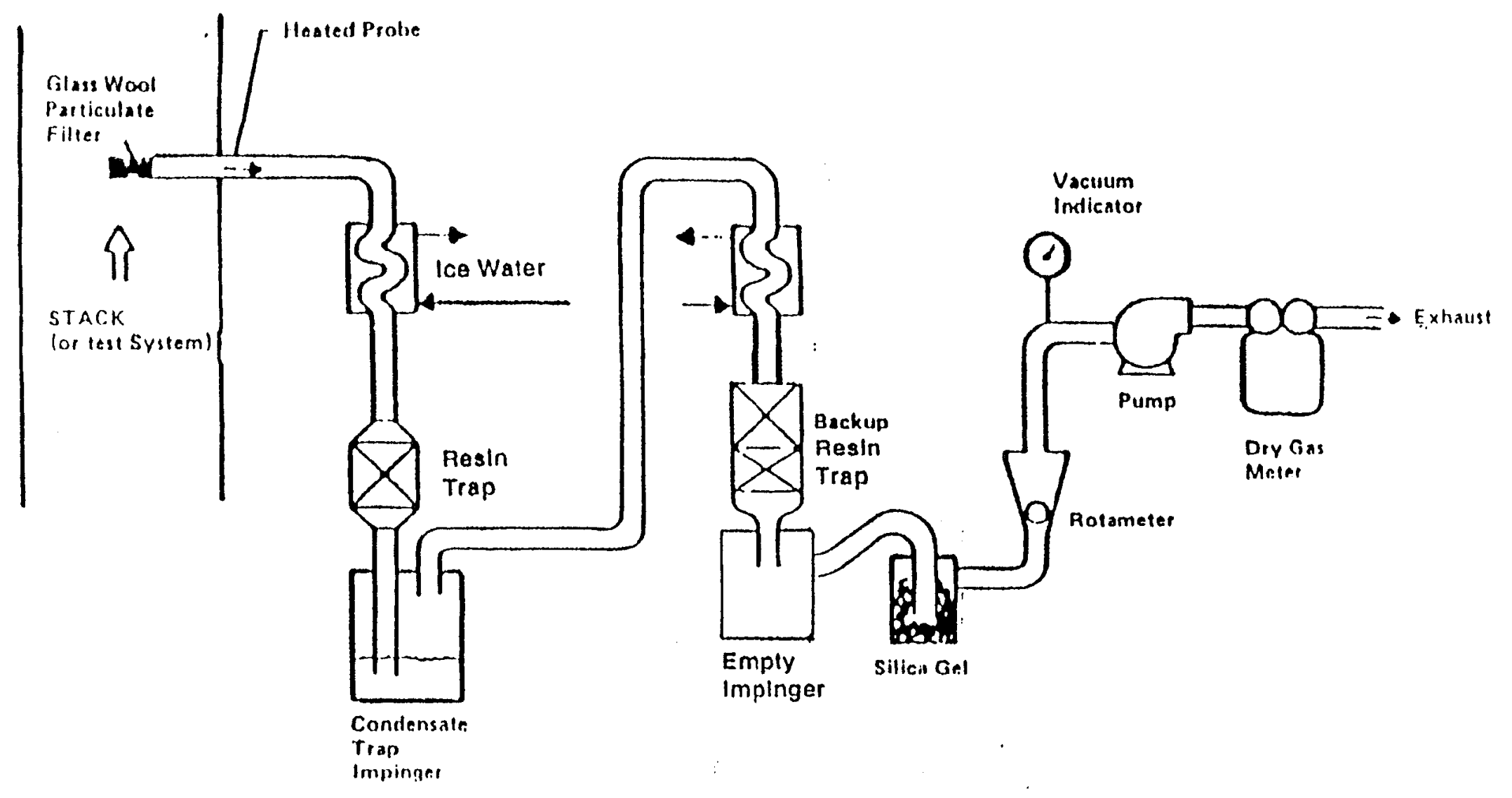

Schematic of Volatile Organic Sampling Train (VOST). 


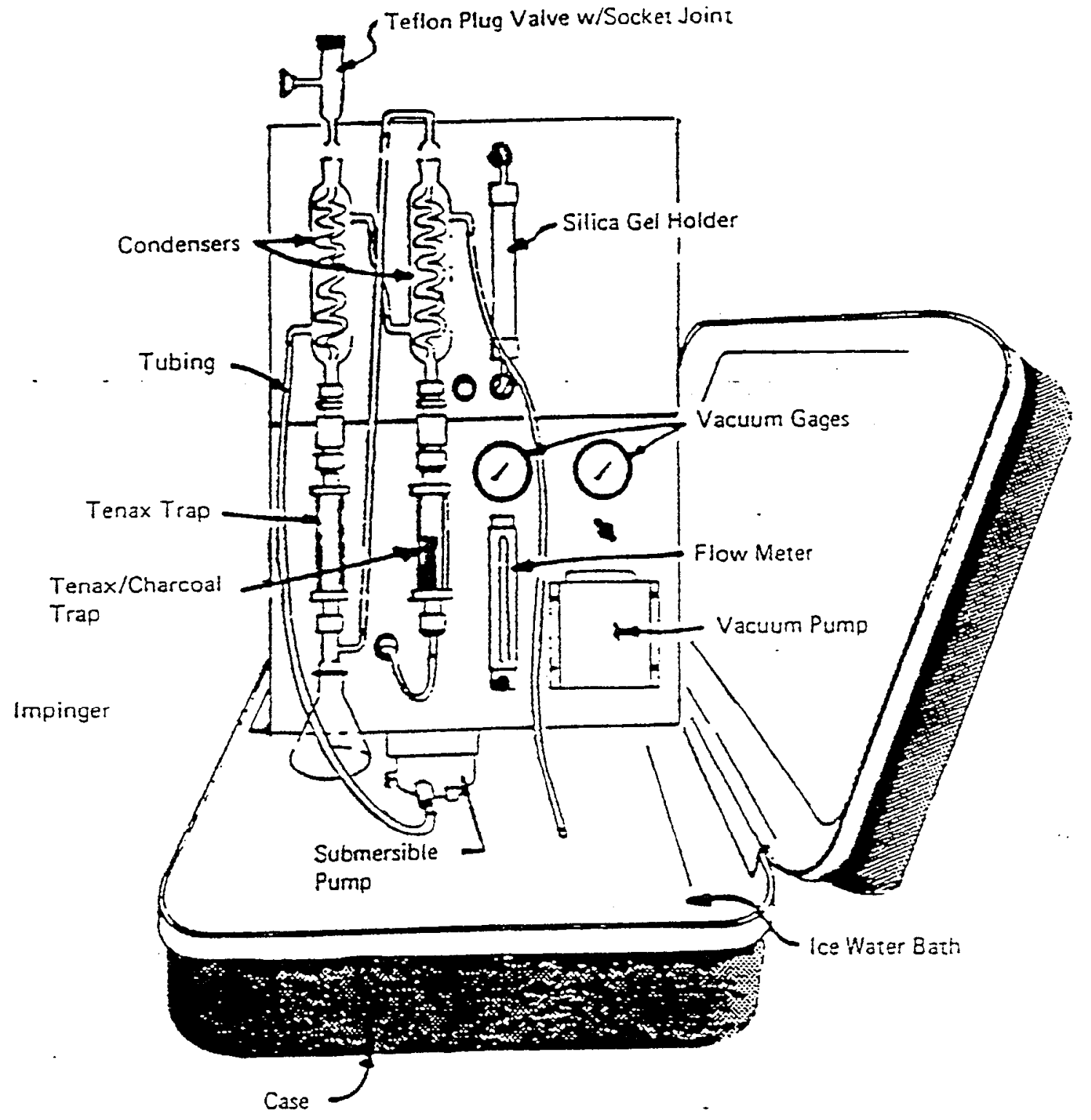

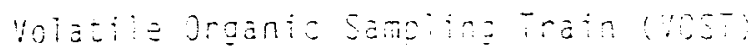




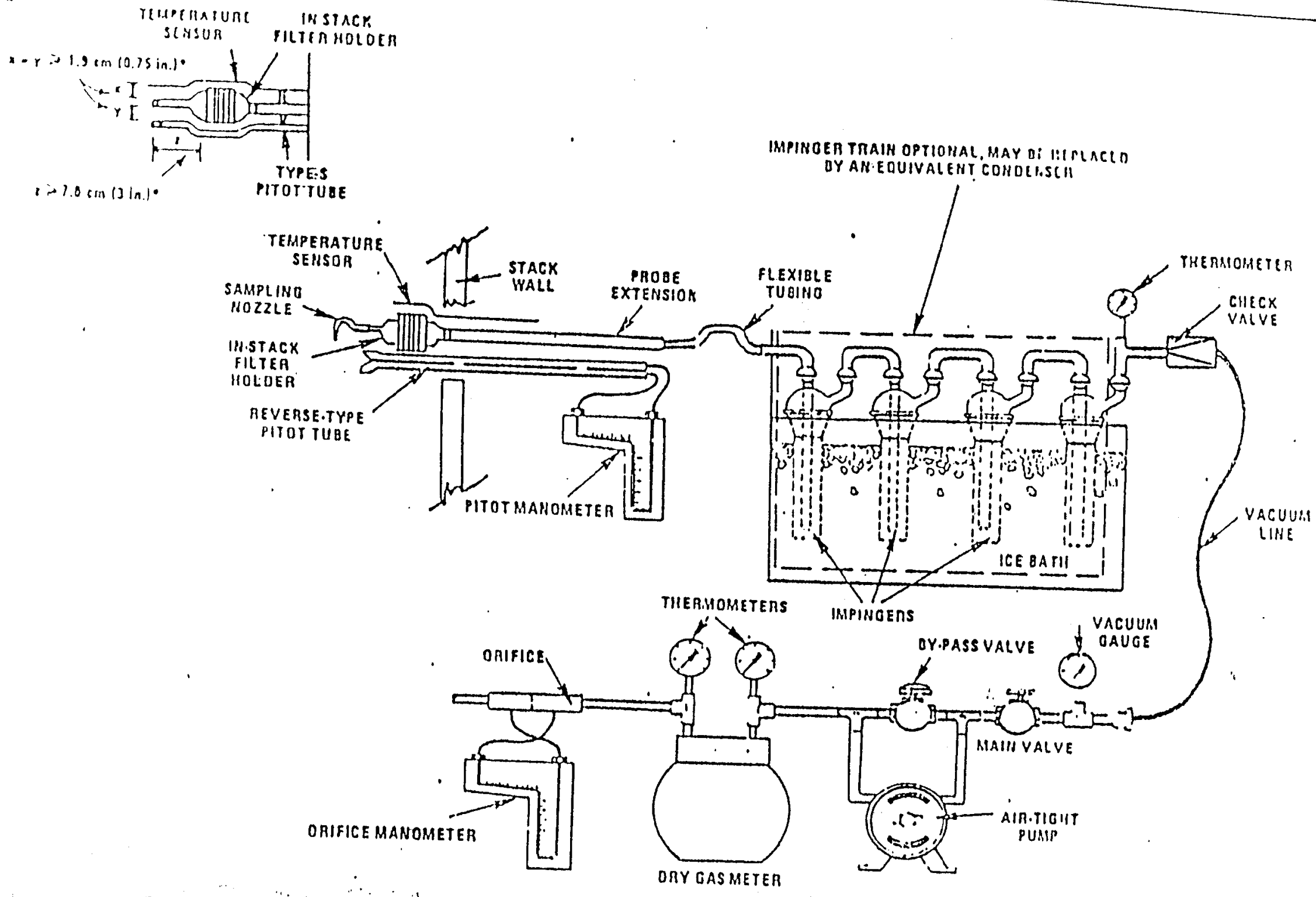

Partlculate-Saınpling Traln, Equipped with In.Stack Filler. 


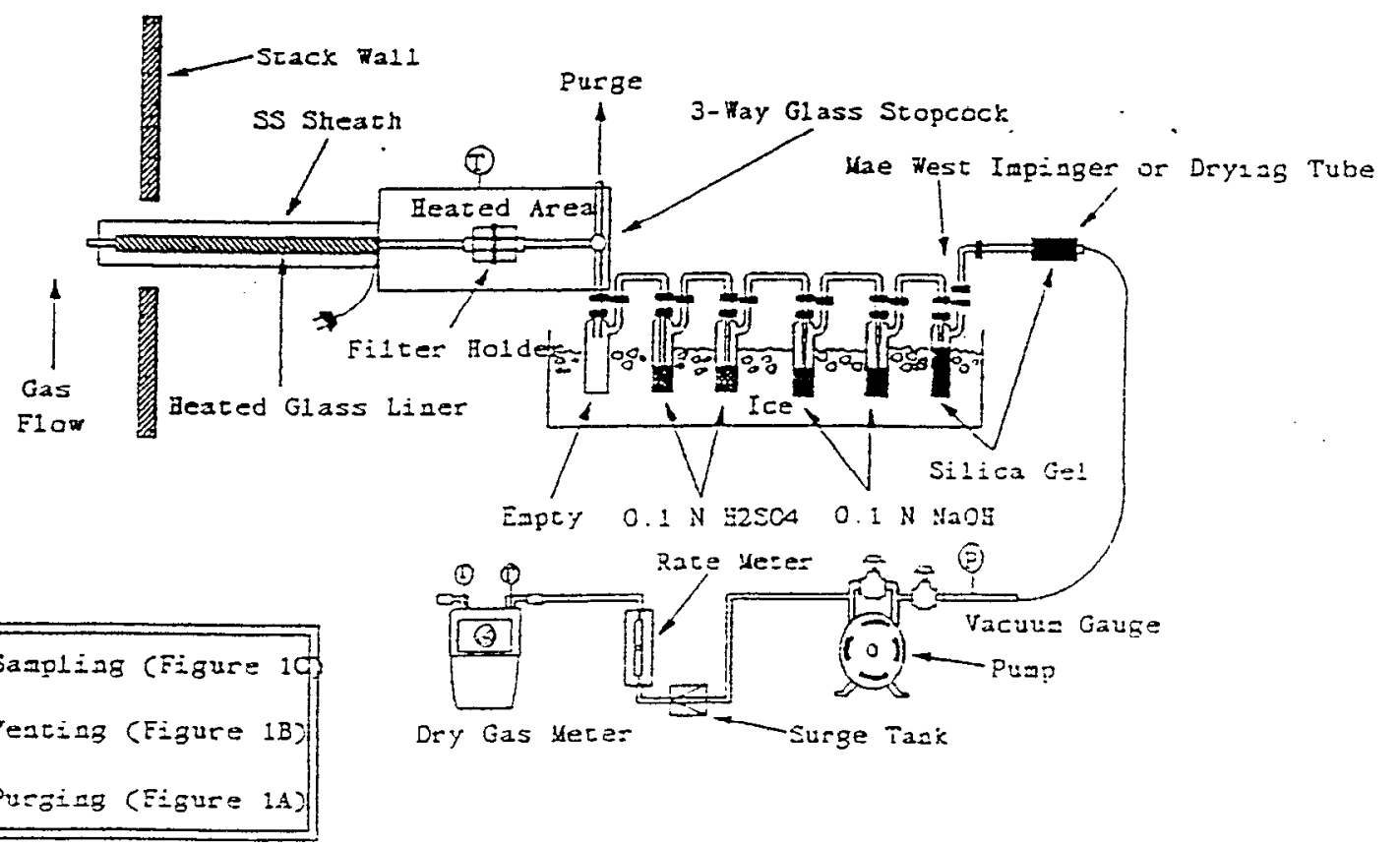

$$
\begin{aligned}
& \text { Method } 26 \text { foost } \\
& \text { Sampling iraia. }
\end{aligned}
$$




\section{AYALYTICAL CHEMISTS}

October 21, 1998

Best Environmental, Inc. 15890 Foothill Blvd, San Leandro, CA 94578

Sample Site: LLNL

Description: RIMS/114-IMP-CAT-OUT Sampled by:

Type of Sample: Non Potable Water
LAB No: SP 807981-15

RE: Radiological Analysis
Sampled : August 19, 1998
Received : September 25, 1998
Completed : October 20, 1998
QA/QC ID\# : 80798115- A

\section{Analytical Results}

\begin{tabular}{lcccc}
\hline & EPA & & & \\
\multicolumn{1}{c}{ CONSTITUENT } & METHOD & UNITS & RESULTS & ERROR \\
\hline \hline Gross Alpha & 9310 & $\mathrm{pCi} / \mathrm{L}$ & 1 & \pm 1 \\
Gross Beta & 9310 & $\mathrm{pCi} / \mathrm{L}$ & 1 & \pm 2 \\
Tritium & 906.0 & $\mathrm{pCi} / \mathrm{L}$ & 900 & \pm 300 \\
\hline \hline
\end{tabular}

CLi L = pico Curies per Liter $\quad p C i / m l=$ pico Curies per milliliter

Containers: (a) Glass

If you have any questions, piease call.

FGL ENVIRONMENTAL

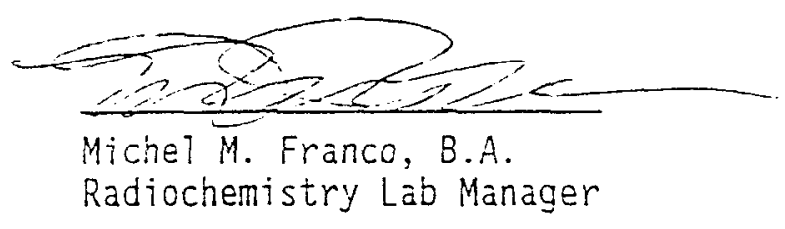

MMF : vt 


\section{AYALYTICAL CHEMISTS}

October 22, 1998

Best Environmenta], Inc. 15890 Foothi71 BTvd, San Leandro, CA 94578

Sample Site: LLNL

Description: RIMS/114-F/H-CAT-OUT

Sampled by :

Type of Sample: Solid
LAB No: SP 807981-13

RE: Radiological Analysis
Sampled : August 19, 1998
Received : September 25, 1998
Completed : October 13, 1998
QA/QC ID $\frac{\pi}{\pi}: 80798113-\mathrm{A}$

\section{Analytical Results}

\begin{tabular}{lllcl}
\hline \hline CONSTITUENT & EPA & & & \\
& METHOD & UNITS & RESULTS & ERROR \\
\hline \hline Gross A7pha & 9310 & $\mathrm{pCi} /$ samp & $0.0 \pm 1$ \\
Gross Beta & 9310 & $\mathrm{pCi} /$ samp & $0.0 \pm 1$ \\
Tritium & $\mathrm{H}-1$ & $\mathrm{pCi} /$ samp & $0.0 \pm 2$ \\
\hline
\end{tabular}

pCi $/ L=$ pico Curies per Liter $p C i / m l=$ pico Curies per milliliter Containers: (a) Plastic

If you have any questions, please call.

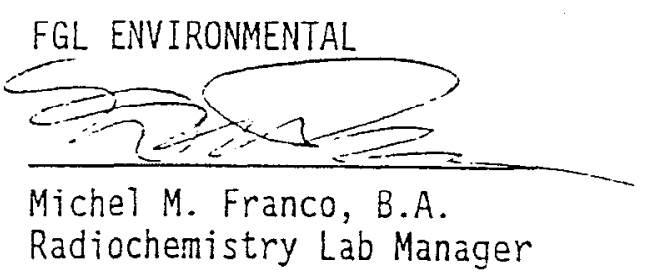

MMF :vt 


\section{ANALYTICAL CHEMISTS}

October 22, 1998

Best Environmental, Inc. 15890 Foothill Blvd, San Leandro, CA 94578

Sample Site: LLNL

Description: RIMS/114-Fi1ter-CAT-OUT

Sampled by:

Type of Sample: Air Filter
LAB No: SP 807981-14

RE: Radiological Analysis
Sampled : August 19, 1998

Received : September 25, 1998

Completed : October 19, 1998

QA/QC ID

\section{Analytical Results}

\begin{tabular}{lcccc}
\hline \hline & EPA & & & \\
CONSTITUENT & METHOD & UNITS & RESULTS & ERROR \\
\hline \hline Gross Alpha & 9310 & $\mathrm{pCi} / \mathrm{samp}$ & $0.33 \pm 0.45$ \\
Gross Beta & 9310 & $\mathrm{pCi} /$ samp & $0.44=1.2$ \\
Tritium & $\mathrm{H}-1$ & $\mathrm{pCi} / \mathrm{samp}$ & $0.2 \pm 2$ \\
\hline \hline
\end{tabular}

$\mathrm{pCi} / \mathrm{L}=$ pico Curies per Liter $\mathrm{pCi} / \mathrm{mL}=$ pico Curies per milliliter

Containers: (a) Glass

If you have any questions, please call.

FGL ENVIRONMENTAL.

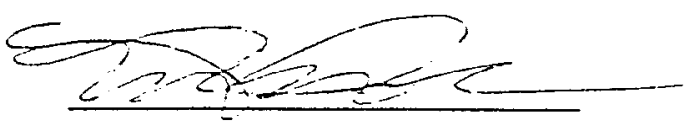

Michel M. Franco, B.A.

Radiochemistry Láb Manager

MMF:vt 


\section{ANALYTICAL CHEMISTS}

October 22, 1998

Best Environmental, Inc. 15890 Foothill Blvd,

San Leandro, CA 94578

Sample Site: LLNL

Description: R4MS/114-F/H-B-OUT-BLK

Sampled by :

Type of Sample: Solid
LAB No: SP 807981-4

RE: Radiological Analysis
Sampled : August 18, 1998
Received : September 25, 1998
Completed : October 13, 1998
QA/QC ID\# : 80798104- A

\section{Analytical Results}

\begin{tabular}{lllll}
\hline \hline & EPA & & & \\
\multicolumn{1}{c}{ CONSTITUENT } & METHOD & UNITS & RESULTS & ERROR \\
\hline \hline Gross Alpha & 9310 & $\mathrm{pCi} / \mathrm{samp}$ & 0.0 & \pm 1 \\
Gross Beta & 9310 & $\mathrm{pCi} / \mathrm{samp}$ & $0.0 \pm \pm 1$ \\
Tritium & $\mathrm{H}-1$ & $\mathrm{pCi} / \mathrm{samp}$ & 0.0 & \pm 2 \\
\hline \hline
\end{tabular}

pCi/L = pico Curies per Liter pCi/ml = pico Curies per milliliter

Containers: (a) Plastic

If you have any questions, please call.

FGL ENVIRONMENTAL

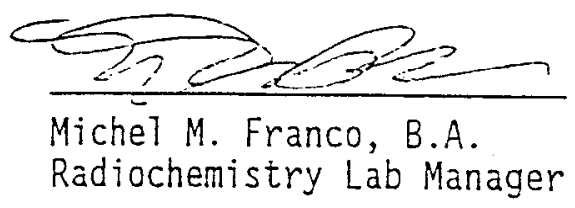

MMF :vt

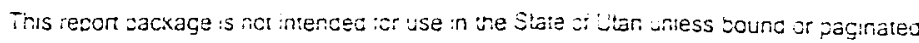




\section{AMALYTICAL CHEMISTS}

October 22, 1998

Best Environmental, Inc. 15890 Foothi11 B7vd, San Leandro, CA 94578

Sample Site: LLNL

Description: R4MS/114-FILTER-B-OUT-BLK Sampled by :

Type of Sample: Air Filter
LAB No: SP 807981-8

RE: Radiological Anatysis

Sampled : August 18, 1998
Received $:$ September 25, 1998
Completed : October 19, 1998
QA/QC ID: $: 80798108-$ A

\section{Analytical Results}

\begin{tabular}{lllll}
\hline & EPA & & & \\
CONSTITUENT & METHOD & UNITS & RESULTS & ERROR \\
\hline \hline Gross Alpha & 9310 & $\mathrm{pCi} /$ samp & $0.00 \pm 0.43$ \\
Gross Beta & 9310 & $\mathrm{pCi} /$ samp & $0.0 \pm 1.3$ \\
Tritium & $\mathrm{H}-1$ & $\mathrm{pCi} / \mathrm{samp}$ & $1.2 \pm \pm 2$ \\
\hline
\end{tabular}

$\mathrm{pCi} / \mathrm{L}=$ pico Curies per Liter $\mathrm{pCi} / \mathrm{ml}=$ pico Curies per milliliter

Containers: (a) Glass

If you have any questions, please call.

FGL ENVIRONMENTAL

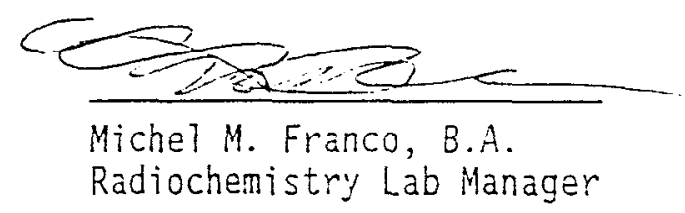

MMF:vt 


\section{AYALYTICAL CHEMISTS}

October 21, 1998

LAB No: SP 807981-12

Best Environmental, Inc.

15890 Foothi17 BTvd,

San Leandro, CA 94578

Sample Site: LLNL

Description: R4MS/114-IMP-B-OUT

Sampled by :

Type of Sample: Non Potable Water
RE: Radiological Analysis

Sampled : August 18, 1998

Received : September 25, 1998

Completed : October 20, 1998

QA/QC ID\# : 80798112- A

\section{Analytical Resuits}

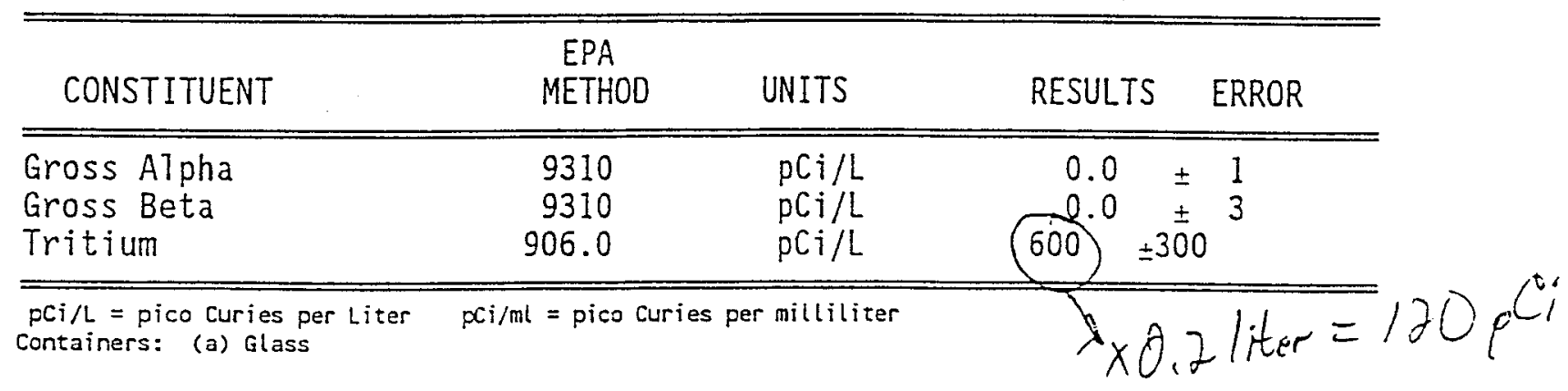

If you have any questions, please call.

FGL ENV IRONMENTAL

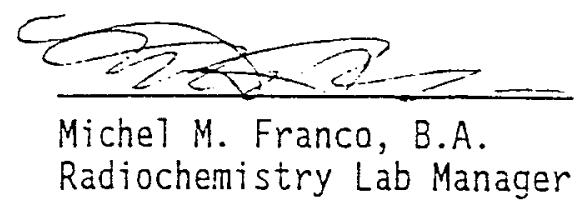

MMF :vt 


\section{Analytical report}

$\begin{array}{ll}\text { Job Name: } & \text { LLNL } \\ \text { Sample Date: } & 8 / 26 / 98 \\ \text { Request by: } & \text { R Best } \\ \text { Analytical Method: } & \text { Method EPA } \\ \text { Date of Anaysis: } & 8 / 31 / 98 \text { to } 9 / 17 / 98 \\ \text { Source: } & \text { GSS outlet }\end{array}$

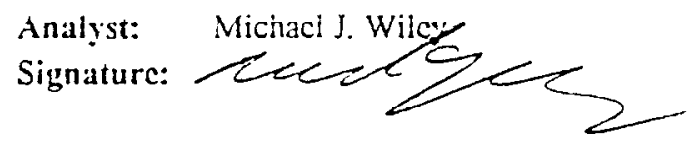

\begin{tabular}{|c|c|c|c|c|c|}
\hline Lab ID Number & $\begin{array}{c}\text { Sample } \\
\text { (ml) }\end{array}$ & $\begin{array}{l}\text { Aliquot } \\
(\mathrm{ml})\end{array}$ & Parameter & $\begin{array}{l}\text { Net Weight } \\
\text { gain, (mg) }\end{array}$ & $\begin{array}{c}\text { Result } \\
\text { Blank Corrected }\end{array}$ \\
\hline $\begin{array}{l}\text { RIM5 (Probe/Nozzle rinsc) } \\
\text { RIM5 (Filtcr) }\end{array}$ & $\begin{array}{l}50.0 \mathrm{ml} \\
\mathrm{N} / \mathrm{A}\end{array}$ & $\begin{array}{l}50.0 \mathrm{ml} \\
\mathrm{N} / \mathrm{A}\end{array}$ & $\begin{array}{l}\text { Particulate } \\
\text { Pariculatc }\end{array}$ & $\begin{array}{l}0.4+\mathrm{mg} \\
0.11 \mathrm{mg}\end{array}$ & $\begin{array}{l}0.71 \mathrm{mg} \\
0.11 \mathrm{mg}\end{array}$ \\
\hline $\begin{array}{l}\text { R2M5 (Probc/Nozzle rinsc) } \\
\text { R2M5 (Filter) }\end{array}$ & $\begin{array}{l}50.0 \mathrm{ml} \\
\mathrm{N} / \mathrm{A}\end{array}$ & $\begin{array}{l}50.0 \mathrm{ml} \\
\mathrm{N} / \mathrm{A}\end{array}$ & $\begin{array}{l}\text { Particulate } \\
\text { Particulatc }\end{array}$ & $\begin{array}{l}0.25 \mathrm{mg} \\
-0.08 \mathrm{mg}\end{array}$ & $\begin{array}{c}0.52 \mathrm{mg} \\
<0.05 \mathrm{mg}\end{array}$ \\
\hline $\begin{array}{l}\text { R3M5 (ProbeNozzle rinsc) } \\
\text { R3M5 (Filter) }\end{array}$ & $\begin{array}{l}50.0 \mathrm{ml} \\
\mathrm{N} / \mathrm{A}\end{array}$ & $\begin{array}{l}50.0 \mathrm{ml} \\
\mathrm{N} / \mathrm{A}\end{array}$ & $\begin{array}{l}\text { Particulate } \\
\text { Particulatc }\end{array}$ & $\begin{array}{l}0.21 \mathrm{mg} \\
-0.0+\mathrm{ing}\end{array}$ & $\begin{array}{l}0.48 \mathrm{mg} \\
<0.05 \mathrm{mg}\end{array}$ \\
\hline $\begin{array}{l}\text { R+M5 (Acctonc blank) } \\
\text { R+M5 (Filtcr blank) }\end{array}$ & $\begin{array}{l}50.0 \mathrm{ml} \\
\mathrm{N} / \mathrm{A}\end{array}$ & $\begin{array}{l}50.0 \mathrm{ml} \\
\mathrm{N} / \mathrm{A}\end{array}$ & $\begin{array}{l}\text { Paniculatc } \\
\text { Paniculatc }\end{array}$ & $\begin{array}{l}-0.27 \mathrm{mg} \\
0.00 \mathrm{mg}\end{array}$ & \\
\hline
\end{tabular}

Comments: $\quad \leq 0.05 \mathrm{mg}=$ Not detcctcd

$\%$ Accionc Residuc $=\quad-0.0007 \%$

Calculations:

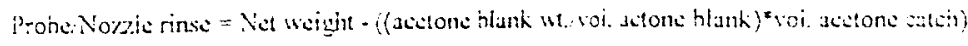

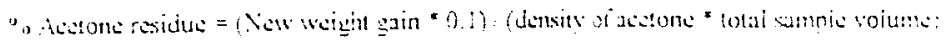

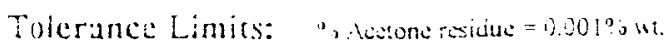

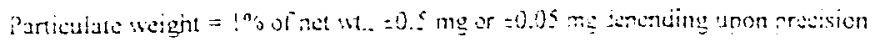




\section{Analytical report}

Job Name: $\quad$ LLNL

Sample Date: $\quad 8 / 26 / 98$

Request by: $\quad$ R. Best

Analyst: Michacl J. Wile

Method 5 EPA

Signature:

Analytical Method: Method 5 EPA

Date of Anaysis: $\quad$ 8/31/98 to 9/17/98

Source: Catalyst outlet

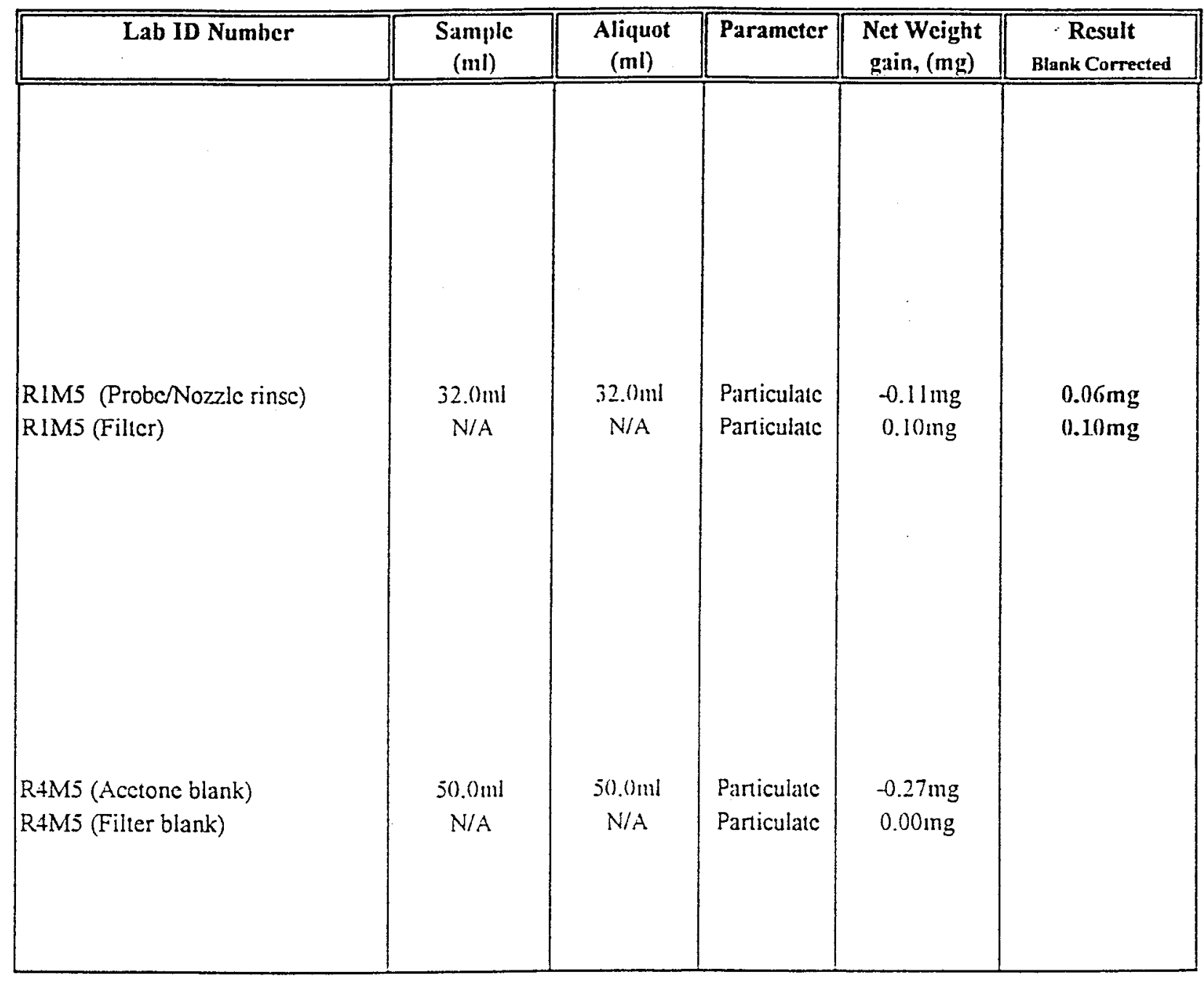

Comments: $\quad \leq 0.05 \mathrm{mg}=$ Nol detected

$\%$ Acctone Residuc $=\quad-0.0007 \%$

Calculations:

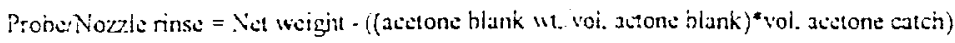

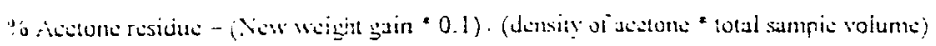

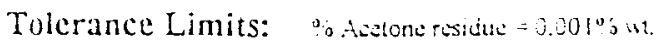

Panicuiate weiggit $=10$, oi ne:, $1 . .=0.5 \mathrm{mg}$ or $=0.05 \mathrm{mg}$ jumending upon presision 